INSTITUTO DE PESQUISAS ENERGÉTICAS E NUCLEARES

Autarquia associada à Universidade de São Paulo

ESTUDO DA CORRELAÇÃO ENTRE NORMAS DA AGÊNCIA INTERNACIONAL DE ENERGIA ATÔMICA E DE MERCADO SOBRE SISTEMA DE GESTÃo APLICÁVEL À OPERAÇÃO DE PLANTA DE CONVERSÃO DE UF

DIRCEU PAULO DE OLIVEIRA

Dissertação apresentada como parte dos requisitos para a obtenção do grau de Mestre em Ciências na Área de

Tecnologia Nuclear - Aplicações.

Orientadora:

Profa. Dra. Désirée Moraes Zouain

SÃO PAULO

2008 
INSTITUTO DE PESQUISAS ENERGÉTICAS E NUCLEARES

Autarquia associada à Universidade de São Paulo

ESTUDO DA CORRELAÇÃO ENTRE NORMAS DA AGÊNCIA INTERNACIONAL DE ENERGIA ATÔMICA E DE MERCADO SOBRE SISTEMA DE GESTÃO APLICÁVEL À OPERAÇÃO DE PLANTA DE CONVERSÃO DE UF 6

DIRCEU PAULO DE OLIVEIRA

Dissertação apresentada como parte dos requisitos para a obtenção do grau de Mestre em Ciências na Área de Tecnologia Nuclear - Aplicações.

Orientadora:

Profa. Dra. Désirée Moraes Zouain

SÃO PAULO 


\section{DEDICATÓRIA}

Dedico esta pesquisa aqueles que sempre me apoiaram em todas as minhas investidas e que a todo o momento me fazem entender o verdadeiro sentido da palavra família: Antônio Paulo ("in memória") e Angelica - meus pais, Leila - minha esposa, e Rodrigo, Carolina e Mariana - meus filhos. 


\section{AGRADECIMENTOS}

Agradeço primeiramente a Deus pelos desafios que interpõe em minha vida, dando-me saúde, discernimento e perseverança para enfrentá-los.

Agradeço:

À Profa. Dra. Désirée Moraes Zouain, pelo acompanhamento, orientação e lições aprendidas;

A Direção do Centro Tecnológico da Marinha em São Paulo (CTMSP), pela permissão de desenvolver esta pesquisa e de alguma forma poder contribuir para os projetos do Centro;

Ao Superintendente da Qualidade e Segurança Industrial do CTMSP, Marco Antonio Calixto Pádua, pelo estímulo e apoio incondicional;

Ao Instituto de Pesquisas Energéticas e Nucleares pela oportunidade do mestrado e, em particular, aos professores e funcionários da Comissão de Pós-Graduação pelos ensinamentos, presteza e dedicação;

Ao grande amigo e mestre Álvaro J. A. Calegare, pelos ensinamentos, sempre me incentivando a percorrer os caminhos do aprimoramento profissional;

Aos colegas de trabalho do CTMSP e aqueles que direta ou indiretamente emprestaram seu tempo, contribuindo para o desenvolvimento da pesquisa, em especial a: Wilians R. Baldo, Eduardo Kibrit, Clariton dos Santos, Leila A. M. de Oliveira e Carolina A. M. P. de Oliveira;

Aos amigos pela compreensão de minha ausência; e

À minha família e agregados pelo ânimo constante e paciência, me estimulando sempre a enfrentar a jornada. 


\section{EPÍGRAFE}

"A mente que se abre a uma nova idéia

jamais volta a seu tamanho original".

Albert Einstein (1879-1955)

Físico e Matemático, cuja Teoria da Relatividade Espacial mudou as idéias sobre o espaço, o tempo e a natureza do universo. 


\title{
ESTUDO DA CORRELAÇÃO ENTRE NORMAS DA AGÊNCIA INTERNACIONAL DE ENERGIA ATÔMICA E DE MERCADO SOBRE SISTEMA DE GESTÃo APLICÁVEL À OPERAÇÃO DE PLANTA DE CONVERSÃO DE UF 6
}

\author{
Dirceu Paulo de Oliveira
}

\section{RESUMO}

A Agência - "International Atomic Energy Agency" (IAEA), seguindo a tendência de mercado de integração de sistemas de gestão, decidiu rever as normas de Garantia da Qualidade - IAEA 50-C/SG-Q publicando, em 2006, a norma sobre Sistema de Gestão (SG) - IAEA GS-R-3 e sua guia IAEA GS-G-3.1 e está em vias de publicar uma guia suplementar - IAEA DS349, que consideram a integração das várias funções envolvidas na gestão de instalações nucleares, tais como: segurança, saúde, meio ambiente e qualidade, assegurando que a segurança nuclear não seja comprometida.

As plantas de conversão de "Yellowcake" em UF 6 utilizam e processam materiais radioativos, bem como outras substâncias normalmente encontradas na indústria química convencional, se inserindo no perfil de organizações que requerem um elevado padrão de definição, implementação e melhoria contínua de seus SG, e que, portanto, devem considerar uma abordagem de sistema integrado de gestão (SIG).

Tendo como foco uma planta de conversão de $\mathrm{UF}_{6}$, foi estudada a correlação entre as normas sobre SG da Agência com aquelas de mercado - ISO 9001, ISO 14001 e OHSAS 18001, e com os projetos de normas da Agência - DS316 e DS344, sobre segurança; concluindo-se que, ao se estruturar um SIG de acordo com as normas de SG da Agência, salvo alguns ajustes, estarão sendo atendidas as ISO 9001, ISO 14001 e OHSAS 18001. Por sua vez, a estruturação do SIG deve identificar outros requisitos sobre segurança, saúde e meio ambiente que considerem, também, as características químicas e industriais convencionais da planta, que estão fora do escopo (radiação ionizante) das normas de segurança da Agência. A pesquisa propõe um procedimento documental para um SIG para a planta em questão, fornecendo subsídios para racionalização e conteúdo da documentação identificada, para promoção da integração das funções de SG consideradas. 


\title{
CORRELATION STUDY AMONG THE INTERNATIONAL ATOMIC ENERGY AGENCY STANDARDS AND MARKETS STANDARDS ON MANAGEMENT SYSTEM APPLICABLE TO A UF 6 CONVERSION PLANT OPERATION
}

\section{Dirceu Paulo de Oliveira}

\begin{abstract}
The Agency - International Atomic Energy Agency (IAEA), following the market trend of the management system integration, has decided to revise the quality assurance standards - IAEA 50-C/SG-Q publishing, in 2006, the standard on Management System (MS) - IAEA GS-R-3 and its IAEA GS-G-3.1 guide. Also, the IAEA is about to publish a supplementary guide - IAEA DS349, which consider the integration of several functions involved in management of nuclear facilities, such as: safety, health, environmental and quality, ensuring that nuclear safety is not compromised.

Conversion plants of "Yellowcake" in $\mathrm{UF}_{6}$ use and process radioactive materials, as well as other substances normally found in the chemical conventional industry, inserting themselves in the organization profile that require a high pattern of definition, implementation and continuous improvement of their MS and, therefore, should consider an approach of management integrated system (MIS).

Taking a $\mathrm{UF}_{6}$ conversion plant as focus, the correlation was performed among the Agency MS standards and those of the market - ISO 9001, ISO 14001 and OHSAS 18001, as well as with the Agency drafts standards on safety (DS316 and DS344), concluding that, in structuring an MIS, in compliance with the Agency MS standards, except for some adjustments, the ISO 9001, ISO 14001, and OHSAS 18001 are going to be met. On the other hand, the structuring of MIS should identify other requirements on safety, health and environmental, which also consider the conventional chemical and industrial characteristics that are out of the scope (ionizing radiation) of the safety standards of the Agency. The research proposes a documental procedure for a MIS applicable to this plant, providing elements for rationalization and contents of the identified documentation, for the promotion of the integration of the considered MS functions.
\end{abstract}




\section{SUMÁRIO}

Página

CAPA

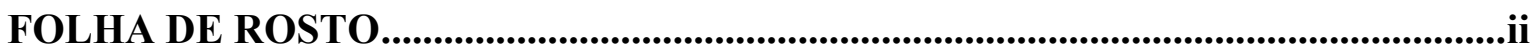

DEDICATÓRIA.................................................................................................................. ii

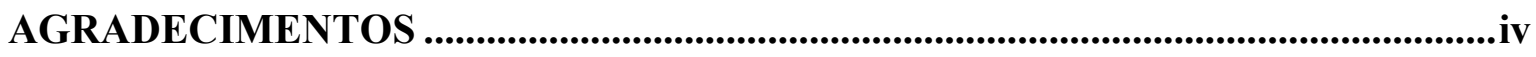

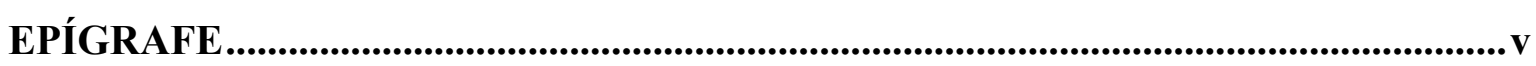

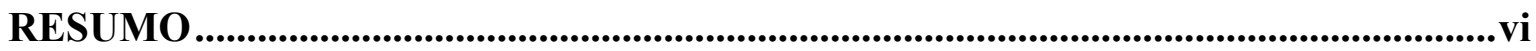

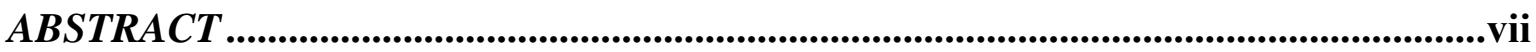

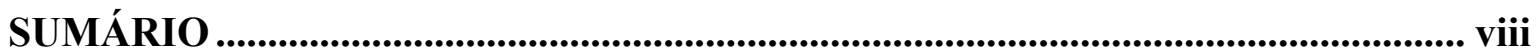

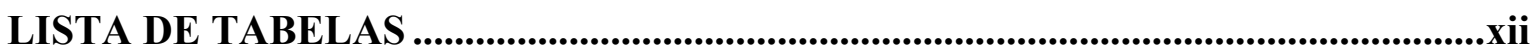

LISTA DE FIGURAS ................................................................................................... xiii

LISTA DE ABREVIATURAS E/OU SIGLAS ................................................................xiv

1 INTRODUÇÃ

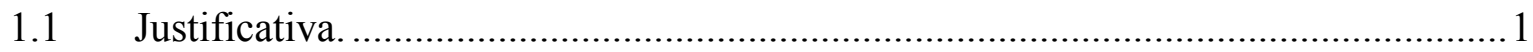

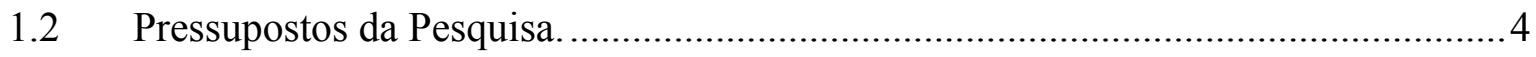

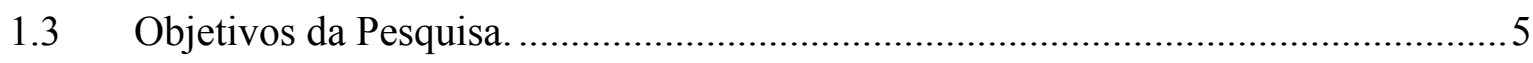

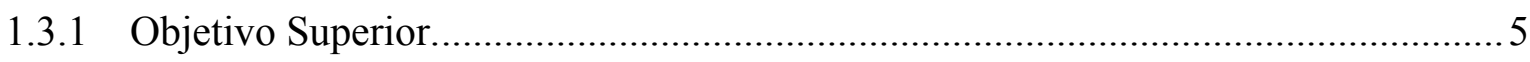

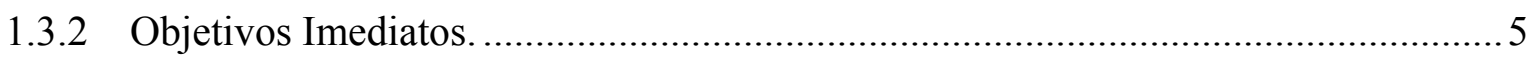

2 METODOLOGIA.....................................................................................................6

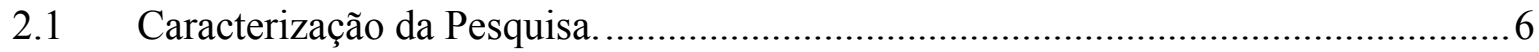

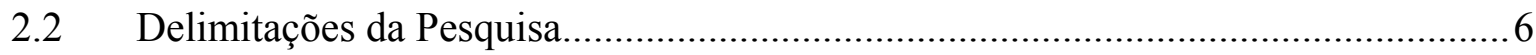

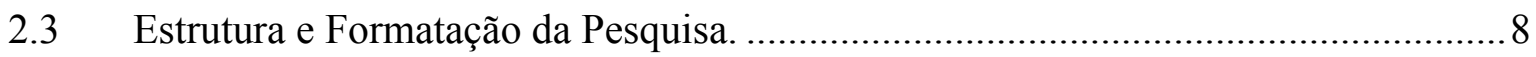

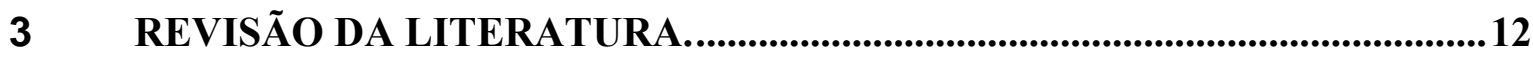

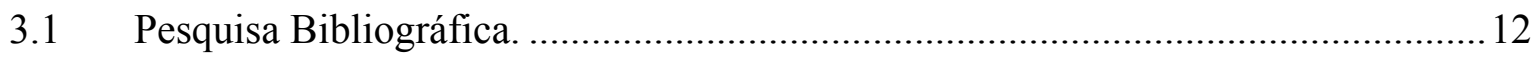

3.1.1 Evolução da Qualidade e das Normas de Sistema de Gestão da Qualidade............ 14

3.1.2 Evolução das Normas de Sistema de Gestão Ambiental. ......................................... 19

3.1.3 Evolução das Normas de Sistema de Gestão de Segurança e Saúde no Trabalho...22

3.1.4 Revisão da Abordagem de Sistema Integrado de Gestão. ........................................24

3.1.5 Evolução das Normas de Sistema de Gestão da IAEA............................................ 30

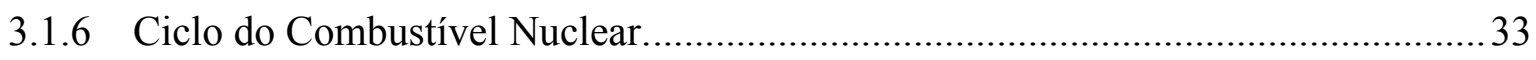


3.1.6.1 "Front End" do Ciclo do Combustível Nuclear.........................................34

3.1.6.2 Irradiação do Combustível Nuclear - Planta de Potência Nuclear............ 37

3.1.6.3 Back End" do Ciclo do Combustível Nuclear. .........................................40

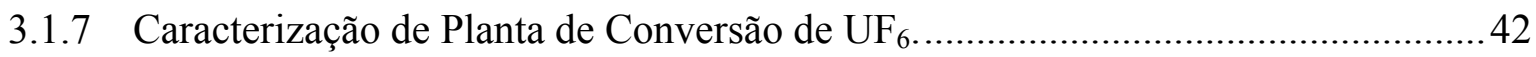

3.1.7.1 Aspectos de Segurança, Ambiental e Qualidade para o Estágio de

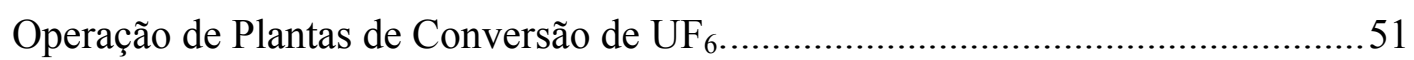

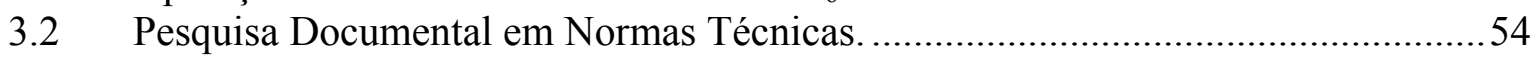

3.2.1 Estado da Arte da Norma de Sistema de Gestão da Qualidade - ISO 9001. ............55

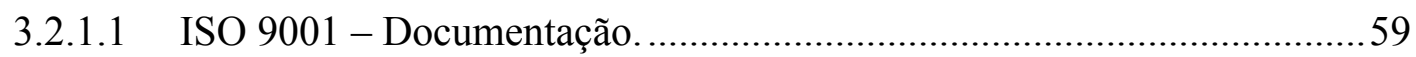

3.2.2 Estado da Arte da Norma de Sistema de Gestão Ambiental - ISO 14001.................63

3.2.2.1 ISO 14001 - Documentação...............................................................67

3.2.3 Estado da Arte da Norma de Sistema de Gestão de Segurança e Saúde no Trabalho

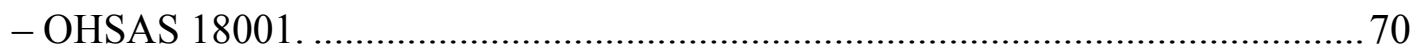

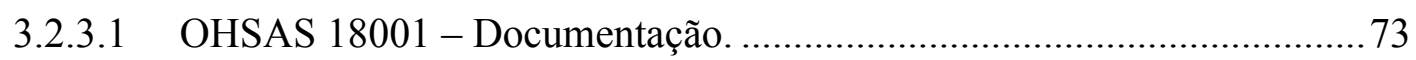

3.2.4 Estado da Arte das Normas de Sistema de Gestão da IAEA (GS-R-3, GS-G-3.1 e

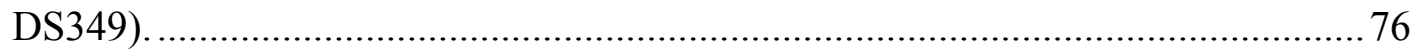

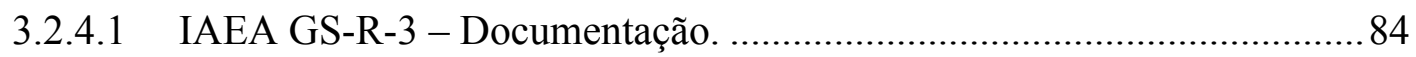

3.2.5 Estado da Arte das Normas Sobre Requisitos de Segurança da Agência, Aplicados ao Estágio de Operação de Plantas de Conversão. .................................................... 88

3.2.5.1 Estado da Arte da Norma Sobre Requisitos de Segurança - IAEA DS316.

3.2.5.2 Estado da Arte da Norma Sobre Requisitos de Segurança - IAEA DS344.

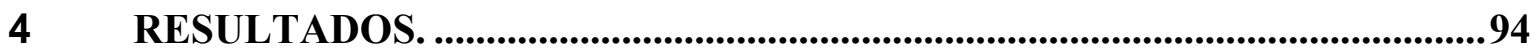

4.1 Resultado das Correlações entre as Normas de SG da IAEA (GS-R-3, GS-G-3.1 e DS349) e as ISO 9001, ISO 14001 e OHSAS 18001.

4.2 Resultado das Correlações entre as Normas de SG da IAEA (GS-R-3, GS-G-3.1 e DS349), ISO 14001 e OHSAS 14001 e os Projetos de Normas de Segurança da IAEA (DS316 e DS344). 95

4.3 Proposição de Procedimento Documental, para o Sistema de Gestão do Estágio de Operação de Plantas de Conversão de $\mathrm{UF}_{6}$. .96

4.3.1 Procedimento Documental - Manual do Sistema de Gestão, Itemização e Conteúdo.

4.3.2 Procedimento Documental - Documentos e Registros Requeridos pelas Normas.101 
5.1 Análise da Correlação entre as Normas de SG da IAEA (GS-R-3, GS-G-3.1 e DS349) e a ISO 9001.

5.2 Análise da Correlação entre as Normas de SG da IAEA (GS-R-3, GS-G-3.1 e DS349) e as ISO 14001 e OHSAS 18001.

5.3 Análise da Correlação entre as Normas de SG da IAEA (GS-R-3, GS-G-3.1 e DS349) e as Normas de Segurança da IAEA (DS316 e DS344).

5.4 Análise da Correlação entre as Normas ISO 14001 e OHSAS 18001 e as Normas de Segurança da IAEA (DS316 e DS344).

5.5 Análise do Procedimento Documental para Sistema de Gestão do Estágio de Operação de Plantas de Conversão de $\mathrm{UF}_{6}$.

6.1 Conclusões.

6.2 Recomendações.

APÊNDICE A - Procedimentos Documentados e Registros Requeridos pela ISO 9001:2000.

APÊNDICE B - Procedimentos Documentados e Documentos e Registros Requeridos pela ISO 14001:2004. 124

APÊNDICE C - Procedimentos e Programas Requeridos pela ISO 14001:2004, que podem ser Documentados ou Não. 125 APÊNDICE D - Procedimentos Documentados e Documentos e Registros Requeridos pela OHSAS 18001:2007.

APÊNDICE E - Procedimentos e Programas Requeridos pela OHSAS 18001:2007, que podem ser Documentados ou Não.

APÊNDICE F - Projetos de Norma da IAEA sobre Sistema de Gestão. 128 APÊNDICE G - Documentos e Registros Requeridos pelas Normas e Projeto de Norma da IAEA (GS-R-3, GS-G-3.1 e DS349). 131

APÊNDICE H - Correlação das Normas de SG da IAEA (GS-R-3, GS-G-3.1 e DS349) e a ISO 9001. 134

APÊNDICE I - Correlação das Normas de SG da IAEA (GS-R-3, GS-G-3.1 e DS349) e as ISO 14001 e OHSAS 18001. .145 APÊNDICE J - Correlação da Documentação Requerida pelas Normas de SG da IAEA (GS-R-3, GS-G-3.1 e DS349) e ISO 9001, ISO 14001 e OHSAS 18001............156 APÊNDICE K - Correlação entre as Normas de SG da IAEA (GS-R-3, GS-G-3.1 e DS349), ISO 14001 e OHSAS 18001 e as Normas de Segurança da IAEA (DS316 e 
DS344). 162

APÊNDICE L - Correlação entre Documentos Requeridos pelas Normas de SG e Segurança da IAEA (GS-R-3, GS-G-3.1, DS349, DS316 e DS344) e ISO 9001, ISO 14001 e OHSAS 18001. 182

ANEXO A - Processos das Plantas de Conversão da CONVERDYN, CAMECO e AREVA. 194

ANEXO B - Itemização da ISO 9001:2000. 196

ANEXO C - Recomendações da ABNT ISO/TR 10013:2002 para Documentação do SGQ. 198

ANEXO D - Sumário das Normas ISO 14001:2004 e de seu Anexo A..........................201

ANEXO E - Sumário das Seções da Norma OHSAS 18001:2007.............................202

ANEXO F - Correspondência entre os Requisitos da OHSAS 18001:2007, ISO 14001:2004 e ISO 9001:2000. 203

ANEXO G - Recomendações da IAEA para Estrutura de Informação de SG. 207

GLOSSÁRIO. .210

REFERÊNCIA BIBLIOGRÁFICA 220 


\section{LISTA DE TABELAS}

Página

TABELA 1 - Tipos de Reatores e Combustíveis Mais Utilizados....................................... 36

TABELA 2 - Tipos de Reatores em Operação Comercial .................................................... 39

TABELA 3 - Plantas Comerciais de Conversão de UF 6 em Operação................................. 43

TABELA 4 - Situação das Plantas de Conversão de UF 6 no Brasil ..................................... 44 


\section{LISTA DE FIGURAS}

Página

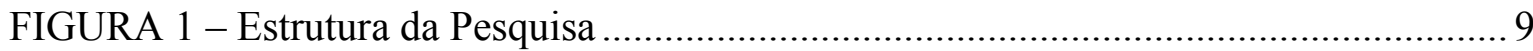

FIGURA 2 - A História da Qualidade ......................................................................... 14

FIGURA 3 - Representação do Sistema de Gestão da Especificação PAS 99 .................... 29

FIGURA 4 - Ilustração Esquemática Básica do Ciclo do Combustível Nuclear ................ 34

FIGURA 5 - Rota dos Processos da Planta de Conversão de UF $_{6}$ da Pesquisa .................... 45

FIGURA 6 - Modelo Representativo de um Sistema de Gestão da Qualidade - ISO 900157

FIGURA 7 - Modelo Representativo de um Sistema de Gestão Ambiental - ISO 14001 .. 65

FIGURA 8 - Modelo Representativo de um Sistema de Gestão de Segurança e Saúde no

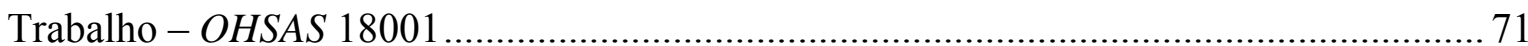

FIGURA 9 - Esquema Representativo do Sistema Integrado de Gestão de uma

Organização 


\section{LISTA DE ABREVIATURAS E/OU SIGLAS}

ABNT - Associação Brasileira de Normas Técnicas.

AEC - United Stated Atomic Energy Commission.

Agência - International Atomic Energy Agency (IAEA).

AQAP - Allied Quality Assurance Publications (NATO).

ASQ - American Society for Quality.

ASTM - American Society for Testing and Materials.

AUS - Australian Uranium Association.

BSI - British Standards Institution.

BSIA - British Standards Institution Americas.

CEA - Centro Experimental Aramar, unidade do CTMSP em Iperó/SP.

CEN - Centro de Engenharia Nuclear do IPEN.

CFR - Code of Federal Regulations (United State).

CNEN - Comissão Nacional de Energia Nuclear.

CSA - Canadian Standards Association.

CTMSP - Centro Tecnológico da Marinha em São Paulo.

DOE - United Stated Department of Energy.

DS - Draft standard (Projeto de norma da IAEA).

ESC - Estruturas, sistemas e componentes importantes à segurança.

FAO - Food and Agriculture Organization of the United Nation.

FAS - Federation of American Scientists.

FCM - Formulário de controle de modificações (MCF - Modification control form).

FIG. - Figura.

HLW - High Level Waste (Rejeito de Alto Nível de Atividade).

HSE - Health And Safety Commission/Executive.

IAEA - International Atomic Energy Agency (Agência).

INIS - International Nuclear Information System.

IPEN - Instituto de Pesquisas Energéticas e Nucleares.

TAB. - Tabela 


\section{INTRODUÇÃO.}

\subsection{Justificativa.}

É crescente a preocupação da sociedade com respeito aos aspectos que afetam a qualidade de vida tais como as questões relacionadas à qualidade dos produtos, meio ambiente e o desenvolvimento sustentado, saúde, segurança, responsabilidade social, entre outras. Como conseqüência, as organizações têm sido compelidas a considerar tais funções em suas estruturas de negócios tornando os processos de gestão mais complexos. O foco de gestão das organizações antes voltado quase que exclusivamente para atender aos requisitos dos consumidores quanto à qualidade dos produtos no sentido de reter mercado, vem sendo ampliado para satisfazer aos requisitos de outras partes interessadas no negócio.

Em virtude do exposto, além das normas de sistema de gestão voltadas à função qualidade, órgãos regulamentadores internacionais e nacionais vêm desenvolvendo outras normas que possibilitem as organizações a atenderem segmentos de gestão, tais como: meio ambiente, saúde, segurança e responsabilidade social. É dentro deste contexto que se insere a necessidade de se estruturar um criterioso e efetivo sistema integrado de gestão que compatibilize os interesses distintos e complementares das várias funções envolvidas em uma organização.

Griffith (2002) se referindo à área de construção no Reino Unido expõe que ${ }^{1}$ :

"Durante o transcorrer dos anos 90 a certificação de sistemas da qualidade ISO 9000 (ISO, 1994) era, em princípio, considerada suficiente para demonstrar o comprometimento das contratadas no fornecimento de produtos e serviços. Contudo, a necessidade de atender à introdução de novas normas, ao aumento do rigor da legislação e às crescentes demandas sociais e de negócios requer que as contratadas demonstrem, também, melhoria no desempenho ambiental e melhor gestão das questões de saúde e segurança. Mais recentemente, a ISO 9001 (ISO, 2000) vem sendo associada à ISO 14001 (ISO, 1996), especificação internacional para sistema de gestão ambiental, e à BSI-OHSAS 18001 (BSI, 1999), especificação para sistema de gestão de saúde e segurança no trabalho. As normas da International Organization for Standardization (ISO) e da British Standards Institution (BSI) contêm elementos que são comuns dentro das funções de gestão e isso desafia hoje a se questionar o uso de sistemas de gestão separados."

Townsend (1999) falando da integração de sistemas de gestão na área de construção do Reino Unido (UK) complementa o texto acima dizendo ${ }^{2}$ :

\footnotetext{
${ }^{1}$ Tradução literal do original em inglês (Griffith, 2002, p. 25-26)

2 Tradução literal do original em inglês (Bhutto \& Griffith, 2004, p. 76).
} 
"Gerentes da qualidade na indústria de manufatura e engenharia reconheceram desde cedo as vantagens de integrar sistemas e pioneiramente vêm integrando a gestão da qualidade a outros sistemas e que, apenas recentemente, organizações da área de construção do Reino Unido vêm se empenhando em traduzir seus sistemas de gestão da qualidade, ambiental e segurança, estruturados em separado, em várias combinações de sistemas ou em um único sistema integrado de gestão para aplicação na organização."

Segundo a British Standards Institution Americas (BSI, 2007a) um sistema integrado de gestão é um sistema de gestão que integra todos os sistemas e processos de uma organização dentro de uma estrutura completa, possibilitando a uma organização trabalhar como uma simples unidade com objetivos unificados.

A abordagem de sistema integrado de gestão veio para suprir a falta de visão mais holística das organizações. O dicionário Michaelis (1998, p. 1109) conceitua holístico como sendo a compreensão da realidade em totalidades integradas onde cada elemento de um campo considerado reflete e contém todas as dimensões do campo, conforme a indicação de um holograma, evidenciando que a parte esta no todo, assim como o todo está na parte, numa inter-relação constante, dinâmica e paradoxal.

Considerando esta visão de gestão integrada, a International Atomic Energy Agency, doravante denominada neste texto como IAEA ou Agência, cujo escopo de atuação inclui o estabelecimento e a promoção da aplicação de normas internacionais de segurança para a gestão de atividades na área nuclear (IAEA, 2006b), decidiu rever a estrutura do código e guias de segurança sobre Garantia da Qualidade - 50-C/SG-Q1/14 (IAEA, 1996), publicando normas sobre Sistema de Gestão, tais como as normas IAEA GS-R-3 (IAEA, 2006a) e IAEA GS-G-3.1 (IAEA, 2006c). Estas normas ampliam a abordagem de gestão incluindo em seu escopo a integração das funções segurança, saúde, ambiental, qualidade, proteção física e economia, para assegurar que a segurança nuclear é apropriadamente considerada em todas as atividades da organização (IAEA, 2006a). Segundo a IAEA (2003, p.2), o termo "Sistema de Gestão" adotado foi considerado mais apropriado do que "Garantia da Qualidade", como expresso na norma anterior, por abranger a gestão efetiva de todas as atividades importantes à organização e não apenas aquelas identificadas através da restrita aplicação da garantia da qualidade tradicional.

Na norma IAEA GS-R-3 (IAEA, 2006a, p. 3) é ressaltado que não é intenção da publicação definir todos os requisitos específicos destinados às funções de segurança, saúde, ambiental, proteção física, qualidade e economia, que já estão estabelecidos em outros documentos (em outras publicações da Agencia e em códigos e normas internacionais), e que seu propósito, complementar, é definir os requisitos de gestão para 
que esses requisitos específicos sejam cumpridos de uma forma integrada. Na norma é ressaltado ainda que os requisitos de sistema integrado de gestão cobrem tópicos relacionados diretamente à segurança nuclear ou são partes de uma estrutura gerencial sem a qual a segurança nuclear não pode ser assegurada e mantida. O termo segurança utilizado no texto da norma tem como significado a segurança nuclear, ou seja, o da obtenção das condições apropriadas de operação, prevenção de acidentes ou a mitigação das conseqüências dos acidentes, resultando na proteção dos trabalhadores, do público e do meio ambiente, contra os riscos indevidos da radiação ionizante (IAEA, 2006a, p. 20). Assim, se deve explicitar quando outros aspectos de segurança não relacionados à segurança nuclear estão sendo considerados, tais como: segurança contra incêndio, química e industrial. (IAEA, 2007b, p. 133).

As plantas de conversão de hexafluoreto de urânio $\left(\mathrm{UF}_{6}\right)$, segundo a Comissão - United State Nuclear Regulatory Commission (USNRC, 2007), usam e processam materiais radioativos, bem como outras substâncias normalmente encontradas na indústria química convencional, os riscos primários associados a uma planta desta natureza são químicos e radiológicos.

Segundo Obadia (2004, p. 8) apesar do expressivo desenvolvimento tecnológico ocorrido nas últimas décadas e dos avanços científicos sobre métodos e técnicas relacionados com a segurança do trabalho e gestão de riscos associados com a operação de processos industriais, a ocorrência de acidentes, em diversos segmentos como da petroquímica, da aviação e mais remotamente da nuclear, é uma constatação de que as características e o desempenho dos sistemas de gestão dessas organizações ainda requerem aprimoramentos.

Nesse contexto, as plantas de conversão de $\mathrm{UF}_{6}$ se inserem no perfil das organizações que requerem um elevado padrão de definição, implementação e melhoria contínua de seus sistemas de gestão, de caráter multifuncional, para o qual se aplica a estruturação de um sistema de gestão que aborde de forma integrada as funções de gestão anteriormente mencionadas, devendo ainda considerar não somente os aspectos de segurança nuclear, mas também outros aspectos de segurança encontrados na indústria química convencional.

A pesquisa tem como propósito estudar as correlações entre a nova abordagem de sistemas de gestão proposta pela Agência e aquelas de normas de mercado sobre gestão da qualidade, meio ambiente, segurança e saúde no trabalho; assim como, propor um 
procedimento documental para um sistema integrado de gestão aplicável à operação de plantas de conversão de $\mathrm{UF}_{6}$.

A pesquisa se insere no contexto atual de aplicação de sistemas integrados de gestão pelas organizações, possuindo caráter inovador no desenvolvimento desta abordagem no país e, em particular, no meio nuclear. Os resultados da pesquisa poderão vir a ser utilizados como fonte de referência para a estruturação de um sistema integrado de gestão para a operação da planta de conversão de $\mathrm{UF}_{6}$ do Centro Tecnológico da Marinha em São Paulo, a qual se encontra no estágio de implantação no Centro Experimental Aramar, no município de Iperó, em São Paulo.

\subsection{Pressupostos da Pesquisa.}

As normas de sistema gestão da Agência, como principal fórum internacional no estabelecimento de recomendações sobre segurança nuclear, devem servir de base à estruturação de sistemas de gestão para instalações nucleares.

As normas de sistema de gestão de mercado por refletirem um apelo da sociedade quanto à aplicação, pelas organizações, de conceitos de gestão que considerem a melhoria na qualidade de vida e o desenvolvimento sustentável, também devem ser consideradas na estruturação de sistemas de gestão para instalações nucleares. Acrescentese que, no caso particular das plantas de conversão de $\mathrm{UF}_{6}$, as normas de mercado devem também ser consideradas pelo fato de apresentarem características normalmente encontradas em uma indústria química convencional.

A multidisciplinaridade que envolve a gestão das organizações na atualidade requer uma visão mais holística que compatibilize os interesses distintos e complementares das várias partes interessadas e envolvidas no negócio, dentro de um sistema de gestão que aborde de forma integrada funções tais como: segurança (tanto nuclear como química, industrial, etc.), saúde, meio ambiente, qualidade, proteção física, economia, entre outras.

Um dos aspectos importantes na estruturação de um sistema integrado de gestão é buscar conciliar a documentação comum aos processos das distintas funções envolvidas; sendo, portanto, fundamental considerar esta abordagem sem que se incorra em prejuízo ao atendimento da eficácia de cada função distintamente.

A estruturação de um sistema de gestão dentro de uma abordagem integrada deve ser suficientemente flexível de modo a acomodar a dinâmica de inovação das distintas funções e interesses considerados. 
Um sistema de gestão estruturado de forma integrado para instalações nucleares deve continuar a dar ênfase à cultura de segurança nuclear e a sua contínua melhoria, objetivando a obtenção de elevados níveis de desempenho neste particular.

\subsection{Objetivos da Pesquisa.}

\subsubsection{Objetivo Superior.}

Contribuir para a estruturação, a adequação e o aprimoramento de sistemas de gestão de organizações do setor nuclear, no que se refere à abordagem integrada das funções segurança nuclear, saúde segurança e no trabalho, meio ambiente e qualidade; de modo a atender as normas da Agência e de mercado.

\subsubsection{Objetivos Imediatos.}

Objetivo 1 - Estudar a abordagem de sistema de gestão recém estruturada em normas publicadas pela IAEA compreendendo sua correlação com aqueles das normas de sistema de gestão atuais de mercado sobre segurança e saúde no trabalho, meio ambiente e qualidade, identificando lacunas, redundâncias e complementaridades entre os seus requisitos.

Objetivo 2 - Estudar os projetos de normas sobre segurança da IAEA, no que se refere ao estágio de operação de plantas de conversão de $\mathrm{UF}_{6}$, compreendendo suas correlações com as normas sobre sistema de gestão, recém publicadas pela IAEA, e as normas de sistemas de gestão atuais de mercado sobre segurança e saúde no trabalho e meio ambiente.

Objetivo 3 - Propor um procedimento documental para um sistema integrado de gestão que considere os elementos das normas de sistema de gestão da IAEA, as normas de sistema de gestão de mercado sobre qualidade, meio ambiente e segurança e saúde no trabalho e as normas de segurança da IAEA quando aplicados à operação de plantas de conversão de $\mathrm{UF}_{6}$. 


\section{METODOLOGIA.}

\subsection{Caracterização da Pesquisa.}

Do ponto de vista da metodologia científica proposta por Gil (1999), esta pesquisa se caracteriza como:

- Quanto à natureza - Aplicada: pois se propõe a gerar conhecimento para aplicação prática e dirigida ao estágio de operação de plantas de conversão de $\mathrm{UF}_{6}$.

- Quanto à forma de abordagem - Qualitativa: pois se pretende a uma interpretação conceitual de normas de sistemas de gestão, aplicadas as diferentes funções, e a atribuição desses conceitos ao aprimoramento de sistemas de gestão de plantas de conversão de $\mathrm{UF}_{6}$, não sendo traduzida em avaliações numéricas.

- Quanto ao caráter - Exploratória: pois visa proporcionar maior familiaridade com os conceitos de sistema de gestão estabelecidos em normas e seu potencial de integração, tornando explícita sua adoção a sistemas de gestão de plantas de conversão de $\mathrm{UF}_{6}$.

- Quanto ao delineamento - Bibliográfica e Documental: pois é elaborada com base em material já publicado, constituído principalmente de publicações normativas, livros, artigos de periódicos e banco de dados especializados de entidades e associações técnico-científicas disponíveis na Internet.

\subsection{Delimitações da Pesquisa.}

As delimitações a seguir apresentadas estabelecem as condições de contorno a que se restringe a pesquisa, em função de seus objetivos imediatos apresentados no item 1.2.3.

Objetivo 1 - Estudar a abordagem de sistema de gestão recém estruturada em normas publicadas pela IAEA compreendendo sua correlação com aqueles das normas de sistema de gestão atuais de mercado sobre segurança e saúde no trabalho, meio ambiente e qualidade, identificando lacunas, redundâncias e complementaridades entre os seus requisitos.

O estudo se propõe a estabelecer um quadro comparativo entre os elementos das normas de sistema de gestão da Agência - IAEA GS-R-3:2006, IAEA GS-G-3.1:2006 e IAEA DS349 rev. 2007, esta última ainda um projeto de norma, com aqueles das normas 
de sistema de gestão de mercado sobre qualidade - ISO 9001:2000, ambiental - ISO 14001:2004 - e segurança e saúde no trabalho - OHSAS 18001:2007, identificando lacunas, redundâncias e complementaridades entre os seus elementos; assim como realizando uma análise dos resultados obtidos.

A pesquisa pretende contribuir com informações que possam dar subsídios aos profissionais responsáveis por instalações nucleares na estruturação de um sistema de gestão que satisfaça de forma integrada, aos elementos comuns e complementares das normas de sistema de gestão da Agência e de mercado acima citadas.

Objetivo 2 - Estudar os projetos de normas sobre segurança da IAEA, no que se refere ao estágio de operação de plantas de conversão de $\mathrm{UF}_{6}$, compreendendo suas correlações com as normas sobre sistema de gestão, recém publicadas pela IAEA, e as normas de sistemas gestão atuais de mercado sobre segurança e saúde no trabalho e meio ambiente.

O estudo se propõe a estabelecer um quadro comparativo entre os elementos específicos sobre segurança nuclear aplicados ao estágio de operação de plantas de conversão de $\mathrm{UF}_{6}$, estabelecidos nos projetos de normas de segurança IAEA DS316 rev. 2006 e IAEA DS344 rev. 2006, com aqueles elementos das normas de sistema de gestão da Agência (IAEA R-3:2006, IAEA GS-G-3.1:2006 e IAEA DS349 rev. 2007) e das normas de sistema de gestão de mercado (Ambiental - ISO 14001:2004 e de segurança e saúde no trabalho - OHSAS 18001:2007), identificando lacunas, redundâncias e complementaridades entre tais elementos; assim como realizando uma análise dos resultados obtidos. Os estudos dos projetos de normas de segurança IAEA DS316 rev. 2006 e IAEA DS344 rev. 2006 serão limitados às seções que se relacionam ao estágio de operação de plantas de conversão de $\mathrm{UF}_{6}$.

Com este estudo a pesquisa pretende contribuir procurando entender como seria a inserção dos elementos específicos de segurança nuclear, aplicados ao estágio de operação de plantas de conversão de $\mathrm{UF}_{6}$, aos elementos de um sistema integrado de gestão estruturado conforme as normas de sistema de gestão da Agência e de mercado acima mencionadas.

Objetivo 3 - Propor um procedimento documental para um sistema integrado de gestão que considere os elementos das normas de sistema de gestão da IAEA, as normas de sistema de gestão de mercado sobre qualidade, meio ambiente e segurança e saúde no trabalho e as normas de segurança da IAEA quando aplicados à operação de plantas de conversão de $\mathrm{UF}_{6}$. 
A pesquisa se propõe a apresentar um procedimento documental que atenda aos elementos das normas de sistema de gestão da Agência (IAEA R-3:2006, IAEA GS-G3.1:2006 e IAEA DS349 rev. 2007) e de mercado (ISO 9001:2000, ISO 14001:2004 e OHSAS 18001:2007), assim como os projetos de normas sobre segurança nuclear da Agência (IAEA DS316 rev. 2006 e IAEA DS344 rev. 2006), quando limitados às seções que se relacionam ao estágio de operação de plantas de conversão de $\mathrm{UF}_{6}$.

Com a proposta de um procedimento documental, a pesquisa pretende contribuir compreendendo como seria a estruturação da documentação para o sucesso de um sistema integrado de gestão para o estagio de operação das plantas de conversão de $\mathrm{UF}_{6}$, que leve em conta as normas citadas; assim como, fornecendo subsídios para esse fim.

A planta de conversão considerada na pesquisa é a planta que converte $\mathrm{U}_{3} \mathrm{O}_{2}$ (Yellowcake) no $\mathrm{UF}_{6}$ (hexafluoreto de urânio) que serve de alimentação às plantas de enriquecimento isotópico do urânio natural.

Adicionalmente, não são considerados nesta pesquisa os requisitos referentes aos processos para transporte de material radioativo ou físsil; para tratamento, manuseio e estoque de rejeitos radioativos; e para proteção radiológica e segurança de fontes radioativas.

\subsection{Estrutura e Formatação da Pesquisa.}

A pesquisa esta estruturada em seis capítulos conforme é mostrado na FIG. 1.

\section{Capítulo 1 - Introdução.}

Neste capítulo é descrita a justificativa da pesquisa e são estabelecidos seus pressupostos e objetivos superiores e imediatos.

\section{Capítulo 2 - Metodologia.}

Neste capítulo a pesquisa é caracterizada dentro do ponto de vista da metodologia científica proposta por Gil (1999), são definidas as delimitações da pesquisa onde se estabelece as condições de contorno com respeito aos objetivos imediatos propostos e, por fim, é delineada a estrutura de abordagem da pesquisa fazendo-se um sumário de seus capítulos e conteúdo. 


\section{Capítulo 3 - Revisão da Literatura.}

A revisão da literatura é composta de uma pesquisa bibliográfica e documental.

Na pesquisa bibliográfica é feita uma revisão da bibliografia com o propósito de situar a evolução das normas sobre sistemas de gestão de mercado, no que diz respeito às funções qualidade, ambiental e segurança e saúde no trabalho, incluindo a evolução da abordagem de sistema integrado de gestão; assim como, situar a evolução das normas da Agência sobre garantia da qualidade para o conceito de sistema de gestão, que aborda de forma integrada as funções: segurança, saúde, ambiental, qualidade, proteção física, econômicas e outras.

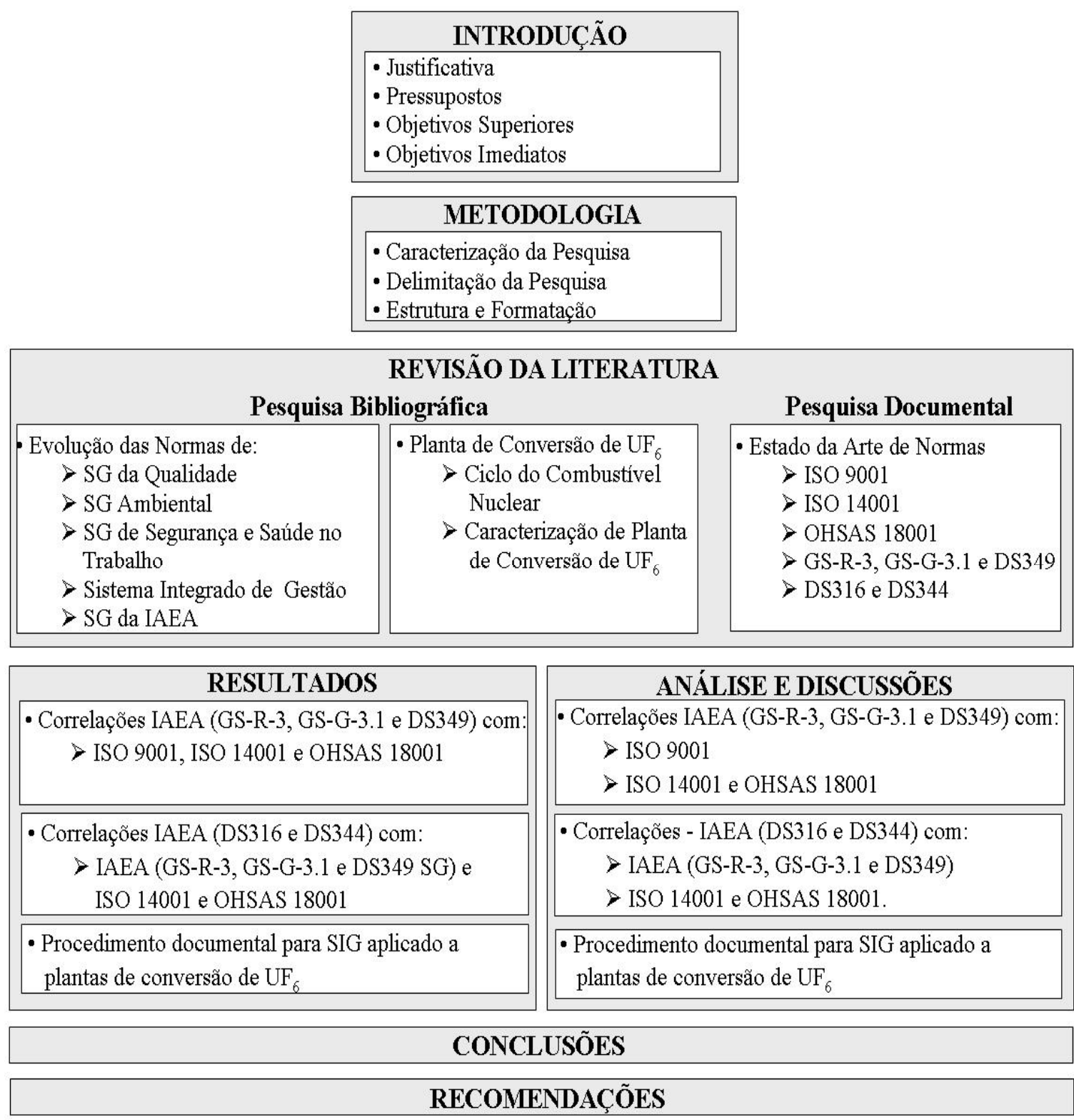

FIGURA 1 - Estrutura da Pesquisa. 
A pesquisa bibliográfica inclui, também, uma revisão do ciclo do combustível nuclear, onde é apresentada uma sinopse das etapas que compreendem o ciclo e caracterizada uma rota de processos para a planta de conversão de $\mathrm{UF}_{6}$, alvo desta pesquisa. Concluindo, é apresentada uma descrição sumária dos processos da planta e são relacionados alguns aspectos sobre segurança e qualidade característicos deste tipo de instalação.

A pesquisa documental teve como propósito fazer uma revisão sobre o estado da arte das normas consideradas na pesquisa, estudando suas estruturas e elementos; em particular, os elementos que se relacionam aos aspectos de documentação requerida pelas normas. O propósito foi atualizar o conhecimento documental, de forma a se obter um suporte para o desenvolvimento da pesquisa quanto ao estudo das correlações entre os elementos das normas consideradas, assim como da proposição de um procedimento documental para o sistema de gestão aplicado a plantas de conversão de $\mathrm{UF}_{6}$.

\section{Capítulo 4 - Resultados.}

Os resultados são apresentados seguindo a formulação dos objetivos da pesquisa, como segue:

- Objetivo 1 - Resultados das correlações entre as normas de sistema de gestão (SG) da IAEA (GS-R-3, GS-G-3.1 e DS349) e as normas sobre SG da qualidade (ISO 9001), ambiental (ISO 14001) e de segurança e saúde no trabalho (OHSAS 18001).

- Objetivo 2 - Resultados das correlações entre as normas de segurança nuclear da IAEA (DS316 e DS344) e as normas de SG da IAEA (GS-R-3, GS-G-3.1 e DS349), ambiental (ISO 14001) e de segurança e saúde no trabalho (OHSAS 18001).

- Objetivo 3 - Proposição de um procedimento documental para um sistema integrado de gestão (SIG) para o estágio de operação de plantas de conversão de $\mathrm{UF}_{6}$, considerando as normas estudadas na pesquisa.

\section{Capítulo 5 - Análise e Discussão dos Resultados.}

A análise e discussão dos resultados são apresentadas seguindo a formulação dos objetivos da pesquisa, ou seja:

- Objetivo 1 - A análise e discussão são subdivididas em dois subgrupos.

Correlações entre as normas de SG da IAEA (GS-R-3, GS-G-3.1 e DS349) e a norma sobre SG da qualidade (ISO 9001). 
Correlações entre as normas de SG da IAEA (GS-R-3, GS-G-3.1 e DS349) e as normas sobre SG ambiental (ISO 14001) e de segurança e saúde no trabalho (OHSAS 18001).

- Objetivo 2 - A análise e discussão são subdivididas em dois subgrupos.

Correlações entre as normas de segurança da IAEA (DS316 e DS344) e as normas de SG da IAEA (GS-R-3, GS-G-3.1 e DS349).

Correlações entre as normas de segurança da IAEA (DS316 e DS344) e as normas sobre SG ambiental (ISO 14001) e de SG de segurança e saúde no trabalho (OHSAS 18001).

- Objetivo 3 - Análise e discussão do procedimento documental para um SIG para o estágio de operação de plantas de conversão de $U_{6}$.

\section{Capítulo 6 - Conclusões.}

Neste capítulo são apresentadas as conclusões referentes às correlações das normas estudadas e sobre o procedimento documental proposto para o SIG.

\section{Capítulo 7- Recomendações.}

Neste capítulo são apresentadas algumas sugestões para estudos futuros sobre correlações de outras normas de sistema de gestão aplicado à operação de plantas de conversão de $\mathrm{UF}_{6}$. 


\section{REVISÃO DA LITERATURA.}

A revisão da literatura foi executada com base em pesquisa de publicações técnicas e normativas em dois segmentos:

- Sistemas de gestão de mercado sobre qualidade, meio ambiente e segurança e saúde no trabalho, bem como sobre a integração destes sistemas de gestão, e sistema de gestão e requisitos de segurança nuclear aplicado a instalações nucleares. O propósito foi obter informações e atualizar o conhecimento, de modo a:

o Pesquisa Bibliográfica - Realizar uma retrospectiva sobre a evolução desses sistemas bem como de suas normas, e

o Pesquisa Documental - Estabelecer o estado da arte das normas de mercado e nucleares, sobre o assunto, estudadas na pesquisa ${ }^{3}$.

- Plantas de conversão de $\mathrm{UF}_{6}$ e o ciclo do combustível nuclear - Pesquisa bibliográfica com o propósito de se obter informações e atualizar o conhecimento de modo a se caracterizar uma rota de processos que descreva uma planta de conversão de $\mathrm{UF}_{6}$, para a pesquisa, e a compreender o meio onde a planta em questão está inserida - o ciclo do combustível nuclear.

\subsection{Pesquisa Bibliográfica.}

A pesquisa bibliográfica foi realizada mediante consulta a livros, artigos de periódicos, dissertações de mestrado, teses de doutorado e a base de dados especializada. Foram consultados os acervos das bibliotecas do Instituto de Pesquisas Energéticas e Nucleares, Comissão Nacional de Energia Nuclear, Engenharia da Produção da Escola Politécnica da Universidade de São Paulo, Faculdade de Economia e Administração da Universidade de São Paulo, Universidade Presbiteriana Mackenzie e Centro Tecnológico da Marinha em São Paulo, assim como as bases de dados destas bibliotecas e de entidades e associações técnico-científicas especializadas nos assuntos tratados nesta pesquisa, como a seguir apresentado:

- American Society for Quality (ASQ). Disponível em: http://www.asq.org/

\footnotetext{
${ }^{3}$ Normas ISO 9001, ISO 14001, OHSAS 18001, IAEA GS-R-3, IAEA GS-G-3.1, IAEA DS349, IAEA DS316 e IAEA DS344.
} 
- Australian Uranium Association - Uranium Information Centre.

Disponível em: http://www.uic.com.au

- Areva NC. Disponível em: http://www.areva-nc.com/

- British Standards Institution. Disponível em: www.bsi-global.com/

- Cameco Corporation. Disponível em:

- Comissão Nacional de Energia Nuclear. Disponível em: http://www.cnen.gov.br/

- Converdyn. Disponível em: http://www.converdyn.com/

- Centro da Qualidade, Segurança e Produtividade. Disponível em: http://www.qsp.org.br/

- Federation of American Scientists. Disponível em: http://www.fas.org/

- International Atomic Energy Agency. Disponível em: http://www.iaea.org/

- International Nuclear Information System. Disponível em: http://inisdb.iaea.org;

- International Organization for Standardization. Disponível em: http://www.iso.org/iso/home.htm

- Instituto de Pesquisas Energéticas e Nucleares. Disponível em: http://www.ipen.br/sitio/

- Portal do Conhecimento Nuclear. Disponível em: http://portalnuclear.cnen.gov.br;

- Technical Committee 176 - International Organization for Standardization. Disponível em: http://www.tc176.org/

- United State Nuclear Regulatory Commission. Disponível em: http://www.nrc.gov/

- Web of Science. Disponível em: www.periodicos.capes.gov.br;

- World Nuclear Association. Disponível em: http://www.worldnuclear.org/

- Internet.

Os resultados da pesquisa bibliográfica são apresentados nos itens a seguir, e compreendem as seguintes revisões:

- Evolução sumária dos conceitos da qualidade, evolução das normas de mercado sobre sistema de gestão da qualidade, ambiental, segurança e saúde no trabalho, 
evolução da abordagem de sistema integrado de gestão e evolução das normas de sistema de gestão da IAEA.

- Ciclo do combustível nuclear.

- Caracterização de planta de conversão de yellowcake em $\mathrm{UF}_{6}$.

\subsubsection{Evolução da Qualidade e das Normas de Sistema de Gestão da Qualidade.}

O ser humano por questões de percepção, de segurança, de interesses comerciais, e outras, sempre almejou e perseguiu a qualidade. O que se modificou com a dinâmica do desenvolvimento, principalmente a partir do século 20 , foi a forma de gerir os recursos disponíveis para obtê-la como decorrência do avanço do conhecimento, das novas tecnologias, mudança de valores culturais e sociais, etc.

A Associação American Society for Quality apresenta em seu sítio na Internet (ASQ, 2005) um texto intitulado - The History of Quality, onde apresenta um quadro resumo sobre a evolução dos conceitos da qualidade até o nascimento da Qualidade Total, reproduzido na FIG. 2.

\begin{tabular}{|c|c|c|c|c|}
\hline \multicolumn{5}{|l|}{ Ano e Período } \\
\hline $1200-1799$ & $1800-1899$ & $1900-1940$ & 1941-1945 & 1946 \\
\hline $\begin{array}{c}\text { Artesão da } \\
\text { Europa Medieval }\end{array}$ & $\begin{array}{l}\text { Orientação } \\
\text { no Produto }\end{array}$ & $\begin{array}{l}\text { Orientação } \\
\text { no Processo }\end{array}$ & $\begin{array}{l}\text { Qualidade durante a } \\
\text { II Guerra Mundial }\end{array}$ & $\begin{array}{c}\text { Apresenta o } \\
\text { Nascimento da } \\
\text { Qualidade Total }\end{array}$ \\
\hline \multicolumn{5}{|c|}{ Prática Chave da Qualidade } \\
\hline \multirow[t]{2}{*}{$\begin{array}{l}\text { Inspeção do } \\
\text { Produto }\end{array}$} & $\begin{array}{c}\text { Inspeção do } \\
\text { Produto }\end{array}$ & $\begin{array}{l}\text { Inspeção do } \\
\text { Produto }\end{array}$ & $\begin{array}{l}\text { Inspeção por } \\
\text { Amostragem }\end{array}$ & \\
\hline & & $\begin{array}{c}\text { Controle } \\
\text { Estatístico da } \\
\text { Qualidade }\end{array}$ & $\begin{array}{c}\text { Controle } \\
\text { Estatístico da } \\
\text { Qualidade }\end{array}$ & \\
\hline
\end{tabular}

FIGURA 2 - A História da Qualidade.

Fonte: http://www.asq.org/portal/page?

O texto da Associação (ASQ, 2005), aqui descrito de forma resumida, aborda que entre os séculos 13 e 18, as categorias profissionais organizadas em sociedade já se preocupavam em desenvolver regras estritas para obter a qualidade dos produtos e serviços. Outra regra também utilizada era a marca dos mestres artesãos para identificar a boa reputação de outros artesãos. Após aquela época, e até o final do século 19, a prática 
da qualidade era a inspeção do produto. A partir de então, o foco no produto se estendeu ao processo quando foram incorporados conceitos e técnicas como o controle estatístico de processo e a inspeção por amostragem, até que; em 1946, surgiram as bases para o nascimento da qualidade total que ampliou a visão de cliente, antes direcionada unicamente ao consumidor, para a visão de partes envolvidas no negócio, que inclui, além dos consumidores, os colaboradores, os fornecedores, os acionistas, a sociedade, etc.; além de introduzir o conceito de melhoria contínua (Ciclo de Planejar, Manter e Melhorar), entre outros métodos e técnicas.

Quanto à evolução dos conceitos de sistemas da qualidade BÁES et. al. (1993, p. 4) expõem que:

“.... o histórico da evolução dos conceitos sobre sistemas da qualidade iniciou-se nos anos 20 por meio do conceito de sistemas de inspeção final e das primeiras teorias de controle estatístico da qualidade. Evoluiu pressionado pelas necessidades das áreas militar e nuclear, passando por Deming, que introduziu a aplicação de técnicas gerenciais e estatísticas; Juran, que apresentou o conceito de conformidade com as especificações, adequação ao uso e ênfase nas ações preventivas; Feigenbaum, que desenvolveu os conceitos de TQC (Total Quality Control), e Ishikawa, com o CWRC (Company Wide Quality Control), programas de qualidade participativa. Em 1970, o mundo reverenciou os produtos japoneses, pelos índices de qualidade e produtividade. E, em 1987, as normas introduziram o conceito de gestão da qualidade, onde a qualidade é fator fundamental para a sobrevivência da empresa e novos negócios."

Segundo Maranhão (2001, p. 29) e Seddon (2000), paralelamente à evolução das práticas da qualidade, a partir da $2^{\mathrm{a}}$ Guerra Mundial, com o aumento da complexidade e do grau de confiabilidade e segurança requeridos pelos produtos usados no meio militar e nuclear, países do ocidente, como os Estados Unidos da América, o Reino Unido e o Canadá, iniciaram o desenvolvimento e aplicação de normas da qualidade para aperfeiçoar seus meios de avaliar as condições dos fornecedores em assegurar a conformidade dos produtos. Neste particular, destacaram-se as normas:

- Militar dos Estados Unidos da América - Mil-Q-9858A “Quality Program Requirements", de 1959;

- Militar da Organização do Tratado do Atlântico Norte - AQAP “Allied Quality Assurance Procedures Specifications", de 1968;

- Nuclear da Comissão de Energia Atômica dos Estados Unidos da América - USAEC-10-CFR-50, Appendices B “Quality Assurance Criteria for Nuclear Power Plants and Fuel Processing Plants", de 1960; e 
- Nuclear da Agência Internacional de Energia Atômica, IAEA 50-C/SGQA - "Quality Assurance for Safety in Nuclear Power Plants - Code and Safety Guides”, de 1978.

Posteriormente, a aplicação de normas da qualidade foi estendida ao mercado consumidor, cujo foco, diferentemente do meio militar e nuclear, que preconizavam respectivamente maior confiabilidade e segurança dos produtos, era o de assegurar a qualidade do produto com o objetivo de satisfazer aos requisitos dos consumidores. Segundo Seddon (2000), o Reino Unido foi um dos primeiros a desenvolver normas comerciais neste sentido, cujo propósito era prover um documento contratual de uso comum no mercado que permitisse demonstrar que a produção era controlada.

Maranhão (1994, p. 14) explana que a Instituição - British Standards Institution (BSI) - publicou em 1979 a série de normas BS 5750 sobre sistema de gestão da qualidade, que eram uma evolução das AQAP. Estas normas, ainda segundo Maranhão, tiveram sua aplicação limitada ao Reino Unido; contudo, com pequenas mudanças, serviram de base à publicação em 1987 da primeira série de normas ISO 9000 pela Organização - International Organization for Standardization (ISO).

Seddon (2000) falando da decisão do governo Britânico em promover a adoção da série de normas BS 5750, como contraponto ao sucesso do Japão com a aplicação dos conceitos e técnicas da qualidade total, expõe que: "Sem dúvida os Ministros do Governo estavam conscientes do "Milagre Japonês" e era concebível que eles acreditassem que esta série de normas de sistema de gestão promoveria o mesmo no Reino Unido ${ }^{4}$.

Segundo Maranhão (1994, p. 14), a estrutura básica da ISO série 9000 publicada em 1987 era composta das seguintes normas ${ }^{5}$ :

- ISO 9000 - Normas de Gestão da Qualidade e Garantia da Qualidade Diretriz para Seleção e Uso.

- ISO 9001 - Sistemas da Qualidade - Modelo de Garantia da Qualidade em Projeto e Desenvolvimento, Fabricação, Montagem e Assistência Técnica.

- ISO 9002 - Sistemas da Qualidade - Modelo para Garantia da Qualidade em Produção e Instalação.

\footnotetext{
${ }^{4}$ Tradução literal do original em inglês (Seddon, 2000).

${ }^{5}$ Segundo Maranhão (1994, p. 16 - notas) esta série de normas era complementada, entre outras, pela ISO 8402 (Definições da Qualidade), ISO 10011 (Guia para Auditoria de Sistemas da Qualidade) e por vários guias, com objetivo de esclarecer detalhes específicos de implantação de Sistemas da Qualidade.
} 
- ISO 9003 - Sistemas da Qualidade - Modelo para Garantia da Qualidade em Inspeção e Ensaios Finais.

- ISO 9004 - Gestão da Qualidade e Elementos do Sistema da Qualidade Diretrizes.

A norma ISO 9000:1987 era a fonte inicial de informações sobre as demais normas da série e destinava-se a estabelecer as diferenças e inter-relações entre os conceitos da qualidade e fornecer as diretrizes para seleção e uso das ISO 9001, ISO 9002 e ISO 9003. Estas últimas eram destinadas a servir como base de contratos entre fornecedores e clientes e, por este motivo, eram conhecidas como - Normas de Qualidade Externas ou Contratuais (Maranhão, 1994, p. 16-17).

Báez et. al. (1993, p. 11) salientam que as ISO 9001, ISO 9002 e ISO 9003 especificavam três níveis seletivos para a organização do sistema da qualidade da empresa contratada fornecedora. Esta seletividade era graduada desde um sistema mais completo ISO 9001, até um sistema mais simples - ISO 9003. A ISO 9001, a mais abrangente, especificava 20 requisitos (elementos) que guiavam as organizações no desenvolvimento dos seus procedimentos da qualidade. Dentre esses requisitos, a ISO 9002 adotava 18 e a ISO 9003 adotava 12.

A ISO 9004:1987 fornecia um conjunto básico de informações para orientar as empresas a se organizarem internamente, de modo a atender aos requisitos de uma das três normas usadas para fins contratuais, citadas no parágrafo anterior. Ela estabelecia diretrizes para implementação dos requisitos definidos pela ISO 9001 (Maranhão, 1994, p. 21).

Menezes et. al. (2001, p. 1) explanam que é política da ISO promover a revisão das normas a cada cinco anos, de modo a mantê-las atuais e consistentes com as exigências do mercado.

$\mathrm{Na}$ revisão da série ISO 9000, publicada em 1994, não houve maiores alterações na arquitetura das normas ISO 9001, ISO 9002 e ISO 9003, exceto a inclusão de alguns elementos adicionais na ISO 9003. A ISO 9000 da versão anterior foi substituída pela ISO 9000-1 sendo ampliada substancialmente, particularmente no que se refere à inclusão de diretrizes conceituais que não existiam na versão anterior (ABNT, 1994, p. 2).

A partir de 1994, a série "ISO 9000” passou a ser conhecida como "família ISO 9000” (Maranhão, 2001, p. 35). 
Segundo Stimson (2006, p. 42), em 2000, a família ISO 9000 foi drasticamente reestruturada para melhorar sua adaptabilidade à forma de se organizar das empresas modernas.

Maranhão (2001, p. 30) explica que a versão 2000 da ISO 9001 teve como intenção encorajar os usuários das normas a agregarem valor às suas atividades e a melhorarem continuamente seu desempenho. A revisão exige dos usuários da norma um maior alinhamento entre suas atividades e as necessidades e expectativas dos clientes.

A família ISO $9000^{6}$ versão 2000 inclui três (3) normas primárias (IAEA, 2002b, p. 4) $)^{7}$ :

- ISO 9000 - Sistemas de Gestão da Qualidade - Fundamentos e Vocabulário.

- ISO 9001 - Sistemas de Gestão da Qualidade - Requisitos (ISO, 2000a).

- ISO 9004 - Sistemas de Gestão da Qualidade - Diretrizes para Melhoria de Desempenho (ISO, 2000b).

A norma ISO 9000 versão 2000 substituiu as normas ISO 8402:94, ISO 90001:94 e ISO 9000-2:94 (ABNT, 2000c, p. 1). A norma foi revisada em 2005 quando foram acrescentadas algumas definições e expandidas ou acrescentadas notas explicativas, de modo a considerar os recentes documentos da família ISO 9000. A ISO 9000 descreve os fundamentos do SGQ e estabelece a terminologia adotada. (ISO, 2005c).

As normas ISO 9001 e ISO 9004 versão 2000 continuam em vigor (ISO, 2007). O relatório da IAEA (2002b, p. 4) descreve que nessa versão as ISO 9001 e ISO 9004 foram desenvolvidas como um par consistente de normas e complementa que: a ISO 9001 define os requisitos do SGQ que uma organização deve cumprir para demonstrar sua capacidade de atender aos requisitos dos clientes e perseguir a satisfação desses clientes; a ISO 9004 fornece um guia dentro de uma extensão mais ampla de objetivos do SGQ do que a ISO 9001; e que estes objetivos incluem a satisfação das partes envolvidas, em adição a dos clientes, e a melhoria do desempenho da organização.

\footnotetext{
${ }^{6}$ Segundo a ABNT (2005a) as normas ABNT NBR série ISO 9000 publicadas pela ABNT, são as versões oficiais Brasileiras equivalentes às normas série ISO 9000 publicadas pela ISO, assim a menos que especificamente mencionado, as siglas ISO 9000, ISO9001 e ISO 9004 serão usadas indistintamente como referência aquelas publicadas pela ABNT quanto pela ISO.

${ }^{7}$ A ISO (2007b) apresenta a relação de normas que compõem a família ISO 9000 incluindo outras além daquelas citadas no texto.
} 
Segundo ainda o relatório da IAEA (2002b, p. 8), a versão 2000 inclui uma mudança radical na estrutura das normas ISO 9001 e ISO 9004. Enquanto mantém a essência dos requisitos originais, a versão 2000 reposicionou os 20 elementos das versões anteriores dentro de cinco seções: sistema de gestão da qualidade; responsabilidade da direção; gestão de recursos; realização do produto; e medição, análise e melhoria.

De Cicco (2003) explica que dentro da nova versão da família, a norma ISO 9001 é agora a única que estabelece requisitos, substituindo as três normas da versão de 1994 - as ISO 9001, ISO 9002 e ISO 9003. Contudo, o relatório da IAEA (2002b, p. 8) informa que a norma ISO 9001:2000 introduz o conceito de exclusão permissível de requisitos como forma de cobrir o completo espectro de organizações e atividades que a podem utilizar.

A nova versão da ISO 9001 promove a adoção da abordagem por processo em oposição à abordagem por procedimento, descrita na versão de 1994, e introduz um requisito adicional definindo um ciclo completo para melhoria da eficácia do SGQ (IAEA, 2002b, p. 8).

Em acréscimo, a família de normas veio possibilitar o alinhamento ou a sua integração com outros sistemas de gestão, tais como: gestão ambiental, gestão de saúde no trabalho e segurança e gestão financeira e de risco (ABNT, 2000a, p. 3).

\subsubsection{Evolução das Normas de Sistema de Gestão Ambiental.}

Moura (2004, p. 6) expõe que na década de 70 surgiu o conceito de "Desenvolvimento Sustentado", o qual admite a utilização dos recursos naturais de que temos necessidade hoje, para permitir uma boa qualidade de vida, porém sem que se comprometa a utilização desses mesmos recursos pelas gerações futuras. Segundo Moura, essa postura reflete, na realidade, um comprometimento entre gerações.

Em 1987, a Comissão da ONU - "Comissão Mundial sobre Meio Ambiente e Desenvolvimento da Organização das Nações Unidas" - publicou um relatório intitulado "Nosso Futuro Comum", o qual contribuiu para disseminar o conceito sobre o desenvolvimento sustentado (Moura, 2004, p. 11).

Em adição ao exposto, Valle (2003, p. 35) coloca que a partir da década de 80 a proteção ambiental passou a ser vista pelos empresários como uma necessidade, pois reduz os desperdícios com materiais e assegura a boa imagem da empresa. 
Segundo Medeiros (2003, p. 35), a década de 80 se encerrou com uma generalização das preocupações com a preservação ambiental.

Segundo Moura (2004, p. 12), em 1992 foi realizada no Rio de Janeiro a Conferência das Nações Unidas sobre o Meio Ambiente e o Desenvolvimento, também conhecida como: Rio 92, Eco 92 ou Cúpula da Terra. Nesta conferência, na qual participaram 170 países, ficou evidenciada uma mudança generalizada de maior preocupação com o meio ambiente, associada à aceitação da necessidade de desenvolvimento, passando a ser mais bem entendida a mútua dependência entre o desenvolvimento e um meio ambiente ecologicamente em equilíbrio, com conservação dos recursos para as gerações futuras (Desenvolvimento sustentável).

A ISO informa em seu sítio na Internet (ISO, 2008a) que, como forma de comprometimento com os objetivos do desenvolvimento sustentado, discutidos na Eco 92, criou em 1993 um comitê técnico, o comitê ISO/TC 207 - "Environmental Management".

Segundo o Comitê ISO/TC207 - "International Organization for Standardization - Technical Committee 207' (ISO, 2008b) - seu escopo de atuação é a padronização de ferramentas e sistemas de gestão ambiental e que suas atividades são baseadas na filosofia de que a melhoria das práticas de gestão é a melhor forma de melhorar o desempenho ambiental das organizações e seus produtos. No sítio na Internet (ISO, 2008b) é colocado que o comitê dá o suporte sob o qual as normas de sistemas de gestão ambiental da família ISO 14000 são desenvolvidas. Como conseqüência, o comitê publicou em 1996 a primeira versão da família de normas ISO 14000 - “Environment Management Systems", em particular, as ISO 14001 e ISO 14004.

A primeira norma publicada sobre sistema de gestão ambiental foi a BS-7750 "Specification for Environment Management Systems", pela BSI em 1992. Esta norma segundo a BSI (2008a) serviu de base à publicação da norma ISO 14001:1996.

Segundo Santos (2008), a família ISO 14000 é derivada da experiência da ISO acumulada na elaboração das normas da família ISO 9000 e da necessidade que diversos países sentiram em criar suas próprias normas de gestão ambiental. Ainda segundo Santos, a partir do estabelecimento dos princípios da qualidade total e do surgimento da série de normas ISO 9000, os conceitos de defeito e de retrabalho foram incorporados à linguagem das empresas e, de lá pra cá, o conceito de defeito foi sendo associado à poluição e o tratamento e disposição final dos resíduos, ao conceito de retrabalho. 
As normas ISO $14001^{8}$ e ISO 14004 foram revisadas respectivamente em 2004 e 2005 (ABNT, 2004a; 2005b).

A edição atual da ISO 14001 busca o esclarecimento da primeira edição, para auxiliar o seu entendimento, e leva em consideração as disposições da ISO 9001:2000 de maneira a aumentar a compatibilidade entre as duas normas, para benefício da comunidade de usuários (ISO, 2004a, p. v).

Segundo texto do sítio na Internet da BSI (2004), para facilitar o seu uso, a numeração dos requisitos e cláusulas da ISO 14001 estão agora mais correlacionadas aos do seu anexo A. Além disso, em muitos casos, os requisitos que estabeleciam que - "a organização deve estabelecer e manter" - foram mudados para - "a organização deve estabelecer, implementar e manter". Da mesma forma, o termo - "pessoal" - foi substituído na norma para - "pessoas que trabalham para a organização ou em nome dela". Esta distinção assegura que contratados externos sejam considerados em certas cláusulas da norma.

A ISO 14001:2004 especifica requisitos para que um sistema de gestão ambiental (SGA) capacite a organização a desenvolver e implementar política e objetivos e elementos que levem em consideração requisitos legais e informações sobre aspectos ambientais significativos. O que se pretende é que a norma se aplique a todos os tipos e portes de organizações e seja adequada a diferentes condições geográficas, culturais e sociais. (ABNT, 2004a, p. 1).

A ISO 14004:2005 fornece assistência às organizações que desejam implementar ou aprimorar um SGA e, por conseqüência, aprimorar seu desempenho ambiental. Ela é coerente com o conceito de desenvolvimento sustentável e compatível com estruturas culturais, sociais e organizacionais diversificadas, assim como com diferentes sistemas de gestão (ABNT, 2005b, p. v).

Moura (2004, p. 15) expõe que, no que diz respeito ao lado empresarial nota-se que, a emissão das normas BS 7750 e, mais recentemente, das normas da família ISO 14000, vêm motivando as empresa a investirem em melhorias ambientais por meio da implantação de SGA e maior cuidado quanto aos processos de fabricação, relacionados aos produtos e rejeitos gerados, visando a atender as expectativas dos consumidores.

\footnotetext{
${ }^{8}$ Segundo a ABNT (2004a, p.iv; 2005b, p.iv) as normas ABNT NBR ISO 14001 e ABNT NBR ISO 14004 publicadas pela ABNT, são as versões oficiais Brasileiras equivalentes às normas ISO 14001 e ISO 14004, assim, a menos que especificamente mencionado, as siglas ISO 14001 e ISO 14004 serão usadas indistintamente como referência aquelas publicadas pela ABNT, quanto pela ISO.
} 


\subsubsection{Evolução das Normas de Sistema de Gestão de Segurança e Saúde no Trabalho.}

Segundo De Cicco (1997), desde a revolução industrial já havia uma preocupação da sociedade na reparação aos danos à saúde e integridade física dos trabalhadores, porém, praticamente não se pensava em qualquer ação, atitude ou medida de prevenção neste sentido. Ainda segundo De Cicco, por volta de 1926, H.W. Heinrich pôde observar através de estudos, o alto custo que representava para a companhia de seguros americana, para a qual trabalhava, reparar os danos decorrentes de acidentes e doenças do trabalho, iniciando atividades que privilegiavam a prevenção de acidentes dentro das empresas. Em 1966, Frank Bird Jr. (norte americano) propôs um novo enfoque ao qual denominou "Loss Control", a partir da idéia de que a empresa deveria se preocupar não somente com os danos aos trabalhadores, mas também com os danos às instalações, aos equipamentos e aos seus bens em geral. Em 1970, John Fletcher (canadense) incrementou o enfoque de Frank Bird Jr englobando as questões de proteção ambiental, de segurança patrimonial e de segurança do produto, ao qual denominou como "Total Loss Control".

Segundo texto da BSI (1996), o bom desempenho em saúde e segurança não é casual, as organizações devem dispensar a mesma importância à obtenção de altos padrões de gestão de segurança e saúde no trabalho, como o fazem com respeito a outros aspectos importantes de suas atividades empresariais. A BSI coloca que esse procedimento requer a adoção de uma abordagem estruturada para com a identificação, avaliação e controle dos riscos relacionados como o trabalho. Assim sendo, a BSI publicou em 1996 a norma sobre gestão de segurança e saúde no trabalho - BS 8800 "Guide to Occupational Health and Safety Management Systems".

Em 1999 foi publicada a especificação OHSAS 18001 - Occupatioanal Health and Safety Management Systems Specification. Esta especificação e sua associada OHSAS 18002:2000 - Guidelines for the implementation of OHSAS 18001, conhecidas como série de avaliação de segurança e saúde no trabalho (Occupational Health and Safety Assessment Series), foram desenvolvidas em resposta à urgente demanda de mercado por um padrão reconhecido de sistema de gestão de segurança e saúde no trabalho, contra o qual os sistemas de gestão das organizações possam ser avaliados e certificados (BSI, 1999).

Segundo Jorgensen et. al. (2004, p. 7), a OHSAS 18001:1999 foi formulada por um corpo de certificadores internacionais com base na BS 8800:1996 sendo usada 
como base para certificação de sistemas de segurança e saúde no trabalho. A organização ISO - "International Organization for Standardization" - por duas vezes votou a possibilidade de desenvolver uma norma neste campo e, em ambos os casos, a proposta não foi aceita. A OHSAS 18001:1999 foi desenvolvida para ser compatível com a ISO 9001:1994 e ISO 14001:1996 de forma a facilitar a integração, pelas organizações, de sistemas de gestão da qualidade, ambiental e de segurança e saúde no trabalho.

Jorgensen et. al. (2004, p. 7) expôs que, em função das novas versões da ISO 9001:2000 e ISO 14001:2004, a OHSAS 18001 iria necessitar de uma revisão, pois ela é baseada nestas duas normas e deveria permanecer compatível com as mesmas.

Segundo a BSI (2007c), a norma OHSAS 18001 foi revisada em 2007 tendo um número significativo de modificações, sendo as principais, sua maior ênfase à "saúde" mais do que à segurança, e uma significativa melhoria de seu alinhamento à ISO 14001:2004, de forma a permitir o desenvolvimento de "sistemas integrados de gestão"

A Risk (2007, p. 5), que publicou a OHSAS 18001 no Brasil, informa que, na revisão de 2007 a OHSAS 18001 se autodenominou uma norma e não uma especificação como na edição anterior. Ainda segundo a Risk, as principais mudanças introduzidas na nova versão foram, entre outras:

- A maior ênfase à importância da "Saúde".

- A melhoria no alinhamento com a ISO 14001:2004 e aumentando a compatibilidade com a ISO 9001:2000.

- A introdução de novos requisitos para considerar a hierarquia dos controles, como parte do planejamento da segurança e saúde no trabalho (SST), para a participação dos trabalhadores e consulta aos terceirizados, para a investigação de incidentes e para a avaliação do atendimento a requisitos legais e outros - neste caso uma nova seção.

- A adição de novas definições e revisão das existentes.

- O tratamento mais explícito para a gestão de mudanças.

A nova edição da OHSAS 18001, segundo ainda a Risk (2007, p. 8), busca esclarecimento da primeira edição, para auxiliar o seu entendimento, e considera às disposições da ISO 9001, ISO 14001, ILO-OSH (International Labour Organization Occupational Safety and Health Management) e de outras normas e publicações sobre SGSST, de maneira a aumentar a compatibilidade entre essas normas, em benefício da comunidade de usuários. 
De acordo com a norma OHSAS 18001 (Risk, 2007, p.16), um sistema de gestão de segurança e saúde no trabalho - SGSST - é a parte do sistema de gestão de uma organização utilizada para desenvolver e implementar sua política de SST e para gerenciar seus riscos de SST. E ainda que, um sistema de gestão inclui a estrutura organizacional, atividades de planejamento (incluindo, por exemplo, a avaliação de riscos e o estabelecimento de objetivos), responsabilidades, práticas, procedimentos, processos e recursos.

\subsubsection{Revisão da Abordagem de Sistema Integrado de Gestão.}

Como conseqüência da crescente preocupação da sociedade com respeito aos aspectos que afetam a qualidade de vida, as organizações têm sido compelidas a considerar na estrutura de seus sistemas de gestão, questões como: qualidade, meio ambiente e o desenvolvimento sustentado, segurança e saúde no trabalho, responsabilidade social, entre outras; tornando cada vez mais complexo o processo de gestão. O foco das organizações antes voltado quase que exclusivamente para atender aos requisitos dos consumidores quanto à qualidade de seus produtos, vem sendo ampliado para satisfazer aos requisitos de outras partes interessadas ou influenciadas pelo negócio. Como decorrência, organizações normalizadoras internacionais e nacionais vêm desenvolvendo normas que possibilitam as organizações a atenderem outros segmentos de gestão, além da qualidade, tais como: meio ambiente e segurança e saúde no trabalho. Griffith (2000, p. 233) expõe que?:

"Na década de 90, a certificação ISO 9000:1994 era, na essência, considerada suficiente para que as empresas demonstrassem seu comprometimento com o fornecimento de produtos e serviços. Entretanto, a necessidade de atender ao surgimento de novas normas, à legislação cada vez mais rigorosa e ao aumento da demanda de negócios, vêm se requerendo das empresas que demonstrem seu desempenho, também, nas questões ambientais e na melhor gestão das questões de saúde e segurança."

Segundo Jorgensen et. al. (2004, p. 10), o foco sobre a capacidade das organizações em lidar com diferentes sistemas de gestão tornou-se mais importante por causa do crescente número de responsabilidades e demandas advindas dos stakeholders (partes interessadas) externos, que resultou em maior complexidade organizacional. A empresa enfrenta desafios em assegurar uma sinergia entre os sistemas de gestão, de se

\footnotetext{
${ }^{9}$ Tradução literal do original em inglês Griffith (2000, p. 233).
} 
adaptar mais rapidamente às mudanças de mercado e de se manter atualizada nas expectativas dos stakeholders, nas mudanças em regulamentações, etc.

Patrício (2004) expõe que, a evolução verificada nos últimos anos nas economias desenvolvidas, em todos os níveis, tem conduzido a uma abordagem de gestão que apresenta uma crescente tendência integradora das vertentes de gestão individuais, tais como: qualidade, ambiental e segurança e saúde no trabalho; a partir do conhecimento cada vez mais aprofundado e rigoroso de cada uma dessas vertentes. Esta perspectiva, embora recente, tem obtido cada vez mais adesão das organizações. De fato, as vantagens da integração têm um impacto substancial no sucesso organizacional, justificando o empenho das pessoas envolvidas em ultrapassar as dificuldades desse percurso. Desta forma, seja com vista à obtenção de certificação ou como guia para a melhoria do desempenho, o desenvolvimento de uma abordagem integrada, destas vertentes, deve orientar as políticas de qualquer organização de pequeno ou grande porte, pública ou privada, de bens ou serviços.

A Instituição BSI, em seu sítio na Internet (2007a), conceitua sistema integrado de gestão (SIG) como sendo um sistema de gestão que integra todos os sistemas e processos organizacionais dentro de uma estrutura única, permitindo à organização trabalhar como uma unidade única, com objetivos unificados. No sítio na Internet a BSI complementa que, com um SIG a organização torna-se um todo unificado, com cada função alinhada a uma única meta que é a de melhorar o desempenho de toda organização. O SIG é um genuíno sistema, coordenando um sistema que é maior do que a soma de suas partes, e que pode realizar mais do que jamais realizou. E ainda que, um SIG provê uma clara descrição holística de todos os aspectos da organização, e de como eles afetam um ao outro, e seus riscos associados. Com o SIG há menos duplicação e torna-se fácil adotar novos sistemas no futuro. Um SIG permite a uma equipe gerencial criar uma estrutura que pode ajudar uma organização a atingir seus objetivos de forma eficaz e eficiente.

Como conseqüência, verifica-se o quão complexo tem se tornado o processo de gestão pelas organizações. De acordo com Lopes et. al. (2002): “A transdisciplinaridade passa a ser a principal dinâmica de uma organização global,...”, e ainda, “... transdisciplinar e não simplesmente multidisciplinar e interdisciplinar”.

Capelas et. al. apud Patrício (2001) explicam que as vantagens da integração dos sistemas são muitas. Desde logo se obtêm ganhos de eficiência resultantes da utilização de estruturas comuns, sobretudo as equipes responsáveis pela gestão dos sistemas, permitindo uma gestão mais eficiente dos recursos humanos da empresa, 
podendo mesmo tal ganho estender-se às auditorias, que poderão ser realizadas conjuntamente. Os encargos com a implantação e manutenção dos sistemas, sobretudo ao nível da gestão documental passam também a ser mais reduzidos.

Segundo Jorgensen et. al. (2004, p. 8), uma condição básica para se integrar sistemas de gestão é o comum entendimento das organizações e de como elas operam. Nos livros textos sobre gestão da qualidade, a versão antiga da ISO 9000 vinha sempre ilustrada por uma pirâmide - simbolizando uma organização estável com política, procedimentos e instruções claras nos níveis estratégicos, táticos e operacionais. Jorgensen et. al. prossegue colocando que, a crítica da gestão pela qualidade total em relação a ISO 9000 tem sido especialmente no sentido de que seja fortalecida a importância do comprometimento da alta direção, da participação dos empregados, tanto quanto para o da criação de uma cultura da qualidade. Essa crítica tem se refletido na norma ISO 14001, que sempre é ilustrada mediante uma espiral focando um processo interativo de atividades, como política, planejamento, implementação, etc.; tão bem quanto uma ênfase na inovação e na melhoria contínua. Ainda segundo Jorgensen et. al., esse entendimento mais dinâmico de organização parece ser, para o momento, o ponto de transformação de como as normas devem ser formuladas.

Jorgensen et. al. (2004, p. 12) expõem ainda que, um SIG consiste dos elementos núcleos das normas, tais com da política, planejamento, implementação, medição e monitoração e análise crítica da gestão, tão bem quanto da organização de um manual comum, com a documentação dos procedimentos, etc. Entretanto, eles enfatizam que isso é apenas o sistema e que para fazer o sistema operar na organização, há um comum desafio no que se refere à obtenção do comprometimento da direção, motivação e participação dos empregados, envolvimento das partes interessadas e foco na contínua melhoria do desempenho nas diferentes áreas. Em outras palavras, o verdadeiro desafio para construir um SIG está na mudança da cultura e tradição organizacional.

Segundo Asif et. al. (2008, p. 5) a importância direcionada à cultura na implementação de um SIG foi ilustrada por Wilkinson e Dale (1999), que observaram que, a cultura organizacional é a questão chave na integração de sistemas de gestão. Ainda segundo Asif et. al., similarmente, Sigler e Pearson (2000) observaram que a cultura é ocasionalmente considerada como uma das razões por trás do sucesso (ou da falha) de qualquer implementação de sistemas.

Segundo Mcdonald et. al. (2003, p. 74) não existe um SIG correto; cada organização deve levar em consideração sua cultura coorporativa e a natureza de seus 
negócios, quando forem decidir quanto ao grau de integração a adotar. Quanto à integração de sistemas da qualidade, ambiental e segurança e saúde no trabalho, em particular, Mcdonald et. al. complementam que são vários os benefícios decorrentes, tais como a:

- Similaridades entre os programas - Todos os três sistemas estão filosoficamente alinhados (a estrutura e a abordagem para atender os requisitos regulatórios são similares).

- Similaridades dos sistemas - Empregados trabalhando em SIG podem executar suas funções usando um único conjunto de instruções de trabalho, ao invés de múltiplos documentos de diferentes sistemas, algumas vezes conflitantes.

- Otimização de recursos- Um sistema que atenda aos requisitos dos três sistemas minimiza os recursos requeridos para desenvolver, implementar e manter estes sistemas em separado.

- Melhoria do desempenho organizacional - Um sistema formal que ajude a identificar problemas potenciais, riscos e perigos pode reduzir ou eliminar reclamações de clientes, não-conformidades de produtos, acidentes, doença ou incidentes ambientais no local de trabalho.

- Integração dos diferentes objetivos dentro da estratégia total de negócios - Elimina a idéia de que qualidade, meio ambiente e segurança e saúde no trabalho são partes separadas ou não essenciais aos negócios.

- Estabelecimento de uma única estrutura para a contínua melhoria de sistemas da qualidade, ambiental e segurança e saúde no trabalho.

Entretanto, Mcdonald et. al. (2003) colocam que existem também limitações para integração desses sistemas, tais como a:

- Tendência em se desenvolver processos burocráticos e com excesso de documentação - Isso é verdadeiro para sistemas individuais de gestão e aumenta para sistemas que pretendem atender múltiplas normas.

- Competição - Se o sistema de gestão da qualidade (SGQ) já existe, os profissionais de meio ambiente e de segurança e saúde no trabalho, freqüentemente, resistem em introduzir seus requisitos dentro do sistema existente; assim como, os profissionais de qualidade resistem em "contaminar" seu sistema com requisitos que não estão relacionados à qualidade dos produtos. 
- Limites no grau de integração - A ISO 14001:1996 e OHSAS 18001:1999 são altamente compatíveis, mas não são facilmente integradas ao SGQ (ISO 9001:2000) existente.

Segundo Jorgensen et. al. (2004, p. 10) o risco na integração de sistemas de gestão das funções citadas, é a possibilidade de se criar uma classificação entre os diferentes aspectos envolvidos, como por exemplo, dando mais atenção aos aspectos da qualidade do que aos de ambiental ou segurança e saúde no trabalho, ou vice-versa. Jorgensen et. al. expõem que, ao se decidir pela implementação de um projeto de SIG, o nível de integração a ser obtido por uma organização dependerá, de ambos, da complexidade de seu sistema ou sistemas de gestão existentes e da vontade da mesma em perseguir a integração.

Asif et. al. (2008, p.9) explanam que várias estratégias para implementação de SIG têm sido descritas pela literatura, tendo diferentes orientações e exibindo variação no grau de integração. Dentre as várias estratégias Asif et. al. apresentam duas que foram propostas por Wilkinson e Dale (2002) para unificação de normas de sistemas de gestão, a de alinhamento e a de integração. Estas estratégias também são descritas por Jorgensen et. al. (2004, p. 11):

- Estratégia de alinhamento - Um paralelismo dos sistemas usando as similaridades das normas (termos e conceitos) para estruturar o sistema, ou seja, somente as partes comuns das normas são adotadas. O propósito do alinhamento é reduzir os custos administrativos e de auditoria. Ainda são usados procedimentos separados para cada área de gestão específica, mas localizados em um único manual.

- Estratégia de integração - Integração completa de todos os procedimentos e instruções relevantes. Abordagem na gestão pela qualidade total (GQT), com foco sobre os empregados, clientes e na melhoria contínua.

De Cicco (2006) transcreve o pronunciamento de John Hele, responsável mundial pela gestão da qualidade da certificadora BSI Management Systems, sobre as vantagens de se integrar sistemas de gestão, tais como os de gestão da qualidade ISO 9001:2000, gestão ambiental ISO 14001:2004 e gestão da segurança da informação ISO/IEC 27001:2005:

"A questão de se integrar sistemas de gestão é uma fonte potencial de desastre se não for bem gerenciada. Com mais de um sistema de gestão em uso, as auditorias ficam mais complicadas, sem falar do seu planejamento e da conformidade com requisitos legais. Faz todo sentido, portanto, estruturar todas elas sob um único sistema integrado. Estamos tentando 
fazer com que os sistemas de gestão evoluam, unificando-os, a fim de tornar a avaliação mais eficiente e eficaz".

Segundo De Cicco (2006), foi por todos esses motivos que a entidade britânica de normas - a BSI - foi instada a desenvolver a primeira especificação do mundo sobre requisitos comuns de SIG, a PAS 99:2006 - "Publicly Available Specification"; a qual pode se constituir no primeiro passo rumo a uma futura norma internacional da ISO sobre o assunto. De Cicco explica ainda que, a PAS 99 fornece um modelo simples para as organizações integrarem em uma única estrutura todas as normas e especificações de sistemas de gestão que venham a adotar.

No guia da BSI (2007b) é informado que a PAS 99 possibilita as organizações, com mais de um sistema de gestão, criar um único sistema de gestão, holístico, tornando as operações mais efetiva. Segundo exposto no guia, a PAS 99 é uma especificação sobre requisitos de SIG baseada nos seis requisitos da ISO guia 72:2001 - "Guidelines for the justification and development of management system standards"; ou seja, política; planejamento, implementação e operação, avaliação do desempenho, melhoria e análise crítica da gestão. A especificação PAS 99 segue a abordagem do PDCA - Planejar, Executar, Verificar e Agir, conforme é mostrado na FIG. 3.

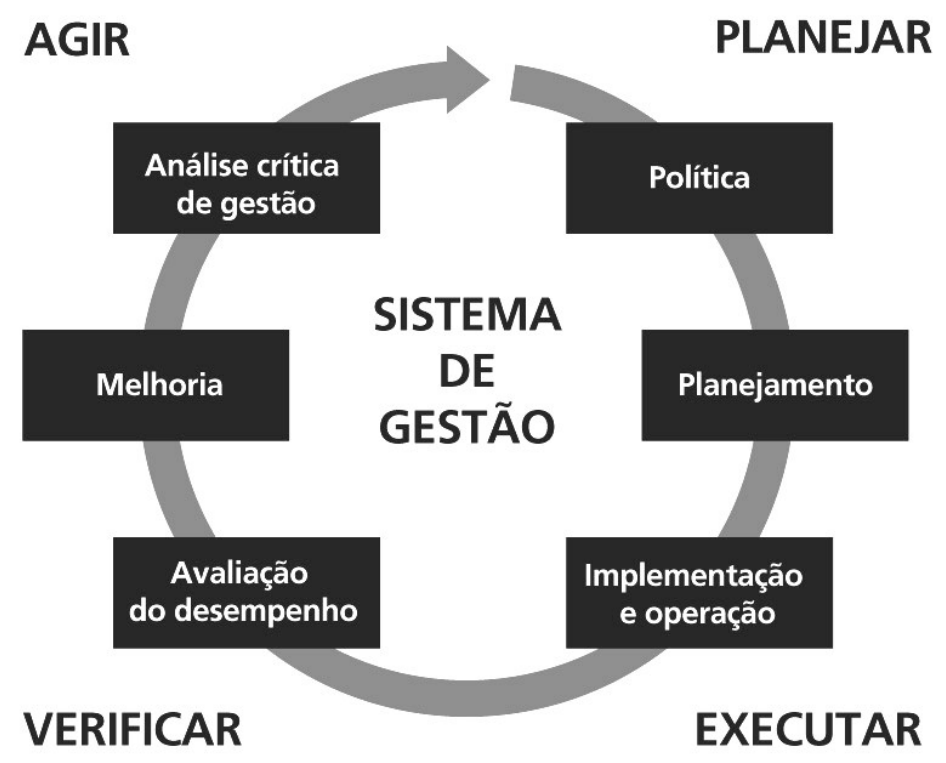

FIGURA 3 - Representação do Sistema de Gestão da Especificação PAS 99.

Fonte: PAS 99 Integrated Management. (www.bsiamerica.com/enus/Forms/Documents/Integrated-Management-Docume.aspx)

De Cicco (2006) expõe que o principal objetivo da PAS 99 é simplificar a implementação de múltiplos sistemas e sua respectiva avaliação de conformidade. Na PAS 99 é enfatizado que as organizações devem incluir como entrada do sistema integrado os 
requisitos específicos das normas por elas adotadas, tais como, por exemplo, os requisitos específicos da ISO 9001, ISO 14001, ISO/IEC 27001, ISO 22000, ISO/IEC 20000 e OHSAS 18001.

No guia da BSI (2007b) é informado que, cumprir os requisitos da PAS 99 não assegura o cumprimento formal ou informal de outras normas ou especificações. No guia é enfatizado que, o propósito da especificação PAS 99 é dar o suporte necessário para que sejam cumpridas todas as normas incorporadas ao sistema integrado de gestão da organização.

Dentro desse contexto de integração de sistemas de gestão, a Agência (International Atomic Energy Agency) está desenvolvendo um novo conjunto de normas de segurança direcionadas ao estabelecimento de requisitos e orientações para sistemas de gestão que integrem os objetivos de segurança, saúde, ambiental e de garantia da qualidade, e que assegure que a segurança nuclear não seja comprometida (IAEA, 2007c). Como resultado, entre outras normas em desenvolvimento, publicou em 2006 a IAEA GSR-3 - "The Management System for Facilities and Activities - Safety Requirements" - e a IAEA GS-G-3.1 - "Application of the Management System for Facilities and Activities Safety Guide".

Segundo artigo publicado pela Agência (Dahlgren et. al., 2007, p. 15), a norma IAEA GS-R-3 aborda, como parte integrante do SIG, a promoção e o suporte de uma forte cultura de segurança e o reforça as questões de liderança e de responsabilidades pela gestão do sistema.

\subsubsection{Evolução das Normas de Sistema de Gestão da IAEA.}

A primeira série de normas sobre qualidade publicada pela Agência foi a 50C/SG-QA - Código e Guias de Segurança, em 1978. A 50-C-QA - norma código da série definia 13 critérios que deveriam ser adotados no estabelecimento e implementação de programas de garantia da qualidade, com o objetivo de prover segurança às plantas nucleares de potência. Em 1996, a série foi revisada, mantendo a mesma estrutura da versão anterior, tendo alterado seu número para 50-C/SG-Q - Código e Guias de Segurança (IAEA, 1996), sendo a Garantia da Qualidade elevada à categoria de Segurança Geral, por se reconhecer a relevância de sua aplicação a outras instalações nucleares além daquela inicialmente prevista - plantas nucleares de potência (IAEA, 2003a/b). 
El Baradei (IAEA, 2006a) relata ${ }^{10}$ que:

"Em meados dos anos 90 foi iniciado pela IAEA um extenso programa de completa modificação de suas normas de segurança, com uma revisão da estrutura do comitê de supervisão e uma abordagem sistemática para atualização de todo o corpo de normas. As novas normas que têm resultado deste programa são de alto valor e refletem as melhores práticas utilizadas pelos estados membros. Com a assistência da Comissão sobre Normas de Segurança, a IAEA está trabalhando para promover a aceitação e uso global de suas normas de segurança."

Dentro deste contexto, a Agência expõe em seu sítio na Internet (IAEA, 2007c) que está desenvolvendo um novo conjunto de normas de segurança direcionadas ao estabelecimento de requisitos e a prover orientações para Sistemas de Gestão, que integrem os objetivos de segurança, saúde, ambiental e de garantia da qualidade. Como resultado das revisões em andamento, a Agência publicou em 2006 as normas:

- IAEA GS-R-3 - "The Management System for Facilities and Activities Safety Requirements", que substitui o código 50-C-Q (IAEA, 2006a, p. 2); e

- IAEA GS-G-3.1 - "Application of the Management System for Facilities and Activities - Safety Guide", que substitui os guias 50-SG-Q1 a Q7 (IAEA, 2006c, p. 1).

O perfil de preparação de documento DPP339 (IAEA, 2003c, p. 2) estabelece o processo para a substituição dos guias de segurança 50-SG-Q8 a 14, que tratam especificamente dos estágios do ciclo de vida de plantas nucleares de potência e outras instalações nucleares, cujo propósito é o de se produzir orientações mais atualizadas que reflitam uma melhoria nas práticas de gestão das instalações nucleares, com base na experiência obtidas pelos estados membros, e que venha a completar e se harmonizar, dentro da nova estrutura de documentos de sistema de gestão da Agência. Com este propósito, o projeto de norma sobre o tema - IAEA DS349 - "Application of the Management System for Facilities - está em fase de aprovação pelos Comitês NUSSC ${ }^{11}$, $\operatorname{RASSC}^{12}$, WASSC ${ }^{13}$, para que seja submetido à Comissão de Normas de Segurança da IAEA (2008c).

O termo "Sistema de Gestão" adotado na série atual de normas, ao invés de "Garantia da Qualidade", como expresso na série anterior, reflete uma evolução da abordagem inicial do conceito de controle da qualidade (controle da qualidade de produtos), para o de garantia da qualidade (sistema para garantir a qualidade de produtos)

\footnotetext{
${ }^{10}$ Tradução livre do original em inglês.

${ }^{11}$ NUSSC - Nuclear Safety Standards Committee

${ }^{12}$ RASSC - Radiation Safety Standards Committee

${ }^{13}$ WASSC - Waste Safety Standards Committee
} 
e, agora, o de gestão da qualidade (sistema para gestão da qualidade). O "Sistema de Gestão" é um conjunto de elementos inter-relacionados e interativos (sistemas) para estabelecer política e objetivos e alcançar estes objetivos (Vincze, 2004a).

A série de normas atual preconiza que o sistema de gestão deve ser obtido de forma a assegurar a proteção das pessoas e do meio ambiente, e que o principal objetivo desse sistema deve ser o de assegurar que a segurança nuclear não seja comprometida (IAEA, 2006a).

Segundo Vincze (2004a), a integração prevista na série tem como propósito garantir que, as questões de economia, meio ambiente, saúde e qualidade, não sejam consideradas separadamente das questões de segurança, de modo a se evitar qualquer impacto potencial negativo em relação à segurança nuclear

Segundo artigo publicado pela Agência sobre melhoria do desempenho organizacional (Dahlgren et. al., 2007, p. 13 - 15), quando comparadas em detalhe as normas IAEA GS-R-3 e 50-C-Q apresentam claros aspectos comuns e também diferenças; entretanto, ressalta que é importante mencionar que ambas as normas buscam assegurar que a segurança seja realçada e não compromissada. O texto expõe as diferenças e similaridades entre as duas normas e apresenta o que é novidade nas normas sobre sistema de gestão da IAEA (GS-R-3 e GS-G-3.1). Em linhas gerais, a IAEA GS-R-3 define requisitos para ajudar as organizações a estabelecer, implementar, avaliar e continuamente melhorar um SG, que integre os elementos de segurança, saúde, ambiental, proteção física, qualidade e economia, para criar uma forte cultura de segurança e a melhoria do desempenho da segurança, em todas as atividades da organização; enquanto que, a 50-C-Q define requisitos para ajudar as organizações a estabelecer e implementar um programa de garantia da qualidade para realçar a segurança nuclear pela continua melhoria dos métodos empregados em busca da qualidade.

Segundo ainda o artigo citado no parágrafo anterior, a norma IAEA GS-R-3 aborda mais elementos que a IAEA 50-C-Q, incluindo, entre outras:

- A promoção e o suporte para uma forte cultura de segurança como parte integrante do SIG.

- O reforço às questões de liderança e de responsabilidades pela gestão, tais como: o desenvolvimento dos valores individuais, valores institucionais $\mathrm{e}$ as expectativas comportamentais para suportar a implementação do sistema de gestão, a comunicação aos individuas da importância de adotar esses valores e expectativas, a promoção do envolvimento de todos os indivíduos na implementação e melhoria do SG, o 
desenvolvimento de políticas organizacionais, o estabelecimento de metas, estratégias, planos e objetivos consistentes com as políticas da organização e o desenvolvimento dessas metas, estratégias, planos e objetivos de uma forma integrada de maneira que seu impacto coletivo sobre a segurança nuclear seja compreendido.

- O fornecimento de requisitos com mais detalhes e específicos, para que a alta direção determine e provenha os recursos necessários para o estabelecimento, a implementação, a avaliação e melhoria contínua do SG.

\subsubsection{Ciclo do Combustível Nuclear.}

Segundo o texto no sítio na Internet da IAEA (2008), o ciclo do combustível nuclear pode ser definido como um conjunto de processos que faz uso de materiais nucleares que posteriormente retornam ao estado normal. Ele se inicia com a mineração de materiais nucleares da natureza e termina com a segura disposição desses materiais na natureza, após seu uso.

Para se produzir energia em um reator nuclear, a partir do urânio, o mesmo deve percorrer uma série de processos, como ilustrado em forma esquemática na FIG. 4.

O conjunto completo de processos para produzir o combustível nuclear a partir do minério de urânio é conhecido como 'front end' do ciclo do combustível nuclear e compreende: a mineração e o beneficiamento do minério de urânio para produção do composto $\mathrm{U}_{3} \mathrm{O}_{8}$, o qual é mais conhecido como 'yellowcake'; a conversão do 'yellowcake' em óxido de urânio $\left(\mathrm{UO}_{2}\right)$ ou em hexafluoreto de urânio $\left(\mathrm{UF}_{6}\right)$; o enriquecimento isotópico do $\mathrm{UF}_{6}$; e a fabricação de pastilhas de combustível, a partir do óxido urânio natural $\left(\mathrm{UO}_{2}\right)$ ou da conversão do $\mathrm{UF}_{6}$ enriquecido em $\mathrm{UO}_{2}$, para formar o elemento combustível (IAEA, 2008).

O combustível é então irradiado em um reator nuclear para produção de energia (IAEA, 2008).

Após produzir energia no reator, o combustível nuclear torna-se combustível irradiado. O combustível irradiado é então tratado em um conjunto de processos conhecidos como o 'back end' do ciclo do combustível nuclear, que são os seguintes: armazenagem temporária no reator; o reprocessamento para separação do $\mathrm{U}$ e $\mathrm{Pu}$ dos produtos de rejeito, se for reciclado; e a armazenagem monitorada fora do reator ou a disposição final dos rejeitos de alto nível de atividade (IAEA, 2008; AUA, 2007). 
Nos itens subseqüentes são apresentados, de forma resumida, os processos do ciclo do combustível nuclear, ilustrados na FIG. 4.

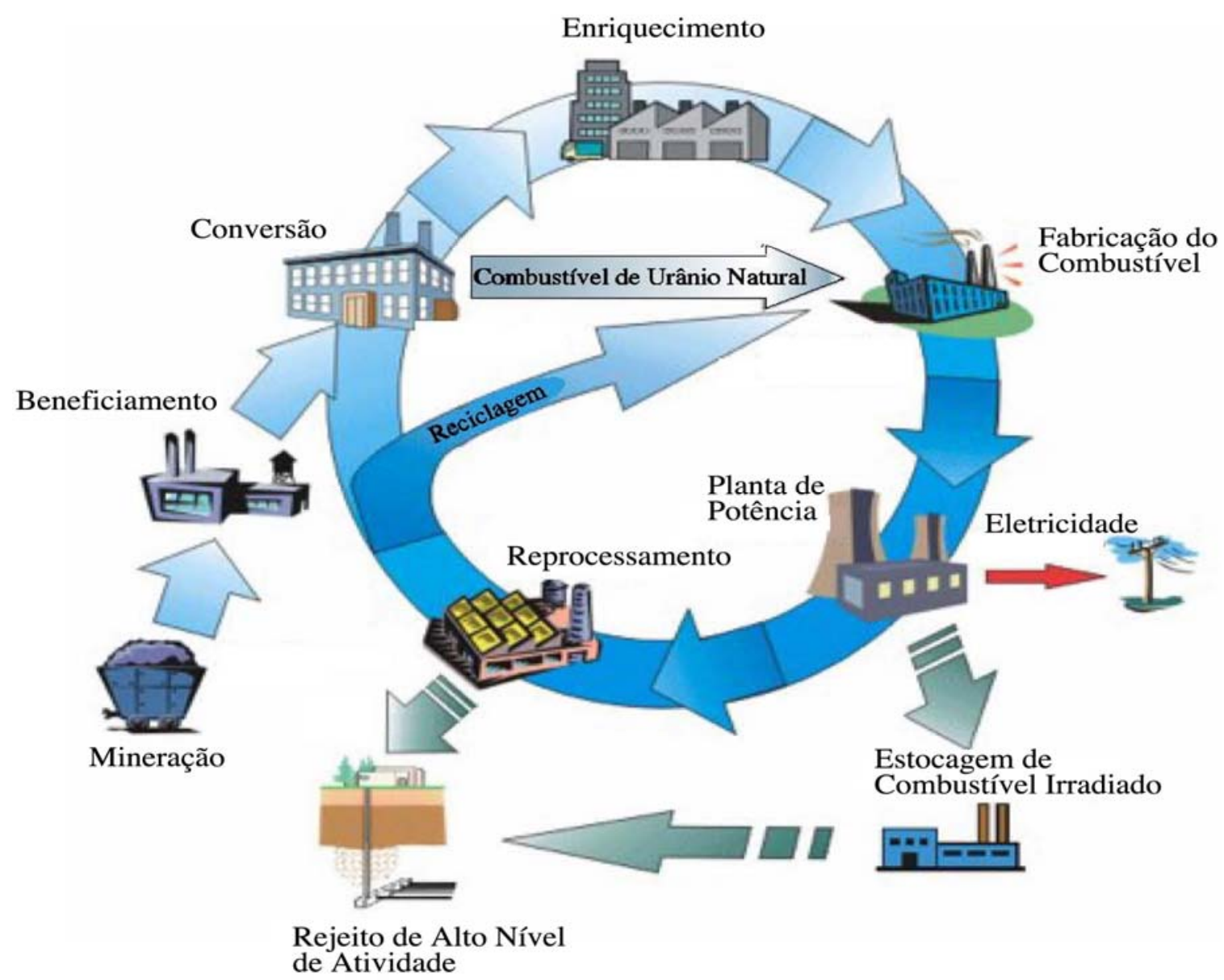

FIGURA 4 - Ilustração Esquemática Básica do Ciclo do Combustível Nuclear.

Fonte: Adaptação da ilustração apresentado pela Agência (IAEA, 2008).

\subsubsection{1 "Front End" do Ciclo do Combustível Nuclear.}

\section{Mineração e Beneficiamento do Minério de Urânio.}

O processo consiste na extração do minério de urânio de minas tanto na superfície (a céu aberto) como no subsolo, mediante técnicas de mineração que dependem da profundidade de onde o minério é encontrado (WNA, 2007).

O minério de urânio sofre um tratamento físico inicial (trituração) e é transportado para beneficiamento aonde é dissolvido por ácido sulfúrico. Este processo é conhecido como lixiviação e serve para separar o urânio de resíduos de rocha. O urânio lixiviado é retirado da solução, na maioria dos casos, por meio de extração por solvente. Ele é então recuperado da solução e precipitado como um concentrado de óxido de urânio, 
conhecido como "yellowcake", contendo geralmente mais do que $80 \%$ de urânio (CNEN, s.d.; WNA, 2007).

\section{Conversão.}

A conversão é um processo que altera a composição química do material nuclear de modo a facilitar o seu uso futuro, em particular, para prover material de alimentação para a separação isotópica ou para a fabricação do combustível do reator nuclear (IAEA, 2002a, p. 34).

Nesta etapa o 'yellowcake' é convertido em óxidos de urânio $\left(\mathrm{UO}_{3}\right.$ ou $\left.\mathrm{UO}_{2}\right)$ ou em hexafluoreto de urânio $\left(\mathrm{UF}_{6}\right)$ (IAEA, 2008). A conversão para o gás $\mathrm{UF}_{6}$ é executada para produzir material para separação isotópica (IAEA, 2002a, p. 34).

Segundo glossário da IAEA (2002a, p. 34), para a produção do UF $_{6}$ as plantas de conversão podem utilizar também óxidos de urânio provenientes de unidades de reprocessamento do combustível nuclear irradiado.

$\mathrm{Na}$ conversão para o $\mathrm{UO}_{2}$ ou $\mathrm{UF}_{6}$, o concentrado de urânio (yellowcake) é dissolvido em ácido nítrico e submetido a uma série de processos químicos onde as impurezas são removidas, sendo o urânio primeiramente refinado como dióxido de urânio $\left(\mathrm{UO}_{2}\right)$, que pode ser usado como combustível em reatores que não requeiram urânio enriquecido. Entretanto, na maioria dos casos o urânio é em seguida combinado com flúor para obtenção do gás puro de urânio - o $\mathrm{UF}_{6}$, que é solidificado (cristalizado) em cilindros apropriados, os quais são enviados para as unidades de enriquecimento isotópico (USNRC, 2007; WNA, 2008a).

$\mathrm{O} \mathrm{UF}_{6}$ é o produto preponderante neste estágio do ciclo do combustível nuclear, pois ele é facilmente sublimado e assim utilizado no estágio de enriquecimento isotópico. O urânio enriquecido é empregado nos reatores tipo - "Light Water Reactors" (LWR), os mais usados no mundo. Para os reatores tipo - "Pressurized Heavy Water Reactor" (PHWR), que em geral usam o óxido de urânio natural como combustível, a conversão para o $\mathrm{UF}_{6}$ não é necessária, neste caso o urânio natural é purificado e convertido para $\mathrm{UO}_{2}$. Os reatores tipo - "Gas Cooled Reactor" (Magnox) usam urânio natural na forma de metal (IAEA, 2008).

Na TAB. 1 se observa que $81,6 \%$ dos reatores em operação e construção no mundo utilizam o combustível nuclear $\mathrm{UO}_{2}$ enriquecido, $10,1 \%$ utilizam o $\mathrm{UO}_{2}$ natural e os demais $(8,2 \%)$ utilizam outros tipos de combustíveis. 
Uma quantidade de tipos de processos de enriquecimento tem sido testada em laboratório; mas somente dois, o processo de difusão gasosa e o processo por centrifugação, são operados em escala comercial. Em ambos os processos o gás UF 6 é usado como material de alimentação (WNA, 2008a).

TABELA 1 - Tipos de Reatores e Combustíveis Mais Utilizados.

\begin{tabular}{l|l|c|c|c|c|c|c}
\hline \multicolumn{2}{c|}{ Tipo de Reator } & $\begin{array}{c}\text { Combustível } \\
\text { Utilizado }\end{array}$ & $\begin{array}{c}\text { Em } \\
\text { Opera- } \\
\text { ção }\end{array}$ & $\begin{array}{c}\text { Em } \\
\text { Cons- } \\
\text { trução }\end{array}$ & $\begin{array}{c}\text { Total } \\
\text { por } \\
\text { Tipo }\end{array}$ & $\begin{array}{c}\text { \%o } \\
\text { Rel. } \\
14\end{array}$ & $\begin{array}{c}\% \\
\text { Acum. } \\
15\end{array}$ \\
\hline PWR & $\begin{array}{l}\text { Refrigerado } \\
\text { a água } \\
\text { Pressurizada }\end{array}$ & $\begin{array}{c}\mathrm{UO}_{2} \\
\text { Enriquecido } \\
\text { até } 4,95 \%\end{array}$ & 265 & 25 & 290 & 61,3 & 61,3 \\
\hline BWR & $\begin{array}{l}\text { Refrigerado } \\
\text { a água fervente }\end{array}$ & $\begin{array}{c}\mathrm{UO}_{2} \\
\text { Enriquecido } \\
\text { até 4,95\% }\end{array}$ & 94 & 2 & 96 & 20,3 & 81,6 \\
\hline PHWR & $\begin{array}{l}\text { Refrigerado } \\
\text { a água pesada } \\
\text { Pressurizada }\end{array}$ & $\begin{array}{c}\mathrm{UO}_{2} \\
\text { natural }\end{array}$ & 44 & 4 & 48 & 10,1 & 91,8 \\
\hline Outros & & Outros & 36 & 3 & 39 & 8,2 & 100 \\
\hline
\end{tabular}

Fonte - Dados obtidos no sítio na Internet da IAEA (2008d) - "Power Reactor Information System".

\section{Enriquecimento Isotópico do $\mathbf{U F}_{6}$.}

O processo por difusão gasosa consiste em utilizar o gás $U_{6}$ a uma temperatura superior a $55^{\circ} \mathrm{C}$, que flui por meio de membranas porosas também denominadas "barreiras de difusão". Por diferença de massa entre os átomos de ${ }^{235} \mathrm{U}$ (mais leves e, portanto, mais rápidos) e os de ${ }^{238} \mathrm{U}$ (mais pesados e, mais lentos), efetua-se a separação isotópica (CNEN, s.d.).

O processo por centrifugação utiliza o gás $U_{6}$ que é introduzido em uma centrifuga, onde, por diferença de peso dos átomos de ${ }^{235} \mathrm{U} \mathrm{e}^{238} \mathrm{U}$, ocorre o enriquecimento isotópico (CNEN, s.d.).

Outros processos de enriquecimento disponíveis são o aerodinâmico, a raios laser, eletromagnético e químico. O processo aerodinâmico existe em duas variações: o processo por Jato Centrífugo e o processo Vortex. Ambos utilizam o gás $\mathrm{UF}_{6}$ misturado a um gás leve, que depois de comprimido descreve uma trajetória curva, onde o ${ }^{238} \mathrm{U}$ (mais pesado) tende a se concentrar na parte exterior e o ${ }^{235} \mathrm{U}$ (mais leve) na parte interior. No

\footnotetext{
$14 \%$ Rel. - porcentagem relativa.

$15 \%$ Acum. - porcentagem acumulado.
} 
final da curva se obtém duas correntes gasosas de urânio, separadas, sendo uma delas mais concentrada em ${ }^{235} \mathrm{U}$ (CNEN, s.d.).

\section{Fabricação do Combustível Nuclear.}

$\mathrm{O}$ urânio enriquecido na forma de $\mathrm{UF}_{6}$ é convertido em pó de $\mathrm{UO}_{2}$ para produzir o combustível para a tecnologia de reatores LWR (Light Water Reactors). O pó de $\mathrm{UO}_{2}$ é então prensado e conformado em pastilhas que são sinterizadas e usinadas para que se obtenham a densidade e a dimensão requeridas. As pastilhas de combustível são inseridas em tubos de zircaloy ou aço inoxidável, os quais são selados em ambas as extremidades. Estas varetas são fixadas em paralelo, em espaçadores para formar o elemento combustível do reator (IAEA, 2008).

Um procedimento similar é adotado para a fabricação do combustível de $\mathrm{UO}_{2}$ natural para alguns tipos de reatores (IAEA, 2008).

Há também a possibilidade da fabricação do combustível nuclear a partir do óxido misto (MOX). O processo inclui a conversão dos nitratos de uranilo e plutônio em óxidos urânio e plutônio $\left(\mathrm{UO}_{2}\right.$ e $\left.\mathrm{PuO}_{2}\right)$, que poderá ser realizada tanto na unidade de reprocessamento quanto na fabricação do combustível. Após a conversão, os óxidos de urânio e plutônio são misturados e prensados e sinterizados em pastilhas de $\mathrm{UO}_{2}$ e $\mathrm{PuO}_{2}$, que são inseridas em tubos, formando assim as varetas de combustíveis (Zouain, 1981, p. 87-88; IAEA, 2002a, p. 34).

\subsubsection{Irradiação do Combustível Nuclear - Planta de Potência Nuclear.}

Um reator nuclear produz e controla a liberação de energia proveniente da fissão do átomo de certos elementos (WNA, 2008b).

Os reatores de potência são projetados com a finalidade de gerar energia elétrica, enquanto os reatores de pesquisa servem como fontes de nêutrons para propósitos diversos, que abrangem desde experimentos em física nuclear básica até irradiações para produção de radioisótopos utilizados em atividades industriais, agrícolas e medicinais (Terremoto, 2004, p. 91). Nos reatores de uso naval a energia é utilizada para produzir o vapor que movimenta as turbinas para a propulsão (WNA, 2008b).

O princípio para uso do potencial nuclear para produção de energia elétrica é o mesmo em muitos reatores. O calor proveniente da energia liberada pela contínua fissão dos átomos do combustível é absorvido para produzir vapor, por meio de gás ou água. $\mathrm{O}$ 
vapor é então usado para movimentar turbinas para produção de eletricidade (da mesma forma como ocorre nas plantas que se utilizam de combustível fóssil) (WNA, 2008b).

Há diversas formas de utilização do urânio como combustível nuclear em um reator. Uma possibilidade é o uso de urânio puro (Terremoto, 2004, p. 91). No caso de reatores rápidos o ${ }^{239} \mathrm{Pu}$ é um combustível nuclear importante, sendo usado na forma de dióxido de plutônio $\left(\mathrm{PuO}_{2}\right)$ misturado com dióxido de urânio $\left(\mathrm{UO}_{2}\right)$ para constituir um combustível de óxido misto (MOX), que contém cerca de 25\% em massa de $\mathrm{PuO}_{2}$. Estes reatores são adequados para proporcionar a regeneração do combustível nuclear, através da transformação de núcleos de ${ }^{238} \mathrm{U}$ em novos núcleos de ${ }^{239} \mathrm{Pu}$ (Terremoto, 2004, p. 104).

Outra possibilidade, mais amplamente utilizada como combustível nuclear, consiste em usar o $\mathrm{UO}_{2}$, sendo que na maioria dos casos é usado o $\mathrm{UO}_{2}$ enriquecido. $\mathrm{O}$ $\mathrm{UO}_{2}$ possui um ponto de fusão muito elevado $\left(2730^{\circ} \mathrm{C}\right)$ possibilitando aos reatores que os utiliza operar a temperaturas mais elevadas do que os reatores que usam o urânio metálico (Terremoto, 2004, p. 104; WNA, 2008b).

Os tipos de reatores em operação comercial estão apresentados na TAB. 2, sendo os seguintes os tipos de reatores existentes (Terremoto, 2004, p. 104):

- PWR - Reator refrigerado a água pressurizada (Pressurized Water Reactor).

- BWR - Reator refrigerado a água fervente (Boiling Water Reactor).

- PHWR (CANDU)- Reator refrigerado a água pesada pressurizada (Pressurized Heavy Water Reactor).

- GCR - Reator refrigerado a gás (Gas-Cooled Reactor)

- AGR - Reator avançado refrigerado a gás (Advanced Gas-cooled Reactor).

- HTGR - Reator refrigerado a gás com temperatura elevada (HighTemperature Gas-Cooled Reactor).

- SGHWR - Reator gerador de vapor moderado a água pesada (SteamGenerating Heavy-Water Reactor).

- RBMK - Reator refrigerado a água fervente e moderado a grafite (Light Water Graphite Reactor).

- FBR - Reator rápido (Fast Neutron Reactor).

O reator PWR é o tipo mais comum em uso para geração de potência e para propulsão nuclear. Ele usa a água comum como líquido refrigerante e como moderador. $\mathrm{O}$ 
projeto do PWR se distingue por ter um circuito primário onde o líquido refrigerante circula através do núcleo do reator a elevada pressão, e um circuito secundário aonde o vapor é gerado para movimentar a turbina (WNA, 2008b).

TABELA 2 - Tipos de Reatores em Operação Comercial.

\begin{tabular}{|c|c|c|c|c|c|c|}
\hline $\begin{array}{l}\text { Tipo de } \\
\text { Reator }\end{array}$ & $\begin{array}{c}\text { Países } \\
\text { Principais }\end{array}$ & $\begin{array}{l}\text { Quanti- } \\
\text { dade }\end{array}$ & $G W e^{16}$ & Combustível & Refrigerante & Moderador \\
\hline PWR & $\begin{array}{l}\text { EUA }^{17}, \\
\text { França, } \\
\text { Japão e } \\
\text { Rússia }\end{array}$ & 264 & 250.5 & $\begin{array}{l}\mathrm{UO}_{2} \\
\text { enriquecido }\end{array}$ & Água & Água \\
\hline BWR & $\begin{array}{c}\text { EUA, } \\
\text { Japão e } \\
\text { Suécia }\end{array}$ & 94 & 86.4 & $\begin{array}{l}\mathrm{UO}_{2} \\
\text { enriquecido }\end{array}$ & Água & Água \\
\hline $\begin{array}{l}\text { 'CANDU' } \\
\text { (PHWR) }\end{array}$ & Canadá & 43 & 23.6 & $\begin{array}{c}\mathrm{UO}_{2} \\
\text { natural }\end{array}$ & $\begin{array}{l}\text { Água } \\
\text { pesada }\end{array}$ & $\begin{array}{l}\text { Água } \\
\text { Pesada }\end{array}$ \\
\hline $\begin{array}{l}\text { AGR \& } \\
\text { Magnox }\end{array}$ & $\begin{array}{l}\text { Reino } \\
\text { Unido }\end{array}$ & 18 & 10.8 & $\begin{array}{c}\mathrm{UO}_{2} \\
\text { Natural } \\
\text { (metal) }\end{array}$ & $\mathrm{CO}_{2}$ & Grafite \\
\hline RBMK & Rússia & 12 & 12.3 & $\stackrel{\mathrm{UO}_{2}}{\text { enriquecido }}$ & Água & Grafite \\
\hline FBR & $\begin{array}{l}\text { França, } \\
\text { Japão e } \\
\text { Rússia }\end{array}$ & 4 & 1.0 & $\begin{array}{c}\mathrm{PuO}_{2} \\
\mathrm{e} \\
\mathrm{UO}_{2}\end{array}$ & $\begin{array}{l}\text { Sódio } \\
\text { líquido }\end{array}$ & Não \\
\hline Outros & Rússia & 4 & 0.05 & $\begin{array}{c}\mathrm{UO}_{2} \\
\text { enriquecido }\end{array}$ & Água & Grafite \\
\hline TOTAL & & 439 & 384.6 & & & \\
\hline
\end{tabular}

Fonte - "Nuclear Engineering International Handbook"- 2007, dados obtidos no sítio na Internet - "Nuclear Power Reactor" da WNA (2008b)

O projeto do reator BWR tem muita similaridade ao PWR, exceto que dispõe de apenas um circuito no qual a água, a baixa pressão, no núcleo, entra em ebulição a aproximadamente $285^{\circ} \mathrm{C}$. O reator é projetado para operar com 12 a $15 \%$ de vapor de água

${ }^{16}$ GWE - Soma total em Giga Watt electrical dos reatores do tipo em operação.

17 EUA - Estados Unidos da America. 
no topo do núcleo. $\mathrm{O}$ vapor produzido movimenta as turbinas, a qual faz parte do circuito do reator, isso significa que a turbina deve ser blindada e que deve ser provida proteção radiológica durante a manutenção. A radioatividade na água é de vida curta, de forma que a sala da turbina pode ser acessada prontamente após o reator ser desligado (WNA, 2008b).

O projeto do reator PHWR (CANDU) foi desenvolvido pelo Canadá nos anos 50. Ele usa o oxido de urânio natural $\left(0,7 \%{ }^{235} \mathrm{U}\right)$ como combustível, conseqüentemente, necessita de um moderador mais eficiente, que no caso é a água pesada $\left(\mathrm{D}_{2} \mathrm{O}\right)$. Com o sistema CANDU, o moderador é enriquecido (isto é, a água) ao invés do combustível. Como no caso do PWR, o líquido refrigerante do primário gera o vapor do circuito secundário para movimentar as turbinas (WNA, 2008b).

\subsubsection{Back End" do Ciclo do Combustível Nuclear.}

\section{Estocagem do Combustível Irradiado.}

Os elementos de combustíveis irradiados retirados do núcleo do reator são altamente radioativos e liberam muito calor. Por esse motivo, eles são estocados em piscinas especiais que geralmente estão localizadas no sítio do reator, de forma a permitir que tanto o seu calor como a radioatividade diminuam. A água nas piscinas serve ao duplo propósito de agir como uma barreira contra a radiação e para a dispersão do calor do combustível irradiado (WNA, 2008b).

O combustível irradiado pode ser estocado com segurança por longos períodos nessas piscinas. Ele também pode ser estocado a seco em instalações especiais. Contudo, esses tipos de estocagens são apenas uma etapa intermediária antes do envio do mesmo para reprocessamento ou para disposição final (WNA, 2008b).

\section{Reprocessamento do Combustível Irradiado.}

Ao se realizar a etapa de reprocessamento do combustível irradiado o que se pretende é a recuperação do material físsil inserido nele (Zouain, 1981, p. 65-67). A outra opção é sua estocagem por um longo período e sua disposição final (AUA, 2007).

O combustível irradiado contém aproximadamente (AUA, 2007):

- $96 \%$ de urânio natural, dos quais o ${ }^{235} \mathrm{U}$ fissionável nele contido foi reduzido a menos do que $1 \%$.

- $1 \%$ de Pu (Plutônio) 
- $3 \%$ de produtos residuais radioativos de alta atividade.

O reprocessamento separa urânio e plutônio dos produtos residuais. O urânio recuperado retorna à planta de conversão para sua reconversão, em $U_{6}$, e subseqüente enriquecimento. O plutônio grau reator pode ser misturado ao urânio enriquecido para produzir o combustível de oxido misto (MOX) em instalação de fabricação do combustível (AUA, 2007).

Os produtos finais do reprocessamento são soluções de nitrato de uranilo $\mathrm{UO}_{2}$ $\left(\mathrm{NO}_{3}\right)_{2}$ e nitrato de plutônio $\mathrm{Pu}\left(\mathrm{NO}_{3}\right)_{4}$ (Zouain, 1981, p. 72).

Segundo o texto no sítio na Internet da IAEA (2008) o combustível de óxido misto (MOX) é o que mais comumente usa material reprocessado. O reprocessamento é baseado em processos químicos e físicos para separar o material requerido do combustível nuclear irradiado.

As unidades de reprocessamento de urânio compreendem piscinas de recepção e estocagem de combustível irradiado, instalações de cisalhamento dos elementos combustíveis em ácido nítrico, e uma seqüência de ciclos de extração, separação e purificação do plutônio e do urânio, além de outras unidades de pré-tratamento de rejeitos, e locais para estocagem temporária e concentração de resíduos de atividade média, assim como para os de atividade de alta e rejeitos orgânicos (Zouain, 1981, p. 65-67).

\section{Disposição Final dos Rejeitos de Alto Nível de Atividade.}

Disposição final dos rejeitos radioativos provenientes das várias etapas do ciclo do combustível. As formas de envasamento dos rejeitos são (AUA, 2007):

- Vitrificação dos rejeitos de alta atividade selados em contêineres de aço inoxidável; ou

- Encapsulamento das varetas de combustível irradiado em metais resistentes à corrosão, tais como aço inoxidável ou cobre.

O plano mais aceitável por vários países é o de proceder à disposição final, enterrando o material envasado como acima descrito, em profundidade no subsolo, em estruturas rochosas estáveis. Muitos países pretendem introduzir a disposição final em alguma época após 2010 quando a quantidade de material a ser disposto se tornará economicamente justificado (AUA, 2007). 


\subsubsection{Caracterização de Planta de Conversão de $\mathbf{U F}_{6}$.}

Como subsídio para o desenvolvimento desta pesquisa é caracterizada, a

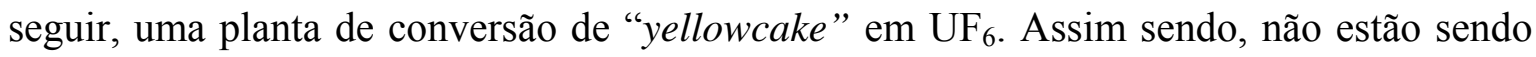
consideradas na pesquisa as plantas de conversão que convertem o $\mathrm{UF}_{6}$ para o $\mathrm{UO}_{2}$; os nitratos de $\mathrm{U}$ ou $\mathrm{Pu}$ para os óxidos de $\mathrm{U}$ ou $\mathrm{Pu}$, ou em óxidos mistos (MOX), e as que convertem óxidos de $\mathrm{U}$ ou $\mathrm{Pu}$ em metais de $\mathrm{U}$ ou $\mathrm{Pu}$.

Tomando por base dados disponíveis no sítio na Internet Nuclear Fuel Cycle Simulation System da IAEA (2008a) é apresentado na TAB. 3 um quadro contendo a relação das plantas comerciais de conversão de $\mathrm{UF}_{6}$, em operação no mundo, e na TAB. 4 a situação das plantas piloto desse tipo, no Brasil.

Segundo o descrito no projeto de norma da IAEA (2006, p. 6) estão sendo usados atualmente no mundo, em grande escala industrial, diferentes processos de conversão de "yellowcake" em $\mathrm{UF}_{6}$.

O sítio na Internet da Federation of American Scientists (FAS, 2008) coloca que existe uma diferença primária nos tipos de processos comerciais utilizados hoje no mundo, para produzir $\mathrm{UF}_{6}$ a partir do "Yellowcake". Uma diferença está no processo de purificação do urânio, que pode ser:

- Processo de purificação por via úmida - O urânio é purificado por extração por solvente antes da conversão (fluoração) para $\mathrm{UF}_{6}$; ou

- Processo de purificação por via seca - O urânio é purificado por destilação fracionada após a conversão (fluoração) para $\mathrm{UF}_{6}$.

No sítio na Internet (FAS, 2008) é exposto que no processo por via úmida o “yellowcake” é dissolvido em ácido nítrico $\left(\mathrm{HNO}_{3}\right)$ e o resíduo insolúvel é removido por filtragem ou centrifugação. O urânio é separado da solução ácida por extração líquidolíquido, o nitrato de uranilo produzido é decomposto para trióxido de urânio $\left(\mathrm{UO}_{3}\right)$ via denitração térmica, e o $\mathrm{UO}_{3}$ é reduzido para dióxido de urânio $\left(\mathrm{UO}_{2}\right)$ usando hidrogênio puro ou proveniente do craqueamento da amônia $\left(\mathrm{NH}_{3}\right)$. Em muitos casos, na etapa de extração é usado o tri-n-butil fosfato (TBP) diluído em um hidrocarboneto para separar o urânio de suas impurezas.

Continuando, é exposto no sítio na Internet (FAS, 2008) que, no processo por via seca, as etapas de conversão e purificação ocorrem durante o processo. Se o "yellowcake" for produzido pelo processo de lixiviação alcalina (resultando em $\mathrm{Na}_{2} \mathrm{U}_{2} \mathrm{O}_{7}$ ), o sódio deve ser removido do material pela digestão parcial em ácido sulfúrico seguido 
pela precipitação do diuranato de amônio $\left[\left(\mathrm{NH}_{4}\right)_{2} \mathrm{U}_{2} \mathrm{O}_{7}\right]$, em amônia. $\mathrm{O}$ sal de urânio contido na amônia é decomposto para $\mathrm{UO}_{3}$ por aquecimento, e o $\mathrm{UO}_{3}$ é reduzido para $\mathrm{UO}_{2}$ usando hidrogênio puro ou proveniente do craqueamento da amônia $\left(\mathrm{NH}_{3}\right)$.

TABELA 3 - Plantas Comerciais de Conversão de UF 6 em Operação.

\begin{tabular}{|c|c|c|c|}
\hline Planta & Processo & País & $\begin{array}{c}\text { Capacidade } \\
\text { de Projeto } \\
\text { t HM/ano }\end{array}$ \\
\hline Cameco - Blind River $\left(\mathrm{UO}_{3}\right)$ & $\begin{array}{l}\text { "Yellowcake” } \\
(\mathrm{YC}) \text { para } \mathrm{UO}_{3}\end{array}$ & \multirow{2}{*}{ Canadá } & 18000 \\
\hline Cameco - Port Hope $\left(\mathrm{UF}_{6}\right)$ & $\mathrm{UO}_{3}$ para $\mathrm{UF}_{6}$ & & 12500 \\
\hline Metropolis / Converdyn & $\mathrm{YC}_{\text {para }} \mathrm{UF}_{6}$ & EUA $^{19}$ & 17600 \\
\hline Comurhex Malvesi $\left(\mathrm{UF}_{4}\right)$ & $\mathrm{YC}$ para $\mathrm{UF}_{4}$ & \multirow{2}{*}{ França } & 14000 \\
\hline Comurhex Pierrelatte $\left(\mathrm{UF}_{6}\right)$ & $\mathrm{UF}_{4}$ para $\mathrm{UF}_{6}$ & & 14000 \\
\hline $\begin{array}{l}\text { BNFL Springfields Main Line } \\
\text { Chemical Plant }\end{array}$ & YC para $U_{4}$ & \multirow{2}{*}{$\begin{array}{l}\text { Reino } \\
\text { Unido }\end{array}$} & 10000 \\
\hline $\begin{array}{l}\text { BNFL Springfields Line } 4 \\
\text { Hex Plant }\end{array}$ & $\mathrm{UF}_{4}$ para $\mathrm{UF}_{6}$ & & 6000 \\
\hline Angarsk & $\mathrm{YC}_{\text {para }} \mathrm{UF}_{6}$ & \multirow{2}{*}{ Rússia } & 20000 \\
\hline Ekaterinburg (Sverdlovsk-44) & YC para $U_{6}$ & & 4000 \\
\hline Lanzhou & $\mathrm{UO}_{3}$ para $\mathrm{UF}_{6}$ & China & 400 \\
\hline Complejo Fabril Cordoba & $\mathrm{YC}$ para $\mathrm{UO}_{2}$ & \multirow{2}{*}{ Argentina } & 150 \\
\hline Pilcaniyeu - 1 & $\mathrm{UO}_{2}$ para $\mathrm{UF}_{6}$ & & 62 \\
\hline
\end{tabular}

Fonte: Dados obtidos no sítio na Internet da IAEA (2008a)

No sítio na Internet (FAS, 2008) é exposto ainda que as etapas remanescentes usadas para produzir o $\mathrm{UF}_{6}$ são similares para ambos os processos, onde o $\mathrm{UO}_{2}$ é convertido para $\mathrm{UF}_{4}$ por hidrofluoração (usando o gás fluoreto de hidrogênio). $\mathrm{O}_{\mathrm{UF}}$ (impuro, no caso do processo por via seca) é convertido para $\mathrm{UF}_{6}$ usando gás flúor $\left(\mathrm{F}_{2}\right)$

\footnotetext{
${ }^{18}$ Toneladas de Metal Pesado/ano.

${ }^{19}$ EUA - Estados Unidos da America.
} 
gerado por eletrólise. No processo por via seca, o $\mathrm{UF}_{6}$ é purificado em dois estágios na etapa de destilação.

TABELA 4 - Situação das Plantas de Conversão de UF 6 no Brasil.

\begin{tabular}{l|c|c|c}
\hline \multicolumn{1}{c|}{ Planta Piloto de Conversão } & Processo & Situação & $\begin{array}{c}\text { Capacidade } \\
\text { de Projeto } \\
\text { t HM/ano }\end{array}$ \\
\hline $\begin{array}{l}\text { Instituto de Pesquisas } \\
\text { Energéticas e Nucleares }\end{array}$ & $\mathrm{YC} \mathrm{para} \mathrm{UF}_{6}$ & Fechada & 90 \\
\hline Centro Experimental Aramar & $\mathrm{YC} \mathrm{para} \mathrm{UF}_{6}$ & Em construção & 40 \\
\hline
\end{tabular}

Fonte: Dados obtidos no sítio na Internet da IAEA (2008a)

Segundo é informado no sítio na Internet (FAZ, 2008), o processo de fluoração direta do $\mathrm{UO}_{3}$ para obtenção do $\mathrm{UF}_{6}$ tem sido também utilizado, porém este procedimento é mais aconselhável para plantas de pequena capacidade de produção.

A ConverDyn dos Estados Unidos da América informa em seu sítio na Internet (ConverDyn, 2008) que sua planta de produção de $\mathrm{UF}_{6}$ - Honeywell's Metropolis Works (Honeywell-MTW) é a única a usar o processo de purificação por via seca.

Segundo o texto no sítio na Internet da World Nuclear Association (WNA, 2008a) outra diferença nos processos consiste no meio utilizado para hidrofluoração do $\mathrm{UO}_{2}$ para obtenção do $\mathrm{UF}_{4}$, que pode ser:

- Hidrofluoração por via seca - utilizando o HF anidro; ou

- Hidrofluoração por via úmida - utilizando o HF aquoso.

A Cameco do Canadá expõe em seu sítio na Internet (Cameco, 2008) que sua planta Port Hope é a única a usar o processo de hidrofluoração por via úmida.

No anexo A é apresentado um sumário dos processos utilizados pelas empresas ConverDyn dos Estados Unidos da América, Cameco do Canadá e Areva da França.

Comparando os processos utilizados pela refinaria Blind River da Cameco, com aqueles da COMURHES-Malvési da Areva se observa outra diferença nas rotas das plantas de conversão. Enquanto a primeira utiliza o processo de concentração ("boildown") do nitrato de uranilo, seguido de sua denitração térmica para obtenção do $\mathrm{UO}_{3}$; a segunda utiliza os processos de precipitação do diuranato de amônio (DUA), seguido de sua calcinação para obtê-lo. 


\section{Caracterização da Planta de Conversão de $\mathrm{UF}_{6}$ Utilizada na Pesquisa.}

Na FIG. 5 é apresentado um diagrama esquemático da rota dos processos de uma planta de conversão do "yellowcake" em $\mathrm{UF}_{6}$, que utiliza os processos de purificação do urânio por via úmida, de obtenção do $\mathrm{UO}_{3}$ via precipitação do DUA seguido de sua calcinação e de hidrofluoração por via seca. O diagrama apresentado na FIG. 5 é uma transcrição daquele ilustrado em projeto de norma da IAEA (2006d, p. 53) do qual foram extraídos os processos decorrentes de outras rotas de conversão, que não estão sendo consideradas na pesquisa. Assim sendo, foram extraídos de diagrama apresentado no projeto de norma citado, os processos de obtenção do $\mathrm{UF}_{6}$ por meio do diuranato de potássio (KDU) impuro ou do nitrato de uranilo purificado, recebido de plantas de reprocessamento de urânio, além dos processos de purificação do urânio por via seca, de hidrofluoração do $\mathrm{UO}_{2}$ por via úmida e os processos de precipitação, filtração e calcinação do $\mathrm{UF}_{4}$.

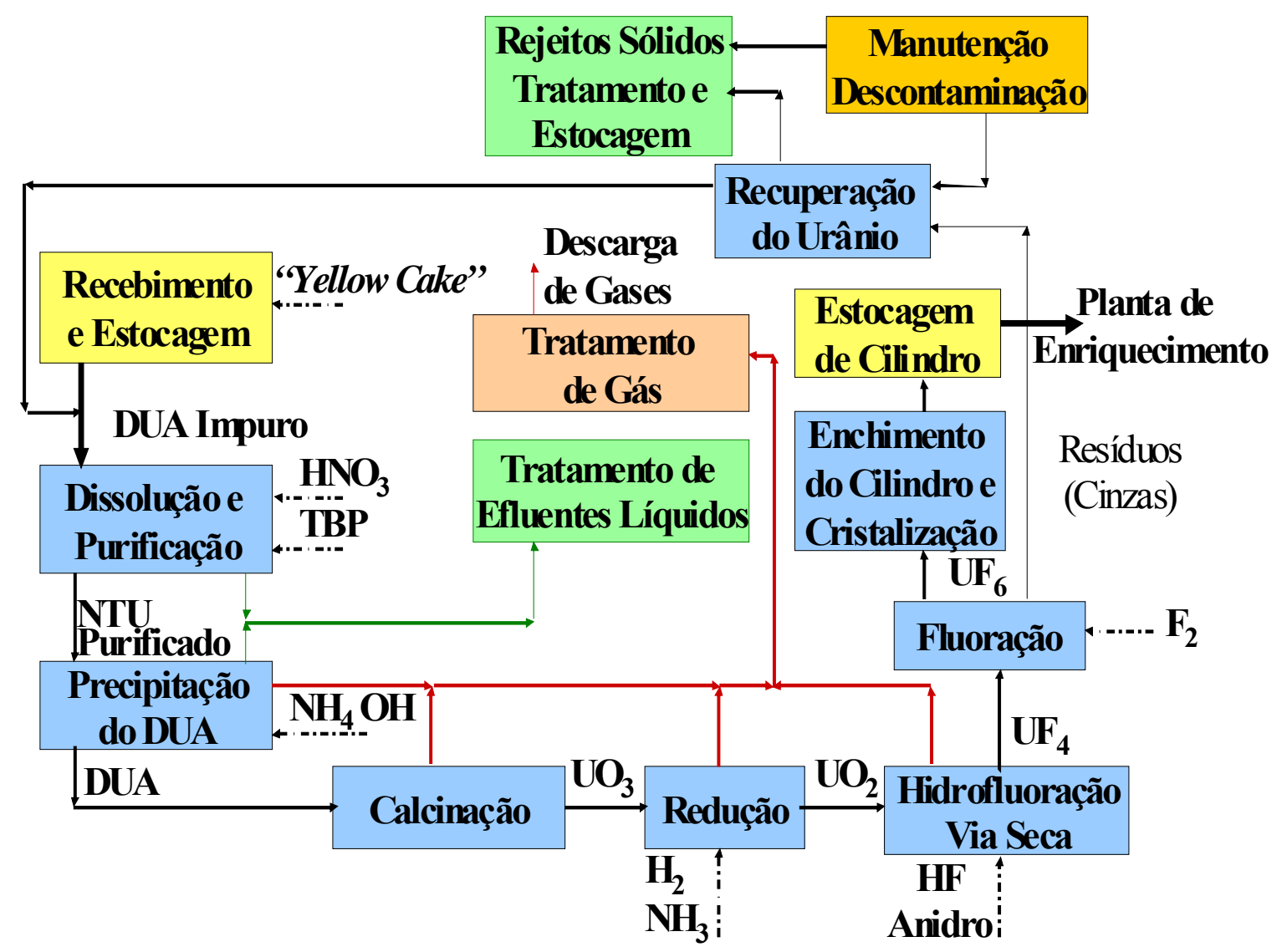

FIGURA 5 - Rota dos Processos da Planta de Conversão de UF $_{6}$ da Pesquisa. Fonte: Adaptação do diagrama apresentado pela IAEA (2006e, anexo I)

A seguir é feita uma descrição sumária de cada um dos processos que compõem a rota descrita na FIG. 5, tomando por base a descrição de processos disponíveis 
na bibliografia e na documentação consultada. É feita também uma descrição sumária do processo de produção de flúor. Segundo Marin $(1999$, p. 34) é uma característica comum às plantas comerciais de produção de $\mathrm{UF}_{6} \mathrm{o}$ uso do flúor elementar, produzido na própria instalação.

A planta de conversão assim descrita não representa uma instalação específica, mas sim a caracterização de uma planta a ser utilizada nesta pesquisa. Para descrição dos processos apresentados na FIG. 5 foram consultadas as seguintes bibliografias e documentação:

- Análise de Perigos em uma Instalação de Produção de Hexafluoreto de Urânio - Dissertação de Mestrado. (Marin, 1999).

- Airborne Effluent. Control at Fuel Enrichment, Conversion, And Fabrication Plants (Mitchell, 1976).

- Ciclo do Combustível Nuclear - Da Mina À Fabricação de Elemento Combustível (CNEN, s.d.).

- Conversion (WNA, 2008a).

- Fundamentos de Tecnologia Nuclear (Aquino, 2004).

- Nuclear Chemical Engineering (Benedict et. al., 1957).

- Uranium Production (FAS, 2008).

- Uranium Production Technology (Harrington et. al., 1959).

- Projeto de norma DS344 da IAEA (2006e).

\section{Recebimento e Estocagem de "Yellowcake".}

O processo compreende o manuseio do concentrado em tambores e sua pesagem, amostragem e armazenagem. O concentrado de urânio, mais conhecido como Yellowcake, é constituído normalmente, segundo Marin (1999), por:

- Diuranato de amônio - $\left(\mathrm{NH}_{4}\right)_{2} \mathrm{U}_{2} \mathrm{O}_{7}$

- Octóxico de triurânio - $\mathrm{U}_{3} \mathrm{O}_{8}$

- Trióxido de urânio - $\mathrm{UO}_{3}$

As plantas de conversão de $\mathrm{UF}_{6}$ como toda planta química dispõe também de processos de estocagem de outros produtos químicos, tais como: ácido fluorídrico (HF), hidrogênio $\left(\mathrm{H}_{2}\right)$, amônia $\left(\mathrm{NH}_{3}\right)$, ácido nítrico $\left(\mathrm{HNO}_{3}\right)$, etc. (IAEA, 2006e). 


\section{Dissolução.}

O "yellowcake" é dissolvido em ácido nítrico $\left(\mathrm{HNO}_{3}\right)$ em um reator de dissolução, sendo formando uma solução de nitrato de uranilo (NTU) impuro que é maturado e filtrado para melhorar o rendimento da etapa de purificação. (WNA, 2008a).

Os tipos de reações químicas que ocorrem no processo são os seguintes (Marin, 1999):

$$
\begin{array}{lll}
\left(\mathrm{NH}_{4}\right)_{2} \mathrm{U}_{2} \mathrm{O}_{7}+6 \mathrm{HNO}_{3} & \longrightarrow & 2 \mathrm{NH}_{4} \mathrm{NO}_{3}+2 \mathrm{UO}_{2}\left(\mathrm{NO}_{3}\right)_{2}+3 \mathrm{H}_{2} \mathrm{O} \\
\mathrm{U}_{3} \mathrm{O}_{8}+2 \mathrm{HNO}_{3} & \longrightarrow & \mathrm{UO}_{2}\left(\mathrm{NO}_{3}\right)_{2}+\mathrm{H}_{2} \mathrm{O} \\
\mathrm{UO}_{3}+8 \mathrm{HNO}_{3} & \longrightarrow & \mathrm{UO}_{2}\left(\mathrm{NO}_{3}\right)_{2}+2 \mathrm{NO}_{2}+4 \mathrm{H}_{2} \mathrm{O}
\end{array}
$$

\section{Purificação.}

A purificação justifica-se para a obtenção de um material com o chamado “grau nuclear". O objetivo é a remoção de impurezas capazes de absorver nêutrons,

diminuindo o rendimento de fissão do ${ }^{235} \mathrm{U}$, e impedir a presença de outras impurezas que comprometem as propriedades cerâmicas e mecânicas do combustível nuclear (Aquino, 2004).

A solução de NTU impuro obtida no processo de dissolução é alimentada em um processo de extração por solvente em coluna pulsada, usando tri-n-butil fosfato (TBP) (Aquino, 2004). Devido suas propriedades físicas, é necessário diluir o TBP em um solvente inerte para a adequada realização dos processos de extração líquido-líquido (Harrington, 1959, p. 27). Alguns solventes utilizados são o querosene, o hexano e o dodecano (WNA, 2008a; Marin, 1999, p. 29; Harrington, 1959, p. 28). O processo é operado em um sistema com três colunas onde a primeira é de extração, a segunda é de lavagem e a terceira de reextração. A extração é a retirada do urânio da fase aquosa (NTU impuro) pela fase orgânica (TBP). Na coluna de lavagem se procede a lavagem do extrato orgânico (fase orgânica carregada em urânio). Esta operação pode ser realizada usando uma solução de $\mathrm{HNO}_{3}$ diluído. O extrato orgânico lavado passa para a etapa de reextração que é realizada em coluna pulsada, onde ocorre a transferência do NTU (puro) da fase orgânica para a fase aquosa. (Aquino, 2004; FAS, 2008; WNA; 2008a). 
As reações químicas que ocorrem no processo são as seguintes (Marin, 1999):

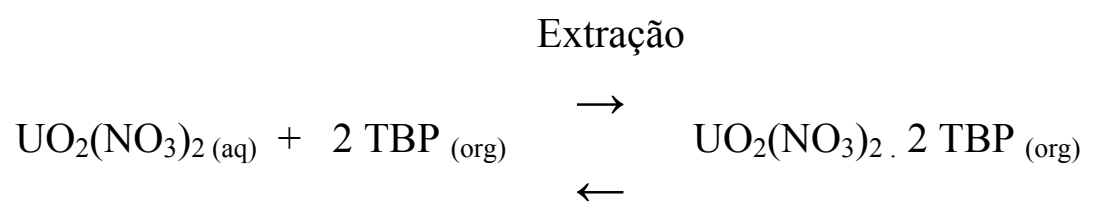

Reextração

\section{Precipitação do DUA.}

A precipitação do DUA é justificada pela necessidade de se trabalhar com volumes menores do produto (Aquino, 2004).

A solução de NTU puro reage com amônia gasosa $\left(\mathrm{NH}_{3}\right)$ em reator de precipitação formando uma suspensão do DUA que é precipitado e filtrado para formação da torta DUA.

A reação química que ocorre no processo é a seguinte:

$$
2 \mathrm{UO}_{2}\left(\mathrm{NO}_{3}\right)_{2}+6 \mathrm{NH}_{3}+3 \mathrm{H}_{2} \mathrm{O} \quad \longrightarrow \quad\left(\mathrm{NH}_{4}\right)_{2} \mathrm{U}_{2} \mathrm{O}_{7}+4 \mathrm{NH}_{4} \mathrm{NO}_{3}
$$

\section{Calcinação.}

A torta DUA obtida no processo anterior é calcinada em forno elétrico produzindo o trióxido de urânio $\left(\mathrm{UO}_{3}\right)$. A reação que ocorre no processo é a seguinte (Aquino, 2004, p. 3):

$$
\left(\mathrm{NH}_{4}\right)_{2} \mathrm{U}_{2} \mathrm{O}_{7} \quad \longrightarrow \quad 2\left(\mathrm{UO}_{3}\right)+2\left(\mathrm{NH}_{3}\right) \uparrow+\mathrm{H}_{2} \mathrm{O} \uparrow
$$

\section{Redução.}

A redução do trióxido de urânio $\left(\mathrm{UO}_{3}\right)$ em dióxido de urânio $\left(\mathrm{UO}_{2}\right)$ é realizada em reator de leito móvel, onde o $\mathrm{UO}_{3}$ sólido é alimentado e escoa em contracorrente com o hidrogênio $\left(\mathrm{H}_{2}\right)$ (agente redutor), ocorrendo sua redução em $\mathrm{UO}_{2} . \mathrm{O} \mathrm{H}_{2}$ é obtido no próprio meio pelo craqueamento da amônia (Aquino, 2004, p. 3; FAS 2008; WNA, 2008a).

As reações químicas que ocorrem no processo são as seguintes (Aquino, 2004, p. 3):

$$
\begin{aligned}
& 2 \mathrm{NH}_{3}+\mathrm{Q} \quad \longrightarrow \quad 3 \mathrm{H}_{2}+\mathrm{N}_{2} \quad \text { (craqueamento da amônia) } \\
& \mathrm{UO}_{3}+\mathrm{H}_{2} \quad \longrightarrow \quad \mathrm{UO}_{2}+\mathrm{H}_{2} \mathrm{O} \quad \text { (redução do } \mathrm{UO}_{3} \text { ) }
\end{aligned}
$$




\section{Hidrofluoração por Via Seca.}

A hidrofluoração do dióxido de urânio $\left(\mathrm{UO}_{2}\right)$ para obtenção do tetrafluoreto de urânio $\left(\mathrm{UF}_{4}\right)$ é justificada pela necessidade de se economizar energia elétrica no processo de conversão para o $\mathrm{UF}_{6}$. Para a preparação do $\mathrm{UF}_{6}$ é preciso flúor $\left(\mathrm{F}_{2}\right)$ que se obtém por eletrólise do ácido fluorídrico $(\mathrm{HF})$, enquanto que o $\mathrm{UF}_{4}$ se obtém usando diretamente o HF (Aquino, 2004, p. 3).

A hidrofluoração é realizada em reator de leito móvel onde o $\mathrm{UO}_{2}$ reage com o HF anidro produzindo o $\mathrm{UF}_{4}$ em pó (Aquino, 2004, p. 3; FAS 2008; WNA, 2008a).

A reação química que ocorre no processo é a seguinte (Aquino, 2004, p. 3):

$$
\mathrm{UO}_{2}+4 \mathrm{HF} \quad \rightarrow \quad \mathrm{UF}_{4}+2 \mathrm{H}_{2} \mathrm{O} \quad \text { (fluoretação do } \mathrm{UO}_{2} \text { ) }
$$

Segundo Aquino (2004, p. 3) o reator de leito é constituído de duas regiões onde na primeira, ocorre a redução do $\mathrm{UO}_{3}$ sólido em $\mathrm{UO}_{2}$, e na outra região, se processa a hidrofluoração do $\mathrm{UO}_{2} \mathrm{em} \mathrm{UF}_{4}$.

\section{Fluoração.}

O processo de fluoração do $\mathrm{UF}_{4}$ é necessário para obtenção do urânio na forma de hexafluoreto de urânio $\left(\mathrm{UF}_{6}\right)$ gasoso. $\mathrm{O}$ processo de enriquecimento isotópico necessita de urânio sob uma forma química estável, na forma gasosa, sob condições razoáveis de temperatura e pressão, sendo $\mathrm{o}_{\mathrm{UF}_{6}} \mathrm{o}$ único composto de urânio que preenche estes requisitos. (Aquino, 2004)

A produção do $U_{6}$ é feita em reator de chama por síntese entre o $U_{4}$ (em pó), que é alimentado no reator, e o flúor elementar gasoso ( $\left.F_{2}\right)$. (FAZ, 2008; WNA, 2008a).

O material sólido que não reagiu no processo é recolhido em um receptor de cinzas para recuperar o urânio, na forma de $\mathrm{UF}_{4}$. Os gases de $\mathrm{UF}_{6}$ produzidos são condensados em armadilhas frias (dessublimadores) primárias, onde o $\mathrm{UF}_{6}$ é cristalizado. (Marin, 1999).

$\mathrm{O} \mathrm{UF}_{4}$ residual é misturado ao $\mathrm{UF}_{6}$ novo em uma etapa de fluoração secundária. Da mesma forma como na etapa anterior os gases de $\mathrm{UF}_{6}$ são condensados em armadilhas frias (dessublimadores) secundárias sendo cristalizado e o material sólido que não reagiu é recolhido. (Marin, 1999).

A reação química que ocorre no processo é a seguinte (Aquino, 2004, p. 3):

$$
\mathrm{UF}_{4(\mathrm{~s})}+\mathrm{F}_{2(\mathrm{~g})} \rightarrow \mathrm{UF}_{6(\mathrm{~g})}\left(\text { fluoração do } \mathrm{UF}_{4}\right)
$$




\section{Enchimento de Cilindros e Cristalização do UF 6 .}

Após a produção, o $U_{6}$ é direcionado para dessublimadores onde se solidificam por resfriamento. Os dessublimadores, por sua vez, são aquecidos transformando o $\mathrm{UF}_{6}$ para a fase líquida. O líquido é transferido para cilindros especialmente projetados. Quando resfriado, o $\mathrm{UF}_{6}$ líquido dentro do cilindro se torna um sólido cristalizado branco.

\section{Estocagem de Cilindros.}

Os cilindros com $\mathrm{UF}_{6}$ cristalizado são estocados por um período e enviados para as usinas de enriquecimento isotópico de urânio. (WNA, 2008a; Marin 1999).

\section{Tratamento de Gases de Descarga.}

Os gases provenientes dos processos de precipitação do DUA, calcinação, redução, hidrofluoração e fluoração são tratados em colunas de lavagem de gases e liberados para atmosfera, e os efluentes líquidos provenientes da lavagem encaminhados para o processo de tratamento de efluentes líquidos.

\section{Tratamento de Efluentes Líquidos.}

Os efluentes líquidos provenientes dos processos de dissolução, purificação e precipitação, assim como do processo de tratamento dos gases de descarga, são tratados, sendo algumas soluções químicas regeneradas para reaproveitamento nos processos. $\mathrm{O}$ subproduto, contendo urânio, é encaminhado para o processo de recuperação de urânio.

\section{Recuperação do Urânio.}

A finalidade é recuperar o urânio disponível nas soluções provenientes do processo de tratamento de efluentes líquidos, bem como dos rejeitos sólidos contendo urânio, provenientes do processo de hidrofluoração e fluoração. O objetivo é recuperar o urânio na forma de nitrato de uranilo que é re-encaminhado para o processo de dissolução / purificação.

\section{Tratamento e Estocagem de Rejeitos Sólidos.}

Os rejeitos sólidos provenientes do processo de recuperação de urânio são tratados quimicamente, sendo, a solução líquida resultante deste processo estocada para 
futura evaporação e os rejeitos sólidos estocados em tambores destinados à imobilização. A solução líquida estocada é tratada em um processo de evaporação sendo os rejeitos sólidos resultantes destinados também à imobilização.

\section{Produção de Flúor.}

O flúor produzido é utilizado no processo de fluoração do $U_{4}$ para produção do $\mathrm{UF}_{6}$.

A produção do flúor é feita por eletrólise do HF (Aquino, 2004). A eletrólise e realizada em célula que produz ao mesmo tempo flúor e hidrogênio, em compartimentos separados. O contato entre os dois gases deve ser evitado, face à reação explosiva.

A reação química que ocorre no processo é a seguinte (Aquino, 2004, p. 4):

$$
2 \mathrm{HF}+\mathrm{e}^{-} \quad \rightarrow \quad \mathrm{F}_{2}+\mathrm{H}_{2}
$$

\subsubsection{Aspectos de Segurança, Ambiental e Qualidade para o Estágio de Operação de Plantas de Conversão de $\mathbf{U F}_{6}$.}

\section{Aspectos de Segurança e Ambiental.}

O projeto de norma IAEA DS344 (IAEA, 2006) que faz parte da revisão documental desta pesquisa, fornece recomendações sobre segurança aplicáveis às plantas de conversão. Apresentaremos aqui algumas informações julgadas importantes a esta seção, deixando maiores detalhes para a revisão documental da norma.

O projeto de norma (IAEA, 2006e, p. 40) expõe algumas características distintas das plantas de conversão, tais como:

- O material radioativo utilizado na planta possui radiotoxidade relativamente baixa, mas com potencial de gerar impactos químicos e toxicológicos aos trabalhadores, ao publico e ao meio ambiente, devido: à grande quantidade de $\mathrm{UF}_{6}$, aos produtos de reação $\left(\mathrm{UO}_{2} \mathrm{~F}_{2}, \mathrm{HF}\right)$ associados com a operação de $\mathrm{UF}_{6}$ líquido e a estocagem e manuseio de grande quantidade de compostos de urânio sólido.

- As condições para incêndio e explosões que resultem em liberação radiológica são potenciais, como aquelas decorrentes da explosão de $\mathrm{H}_{2}$ nos fornos de redução.

- Os riscos químicos são significativos devido à grande quantidade de HF anidro líquido e amônia $\left(\mathrm{NH}_{3}\right)$ que estão presentes no processo. 
Como conseqüência, o projeto de norma (IAEA, 2006e, p. 11) recomenda focar atenção nas seguintes situações de risco:

- Liberação de $\mathrm{HF}$ e $\mathrm{NH}_{3}$.

- Liberação de $\mathrm{UF}_{6}$.

- Incêndio de grandes proporções devido ao $\mathrm{H}_{2}$ ou solventes.

- Explosão no processo de redução $\left(\mathrm{H}_{2}\right)$.

Os três primeiros tipos de riscos acima citados são, segundo o projeto de norma da IAEA (2006e, p. 11), eventos de maior significância com relação à segurança, pois resultam em conseqüências químicas e radiológicas aos trabalhadores, dentro do sítio, e podem resultar também em algumas conseqüências adversas fora do sítio, assim como ao meio ambiente. O quarto tipo de risco não tem conseqüências significativas fora do sítio.

O projeto de norma da IAEA (2006e, p. 5-8) ressalta ainda que as plantas de conversão processam produtos químicos perigosos, os quais podem ser tóxicos, corrosivos, combustíveis e explosivos. Um perigo significativo é a perda dos meios de confinamento resultando em liberação de $\mathrm{UF}_{6}$ e em perigos químicos decorrentes do $\mathrm{HF}$ e $\mathrm{F}_{2}$. Quando o $\mathrm{UF}_{6}$ é liberado, ele reage com a umidade do ar formando HF e fluoreto de uranilo solúvel $\left(\mathrm{UO}_{2} \mathrm{~F}_{2}\right)$, os quais produzem perigos adicionais à segurança.

Como as plantas processam apenas urânio natural (com grau de enriquecimento inferior a 1\%), não há risco de ocorrer criticalidade Neste caso, a radiotoxidade é baixa sendo limitada à possibilidade de ocorrer conseqüências radiológicas externas seguidas de potenciais acidentes. Além disso, a toxidade química do urânio na forma solúvel, como o $\mathrm{UF}_{6}$, é mais significativa do que a sua radiotoxidade (IAEA, 2006e, p. 5 e 8$)$.

Marin (1999, 125), em uma das conclusões de seu projeto de dissertação, verifica que neste tipo de planta os perigos maiores estão associados a substâncias químicas convencionais $\left(\mathrm{NH}_{3}, \mathrm{HF}, \mathrm{HNO}_{3}\right)$ e não ao $\mathrm{UF}_{6}$ produzido, pois para a situação mais provável de liberação de $\mathrm{UF}_{6}$, as conseqüências atingem distâncias de 1600 metros, enquanto que para outras situações (isto é, para o $\mathrm{NH}_{3}, \mathrm{HF}$ e $\mathrm{HNO}_{3}$ ) as distâncias de impacto podem superar 40.000 metros.

Marin $(1999,115)$ aponta ainda em sua pesquisa outros eventos que podem ocorrer nestes tipos de plantas: 
- Produção de flúor - Explosão nas células eletrolíticas por polarização do ânodo, corrosão das conexões, bipolarização do diafragma, desequilíbrio de pressão entre os compartimentos anódicos e catódicos.

- Processo de purificação - Incêndio na área de extração com solvente pelo derramamento do conteúdo da coluna de extração.

- Processos que geram rejeitos líquidos (Dissolução, precipitação e purificação) - Rompimento das bacias de contenção causando danos ao meio ambiente com radionuclídeos.

Marin (1999) elaborou um projeto de dissertação sobre "Análise de Perigos em uma Instalação de Produção de Hexafluoreto de Urânio", utilizando como base para o projeto a planta "Kerr Mc Sequoyah Hexafluoride Plant" (Kerr), dos Estados Unidos da América, que foi descomissionada em 1996. Da mesma forma como a planta caracterizada nesta pesquisa, a planta "Kerr" utilizava os processos de purificação por via úmida e o de hidrofluoração por via seca, utilizando HF anidro e gasoso. Entretanto, as plantas se diferem quanto aos processos utilizados para transformação do NTU (puro) em $\mathrm{UO}_{3}$. Enquanto a "Kerr" utilizava o processo de denitração térmica (calcinação), a planta desta pesquisa se refere ao processo de precipitação do DUA, seguido de sua calcinação.

\section{Aspectos da Qualidade.}

A norma da "American Society for Testing and Materials" (ASTM, 1991, p. 1), expõe que é requerido das plantas de conversão o atendimento aos vários requisitos estabelecidos pelas agências reguladoras, códigos, clientes, e pela própria organização. Assim sendo, é significante prover uma abordagem planejada e sistemática para atender os requisitos da qualidade, tanto operacional, quanto dos produtos da instalação, ou seja, o estabelecimento de um programa de garantia da qualidade ${ }^{20}$ para a instalação. A norma expõe ainda que há um potencial de exposição química e radiológica para os empregados, o público e o meio ambiente, e que este potencial é reduzido quando da adoção da abordagem mencionada anteriormente.

Quanto ao aspecto de qualidade dos produtos da instalação, o mercado dispõe de normas que estabelecem os requisitos técnicos de qualidade correspondentes. Como

\footnotetext{
${ }^{20}$ A IAEA modificou o enfoque anterior em garantia da qualidade para sistema da gestão, e está substituindo as normas sobre o assunto (50-C/SG-Q) pelas normas de SG alvo desta pesquisa (IAEA GS-R-3, IAEA GSG-3.1 e pela futura norma que resultará do projeto IAEA DS349). (IAEA, 2006, p. 2; 2006d, p. 14).
} 
exemplo, para o caso do $\mathrm{UF}_{6}$ natural comercial ${ }^{21}$, a ser fornecido para alimentação das plantas de enriquecimento isotópico, o mercado dispõe da norma ASTM C 787 (ASTM, 1996), que estabelece os requisitos da qualidade, tais como, entre outros aspectos, a definição dos limites de impurezas e de isótopos de urânio contidos no produto, como citados a seguir:

- Limites para concentração de isótopos secundários, tais como (em $\mu \mathrm{g} / \mathrm{gU}):{ }^{232} \mathrm{U}(0,00001),{ }^{234} \mathrm{U}(58,0)$ e ${ }^{236} \mathrm{U}(20,0)$. A medida da concentração de ${ }^{236} \mathrm{U}$, por exemplo, é um indicador de contaminação.

- Limite para o total de conteúdo de elementos que formam fluoretos não voláteis, tais como: alumínio, bário, berílio, cádmio, cálcio, ferro, lítio, magnésio, prata, entre outros. A pressão de vapor de $100 \mathrm{kPa}$ ou menos, e a $300^{\circ} \mathrm{C}$, não deve exceder a 300 $\mu \mathrm{g} / \mathrm{gU}$.

- Limites específicos para elementos, tais como (em $\mu \mathrm{g} / \mathrm{gU})$ : antimônio (1), arsênico (3), boro (1), cromo (10), fósforo (50), entre outros.

- Limite para o tecnécio $\left({ }^{99} \mathrm{Tc}\right)$ que não deve exceder a $0,001 \mu \mathrm{g} / \mathrm{gU}$.

- Etc.

\subsection{Pesquisa Documental em Normas Técnicas.}

A pesquisa documental foi realizada em normas técnicas em vigor sobre sistema de gestão da Agência e sistema de gestão de mercado, ou seja, qualidade, ambiental e segurança e saúde no trabalho. No caso da Agência também foram pesquisados projetos de norma considerados importantes à pesquisa, como aqueles sobre requisitos para segurança nuclear de instalações do ciclo de combustível nuclear. Os projetos de normas da Agência estudados são documentos em vias de emissão como normas, sendo elaborados por comitês técnicos constituídos por representantes nomeados criteriosamente pela IAEA. A pesquisa documental incluiu as seguintes normas e projetos de normas:

- ABNT NBR ISO 9001:2000 (ABNT, 2000a), incluindo considerações sobre a ABNT NBR ISO 9004:2000 (ABNT, 2000b).

${ }^{21} \mathrm{UF}_{6}$ natural comercial $-\mathrm{UF}_{6}$ de urânio natural não irradiado (contendo $0,711 \pm 0,004 \mathrm{~g}$ de ${ }^{235} \mathrm{U}$ por $100 \mathrm{~g}$ de Urânio) (ASTM, 1996). 
- ABNT NBR ISO 14001:2004 (ABNT, 2004), incluindo considerações sobre a ABNT NBR ISO 14004:2005 (ABNT, 2005b).

- OHSAS 18001:2007 (Risk, 2007), incluindo considerações sobre a OHSAS 18002:2000 (BSI, 2000).

- IAEA GS-R-3:2006 (IAEA, 2006a).

- IAEA GS-G-3.1:2006 (IAEA, 2006c).

- IAEA DS349 Rev. 2007 (IAEA, 2007a).

- IAEA DS316 Rev. 2006 (IAEA, 2006d), seções referentes ao estágio de operação de instalações do ciclo do combustível nuclear.

- IAEA DS344 Rev. 2006 (IAEA, 2006e), seções referentes ao estágio de operação de instalações de conversão do "Yellowcake" em UF 6 .

\subsubsection{Estado da Arte da Norma de Sistema de Gestão da Qualidade - ISO 9001.}

Segundo descrito na norma ISO 9000 (ABNT, 2005a, p. 1), a abordagem de sistema de gestão da qualidade (SGQ) incentiva as organizações a analisar os requisitos do cliente, definir os processos que contribuem para a obtenção de um produto que é aceitável para o cliente e manter estes processos sob controle. Um SGQ pode fornecer a estrutura de ampliar a satisfação dos clientes e de outras partes interessadas. Ele fornece confiança à organização e a seus clientes de que ela é capaz de fornecer produtos que atendam aos requisitos de forma consistente.

As normas da família ${ }^{22}$ ISO 9000 foram desenvolvidas para apoiar as organizações, de todos os tipos e tamanhos, na implementação e operação de SGQ eficazes (ABNT, 2005a, p. v). As duas normas da família, em vigor, utilizadas para estruturação de SGQ pelas organizações, são as seguintes:

- ISO 9001:2000 23 - Sistemas de Gestão da Qualidade - Requisitos (ABNT, 2000a) - A norma especifica requisitos para o SGQ, onde uma organização precisa demonstrar sua capacidade para fornecer produtos que atendam aos requisitos do cliente e aos requisitos regulamentares aplicáveis, e tem como propósito aumentar a satisfação do cliente (ABNT, 2005a, p. v).

\footnotetext{
${ }^{22}$ Segundo a ABNT (2005a) as normas ABNT NBR família ISO 9000 publicadas pela ABNT, são as versões oficiais Brasileiras equivalentes às normas ISO família 9000 publicadas pela ISO, assim, a menos que especificamente mencionado, as siglas ISO 9000, ISO 9001 e ISO 9004 serão usadas indistintamente como referência aquelas publicadas pela $\mathrm{ABNT}$, quanto pela ISO.

${ }^{23}$ A norma ABNT NBR ISO 9001:2000 é equivalente à ISO 9001:2000 (ABNT, 2000a, p. 1).
} 
- ISO 9004:2000 24 - Sistemas de Gestão da Qualidade - Diretrizes para Melhoria de Desempenho (ABNT, 2000b). A norma fornece diretrizes que consideram tanto a eficácia como a eficiência do SGQ. O objetivo da norma é melhorar o desempenho da organização, e a satisfação dos clientes e das outras partes interessadas (ABNT, 2005a, p. v).

A família ISO 9000 distingue dois tipos de requisitos (ABNT, 2005a, p. 2):

- Requisitos para produtos - As normas da família ISO 9000 não estabelecem requisitos para produtos. Estes requisitos podem ser especificados pelos clientes ou pela própria organização fornecedora dos produtos, antecipando-se aos requisitos dos clientes, ou por regulamentação. As normas esclarecem que os requisitos para produtos e, em alguns casos, para os processos associados, podem estar contidos em, por exemplo, especificações técnicas, normas de produto, normas de processo, acordos contratuais e requisitos regulamentadores (ABNT, 2005a, p. 2).

- Requisitos para SGQ - Os requisitos para SGQ, como já mencionado anteriormente, são especificados pela norma ISO 9001. Eles são genéricos e aplicáveis às organizações de qualquer setor da indústria ou economia, independentemente da categoria do produto ofertado (ABNT, 2005a, p. 2). Os requisitos para SGQ são complementares aos requisitos para produtos (ABNT, 2000a, p. 1).

A ISO 9001 especifica requisitos de SGQ que podem ser usados pelas organizações para aplicação interna, para certificação ou para fins contratuais. Ela está focada na eficácia do SGQ em atender aos requisitos dos clientes (ABNT, 2000a, p. 3).

Além dos requisitos estabelecidos pela ISO 9001, a ISO 9004 fornece diretrizes complementares que orientam as organizações a estruturarem um SGQ que considere, tanto a eficácia como a eficiência e, por conseqüência, o potencial para melhoria do desempenho de uma organização. Quando comparada com a ISO 9001, os objetivos de satisfação dos clientes e qualidade do produto são estendidos para considerar a satisfação das partes interessadas e o desempenho das organizações (ABNT, 2000b, p. 3).

A ISO 9004 consiste em diretrizes e recomendações e não tem propósitos de uso regulamentar ou contratual para certificação, nem como guia para implementação da ISO 9001 (ABNT, 2000b, p. 3).

O foco da ISO 9001 é a satisfação do cliente. Ela tem como objetivo fornecer produtos que atendam aos requisitos do cliente e aos requisitos regulamentares aplicados; e

\footnotetext{
${ }^{24}$ A norma ABNT NBR ISO 9004:2000 é equivalente à ISO 9004:2000 (ABNT, 2000b, p. 1).
} 
pretende aumentar a satisfação do cliente por meio da aplicação efetiva do SGQ (ABNT, 2000a, p. 3 e 5).

O foco da ISO 9004 é obter a melhoria contínua, medida por meio da satisfação dos clientes e de outras partes interessadas (ABNT, 2000b, p. 3). As partes interessadas das organizações incluem:

- Clientes e usuários finais.

- Pessoas na organização.

- Proprietários e investidores.

- Fornecedores e parceiros.

- Sociedade na figura da comunidade e do público atingido pela organização ou seu s produtos.

O modelo de SGQ proposto pela família ISO 9000 se baseia em processo como é mostrado na FIG. 6. O modelo estabelece um papel significativo dos clientes (ISO 9001) e das outras partes interessadas (ISO 9004), na definição dos requisitos como entradas, e a monitoração da satisfação desses clientes e partes interessadas (ABNT, 2000a, p. 2; 2000b, p. 2).

Na FIG. 6 é ilustrada a ligação dos processos do modelo de SGQ, porém não apresenta estes processos em nível detalhado (ABNT, 2005a, p. 2). Os detalhes para definição desses processos são apresentados em forma de requisitos e diretrizes complementares, nas seções de 4 a 8 das normas ISO 9001 e ISO 9004, respectivamente.

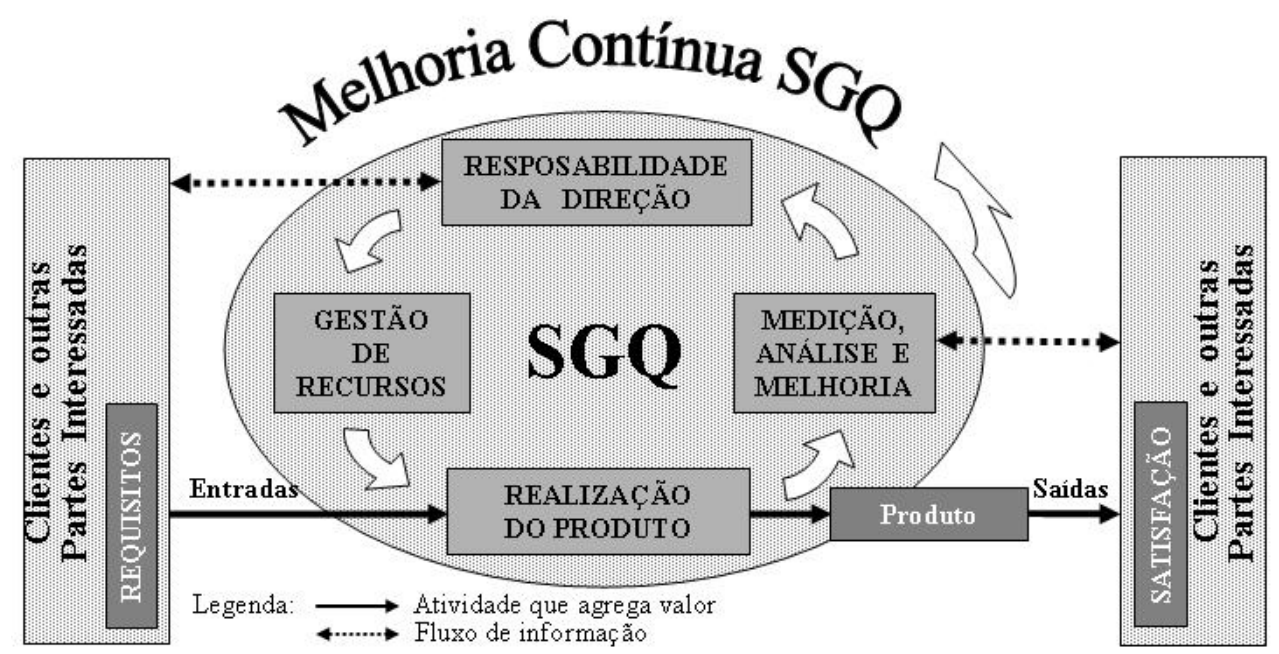

FIGURA 6 - Modelo Representativo de um Sistema de Gestão da Qualidade - ISO 9001. Fonte: Adaptado da FIG. 1 "Modelo de um processo baseado no sistema de gestão da qualidade", apresentado pela ISO (ABNT, 2005a, p. 2) 
A seguir é apresentado um sumário das seções que descrevem os processos do modelo de SGQ da ISO 9001:2000, que é a norma utilizada na pesquisa. O anexo B apresenta a itemização dessa norma.

\section{Seção 4 - Sistema da Gestão da Qualidade.}

A norma ISO 9001 (ABNT, 2000a, p. 4-5) estabelece requisitos gerais e de documentação para o SGQ, nos quais é requerido que o SGQ seja estabelecido, implementado, mantido e continuamente melhorado e que os seus processos sejam identificados e gerenciados pela organização.

\section{Seção 5 - Responsabilidade da Direção.}

A norma ISO 9001 (ABNT, 2000a, p. 5-6) requer que a alta direção demonstre o seu comprometimento com o SGQ; assegure o foco no cliente; assegure o estabelecimento de uma política da qualidade apropriada e entendida por toda a organização; assegure o planejamento da qualidade que defina os objetivos da qualidade, assim como a forma e os meios para alcançá-los; assegure a definição das responsabilidades e autoridades pelo SGQ e sua adequada comunicação a todos os níveis da organização; indique um membro da organização com autoridade e responsabilidade pela gestão do SGQ e seus processos; e execute, a intervalos planejados, uma análise crítica para avaliar a adequação do SGQ.

\section{Seção 6 - Gestão de Recursos.}

A norma ISO 9001 (ABNT, 2000a, p. 4-5) requer que a organização determine e provenha os recursos necessários para implementar, manter e continuamente melhor o SGQ, incluindo recursos humanos, de infra-estrutura e de ambiente de trabalho.

\section{Seção 7 - Realização do Produto.}

A norma ISO 9001 (ABNT, 2000a, p. 7-10) requer que a organização planeje e desenvolva processos específicos para a realização do produto, coerentes com os outros requisitos de processos do SGQ; determine e analise criticamente os requisitos relacionados ao produto e estabeleça uma comunicação eficaz com os clientes neste sentido; planeje, controle o desenvolva o projeto do produto; assegure a conformidade dos produtos adquiridos; planeje e realize a produção e o fornecimento de serviço sob 
condições controladas, validando processos cujo resultado não possa ser verificado por monitoração ou medição subseqüente; identifique e faça o rastreamento do produto ao longo da produção quando apropriado; identifique, verifique, proteja, e salvaguarde a propriedade do cliente; preserve o produto até entrega no destino pretendido; e determine as medições e monitorações que evidenciem a conformidade do produto, assim como determine e controle os dispositivos de medição e monitoração respectivos.

\section{Seção 8 - Medição, Análise e Melhoria.}

A norma ISO 9001 (ABNT, 2000a, p. 10-12) requer que a organização planeje e implemente os processos necessários a monitoramento, medição, análise e melhoria do SGQ para demonstrar a conformidade do produto, assegurar a conformidade do SGQ e melhorar continuamente a eficácia do SGQ. Para este fim, requer que sejam realizadas: a monitoração, medição e análise da satisfação dos clientes; auditorias internas do SGQ; a medição e monitoramento dos processos; a medição e monitoramento dos produtos; o controle dos produtos não-conformes; e a análise de dados da adequação e eficácia do SGQ. Como resultado, requer que a eficácia do SGQ seja melhorada continuamente e que sejam executadas ações corretivas e preventivas para eliminar causas de não conformidades atuais ou potenciais.

\subsubsection{ISO 9001 - Documentação.}

Segundo o relatório técnico da ABNT (2002, p. 2), a família ISO 9000 requer que o SGQ seja documentado; entretanto, a organização tem flexibilidade na escolha da forma de documentar, desenvolvendo a quantidade de documentação necessária para demonstrar o efetivo planejamento, operação, controle e contínua melhoria do seu SGQ e seus processos.

A ISO 9000 (ABNT, 2005a, p. 5) estabelece que cabe a organização determinar a extensão da documentação necessária ao seu SGQ, assim como os meios a utilizar, levando em conta fatores, tais como: o tipo e tamanho da organização, a complexidade e interação dos processos, a complexidade dos produtos, os requisitos do cliente, os requisitos regulamentares aplicáveis, a capacidade do pessoal e o grau necessário requerido para demonstrar o atendimento aos requisitos do SGQ.

A ISO 9001 (ABNT, 2000a, p. 4) requer que seja documentado no SGQ, a:

- Declaração da política da qualidade. 
- Declaração dos objetivos da qualidade.

- Manual da qualidade.

- Procedimentos requeridos pela norma.

- Documentos necessários à organização para assegurar o planejamento, a operação e o controle eficazes de seus produtos.

- Registros requeridos pela norma.

\section{Declaração da Política e Objetivos da Qualidade}

A ISO 9000 (ABNT, 2005a, p. 3) requer que a política da qualidade e os objetivos da qualidade sejam estabelecidos para proporcionar um foco para dirigir a organização. Ela acrescenta que, tanto a política quanto os objetivos determinam os resultados desejados e auxiliam a organização na aplicação de seus recursos para alcançar esses resultados. A política da qualidade fornece uma estrutura para estabelecer e analisar criticamente os objetivos da qualidade, que devem ser consistentes com a política e com o comprometimento para melhoria contínua. O cumprimento dos objetivos pode ter um impacto positivo na qualidade do produto, na eficácia operacional e no desempenho financeiro, conduzindo assim à satisfação e confiança das partes interessadas.

A ISO 9001 (ABNT, 2000a, p. 5) requer que a política da qualidade:

a) Seja apropriada ao propósito da organização,

b) Inclua o comprometimento com o atendimento aos requisitos e com a melhoria contínua da eficácia do SGQ,

c) Proporcione uma estrutura para estabelecimento e análise crítica dos objetivos da qualidade,

d) Seja comunicada e entendida por toda a organização, e

e) Seja analisada criticamente para manutenção de sua adequação.

A ISO 9001 (ABNT, 2000a, p. 5) requer que os objetivos da qualidade, incluindo aqueles necessários para atender aos requisitos do produto, sejam estabelecidos nas funções e nos níveis pertinentes da organização e sejam mensuráveis.

\section{Manual da Qualidade}

A ISO 9001 (ABNT, 2000a, p. 4) requer que o manual da qualidade inclua: 
- Escopo do SGQ, com detalhes e justificativas quanto a quaisquer exclusões $^{25}$.

- Procedimentos documentados estabelecidos pelo SGQ, ou referência a eles.

- Descrição da interação entre os processos do SGQ.

Na ISO 9000 (ABNT, 2005a, p. 17) o manual da qualidade é definido como o documento que especifica o SGQ da organização; ou seja, especifica o conjunto de elementos inter-relacionados ou interativos para estabelecer políticas e objetivos, e para atingir estes objetivos, no que diz respeito à qualidade; ou ainda, estabelece um sistema de gestão para dirigir e controlar uma organização no que diz respeito à qualidade (ABNT, 2005a, p. 9).

$\mathrm{O}$ anexo $\mathrm{C}$ transcreve o conteúdo e apresenta a itemização para manual da qualidade recomendados pelo relatório técnico da ABNT (2002).

\section{Procedimentos Documentados.}

Segundo a ISO 9000`(ABNT, 2005a, p. 11) um procedimento é uma forma especificada de executar uma atividade ou um processo, podendo ser documentado ou não. Quando um procedimento é documentado, o termo "procedimento escrito" ou "procedimento documentado" é freqüentemente usado.

A ISO 9001 (ABNT, 2000a, p. 4) descreve que o termo "procedimento documentado" significa que o procedimento é estabelecido, documentado, implementado e mantido. Os procedimentos documentados requeridos são:

- Controle de documentos (ABNT, 2000a, p. 4)

- Controle de registro (ABNT, 2000a, p. 5)

- Auditoria interna (ABNT, 2000a, p. 11)

- Controle de produto não-conforme (ABNT, 2000a, p. 11)

- Ação corretiva (ABNT, 2000a, p. 12)

- Ação preventiva (ABNT, 2000a, p. 12)

\footnotetext{
${ }^{25}$ Quando alguns requisitos da norma ISO 9001 não puderem ser aplicados devido à natureza de uma organização e seus produtos, eles podem ser considerados para exclusão. As exclusões estão limitadas aos requisitos contidos na seção 7 da norma e desde que tais exclusões não afetem a capacidade ou responsabilidade da organização de fornecer produtos que atendam aos requisitos dos clientes e requisitos regulamentares aplicáveis (ABNT, 2000a, p. 5).
} 
Segundo a guia sobre requisitos de documentação da ISO (2001, p. 4), algumas organizações (particularmente grandes organizações, ou aquelas com processos mais complexos) podem requerer procedimentos documentados adicionais, particularmente aqueles relativos aos processos de realização do produto.

$\mathrm{O}$ anexo $\mathrm{C}$ transcreve o conteúdo e apresenta a itemização para procedimento documentado recomendados pelo relatório técnico da ABNT (2002).

\section{Documentos Necessários à Organização para Assegurar o Planejamento, a Operação e o Controle Eficazes de seus Produtos.}

Segundo a guia sobre requisitos de documentação da ISO (2001, p. 4), para que uma organização demonstre uma efetiva implementação do seu SGQ pode ser necessário o desenvolvimento de outros documentos, além dos procedimentos documentados. Segundo ainda a guia, existem vários requisitos na ISO 9001 onde a organização pode agregar valor ao seu SGQ e demonstrar conformidade mediante a preparação de outros documentos. Exemplos desses documentos podem incluir:

- Planos da qualidade.

- Instruções de trabalho e testes.

- Mapas, diagramas de fluxo e descrição dos processos.

- Planos de inspeções e testes.

- Especificações.

- Documentos contendo comunicações internas.

- Cronogramas de produção.

- Lista de fornecedores qualificados.

- Cartas de controle da organização.

Segundo definido pela ISO 9000 (ABNT, 2005a, p. 17), os planos da qualidade especificam quais procedimentos e recursos associados devem ser aplicados, por quem e quando, a um empreendimento, produto, processo ou contrato específico.

Segundo o relatório sobre documentação da ISO (ABNT, 2002, p. 2), as instruções de trabalho descrevem detalhadamente como executar uma tarefa, podendo ser documentadas ou não (descrição escritas detalhadas, fluxogramas, gabaritos, modelos, notas técnicas incorporadas a desenhos, etc.).

A ISO 9000 (ABNT, 2005a, p. 17) define que as especificações estabelecem requisitos de produto, processo, ensaios, etc. 
$\mathrm{O}$ anexo $\mathrm{C}$ apresenta informações sobre alguns dos documentos acima citados, transcritas do relatório sobre documentação da ISO (ABNT, 2002).

\section{Registros}

A ISO 9000 (ABNT, 2005a, p. 17) define que os registros apresentam os resultados obtidos ou fornecem evidência das atividades realizadas.

No apêndice A é apresentada uma relação de registros requeridos pela ISO 9001 e que são citados na guia de requisitos de documentação da ISO (2000b, p. 4). Segundo a guia, as organizações são livres para desenvolver registros que possam ser necessários para demonstrar conformidade de seus processos, produtos e SGQ.

\section{Estrutura de Documentação do SGQ}

O relatório técnico da ISO (ABNT, 2002, p. 9) propõe uma estrutura hierárquica para a documentação que compõe o SGQ. A hierarquia dos documentos é representada em três níveis, pela pirâmide ilustrada no anexo C. Entretanto, segundo o relatório, o número de níveis pode ser ajustado para satisfazer as necessidades da organização.

\subsubsection{Estado da Arte da Norma de Sistema de Gestão Ambiental - ISO 14001}

As normas da série ISO $14000^{26}$ foram desenvolvidas para prover às organizações, de todos os tipos e portes, de elementos de um sistema de gestão ambiental (SGA) eficaz, que possam ser integrados a outros elementos de gestão, e auxiliá-las a alcançar seus objetivos ambientais e econômicos, com o propósito de equilibrar a proteção ambiental e a prevenção da poluição, com as necessidades socioeconômicas (ABNT, 2004, p. v).

As duas normas da série, em vigor, utilizadas para estruturação de SGA pelas organizações, são as seguintes:

a) ISO 14001:2004 ${ }^{27}$ - Sistema de Gestão Ambiental - Requisitos com orientação para uso (ABNT, 2004) - Especifica os requisitos para um SGA, permitindo a

\footnotetext{
${ }^{26}$ Segundo as normas da ABNT (2004, p.iv; 2005c, p. iv) a família ABNT NBR ISO 14000 publicadas pela ABNT, são as versões oficiais Brasileiras equivalentes à família ISO 14000 publicadas pela ISO, assim a menos que especificamente mencionado, as siglas ISO 14001 e ISO 14004 serão usadas indistintamente como referência aquelas publicadas pela ABNT quanto pela ISO.

${ }^{27}$ A norma ABNT NBR ISO 14001:2004 é equivalente à ISO 14001:2004 (ABNT, 2004a, p. iv).
} 
organização desenvolver e implementar uma política e objetivos que levem em conta os requisitos legais e outros por ela subscritos e informações referentes aos aspectos ambientais significativos. A norma aplica-se aos aspectos ambientais que a organização identifica como aqueles que possa controlar e aqueles que possa influenciar. Em si, não estabelece critérios específicos de desempenho ambiental (ABNT, 2004, p. 1)

b) ISO $14004: 2005^{28}$ - Sistema de gestão ambiental - Diretrizes gerais sobre princípios, sistemas e técnicas de apoio (ABNT, 2005b) - Provê orientação para o estabelecimento, implementação, manutenção e melhoria de um SGA e sua coordenação com outros sistemas de gestão.

Dentre as duas normas citadas, somente a ISO 14001 contém requisitos para SGA que podem ser auditados para fins de certificação ou de autodeclaração. A ISO 14004 não estabelece requisitos, ela descreve os elementos de um SGA e fornece às organizações diretrizes de como estabelecer, manter e aprimorar um SGA. Embora as diretrizes da ISO 14004 sejam coerentes com o modelo da ISO 14001, não se pretende que elas forneçam interpretação dos requisitos da ISO 14001 (ABNT, 2005b, p. v).

Os requisitos estabelecidos pela ISO 14001 têm como propósito permitir a estruturação de um SGA que capacite as organizações a desenvolver e implementar políticas e objetivos que levem em consideração requisitos legais e informações sobre aspectos ambientais significativos (ABNT, 2004, p. v).

A ISO 14001 não estabelece requisitos absolutos para o desempenho ambiental além dos comprometimentos, expressos na política ambiental, de estar em conformidade com os requisitos legais ou outros subscritos pela organização, com a prevenção da poluição e com a melhoria contínua. Ela também não inclui requisitos específicos de outros sistemas de gestão, tais como aqueles para: qualidade, segurança e saúde ocupacional, finanças ou gerenciamento de risco; muito embora seus elementos possam ser alinhados ou integrados com os de outros sistemas de gestão (ABNT, 2004, p. vii).

A ISO 14001 leva em conta as disposições da ISO 9001:2000 de maneira a aumentar a compatibilidade entre as duas normas, para benefício da comunidade de usuários (ABNT, 2004, p.v). O anexo F apresenta a correlação entre os requisitos da ISO 14001:2004, ISO 9001:2000 e OHSAS 18001:2007.

O SGA das ISO 14001 e ISO 14004 se baseia na metodologia conhecida como PDCA $^{29}$ e está representada na FIG. 7. O PDCA é um processo contínuo iterativo e que

\footnotetext{
${ }^{28}$ A norma ABNT NBR ISO 14004:2005 (ABNT, 2005b, p. iv) é equivalente à ISO 14004:2004.

${ }^{29}$ PDCA - Plan-Do-Check-Act (Planejar-Executar-Vericar-Agir) (ABNT, 2004, p. vi).
} 
possibilita a organização estabelecer, implementar e manter sua política ambiental, com base na liderança e comprometimento da alta administração em relação ao SGA. Este processo contínuo possibilita à organização melhorar continuamente seu SGA e seu desempenho ambiental global (ABNT, 2005b, p. 5-6).

As seções 4 das ISO 14001 e ISO 14004 descrevem, respectivamente, os requisitos e os elementos de um SGA. Os retângulos da FIG. 7 representam a primeira quebra das subseções da seção 4 das normas em questão que, para maior facilidade de uso, possuem a mesma numeração. Entretanto, a norma ISO 14004 possui subseções extras onde são incluídas diretrizes detalhadas ou adicionais, consideradas úteis a uma eficaz implementação do SGA (ABNT, 2005b, p. v).

Por ser a norma utilizada na pesquisa, é feita a seguir uma descrição sumária dos elementos (requisitos) do SGA da ISO 14001, apresentados em sua seção 4.

O anexo A da ISO 14001 apresenta um texto adicional referente a cada subseção da seção 4 da norma. Para facilidade de uso, as subseções do anexo A da norma possuem números correlatos às subseções do seu texto principal (ABNT, 2004, p. v).

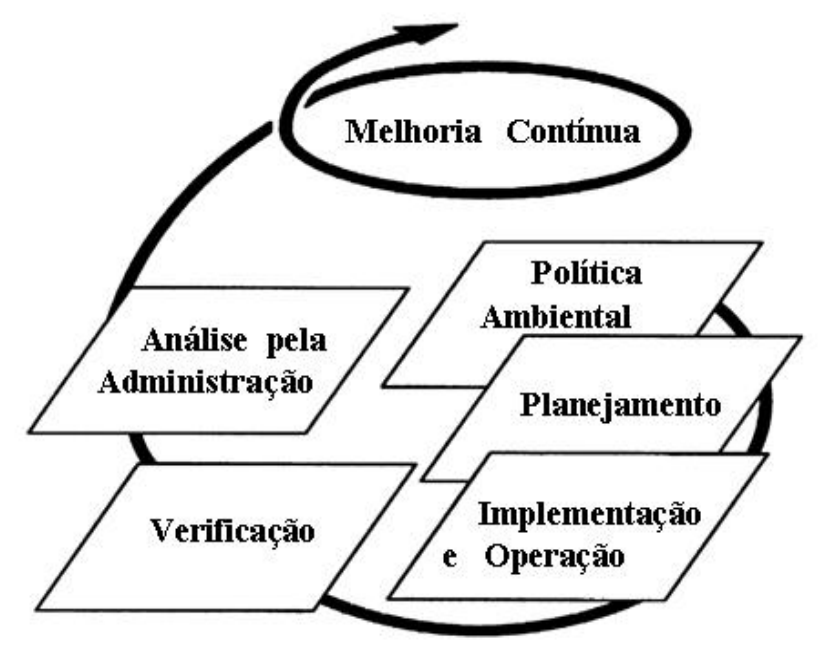

FIGURA 7 - Modelo Representativo de um Sistema de Gestão Ambiental - ISO 14001. Fonte: Modelo de sistema de gestão ambiental para ISO 14001 (ABNT, 2004, p. vi)

Segundo a ISO 14001 (ABNT, 2004, p. 11) o texto adicional fornecido em seu anexo A, tem caráter estritamente informativo e tem por propósito prevenir uma interpretação errônea dos requisitos contidos nas subseções do texto principal. O anexo D desta pesquisa apresenta um sumário das subseções da norma, correlacionadas com as subseções de seu anexo A. 


\section{Subseções 4.1 e 4.2 - Requisitos Gerais e Política Ambiental.}

A ISO 14001 (ABNT, 2004, p. 4) requer que o SGA seja estabelecido, documentado, implementado, mantido e continuamente melhorado em conformidade com os seus requisitos e que se determine como esse SGA irá atender a esses requisitos. A norma requer que a alta direção defina e assegure a implementação de uma política ambiental.

\section{Subseções 4.3 - Planejamento do SGA.}

A ISO 14001 (ABNT, 2004, p. 5) requer que a organização:

- Identifique os aspectos ambientais que possa controlar e aqueles que possa influenciar e determine aqueles que possam ter impactos significativos sobre o meio ambiente.

- Identifique os requisitos legais aplicáveis e requisitos subscritos relacionados aos seus aspectos ambientais.

- Estabeleça, implemente e mantenha objetivos ambientais, mensuráveis, coerentes com a política ambiental, e estabeleça, implemente e mantenha programas para atingir esses objetivos.

\section{Subseções 4.4 - Implementação e Operação do SGA.}

A ISO 14001 (ABNT, 2004, p. 6-8) requer que a organização:

- Assegure disponibilidade de recursos para estabelecer, implementar, manter e melhorar o SGA.

- Defina, documente e comunique as responsabilidades e autoridades pelo SGA e indique representantes específicos da administração para assegurar o estabelecimento, implementação, manutenção e melhoria do SGA.

- Assegure as competências, treinamento e conscientização em relação ao SGA e as tarefas que tenham o potencial de causar impactos ambientais significativos.

- Estabeleça, implemente e mantenha comunicação interna e com as partes interessadas externas, com relação aos aspectos ambientais e SGA.

- Documente o SGA conforme requerido pela norma e controle esses documentos.

- Identifique e planeje as operações associadas aos aspectos ambientais significativos, de acordo com sua política, objetivos e metas ambientais. 
- Identifique potenciais situações de emergência e potenciais acidentes que possam ter impacto no meio ambiente e defina como responder às situações reais de emergência e aos acidentes, e como previr e mitigar os impactos ambientais adversos associados

\section{Subseções 4.5 - Verificação.}

A norma ISO 14001 (ABNT, 2004, p. 8-9) requer que a organização:

- Monitore e meça regularmente as características principais de suas operações que possam ter impacto ambiental significativo.

- Avalie periodicamente o atendimento aos requisitos legais aplicáveis e a outros requisitos por ela subscritos.

- Trate as não-conformidades reais e potenciais e execute ações corretivas e preventivas correspondentes.

- Estabeleça e mantenha registros para demonstrar a conformidade com os requisitos do SGA e resultados obtidos e que estabeleça, implemente e mantenha controle para esses registros.

- Assegure a condução de auditorias internas do SGA, a intervalos planejados, levando em consideração a importância ambiental das operações e resultado de auditorias anteriores.

- Análise o SGA a intervalos planejados, para assegurar sua contínua adequação, pertinência e eficácia. A norma requer que está análise seja realizado pela alta administração.

\subsubsection{ISO 14001 - Documentação.}

A ISO 14001 (ABNT, 2004, p. 7 e 17) requer que se documente no SGA, a:

- Declarações da política, objetivos e metas ambientais.

- Descrição do escopo do SGA.

- Descrição dos principais elementos do SGA e sua interação e referência aos documentos associados.

- Documentos, incluindo registros, requeridos pela norma. 
- Documentos, incluindo registros, determinados pela organização como sendo necessários para assegurar o planejamento, operação e controle eficazes dos processos que estejam associados com seus aspectos ambientais significativos.

Segundo a ISO 14004 (ABNT, 2005b, p. 27) o propósito da documentação do SGA é prover informações necessárias aos empregados e a outras partes interessadas, conforme apropriado, devendo refletir a cultura e as necessidades da organização, acrescentando e aprimorando o sistema de informações existente

A extensão da documentação pode diferir de uma organização para outra, dependendo do seu porte, tipo e atividades, produtos e serviços, da complexidade dos processos e suas interações, e da competência do pessoal (ABNT, 2004, p. 17).

A ISO 14001 (ABNT, 2004, p. 17) requer que o nível de detalhamento da documentação seja suficiente para descrever os elementos principais do SGA da organização, fornecendo orientação sobre fontes de informação mais detalhadas sobre o funcionamento de partes específicas do SGA.

\section{Declarações da Política, Objetivos e Metas Ambientais}

A ISO 14001 (ABNT, 2004, p. 12) se refere à política ambiental como a força motriz para a implementação e aprimoramento do SGA de uma organização, permitindo que seu desempenho ambiental seja mantido e potencialmente aperfeiçoado. Ela requer (ABNT, 2004, 4) que a alta direção da organização defina e documente a política ambiental da organização, considerando que:

a) Seja apropriada à natureza, escala e impactos ambientais de suas atividades, produtos e serviços.

b) Inclua o comprometimento com a melhoria contínua e com a prevenção de poluição.

c) Inclua o comprometimento em atender aos requisitos legais aplicáveis e outros requisitos subscritos pela organização que se relacionem a seus aspectos ambientais.

d) Forneça a estrutura para o estabelecimento e análise dos objetivos e metas ambientais,

e) Seja documentada, implementada e mantida,

f) Seja comunicada a todos que trabalhem na organização ou que atuem em seu nome,

g) Esteja disponível para o público. 
A ISO 14001 (ABNT, 2004, p. 15) requer que os objetivos e metas sejam específicos e mensuráveis, sempre que possível, e que os objetivos considerem questões de curto e de longo prazo e, ainda, ainda (ABNT, 2004, p. 5) que os objetivos e metas sejam estabelecidos nas funções e níveis relevantes da organização

\section{Descrição do Escopo do SGA.}

A ISO 14001 (ABNT, 2004, p. 4) requer que a organização defina e documente o escopo de seu SGA. A norma (ABNT, 2004, p. 12) recomenda que a área de aplicação da política (ou seja, seu escopo) seja claramente identificável e reflita sua natureza singular, escala e os impactos ambientais das atividades, produtos e serviços dentro do escopo definido do SGA e, ainda, que ao definir o escopo de seu SGA sejam esclarecidos os limites até onde o SGA é aplicado, especialmente quando a organização fizer parte de uma organização maior. Uma vez definido o escopo, todas as atividades, produtos e serviços incluídos no escopo têm que ser considerados no SGA, caso alguns sejam excluídos, é recomendável que a organização seja capaz de explicar a exclusão. A credibilidade do SGA irá depender da escolha dos limites organizacionais para o sistema.

A ISO 14001 (ABNT, 2004, p. 13) recomenda que a organização identifique os aspectos ambientais dentro do escopo do seu SGA.

\section{Descrição dos Principais Elementos do SGA e sua Interação e Referência aos Documentos Associados.}

A norma não fornece informações quanto à descrição do SGA.

\section{Documentos, incluindo Registros, Requeridos pela Norma.}

No apêndice B são relacionados os documentos, incluindo procedimentos, e os registros a serem documentados como requerido na seção 4 (ABNT, 2004, p. 4-10).

\section{Documentos, incluindo Registros, Determinados pela Organização como sendo}

Necessários para Assegurar o Planejamento, Operação e Controle Eficazes dos

Processos que estejam Associados com seus Aspectos Ambientais Significativos.

A ISO 14001 (ABNT, 2004, p. 5-9) requer em vários de seus requisitos que sejam estabelecidos, implementados e mantidos procedimentos, definindo as ações necessárias para atender ao requisito em particular (Ver relação no apêndice C). Segundo a 
norma (ABNT, 2004, p. 4), procedimento é a forma especificada de executar uma atividade ou um processo, podendo ser documentado ou não. A ISO 14001 recomenda (ABNT, 2004, p. 17) que qualquer decisão de documentar procedimentos seja baseada em questões, tais como:

- As conseqüências, inclusive aquelas relativas ao meio ambiente, de não fazê-lo.

- A necessidade de demonstrar o atendimento a requisitos legais e outros requisitos subscritos pela organização, a necessidade de se assegurar que a atividade seja realizada de forma constante.

- Necessidade de se assegurar que a atividade seja realizada de forma constante.

- As vantagens de agir assim que podem incluir a implementação facilitada por meio da comunicação e treinamento, manutenção e revisão facilitada, menor risco de ambigüidades e desvios, capacidade de demonstração e visibilidade.

- Os requisitos da norma.

Para que uma organização faça uma gestão eficaz dos seus processos-chave (ou seja, aqueles relacionados com seus aspectos ambientais significativos identificados), a ISO 14004 (ABNT, 2005b, p.27) recomenda que ela estabeleça procedimentos que descrevam, com detalhamento apropriado, uma maneira especificada de realizar cada processo. Quando decidir não documentar um procedimento, a organização deve informar os empregados envolvidos por meio de comunicação ou treinamento dos requisitos ambientais a serem satisfeitos.

\subsubsection{Estado da Arte da Norma de Sistema de Gestão de Segurança e Saúde no Trabalho - OHSAS 18001.}

As normas OHSAS para a gestão da segurança e saúde no trabalho têm por objetivo fornecer às organizações elementos de um sistema de gestão de segurança e saúde no trabalho (SGSST) eficaz, que possam ser integrados a outros requisitos de gestão, e que possam auxiliá-las a alcançar seus objetivos de segurança e saúde no trabalho (SST) e econômicos (Risk, 2007, p. 7).

As duas normas OHSAS, em vigor, são as seguintes:

- OHSAS 18001:2007 - Sistemas de Gestão de Segurança e Saúde no Trabalho - Requisitos (Risk, 2007) - Especifica os requisitos (elementos) para um SGSST, 
para permitir a organização controlar os seus riscos de acidentes e doenças ocupacionais e melhorar o seu desempenho da SST; porém, não estabelece critérios específicos de SST, nem fornece especificações detalhadas para o desempenho de um sistema de gestão.

- OHSAS 18002:2000 - Sistemas de Gestão de Segurança e Saúde no Trabalho - Diretrizes para a Implementação da OHSAS 18001 (BSI, 2000) - Provê orientações genéricas para aplicação da OHSAS 18001. Ela explica os princípios delineados pela OHSAS 18001 e descreve a intenção, as entradas típicas, os processos e as saídas típicas, referentes a cada um dos requisitos da OHSAS 18001. A finalidade é a compreensão e a implementação da OHSAS 18001. A norma não cria requisitos adicionais aos da OHSAS 18001, nem prescreve uma abordagem obrigatória para implementação da OHSAS 18001.

A OHSAS 18001 descreve os requisitos para o SGSST de uma organização e pode ser utilizado para certificação, registro e para auto-declaração do SGSST. Organizações que necessitam mais orientações genéricas sobre uma gama variada de questões relativas à SST devem buscá-las na OHSAS 18002 (Risk, 2007, p. 8).

Os requisitos estabelecidos pela OHSAS 18001 têm como propósito permitir a uma organização desenvolver e implementar uma política e objetivos que levem em consideração requisitos legais e informações sobre os riscos de SST (Risk, 2007, p. 7).

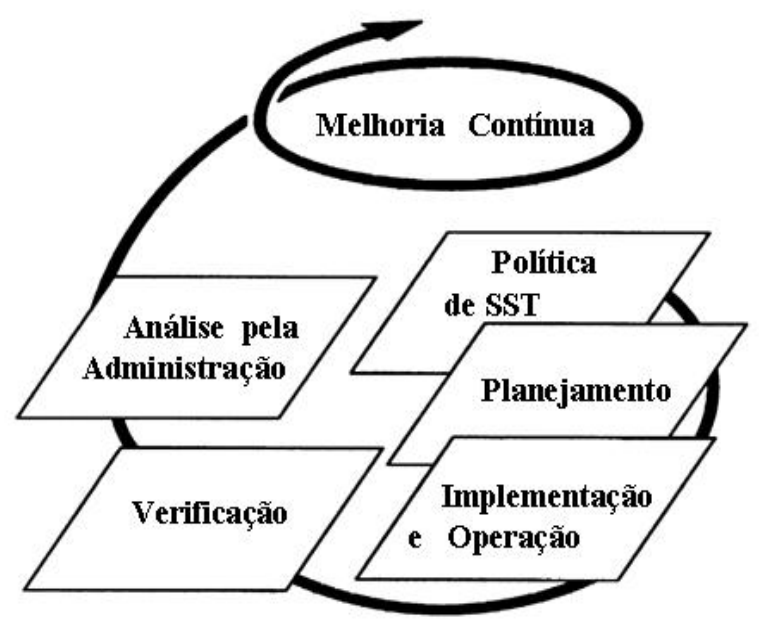

FIGURA 8 - Modelo Representativo de um Sistema de Gestão de Segurança e Saúde no Trabalho - OHSAS 18001.

Fonte: Modelo de SGSST - OHSAS 18001 (Risk, 2007, p. 9) e OHSAS 18002 (BSI, 2000, p. 4)

A OHSAS 18001 (Risk, 2007, p. 8) considera as disposições da ISO 9001, ISO 14001, ILO-OSH e de outras normas e publicações sobre SGSST, de maneira a aumentar a compatibilidade entre essas normas, em benefício da comunidade de usuários. $\mathrm{O}$ anexo $\mathrm{F}$ 
apresenta a correlação entre os requisitos da OHSAS 18001:2007, ISO 14001:2004 e ISO 9001:2000.

O modelo de SGSST da OHSAS 18001 se baseia na metodologia conhecida como PDCA ${ }^{30}$, e está representada na FIG. 8. No anexo E desta pesquisa é apresentado um sumário das subseções da norma.

\section{Subseções 4.1 e 4.2 - Requisitos Gerais e Política de SST.}

A OHSAS 18001 (Risk, 2007, p. 17) requer que o SGSST seja estabelecido, documentado, implementado, mantido e continuamente melhorado em conformidade com os requisitos da norma e determine como a organização irá atender a esses requisitos. A norma requer também que a alta direção defina e assegure a implementação de uma política de SST.

\section{Subseções 4.3 - Planejamento.}

A OHSAS 18001 (ABNT, 2004, p. 5) requer que a organização identifique continuamente os perigos, avalie os riscos e determine os controles necessários à redução dos riscos; identifique os requisitos legais aplicáveis e outros requisitos de SST que lhe são aplicáveis; e estabeleça, implemente e mantenha os objetivos de SST (mensuráveis e coerentes com a política de SST), e estabeleça, implemente e mantenha programas para atingir esses objetivos e metas.

\section{Subseções 4.4 - Implementação e Operação.}

A norma OHSAS 18001 (Risk, 2007, p. 20) requer que a alta direção assuma a responsabilidade pela SST e pelo SGSST demonstrado seu comprometimento; assegurando a disponibilidade de recursos para o sistema; definindo, documentando e comunicando as funções, responsabilidades, prestação de contas e autoridades por esse sistema; e indicando os representantes específicos da alta direção com responsabilidades específicas pela SST. Complementando, a norma requer que a organização:

- Assegure as competências, treinamento e conscientização em relação ao SGSST, os riscos de SST associados às tarefas, entre outros aspectos.

- Estabeleça, implemente e mantenha comunicação interna e com os terceirizados e outros visitantes com relação aos seus perigos de SST e ao seu SGSST.

\footnotetext{
${ }^{30}$ PDCA - Plan-Do-Check-Act (Planejar-Executar-Vericar-Agir) (Risk, 2007, p. 9).
} 
- Estabeleça, implemente e mantenha a participação de seus trabalhadores e a consulta aos terceirizados quando a aspectos do SGSST.

- Documente o SGSST conforme requerido pela norma e controle os documentos respectivos.

- Determine as operações e atividades associadas aos perigos identificados e implemente e mantenha controles em relação a esses perigos.

- Identifique o potencial para situações de emergência e responda a tais situações.

\section{Subseções 4.5 - Verificação.}

A OHSAS 18001 (Risk, 2007, p. 24-28) requer que a organização:

- Monitore e meça regularmente o desempenho da SST.

- Avalie periodicamente o atendimento aos requisitos legais aplicáveis e a outros requisitos por ela subscritos.

- Execute investigação e análise de incidente e comunique os resultados.

- Trate as não-conformidades reais e potenciais e execute ações corretivas e preventivas correspondentes.

- Estabeleça e mantenha registros para demonstrar a conformidade com os requisitos do SGSST, e estabeleça, implemente e mantenha controle para esses registros.

- Assegure a condução de auditorias internas do SGSST, a intervalos planejados.

- Análise criticamente o SGSST a intervalos planejados, para assegurar sua contínua adequação, pertinência e eficácia. A norma requer que está análise seja realizado pela alta administração.

\subsubsection{OHSAS 18001 - Documentação.}

A OHSAS 18001 (Risk, 2007, p. 22-23) requer que se documente no SGSST, a:

- Declaração da política e os objetivos de SST.

- Descrição do escopo do SGSST.

- Descrição dos principais elementos do SGSST e sua interação e referência aos documentos associados. 
- Documentos, incluindo registros, exigidos pela OHSAS 18001.

- Documentos, incluindo registros, determinados pela organização como sendo necessários para assegurar o planejamento, operação e controle eficazes dos processos que estejam associados à gestão de seus riscos de SST.

A OHSAS 18002 (BSI, 2000, p. 26) recomenda que a organização documente suficientemente o seu SGSST, assegurando seu adequado entendimento e eficaz e eficiente operacionalização. A norma complementa que a organização deve fazer uma análise crítica de sua documentação existente sobre SST e das informações necessárias para seu SGSST, antes de desenvolver a documentação. Se a organização já possuir um SGSST estabelecido e documentado pode ser mais conveniente e efetivo, que ela desenvolva um documento resumo, que descreva a inter-relação entre os procedimentos existentes e os requisitos da OHSAS 18001.

\section{Documentação da Política e Objetivos de SST.}

A OHSAS 18001 (Risk, 2007, p. 17) requer que a alta direção defina e documente a política de SST da organização, e assegure que esta política:

a) Seja apropriada à natureza e escala dos riscos de SST da organização.

b) Inclua um comprometimento com a prevenção de lesões e doenças e com a melhoria contínua da gestão e do desempenho da SST.

c) Inclua um comprometimento em atender, pelo menos, aos requisitos legais aplicáveis e outros requisitos subscritos pela organização que se relacionem a seus perigos de SST.

d) Forneça um arcabouço para o estabelecimento e análise crítica dos objetivos de SST.

e) Seja documentada, implementada e mantida.

f) Seja comunicada a todos que trabalhem sob o controle da organização, com intuito de que elas tenham ciência de suas obrigações individuais em relação à SST.

g) Esteja disponível às partes interessadas.

h) Seja periodicamente analisada criticamente para assegurar que permanece pertinente e apropriada à organização.

A OHSAS 18001 (Risk, 2007, p. 19) requer que os objetivos sejam estabelecidos nas funções e níveis pertinentes da organização e que sejam mensuráveis, quando exeqüível, e coerentes com a política de SST, e requer, ainda, que os objetivos 
incluam um comprometimento com a prevenção de lesões e doenças, com o atendimento a requisitos legais aplicáveis e outros requisitos subscritos e com a melhoria contínua.

\section{Descrição do Escopo do SGSST.}

A OHSAS 18001 (Risk, 2007, p. 17) requer que a organização defina e documente o escopo de seu SGSST.

A OHSAS 18002 (BSI, 2000, p. 5) recomenda que seja estabelecido e mantido um SGSST em conformidade com os requisitos da OHSAS 18001, explicando que esta abordagem auxilia a organização a atender os regulamentos legais e outros sobre SST. Ela expõe que a organização tem liberdade e flexibilidade para definir suas fronteiras com relação à aplicação da OHSAS 18001 e pode escolher implementá-la, em toda organização ou em uma unidade ou atividade operacional específica; entretanto, a norma recomenda que se tenha atenção ao definir estas fronteiras e o escopo do SGSST, orientando que não se deve tentar limitar o escopo, excluindo operações ou atividade que influenciem em todas as suas operações ou que possam impactar sobre a SST de seus empregados e de outras partes envolvidas.

A OHSAS 18002 (BSI, 2000, p.5) expõe que a identificação dos perigos, avaliação dos riscos e controle dos riscos e seus resultados devem ser a base para todo o seu SGSST.

\section{Descrição dos Principais Elementos do SGSST e sua Interação e Referência aos} Documentos Associados.

A norma não fornece informações quanto à descrição do SGA.

\section{Documentos, incluindo Registros, Requeridos pela Norma.}

No apêndice D estão relacionados os documentos, incluindo procedimentos, e registros que devem ser documentados segundo a OHSAS 18001 (Risk, 2007, p.17-28).

\section{Documentos, incluindo Registros, Determinados pela Organização como sendo}

Necessários para Assegurar o Planejamento, Operação e Controle Eficazes dos Processos que estejam Associados à Gestão de seus Riscos de SST.

A OHSAS 18001 requer em vários de seus requisitos que sejam estabelecidos, implementados e mantidos procedimentos, definindo as ações necessárias para atender o 
requisito em particular. O apêndice E relaciona os procedimentos requeridos pela OHSAS 18001, que podem ser documentados ou não.

\subsubsection{Estado da Arte das Normas de Sistema de Gestão da IAEA (GS-R-3, GS-G-3.1 e DS349).}

A Agência em seu sítio na Internet (IAEA, 2008c) apresenta a relação de normas sobre sistema de gestão, por ela publicadas ou em projeto, transcritas a seguir:

- IAEA GS-R-3 - The Management System for Facilities and Activities Safety Requirements, publicada em 2006 (IAEA, 2006a).

- IAEA GS-G-3.1- Application of the Management System for Facilities and Activities - Safety Guide, publicada em 2006 (IAEA, 2006c).

- Projeto de norma IAEA DS349 - Application of the Management Systems for Nuclear Facilities. (IAEA, 2007a), em preparação.

- Norma IAEA GS-G-3.2 - The Management System for Technical Services in Radiation Safety (IAEA, 2008d).

- Projeto de norma IAEA DS326 - TS-G-1.3 - Management Systems for the Safe Transport of Radioactive Material (IAEA, 2007c), em preparação.

- Norma IAEA GS-G-3.3 - The Management System for Processing, Handling and Storage of Radioactive Waste (IAEA, 2008e).

- Norma IAEA GS-G-3.4 - The Management System for the Disposal of Radioactive Waste (IAEA, 2008f).

A IAEA GS-R-3 é a norma da IAEA sobre requisitos para o estabelecimento, implementação, avaliação e continua melhoria de um sistema de gestão (SG) para instalações e atividades da área nuclear (IAEA, 2006, p. 1). A IAEA GS-G-3.1 é uma norma guia complementar à IAEA GS-R-3, a qual fornece orientações genéricas para ajudar no estabelecimento, implementação, avaliação e continua melhoria do SG (IAEA, 2006c, p. 1). A norma guia a ser publicada, como resultado do projeto de norma IAEA DS349, proverá orientações suplementares às orientações genéricas da IAEA GS-G-3.1, para possibilitar as instalações nucleares atenderem aos requisitos da IAEA GS-R-3 (IAEA, 2007a, p. 1). Em adição, as normas guias IAEA GS-G-3.1 e IAEA DS349, outras normas guias estão em vias de ser publicadas pela Agência, como decorrência dos demais projetos de norma citados no parágrafo anterior. Estas últimas proverão orientações adicionais para ao sistema de gestão, quando aplicadas a atividades específicas. A seguir é 
feita a pesquisa documental das normas IAEA GS-R-3 e IAEA GS-G-3.1 e do projeto de norma IAEA DS349. O objetivo e escopo de aplicação dos demais projetos de norma são apresentados no apêndice $\mathrm{F}$.

As normas IAEA GS-R-3, IAEA GS-G-3.1 e IAEA DS349 são aplicáveis ao estabelecimento, implementação, avaliação e continua melhoria do SG para (IAEA, 2006a, p. $3 ; 2006$ c, p. 2; 2007a, p. 2):

- Instalações nucleares;

- Atividades que usam fontes de radiação ionizantes;

- Gestão de rejeitos radioativos;

- Transporte de materiais radioativos;

- Atividades de proteção radioativa;

- Quaisquer outras práticas ou circunstâncias na qual as pessoas possam estar expostas à radiação ionizante, de ocorrências naturais ou fontes artificiais; e

- A regulamentação de tais instalações e atividades.

Em adição, essas normas são aplicáveis a todos os estágios do ciclo de vida das instalações nucleares e a completa duração das atividades em situações normais, transientes e de emergência o que inclui qualquer subseqüente período de controle institucional que possa ser necessário. Os estágios do ciclo de vida de uma instalação nuclear incluem, usualmente: a aprovação do sítio, o projeto, a construção, o comissionamento, a operação e o descomissionamento (extinção ou fechamento) (IAEA, 2006a, p. 3; 2006c, p. 2; 2007a, p. 1-2).

\section{Norma sobre Requisitos de Segurança - IAEA GS-R-3}

O objetivo da IAEA GS-R.3 é definir os requisitos para o estabelecimento, implementação, avaliação e continua melhoria de um sistema de gestão (SG) que integre elementos de segurança, saúde, ambiental, proteção física, qualidade e econômicos de modo a assegurar que a segurança nuclear é apropriadamente considerada em todas as atividades da organização (IAEA, 2006a, p. 3).

O principal objetivo dos requisitos para SG definidos na IAEA GS-R.3 é assegurar que a segurança nuclear não seja comprometida, por considerar as implicações de todas as ações que dizem respeito à segurança nuclear como um todo, e não em sistemas de gestão separados (IAEA, 2006a, p. 3). 
A IAEA GS-R.3 não tem a intenção de definir todos os requisitos específicos sobre saúde, meio ambiente, qualidade e economia, que já estão estabelecidos em outros documentos (publicações da IAEA e em normas e códigos internacionais). Entretanto, ela tem como objetivo definir os requisitos para realizar a gestão para o cumprimento desses requisitos, de uma forma integrada (IAEA, 2006a, p. 3-4).

O termo segurança utilizado no texto da norma tem como significado a segurança nuclear (IAEA, 2006a, p. 20). O glossário de termos da IAEA (2007b, p. 133) explica que nas suas publicações, segurança significa - segurança nuclear, devendo-se explicitar quando outros tipos de segurança também estiverem sendo consideradas (tais como: segurança contra incêndio, segurança industrial convencional, entre outras). Esses outros aspectos de segurança são definidos em outras publicações e, quando aplicáveis a uma instalação nuclear, poderão ser incorporados ao SG da organização, utilizando-se a norma IAEA GS-R-3 como base para a integração.

Os requisitos do sistema integrado de gestão (SIG) definidos na IAEA GS-R.3 cobrem tópicos diretamente relacionados à segurança nuclear ou que são parte da estrutura gerencial sem a qual a segurança nuclear não possa ser assegurada ou mantida. Assim, tópicos tais como comprometimento da direção, comunicação e outros estão inclusos dentro da perspectiva de se buscar o reforço da segurança nuclear, tanto quanto o seu desempenho (IAEA, 2006a, p. 4).

\section{Norma Guia - IAEA GS-G-3.1.}

O objetivo da IAEA GS-G-3.1 é prover orientações genéricas, complementares, para o estabelecimento, implementação, avaliação e continua melhoria de um SG que integre elementos de segurança, saúde, ambiental, proteção física, qualidade e econômicos de forma a atingir os requisitos estabelecidos pela norma IAEA GS-R-3. A norma guia fornece também exemplos ilustrativos de aplicação dos requisitos do SG (IAEA, 2006c, p. 1-2).

\section{Projeto de Norma (Guia) - IAEA DS349.}

O objetivo do IAEA DS349 é prover orientações suplementares aquelas fornecidas pelo guia IAEA GS-G-3.1, para o estabelecimento, implementação, avaliação e contínua melhoria de um SG que integre os elementos de segurança, saúde, ambientais, 
proteção física, qualidade e econômicos. Todos seus tópicos têm correspondência com os requisitos da norma IAEA GS-R-3 (IAEA, 2007a, p. 1-2).

As orientações do projeto de norma IAEA DS349 devem ser usadas em conjunto com as orientações genéricas do guia IAEA GS-G-3.1 (IAEA, 2006c). Uma indicação é fornecida em cada seção do projeto de norma informando se está sendo fornecida orientação suplementar ao guia IAEA GS-G-3.1 ou se não há orientação suplementar a ser dada (IAEA, 2007a, p. 2).

Em acréscimo, o projeto de norma IAEA DS349 possui apêndices que fornecem orientações adicionais para o SG das instalações, tais como para a metodologia de gradação do SG e para os estágios de aprovação de pesquisa e desenvolvimento, aprovação do sítio, projeto, construção, comissionamento, operação e o descomissionamento das instalações. Tendo em vista a abordagem desta pesquisa, no final desta seção, é apresentado um sumário sobre o apêndice VII do IAEA DS349, que trata do estágio de operação de uma instalação.

\section{Estrutura das Normas de Sistema de Gestão da IAEA (GS-R-3, GS-G-3.1 e DS349)}

Na FIG. 9 é mostrada, em forma esquemática, a estrutura de sistema integrado de gestão (SIG) proposto pela nova série de normas de sistema de gestão (SG) da Agência - as normas IAEA GS-R-3, IAEA GS-G-3.1 e IAEA DS349. Na elipse interna da FIG. 9 são apresentados os elementos da estrutura do SG, ou seja, as cinco seções que descrevem os seus requisitos ou orientações, que ao serem estabelecidos, implementados, avaliados e continuamente melhorados, em alinhamento com os objetivos da organização, devem contribuir para o atingimento desses objetivos (IAEA, 2006a, p. 4). Segundo a IAEA GSR-3 (IAEA, 2006a, p. 4-5), a segurança nuclear é o princípio fundamental dentro do SG devendo suplantar todas as demais demandas; sendo assim, o SG deve ser usado para promover e dar suporte a uma forte cultura de segurança nuclear, dentro da organização. De modo a evidenciar este princípio, a cultura de segurança é representada no centro da FIG. 9.

Segundo a IAEA GS-R-3 (IAEA, 2006a, p. 5-6), para operacionalizar o SG de uma organização, são necessários identificar e integrar ao sistema os requisitos específicos de segurança, saúde, qualidade, proteção física, ambiental, econômicos e outros, que são aplicados à organização considerada. Neste sentido, na FIG. 9 é mostrado que estes requisitos são oriundos, segundo a IAEA (2006, p. 5), da legislação de cada país (requisitos estatutários e regulamentares dos estados membros), das publicações de 
segurança da Agência, de outros códigos e normas adotados para uso pela organização e quaisquer outros requisitos formalmente acordados com os "stakeholders". Os stakeholders são as pessoas ou grupos que têm interesse ou são afetados pelo desempenho da organização e podem incluir, segundo a IAEA (2006, p. 5): consumidores, proprietários, operadores, colaboradores, fornecedores, parceiros, sindicatos, grupos profissionais e de negócios, corpo científico, estados membros, agências internacionais relevantes, agências e órgãos reguladores governamentais regionais, nacionais e locais, a mídia, a sociedade, os indivíduos e assim por diante.

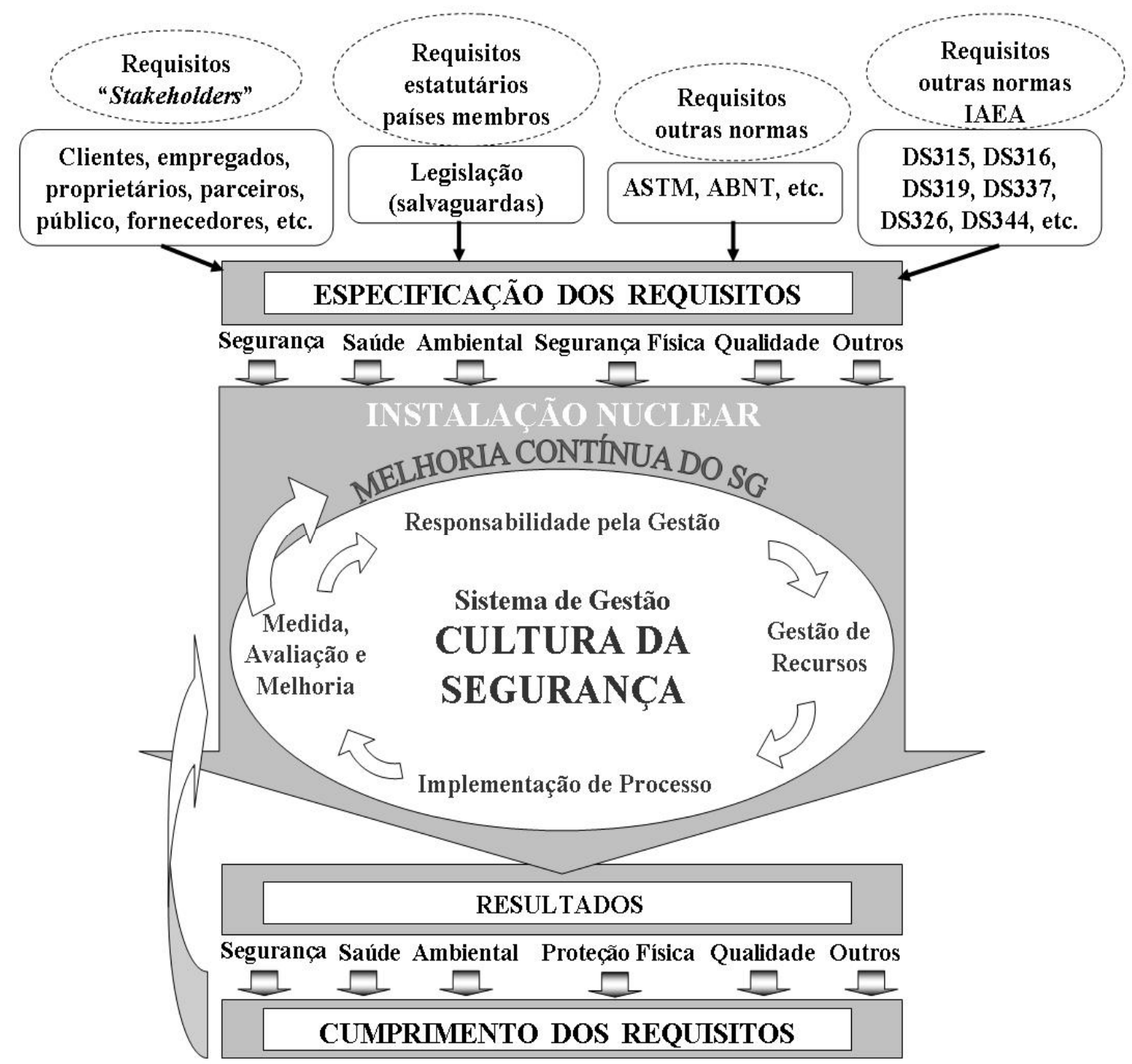

FIGURA 9 - Esquema Representativo do Sistema Integrado de Gestão de uma Organização.

Fonte: Adaptação do esquema apresentado pela IAEA (2005, FIG. 2, p. 18)

As cinco seções que compõem a estrutura das normas de SG em questão são as seguintes (Representadas na parte interna da elipse da FIG. 9):

- Seção 2 - Sistema de gestão. 
- Seção 3 - Responsabilidade da direção.

- Seção 4 - Gestão de recursos.

- Seção 5 - Implementação de processos.

- Seção 6 - Medição, avaliação e melhoria.

Por ser a norma que define os requisitos para o SG, é apresentada a seguir uma descrição sumária do conteúdo das seções que compõem a norma IAEA GS-R-3. Quando julgado conveniente ao esclarecimento de um requisito, a descrição é complementada com as orientações complementares e suplementares das normas IAEA GS-G-3.1 e IAEA DS349, respectivamente.

\section{Seção 2 - Sistema de Gestão.}

A IAEA GS-R-3 requer (IAEA, 2006a, p. 4-7) que:

- O SG seja estabelecido, documentado, implementado, mantido e continuamente melhorado, assegurando que os requisitos de saúde, ambientais, proteção física, qualidade e econômicos não sejam considerados separadamente dos requisitos de segurança, de modo a se evitar impacto negativo na segurança nuclear.

- A segurança nuclear seja considerada fundamental dentro SG, suplantando todas as outras demandas.

- Os requisitos estatutários e regulamentares, quaisquer requisitos acordados com as partes interessadas e todos aqueles requisitos de segurança relevantes da IAEA, sejam identificados e integrados ao SG.

- O SG seja usado para promover e dar suporte a uma forte cultura de segurança. A norma fornece requisitos para este fim.

- No SG seja estabelecida uma gradação na aplicação dos requisitos aplicados aos produtos e atividades de cada processo. A norma fornece as bases a serem consideradas para este fim.

- A documentação do SG seja estabelecida, desenvolvida e entendida pelos que a usam e reflita as características da organização e a complexidade de seus processos.

\section{Seção 3 - Responsabilidade da Direção.}

A IAEA GS-R-3 (IAEA, 2006a, p. 7-9) requer o comprometimento da alta direção e dos gerentes de todos os níveis com o SG e que a alta direção: 
- Considere nos processos do SG as expectativas das partes interessadas e, ao mesmo tempo, assegure que a segurança nuclear não seja comprometida.

- Desenvolva as políticas apropriadas à organização e as suas atividades.

- Planeje objetivos, metas, estratégias e planos de forma integrada e consistentes com as políticas da organização, assegurando suas implementações.

- Seja a derradeira responsável pelo SG, assegurando que o SG está estabelecido, implementado, avaliado e é continuamente melhorado.

A IAEA GS-R-3 (IAEA, 2006a, p. 9) requer que um indivíduo, respondendo diretamente a alta direção, tenha responsabilidade e autoridade específicas pelo SG e que, a organização, retenha total responsabilidade pelo SG, mesmo quando uma organização externa esteja envolvida.

\section{Seção 4 - Gestão de Recursos.}

A IAEA GS-R-3 (IAEA, 2006a, p. 9-10) requer que a alta direção determine e provenha os recursos necessários para o SG (Recursos humanos, de infra-estrutura e de ambiente de trabalho).

\section{Seção 5 - Implementação dos Processos.}

A IAEA GS-R-3 (IAEA, 2006a, p. 10-11) requer que sejam identificados e desenvolvidos os processos do SG necessários para alcançar as metas, prover os meios para satisfazer todos os requisitos e fornecimento (entrega) dos produtos da organização. Requer, também, que sejam determinadas as seqüências e interações desses processos e os métodos que assegurem suas implementações e controle.

A IAEA GS-R-3 (IAEA, 2006a, p.11) requer que seja assegurada uma efetiva comunicação e clara delegação de responsabilidades para atividades com interfaces entre diferentes indivíduos ou grupos.

$\mathrm{Na}$ gestão de cada processo a GS-R-3 (IAEA, 2006a, p.11-12) requer que sejam:

- Designados, para cada processo, um indivíduo com responsabilidade e autoridade por sua gestão.

- Especificadas, se e quando, as atividades de inspeção, teste, verificação e validação sejam executadas. E, ainda, que os indivíduos ou grupos designados para estas atividades sejam diferentes daqueles que originalmente executaram o trabalho. 
- Realizados os trabalhos sob condições controladas.

- Identificados no SG os processos contratados externamente e que a organização retenha responsabilidade sobre eles.

A IAEA GS-R-3 (IAEA, 2006a, p.12-14) requer que sejam desenvolvidos os seguintes processos genéricos do $\mathrm{SG}$ :

- Controle de documentos.

- Controle de produtos.

- Controle de registros.

- Compras.

- Comunicação.

- Gestão das mudanças organizacionais.

O IAEA DS349 (IAEA, 2007a, p.56-90) complementa os processos acima que, segundo o projeto de norma, são comuns aos vários estágios do ciclo de vida das instalações nucleares. Os processos são os seguintes:

- Gestão do empreendimento (“Project”).

- Planejamento e controle do trabalho.

- A avaliação de risco do local de trabalho.

- Segurança do pessoal.

- Controle e supervisão dos contratados.

- Projeto.

- Gestão da configuração.

- Manuseio e estoque.

- Gestão do inventário.

- Identificação e etiquetagem dos sistemas, estruturas e componentes.

- Gestão de rejeitos.

- Interface regulatória.

- Informação tecnológica.

- Proteção contra incêndio.

- Proteção física.

Seção 6 - Medição, Avaliação e Melhoria.

A IAEA GS-R-3 (IAEA, 2006a, p.15-17) requer que sejam:

- Monitoradas e medidas a eficácia do SG. 
- Realizadas auto-avaliações pela alta direção e pelos gerentes de todos os outros níveis quanto ao desempenho do trabalho e a melhoria da cultura de segurança.

- Conduzidas regularmente avaliações independentes do SG, apoiadas pela alta direção.

- Estabelecida uma unidade organizacional com responsabilidade e suficiente autoridade para conduzir as avaliações independentes.

- Avaliado pela alta direção os resultados das avaliações independentes e que esta tome quaisquer ações que julgue necessárias, justificando as razões.

- Conduzidas análises críticas a intervalos planejados para assegurar a adequabilidade e a eficácia do SG.

- Determinadas as causas das não-conformidades e tomadas ações para correção.

- Identificados os processos e produtos não-conforme e sejam segregados, controlados, registrados e reportados aos níveis apropriados da organização.

- Determinadas e implementadas ações corretivas e preventivas para eliminar não-conformidades reais e potenciais.

- Identificadas oportunidades de melhoria do SG e selecionadas, planejadas e registradas ações para melhoria dos processos.

\section{Apêndice VII da IAEA DS349}

\section{Sistema de Gestão para o Estágio de Operação de Instalações Nucleares.}

$\mathrm{O}$ apêndice (IAEA, 2007a, p. 131) relaciona quais normas devem ser consideradas na identificação de requisitos para o desenvolvimento e implementação do SG para o estágio em questão. Além das normas de SG da IAEA tratadas neste item, o apêndice relaciona uma série de normas da IAEA sobre segurança na operação que são aplicáveis as plantas nucleares de potência ${ }^{31}$. O apêndice faz, também, considerações quanto à gradação dos requisitos do $\mathrm{SG}$, a ser adotada no estágio de operação.

\subsubsection{IAEA GS-R-3 - Documentação.}

A norma (IAEA, 2006a, p. 7) requer que a documentação do SG inclua:

\footnotetext{
${ }^{31}$ O apêndice não faz referência aos IAEA DS316 e IAEA DS344 que, a semelhança daqueles indicados no apêndice para plantas de potência, trata de requisitos segurança aplicáveis a outras instalações do ciclo de combustível. (Nota do autor)
} 
- Declaração das políticas da organização.

- Descrição do SG.

- Descrição da estrutura da organização.

- Descrição das responsabilidades, prestações de contas, níveis de autoridade e interações funcionais dos trabalhos de gerenciamento, execução e avaliação.

- Descrição dos processos e informações suportes que expliquem como o trabalho é preparado, analisado, executado, registrado, avaliado e melhorado.

A norma IAEA GS-G-3.1 orienta (IAEA, 2006c, p. 14-15) a adoção da uma estrutura de informação em três níveis. Esta estrutura, segundo a norma, promove a clareza das informações e evita repetições, pois estabelece a quantidade de informação e o nível de detalhe, para cada tipo de documento, e o uso de referencias cruzadas entre os documentos específicos nos diferentes níveis. Esta estrutura é apresentada no anexo G.

\section{Declaração das Políticas da Organização.}

A norma IAEA GS-R-3 requer (IAEA, 2006, p. 8) que a alta direção desenvolva as políticas da organização.

O projeto de norma IAEA DS349 orienta (IAEA, 2007a, p. 33) que deve ser desenvolvida uma única política integrada ou uma integração de políticas que inclua, entre outras, políticas de:

- Segurança (segurança nuclear e segurança e saúde dos indivíduos).

- Ambiental.

- Qualidade.

- Gestão de mudanças.

- Proteção física (“security”).

O projeto de norma IAEA DS349 (IAEA, 2007a, p. 34) descreve ainda que devido à similaridade e a natureza das políticas de segurança nuclear, segurança e saúde dos indivíduos e ambiental, algumas organizações decidem combinar estas políticas em uma única. O projeto de norma orienta, ainda, que cada instalação nuclear deve emitir uma política para promoção e gestão de mudanças que seja compatível com a visão e os valores da instalação. 


\section{Descrição do SG.}

As normas IAEA GS-R-3 não fornece orientações específicas para a descrição do SG. Entretanto, a norma IAEA GS-G-3.1 (IAEA, 2006c, p. 15) recomenda que no nível 1 de informação (ver anexo $G$ ) seja apresentada uma visão geral de como a organização e seu SG estão delineados para atender suas políticas e objetivos; ou seja, uma visão geral das políticas e objetivos da organização e a descrição do SG que direcione os requisitos que são aplicáveis aos trabalhos da organização. A referida norma ainda recomenda a apresentação de uma visão geral dos processos da organização.

\section{Descrição da Estrutura da Organização.}

A norma IAEA GS-R-3, bem como as normas IAEA GS-G-3.1 e IAEA DS349, não fornecem orientações específicas para a descrição da estrutura da organização.

\section{Descrição das Responsabilidades, Prestações de Contas, Níveis de Autoridade e Interações Funcionais dos Trabalhos de Gerenciamento, Execução e Avaliação.}

A norma IAEA GS-R-3 não fornece requisito ou orientação específica para este tópico. Entretanto, a norma IAEA GS-G-3.1 (IAEA, 2006c, p. 15) recomenda que no nível 1 de informação (ver anexo G) sejam apresentados os níveis de autoridade e responsabilidades e prestações de contas da alta direção e das unidades organizacionais, bem como a autoridade e responsabilidade dos indivíduos designados pela gestão de cada processo. Em acréscimo, a referida norma (IAEA, 2006c, p. 17) recomenda que seja efetuada uma descrição dos cargos para que, entre outros aspectos, a alta direção possa comunicar a todos os indivíduos as responsabilidades, autoridades e interfaces do SG.

\section{Descrição dos Processos e Informações Suportes que Expliquem como o Trabalho é Preparado, Analisado, Executado, Registrado, Avaliado e Melhorado.}

A norma IAEA GS-R-3 não fornece requisito ou orientação específica para este tópico. Entretanto, as normas de SG - IAEA GS-R-3, IAEA GS-G.3.1 e IAEA DS349, em certos requisitos e orientações de seus textos, citam a necessidade de documentos neste sentido. Em adição a norma IAEA GS-G-3.1 (IAEA, 2006c, p. 15) recomenda que a descrição dos processos seja realizada em dois níveis (ver detalhes no anexo $G$ ):

- Nível 2 - Descrição dos processos que devem ser implementados para atender as políticas e objetivos da organização, especificando a unidade organizacional 
responsável por realizá-los. Segundo a norma (IAEA, 2006c, p. 16), não é usual neste nível prover detalhes de como executar as tarefas técnicas, as quais devem ser detalhadas nos documentos de nível 3.

- Nível 3 - A norma IAEA GS-G-3.1 (IAEA, 2006c, p. 15) coloca que neste nível, devem ser fornecidas instruções e orientações detalhadas que possibilitem a realização dos processos, especificando o indivíduo ou a unidade responsável pela execução do trabalho.

Na norma IAEA GS-G-3.1 (IAEA, 2006c, p. 32) é colocado que não existe um simples catálogo listando os processos que devem ser documentados. E acrescenta que, cada organização deve determinar quais processos devem ser documentados levando em conta a natureza das atividades da organização e sua estratégia geral, ou mais especificamente, deve considerar:

- Os efeitos do processo com relação aos elementos segurança, saúde, meio ambiente, proteção física, qualidade e econômicos.

- Requisitos estatutários e regulatórios.

- A satisfação das partes interessadas.

- Riscos econômicos.

- Eficácia e eficiência dentro da organização.

- Níveis de competência dos indivíduos.

- Necessidade de retenção do conhecimento dos processos.

- Complexidade dos processos.

A IAEA GS-G-3.1 (IAEA, 2006c, p. 32) e o IAEA DS349 (IAEA, 2007a, p. 45-47) descrevem que algumas organizações têm encontrado benefício em estruturar os processos em três grupos:

- Processos de gestão - Aqueles que asseguram a operação do SG, são utilizados especialmente pela alta direção, para que descreva como é por ela estabelecida e comunicada expectativas e exercido controle sobre o SG.

- Processos chaves - Aqueles que produzem os resultados que são críticos para o sucesso da instalação ou atividade (Processos de operação, de manutenção e suporte de engenharia).

- Processos suportes - Aqueles que fornecem serviços de infra-estrutura necessária para execução dos processos chaves e de gestão. 


\subsubsection{Estado da Arte das Normas Sobre Requisitos de Segurança da Agência, Aplicados ao Estágio de Operação de Plantas de Conversão.}

A Agência desenvolve as seguintes normas sobre segurança que são aplicáveis ao estágio de operação de plantas de conversão:

- IAEA DS316 (IAEA, 2006d) - Safety of Fuel Cycle Facility (Safety Requirements) - $\mathrm{O}$ objetivo é estabelecer requisitos que devem ser satisfeitos para assegurar a segurança para todos os estágios ${ }^{32}$ do ciclo de vida de instalações do ciclo do combustível nuclear (IAEA, 2006d, p. 2).

- IAEA DS344 (IAEA, 2006e) - Safety of Conversion and Enrichment Facilities (Safety Guide) - O objetivo é estabelecer recomendações que podem ser satisfeitos para assegurar a segurança para todos os estágios do ciclo de vida de instalações de conversão e de enriquecimento (IAEA, 2006e, p. 5).

A IAEA (2006d, p. 5) ressalta que os projetos de normas IAEA DS316 e IAEA DS344 abordam segurança dentro do contexto dos fundamentos de segurança da Agência de proteção das pessoas e do meio ambiente contra os efeitos nocivos da radiação ionizante. Assim sendo, segundo a IAEA (2006d, p. 86), segurança significa a obtenção de apropriadas condições de operação, prevenção de acidentes ou mitigação das conseqüências de acidentes, que resultem na proteção dos trabalhadores, do público e do meio ambiente contra perigos indevidos à radiação. O IAEA DS316 (IAEA, 2006d, p. 5). descreve que as instalações do ciclo do combustível podem incluir processos industriais que adicionam perigos ao pessoal do sítio e ao meio ambiente. Esses perigos puramente industriais, segundo o projeto de norma, estão fora do seu escopo mas devem ser também considerados. Segundo ainda o IAEA DS316, informações relativas a perigos químicos podem ser obtidos nos guias de segurança da IAEA e em outras normas da indústria química.

\subsubsection{Estado da Arte da Norma Sobre Requisitos de Segurança - IAEA DS316.}

O IAEA DS316 (IAEA, 2006d, p. 1) trata de requisitos de segurança das instalações do ciclo do combustível nuclear; entretanto, segundo o projeto de norma, não estão incluídos em seu escopo os reatores e as instalações de mineração e de disposição de rejeitos.

\footnotetext{
${ }^{32}$ Estágios do ciclo de vida - definição do local, projeto, construção, operação e descomissionamento (IAEA, 2006d, p. 2).
} 
Tendo em vista as limitações da pesquisa, a revisão documental do projeto de norma foi feita considerando apenas os elementos (requisitos e recomendações) que são aplicáveis ao estágio de operação de plantas de conversão de $U_{6}$.

O IAEA DS316 é estruturado em dez seções e três apêndices, a saber:

Seção 1 - Introdução.

Seção 2 - Objetivos, conceitos e princípios de segurança.

Seção 3 - Estrutura legal e supervisão regulatória.

Seção 4 - Gestão e verificação de segurança.

Seção 5 - Aprovação do Sítio

Seção 6 - Projeto.

Seção 7 - Construção.

Seção 8 - Comissionamento.

Seção 9 - Operação.

Seção 10 - Descomissionamento.

Apêndice I: Requisitos específicos para instalações de fabricação de combustível de urânio.

Apêndice II: Requisitos específicos para instalações de fabricação do combustível MOX.

Apêndice III: Requisitos específicos para instalações de conversão e de enriquecimento.

Na seção 2 (IAEA, 2006d, p. 5), o IAEA DS316 além de apresentar os objetivos e os conceitos e princípios de segurança da Agência, ou seja, os fundamentos de segurança, o princípio de otimização da proteção - $\operatorname{ALARA}^{33}$ e o conceito de defesa em profundidade; apresenta o documento "safety case" que, segundo o projeto de norma, deve ser o documento base aos estágios das instalações do ciclo de combustível nuclear. $\mathrm{O}$ safety case, segundo o IAEA 316 (IAEA, 2006d, p. 7) estabelece e justifica a segurança das instalações, através de uma série de documentos que o compõe, e que no mínimo inclui o:

- RAS - Relatório de análises de segurança.

- LCO - Limites e controles operacionais.

${ }^{33}$ Princípio de otimização da proteção - ALARA - Tão baixo quanto razoavelmente exeqüível (IAEA, 2006d, p. 5). 
Considerando os interesses desta pesquisa, a revisão documental se limitou às seções 4 e 9 e ao apêndice III (dos itens 18 a 29) do IAEA DS316, que tratam do estágio de operação das instalações do ciclo do combustível.

\section{Seção 4. Gestão e Verificação de Segurança.}

Nesta seção (IAEA, 2006d, p. 12- 17) se define os requisitos que são comuns a todos os estágios das instalações, desde o projeto até o descomissionamento e é descrito que, para cumprir sua principal responsabilidade, que é o de assegurar a segurança em todos os estágios do ciclo de vida da instalação, a organização operadora deve:

- Estabelecer e implementar políticas de segurança, saúde e ambiental, alinhadas às normas nacionais e internacionais, e assegurar que seja dado a esse assunto a mais alta prioridade.

- Estabelecer uma estrutura organizacional que permita que essas políticas sejam anunciadas, com uma clara definição de responsabilidades e prestação de contas, assim como definidas as linhas de autoridade e de comunicação.

- Introduzir um regime de garantia da qualidade (GQ) cobrindo todos os aspectos do ciclo de vida da instalação ${ }^{34}$.

- Desenvolver e manter uma efetiva cultura de segurança.

- Preparar procedimentos de gestão de acidentes e planos de emergência no sítio, de acordo com o potencial de perigo.

\section{Seção 9 - Operação.}

O IAEA DS316 (IAEA, 2006d, p. 37-48) esclarece que a implementação dos requisitos mencionados na seção 4 é da maior importância para a segura operação das instalações, em especial os requisitos sobre segurança, saúde e ambiental e cultura de segurança e que, nesta seção, a norma dá ênfase aos aspectos de segurança e provem requisitos específicos aplicados ao estágio de operação das instalações.

${ }^{34}$ A IAEA DS316 em nota de rodapé (IAEA,2006d, p. 14) faz referência às normas IAEA GS-R-3, IAEA GS-G-3.1 e IAEA DS3349, como substitutas as normas 50-C/SG-Q1-Q14, no assunto sobre garantia da qualidade. 
$\mathrm{Na}$ seção são estabelecidos requisitos sobre estrutura organizacional e responsabilidades pela operação; organização de interfaces; qualificação e treinamento do pessoal; quantidade mínima de pessoal; estruturação de comitês de segurança; gestão de documentação; controle de mudança organizacional; comunicação com os órgãos regulatórios; instruções operacionais; manutenção, teste e inspeções periódicas; controle de modificações; proteção à radiação durante a operação; controle de criticalidade durante a operação; rejeitos radioativos e gestão de efluentes durante a operação; gestão de segurança industrial e química durante a operação; preparação de emergência; e verificação da segurança.

\section{Apêndice III de 18 a 29 - Operação.}

No apêndice (IAEA, 2006d, p. 67-69) são tratados os requisitos específicos ao estágio de operação das instalações de conversão e de enriquecimento, que serão posteriormente complementados pelos requisitos do projeto de norma IAEA DS344.

No apêndice são estabelecidos requisitos sobre qualificação e treinamento de pessoal; manutenção e testes e inspeções periódicas; controle de criticalidade; riscos de sobre enchimento de cilindros; risco de sobre alimentação de cilindros; e planejamento e preparação de emergência.

\subsubsection{Estado da Arte da Norma Sobre Requisitos de Segurança - IAEA DS344.}

O IAEA DS344 suplementa os requisitos do IAEA DS316, fornecendo recomendações de boas práticas para o atendimento aos requisitos descritos nas suas seções de 5 a 10 e apêndice III, no que se refere às questões de segurança das instalações de conversão e enriquecimento (IAEA, 2006e, p. 5).

Tendo em vista as limitações da pesquisa, a revisão documental do projeto de norma foi feita abordando apenas as recomendações aplicadas ao estágio de operação das plantas de conversão de $\mathrm{UF}_{6}$.

O projeto de norma IAEA DS344 é estruturado em oito seções, a saber:

Seção 1 - Introdução.

Seção 2 - Recomendações gerais de segurança para IC e IE.

Seção 3 - Aprovação do sítio.

Seção 4 - Projeto.

Seção 5 - Construção. 
Seção 6 - Comissionamento.

Seção 7 - Operação.

Seção 8 - Descomissionamento.

O IAEA DS344 (IAEA, 2006e, p. 4-5) descreve que nas plantas de conversão são manuseados, processados, tratados e estocados urânio e seus rejeitos em toda a instalação. O projeto de norma descreve ainda que esse tipo de planta processa e usa grande quantidade de produtos químicos perigosos, que podem ser tóxicos, corrosivos, combustíveis e explosivos. Segundo ainda o projeto de norma, para garantir a segurança, em acréscimo às medidas da engenharia de segurança, os processos desse tipo de planta dependem em grande extensão da intervenção e controle dos operadores.

Segundo o IAEA DS344 (IAEA, 2006e, p. 5 e 8) um perigo significativo associado às plantas é a perda dos meios de confinamento, resultando em liberação de $\mathrm{UF}_{6}$. Quando o $\mathrm{UF}_{6}$ é liberado ele reage com a umidade do ar formando HF e fluoreto de uranilo solúvel, os quais produzem perigos adicionais à segurança.

O IAEA DS344 (IAEA, 2006e, p. 8) descreve que em companhia do $\mathrm{UF}_{6}$ grandes quantidades de produtos químicos perigosos, tais como $\mathrm{HF}, \mathrm{F}_{2}$ e $\mathrm{NH}_{3}$, estão presentes nas plantas de conversão de $\mathrm{UF}_{6}$; portanto, a análise de segurança deste tipo de planta deve considerar, também, os impactos decorrentes dos produtos químicos nela processados.

As plantas de conversão de $\mathrm{UF}_{6}$ utilizam apenas urânio natural; portanto, segundo o projeto de norma (IAEA, 2006e, p. 5), não há risco de que ocorra a criticalidade (A criticalidade pode ocorrer quando o grau de enriquecimento do urânio é superior a 1\%).

No caso desse tipo de planta a radiotoxidade é baixa, sendo, portanto, limitada à possibilidade de que ocorram conseqüências radiológicas externas, seguido de potenciais acidentes. Além disso, a toxidade química do urânio na forma solúvel, como o UF 6 , é mais significativa do que a sua radiotoxidade. (IAEA, 2006e, p. 8).

Complementando, o IAEA DS344 (IAEA, 2006e, p. 11) recomenda focar atenção nas seguintes situações de riscos, quando definindo no projeto, as bases de acidentes para esse tipo de planta:

- Liberação de $\mathrm{HF}$ e $\mathrm{NH}_{3}$.

- Liberação de $\mathrm{UF}_{6}$.

- Incêndio de grandes proporções devido ao $\mathrm{H}_{2}$ ou solventes.

- Explosão no processo de redução $\left(\mathrm{H}_{2}\right)$. 
Segundo o projeto de norma (IAEA, 2006e, p. 11), os três primeiros tipos de acidentes são eventos de maior significância com relação à segurança, pois resultam em conseqüências químicas e radiológicas aos trabalhadores, dentro do sítio, e podem resultar também em algumas conseqüências adversas fora do sítio, assim como ao meio ambiente. O quarto tipo de acidente não tem conseqüências significativas fora do sítio.

Considerando os interesses desta pesquisa, a revisão documental se limitou à seção 7 que trata do estágio de operação das instalações.

\section{Seção 7 - Operação.}

A seção 7 (IAEA, 2006e, p. 40-50) contém recomendações específicas de boas práticas para que se alcance o nível de segurança requerido para plantas de conversão de $\mathrm{UF}_{6}$. $\mathrm{Na}$ seção são apresentadas as características das plantas de conversão de $\mathrm{UF}_{6}$ e fornecidas recomendações para: qualificação e treinamento de pessoal; operação da instalação; manutenção e testes e inspeções periódicas; controle de modificações; proteção radiológica; gestão de segurança convencional, gestão de rejeitos e planejamento e preparação de emergência. $O$ projeto de norma acrescenta outras recomendações não aplicadas a este tipo de planta e ao estágio de operação da instalação, tais como: estocagem de "tails" e prevenção da criticalidade.

A norma recomenda (IAEA, 2006e, p. 40) que na definição dos requisitos de segurança sejam consideradas às seguintes características distintas, de plantas de conversão:

- O material radioativo utilizado possui radiotoxidade relativamente baixa, mas com potencial de gerar impactos químicos e toxicológicos aos trabalhadores, ao publico e ao meio ambiente, devido: a grande quantidade de $\mathrm{UF}_{6}$, aos produtos de reação $\left(\mathrm{UO}_{2} \mathrm{~F}_{2}, \mathrm{HF}\right)$ associados com a operação de $\mathrm{UF}_{6}$ líquido e a estocagem e manuseio de grande quantidade de compostos de urânio sólido.

- As condições para incêndio e explosões que resultem em liberação radiológica são potenciais (Tais como as decorrentes da explosão de $\mathrm{H}_{2}$ nos fornos de redução).

- Os riscos químicos são significativos devido à grande quantidade de HF anidro líquido e amônia $\left(\mathrm{NH}_{3}\right)$ que estão presentes no processo. 


\section{RESULTADOS.}

Os resultados da pesquisa são apresentados seguindo a formulação dos objetivos, ou seja:

- Objetivo 1 - Resultados das correlações das normas de sistema de gestão (SG) da Agência (IAEA GS-R-3:2006, IAEA GS-G-3.1:2006 e IAEA DS349 rev. 2007), com as normas de SG de mercado, sobre qualidade (ISO 9001:2000), ambiental (ISO 14001:2004) e segurança e saúde no trabalho (OHSAS 18001:2007).

- Objetivo 2 - Resultados das correlações dos projetos de normas sobre segurança nuclear aplicados ao estágio de operação de plantas de conversão de UF $_{6}$ (IAEA DS316 rev. 2006 e IAEA DS344 rev. 2006), com as normas de SG da Agência (IAEA R3:2006, IAEA GS-G-3.1:2006 e IAEA DS349 rev. 2007) e as normas de SG de mercado, sobre ambiental (ISO 14001:2004) e segurança e saúde no trabalho (OHSAS 18001:2007).

- Objetivo 3 - Proposta de um procedimento documental para um SG aplicado ao estágio de operação de plantas de conversão de $\mathrm{UF}_{6}$, que atenda as normas de SG da Agência (IAEA R-3:2006, IAEA GS-G-3.1:2006 e IAEA DS349 rev. 2007) e de mercado (ISO 9001:2000, ISO 14001:2004 e OHSAS 18001:2007), assim como aos projetos de normas sobre segurança nuclear da Agência (IAEA DS316 rev. 2006 e IAEA DS344 rev. 2006).

\subsection{Resultado das Correlações entre as Normas de SG da IAEA (GS-R-3, GS-G-3.1 e DS349) e as ISO 9001, ISO 14001 e OHSAS 18001.}

O estudo das correlações entre os elementos das normas sobre SG da IAEA (GS-R-3, GS-G-3.1 e DS349) e os elementos das normas de mercado de qualidade (ISO 9001), ambiental (ISO 14001) e de segurança e saúde no trabalho (OHSAS 18001), utilizou como base preliminar para seu desenvolvimento, as correlações apresentadas nas seguintes referências:

- Correspondência entre a OHSAS 18001:2007, a ISO 14001:2004 e a ISO 9001:2000, disponível na tabela A.1 da norma OHSAS 18001 (Risk, 2007, p. 29), a qual é reproduzida no anexo $\mathrm{F}$ desta pesquisa; e

- Correspondência entre as normas IAEA GS-R-3, IAEA GS-G-3.1, IAEA DS 349, NBR ISO 9001:2000 e CNEN-NN-1.16, disponível no apêndice B da dissertação de mestrado de Kibrit (2008, p. 155). 
O estudo compreendeu o cruzamento das correlações das referências citadas, sendo complementado por uma revisão da composição obtida, cujos resultados são apresentados nos apêndices H (indexado pela ISO 9001) e I (indexado pelas ISO $14001 \mathrm{e}$ OHSAS 18001). A revisão compreendeu a verificação da propriedade das correlações obtidas, que foi ajustada quando julgado conveniente. Foi estabelecido um grau de correlação no qual um dado elemento da IAEA GS-R-3, complementado ou suplementado por elementos das IAEA GS-G-3.1 e IAEA DS349, satisfazem a um dado elemento da ISO 9001, ISO 14001 ou OHSAS 18001, como segue

- SC - Satisfazem completamente.

- SP - Satisfazem quando tratados em conjunto com outros elementos da IAEA GS-R-3; IAEA GS-G-3.1 ou IAEA DS349, indicados.

- NCp - Necessitam complemento (Cp) para satisfazer. Os complementos não se obtêm em outros elementos das IAEA GS-R-3; IAEA GS-G-3.1 ou IAEA DS349.

- Cp - Complemento a ser incorporado aos elementos da IAEA GS-R-3; IAEA GS-G-3.1 ou IAEA DS349, para satisfazer o elemento da norma analisada.

- Ad - Adicionam detalhes ou orientações.

- NR - Não possuem relação.

Um estudo complementar foi feito correlacionando documentos e registros requeridos pelas normas em questão, cujo resultado é apresentado no apêndice J. No apêndice os documentos e registros são correlacionados por processos, identificados a partir dos elementos das normas de SG da IAEA.

\subsection{Resultado das Correlações entre as Normas de SG da IAEA (GS-R-3, GS-G-3.1 e DS349), ISO 14001 e OHSAS 14001 e os Projetos de Normas de Segurança da IAEA (DS316 e DS344).}

O estudo das correlações entre os elementos (requisitos e orientações) das normas de SG da IAEA, com os elementos das normas ISO 14001 e OHSAS 18001, foi realizado na seção anterior. Nesta seção, o estudo é complementado estabelecendo-se a correlação com os elementos sobre segurança nuclear dos projetos de normas da IAEA DS316 (IAEA, 2006d) e DS344 (IAEA, 2006e).

Em função das delimitações da pesquisa, o estudo se limitou aos elementos (requisitos e recomendações) relativos ao estágio de operação de plantas de conversão de 
$\mathrm{UF}_{6}$, a partir do "yellowcake", doravante denominadas - plantas de conversão, sendo considerados:

- Seção 4 do IAEA DS316 - Gestão e verificação da segurança.

- Seção 9 do IAEA DS316 - Operação.

- Apêndice III do IAEA DS316 (Itens de 18 ao 29) - Requisitos específicos a instalações de conversão e instalações de enriquecimento - Operação.

- Seção 7 do IAEA DS344- Operação. Neste caso, não foram considerados aspectos relativos a instalações de enriquecimento de urânio e de reprocessamento de urânio e urânio reciclado, e a criticalidade.

O resultado da correlação é apresentado no apêndice $K$, onde é indicado a esquerda de cada elemento do IAEA DS316 ou IAEA DS344, se o mesmo:

- Dt - Detalha os elementos das normas de SG da IAEA, ISO 14001 ou OHSAS 18001, quando aplicado a plantas de conversão; ou

- NDt - Não detalha, mas apresenta requisitos genéricos correlacionados aos elementos das normas de SG da IAEA, ISO 14001 ou OHSAS 18001.

$\mathrm{O}$ apêndice $\mathrm{K}$ apresenta uma descrição sintética da maioria dos elementos dos IAEA DS316 e IAEA DS344, permitindo seu entendimento direto na leitura do próprio apêndice. Os demais elementos são apresentados apenas por título.

Um estudo complementar foi feito correlacionando os documentos e registros requeridos pelas normas em questão, cujo resultado é apresentado nos apêndices L (documentos) e M (registros), onde se incluem os documentos e registros requeridos pela ISO 9001, derivados da correlação apresentada no apêndice J. Nos apêndices L e M os documentos e registros são correlacionados por processos, identificados a partir dos elementos das normas de SG da IAEA.

\subsection{Proposição de Procedimento Documental, para o Sistema de Gestão do Estágio de Operação de Plantas de Conversão de UF $_{6}$.}

O procedimento documental proposto leva em conta o atendimento as normas de SG da IAEA (GS-R-3:2006, GS-G-3.1:2006 e DS349), projetos de normas sobre segurança da IAEA (DS316 e DS344) e as normas de SG de mercado SG ISO 9001, ISO 14001 e OHSAS 18001 e é aplicado ao estágio de operação de planas de conversão de $\mathrm{UF}_{6}$. Para a elaboração da proposta foram considerados: 
- Os resultados dos estudos de correlações entre os elementos das normas e projetos de normas citadas e, em particular, aqueles sobre as correlações da documentação respectiva, disponíveis nos apêndices $\mathrm{L}$ e $\mathrm{M}$.

- Os requisitos específicos sobre a documentação do SG das normas IAEA GS-R-3 (IAEA, 2006a, p. 7), ISO 9001 (ABNT, 2000a, p. 4), ISO 14001 (ABNT, 2004, p. 7) e OHSAS 18001 (Risk, 2007, p. 22).

- As diretrizes para estrutura de documentação do relatório técnico, ABNT ISO/TR 10013 (ABNT, 2002), e as recomendações sobre estrutura de informação da norma, IAEA GS-G-3.1 (IAEA, 2006c, p. 14-15), sumariadas nesta pesquisa nos anexos D e I, respectivamente.

Com base nas considerações acima, a pesquisa sugere que o procedimento documental seja organizado em dois grupos:

a) Manual do sistema de gestão - É proposta uma itemização e o conteúdo para o manual do SG, que compõe basicamente a informação de nível 1 recomendada pela IAEA GS-G-3.1 (IAEA, 2006c, p. 14), acrescida dos requisitos para o manual da qualidade da ISO 9001 (ABNT, 2000a, p. 4), sendo considerada a exigência ou orientação mais abrangente.

b) Documentos e registros requeridos pelas normas - Documentos, incluindo registros, que compõe as informações dos níveis 2 e 3, segundo a IAEA GS-G3.1 (IAEA, 2006c, p. 14-15).

\subsubsection{Procedimento Documental - Manual do Sistema de Gestão, Itemização e Conteúdo.}

\section{A - Declaração das Políticas da Organização.}

Estabelecer uma única política integrada ou um conjunto integrado de políticas, que inclua os seguintes tópicos ${ }^{35}$ (IAEA, 2007a, p. 33):

- Segurança, incluindo segurança nuclear e segurança e saúde dos indivíduos.

- Ambiental.

- Qualidade.

- Mudança organizacional.

\footnotetext{
${ }^{35}$ Não está sendo abordados na pesquisa aspectos sobre proteção física, econômicos, responsabilidade social, entre outros.
} 
Em função das similaridades em conteúdo e natureza, as políticas de segurança e ambiental podem ser combinadas em uma única política (IAEA, 2007a, p. 34).

Por serem mais completas e abrangentes, as recomendações do IAEA DS349 (IAEA, 2007a, p. 33-36) devem ser consideradas na descrição das políticas.

\section{B - Declaração dos Objetivos da Organização.}

Estabelecer objetivos mensuráveis para o SG, nos níveis pertinentes da organização, consistentes com as políticas e que levem em conta os interesses e expectativas das partes interessadas nos processos e produtos da organização, assegurando, ao mesmo tempo, que os requisitos regulamentares sejam atendidos e que a segurança não seja comprometida (ABNT, 2000a, p. 5; IAEA, 2006a, p. 8; 2006c, p. 22).

\section{C - Descrição do Escopo do SG.}

Indicar a organização à qual se aplica o SG (ABNT, 2002, p. 4). Por exemplo, a planta de conversão de "yellowcake" em $\mathrm{UF}_{6}$, estágio de operação.

Indicar as funções que estão sendo consideradas e integradas ao SG (IAEA, 2006a, p. 5; ABNT, 2002, p. 4). Por exemplo, segurança nuclear, segurança e saúde dos indivíduos, ambiental e qualidade.

Indicar as normas, códigos, regulamentos e outras publicações identificadas e adotadas para definição das funções acima, levando em conta os aspectos acordados com as partes interessadas (IAEA, 2006a, p. 5; ABNT, 2002, p. 4). Exemplo: As normas que fazem parte desta pesquisa.

Indicar possíveis exclusões de requisitos das normas que não estão sendo considerados no SG em particular, detalhando e justificando esta decisão (ABNT, 2000a, p. 4). Por exemplo, os requisitos de projeto definidos pelas normas de SG da IAEA e da ISO 9001, que não se aplicam ao estágio de operação de uma planta de conversão (IAEA, 2007, p. 66-80; ABNT, 2000a, p. 8-9).

\section{D - Estrutura Organizacional e Níveis de Autoridade, Responsabilidade e}

\section{de Prestação de Contas.}

Apresentar um organograma da organização e descrever as responsabilidades, prestações de contas e níveis de autoridade e interações funcionais daqueles que gerenciam, executam e avaliam os trabalhos (IAEA, 2006a, p. 7), incluindo: 
- Os níveis de responsabilidade, autoridade e prestação de contas da alta direção e das unidades da organização (IAEA, 2006c, p. 15).

- As responsabilidades e prestações de contas de todo o pessoal que controla e conduz operações que afetam à segurança, assim como das pessoas responsáveis diretamente pela supervisão deste pessoal e das operações respectivas (IAEA, 2006d, p. 13)

- A indicação de um indivíduo que tenha responsabilidades e autoridades específicas pelo SG e se reporte diretamente à alta direção (IAEA, 2006a, p. 9; ABNT, 2000a, p. 6).

- A constituição de comitês de segurança interna, com independência de seus membros, na extensão necessária, aos gerentes operacionais que conduzem assuntos de segurança (IAEA, 2006d, p. 39). Para atender as normas ISO 14001 e OHSAS 18001, deve-se deixar claro que estes comitês representam a alta direção com funções, responsabilidades e autoridades específicas pelo SGA (ISO 14001) e SGSST (OHSAS 18001).

- A constituição da função de proteção radiológica, cujo pessoal designado para a função tenha acesso ao nível gerencial com autoridade para estabelecer e implementar procedimentos operacionais (IAEA, 2006d, p. 43).

- A constituição de uma unidade organizacional com responsabilidade e suficiente autoridade pela condução de avaliações independentes. A unidade pode ser constituída por um único indivíduo ou por uma organização externa (IAEA, 2006a, p. 15).

- A designação de indivíduo para cada processo com autoridade e responsabilidade pelo mesmo (IAEA, 2006a, p. 11).

- A designação especifica de indivíduos para preparação, análise crítica ou aprovação de documentos (IAEA, 2006a, p. 12).

- A designação de indivíduos ou grupos para execução de inspeção, teste, verificação e validação de cada processo, diferentes daqueles que realizaram o trabalho (IAEA, 2006a, p. 13).

\section{E - Estrutura da documentação do SG.}

Definir a estrutura de documentação atendendo aos requisitos específicos sobre o assunto das normas e códigos aplicáveis a um SG em particular. Por exemplo, adotar como base a sugestão do procedimento documental desta pesquisa. 
As diretrizes do relatório técnico ABNT ISO/TR 10013 (ABNT, 2002) e as recomendações da IAEA GS-G-3.1 (IAEA, 2006c, p. 14-15), resumidas nos anexos D e J, apresentam propostas, para uma hierarquia de documentação, que são similares na sua estrutura e atende aos requisitos das normas e projetos de normas consideradas na pesquisa. A proposta estabelece três níveis de documentação sendo o primeiro, aquele que contém as informações aqui propostas para o manual do sistema, e o segundo e terceiro, aqueles que compõem o conjunto de documentos e registros para implementação dos processos e que serão tratados adiante.

\section{F - Descrição da Interação entre os Processos do SG da Organização.}

Descrever a interação dos processos do SG levando em conta as peculiaridades do estágio de operação de uma planta de conversão.

A ISO 9001 (ABNT, 2000a, p. 4) requer que o manual inclua a descrição da interação entre os processos do SG ou, quando aplicável, os procedimentos documentados sobre os mesmos, ou referenciais a eles. Por sua vez, a IAEA GS-G-3.1 (IAEA, 2006c, p. 15) orienta que a descrição dos processos deve compor o nível 2 de informação e que, no nível 1, seja apresentada uma visão geral desses processos. Assim sendo, de forma a atender as duas normas, sugere-se seguir o requerido pela ISO 9001, descrevendo-se a interação entre os processos no manual de SG. Entretanto, quando esta descrição estiver detalhada em um procedimento documentado (no nível 2 de documentação), sugere-se apresentar no manual uma visão geral dos mesmos, atendendo a IAEA GS-G-3.1, fazendo referencia ao procedimento documentado, de modo a atender a ISO 9001.

Os processos que definem o SG para o estágio de operação da planta de conversão de $\mathrm{UF}_{6}$, incluem, além de outros não identificados na pesquisa:

- Processos correspondentes aos elementos das normas SG da IAEA (GSR-3, GS-G-3.1 e DS349) tratados no item 3.2.4 da pesquisa, no tópico - Seção 5 (Implementação de Processos), podendo ser excluídos, no caso da planta da pesquisa, aqueles relativos às atividades de projeto, como mencionado na alínea $\mathrm{C}$.

- Processos apresentados na FIG. 5 - "Rota dos Processos da Planta de Conversão de $\mathrm{UF}_{6}$ ", que são aqueles que fazem parte da realização do produto ${ }^{36}$ da planta,

\footnotetext{
${ }^{36}$ Processo de realização - Inclui todos os processos que provêem os resultados intencionais da organização (ISO, 2004d).
} 
denominados pela Agência como processos chave ${ }^{37}$. A FIG. 5 apresenta uma visão geral da interação desses processos, mas não esgota em si a relação e a descrição dos mesmos. Os processos são os de recebimento e estocagem de "Yelowcake"; dissolução e purificação do "Yelowcake"; precipitação do DUA; calcinação; de redução; hidrofluoração; de fluoração; enchimento de cilindro e cristalização; produção do flúor; tratamento de efluentes líquidos, de gases e de resíduos sólidos; recuperação do urânio, entre outros.

\subsubsection{Procedimento Documental - Documentos e Registros Requeridos pelas Normas.}

O procedimento documental apresenta os documentos e registros identificados no estudo para compor a documentação de segundo e terceiro níveis do SG, segundo a IAEA GS-G-3.1 (IAEA, 2006c, p. 14-15), e que sejam aplicáveis a uma planta de conversão de $\mathrm{UF}_{6}$, compreendendo:

- Procedimentos, planos, programas, registros, entre outros, que foram identificados no estudo e organizados nos apêndices L e M por processo, segundo os elementos das normas de SG da IAEA (Mas completos e abrangentes).

- Documentos e registros necessários à implementação dos processos de realização da planta de conversão, tais como aqueles apresentados na FIG. 5 do item 3.1.7.

- Outros documentos e registros determinados pela organização como importantes para definição de seus processos com base em suas estratégias gerais (IAEA, 2006c, p. 32).

A - Procedimentos, planos, programas, registros, entre outros, relacionados por processo nos apêndices $L$ e $M$.

Para a integração dos sistemas, a procedimento documental propõe a racionalização da quantidade de documentos e registros requeridos nos apêndices L e M. Assim sendo, sempre que for possível e conveniente, deve-se buscar em cada processo a unificação, por tipo, dos documentos ou registros de mesmas características, requeridos pelas diferentes normas. O conteúdo para o tipo de documento ou registro deve levar em conta o disposto no elemento (requisito ou recomendação) mais completo e abrangente dentre aqueles das normas considerados, ou uma composição dos mesmos.

\footnotetext{
${ }^{37}$ Processos chave - Processos que produzem os resultados que são críticos ao sucesso do estabelecimento ou atividade nuclear (IAEA, 2007a, p.46).
} 
De modo a promover à racionalização, a correlação dos documentos e registros nos apêndices L e M, possuem a seguinte nomenclatura:

- Em verde - Procedimentos da ISO 14001 ou OHSAS 18001 que não se requer que sejam necessariamente documentados.

- Em azul - Documentos ou registros das diferentes normas que podem ser considerados para racionalização, no processo específico.

- Em cinza - Documento ou registro que, em um processo específico, possui similaridade unicamente com aquele da ISO 14001 ou OHSAS 18001, indicado ao seu lado, e que portando deve ser considerado na racionalização.

Em função do exposto, o procedimento documental sugere que se racionalizem por tipo e conteúdo documentos e registros, tais como:

- Procedimento para controle de documentos, controle de registro, controle de não conformidade, ação corretiva e ação preventiva com conteúdo de acordo com normas de SG da IAEA (Mais completos e abrangentes), exceto que o de ação preventiva deve considerar também as investigações de incidentes, que são requeridas pela OHSAS 18001. A documentação destes procedimentos é requerida de forma explicita somente pela ISO 9001; entretanto, todas as normas de SG requerem esses processos.

- Procedimento de auditoria interna - Ampliar o procedimento considerando outras formas de avaliações independentes requeridas pelas normas de SG da IAEA. A documentação deste procedimento é requerida de forma explicita, somente pela ISO 9001, entretanto, todas as normas de SG tratam deste processo.

- Registros de educação, treinamento, habilidade e experiência para o processo de recursos humanos - Diferentemente das demais normas as de SG da IAEA não deixam explícito que requerem estes tipos de registros; entretanto, o conteúdo dos mesmos deve considerar o disposto nos elementos das normas de SG da IAEA (Mais completos e abrangentes).

- Relatórios de análise de segurança (que faz parte do "Safety Case"). Tipo particular de documento para instalações nucleares; portanto, o modelo de conteúdo deve seguir as normas da Agência. Entretanto, em benefício da racionalização, deve-se considerar a adoção do modelo para o conteúdo da documentação das questões ambientais e de segurança e saúde no trabalho, que estão fora do escopo das normas de segurança da Agência, tais como: documentação para identificação dos aspectos ambientais e determinação daqueles com impactos significativos no meio ambiente (ISO 14001) e para 
identificação de perigos, avaliação de riscos e determinação dos controles (OHSAS 18001).

Os documentos e registros requeridos pelos IAEA DS316 e IAEA DS344, identificados em amarelo nos apêndices L e M, são relativos à função de segurança nuclear do estágio de operação de plantas de conversão, devendo compor, com suas peculiaridades, a documentação do SG. Exemplos:

- Programa de Garantia da Qualidade - Estabelecer um SG que atenda as normas de SG da IAEA e que integre a função qualidade como definida pela norma ISO 9001.

- Formulário de controle de modificação (requerido pelo IAEA DS344) é uma forma particular de documentar as mudanças permanentes ou temporárias que ocorrem em uma instalação nuclear (requerido pelo IAEA DS349).

- Registro de inspeção periódica de cilindro de $\mathrm{UF}_{6}$ (requerido pelo IAEA DS316) é uma forma de aplicação específica do relatório de inspeção e teste (requerido pelo IAEA DS349).

- Procedimento sobre monitoração de concentração de gases inflamáveis (requerido pelo IAEA DS316) deve compor a relação de procedimentos para controlar situações que possam acarretar desvios de SST (requeridos pela OHSAS 18001).

- O programa de proteção radiológica (requerido pela IAEA DS316) deve compor a relação de documentos com informações para monitorar o desempenho, os controles operacionais e a conformidade com objetivos, requerido pela ISO 14001.

\section{B - Documentos e registros necessários à implementação dos processos de realização da planta de conversão.}

Documentos e registros necessários à operacionalização dos processos da planta de conversão, apresentados na FIG. 5, de forma a garantir a eficácia dos processos e qualidade dos produtos (ver item 3.1.7.1 - Aspectos da qualidade) e atender aos requisitos de segurança química e industrial e ambiental da planta, não abordados pelas normas de segurança da Agência (ver item 3.2.5). Neste sentido, as normas de SG da IAEA e de SG ISO 9001, ISO 14001 e OHSAS 18001, requerem que sejam desenvolvidos documentos, tais como:

- Procedimentos operacionais, para monitorar e medir regularmente a qualidade dos produtos, o desempenho ambiental e de segurança e saúde no trabalho, para permissão de desvio e concessões. 
- Planos e programas de treinamento de recursos humanos, de preservação, manutenção ou substituição do patrimônio, de inspeções e testes, programas de segurança industrial.

- Registros de avaliação de riscos, de evidência de que os processos de realização e o produto resultante atende a especificação, do status da calibração de equipamentos de medição e teste, entre outros.

A norma ASTM (1991, p. 5) sobre garantia da qualidade de plantas de conversão relaciona documentos, tais como:

- Procedimentos escritos e qualificados para controle dos processos químicos com vistas a assegurar consistência à operação.

- Procedimentos escritos e aprovados para execução dos processos especiais $^{38}$

- Procedimentos escritos para execução de inspeções em processo ${ }^{39}$, finais $^{40}$ e em serviço ${ }^{41}$ que identifiquem as características, métodos, critérios de aceitação, etc.

Finalmente devem ser incluídos no SG outros documentos e registros determinados pela organização como importantes para definição de seus processos com base em suas estratégias gerais (IAEA, 2006c, p. 32).

\footnotetext{
${ }^{38}$ Processo especial - Processo cujo resultado é altamente dependente do controle do processo ou habilidade do operador, ou ambos, e cuja qualidade especificada não possa ser determinada por inspeção ou teste no produto (ABNT, 1991, p. 1).

${ }^{39}$ Inspeções no processo são executadas durante o curso de produção para verificar se os requisitos de qualidade de um item ou o desempenho de uma atividade estão sendo obtidos antes de ser completado (ABNT, 1991, p. 5).

40 Inspeções finais são executadas depois de completado um item ou atividade para estabelecer conclusivamente a conformidade com os requisitos (ABNT, 1991, p. 5).

${ }^{41}$ Inspeções em serviço no curso das operações para demonstrar que as características das ESC permanecem dentro dos limites aceitáveis (LCO) (ABNT, 1991, p. 5).
} 


\section{ANÁLISE E DISCUSSÃO DOS RESULTADOS.}

A análise dos resultados é apresentada seguindo a formulação dos objetivos da pesquisa como segue:

- Objetivo 1 - A análise é apresentada em dois subgrupos.

Análise da correlação entre as normas de SG da IAEA (GS-R-3, GS-G-3.1 e DS349) e a norma sobre SG da qualidade (ISO 9001).

Análise da correlação entre as normas de SG da IAEA (GS-R-3, GS-G-3.1 e DS349) e as normas sobre SG ambiental (ISO 14001) e de segurança e saúde no trabalho (OHSAS 18001).

- Objetivo 2 - A análise é apresentada em dois subgrupos.

Análise da correlação entre as normas de segurança da IAEA (DS316 e DS344) e as normas de SG da IAEA (GS-R-3, GS-G-3.1 e DS349).

Análise da correlação entre as normas de segurança da IAEA (DS316 e DS344) e as normas sobre SG, ambiental (ISO 14001) e segurança e saúde no trabalho (OHSAS 18001).

- Objetivo 3 - Análise do procedimento documental proposto para um SG para o estágio de operação de plantas de conversão de $U_{6}$.

\subsection{Análise da Correlação entre as Normas de SG da IAEA (GS-R-3, GS-G-3.1 e DS349) e a ISO 9001.}

Duas considerações iniciais devem ser feitas com relação às normas de SG da IAEA em questão e a ISO 9001, ou seja:

- Quanto ao foco - Enquanto as primeiras focam a obtenção e intensificação da segurança nuclear (IAEA, 2006a, p. 5), a segunda foca o atendimento e aumento da satisfação dos clientes com os produtos (ABNT, 2000, p. 5).

- Quanto à abordagem:

o As normas da IAEA estabelecem elementos (requisitos e orientações) para a estruturação de um SG que integre funções, tais como: segurança, saúde, ambiental, qualidade, entre outros (IAEA, 2006a, p. 3). Por sua vez, a ISO 9001 estabelece elementos (requisitos) para estruturação de um SG voltado a função qualidade; entretanto, o SG resultante possibilita o alinhamento ou a integração de outros elementos de SG, tais como aqueles 
das funções: segurança e saúde no trabalho, ambiental, entre outros (ABNT, 2000, p. 3).

o As normas da Agência abordam aspecto como cultura de segurança, incluído cultura da organização e questões de liderança e de comprometimento da alta direção (desenvolvimento dos valores individuais e institucionais e das expectativas comportamentais para suportar a implementação do SG, envolvimento de todos os indivíduos na implementação e melhoria do SG, etc.) (IAEA, 2006c, p. 9 e 18-19), atendendo o observado por Wilkinson et. al. (1999) e Sigler et. al. (2000), quanto à importância fundamental do desenvolvimento destes aspectos para o sucesso da implementação de um sistema, em particular do SIG.

o As normas de SG da IAEA abordam mais elementos e incorporam e fornecem mais detalhes aos elementos correspondentes da ISO 9001. Assim sendo, o SG de uma organização que atenda as normas de SG da IAEA estará, salvo os esclarecimentos e complementos abaixo indicados, atendendo a norma ISO 9001.

A análise foi realizada com base nas correlações apresentadas nos apêndices $\mathrm{H}$ (elementos) e J (documentação).

\section{Documentação Requerida}

No apêndice $J$ são mostradas as lacunas entre a documentação requerida pelas normas de SG da IAEA e a ISO 9001. Assim sendo, alguns documentos e registros requeridos $^{42}$ pela ISO 9001 não o são pelas normas de SG da IAEA; entretanto, a IAEA GS-G-3.1 (IAEA, 2006c, p. 32) orienta que se determinem quais processos devem ser documentados, considerando: os requisitos regulatórios e estatutários aplicáveis, a natureza das atividades da organização e suas estratégias gerais. Portanto, se além de outras estratégias for interesse atender a ISO 9001, a organização estruturada de acordo com as normas de SG da IAEA deve formalizar, em seu SG, que se documente:

- O sistema de gestão em um manual - A norma ISO 9001 requer um manual que descreva o SGQ. A norma IAEA GS-G-3.1 (IAEA, 2006c, p. 14-15) orienta que as

\footnotetext{
${ }^{42} \mathrm{O}$ termo "requerido" aqui utilizado tem o sentido de explicitamente requerido pela norma. Logo, não deve ter a conotação de que a norma não possa estar considerando implicitamente a necessidade do documento ou registro (Nota do autor).
} 
informações do SG sejam estruturadas em três níveis e que no nível um sejam providas, informações similares aquelas da ISO 9001 para o manual da qualidade.

- Procedimentos para controle de documentos, controle de registros, auditoria interna, controle de produto não-conforme, ação corretiva e ação preventiva.

- Registros de análise crítica dos requisitos relacionados com o produto e ações resultantes; de educação, treinamento, habilidade e experiência; de avaliação de fornecedores; de validação de processos de produção e serviços associados; e de análise crítica do SQ pela Direção. Este último tipo de registro foi incluído, pois seu escopo é mais abrangente do que o requerido pela IAEA para comentários e resoluções de análise crítica de documentos do SG.

\section{Comprometimento da Direção}

As normas de SG da IAEA são mais abrangentes requerendo que o gerente sênior desenvolva valores individuais e institucionais e expectativas comportamentais para sustentação do SG, atuando como exemplo na promulgação desses valores e expectativas.

\section{Foco no Cliente}

As normas de SG da IAEA são mais abrangentes pois ampliam o espectro de satisfação que inclui as partes interessadas nas atividades e interações dos processos do SG, e não só ao cliente consumidor como prevê a ISO 9001. Além disso, requerem que o atendimento as expectativas das partes interessadas sejam satisfeitas assegurando, ao mesmo tempo, que a segurança nuclear não seja comprometida.

\section{Responsabilidade e Autoridade}

As normas de SG da IAEA são mais rigorosas estabelecendo que:

- O indivíduo que coordena o SG tenha responsabilidade e autoridade específica para este fim (IAEA, 2006a, p. 9). A ISO 9001 (ABNT, 2000a, p. 6) requer que a responsabilidade e autoridade sejam independentemente de outras responsabilidades.

- Para cada processo seja designado um indivíduo com autoridade e responsabilidade pelo processo $^{43}$ (IAEA, 2006a, p. 11).

\footnotetext{
${ }^{43}$ A ISO 9001 não estabelece este requisito, porém a ISO 9004 (ABNT, 2000b, p. 8) recomenda esta prática.
} 
- As atividades de inspeção, teste, verificação e validação de cada processo sejam executadas por indivíduos ou grupos que não tenham executado o trabalho, originalmente (IAEA, 2006a, p. 12).

- Todos os indivíduos envolvidos na preparação, análise crítica ou aprovação de documentos sejam especificamente designados para o trabalho (IAEA, 2006a, p. 12).

- Uma unidade organizacional seja estabelecida com responsabilidade e suficiente autoridade pela condução de avaliações independentes, podendo ser um indivíduo ou uma organização externa (IAEA, 2006a, p. 15).

- A análise dos resultados de avaliações independentes, assim como a tomada de qualquer ação necessária, seja conduzida pela alta direção (IAEA, 2006a, p. 16). A ISO 9001 requer (ABNT, 2000a, p. 11) que sejam de responsabilidade da área auditada.

\section{Determinação dos Requisitos dos Clientes}

A ISO 9001 (ABNT, 2000a, p. 7) fornece mais detalhes do que as normas de SG da IAEA, como: requisitos de entrega e pós-entrega e os não declarados pelo cliente, mas necessários para o uso especificado ou intencional, onde conhecido.

\section{Validação dos Processos de Produção e Fornecimento de Serviços}

A ISO 9001 (ABNT, 2000a, p. 9), diferentemente da IAEA GS-R-3 (IAEA, 2006a, p. 12), deixa claro quais processos devem ser validados (aqueles cuja saída resultante não possa ser verificada por monitoramento ou medição subseqüente, incluindo quaisquer processos onde as deficiências só fiquem aparentes depois que o produto esteja em uso ou o serviço concluído).

\section{Propriedade do Cliente}

Este requisito, abordado pela ISO 9001 (ABNT, 2000a, p. 10), não é tratado explicitamente pelas normas de SG da IAEA; porém, o IAEA DS349 (IAEA, 2007a, p. 10) fornece orientação para que este requisito seja atendido, em gestão de patrimônio material. 


\section{Inspeção e Testes}

A norma ISO 9001 não prevê, como as normas de SG da IAEA, requisito para materiais e espécimes de teste; assim como seus registros associados, tenham seus prazos de retenção estabelecidos (IAEA, 2006a, p. 13).

\section{Avaliação Independente do SG}

As normas de SG da IAEA (2006c, p. 55; 2007a, p. 99-100) requerem outros tipos de avaliações independentes, além auditoria interna requerido pela ISO 9001 (ABNT, 2000a, p. 11), ou seja:

- Supervisão sobre áreas específicas ou atividades.

- Avaliações pelos pares em assuntos específicos à segurança.

- Análise do conteúdo técnico de atividades e processos.

- Avaliações sobre a cultura de segurança.

\section{Não-Conformidades}

As normas de SG da IAEA requerem que as não-conformidades sejam identificadas nos produtos e processos (IAEA, 2006a, p. 16), enquanto a ISO 9001 menciona apenas para produtos (ABNT, 2000a, p. 11).

\section{Requisitos das Normas de SG da IAEA Não Abordados pela ISO 9001}

No apêndice H são indicados com "NR" os requisitos não abordados pela norma ISO 9001, tais como:

- Sistema integrado de gestão.

- Cultura de segurança.

- Gradação da aplicação dos requisitos do sistema de gestão.

- Mudança na gestão organizacional.

- Auto-avaliação.

- Alguns processos específicos, denominados pela IAEA como comuns a todos os estágios (avaliação de risco do local de trabalho; segurança industrial; segurança radiológica; gestão de rejeitos; gestão ambiental; entre outros). 


\subsection{Análise da Correlação entre as Normas de SG da IAEA (GS-R-3, GS-G-3.1 e DS349) e as ISO 14001 e OHSAS 18001.}

Devido à similaridade de conteúdo e natureza dos assuntos e de estrutura das normas, a correlação entre os elementos da ISO 14001 e da OHSAS 18001 com aqueles das normas de SG da IAEA será analisada em conjunto.

Os elementos das normas de SG da IAEA, salvo os esclarecimentos e complementos abaixo indicados, permitem a estruturação de um SG que atenda aos requisitos das normas ISO 14001 e OHSAS 18001.

A análise foi realizada com base nas correlações apresentadas nos apêndices I (requisitos) e J (documentação).

\section{Documentação Requerida.}

No apêndice $J$ são mostradas as lacunas entre a documentação requerida pelas normas de SG da IAEA e aquelas das ISO 14001 e OHSAS 18001. Assim sendo, alguns documentos e registros requeridos $^{44}$ pelas ISO 14001 e OHSAS 18001 não o são pelas normas de SG da IAEA; entretanto, a IAEA GS-G-3.1 (IAEA, 2006c, p. 32) orienta que se determine quais processos devem ser documentados, considerando: os requisitos regulatórios e estatutários aplicáveis, a natureza das atividades da organização e suas estratégias gerais. Portanto, se além de outras estratégias for interesse atender a ISO 14001 ou a OHSAS 18001, ou ambas, a organização, estruturada de acordo com as normas de SG da IAEA, deve formalizar em seu SG, que se documente:

- Procedimentos para controlar situações onde a ausência deles possa causar desvios em relação à política e objetivos ambientais ou de segurança e saúde no trabalho (SST).

- Para atender a ISO 14001 - Documentos com informações para monitorar o desempenho, os controles operacionais pertinentes e a conformidade com os objetivos e metas ambientais; registros dos resultados das avaliações periódicas do atendimento aos requisitos legais aplicáveis; registros dos resultados das avaliações periódicas do atendimento aos outros requisitos por ela subscritos; registros das análises críticas do SGA pela alta administração e documentação da identificação dos aspectos ambientais e a determinação dos impactos significativos sobre o meio ambiente.

\footnotetext{
${ }^{44} \mathrm{O}$ termo "requerido" aqui utilizado tem o sentido de explicitamente requerido pela norma (Nota do autor).
} 
- Para atender a OHSAS 18001, registros de dados e resultados do monitoramento e medição para subseqüente análise de ações corretivas e ações preventivas; registros dos resultados das avaliações periódicas do atendimento aos requisitos legais aplicáveis; registros dos resultados das avaliações periódicas do atendimento aos outros requisitos por ela subscritos e registro das análises crítica do SGSST pela direção.

- A decisão da organização em comunicar externamente seus aspectos ambientais significativos (requerido pela ISO 14001) e as comunicações pertinentes sobre perigos de SST, oriundas de partes interessadas externas (requerido pela OHSAS 18001). As normas de SG da IAEA não mencionam esses tipos de comunicação; entretanto, a IAEA GS-G-3.1 (IAEA, 2006c, p. 45) orienta que o processo de comunicação faça uso de canais apropriados, tais como cartas, e-mails e reuniões pessoais.

- As informações sobre a identificação dos aspectos ambientais e a determinação dos impactos significativos, requerido pela ISO 14001 (ABNT, 2004, p. 5), e os resultados da identificação de perigos, da avaliação de riscos e da determinação dos controles necessários, requeridos pela OHSAS 18001 (Risk, 2007, p. 19). As normas de SG da IAEA não são explicitas neste sentido; entretanto, essas informações são fornecidas nos relatórios de análise de segurança $(\mathrm{RAS})^{45}$ que, segundo a norma IAEA DS349 (IAEA, 2007a, p. 75), são documentos requeridos por alguns países membros da Agência, sendo publicados no estágio de projeto da instalação nuclear e, atualizados, nos demais estágios.

\section{Procedimentos para o Desenvolvimento dos Processos.}

As ISO 14001 e OHSAS 18001 definem procedimentos (relacionados nos apêndices $\mathrm{C}$ e E) como forma especificada de executar uma atividade ou um processo, podendo ser documentado ou não (ABNT, 2004, p. 4; Risk, 2007, p. 15). Essas normas definem procedimento como forma especificada de executar ou um processo. Por sua vez, a IAEA GS-G-3.1 (IAEA, 2006c, p. 32) orienta que os processos sejam identificados, desenvolvidos e gerenciados da forma mais apropriada e que se determine quais devam ser documentados. A IAEA GS-R-3 (IAEA, 2006a, p. 11) requer que se assegure no desenvolvimento dos processos o atendimento às funções segurança, ambiental, entre

\footnotetext{
${ }^{45}$ O RAS descreve os aspectos significativos à segurança e discute a implementação de princípios e critérios aplicados durante a fase de projeto, para a proteção do pessoal operacional, do público e do meio ambiente. Em adição, contem análises dos perigos associados com a operação da instalação e análises de seqüências de acidentes e de características incorporadas ao projeto, para evitar ou minimizar a probabilidade de ocorrência de acidentes e mitigar suas conseqüências (IAEA, 2006d, p. 7).
} 
outras. Portanto, as ISO 14001 e OHSAS 18001 serão atendidas à medida que se desenvolvam os processos dos elementos das normas de SG da IAEA a eles correlacionados no apêndice I, com exceção dos seguintes:

- Preparação e resposta de emergência - As normas de SG da IAEA não tratam deste assunto; entretanto, a IAEA GS-R-3 (IAEA, 2006a, p. 5) requer que sejam identificados e integrados ao SG os requisitos contidos na IAEA GS-R-2 (FAO et. al., 2002), sobre o tema. No entanto, esta norma tem sua aplicação específica às práticas e fontes que têm potencial de causar exposição à radiação ionizante e contaminação radioativa ao meio ambiente, não abordando aspectos de preparação e resposta de emergência, comuns a, por exemplo, uma planta química convencional. Portanto, para que as ISO 14001 e OHSAS 18001 sejam atendidas o SG de uma instalação nuclear deve prever a implementação de procedimentos, para identificar o potencial para situações de emergência e para responder a tais situações, que considerem outros elementos, além daqueles puramente nucleares da IAEA GS-R-2.

- Avaliação do atendimento a requisitos legais e outros - A IAEA GS-G3.1 (IAEA, 2006c, p. 20) aborda sobre requisitos legais, porém nada mencionando sobre outros requisitos subscritos pelas organizações e que também devem ser considerados.

\section{Responsabilidade e Autoridade.}

Para atender a ISO 14001 e OHSAS 18001, um SG estruturado segundo as normas de SG da IAEA deve prever a indicação de representantes os quais, independentemente de outras responsabilidades, tenham função, responsabilidade e autoridade específicas pelo SGA, ISO 14001 (ABNT, 2004, p. 6), e pelo SGSST, OHSAS 18001 (Risk, 2007, p. 20), ou estabelecer que o indivíduo que responde diretamente a alta direção, com responsabilidade e autoridade específica pelo SG (IAEA, 2006a, p. 9), responda também pelo SGA e SGSST.

A norma OHSAS 18001 (Risk, 2007, p. 21) requer que seja assegurado que pessoas nos locais de trabalho assumam responsabilidades por aspectos de SST, o que é atendido pela IAEA GS-G-3.1 (IAEA, 2006c, p. 36) quando orienta que seja designado um indivíduo com autoridade e responsabilidade pela gestão de cada processo e que o mesmo tenha autoridade para avaliar a segurança envolvida no processo.

As ISO 14001 e OHSAS 14001 não tratam dos seguintes elementos abordados pelas normas de SG da IAEA: 
- Designação de um indivíduo com autoridade e responsabilidade pela gestão de cada processo (IAEA, 2006a, p. 11).

- Assegurar que os responsáveis de cada processo reportem periodicamente ao indivíduo responsável pelo SG a situação de seus processos, fornecendo subsídios para reportar o desempenho do SG como um todo (IAEA, 2007a, p. 37).

- Designação específica dos indivíduos envolvidos na preparação, análise crítica ou aprovação de documentos (IAEA, 2006a, p. 12).

- Estabelecimento de uma unidade organizacional com responsabilidade e suficiente autoridade pela condução de avaliações independentes, podendo ser um indivíduo ou organização externa (IAEA, 2006a, p. 15).

- Condução pela alta direção da análise dos resultados de avaliações independentes, assim como da tomada de qualquer ação necessária (IAEA, 2006a, p. 16).

\section{Avaliação do Sistema de Gestão (SG).}

Além de auditoria interna previstas nas normas da ISO 14001 (ABNT, 2004b, p. 9) e OHSAS 14001 (Risk, 2007, p. 27), as normas de SG da IAEA (2006c, p. 55; 2007a, p. 99-100) requerem:

- Supervisão sobre áreas específicas ou atividades,

- Avaliações pelos pares em assuntos específicos à segurança.

- Avaliações do conteúdo técnico de atividades e processos.

- Avaliações sobre a cultura de segurança.

\section{Requisitos das Normas de SG da IAEA Não Abordados pela ISO 14001 e OHSAS} 18001.

No apêndice I são indicados com "NR" os requisitos não abordados pelas normas ISO 14001 e OHSAS 18001, tais como:

- Sistema integrado de gestão.

- Cultura de segurança.

- Gradação da aplicação dos requisitos do sistema de gestão.

- Satisfação das partes interessadas.

- Infra-estrutura e ambiente de trabalho.

- Auto-avaliação. 
- Processos específicos, denominados pela IAEA como comuns a todos os estágios das instalações nucleares, e que não se aplicam as questões ambientais e de segurança e saúde no trabalho.

\subsection{Análise da Correlação entre as Normas de SG da IAEA (GS-R-3, GS-G-3.1 e DS349) e as Normas de Segurança da IAEA (DS316 e DS344).}

Como análise inicial ao estudo de correlação em pauta, ressalta-se que em função de suas naturezas, os projetos de normas IAEA DS316 e IAEA DS344 não introduzem elementos adicionais sobre $\mathrm{SG}$ aqueles das normas de SG da IAEA. Ao contrário, eles fornecem detalhes, complementam ou reforçam aqueles elementos, direcionando sua aplicação à função segurança de instalações do ciclo do combustível nuclear $\left(\right.$ IAEA DS316) ${ }^{46}$ e, mais particularmente, as instalações da conversão e de enriquecimento (IAEA DS344). Portanto, todos os elementos (requisitos e recomendações) dos IAEA DS316 e IAEA DS344 são associados a um ou mais elementos das normas de SG da IAEA, conforme pode ser observado no apêndice K. A seguir são analisados alguns desses elementos:

- O IAEA DS316 (IAEA, 2006d, p. 15 e 48) reforça a IAEA GS-R-3 (IAEA, 2006a, p. 6) quanto à adoção e a implementação de princípios e processos para se atingir uma efetiva cultura de segurança, incluindo a sua avaliação periódica. Segundo o IAEA DS316, na obtenção de altos padrões de segurança, de saúde e ambientais as organizações freqüentemente enfrentam situações de desafios onde a conscientização e comprometimento dos indivíduos com relação à segurança é essencial.

- O IAEA DS316 (IAEA, 2006d, p. 13) complementa a IAEA GS-G-3.1 e IAEA DS349 (IAEA, 2006c, p. 36; 2007a, p. 13) quanto a responsabilidades pelos processos, estabelecendo que se defina claramente as responsabilidades e prestações de conta de todo o pessoal que controla e conduz operações que afetam à segurança, assim como esteja identificado, de forma clara e a todo tempo, a pessoa responsável diretamente pela supervisão deste pessoal e de suas operações respectivas.

- O IAEA DS316 (IAEA, 2006d, p. 39) complementa as responsabilidades e autoridade pelo SG da IAEA GS-G-3.1 (IAEA, 2006c, p. 23) requerendo que se estabeleça um ou mais comitês interno de segurança, e que seus membros, na extensão

\footnotetext{
${ }^{46}$ Para o propósito da IAEA DS316, reatores e instalações de mineração e de rejeitos não são considerados (IAEA, 2006d, p. 1).
} 
necessária, sejam independentes dos gerentes operacionais que conduzem assuntos de segurança.

- O IAEA DS316 (IAEA, 2006d, p. 43) complementa as responsabilidades e autoridade pelo SG da IAEA GS-G-3.1 (IAEA, 2006c, p. 23) requerendo que seja estabelecida a função de proteção radiológica, cujo pessoal designado deve ter acesso ao nível gerencial com autoridade para estabelecer e implementar procedimentos operacionais.

- O IAEA DS316 (IAEA, 2006d, p. 7 e 17) detalha os documentos resultantes da condução de análise de segurança da IAEA DS 349 (IAEA, 2007a, p. 7) requerendo que o "Safety Case", incluindo os demais documentos que o compõe ${ }^{47}$, seja a base para a operação segura da instalação e uma importante fonte de ligação entre a organização e a agência reguladora.

- O IAEA DS316 (IAEA, 2006d, p. 14) complementa o requisito sobre administração do empreendimento do IAEA DS349 (IAEA, 2007a, p. 58) requerendo que seja descrito e estabelecido um Programa de Garantia da Qualidade (PGQ) para a instalação, de acordo com as normas $50-\mathrm{C} / \mathrm{SG}-\mathrm{Q}^{48}$. O programa é importante para garantir que os requisitos operacionais estejam definidos e sejam executados de acordo com o necessário padrão e grau de rigor.

- Além do "Safety Case" e do PGQ os apêndices L e M apresentam outros documentos requeridos pelos IAEA DS316 e IAEA DS344, em acréscimo ou complementaridade, ou que direcionam aplicações especificas, dos daqueles das normas de SG da IAEA.

\subsection{Análise da Correlação entre as Normas ISO 14001 e OHSAS 18001 e as Normas de Segurança da IAEA (DS316 e DS344).}

As ISO 14001 e OHSAS 18001 são normas de aplicação genérica a qualquer tipo de organização, enquanto que os IAEA DS316 e IAEA DS344 são projetos de norma de segurança destinados a uma aplicação específica. Portanto, os elementos destas últimas detalham, complementam ou especificam a aplicação daqueles das normas ISO $14001 \mathrm{e}$ OHSAS 18001 que lhes são correlacionados, quando aplicados a uma instalação do ciclo

\footnotetext{
${ }^{47}$ O glossário define e apresenta o conteúdo do "safety case".

${ }^{48}$ Conforme previsto pela IAEA DS316 (IAEA, 2006d, p. 14), em nota de rodapé, a IAEA está substituindo as 50-C/SG-Q pelas normas de SG alvo desta pesquisa (IAEA GS-R-3, IAEA GS-G-3.1 e pela futura norma que resultará do projeto IAEA DS349).
} 
do combustível nuclear (IAEA DS316) ${ }^{49}$ e, mais particularmente, a instalações de conversão ou de enriquecimento (IAEA DS344). Entretanto, os IAEA316 e IAEA DS344 abordam segurança dentro do contesto da obtenção de apropriadas condições de operação, prevenção de acidentes ou mitigação das conseqüências de acidentes, que resultem na proteção dos trabalhadores, do público e do meio ambiente contra perigos indevidos à radiação ionizante. Portanto, não consideram as questões de segurança (incluindo as questões ambientais) relacionadas a perigos puramente industriais e químicos que não estejam relacionadas à radiação ionizante (IAEA, 2006d, p. 5).

No apêndice K são indicados os elementos dos IAEA DS316 e IAEA DS344 que detalham ou complementam àqueles das ISO 14001 e OHSAS 18001. Alguns elementos foram selecionados e são analisados a seguir:

- A IAEA DS 316 (IAEA, 2006d, p. 39 e 43) requer o estabelecimento de comitês internos de segurança e da função de proteção radiológica, e a designação de pessoal para controle e condução de operações que afetam à segurança. A ISO 14001 e OHSAS 18001 tratam o assunto de forma genérica requerendo que a alta direção indique representantes os quais, independentemente de outras responsabilidades, tenham função, responsabilidade e autoridade específicas pelo SGA e SGSST.

- A ISO 14001 e OHSAS 18001 especificam de forma genéricas requisitos para competência, treinamento e conscientizarão. Os IAEA DS316 e IAEA DS344, detalham esta necessidade requerendo, por exemplo: treinamento para o pessoal de operação em detecção de nuvem de $\mathrm{UO}_{2} \mathrm{~F}_{2}$; treinamento para prevenção e mitigação de incêndio e explosão com liberação radiológica, treinamento em incêndio decorrente da explosão de $\mathrm{H}_{2}$ em forno de redução; exercício periódico em preparação de emergência dentro e fora do sítio, qualificação e experiência do pessoal que exerce função de proteção radiológica e função de inspeção; e disponibilidade de pessoal em quantidade mínima para garantir a segurança na execução de atividades de operação e em condições de acidentes.

- Conforme pode ser observado nos apêndices L e M, os IAEA DS316 e IAEA DS344 detalham o conteúdo de documentos requeridos pela ISO 14001 e OHSAS 18001, como por exemplo: procedimentos de emergência dentro do sítio, e quando aplicável fora do sítio; planos de emergência para perigos radiológicos e não radiológicos; procedimentos de gestão de acidentes; históricos e dados de modificações; registro de eventos e incidentes; registros de dados de operação da instalação; procedimentos escritos

${ }^{49}$ A IAEA DS316 não se aplica a reatores e instalações de mineração e de rejeitos (IAEA, 2006d, p. 1). 
sobre concentração de gases inflamáveis; programas de rotinas de supervisão de contaminação no ar e superfícies por radiação; registros de dados de proteção radiológica que incluam a monitoração do pessoal; registros de controle de dose ocupacional de radiação, entre outros.

- A IAEA DS316 (IAEA, 2006d, p. 14) requer o estabelecimento de um sistema da qualidade ou garantia da qualidade pelas organizações (PGQ) que não é requerido pelas ISO 14001 e OHSAS 18001.

- O IAEA DS316 (IAEA, 2006d, p. 7 e 17) requer um "Safety Case" que é um conjunto de argumentos e evidências para demonstrar a segurança de uma instalação ou atividade, que normalmente inclui uma análise de segurança e provisões para minimizar o risco ao público, ao pessoal de operação e ao ambiente. Portanto, com exceção dos aspectos de segurança puramente industriais e químicos, que não estão relacionadas à radiação ionizante, a serem analisados à parte, o "Safety Case" fornece informações que satisfazem a documentação para:

o Identificação dos aspectos ambientais que a organização possa controlar e aqueles que possa influenciar e determinação daqueles que possam ter impactos significativos sobre o meio ambiente (requerida pela ISO 14001).

o Identificação de perigos, avaliação de riscos e determinação dos controles necessários à redução dos riscos (requerida pela OHSAS 18001).

- Finalmente, as normas ISO 14001 e OHSAS 18001, diferentemente dos IAEA DS316 e IAEA DS344, não estabelecem requisitos para cultura de segurança, assim como para auto-avaliação do desempenho operacional e da segurança e proteção física.

\subsection{Análise do Procedimento Documental para Sistema de Gestão do Estágio de Operação de Plantas de Conversão de UF $_{6}$.}

Tendo como propósito a obtenção de um SG que integre os requisitos das normas e projetos de normas citados sobre segurança nuclear, segurança e saúde do trabalho, ambiental e qualidade, ressalta-se que o procedimento documental para um SG deve considerar a racionalização da quantidade de documentos e registros requeridos pelas diferentes normas. A racionalização deve buscar tanto para a definição dos tipos de documentos e registros, quanto para seu conteúdo, o requisito, a orientação ou a 
recomendação mais abrangente e completa, dentre aquelas apresentadas pelas normas, códigos e ou ainda, uma composição destas que se complementa. 


\section{CONCLUSÕES E RECOMENDAÇÕES.}

\subsection{Conclusões.}

A Agência - International Atomic Energy Agency - vem desenvolvendo um extenso programa de modificação de suas normas de sistema de gestão que, segundo ElBaradei $^{50}$, refletem as melhores práticas utilizadas no mundo. Uma destas práticas é a tendência de mercado de aumentar a compatibilidade entre as normas de sistemas de gestão, em busca da integração. Esta prática foi adotada pela Agência com a recente publicação de normas sobre sistema de gestão (SG), que definem requisitos e orientações que objetivam integrar as várias funções envolvidas, com foco em assegurar e reforçar a segurança das instalações nucleares.

Esta pesquisa buscou inicialmente uma equiparação entre as visões de mercado e da Agência com respeito à gestão das funções de segurança nuclear, segurança e saúde no trabalho, ambiental e qualidade, concluindo que as normas de SG da Agência, por serem de integração, abordam mais elementos e incorporam e fornecem mais detalhes aos elementos das demais normas de SG estudadas. Além disso, diferentemente das outras normas, elas abordam aspectos sobre cultura de segurança, que inclui a cultura da organização e questões de liderança e de comprometimento da alta direção que são fundamentais ao sucesso da implementação de um sistema gestão.

A pesquisa mostrou que, salvo alguns esclarecimentos ou ajustes sobre elementos não abordados de forma explicita pela Agência, ao se implementar um SG de acordo com as normas de SG da IAEA (GS-R-3, GS-G-3.1 e DS349), que considere as funções qualidade, ambiental, e de segurança e saúde no trabalho, estarão sendo atendidas as estruturas das ISO 9001, ISO 14001 e OHSAS 18001. Como contribuição, a pesquisa identifica as complementaridades e lacunas entre os elementos das normas de SG estudadas, publicando tabelas de correlações e fornecendo orientações para a estruturação de um sistema integrado de gestão (SIG) que suporte os elementos de todas as normas consideradas.

As normas de SG não estabelecem requisitos técnicos sobre segurança, saúde, meio ambiente e qualidade, entre outros, aplicáveis aos processos e produtos específicos de uma instalação. Estes requisitos são identificados em outras fontes e devem ser integrados ao sistema de gestão. Tendo como foco o estágio de operação de uma planta de conversão

\footnotetext{
${ }^{50}$ Mohamed ElBaradei é o Diretor Geral da IAEA - Nota do autor.
} 
de "Yellowcake" em UF 6 , o estudo buscou avaliar como seria a inserção de elementos específicos sobre requisitos de segurança da planta, em um SG estruturado de acordo com as normas de SG da Agência e de mercado.

Nesse contexto, foi estudada a correlação dos projetos de normas de segurança nuclear IAEA DS316 e IAEA DS344, com as normas de SG da IAEA, ISO 14001 e OHSAS 18001, quando aplicadas a uma planta de conversão de $U_{6}$, concluindo-se que os elementos das duas primeiras normas, detalham e complementam os elementos das demais, instituindo funções de responsabilidades e autoridade pelo SG (tais como: estabelecimento de comitês de segurança e da função de proteção radiológica, definição de pessoal que controla e conduz operações que afetam à segurança); definindo a aplicação de documentos e registros específicos à segurança nuclear; definindo elementos específicos para treinamento, qualificação, experiência e disponibilidade de pessoal, assim como, reforçando os requisitos sobre cultura de segurança das normas de SG da IAEA e abordando aspectos não tratados pelas ISO 14001 e OHSAS 18001, tais como: cultura de segurança, auto-avaliação do desempenho operacional e da segurança e proteção física, entre outros aspectos. Como contribuição a pesquisa estabelece uma tabela de correlação entre os elementos das normas de segurança da Agência e as normas de SG da Agência e de Mercado estudadas, que evidenciam os detalhes a serem incorporados ao SG, fornecendo também, orientações para ajustes e inserção dos requisitos de segurança da tabela, ao SG.

Os IAEA DS316 e IAEA DS344 abordam segurança dentro do contexto de proteção das pessoas e do meio ambiente contra os efeitos nocivos da radiação ionizante, ou seja, segurança no sentido de obtenção de apropriadas condições de operação, prevenção de acidentes ou mitigação das conseqüências de acidentes, que resultem na proteção dos trabalhadores, do público e do meio ambiente contra perigos indevidos à radiação. Entretanto, além de compostos de urânio, as plantas de conversão de $\mathrm{UF}_{6}$, manuseiam e processam grande quantidade de produtos químicos perigosos, que podem ser tóxicos, corrosivos, combustíveis e explosivos. Em acréscimo, as plantas de conversão incluem processos industriais que adicionam perigos ao pessoal do sítio e ao meio ambiente. Portanto, a pesquisa conclui que a análise de segurança deste tipo de planta deve considerar também os impactos decorrentes dos produtos químicos e dos perigos decorrentes dos processos indústrias, que não são tratados pelos projetos de normas de segurança da Agência.

$\mathrm{O}$ mesmo raciocínio se aplica às questões sobre requisitos específicos da 
qualidade. A pesquisa identificou a norma ASTM C 1188 sobre programa de garantia da qualidade para plantas de conversão, que fornece recomendações práticas nesse sentido, e a norma ASTM C 787 que especifica a qualidade requerida para o produto final (UF $\left.{ }_{6}\right)$ a ser fornecido para utilização nas plantas de enriquecimento. Entretanto, é necessário identificar publicações que especifiquem a qualidade requerida para os produtos intermediários utilizados nos processos de planta de conversão de $\mathrm{UF}_{6}$, inclusive para aqueles adquiridos de fornecedores, de forma a se completar os requisitos da qualidade para estruturação de um sistema de gestão que atenda as normas de SG da Agência.

Finalmente, a pesquisa buscou compreender como seria a estruturação da documentação para o sucesso de um SIG, aplicado ao estágio de operação de uma planta de conversão de $\mathrm{UF}_{6}$, que viesse a utilizar na sua concepção, as normas estudadas na pesquisa, propondo um procedimento documental para este fim.

O procedimento documental que foi proposto identifica os documento e registros requeridos pelas normas e projetos de norma da pesquisa e os organiza em dois grupos:

- Manual do sistema de gestão, com conteúdo que atende as informações de nível 1 das orientações da IAEA GS-G-3.1 e o requerido para manual da qualidade da ISO 9001.

\section{- Documentos e registros que fornecem informações para a implementação dos processos do SG - O estudo organiza a documentação (procedimentos, planos, programas, instruções, registros, etc.) por processo do SIG. Esta documentação é aquela que compõe as informações de níveis 2 e 3 segundo a IAEA GS-G- 3.1 .}

A proposta de procedimento documental conclui que ao ser estruturada a documentação, que integre os elementos das normas de SG citadas e de segurança nuclear, deve ser considerada a racionalização dos documentos e registros requeridos em cada processo desse sistema. A pesquisa identifica os documentos e registros que podem ser considerados para racionalização e apresenta recomendações para o estabelecimento do conteúdo dos documentos e registros a serem racionalizados, que deve levar em conta o elemento mais abrangente e completo dentre aqueles apresentados pelas normas, ou uma composição destes elementos que se complemente. 


\subsection{Recomendações.}

Dentro do programa de revisão de normas em desenvolvimento pela Agência vem sendo introduzida uma nova abordagem aos requisitos e orientações aplicáveis às instalações nucleares. Destarte, importante se faz ressaltar a relevância no aprofundamento do conteúdo de tais normas e projetos de normas, com o propósito de se realçar suas essências, contribuindo, assim, à sua aplicação prática, tal como se procurou com as normas e os projetos de normas tratados nesta pesquisa. Neste contexto, recomenda-se complementar o objeto desta pesquisa, estudando as normas e projetos de norma indicados no sítio na Internet da IAEA (2008c), em particular aqueles a seguir relacionados sobre sistema de gestão, os quais, também, são de interesse à operação de plantas de conversão de $\mathrm{UF}_{6}$ :

- IAEA DS326 - TS-G-1.3 Management Systems for the Safe Transport of Radioactive Material (IAEA, 2007c).

- IAEA GS-G-3.2 - . The Management System for Technical Services in Radiation Safety (IAEA, 2008d).

- IAEA GS-G-3.3 - The Management System for Processing, Handling and Storage of Radioactive Waste (IAEA, 2008e).

- IAEA GS-G-3.4 - The Management System for the Disposal of Radioactive Waste (IAEA, 2008f).

Recomenda-se também identificar e incorporar ao estudo desta pesquisa, normas, códigos, especificações, e outras publicações que tratem de segurança química e industrial, não abordados pelas normas da Agência, assim como sobre requisitos de qualidade, para os produtos e processos da planta. 


\section{APÊNDICE A - Procedimentos Documentados e Registros Requeridos pela ISO} 9001:2000.

\begin{tabular}{|c|c|c|}
\hline Item & $\begin{array}{l}\text { Procedimento } \\
\text { Documentado }\end{array}$ & Registro \\
\hline 4.2 .3 & Controle de documentos & \\
\hline 4.2 .4 & Controle de registro & \\
\hline 5.6 & & Análise crítica pela Direção \\
\hline 6.2 .2 & & Educação, treinamento e, habilidade e experiência \\
\hline 7.1 & & $\begin{array}{l}\text { Evidência de que os processos de realização e o } \\
\text { produto resultante atende a especificação }\end{array}$ \\
\hline 7.2 .2 & & $\begin{array}{l}\text { Análise crítica dos requisitos relacionados com o } \\
\text { produto e ações resultantes }\end{array}$ \\
\hline 7.3 .2 & & Entrada de projeto e de desenvolvimento \\
\hline 7.3.4 & & $\begin{array}{l}\text { Análise crítica de projeto e de desenvolvimento e } \\
\text { de quaisquer ações necessárias }\end{array}$ \\
\hline 7.3 .5 & & $\begin{array}{l}\text { Verificação de projeto e de desenvolvimento e de } \\
\text { quaisquer ações necessárias }\end{array}$ \\
\hline 7.3.6 & & $\begin{array}{l}\text { Validação de projeto e de desenvolvimento e de } \\
\text { quaisquer ações necessárias }\end{array}$ \\
\hline 7.3 .7 & & $\begin{array}{l}\text { Análise crítica de alterações de projeto e de } \\
\text { desenvolvimento e de quaisquer ações necessárias }\end{array}$ \\
\hline 7.4.1 & & $\begin{array}{l}\text { Avaliação de fornecedores e de quaisquer ações } \\
\text { necessárias }\end{array}$ \\
\hline 7.5 .2 & & $\begin{array}{l}\text { Validação de processos de produção e de serviços } \\
\text { associados }\end{array}$ \\
\hline 7.5.3 & & Identificação única do produto e rastreabilidade \\
\hline 7.5 .4 & & Propriedade do cliente \\
\hline 7.6 & & $\begin{array}{l}\text { Resultados de calibração e verificação de } \\
\text { dispositivos de medição e monitoramento }\end{array}$ \\
\hline 8.2 .2 & Auditoria interna & Auditoria interna \\
\hline 8.2 .4 & & Monitoramento e medição de produto \\
\hline 8.3 & $\begin{array}{l}\text { Controle de produto não- } \\
\text { conforme }\end{array}$ & Controle do produto não-conforme \\
\hline 8.5 .2 & Ação corretiva & Ação corretiva executada \\
\hline 8.5 .3 & Ação preventiva & Ação preventiva executada \\
\hline
\end{tabular}




\section{APÊNDICE B - Procedimentos Documentados e Documentos e Registros Requeridos pela ISO 14001:2004.}

\begin{tabular}{|c|c|c|}
\hline Item & $\begin{array}{l}\text { Procedimento } \\
\text { Documentado }\end{array}$ & Documento ou Registro \\
\hline 4.3 .1 & & $\begin{array}{l}\text { Documentar informações sobre a identificação dos } \\
\text { aspectos ambientais que a organização possa } \\
\text { controlar e aqueles que ela possa influenciar, } \\
\text { assim como determinar os aspectos com impactos } \\
\text { significativos sobre o meio ambiente }\end{array}$ \\
\hline 4.4 .1 & & $\begin{array}{l}\text { Documentar das funções, responsabilidades e } \\
\text { autoridade pelo SGA, com a indicação dos } \\
\text { representastes específicos para o SGA }\end{array}$ \\
\hline 4.4 .2 & & $\begin{array}{l}\text { Registros associados à competência do pessoal } \\
\text { que realiza tarefas que tenham o potencial de } \\
\text { causar impactos ambientais significativos }\end{array}$ \\
\hline 4.4 .2 & & $\begin{array}{l}\text { Registros associados ao treinamento, ou outra } \\
\text { ação, identificado por ela como necessário por sua } \\
\text { associação aos aspectos ambientais e ao seu SGA }\end{array}$ \\
\hline 4.4 .3 & & $\begin{array}{l}\text { Documentar a decisão da organização de realizar, } \\
\text { ou não, comunicação externa sobre seus aspectos } \\
\text { ambientais significativos }\end{array}$ \\
\hline 4.4 .6 & $\begin{array}{l}\text { Procedimentos p/ contro- } \\
\text { lar as operações associa- } \\
\text { das aos seus aspectos am- } \\
\text { bientais significativos, em } \\
\text { situações onde a ausência } \\
\text { dos procedimentos possa } \\
\text { acarretar desvios em rela- } \\
\text { ção à SST, determinando } \\
\text { os critérios operacionais }\end{array}$ & \\
\hline 4.5 .1 & & $\begin{array}{l}\text { Documentar informações } \mathrm{p} / \text { monitorar o desempe- } \\
\text { nho, os controles operacionais pertinentes e a con- } \\
\text { formidade com os objetivos e metas ambientais }\end{array}$ \\
\hline 4.5 .1 & & $\begin{array}{l}\text { Registros associados à calibração e verificação } \\
\text { dos equipamentos utilizados na monitoração e } \\
\text { medição }\end{array}$ \\
\hline 4.5.2.1 & & $\begin{array}{l}\text { Registros de resultados avaliações periódicas do } \\
\text { atendimento aos requisitos legais aplicáveis }\end{array}$ \\
\hline 4.5.2.2 & & $\begin{array}{l}\text { Registros de resultados avaliações periódicas do } \\
\text { atendimento a outros requisitos por ela subscritos }\end{array}$ \\
\hline 4.5 .3 & & $\begin{array}{l}\text { Registros dos resultados das ações corretivas e } \\
\text { preventivas executadas }\end{array}$ \\
\hline 4.5 .5 & & $\begin{array}{l}\text { Registros associados ao planejamento e condução } \\
\text { de auditorias e relatar os resultados das mesmas }\end{array}$ \\
\hline 4.6 & & $\begin{array}{l}\text { Registros das análises crítica do SGA pela alta } \\
\text { administração }\end{array}$ \\
\hline
\end{tabular}


APÊNDICE C - Procedimentos e Programas Requeridos pela ISO 14001:2004, que podem ser Documentados ou Não.

\begin{tabular}{|l|l|}
\hline \multicolumn{1}{|c|}{ Item } & \multicolumn{1}{c|}{ PROCEDIMENTO } \\
\hline 4.3 .1 & $\begin{array}{l}\text { Identificação dos aspectos ambientais e determinação dos que possam ter } \\
\text { impactos ambientais significativos }\end{array}$ \\
\hline 4.3 .2 & $\begin{array}{l}\text { Identificar e ter acesso a requisitos legais e a outros subscritos e determinar } \\
\text { como se aplicam aos seus aspectos ambientais }\end{array}$ \\
\hline 4.4 .2 & $\begin{array}{l}\text { Conscientização do pessoal que trabalham para a organização ou em nome } \\
\text { dela em aspectos SGA }\end{array}$ \\
\hline 4.4 .3 & $\begin{array}{l}\text { Comunicação interna e comunicações pertinentes oriundas de partes } \\
\text { interessadas sobre seus aspectos ambientais e SGA }\end{array}$ \\
\hline 4.4 .5 & Controle de documentos \\
\hline $4.4 .6 c$ & $\begin{array}{l}\text { Associados aos aspectos ambientais significativos de produtos e serviços } \\
\text { utilizados pela organização }\end{array}$ \\
\hline 4.4 .7 & $\begin{array}{l}\text { Identificar potenciais situações de emergência e potenciais acidentes com } \\
\text { impacto ao meio ambiente, e como a organização responderá a estes }\end{array}$ \\
\hline 4.5 .1 & $\begin{array}{l}\text { Monitorar e medir regularmente as características principais de suas operações } \\
\text { que possam ter um impacto ambiental significativo }\end{array}$ \\
\hline 4.5 .2 .1 & Avaliar periodicamente o atendimento aos requisitos legais aplicáveis \\
\hline 4.5 .2 .2 & Avaliar periodicamente o atendimento a outros requisitos subscritos \\
\hline 4.5 .3 & $\begin{array}{l}\text { Tratar não-conformidades reais e potenciais e executar ações corretivas e } \\
\text { preventivas }\end{array}$ \\
\hline 4.5 .4 & Controle de registros \\
\hline 4.5 .5 & Planejamento, condução e relatar os resultados de auditorias \\
\hline & \multicolumn{2}{|c|}{} \\
\hline
\end{tabular}

\begin{tabular}{|l|l|}
\hline \multicolumn{1}{|c|}{ Item } & \multicolumn{1}{c|}{ PROGRAMA } \\
\hline 4.3 .3 & Atingir os objetivos e metas da organização \\
\hline 4.5 .5 & Auditorias \\
\hline
\end{tabular}


APÊNDICE D - Procedimentos Documentados e Documentos e Registros Requeridos pela OHSAS 18001:2007.

\begin{tabular}{|c|c|c|}
\hline Item & $\begin{array}{l}\text { Procedimento } \\
\text { Documentado }\end{array}$ & Documento ou Registro \\
\hline 4.3 .1 & & $\begin{array}{l}\text { Documentar os resultados da identificação de } \\
\text { perigos, da avaliação de riscos e dos controles } \\
\text { determinados }\end{array}$ \\
\hline 4.4.1 & & $\begin{array}{l}\text { Documentar as funções, responsabilidades, } \\
\text { prestações de contas e autoridades pelo SST e } \\
\text { identificar pessoa com responsabilidades e } \\
\text { autoridades específicas pelo SST }\end{array}$ \\
\hline 4.4 .2 & & $\begin{array}{l}\text { Registros associados à competência do } \\
\text { pessoal que realiza tarefas que possa causar } \\
\text { impacto na SST }\end{array}$ \\
\hline 4.4 .2 & & $\begin{array}{l}\text { Registros associados ao treinamento, ou outra } \\
\text { ação, identificado como necessário por sua } \\
\text { associação aos riscos e seu SST }\end{array}$ \\
\hline 4.4.3.1 & & $\begin{array}{l}\text { Documentar as comunicações pertinentes } \\
\text { oriundas de partes interessadas }\end{array}$ \\
\hline 4.4 .6 & $\begin{array}{l}\text { Procedimentos para cobrir } \\
\text { situações em que sua ausência } \\
\text { possa acarretar desvios em } \\
\text { relação à política e aos } \\
\text { objetivos de SST }\end{array}$ & \\
\hline 4.5 .1 & & $\begin{array}{l}\text { Registros de dados e resultados do } \\
\text { monitoramento e medição suficientes para } \\
\text { subseqüente análise de ações corretivas e } \\
\text { ações preventivas }\end{array}$ \\
\hline 4.5 .1 & & $\begin{array}{l}\text { Registros associados à calibração e } \\
\text { verificação dos equipamentos utilizados na } \\
\text { monitoração e medição }\end{array}$ \\
\hline 4.5.2.1 & & $\begin{array}{l}\text { Registros dos resultados das avaliações } \\
\text { periódicas do atendimento aos requisitos } \\
\text { legais aplicáveis }\end{array}$ \\
\hline 4.5.2.2 & & $\begin{array}{l}\text { Registros dos resultados das avaliações } \\
\text { periódicas do atendimento aos outros } \\
\text { requisitos por ela subscritos }\end{array}$ \\
\hline 4.5.3.1 & & $\begin{array}{l}\text { Registros dos resultados das investigações de } \\
\text { incidentes }\end{array}$ \\
\hline 4.5.3.2 & & $\begin{array}{l}\text { Registros dos resultados das ações corretivas } \\
\text { e ações preventivas }\end{array}$ \\
\hline 4.5 .5 & & $\begin{array}{l}\text { Registros para relatar os resultados das } \\
\text { auditorias }\end{array}$ \\
\hline 4.6 & & $\begin{array}{l}\text { Registros das análises crítica do SGSST pela } \\
\text { direção }\end{array}$ \\
\hline
\end{tabular}


APÊNDICE E - Procedimentos e Programas Requeridos pela OHSAS 18001:2007, que podem ser Documentados ou Não.

\begin{tabular}{|l|l|}
\hline \multicolumn{1}{|c|}{ Item } & \multicolumn{1}{c|}{ PROCEDIMENTO } \\
\hline 4.3 .1 & $\begin{array}{l}\text { A identificação contínua de perigos, a avaliação de riscos e a determinação } \\
\text { dos controles necessários }\end{array}$ \\
\hline 4.3 .2 & $\begin{array}{l}\text { Identificar e ter acesso à legislação a outros requisitos de SST que lhe são } \\
\text { aplicáveis }\end{array}$ \\
\hline 4.4 .2 & $\begin{array}{l}\text { Conscientização das pessoas que trabalhem sob seu controle em todos os } \\
\text { aspectos da SST e treinamento }\end{array}$ \\
\hline 4.4 .3 .1 & $\begin{array}{l}\text { Comunicação interna, com terceirizados e outros visitantes e comunicações } \\
\text { pertinentes oriundas de partes interessadas externas sobre seus perigos e ao } \\
\text { SST }\end{array}$ \\
\hline 4.4 .3 .2 & $\begin{array}{l}\text { Participação dos trabalhadores em assuntos SST e consulta aos } \\
\text { terceirizados quando existirem mudanças que afetem a SST }\end{array}$ \\
\hline 4.4 .5 & Controle de documentos \\
\hline 4.4 .7 & $\begin{array}{l}\text { Identificar o potencial para situações de emergência e para responder a tais } \\
\text { situações }\end{array}$ \\
\hline 4.5 .1 & Monitorar e medir regularmente o desempenho da SST \\
\hline 4.5 .1 & $\begin{array}{l}\text { Calibração e manutenção de equipamentos monitoração e medição de } \\
\text { desempenho }\end{array}$ \\
\hline 4.5 .2 .1 & Avaliar periodicamente o atendimento aos requisitos legais aplicáveis \\
\hline 4.5 .2 .2 & Avaliar periodicamente o atendimento a outros requisitos por ela subscritos \\
\hline 4.5 .3 .1 & Registrar, investigar e analisar incidentes \\
\hline 4.5 .3 .2 & $\begin{array}{l}\text { Tratar as não-conformidades reais e potenciais, e para executar ações } \\
\text { corretivas e ações preventivas }\end{array}$ \\
\hline 4.5 .4 & Controle de registros \\
\hline 4.5 .5 & Auditoria interna. \\
\hline 4.3 .3 & Atingir os objetivos da organização \\
\hline 4.5 .5 & Auditorias \\
\hline
\end{tabular}




\section{APÊNDICE F - Projetos de Norma da IAEA sobre Sistema de Gestão.}

Além das normas (IAEA GS-R-3, IAEA GS-G-3.1) e projeto de norma (IAEA DS349) apresentados no texto da pesquisa, o sítio na Internet da IAEA (2008c) inclui outros normas e projetos de normas sobre sistema de gestão (SG), cujo objetivo e escopo e a seguir expostos.

Norma IAEA GS-G-3.2:2008 (IAEA, 2008d)

The Management System for Technical Services in Radiation Safety

(Sistema de Gestão para Serviços Técnicos em Segurança à Radiação).

O objetivo do guia de segurança é fornecer orientação para que, os prestadores de serviços técnicos de segurança radioativa, desenvolvam e implementem os requisitos do SG.

Os serviços cobertos pelo guia podem incluir:

- Consultoria e manutenção, tais como: consultoria em segurança radioativa; cálculo de blindagem; modelagem para avaliação de dose, contaminação e ventilação; serviços de manutenção cobrindo operações internas tanto quanto a contratação de serviços de organizações externas.

- Calibração e testes, tais como: serviços de monitoração incluindo, indivíduo, local de trabalho e meio ambiente; serviços de calibração e verificação de calibração para monitoração de instrumentos e fontes de radiação

Estão fora do escopo do guia assuntos sobre sistemas de gestão para transporte gestão de rejeitos, educação e treinamento, além de serviços de segurança radioativa fornecidos por prestadores de serviços técnicos nessas áreas temáticas.

O guia pode ser usado por organizações que estão diretamente envolvidas, ou que regulam as instalações e atividades descritas acima, assim como por fornecedores de produtos relacionados à segurança nucleares, para os quais se requer que incorporem uma parte ou todos os requisitos da norma GS-R-3 (IAEA, 2006a).

Projeto de Norma IAEA DS326 (IAEA, 2007c) (TS-G-1.3).

Management Systems for the Safe Transport of Radioactive Material

(Sistemas de Gestão para Transporte Seguro de Materiais Radioativos).

O objetivo do guia de segurança é fornecer orientação para a implementação dos requisitos da norma IAEA GS-R-3 (IAEA, 2006a) para estabelecer, implementar, avaliar e continuamente melhorar um SG para o transporte de materiais radioativos, assim como para implementação dos requisitos estabelecidos na norma TS-R-1 ${ }^{51}$, sobre garantia da qualidade e programas de garantia da qualidade dentro do SG para transporte.

O guia de segurança se aplica para SG para todas as atividades relativas a transporte de materiais radioativos, incluindo, entre outras: projeto, fabricação, montagem, inspeção, testes, manutenção, reparo, modificações, uso, aquisição, manuseio, distribuição, estocagem, limpeza e disposição e embalagem de material radiativo.

\footnotetext{
${ }^{51}$ IAEA Safety Standards Series No. TS-R-1 - Regulations for the Safe Transport of Radioactive Material.
} IAEA: Vienna, 2005. 
Norma IAEA GS-G-3.3 (IAEA, 2008e).

The Management System for Processing, Handling and Storage of Radioactive Waste (Sistemas de Gestão para Processamento, Manuseio e Estoque de Rejeitos Radioativos).

O objetivo do guia de segurança é fornecer orientação para o desenvolvimento e implementação de SG para o:

- Pré-tratamento (coleta, segregação, regulagem e descontaminação química). composição).

- Tratamento (redução de volume, atividade de remoção e mudança de

- Condicionamento (imobilização, embalagem e sobre embalagem).

- Estoque de rejeitos radioativos.

O escopo do guia inclui também a aplicação dos sistemas de gestão para os processos e atividades relativas à gestão de rejeitos, tais como: geração de rejeitos; caracterização de rejeitos; controle de descarga; limpeza, estratégias de embalagem; projeto e fabricação de contêineres; manuseio de rejeitos embalados; avaliação de segurança; e autorização regulatória (licenciamento).

O guia inclui ainda é a aplicado ao estabelecimento de sistemas de gestão para o gerenciamento de todos os tipos de rejeitos, inclusive rejeitos operacionais, considerando tanto, atividades do:

- Ciclo de do combustível nuclear, incluindo: mineração, extração e beneficiamento; conversão do urânio; enriquecimento do urânio; fabricação do combustível; operação do reator; reprocessamento do combustível; gerenciamento do combustível irradiado não reprocessado; gerenciamento de rejeito e descomissionamento.

- Ciclo de combustível não nuclear, tais como: mineração, extração e beneficiamento e processamento de mineral e recursos não-urânicos (rejeitos de radionuclídeos contidos naturalmente em fertilizantes, óleos e gás, e outros); atividades hospitalares; atividades em laboratórios; atividades instalações de pesquisa; atividades em indústrias; atividades hospitalares; e descomissionamento ou limpeza de instalações que não executem mais atividades.

O guia pode ser usado por organizações que estão diretamente envolvidas ou que regulam as instalações e atividades descritas acima, assim como por fornecedores de produtos relacionados à segurança nucleares, para os quais se requer que incorporem uma parte ou todos os requisitos da norma GS-R-3 (IAEA, 2006a). Ele também é útil para legisladores, e para os membros do público e outras partes interessadas na indústria nuclear.

Norma IAEA GS-G-3.4 (IAEA, 2008f).

The Management System for the Disposal of Radioactive Waste.

(Sistemas de Gestão para Disposição de Rejeitos Radioativos).

O objetivo do guia de segurança é fornecer recomendações para o desenvolvimento e implementação de SG para todas as fases das instalações e para a disposição de rejeitos radioativos e atividades relacionadas.

O seu escopo inclui o SG para gerenciamento dos diferentes estágios das instalações de disposição de rejeitos, tais como: aprovação do sítio, projeto e construção; operação; fechamento; e período de controle institucional.

O escopo se aplica também o SG para os vários tipos de instalações de disposição, para diferentes categorias de rejeitos radioativos, tais como: extensão da monitoração e supervisão durante o período de controle de atividades institucionais e da 
fase de pós-fechamento; avaliação de segurança e desempenho e desenvolvimento do "Safety Case" para instalações de disposição de rejeitos; e autorização regulatória (Licenciamento)

O guia pode ser usado por organizações que estão diretamente envolvidas ou que regulam as instalações e atividades descritas acima, assim como por fornecedores de produtos relacionados à segurança nucleares, para os quais se requer que incorporem uma parte ou todos os requisitos da norma GS-R-3 (IAEA, 2006a). Ele também é útil para legisladores, e para os membros do público e outras partes interessadas na indústria nuclear. 


\section{APÊNDICE G - Documentos e Registros Requeridos pelas Normas e Projeto de} Norma da IAEA (GS-R-3, GS-G-3.1 e DS349).

\begin{tabular}{|c|c|c|c|c|}
\hline PROCESSO & $\begin{array}{l}\text { IAEA } \\
\text { GS- } \\
\text { R-3 } \\
\end{array}$ & $\begin{array}{l}\text { IAEA } \\
\text { GS- } \\
\text { G-3.1 } \\
\end{array}$ & $\begin{array}{l}\text { IAEA } \\
\text { DS } \\
349 \\
\end{array}$ & Documento ou Registro \\
\hline $\begin{array}{l}\text { Documenta- } \\
\text { ção do SG }\end{array}$ & $\begin{array}{l}2.8- \\
2.10\end{array}$ & & & $\begin{array}{l}\text { Documentação das políticas declaradas da } \\
\text { organização }\end{array}$ \\
\hline $\begin{array}{l}\text { Documenta- } \\
\text { ção do SG }\end{array}$ & $\begin{array}{l}2.8- \\
2.10\end{array}$ & & & Descrição do SG da organização \\
\hline $\begin{array}{l}\text { Documenta- } \\
\text { ção do SG }\end{array}$ & $\begin{array}{l}2.8- \\
2.10\end{array}$ & & & Descrição do SG da organização \\
\hline $\begin{array}{l}\text { Documenta- } \\
\text { ção do SG }\end{array}$ & $\begin{array}{l}2.8- \\
2.10\end{array}$ & & & Descrição da estrutura da organização \\
\hline $\begin{array}{l}\text { Documenta- } \\
\text { ção do SG }\end{array}$ & $\begin{array}{l}2.8- \\
2.10\end{array}$ & & & $\begin{array}{l}\text { Descrição das responsabilidades funcionais, } \\
\text { prestação de contas, níveis de autoridade e } \\
\text { interação dos trabalhos gerenciais, de } \\
\text { execução e avaliação }\end{array}$ \\
\hline $\begin{array}{l}\text { Documenta- } \\
\text { ção do SG }\end{array}$ & $\begin{array}{l}2.8- \\
2.10\end{array}$ & & & $\begin{array}{l}\text { Descrição dos processos e informações } \\
\text { suportes para os trabalhos SG da organização }\end{array}$ \\
\hline $\begin{array}{l}\text { Documenta- } \\
\text { ção do SG }\end{array}$ & & $\begin{array}{l}2.45- \\
2.62\end{array}$ & $\begin{array}{l}2.36- \\
2.38\end{array}$ & $\begin{array}{l}\text { Documentos que descrevem o SG, } \\
\text { estabelecendo todos os controles e medidas } \\
\text { para a organização atingir suas metas }\end{array}$ \\
\hline Planejamento & $\begin{array}{l}3.8- \\
3.11\end{array}$ & & & $\begin{array}{l}\text { Estabelecimento de objetivos e metas (Plano } \\
\text { de negócio) }\end{array}$ \\
\hline $\begin{array}{l}\text { Responsabili- } \\
\text { dade e autori- } \\
\text { dade pelo SG }\end{array}$ & $\begin{array}{l}3.12- \\
3.14\end{array}$ & & & $\begin{array}{l}\text { Indivíduo com responsabilidade e autoridade } \\
\text { específica pelo SG (Norma não menciona } \\
\text { documentar) }\end{array}$ \\
\hline $\begin{array}{l}\text { Acordos de } \\
\text { interfaces }\end{array}$ & & $\begin{array}{l}2.28- \\
2.31\end{array}$ & & $\begin{array}{l}\text { Memorando de entendimento escrito que } \\
\text { formalize acordos de interfaces }\end{array}$ \\
\hline $\begin{array}{l}\text { Implementa- } \\
\text { ção do SG }\end{array}$ & & $\begin{array}{l}2.24- \\
2.27\end{array}$ & & Plano para a completa implementação do SG \\
\hline $\begin{array}{l}\text { Implementa- } \\
\text { ção do SG }\end{array}$ & & $\begin{array}{l}2.24- \\
2.27\end{array}$ & & $\begin{array}{l}\text { Planos para avaliação da efetividade das } \\
\text { instruções de trabalho e suas implementações }\end{array}$ \\
\hline $\begin{array}{l}\text { Cultura de } \\
\text { segurança }\end{array}$ & & & 2.9 & $\begin{array}{l}\text { Planos para objetivos e prioridades de curto e } \\
\text { longo prazo, incluindo cultura de segurança }\end{array}$ \\
\hline $\begin{array}{l}\text { Cultura de } \\
\text { segurança }\end{array}$ & & & 2.10 & $\begin{array}{l}\text { Plano p/ sucessão c/ desenvolvimento futuros } \\
\text { gerentes, incluindo aspectos cultura segurança }\end{array}$ \\
\hline $\begin{array}{l}\text { Cultura de } \\
\text { segurança }\end{array}$ & & & 2.12 & $\begin{array}{l}\text { Registro de horas extras para avaliação das } \\
\text { condições (pressão) de trabalho }\end{array}$ \\
\hline $\begin{array}{l}\text { Cultura de } \\
\text { segurança }\end{array}$ & & & $\begin{array}{l}2.17- \\
2.21\end{array}$ & $\begin{array}{l}\text { Programa específico de mudança de cultura de } \\
\text { segurança }\end{array}$ \\
\hline $\begin{array}{l}\text { Responsabili- } \\
\text { dade e autori- } \\
\text { dade pelo SG }\end{array}$ & & & $\begin{array}{l}3.19- \\
3.20\end{array}$ & $\begin{array}{l}\text { Relatórios periódicos, dos donos dos } \\
\text { processos, sobre o status de seus processos de } \\
\text { SG }\end{array}$ \\
\hline $\begin{array}{l}\text { Recursos } \\
\text { humanos }\end{array}$ & & & 4.11 & $\begin{array}{l}\text { Plano de recurso humano que defina } \\
\text { quantidade e níveis de competência do pessoal }\end{array}$ \\
\hline
\end{tabular}




\begin{tabular}{|c|c|c|c|c|}
\hline PROCESSO & $\begin{array}{c}\text { IAEA } \\
\text { GS- } \\
\text { R-3 } \\
\end{array}$ & $\begin{array}{c}\text { IAEA } \\
\text { GS- } \\
\text { G-3.1 } \\
\end{array}$ & $\begin{array}{c}\text { IAEA } \\
\text { DS } \\
349 \\
\end{array}$ & Documento ou Registro \\
\hline $\begin{array}{l}\text { Recursos } \\
\text { humanos }\end{array}$ & & $\begin{array}{l}4.6- \\
4.25\end{array}$ & & $\begin{array}{l}\text { Planos de treinamento individual para alta } \\
\text { direção }\end{array}$ \\
\hline Infra-estrutura & & $\begin{array}{l}4.26- \\
4.28\end{array}$ & & Planos para infra-estrutura \\
\hline Infra-estrutura & & & $\begin{array}{l}4.12- \\
4.15\end{array}$ & $\begin{array}{l}\text { Plano de preservação, manutenção, destaque } \\
\text { ou substituição do patrimônio }\end{array}$ \\
\hline Infra-estrutura & & & $\begin{array}{l}4.12- \\
4.15\end{array}$ & $\begin{array}{l}\text { Registros de todo material, patrimoniado, } \\
\text { significativo }\end{array}$ \\
\hline $\begin{array}{l}\text { Controle de } \\
\text { documentos }\end{array}$ & $\begin{array}{l}5.12- \\
5.13\end{array}$ & & & Registrar mudanças nos documentos de SG \\
\hline $\begin{array}{l}\text { Controle de } \\
\text { documentos }\end{array}$ & & II.11 & & $\begin{array}{l}\text { Registro de comentários e resoluções de } \\
\text { análise crítica de documentos do SG }\end{array}$ \\
\hline $\begin{array}{l}\text { Controle de } \\
\text { documentos }\end{array}$ & & II. 25 & & $\begin{array}{l}\text { Registro de recebimento e correção de docu- } \\
\text { mentos gerados e controlados externamente }\end{array}$ \\
\hline $\begin{array}{l}\text { Controle de } \\
\text { documentos }\end{array}$ & & II.27 & & $\begin{array}{l}\text { Registro em forma de cópia mestra de } \\
\text { documentos dos SG, cancelados }\end{array}$ \\
\hline $\begin{array}{l}\text { Controle de } \\
\text { produtos }\end{array}$ & $\begin{array}{l}5.14- \\
5.20 \\
\end{array}$ & & & $\begin{array}{l}\text { Registrar a identificação única do produto, } \\
\text { quando requerido rastreabilidade }\end{array}$ \\
\hline $\begin{array}{l}\text { Controle de } \\
\text { produtos }\end{array}$ & & $\begin{array}{l}5.29- \\
5.33\end{array}$ & & $\begin{array}{l}\text { Registrar a mudança nos valores dos } \\
\text { indicadores de desempenho de cada processo }\end{array}$ \\
\hline $\begin{array}{l}\text { Controle de } \\
\text { produtos }\end{array}$ & & & $\begin{array}{l}4.12- \\
4.15\end{array}$ & $\begin{array}{l}\text { Relatório de inspeções e testes, conforme } \\
\text { requerido }\end{array}$ \\
\hline $\begin{array}{l}\text { Controle de } \\
\text { produtos }\end{array}$ & & & $\begin{array}{l}4.12- \\
4.15 \\
\end{array}$ & Documentar e avaliar os resultados de testes \\
\hline $\begin{array}{l}\text { Controle de } \\
\text { produtos }\end{array}$ & & & $\begin{array}{l}4.12- \\
4.15 \\
\end{array}$ & Planos de inspeção e testes \\
\hline $\begin{array}{l}\text { Controle de } \\
\text { equipamentos } \\
\text { de inspeção e } \\
\text { teste }\end{array}$ & & & $\begin{array}{l}5.18- \\
5.19\end{array}$ & $\begin{array}{l}\text { Procedimentos de calibração de equipamentos } \\
\text { de inspeção e teste }\end{array}$ \\
\hline $\begin{array}{l}\text { Segurança } \\
\text { industrial }\end{array}$ & & & $\begin{array}{l}5.52- \\
5.57 \\
\end{array}$ & Programa de segurança industrial \\
\hline $\begin{array}{l}\text { Controle e } \\
\text { supervisão de } \\
\text { contratados }\end{array}$ & & & $\begin{array}{l}5.59- \\
5.63\end{array}$ & $\begin{array}{l}\text { Relatório de análise de segurança de } \\
\text { contratados cujo trabalho tem impacto na } \\
\text { segurança nuclear }\end{array}$ \\
\hline Projeto & & & $\begin{array}{l}5.90- \\
5.91\end{array}$ & $\begin{array}{l}\text { Relatórios de análise de segurança e de } \\
\text { análises de segurança probabilística, } \\
\text { atualizados quando requerido }\end{array}$ \\
\hline Projeto & & & $\begin{array}{l}5.93- \\
5.113 \\
\end{array}$ & $\begin{array}{l}\text { Documento de especificação de requisitos de } \\
\text { teste }\end{array}$ \\
\hline Projeto & & & $\begin{array}{c}5.114- \\
5.119\end{array}$ & $\begin{array}{l}\text { Documentar mudanças permanentes ou } \\
\text { temporárias durante a construção, } \\
\text { comissionamento e operação }\end{array}$ \\
\hline Projeto & & & $\begin{array}{c}5.114- \\
5.119\end{array}$ & $\begin{array}{l}\text { Procedimento para permissão de desvio e } \\
\text { concessões }\end{array}$ \\
\hline
\end{tabular}




\begin{tabular}{|c|c|c|c|c|}
\hline PROCESSO & $\begin{array}{l}\text { IAEA } \\
\text { GS- } \\
\text { R-3 } \\
\end{array}$ & $\begin{array}{c}\text { IAEA } \\
\text { GS- } \\
\text { G-3.1 } \\
\end{array}$ & $\begin{array}{c}\text { IAEA } \\
\text { DS } \\
349 \\
\end{array}$ & Documento ou Registro \\
\hline $\begin{array}{l}\text { Controle de } \\
\text { configuração }\end{array}$ & & & $\begin{array}{l}5.120- \\
5.127\end{array}$ & Documentação de configuração da instalação \\
\hline $\begin{array}{l}\text { Manuseio e } \\
\text { estoque }\end{array}$ & & & $\begin{array}{c}5.131- \\
5.139 \\
\end{array}$ & $\begin{array}{l}\text { Documentar a remoção e entrada de itens } \\
\text { estocados }\end{array}$ \\
\hline $\begin{array}{l}\text { Gestão do } \\
\text { inventário }\end{array}$ & & & $\begin{array}{c}5.140- \\
5.141\end{array}$ & $\begin{array}{l}\text { Registro de inventário do material estocado } \\
\text { (alinhado ao processo de aquisição) }\end{array}$ \\
\hline $\begin{array}{l}\text { Gestão de } \\
\text { rejeitos }\end{array}$ & & & $\begin{array}{l}5.144- \\
5.149\end{array}$ & Registros de controle de rejeitos radioativos \\
\hline $\begin{array}{l}\text { Auto- } \\
\text { avaliação }\end{array}$ & & $\begin{array}{l}6.6- \\
6.11\end{array}$ & & $\begin{array}{l}\text { Registrar resultados e decisões das auto- } \\
\text { avaliações realizadas pela alta direção }\end{array}$ \\
\hline $\begin{array}{l}\text { Auto- } \\
\text { avaliação }\end{array}$ & & & $\begin{array}{l}6.4- \\
6.20\end{array}$ & $\begin{array}{l}\text { Documentar razões de não ser necessário } \\
\text { ações assuntos identificados na auto-avaliação }\end{array}$ \\
\hline $\begin{array}{l}\text { Auto- } \\
\text { avaliação }\end{array}$ & & & $\begin{array}{l}6.4- \\
6.20 \\
\end{array}$ & Planejar auto-avaliações \\
\hline $\begin{array}{l}\text { Avaliação } \\
\text { independente }\end{array}$ & $\begin{array}{c}6.3- \\
6.6 \\
\end{array}$ & & & $\begin{array}{l}\text { Registrar decisões e razões ações alta direção } \\
\text { resultados avaliações independentes }\end{array}$ \\
\hline $\begin{array}{l}\text { Avaliação } \\
\text { independente }\end{array}$ & & $\begin{array}{l}6.22- \\
6.30\end{array}$ & & Planos de avaliações independentes \\
\hline $\begin{array}{l}\text { Avaliação } \\
\text { independente }\end{array}$ & & & $\begin{array}{l}6.22- \\
6.25\end{array}$ & $\begin{array}{l}\text { Relatórios escritos e problemas e boas práti- } \\
\text { cas observadas na avaliação independente } \\
\text { pelos colegas }\end{array}$ \\
\hline $\begin{array}{l}\text { Avaliação } \\
\text { independente }\end{array}$ & & & $\begin{array}{l}6.22- \\
6.25 \\
\end{array}$ & $\begin{array}{l}\text { Plano de ação para melhoria decorrente da } \\
\text { avaliação independente pelos colegas }\end{array}$ \\
\hline $\begin{array}{l}\text { Avaliação } \\
\text { independente }\end{array}$ & & $\begin{array}{c}6.31- \\
6.44 \\
\end{array}$ & & Relatórios de avaliação independente \\
\hline $\begin{array}{l}\text { Avaliação } \\
\text { independente }\end{array}$ & & IV.12 & & $\begin{array}{l}\text { Relatório de resultados da avaliação } \\
\text { independente }\end{array}$ \\
\hline $\begin{array}{l}\text { Controle de } \\
\text { Não } \\
\text { Conformidade }\end{array}$ & $\begin{array}{l}6.11- \\
6.16\end{array}$ & & & $\begin{array}{l}\text { Registrar não-conformidades de produtos e } \\
\text { processos }\end{array}$ \\
\hline $\begin{array}{l}\text { Controle de } \\
\text { Não } \\
\text { Conformidade }\end{array}$ & & $\begin{array}{l}6.50- \\
6.58\end{array}$ & & Registrar produtos não-conformes \\
\hline $\begin{array}{l}\text { Controle de } \\
\text { Não } \\
\text { Conformidade }\end{array}$ & & $\begin{array}{l}6.59- \\
5.65\end{array}$ & & Relatório de não-conformidade \\
\hline $\begin{array}{l}\text { Ações } \\
\text { corretivas }\end{array}$ & $\begin{array}{l}6.11- \\
6.16\end{array}$ & $\begin{array}{l}6.66- \\
6.75\end{array}$ & & $\begin{array}{l}\text { Documentar não-conformidade e ações } \\
\text { tomadas para corrigi-la }\end{array}$ \\
\hline $\begin{array}{l}\text { Ações } \\
\text { preventivas }\end{array}$ & & & $\begin{array}{l}6.47- \\
6.49\end{array}$ & $\begin{array}{l}\text { Documentar todas as propostas de ações } \\
\text { preventivas }\end{array}$ \\
\hline $\begin{array}{l}\text { Melhoria do } \\
\text { SG }\end{array}$ & $\begin{array}{l}6.17- \\
6.18\end{array}$ & & & $\begin{array}{l}\text { Registrar ações para melhoria dos processos } \\
\text { SG }\end{array}$ \\
\hline $\begin{array}{l}\text { Melhoria do } \\
\text { SG }\end{array}$ & & & & $\begin{array}{l}\text { Planos de melhoramento, incluindo provisões } \\
\text { de recurso }\end{array}$ \\
\hline
\end{tabular}


APÊNDICE H - Correlação das Normas de SG da IAEA (GS-R-3, GS-G-3.1 e DS349) e a ISO 9001.

\begin{tabular}{|c|c|c|c|c|c|c|c|c|c|c|c|c|}
\hline \multicolumn{13}{|c|}{ Grau de correlação: Elementos das normas de SG da IAEA, descritos na linha: } \\
\hline $\mathrm{SC}$ & \multicolumn{12}{|c|}{ Satisfazem completamente um dado elemento de outra norma. } \\
\hline $\mathrm{SP}$ & \multicolumn{12}{|c|}{ Satisfazem um dado elemento de outra norma, quando tratado em conjunto com outros elementos das normas de SG da IAEA, indicados nas outras linhas. } \\
\hline $\mathrm{NCp}$ & \multicolumn{12}{|c|}{ Necessitam complemento (Cp) para satisfazer um dado elemento de outra norma, que não são obtidos em outros elementos das normas de SG da IAEA. } \\
\hline $\mathrm{Cp}$ & \multicolumn{12}{|c|}{ Complemento a ser incorporado aos elementos das normas de SG da IAEA, para satisfazer um dado elemento de outra norma. } \\
\hline Ad & \multicolumn{12}{|c|}{ Adicionam detalhes ou orientações a um dado elemento de outra norma. } \\
\hline NR & \multicolumn{12}{|c|}{ Não possui correlação com dado elemento de outra norma. } \\
\hline $\mathrm{JC}$ & \multicolumn{12}{|c|}{ Já foram considerados para o dado elemento de outra norma. } \\
\hline & \multicolumn{12}{|c|}{ Não possui correlação com elementos da IAEA, mas há correlação entre elementos das ISO 14001 e OHSAS 18001, entre si. } \\
\hline GS-R-3 & GS-G-3.1 & DS 349 & $\begin{array}{c}\text { Sistema de Gestão } \\
\text { IAEA }\end{array}$ & \multicolumn{3}{|c|}{$\begin{array}{l}\text { Sistema de Gestão da Qualidade } \\
\text { ISO } 9001\end{array}$} & \multicolumn{3}{|r|}{$\begin{array}{l}\text { Sistema de Gestão Ambiental } \\
\text { ISO } 14001\end{array}$} & \multicolumn{3}{|c|}{$\begin{array}{l}\text { Sistema de Gestão de Segurança e Saúde no Trabalho } \\
\text { OHSAS } 18001\end{array}$} \\
\hline 2 & 2 & 2 & $\begin{array}{l}\text { SISTEMA DE GESTÃo } \\
\text { (Título) }\end{array}$ & & 4 & \begin{tabular}{|l|} 
SISTEMA DE GESTÃO DA \\
QUALIDADE (Título)
\end{tabular} & & 4 & REQUISITOS DO SGA (Título) & & 4 & REQUISITOS DO SGSST (Título) \\
\hline $\begin{array}{c}2.1 \mathrm{a} \\
2.4\end{array}$ & & & REQUISITOS GERAIS & Ad & 4.1 & Requisitos gerais & $\mathrm{SC}$ & 4.1 & Requisitos gerais & $\mathrm{SC}$ & 4.1 & Requisitos gerais \\
\hline \multirow[t]{3}{*}{$\begin{array}{c}5.1 \mathrm{a} \\
5.5\end{array}$} & 5.1 a 5.9 & 5.1 & $\begin{array}{l}\text { DESENVOLVIMENTO DE } \\
\text { PROCESSOS }\end{array}$ & $\mathrm{SC}$ & 4.1 & Requisitos gerais & $\mathrm{NCp}$ & 4.4 .6 & Controle operacional & $\mathrm{NCp}$ & 4.4.6 & Controle operacional \\
\hline & $\begin{array}{c}5.18 \mathrm{a} \\
5.23\end{array}$ & & $\begin{array}{l}\text { Processos contratados de } \\
\text { outras organizações }\end{array}$ & $\mathrm{Ad}$ & 4.1 & Requisitos gerais & $\mathrm{Ad}$ & 4.5 .1 & Monitoração e medição & $\mathrm{Ad}$ & 4.5 .1 & Monitoramento e medição do desempenho \\
\hline & & & & & 4.2 & $\begin{array}{l}\text { REQUISITOS DE } \\
\text { DOCUMENTAÇÃO (Título) }\end{array}$ & & & & & & \\
\hline $\begin{array}{l}2.8 \mathrm{a} \\
2.10\end{array}$ & & & $\begin{array}{l}\text { DOCUMENTAÇÃO DO } \\
\text { SISTEMA DE GESTÃO }\end{array}$ & $\mathrm{NCp}$ & 4.2.1 & Generalidades & $\mathrm{NCp}$ & 4.4.4 & Documentação & $\mathrm{NCp}$ & 4.4.4 & Documentação \\
\hline $\begin{array}{l}2.8 \mathrm{a} \\
2.10\end{array}$ & & & $\begin{array}{l}\text { DOCUMENTAÇÃO DO } \\
\text { SISTEMA DE GESTÃO }\end{array}$ & $\mathrm{Cp}$ & 4.2 .1 & $\begin{array}{l}\text { Generalidades ( } 6 \text { procedimentos } \\
\text { documentados requeridos pela norma) }\end{array}$ & $\mathrm{Cp}$ & 4.4.4 & $\begin{array}{l}\text { Documentos (Procedimentos controle } \\
\text { situações ambientais) }\end{array}$ & $\mathrm{Cp}$ & 4.4.4 & $\begin{array}{l}\text { Documentos (Procedimentos para cobrir } \\
\text { situações de SST) }\end{array}$ \\
\hline $\begin{array}{l}2.8 \mathrm{a} \\
2.10\end{array}$ & & & $\begin{array}{l}\text { DOCUMENTAÇÃO DO } \\
\text { SISTEMA DE GESTÃO }\end{array}$ & $\mathrm{Cp}$ & 4.2.1 & $\begin{array}{l}\text { Generalidades (Registros requeridos } \\
\text { pela norma) }\end{array}$ & $\mathrm{Cp}$ & 4.4.4 & $\begin{array}{l}\text { Documentos (Registros requeridos pela } \\
\text { norma) }\end{array}$ & $\mathrm{Cp}$ & 4.4.4 & $\begin{array}{l}\text { Documentos (Registros requeridos pela } \\
\text { norma) }\end{array}$ \\
\hline $\begin{array}{l}3.8 \mathrm{a} \\
3.11\end{array}$ & $\begin{array}{c}3.13 \mathrm{a} \\
3.16\end{array}$ & & PLANEJAMENTO & $\mathrm{NCp}$ & 4.2 .1 & Generalidades (Objetivos SGQ) & $\mathrm{NCp}$ & 4.4 .4 & Documentação (Objetivos SGA) & $\mathrm{NCp}$ & 4.4.4 & Documentação (Objetivos SGSST) \\
\hline $\begin{array}{l}2.8 \mathrm{a} \\
2.10\end{array}$ & $\begin{array}{ll}2.45 \mathrm{a} \\
2.62\end{array}$ & $\begin{array}{c}2.36 \mathrm{a} \\
2.38\end{array}$ & $\begin{array}{l}\text { DOCUMENTAÇÃO DO } \\
\text { SISTEMA DE GESTÃOO }\end{array}$ & $\mathrm{Cp}$ & 4.2 .2 & Manual da qualidade & $\mathrm{Ad}$ & 4.4.4 & Documentação & $\mathrm{Ad}$ & 4.4.4 & Documentação \\
\hline $\begin{array}{l}5.12 \mathrm{a} \\
5.13\end{array}$ & $\begin{array}{c}5.24 \mathrm{a} \\
5.28\end{array}$ & & Controle de documentos & $\mathrm{NCp}$ & 4.2 .3 & Controle de documentos & $\mathrm{SC}$ & 4.4.5 & Controle de documentos & $\mathrm{SC}$ & 4.4.5 & Controle de documentos \\
\hline $\begin{array}{l}5.12 \mathrm{a} \\
5.13\end{array}$ & $\begin{array}{c}5.24 \mathrm{a} \\
5.28\end{array}$ & & Controle de documentos & $\mathrm{Cp}$ & 4.2 .3 & $\begin{array}{l}\text { Controle de documento } \\
\text { (Procedimento documentado) }\end{array}$ & $\mathrm{JC}$ & 4.4.5 & Controle de documentos & $\mathrm{JC}$ & 4.4.5 & Controle de documentos \\
\hline $\begin{array}{c}5.21 \mathrm{a} \\
5.22\end{array}$ & $\begin{array}{c}5.35 \mathrm{a} \\
5.49\end{array}$ & & Controle de registros & $\mathrm{NCp}$ & 4.2.4 & Controle de registros & $\mathrm{SC}$ & 4.5 .4 & Controle de registros & $\mathrm{SC}$ & 4.5.4 & Controle de registros \\
\hline $\begin{array}{ll}5.21 \mathrm{a} \\
5.22\end{array}$ & $\begin{array}{l}5.35 \mathrm{a} \\
5.49\end{array}$ & & Controle de registros & $\mathrm{Cp}$ & 4.2.4 & $\begin{array}{l}\text { Controle de registros (Procedimento } \\
\text { documentado) }\end{array}$ & $\mathrm{JC}$ & 4.5 .4 & Controle de registros & $\mathrm{JC}$ & 4.5.4 & Controle de registros \\
\hline
\end{tabular}




\begin{tabular}{|c|c|c|c|c|c|c|c|c|c|c|c|c|}
\hline \multirow{2}{*}{$\frac{\text { GS-R-3 }}{3}$} & \multirow{2}{*}{$\frac{\text { GS-G-3.1 }}{3}$} & \multirow{2}{*}{$\begin{array}{c}\text { DS } 349 \\
3\end{array}$} & \multirow{2}{*}{ 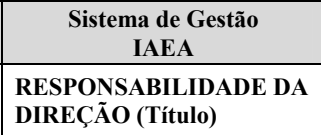 } & \multicolumn{3}{|c|}{$\begin{array}{l}\text { Sistema de Gestão da Qualidade } \\
\text { ISO 9001 } \\
\end{array}$} & \multicolumn{3}{|r|}{$\begin{array}{c}\text { Sistema de Gestão Ambiental } \\
\text { ISO } 14001 \\
\end{array}$} & \multicolumn{3}{|c|}{$\begin{array}{c}\text { Sistema de Gestão de Segurança e Saúde no Trabalho } \\
\text { OHSAS } 18001\end{array}$} \\
\hline & & & & & 5 & $\begin{array}{l}\text { RESPONSABILIDADE DA } \\
\text { DIREÇÃO (Título) }\end{array}$ & & & & & & \\
\hline $\begin{array}{c}3.1 \mathrm{a} \\
3.5 \\
\end{array}$ & 3.1 a 3.7 & & $\begin{array}{l}\text { COMPROMETIMENTO DA } \\
\text { DIREÇÃO }\end{array}$ & $\mathrm{SC}$ & 5.1 & Comprometimento da direção & $\mathrm{JC}$ & 4.4 .1 & $\begin{array}{l}\text { Recursos, funções, responsabilidades e } \\
\text { autoridades }\end{array}$ & $\mathrm{JC}$ & 4.4.1 & $\begin{array}{l}\text { Recursos, funções, responsabilidades, } \\
\text { prestação de contas e autoridades }\end{array}$ \\
\hline 3.6 & 3.8 & & $\begin{array}{l}\text { SATISFAÇÃO DAS } \\
\text { PARTES INTERESSADAS }\end{array}$ & $\mathrm{SC}$ & 5.2 & Foco no cliente & $\mathrm{JC}$ & 4.3 .1 & $\begin{array}{l}\text { Aspectos ambientais e determinação de } \\
\text { impactos ambientais }\end{array}$ & $\mathrm{JC}$ & 4.3 .1 & $\begin{array}{l}\text { Identificação de perigo, avaliação de riscos } \\
\text { e determinação de controles }\end{array}$ \\
\hline \multirow[t]{5}{*}{3.7} & $\begin{array}{c}3.10 \mathrm{a} \\
3.12\end{array}$ & & $\begin{array}{l}\text { POLÍTICAS } \\
\text { ORGANIZACIONAIS } \\
\end{array}$ & SP & 5.3 & Política da qualidade & SP & 4.2 & Política ambiental & SP & 4.2 & Política de SST \\
\hline & & $\begin{array}{c}3.6 \mathrm{a} \\
3.8 \\
\end{array}$ & $\begin{array}{l}\text { Desenvolvimento das } \\
\text { políticas }\end{array}$ & Ad & 5.3 & Política da qualidade & $\mathrm{Ad}$ & 4.2 & Política ambiental & Ad & 4.2 & Política de SST \\
\hline & & $\begin{array}{l}3.9 \mathrm{a} \\
3.14 \\
\end{array}$ & Implementação das políticas & $\mathrm{Ad}$ & 5.3 & Política da qualidade & Ad & 4.2 & Política ambiental & Ad & 4.2 & Política de SST \\
\hline & & 3.16 & Política da qualidade & SP & 5.3 & Política da qualidade & NR & & & NR & & \\
\hline & & & & & 5.4 & PLANEJAMENTO (Título) & & 4.3 & PLANEJAMENTO (Título) & & 4.3 & PLANEJAMENTO (Título) \\
\hline \multirow[t]{2}{*}{$\begin{array}{l}3.8 \mathrm{a} \\
3.11 \\
\end{array}$} & $\begin{array}{c}3.13 \mathrm{a} \\
3.16 \\
\end{array}$ & & PLANEJAMENTO & $\mathrm{SC}$ & 5.4 .1 & Objetivos da qualidade & $\mathrm{SP}$ & 4.3.3 & Objetivos, metas e programas & SP & 4.3.3 & Objetivos e programas \\
\hline & $\begin{array}{c}2.24 \mathrm{a} \\
2.27 \\
\end{array}$ & & Plano de implementação & SP & 5.4 .2 & Planejamento do SGQ & Ad & 4.3 .3 & Objetivos, metas e programas & Ad & 4.3 .3 & Objetivos e programas \\
\hline $\begin{array}{l}3.8 \mathrm{a} \\
3.11\end{array}$ & $\begin{array}{c}3.13 \mathrm{a} \\
3.16\end{array}$ & & PLANEJAMENTO & SP & 5.4 .2 & Planejamento do SGQ & $\mathrm{JC}$ & 4.3.3 & Objetivos, metas e programas & $\mathrm{JC}$ & 4.3 .3 & Objetivos e programas \\
\hline \multirow[t]{2}{*}{$\begin{array}{c}5.28 \mathrm{a} \\
5.29 \\
\end{array}$} & $\begin{array}{c}5.56 \mathrm{a} \\
5.71 \\
\end{array}$ & & $\begin{array}{l}\text { Gestão de alteração } \\
\text { organizacional }\end{array}$ & SP & 5.4 .2 & Planejamento do SGQ & $\mathrm{JC}$ & 4.6 & $\begin{array}{l}\text { Análise pela administração (Neste caso, não } \\
\text { relacionado ISO 9001e OHSAS) }\end{array}$ & $\mathrm{JC}$ & 4.3.1 & $\begin{array}{l}\text { Identificação de perigo, avaliação de riscos } \\
\text { e determinação de controles }\end{array}$ \\
\hline & & & & & 5.5 & $\begin{array}{l}\text { RESPONSABILIDADE, } \\
\text { AUTORIDADE E } \\
\text { COMUNICAÇÃO (Título) }\end{array}$ & & & & & & \\
\hline $\begin{array}{l}2.8 \mathrm{a} \\
2.10\end{array}$ & & & $\begin{array}{l}\text { DOCUMENTAÇÃO DO } \\
\text { SISTEMA DE GESTÃO }\end{array}$ & SP & 5.5 .1 & Responsabilidade e autoridade & $\mathrm{NCp}$ & 4.4.1 & $\begin{array}{l}\text { Recursos, funções, responsabilidades e } \\
\text { autoridades }\end{array}$ & $\mathrm{NCp}$ & 4.4.1 & $\begin{array}{l}\text { Recursos, funções, responsabilidades, } \\
\text { prestação de contas e autoridades }\end{array}$ \\
\hline $\begin{array}{l}3.1 \mathrm{a} \\
3.5\end{array}$ & 3.1 a 3.7 & & $\begin{array}{l}\text { COMPROMETIMENTO DA } \\
\text { DIREÇÃO }\end{array}$ & SP & 5.5 .1 & Responsabilidade e autoridade & $\mathrm{NCp}$ & 4.4.1 & $\begin{array}{l}\text { Recursos, funções, responsabilidades e } \\
\text { autoridades }\end{array}$ & $\mathrm{NCp}$ & 4.4.1 & $\begin{array}{l}\text { Recursos, funções, responsabilidades, } \\
\text { prestação de contas e autoridades }\end{array}$ \\
\hline \multirow[t]{2}{*}{$\begin{array}{l}3.12 \mathrm{a} \\
3.14\end{array}$} & $\begin{array}{c}3.17 \mathrm{a} \\
3.20\end{array}$ & $\begin{array}{c}3.19 \mathrm{a} \\
3.20\end{array}$ & $\begin{array}{l}\text { RESPONSABILIDADE / } \\
\text { AUTORIDADE PELO } \\
\text { SISTEMA DE GESTÃO } \\
\end{array}$ & SP & 5.5 .1 & Responsabilidade e autoridade & $\mathrm{NCp}$ & 4.4.1 & $\begin{array}{l}\text { Recursos, funções, responsabilidades e } \\
\text { autoridades }\end{array}$ & $\mathrm{NCp}$ & 4.4.1 & $\begin{array}{l}\text { Recursos, funções, responsabilidades, } \\
\text { prestação de contas e autoridades }\end{array}$ \\
\hline & 5.14 a 17 & & $\begin{array}{l}\text { Responsabilidades pelos } \\
\text { processos }\end{array}$ & Ad & 5.5 .1 & Responsabilidade e autoridade & $\mathrm{JC}$ & 4.4.1 & $\begin{array}{l}\text { Recursos, funções, responsabilidades e } \\
\text { autoridades }\end{array}$ & $\mathrm{Cp}$ & 4.4.1 & $\begin{array}{l}\text { Assegurar que pessoas nos locais de } \\
\text { trabalho assumam responsabilidades por } \\
\text { aspectos de SST }\end{array}$ \\
\hline 3.13 & 3.18 & 3.19 & $\begin{array}{l}\text { Indivíiduo com responsabili- } \\
\text { dade e autoridade pelo SG }\end{array}$ & $\mathrm{SC}$ & 5.5 .2 & Representante da direção pelo SGQ & $\mathrm{Cp}$ & 4.4.1 & Representantes da direção pelo SGA & $\mathrm{Cp}$ & 4.4.1 & Representantes da direção pelo SGSST \\
\hline $\begin{array}{c}5.26 \mathrm{a} \\
5.27\end{array}$ & $\begin{array}{l}5.52 \mathrm{a} \\
5.55\end{array}$ & & Comunicação & $\mathrm{SC}$ & 5.5 .3 & Comunicação interna & $\mathrm{SC}$ & 4.4.3 & Comunicação & $\mathrm{SC}$ & $\begin{array}{c}4.4 .3 . \\
1\end{array}$ & Comunicação \\
\hline
\end{tabular}




\begin{tabular}{|c|c|c|c|c|c|c|c|c|c|c|c|c|}
\hline \multirow{2}{*}{\begin{tabular}{|c|} 
GS-R-3 \\
$5.26 \mathrm{a}$ \\
5.27 \\
\end{tabular}} & \multirow[t]{2}{*}{ GS-G-3.1 } & \multirow[t]{2}{*}{ DS 349} & \multirow{2}{*}{$\begin{array}{l}\begin{array}{c}\text { Sistema de Gestão } \\
\text { IAEA }\end{array} \\
\text { Comunicação }\end{array}$} & \multicolumn{3}{|c|}{$\begin{array}{l}\text { Sistema de Gestão da Qualidade } \\
\text { ISO } 9001\end{array}$} & \multicolumn{3}{|r|}{$\begin{array}{l}\text { Sistema de Gestão Ambiental } \\
\text { ISO } 14001\end{array}$} & \multicolumn{3}{|c|}{$\begin{array}{l}\text { Sistema de Gestão de Segurança e Saúde no Trabalho } \\
\text { OHSAS } 18001\end{array}$} \\
\hline & & & & $\mathrm{JC}$ & 5.5 .3 & Comunicação interna & $\mathrm{JC}$ & 4.4 .3 & $\begin{array}{l}\text { Comunicação (Neste caso, não relacionado } \\
\text { ISO 9001e OHSAS 18001) }\end{array}$ & $\mathrm{SP}$ & 4.3.2 & Requisitos legais e outros \\
\hline & & & & & 5.6 & $\begin{array}{l}\text { ANÁLISE CRÍTICA PELA } \\
\text { DIREÇÃO (Título) }\end{array}$ & & & & & & \\
\hline $\begin{array}{c}5.28 \mathrm{a} \\
5.29\end{array}$ & $\begin{array}{c}5.56 \mathrm{a} \\
5.71\end{array}$ & & $\begin{array}{l}\text { Gestão de alteração } \\
\text { organizacional }\end{array}$ & $\mathrm{Ad}$ & 5.6 .1 & Generalidades & $\mathrm{JC}$ & 4.6 & $\begin{array}{l}\text { Análise pela administração (Neste caso, não } \\
\text { relacionado ISO 9001e OHSAS 18001) }\end{array}$ & SP & 4.3.1 & $\begin{array}{l}\text { Identificação de perigo, avaliação de riscos } \\
\text { e determinação de controles }\end{array}$ \\
\hline $\begin{array}{l}6.7 \mathrm{a} \\
6.10\end{array}$ & $\begin{array}{c}6.45 \mathrm{a} \\
6.46\end{array}$ & & $\begin{array}{l}\text { ANÁLISE CRÍTICA DO } \\
\text { SISTEMA DE GESTÃO }\end{array}$ & $\mathrm{SC}$ & 5.6 .1 & Generalidades & $\mathrm{SC}$ & 4.6 & Análise pela administração & $\mathrm{SC}$ & 4.6 & Análise crítica pela direção \\
\hline $\begin{array}{c}5.28 \mathrm{a} \\
5.29\end{array}$ & $\begin{array}{c}5.56 \mathrm{a} \\
5.71\end{array}$ & & $\begin{array}{l}\text { Gestão de alteração } \\
\text { organizacional }\end{array}$ & $\mathrm{Ad}$ & 5.6 .2 & Entradas para a análise crítica & $\mathrm{Ad}$ & 4.6 & Análise pela administração & Ad & 4.6 & Análise crítica pela direção \\
\hline \multirow[t]{3}{*}{$\begin{array}{c}5.28 \mathrm{a} \\
5.29\end{array}$} & $\begin{array}{c}5.56 \mathrm{a} \\
5.71\end{array}$ & & $\begin{array}{l}\text { Gestão de alteração } \\
\text { organizacional }\end{array}$ & $\mathrm{JC}$ & 5.6 .2 & Entradas para a análise crítica & $\mathrm{Ad}$ & 4.4 .3 & Comunicação & SP & $\begin{array}{c}4.4 .3 . \\
2\end{array}$ & Participação e consulta \\
\hline & 6.47 & & Entradas da análise crítica & $\mathrm{SC}$ & 5.6 .2 & Entradas para a análise crítica & $\mathrm{Ad}$ & 4.6 & Análise pela administração & $\mathrm{Ad}$ & 4.6 & Análise crítica pela direção \\
\hline & $\begin{array}{c}6.48 \mathrm{a} \\
6.49\end{array}$ & & Saídas da análise crítica & $\mathrm{SC}$ & 5.6 .3 & Saídas da análise crítica & $\mathrm{Ad}$ & 4.6 & Análise pela administração & $\mathrm{Ad}$ & 4.6 & Análise crítica pela direção \\
\hline 4 & 4 & 4 & $\begin{array}{l}\text { GESTÃo DE RECURSOS } \\
\text { (Título) }\end{array}$ & & 6 & GESTÃo DE RECURSOS (Título) & & & & & & \\
\hline \multirow[t]{2}{*}{$\begin{array}{ll}4.1 \mathrm{a} \\
4.2\end{array}$} & 4.1 a 4.2 & & PROVISÃO DE RECURSOS & $\mathrm{SC}$ & 6.1 & Provisão de recursos & $\mathrm{NCp}$ & 4.4.1 & $\begin{array}{l}\text { Recursos, funções, responsabilidades e } \\
\text { autoridades }\end{array}$ & $\mathrm{NCp}$ & 4.4 .1 & $\begin{array}{l}\text { Recursos, funções, responsabilidades, } \\
\text { prestação de contas e autoridades }\end{array}$ \\
\hline & & & & & 6.2 & RECURSOS HUMANOS (Título) & & & & & & \\
\hline \multirow[t]{2}{*}{$\begin{array}{c}4.3 \mathrm{a} \\
4.4\end{array}$} & & & RECURSOS HUMANOS & $\mathrm{SC}$ & 6.2 .1 & Generalidades & $\mathrm{JC}$ & 4.4.2 & $\begin{array}{l}\text { Competência, treinamento e } \\
\text { conscientização. }\end{array}$ & $\mathrm{JC}$ & 4.4.2 & $\begin{array}{l}\text { Competência, treinamento e } \\
\text { conscientização. }\end{array}$ \\
\hline & & 4.11 & RECURSOS HUMANOS & Ad & 6.2 .1 & Generalidades & Ad & 4.4.2 & $\begin{array}{l}\text { Competência, treinamento e } \\
\text { conscientização. }\end{array}$ & $\mathrm{Ad}$ & 4.4.2 & $\begin{array}{l}\text { Competência, treinamento e } \\
\text { conscientização. }\end{array}$ \\
\hline $\begin{array}{c}4.3 \mathrm{a} \\
4.4\end{array}$ & 4.6 a 4.25 & & RECURSOS HUMANOS & $\mathrm{SC}$ & 6.2 .2 & $\begin{array}{l}\text { Competência, conscientização e } \\
\text { treinamento }\end{array}$ & $\mathrm{SC}$ & 4.4.2 & $\begin{array}{l}\text { Competência, treinamento e } \\
\text { conscientização. }\end{array}$ & $\mathrm{SC}$ & 4.4 .2 & $\begin{array}{l}\text { Competência, treinamento e } \\
\text { conscientização. }\end{array}$ \\
\hline \multirow[t]{5}{*}{4.5} & $\begin{array}{c}4.26 \mathrm{a} \\
4.28\end{array}$ & & $\begin{array}{l}\text { INFRA-ESTRUTURA E } \\
\text { AMBIENTE DE } \\
\text { TRABALHO }\end{array}$ & $\mathrm{SC}$ & 6.3 & Infra-estrutura & $\mathrm{NCp}$ & 4.4.1 & $\begin{array}{l}\text { Recursos, funções, responsabilidades e } \\
\text { autoridades }\end{array}$ & $\mathrm{NCp}$ & 4.4.1 & $\begin{array}{l}\text { Recursos, funções, responsabilidades, } \\
\text { prestação de contas e autoridades }\end{array}$ \\
\hline & & 5.129 & Manutenção & $\mathrm{Ad}$ & 6.3 & Infra-estrutura & Ad & 4.4.6 & Controle operacional & $\mathrm{Ad}$ & 4.4.6 & Controle operacional \\
\hline & & 5.129 & Manutenção & $\mathrm{JC}$ & 6.3 & Infra-estrutura & $\mathrm{NCp}$ & 4.5 .1 & Monitoração e medição & $\mathrm{NCp}$ & 4.5 .1 & Monitoramento e medição do desempenho \\
\hline & 4.29 & & Ambiente de trabalho & $\mathrm{SC}$ & 6.4 & Ambiente de trabalho & NR & & & NR & & \\
\hline & & 5.130 & Housekeeping e limpeza & $\mathrm{Ad}$ & 6.4 & Ambiente de trabalho & Ad & 4.4.6 & Controle operacional & $\mathrm{Ad}$ & 4.4.6 & Controle operacional \\
\hline
\end{tabular}




\begin{tabular}{|c|c|c|c|c|c|c|c|c|c|c|c|c|}
\hline \multirow[t]{2}{*}{ GS-R-3 } & \multirow[t]{2}{*}{ GS-G-3.1 } & \multirow[t]{2}{*}{ DS 349} & \multirow[t]{2}{*}{$\begin{array}{l}\text { Sistema de Gestão } \\
\text { IAEA }\end{array}$} & \multicolumn{3}{|c|}{$\begin{array}{l}\text { Sistema de Gestão da Qualidade } \\
\text { ISO } 9001\end{array}$} & \multicolumn{3}{|r|}{$\begin{array}{l}\text { Sistema de Gestão Ambiental } \\
\text { ISO } 14001\end{array}$} & \multicolumn{3}{|c|}{$\begin{array}{l}\text { Sistema de Gestão de Segurança e Saúde no Trabalho } \\
\text { OHSAS } 18001\end{array}$} \\
\hline & & & & & 7 & $\begin{array}{l}\text { REALIZAÇÃO DO PRODUTO } \\
\text { (Título) }\end{array}$ & & 4.4 & $\begin{array}{l}\begin{array}{l}\text { IMPLEMENTAÇÃO E OPERAÇÃO } \\
\text { (Título) }\end{array} \\
\end{array}$ & & 4.4 & $\begin{array}{l}\text { IMPLEMENTAÇÃO E OPERAÇÃO } \\
\text { (Título) }\end{array}$ \\
\hline $\begin{array}{c}5.1 \mathrm{a} \\
5.5\end{array}$ & 5.1 a 5.9 & 5.1 & $\begin{array}{l}\text { DESENVOLVIMENTO DE } \\
\text { PROCESSOS }\end{array}$ & SP & 7.1 & $\begin{array}{l}\text { Planejamento da realização do } \\
\text { produto }\end{array}$ & $\mathrm{JC}$ & 4.4.6 & Controle operacional & $\mathrm{JC}$ & 4.4.6 & Controle operacional \\
\hline \multirow[t]{5}{*}{$\begin{array}{l}5.1 \mathrm{a} \\
5.5\end{array}$} & 5.1 a 5.9 & 5.1 & $\begin{array}{l}\text { DESENVOLVIMENTO DE } \\
\text { PROCESSOS }\end{array}$ & $\mathrm{JC}$ & 7.1 & $\begin{array}{l}\text { Planejamento da realização do } \\
\text { produto (Neste caso, não relacionado } \\
\text { ISO } 14001 \text { e OHSAS 18001) }\end{array}$ & $\mathrm{Cp}$ & 4.4.7 & $\begin{array}{l}\text { Preparação e resposta a emergência (Definir } \\
\text { processo) }\end{array}$ & $\mathrm{Cp}$ & 4.4.7 & $\begin{array}{l}\text { Preparação e resposta a emergência } \\
\text { (Definir processo) }\end{array}$ \\
\hline & & $\begin{array}{c}5.24 \mathrm{a} \\
5.41\end{array}$ & $\begin{array}{l}\text { Administração do } \\
\text { empreendimento (Project) }\end{array}$ & SP & 7.1 & $\begin{array}{l}\text { Planejamento da realização do } \\
\text { produto }\end{array}$ & NR & & & NR & & \\
\hline & & $\begin{array}{l}5.42 \mathrm{a} \\
5.43\end{array}$ & $\begin{array}{l}\text { Planejamento e controle do } \\
\text { trabalho }\end{array}$ & SP & 7.1 & $\begin{array}{l}\text { Planejamento da realização do } \\
\text { produto }\end{array}$ & SP & 4.3.1 & $\begin{array}{l}\text { Aspectos ambientais e determinação de } \\
\text { impactos ambientais }\end{array}$ & SP & 4.3.1 & $\begin{array}{l}\text { Identificação de perigo, avaliação de riscos } \\
\text { e determinação de controles }\end{array}$ \\
\hline & & $\begin{array}{c}5.42 \mathrm{a} \\
5.43\end{array}$ & $\begin{array}{l}\text { Planejamento e controle do } \\
\text { trabalho }\end{array}$ & $\mathrm{JC}$ & 7.1 & $\begin{array}{l}\text { Planejamento da realização do } \\
\text { produto }\end{array}$ & SP & 4.3 .3 & Objetivos, metas e programas & SP & 4.3.3 & Objetivos e programas \\
\hline & & & & & 7.2 & $\begin{array}{l}\text { PROCESSOS RELACIONADOS A } \\
\text { CLIENTES (Título) }\end{array}$ & & & & & & \\
\hline $\begin{array}{l}2.1 \mathrm{a} \\
2.4\end{array}$ & & & REQUISITOS GERAIS & $\mathrm{NCp}$ & 7.2.1 & $\begin{array}{l}\text { Determinação de requisitos } \\
\text { relacionados ao produto }\end{array}$ & SP & 4.3.2 & Requisitos legais e outros & SP & 4.3.2 & Requisitos legais e outros \\
\hline \multirow[t]{7}{*}{3.6} & 3.8 & & $\begin{array}{l}\text { SATISFAČ̃̃O DAS } \\
\text { PARTES INTERESSADAS }\end{array}$ & $\mathrm{NCp}$ & 7.2 .1 & $\begin{array}{l}\text { Determinação de requisitos } \\
\text { relacionados ao produto }\end{array}$ & Ad & 4.3.1 & $\begin{array}{l}\text { Aspectos ambientais e determinação de } \\
\text { impactos ambientais }\end{array}$ & $\mathrm{Ad}$ & 4.3.1 & $\begin{array}{l}\text { Identificação de perigo, avaliação de riscos } \\
\text { e determinação de controles }\end{array}$ \\
\hline & 3.9 & & $\begin{array}{l}\text { Atendimento (Compliance) a } \\
\text { requisitos estatutários e } \\
\text { regulatórios }\end{array}$ & $\mathrm{NCp}$ & 7.2.1 & $\begin{array}{l}\text { Determinação de requisitos } \\
\text { relacionados ao produto }\end{array}$ & $\mathrm{Ad}$ & 4.3.2 & Requisitos legais e outros & $\mathrm{Ad}$ & 4.3.2 & Requisitos legais e outros \\
\hline & & $\begin{array}{c}5.24 \mathrm{a} \\
5.41\end{array}$ & $\begin{array}{l}\text { Administração do } \\
\text { empreendimento (Project) }\end{array}$ & $\mathrm{NCp}$ & 7.2 .1 & $\begin{array}{l}\text { Determinação de requisitos } \\
\text { relacionados ao produto }\end{array}$ & NR & & & NR & & \\
\hline & & $\begin{array}{c}5.24 \mathrm{a} \\
5.41\end{array}$ & $\begin{array}{l}\text { Administração do } \\
\text { empreendimento (Project) }\end{array}$ & $\mathrm{Cp}$ & 7.2 .1 & $\begin{array}{l}\text { Requisitos entrega e pós-entrega e } \\
\text { outros não declarados, relacionados } \\
\text { ao produto }\end{array}$ & NR & & & NR & & \\
\hline & $\begin{array}{c}2.22 \mathrm{a} \\
2.23\end{array}$ & & $\begin{array}{l}\text { Implementando o sistema de } \\
\text { gestão }\end{array}$ & $\mathrm{Ad}$ & 7.2 .2 & $\begin{array}{l}\text { Análise crítica dos requisitos } \\
\text { relacionados ao produto }\end{array}$ & SP & 4.3.2 & Requisitos legais e outros & SP & 4.3.2 & Requisitos legais e outros \\
\hline & & $\begin{array}{c}5.24 \mathrm{a} \\
5.41\end{array}$ & $\begin{array}{l}\text { Administração do } \\
\text { empreendimento (Project) }\end{array}$ & $\mathrm{SC}$ & 7.2 .2 & $\begin{array}{l}\text { Análise crítica dos requisitos } \\
\text { relacionados ao produto }\end{array}$ & NR & & & NR & & \\
\hline & & $\begin{array}{c}5.24 \mathrm{a} \\
5.41\end{array}$ & $\begin{array}{l}\text { Administração do } \\
\text { empreendimento (Project) }\end{array}$ & SP & 7.2 .3 & Comunicação com o cliente & NR & & & NR & & \\
\hline \multirow[t]{4}{*}{$\begin{array}{l}5.26 \mathrm{a} \\
5.27\end{array}$} & $\begin{array}{c}5.52 \mathrm{a} \\
5.55\end{array}$ & & Comunicação & SP & 7.2 .3 & Comunicação com o cliente & $\mathrm{JC}$ & 4.4.3 & Comunicação & $\mathrm{JC}$ & 4.4.3 & Comunicação, participação e consulta \\
\hline & & & & & 7.3 & $\begin{array}{l}\text { PROJETO E } \\
\text { DESENVOLVIMENTO (Título) }\end{array}$ & & & & & & \\
\hline & & $\begin{array}{c}5.64 \mathrm{a} \\
5.66\end{array}$ & Projeto & SP & 7.3.1 & $\begin{array}{l}\text { Planejamento do projeto e } \\
\text { desenvolvimento }\end{array}$ & NR & & & NR & & \\
\hline & & 5.67 & $\begin{array}{l}\text { Iniciação, escopo e } \\
\text { planejamento de projeto }\end{array}$ & $\mathrm{Ad}$ & 7.3.1 & $\begin{array}{l}\text { Planejamento do projeto e } \\
\text { desenvolvimento }\end{array}$ & NR & & & NR & & \\
\hline
\end{tabular}




\begin{tabular}{|c|c|c|c|c|c|c|c|c|c|c|c|c|}
\hline \multirow[t]{2}{*}{ GS-R-3 } & \multirow[t]{2}{*}{ GS-G-3.1 } & \multirow{2}{*}{\begin{tabular}{c|} 
DS 349 \\
$5.70 \mathrm{a}$ \\
5.71 \\
\end{tabular}} & \multirow{2}{*}{\begin{tabular}{l}
\multicolumn{1}{c}{$\begin{array}{c}\text { Sistema de Gestão } \\
\text { IAEA }\end{array}$} \\
$\begin{array}{l}\text { Seleção do projetista } \\
\text { principal }\end{array}$
\end{tabular}} & \multicolumn{3}{|c|}{$\begin{array}{l}\text { Sistema de Gestão da Qualidade } \\
\text { ISO } 9001\end{array}$} & \multicolumn{3}{|r|}{$\begin{array}{l}\text { Sistema de Gestão Ambiental } \\
\text { ISO } 14001\end{array}$} & \multicolumn{3}{|c|}{$\begin{array}{c}\text { Sistema de Gestão de Segurança e Saúde no Trabalho } \\
\text { OHSAS } 18001\end{array}$} \\
\hline & & & & Ad & 7.3.1 & $\begin{array}{l}\text { Planejamento do projeto e } \\
\text { desenvolvimento }\end{array}$ & NR & & & $\mathrm{NR}$ & & \\
\hline & & $\begin{array}{c}5.72 \mathrm{a} \\
5.76\end{array}$ & $\begin{array}{l}\text { Controle do trabalho e plane- } \\
\text { jamento das atividades de } \\
\text { projeto }\end{array}$ & SP & 7.3.1 & $\begin{array}{l}\text { Planejamento do projeto e } \\
\text { desenvolvimento }\end{array}$ & NR & & & NR & & \\
\hline & & $\begin{array}{c}5.68 \mathrm{a} \\
5.69\end{array}$ & $\begin{array}{l}\text { Identificação dos requisitos } \\
\text { de projeto }\end{array}$ & Ad & 7.3.2 & $\begin{array}{l}\text { Entradas de projeto e } \\
\text { desenvolvimento }\end{array}$ & $\mathrm{Ad}$ & 4.3.2 & Requisitos legais e outros & Ad & 4.3.2 & Requisitos legais e outros \\
\hline & & $\begin{array}{c}5.77 \mathrm{a} \\
5.80\end{array}$ & $\begin{array}{l}\text { Identificação e controle das } \\
\text { entradas de projeto }\end{array}$ & $\mathrm{SC}$ & 7.3.2 & $\begin{array}{l}\text { Entradas de projeto e } \\
\text { desenvolvimento }\end{array}$ & $\mathrm{Ad}$ & 4.3.1 & $\begin{array}{l}\text { Aspectos ambientais e determinação de } \\
\text { impactos ambientais }\end{array}$ & $\mathrm{Ad}$ & 4.3.1 & $\begin{array}{l}\text { Identificação de perigo, avaliação de riscos } \\
\text { e determinação de controles }\end{array}$ \\
\hline & & $\begin{array}{c}5.81 \mathrm{a} \\
5.82\end{array}$ & $\begin{array}{l}\text { Análise crítica dos conceitos } \\
\text { de projeto e seleção da } \\
\text { abordagem apropriada }\end{array}$ & Ad & 7.3.2 & $\begin{array}{l}\text { Entradas de projeto e } \\
\text { desenvolvimento }\end{array}$ & NR & & & NR & & \\
\hline & & $\begin{array}{c}5.85 \mathrm{a} \\
5.86\end{array}$ & $\begin{array}{l}\text { Condução de análise concei- } \\
\text { tual de projeto e segurança }\end{array}$ & Ad & 7.3.2 & $\begin{array}{l}\text { Entradas de projeto e } \\
\text { desenvolvimento }\end{array}$ & $\mathrm{Ad}$ & 4.3.1 & $\begin{array}{l}\text { Aspectos ambientais e determinação de } \\
\text { impactos ambientais }\end{array}$ & $\mathrm{Ad}$ & 4.3.1 & $\begin{array}{l}\text { Identificação de perigo, avaliação de riscos } \\
\text { e determinação de controles }\end{array}$ \\
\hline & & $\begin{array}{c}5.87 \mathrm{a} \\
5.89\end{array}$ & $\begin{array}{l}\text { Condução do detalhamento } \\
\text { do projeto e produção da } \\
\text { documentação de projeto }\end{array}$ & $\mathrm{SC}$ & 7.3.3 & Saídas de projeto e desenvolvimento & $\mathrm{Ad}$ & 4.3.1 & $\begin{array}{l}\text { Aspectos ambientais e determinação de } \\
\text { impactos ambientais }\end{array}$ & $\mathrm{Ad}$ & 4.3.1 & $\begin{array}{l}\text { Identificação de perigo, avaliação de riscos } \\
\text { e determinação de controles }\end{array}$ \\
\hline & & $\begin{array}{c}5.90 \mathrm{a} \\
5.91\end{array}$ & $\begin{array}{l}\text { Condução de análise } \\
\text { detalhada de segurança }\end{array}$ & Ad & 7.3.3 & Saídas de projeto e desenvolvimento & SP & 4.3.1 & $\begin{array}{l}\text { Aspectos ambientais e determinação de } \\
\text { impactos ambientais }\end{array}$ & SP & 4.3.1 & $\begin{array}{l}\text { Identificação de perigo, avaliação de riscos } \\
\text { e determinação de controles }\end{array}$ \\
\hline & & $\begin{array}{c}5.90 \mathrm{a} \\
5.91\end{array}$ & $\begin{array}{l}\text { Condução de análise } \\
\text { detalhada de segurança }\end{array}$ & $\mathrm{JC}$ & 7.3.3 & Saídas de projeto e desenvolvimento & $\mathrm{NCp}$ & 4.4.7 & Preparação e resposta a emergência & $\mathrm{NCp}$ & 4.4.7 & Preparação e resposta a emergência \\
\hline & & $\begin{array}{l}5.93 \mathrm{a} \\
5.113 \\
\end{array}$ & $\begin{array}{l}\text { Realização da verificação e } \\
\text { validação de projeto }\end{array}$ & $\mathrm{SC}$ & 7.3.4 & $\begin{array}{l}\text { Análise crítica de projeto e } \\
\text { desenvolvimento }\end{array}$ & $\mathrm{Ad}$ & 4.3.1 & $\begin{array}{l}\text { Aspectos ambientais e determinação de } \\
\text { impactos ambientais }\end{array}$ & $\mathrm{Ad}$ & 4.3.1 & $\begin{array}{l}\text { Identificacacão de perigo, avaliação de riscos } \\
\text { e determinação de controles }\end{array}$ \\
\hline & & $\begin{array}{l}5.93 \mathrm{a} \\
5.113\end{array}$ & $\begin{array}{l}\text { Realização da verificação e } \\
\text { validação de projeto }\end{array}$ & $\mathrm{SC}$ & 7.3.5 & $\begin{array}{l}\text { Verificação de projeto e } \\
\text { desenvolvimento }\end{array}$ & $\mathrm{JC}$ & 4.3.1 & $\begin{array}{l}\text { Aspectos ambientais e determinação de } \\
\text { impactos ambientais }\end{array}$ & $\mathrm{JC}$ & 4.3.1 & $\begin{array}{l}\text { Identificação de perigo, avaliação de riscos } \\
\text { e determinação de controles }\end{array}$ \\
\hline & & $\begin{array}{l}5.93 \mathrm{a} \\
5.113 \\
\end{array}$ & $\begin{array}{l}\text { Realização da verificação e } \\
\text { validação de projeto }\end{array}$ & $\mathrm{SC}$ & 7.3.6 & $\begin{array}{l}\text { Validação de projeto e } \\
\text { desenvolvimento }\end{array}$ & $\mathrm{JC}$ & 4.3.1 & $\begin{array}{l}\text { Aspectos ambientais e determinação de } \\
\text { impactos ambientais }\end{array}$ & $\mathrm{JC}$ & 4.3.1 & $\begin{array}{l}\text { Identificação de perigo, avaliação de riscos } \\
\text { e determinação de controles }\end{array}$ \\
\hline & & $\begin{array}{l}5.93 \mathrm{a} \\
5.113 \\
\end{array}$ & $\begin{array}{l}\text { Realização da verificação e } \\
\text { validação de projeto }\end{array}$ & $\mathrm{JC}$ & 7.3.6 & $\begin{array}{l}\text { Validação de projeto e } \\
\text { desenvolvimento }\end{array}$ & NR & & & $\mathrm{Ad}$ & $\begin{array}{c}4.4 .3 . \\
2\end{array}$ & Participação e consulta \\
\hline & & $\begin{array}{c}5.114 \mathrm{a} \\
5.119\end{array}$ & $\begin{array}{l}\text { Gestão das linhas de base e } \\
\text { controle de alteração de } \\
\text { projeto }\end{array}$ & $\mathrm{SC}$ & 7.3.7 & $\begin{array}{l}\text { Controle de alterações de projeto e } \\
\text { desenvolvimento }\end{array}$ & NR & & & NR & & \\
\hline & & 5.128 & Modificação da instalação & $\mathrm{Ad}$ & 7.3.7 & $\begin{array}{l}\text { Controle de alterações de projeto e } \\
\text { desenvolvimento }\end{array}$ & $\mathrm{Ad}$ & 4.3.1 & $\begin{array}{l}\text { Aspectos ambientais e determinação de } \\
\text { impactos ambientais }\end{array}$ & $\mathrm{Ad}$ & 4.3.1 & $\begin{array}{l}\text { Identificacac̃o de perigo, avaliação de riscos } \\
\text { e determinação de controles }\end{array}$ \\
\hline & & & & & 7.4 & AQUISIÇÃO (Título) & & & & & & \\
\hline & & $\begin{array}{l}4.1 \mathrm{a} \\
4.5\end{array}$ & $\begin{array}{l}\text { Recursos providos por } \\
\text { fornecedores e parceiros }\end{array}$ & $\mathrm{Ad}$ & 7.4.1 & Processo de aquisição & Ad & 4.4.6 & Controle operacional & $\mathrm{Ad}$ & 4.4.6 & Controle operacional \\
\hline $\begin{array}{l}5.23 \mathrm{a} \\
5.25\end{array}$ & $\begin{array}{c}5.50 \mathrm{a} \\
5.51\end{array}$ & & Aquisição & $\mathrm{SC}$ & 7.4.1 & Processo de aquisição & $\mathrm{Ad}$ & 4.4.6 & Controle operacional & Ad & 4.4.6 & Controle operacional \\
\hline & & $\begin{array}{c}5.20 \mathrm{a} \\
5.22\end{array}$ & $\begin{array}{l}\text { Produtos de categoria } \\
\text { comercial }\end{array}$ & $\mathrm{Ad}$ & 7.4.1 & Processo de aquisição & NR & & & NR & & \\
\hline
\end{tabular}




\begin{tabular}{|c|c|c|c|c|c|c|c|c|c|c|c|c|}
\hline \multirow{2}{*}{$\begin{array}{c}\text { GS-R-3 } \\
5.23 \mathrm{a} \\
5.25\end{array}$} & \multirow{2}{*}{$\begin{array}{c}\text { GS-G-3.1 } \\
5.50 \mathrm{a} \\
5.51 \\
\end{array}$} & \multirow[t]{2}{*}{ DS 349} & \multirow{2}{*}{$\begin{array}{l}\begin{array}{c}\text { Sistema de Gestão } \\
\text { IAEA }\end{array} \\
\text { Aquisição }\end{array}$} & \multicolumn{3}{|c|}{$\begin{array}{l}\text { Sistema de Gestão da Qualidade } \\
\text { ISO } 9001\end{array}$} & \multicolumn{3}{|r|}{$\begin{array}{l}\text { Sistema de Gestão Ambiental } \\
\text { ISO } 14001\end{array}$} & \multicolumn{3}{|c|}{$\begin{array}{l}\text { Sistema de Gestão de Segurança e Saúde no Trabalho } \\
\text { OHSAS } 18001\end{array}$} \\
\hline & & & & $\mathrm{SC}$ & 7.4.2 & Informações de aquisição & $\mathrm{JC}$ & 4.4.6 & Controle operacional & $\mathrm{JC}$ & 4.4.6 & Controle operacional \\
\hline \multirow[t]{3}{*}{$\begin{array}{c}5.23 \mathrm{a} \\
5.25\end{array}$} & $\begin{array}{c}5.50 \mathrm{a} \\
5.51\end{array}$ & & Aquisição & $\mathrm{SC}$ & 7.4.3 & Verificação do produto adquirido & $\mathrm{JC}$ & 4.4.6 & Controle operacional & $\mathrm{JC}$ & 4.4.6 & Controle operacional \\
\hline & & $\begin{array}{c}5.59 \mathrm{a} \\
5.63\end{array}$ & $\begin{array}{l}\text { Controle e supervisão de } \\
\text { contratados }\end{array}$ & $\mathrm{Ad}$ & 7.4.3 & Verificaçã̃o do produto adquirido & Ad & 4.4.6 & Controle operacional & Ad & 4.4.6 & Controle Operacional \\
\hline & & & & & 7.5 & $\begin{array}{l}\text { PRODUÇÃO E FORNECIMENTO } \\
\text { DE SERVIÇO (Título) }\end{array}$ & & & & & & \\
\hline $\begin{array}{l}5.6 \mathrm{a} \\
5.10\end{array}$ & $\begin{array}{l}5.10 \mathrm{a} \\
5.23\end{array}$ & & GESTÃO DE PROCESSO & SP & 7.5.1 & $\begin{array}{l}\text { Controle de produção e fornecimento } \\
\text { de serviço }\end{array}$ & $\mathrm{NCp}$ & 4.4.6 & Controle operacional & $\mathrm{NCp}$ & 4.4.6 & Controle operacional \\
\hline \multirow[t]{2}{*}{$\begin{array}{c}5.14 \mathrm{a} \\
5.20\end{array}$} & $\begin{array}{ll}5.29 \mathrm{a} \\
5.33\end{array}$ & & Controle de produtos & SP & 7.5.1 & $\begin{array}{l}\text { Controle de produção e fornecimento } \\
\text { de serviço }\end{array}$ & $\mathrm{Ad}$ & 4.4.6 & Controle operacional & $\mathrm{Ad}$ & 4.4.6 & Controle operacional \\
\hline & & $\begin{array}{l}5.5 \mathrm{a} \\
5.14\end{array}$ & Inspeção e teste & SP & 7.5.1 & $\begin{array}{l}\text { Controle de produção e fornecimento } \\
\text { de serviço }\end{array}$ & $\mathrm{NCp}$ & 4.5 .1 & Monitoração e medição & $\mathrm{NCp}$ & 4.5 .1 & Monitoramento e medição do desempenho \\
\hline $\begin{array}{c}5.14 \mathrm{a} \\
5.20\end{array}$ & $\begin{array}{l}5.29 \mathrm{a} \\
5.33\end{array}$ & & Controle de produtos & $\mathrm{NCp}$ & 7.5.2 & $\begin{array}{l}\text { Validação dos processos de produção } \\
\text { e fornecimento de serviço }\end{array}$ & $\mathrm{JC}$ & 4.4.6 & Controle operacional & $\mathrm{JC}$ & 4.4.6 & Controle operacional \\
\hline $\begin{array}{c}5.14 \mathrm{a} \\
5.20\end{array}$ & $\begin{array}{l}5.29 \mathrm{a} \\
5.33\end{array}$ & & Controle de produtos & $\mathrm{Cp}$ & 7.5.2 & $\begin{array}{l}\text { Validação de processos onde saída } \\
\text { não possa ser verificada por } \\
\text { monitoração }\end{array}$ & $\mathrm{JC}$ & 4.4.6 & Controle operacional & $\mathrm{JC}$ & 4.4.6 & Controle operacional \\
\hline \multirow[t]{7}{*}{$\begin{array}{c}5.14 \mathrm{a} \\
5.20\end{array}$} & $\begin{array}{c}5.29 \mathrm{a} \\
5.33\end{array}$ & & Controle de produtos & SP & 7.5 .3 & Identificação e rastreabilidade & $\mathrm{JC}$ & 4.4.6 & Controle operacional & $\mathrm{JC}$ & 4.4.6 & Controle operacional \\
\hline & & $\begin{array}{c}5.131 \mathrm{a} \\
5.139\end{array}$ & Manuseio e armazenamento & SP & 7.5.3 & Identificação e rastreabilidade & $\mathrm{Ad}$ & 4.4.6 & Controle operacional & $\mathrm{Ad}$ & 4.4.6 & Controle operacional \\
\hline & & $\begin{array}{l}5.142 \mathrm{a} \\
5.143\end{array}$ & $\begin{array}{l}\text { Identificação e etiquetagem } \\
\text { de sistemas, estruturas e } \\
\text { componentes }\end{array}$ & SP & 7.5.3 & Identificação e rastreabilidade & NR & & & NR & & \\
\hline & & $\begin{array}{l}5.120 \mathrm{a} \\
5.127\end{array}$ & Gestão de configuração & Ad & 7.5.3 & Identificação e rastreabilidade & NR & & & NR & & \\
\hline & & $\begin{array}{l}4.12 \mathrm{a} \\
4.15\end{array}$ & $\begin{array}{l}\text { Gestão de patrimônio } \\
\text { material }\end{array}$ & $\mathrm{Cp}$ & 7.5.4 & Propriedade do cliente & $\mathrm{JC}$ & 4.5 .1 & Monitoração e medição & $\mathrm{JC}$ & 4.5 .1 & Monitoramento e medição do desempenho \\
\hline & & $\begin{array}{l}5.131 \mathrm{a} \\
5.139\end{array}$ & Manuseio e armazenamento & $\mathrm{SC}$ & 7.5.5 & Preservação do produto & $\mathrm{JC}$ & 4.4.6 & Controle operacional & $\mathrm{JC}$ & 4.4.6 & Controle operacional \\
\hline & 5.34 & $\begin{array}{c}5.15 \mathrm{a} \\
5.19\end{array}$ & $\begin{array}{l}\text { Equipamentos de medição e } \\
\text { testes }\end{array}$ & $\mathrm{SC}$ & 7.6 & $\begin{array}{l}\text { Controle de dispositivos de medição e } \\
\text { monitoramento }\end{array}$ & $\mathrm{NCp}$ & 4.5 .1 & Monitoração e medição & $\mathrm{NCp}$ & 4.5 .1 & Monitoramento e medição do desempenho \\
\hline \multirow[t]{3}{*}{6} & 6 & 6 & $\begin{array}{l}\text { MEDIÇÃO, AVALIAĈ̃̃̃O } \\
\text { E MELHORIA (Título) }\end{array}$ & & 8 & $\begin{array}{l}\text { MEDIÇÃO, ANÁLISE E } \\
\text { MELHORIA (Título) }\end{array}$ & & 4.5 & VERIFICAÇÃO (Título) & & 4.5 & VERIFICAÇÃO (Título) \\
\hline & 6.1 a 6.3 & & Aspectos gerais & $\mathrm{SC}$ & 8.1 & Generalidades & NR & & & NR & & \\
\hline & & & & & 8.2 & \begin{tabular}{|l|} 
MEDIÇÃO E \\
MONITORAMENTO (Título)
\end{tabular} & & & & & & \\
\hline
\end{tabular}




\begin{tabular}{|c|c|c|c|c|c|c|c|c|c|c|c|c|}
\hline \multirow[t]{2}{*}{ GS-R-3 } & \multirow[t]{2}{*}{ GS-G-3.1 } & \multirow{2}{*}{$\begin{array}{c}\text { DS } 349 \\
3.1 \mathrm{a} \\
3.5 \\
\end{array}$} & \multirow{2}{*}{\begin{tabular}{l}
\multicolumn{1}{c}{$\begin{array}{c}\text { Sistema de Gestão } \\
\text { IAEA }\end{array}$} \\
SATISFAÇ̃̃O DAS \\
PARTES INTERESSADAS
\end{tabular}} & \multicolumn{3}{|c|}{$\begin{array}{l}\text { Sistema de Gestão da Qualidade } \\
\text { ISO 9001 } \\
\end{array}$} & \multicolumn{3}{|r|}{$\begin{array}{c}\text { Sistema de Gestão Ambiental } \\
\text { ISO } 14001 \\
\end{array}$} & \multicolumn{3}{|c|}{$\begin{array}{c}\text { Sistema de Gestão de Segurança e Saúde no Trabalho } \\
\text { OHSAS 18001 }\end{array}$} \\
\hline & & & & $\mathrm{SC}$ & 8.2 .1 & Satisfação dos clientes & Ad & 4.3 .1 & $\begin{array}{l}\text { Aspectos ambientais e determinação de } \\
\text { impactos ambientais }\end{array}$ & Ad & 4.3 .1 & $\begin{array}{l}\text { Identificação de perigo, avaliação de riscos } \\
\text { e determinação de controles }\end{array}$ \\
\hline \multirow[t]{4}{*}{$\begin{array}{c}6.3 \mathrm{a} \\
6.6\end{array}$} & & & $\begin{array}{l}\text { AVALIAÇÃO } \\
\text { INDEPENDENTE }\end{array}$ & Ad & 8.2 .2 & Auditoria interna & Ad & 4.5.5 & Auditoria interna & Ad & 4.5 .5 & Auditoria interna \\
\hline & $\begin{array}{c}6.23 \mathrm{a} \\
6.25 \\
\end{array}$ & & Auditorias internas & $\mathrm{NCp}$ & 8.2 .2 & Auditoria interna & $\mathrm{SC}$ & 4.5.5 & Auditoria interna & $\mathrm{SC}$ & 4.5 .5 & Auditoria interna \\
\hline & $\begin{array}{c}6.23 \mathrm{a} \\
6.25 \\
\end{array}$ & & Auditorias internas & $\mathrm{Cp}$ & 8.2 .2 & $\begin{array}{l}\text { Auditoria interna (Procedimento } \\
\text { documentado) }\end{array}$ & $\mathrm{JC}$ & 4.5.5 & Auditoria interna & $\mathrm{JC}$ & 4.5 .5 & Auditoria interna \\
\hline & & $\begin{array}{c}4.12 \mathrm{a} \\
4.15\end{array}$ & $\begin{array}{l}\text { Gestão de patrimônio } \\
\text { material }\end{array}$ & SP & 8.2 .3 & $\begin{array}{l}\text { Medição e monitoramento de } \\
\text { processos }\end{array}$ & Ad & 4.5 .1 & Monitoração e medição & Ad & 4.5 .1 & Monitoramento e medição do desempenho \\
\hline \multirow[t]{2}{*}{$\begin{array}{l}5.6 \mathrm{a} \\
5.10 \\
\end{array}$} & $\begin{array}{c}5.10 \mathrm{a} \\
5.12\end{array}$ & & $\begin{array}{l}\text { GESTÃO DE PROCESSO } \\
\text { (Geral) }\end{array}$ & SP & 8.2 .3 & $\begin{array}{l}\text { Medição e monitoramento de } \\
\text { processos }\end{array}$ & Ad & 4.5 .1 & Monitoração e medição & Ad & 4.5.1 & Monitoramento e medição do desempenho \\
\hline & $\begin{array}{ll}5.18 \mathrm{a} \\
5.23\end{array}$ & & $\begin{array}{l}\text { Processos contratados de } \\
\text { outras organizações }\end{array}$ & Ad & 8.2 .3 & $\begin{array}{l}\text { Medição e monitoramento de } \\
\text { processos }\end{array}$ & $\mathrm{JC}$ & 4.5 .1 & Monitoração e medição & $\mathrm{JC}$ & 4.5 .1 & Monitoramento e medição do desempenho \\
\hline 6.1 & 6.4 a 6.5 & & $\begin{array}{l}\text { MONITORAÇÃO E } \\
\text { MEDIÇÃOO }\end{array}$ & SP & 8.2 .3 & $\begin{array}{l}\text { Medição e monitoramento de } \\
\text { processos }\end{array}$ & $\mathrm{NCp}$ & 4.5 .1 & Monitoração e medição & $\mathrm{NCp}$ & 4.5 .1 & Monitoramento e medição do desempenho \\
\hline \multirow[t]{6}{*}{6.1} & 6.4 a 6.5 & & $\begin{array}{l}\text { MONITORAÇÃO E } \\
\text { MEDIÇÃO }\end{array}$ & $\mathrm{JC}$ & 8.2 .3 & $\begin{array}{l}\text { Medição e monitoramento de } \\
\text { processos }\end{array}$ & $\mathrm{Cp}$ & 4.5 .1 & \begin{tabular}{|l|} 
Documentos com informações para \\
monitorar desempenho, controles \\
operacionais e conformidade objetivos
\end{tabular} & $\mathrm{Cp}$ & 4.5 .1 & $\begin{array}{l}\text { Registrar dados e resultados do } \\
\text { monitoramento e medição para análise de } \\
\text { ações corretivas e preventivas }\end{array}$ \\
\hline & & 6.1 & Gestão de inadvertência & Ad & 8.2 .3 & $\begin{array}{l}\text { Medição e monitoramento de } \\
\text { processos }\end{array}$ & Ad & 4.5 .1 & Monitoração e medição & $\mathrm{NCp}$ & 4.5 .1 & Monitoramento e medição do desempenho \\
\hline & 3.9 & & $\begin{array}{l}\text { Atendimento (Compliance) a } \\
\text { requisitos estatutários e } \\
\text { regulatórios }\end{array}$ & Ad & 8.2 .4 & Medição e monitoramento de produto & $\mathrm{NCp}$ & 4.5 .2 & $\begin{array}{l}\text { Avaliação do atendimento a requisitos } \\
\text { legais }\end{array}$ & $\mathrm{NCp}$ & 4.5 .2 & $\begin{array}{l}\text { Avaliação do atendimento a requisitos } \\
\text { legais }\end{array}$ \\
\hline & 3.9 & & $\begin{array}{l}\text { Atendimento (Compliance) a } \\
\text { requisitos estatutários e } \\
\text { regulatórios }\end{array}$ & $\mathrm{JC}$ & 8.2 .4 & $\begin{array}{l}\text { Medição e monitoramento de produto } \\
\text { (Neste caso, não relacionado ISO } \\
14001 \text { e OHSAS 18001) }\end{array}$ & $\mathrm{Cp}$ & 4.5 .2 & $\begin{array}{l}\text { Registros de avaliações periódicas } \\
\text { atendimento requisitos legais e outros }\end{array}$ & $\mathrm{Cp}$ & 4.5 .2 & $\begin{array}{l}\text { Registros de avaliações periódicas } \\
\text { atendimento requisitos legais e outros }\end{array}$ \\
\hline & 3.9 & & $\begin{array}{l}\text { Atendimento (Compliance) a } \\
\text { requisitos estatutários e } \\
\text { regulatórios }\end{array}$ & $\mathrm{JC}$ & 8.2.4 & $\begin{array}{l}\text { Medição e monitoramento de produto } \\
\text { (Neste caso, não relacionado ISO } \\
14001 \text { e OHSAS 18001) }\end{array}$ & $\mathrm{Cp}$ & $\begin{array}{c}4.5 .2 . \\
2\end{array}$ & $\begin{array}{l}\text { Avaliação do atendimento a outros } \\
\text { requisitos (incluir) }\end{array}$ & $\mathrm{Cp}$ & 4.5 .2 & $\begin{array}{l}\text { Avaliação do atendimento a outros } \\
\text { requisitos (incluir) }\end{array}$ \\
\hline & & $\begin{array}{l}5.5 \mathrm{a} \\
5.14\end{array}$ & Inspeção e teste & $\mathrm{SP}$ & 8.2 .4 & Medição e monitoramento de produto & $\mathrm{JC}$ & 4.5 .1 & Monitoração e medição & $\mathrm{JC}$ & 4.5 .1 & Monitoramento e medição do desempenho \\
\hline 6.1 & 6.4 a 6.5 & & $\begin{array}{l}\text { MONITORAÇÃO E } \\
\text { MEDIÇÃO }\end{array}$ & SP & 8.2 .4 & Medição e monitoramento de produto & $\mathrm{JC}$ & 4.5 .1 & Monitoração e medição & $\mathrm{JC}$ & 4.5 .1 & Monitoramento e medição do desempenho \\
\hline $\begin{array}{c}6.11 \mathrm{a} \\
6.16\end{array}$ & $\begin{array}{c}6.50 \mathrm{a} \\
6.58\end{array}$ & & $\begin{array}{l}\text { NÃO-CONFORMIDADES, } \\
\text { AÇÕES CORRETIVAS E } \\
\text { PREVENTIVAS }\end{array}$ & $\mathrm{NCp}$ & 8.3 & Controle de produto não-conforme & $\mathrm{SC}$ & 4.5 .3 & $\begin{array}{l}\text { Não-conformidade, ação corretiva e ação } \\
\text { preventiva }\end{array}$ & $\mathrm{SC}$ & 4.5 .3 & $\begin{array}{l}\text { Investigação de acidente, não- } \\
\text { conformidade, ação corretiva e ação } \\
\text { preventiva }\end{array}$ \\
\hline \multirow[t]{2}{*}{$\begin{array}{c}6.11 \mathrm{a} \\
6.16\end{array}$} & $\begin{array}{c}6.50 \mathrm{a} \\
6.58\end{array}$ & & $\begin{array}{l}\text { NÃO-CONFORMIDADES, } \\
\text { AÇÕES CORRETIVAS E } \\
\text { PREVENTIVAS }\end{array}$ & $\mathrm{JC}$ & 8.3 & Controle de produto não-conforme & Ad & 4.4.7 & Preparação e resposta a emergência & Ad & 4.4.7 & Preparação e resposta a emergência \\
\hline & $\begin{array}{c}6.59 \mathrm{a} \\
6.65\end{array}$ & & $\begin{array}{l}\text { Controle de não- } \\
\text { conformidade }\end{array}$ & Ad & 8.3 & Controle de produto não-conforme & Ad & 4.5 .3 & $\begin{array}{l}\text { Não-conformidade, ação corretiva e ação } \\
\text { preventiva }\end{array}$ & Ad & 4.5 .3 & $\begin{array}{l}\begin{array}{l}\text { Investigação de acidente, não- } \\
\text { conformidade, ação corretiva e ação } \\
\text { preventiva }\end{array} \\
\end{array}$ \\
\hline
\end{tabular}




\begin{tabular}{|c|c|c|c|c|c|c|c|c|c|c|c|c|}
\hline \multirow[t]{2}{*}{ GS-R-3 } & \multirow{2}{*}{\begin{tabular}{|c|} 
GS-G-3.1 \\
$6.59 \mathrm{a}$ \\
6.65 \\
\end{tabular}} & \multirow[t]{2}{*}{ DS 349} & \multirow{2}{*}{\begin{tabular}{l}
\multicolumn{1}{c}{$\begin{array}{c}\text { Sistema de Gestão } \\
\text { IAEA }\end{array}$} \\
$\begin{array}{l}\text { Controle de não- } \\
\text { conformidade }\end{array}$ \\
\end{tabular}} & \multicolumn{3}{|c|}{$\begin{array}{l}\text { Sistema de Gestão da Qualidade } \\
\text { ISO 9001 }\end{array}$} & \multicolumn{3}{|r|}{$\begin{array}{c}\text { Sistema de Gestão Ambiental } \\
\text { ISO } 14001 \\
\end{array}$} & \multicolumn{3}{|c|}{$\begin{array}{c}\text { Sistema de Gestão de Segurança e Saúde no Trabalho } \\
\text { OHSAS 18001 }\end{array}$} \\
\hline & & & & $\mathrm{Cp}$ & 8.3 & $\begin{array}{l}\text { Controle de produto não-conforme } \\
\text { (Procedimento documentado) }\end{array}$ & $\mathrm{JC}$ & 4.5 .3 & $\begin{array}{l}\text { Não-conformidade, ação corretiva e ação } \\
\text { preventiva }\end{array}$ & $\mathrm{JC}$ & 4.5 .3 & $\begin{array}{l}\text { Investigação de acidente, não- } \\
\text { conformidade, ação corretiva e ação } \\
\text { preventiva }\end{array}$ \\
\hline & 4.4 & $\begin{array}{l}4.6 \mathrm{a} \\
4.10\end{array}$ & $\begin{array}{l}\text { Gestão de informação e } \\
\text { conhecimento }\end{array}$ & $\mathrm{SC}$ & 8.4 & Análise de dados & $\mathrm{Ad}$ & 4.4.6 & Controle operacional & $\mathrm{Ad}$ & 4.4.6 & Controle operacional \\
\hline & & & & & 8.5 & MELHORIAS (Título) & & & & & & \\
\hline $\begin{array}{c}6.17 \mathrm{a} \\
6.18\end{array}$ & $\begin{array}{c}6.78 \mathrm{a} \\
6.84\end{array}$ & $\begin{array}{c}6.52 \mathrm{a} \\
6.56\end{array}$ & MELHORIAS & $\mathrm{SC}$ & 8.5 .1 & Melhoria contínua & $\mathrm{Ad}$ & 4.6 & Análise pela administração & Ad & 4.6 & Análise crítica pela direção \\
\hline $\begin{array}{c}6.17 \mathrm{a} \\
6.18\end{array}$ & $\begin{array}{c}6.78 \mathrm{a} \\
6.84\end{array}$ & $\begin{array}{c}6.52 \mathrm{a} \\
6.56\end{array}$ & MELHORIAS & $\mathrm{JC}$ & 8.5 .1 & Melhoria contínua & $\mathrm{JC}$ & 4.6 & Análise pela administração & SP & $\begin{array}{c}4.5 .3 . \\
1\end{array}$ & Investigação de incidente \\
\hline \multirow[t]{3}{*}{$\begin{array}{c}6.11 \mathrm{a} \\
6.16\end{array}$} & $\begin{array}{c}6.50 \mathrm{a} \\
6.58\end{array}$ & & $\begin{array}{l}\text { NÃO-CONFORMIDADES, } \\
\text { AÇÕES CORRETIVAS E } \\
\text { PREVENTIVAS }\end{array}$ & Ad & 8.5 .2 & Ação corretiva & $\mathrm{JC}$ & 4.5 .3 & $\begin{array}{l}\text { Não-conformidade, ação corretiva e ação } \\
\text { preventiva }\end{array}$ & $\mathrm{JC}$ & 4.5 .3 & $\begin{array}{l}\text { Investigação de acidente, não- } \\
\text { conformidade, ação corretiva e ação } \\
\text { preventiva }\end{array}$ \\
\hline & $\begin{array}{c}6.66 \mathrm{a} \\
6.75\end{array}$ & $\begin{array}{l}6.35 \mathrm{a} \\
6.46\end{array}$ & Ações corretivas & $\mathrm{NCp}$ & 8.5 .2 & Ação corretiva & Ad & 4.5 .3 & $\begin{array}{l}\text { Não-conformidade, ação corretiva e ação } \\
\text { preventiva }\end{array}$ & $\mathrm{Ad}$ & 4.5 .3 & $\begin{array}{l}\text { Investigação de acidente, não- } \\
\text { conformidade, ação corretiva e ação } \\
\text { preventiva }\end{array}$ \\
\hline & $\begin{array}{l}6.66 \mathrm{a} \\
6.75\end{array}$ & $\begin{array}{c}6.35 \mathrm{a} \\
6.46\end{array}$ & Ações corretivas & $\mathrm{Cp}$ & 8.5 .2 & $\begin{array}{l}\text { Ação corretiva (Procedimento } \\
\text { documentado) }\end{array}$ & $\mathrm{JC}$ & 4.5 .3 & $\begin{array}{l}\text { Não-conformidade, ação corretiva e ação } \\
\text { preventiva }\end{array}$ & $\mathrm{JC}$ & 4.5 .3 & $\begin{array}{l}\text { Investigação de acidente, não- } \\
\text { conformidade, ação corretiva e ação } \\
\text { preventiva }\end{array}$ \\
\hline \multirow[t]{8}{*}{$\begin{array}{c}6.11 \mathrm{a} \\
6.16\end{array}$} & $\begin{array}{c}6.50 \mathrm{a} \\
6.58\end{array}$ & & $\begin{array}{l}\text { NÃO-CONFORMIDADES, } \\
\text { AÇÕES CORRETIVAS E } \\
\text { PREVENTIVAS } \\
\end{array}$ & Ad & 8.5 .3 & Ação preventiva & $\mathrm{JC}$ & 4.5 .3 & $\begin{array}{l}\text { Não-conformidade, ação corretiva e ação } \\
\text { preventiva }\end{array}$ & $\mathrm{JC}$ & 4.5 .3 & $\begin{array}{l}\text { Investigação de acidente, não- } \\
\text { conformidade, ação corretiva e ação } \\
\text { preventiva }\end{array}$ \\
\hline & $\begin{array}{c}6.76 \mathrm{a} \\
6.77\end{array}$ & $\begin{array}{l}6.47 \mathrm{a} \\
6.49\end{array}$ & Ações preventivas & $\mathrm{NCp}$ & 8.5 .3 & Ação preventiva & Ad & 4.5 .3 & $\begin{array}{l}\text { Não-conformidade, ação corretiva e ação } \\
\text { preventiva }\end{array}$ & $\mathrm{Ad}$ & 4.5 .3 & $\begin{array}{l}\text { Investigação de acidente, não- } \\
\text { conformidade, ação corretiva e ação } \\
\text { preventiva }\end{array}$ \\
\hline & $\begin{array}{c}6.76 \mathrm{a} \\
6.77\end{array}$ & $\begin{array}{l}6.47 \mathrm{a} \\
6.49\end{array}$ & Ações preventivas & $\mathrm{Cp}$ & 8.5 .3 & $\begin{array}{l}\text { Ação preventiva (Procedimento } \\
\text { documentado) }\end{array}$ & JC & 4.5 .3 & $\begin{array}{l}\text { Não-conformidade, ação corretiva e ação } \\
\text { preventiva }\end{array}$ & $\mathrm{JC}$ & 4.5 .3 & $\begin{array}{l}\text { Investigação de acidente, não- } \\
\text { conformidade, ação corretiva e ação } \\
\text { preventiva }\end{array}$ \\
\hline & & $\begin{array}{c}2.1 \mathrm{a} \\
2.3\end{array}$ & REQUISITOS GERAIS & $\mathrm{NR}$ & & & NR & & & NR & & \\
\hline & & $\begin{array}{l}\text { Ap. } \\
\text { VII.1 }\end{array}$ & $\begin{array}{l}\text { Requisitos de SG para o } \\
\text { estagio de operação }\end{array}$ & $\mathrm{NR}$ & & & NR & & & NR & & \\
\hline & 2.1 a 2.6 & & $\begin{array}{l}\text { SISTEMA INTEGRADO DE } \\
\text { GESTÃO }\end{array}$ & NR & & & NR & & & NR & & \\
\hline & 2.7 a 2.31 & & ASPECTOS GERAIS & NR & & & NR & & & NR & & \\
\hline & $\begin{array}{c}2.28 \mathrm{a} \\
2.31\end{array}$ & & Organização das interfaces & NR & & & NR & & & NR & & \\
\hline \multirow[t]{2}{*}{2.5} & $\begin{array}{c}2.32 \mathrm{a} \\
2.36\end{array}$ & $\begin{array}{c}2.4 \mathrm{a} \\
2.8 \\
\end{array}$ & $\begin{array}{l}\text { CULTURA DE } \\
\text { SEGURANÇA }\end{array}$ & NR & & & NR & & & NR & & \\
\hline & & 2.9 & $\begin{array}{l}\text { A segurança ocupacional é } \\
\text { valor claramente reconhecido }\end{array}$ & NR & & & NR & & & NR & & \\
\hline
\end{tabular}




\begin{tabular}{|c|c|c|c|c|c|c|c|c|c|c|c|}
\hline \multirow[t]{2}{*}{ GS-R-3 } & \multirow[t]{2}{*}{ GS-G-3.1 } & \multirow{2}{*}{$\begin{array}{c}\text { DS } 349 \\
2.10\end{array}$} & \multirow{2}{*}{ 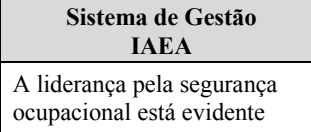 } & \multicolumn{2}{|r|}{$\begin{array}{l}\text { Sistema de Gestão da Qualidade } \\
\text { ISO 9001 }\end{array}$} & \multicolumn{3}{|r|}{$\begin{array}{l}\text { Sistema de Gestão Ambiental } \\
\text { ISO } 14001\end{array}$} & \multicolumn{3}{|c|}{$\begin{array}{l}\text { Sistema de Gestão de Segurança e Saúde no Trabalho } \\
\text { OHSAS } 18001\end{array}$} \\
\hline & & & & NR & & NR & & & NR & & \\
\hline & & 2.11 & $\begin{array}{l}\text { A responsabilidade final pela } \\
\text { segurança ocupacional é } \\
\text { evidente }\end{array}$ & NR & & NR & & & NR & & \\
\hline & & 2.12 & $\begin{array}{l}\text { A segurança ocupacional está } \\
\text { integrada todas as atividades }\end{array}$ & NR & & NR & & & NR & & \\
\hline & & $\begin{array}{l}2.13 \mathrm{a} \\
2.16 \\
\end{array}$ & $\begin{array}{l}\text { A segurança ocupacional é } \\
\text { uma aprendizagem dirigida }\end{array}$ & NR & & NR & & & NR & & \\
\hline & & $\begin{array}{c}2.17 \mathrm{a} \\
2.21\end{array}$ & $\begin{array}{l}\text { Melhorando a cultura de } \\
\text { segurança }\end{array}$ & NR & & NR & & & NR & & \\
\hline & & $\begin{array}{c}2.22 \mathrm{a} \\
2.24\end{array}$ & $\begin{array}{l}\text { Sinais de atenção antecipados } \\
\text { declínio cultura de segurança }\end{array}$ & NR & & NR & & & NR & & \\
\hline & & $\begin{array}{c}2.25 \mathrm{a} \\
2.31\end{array}$ & $\begin{array}{l}\text { Fatores humanos e interação } \\
\text { entre pessoal, tecnologia e a } \\
\text { organização }\end{array}$ & NR & & NR & & & NR & & \\
\hline $\begin{array}{c}2.6 \mathrm{a} \\
2.7\end{array}$ & & $\begin{array}{l}2.32 \mathrm{a} \\
2.35\end{array}$ & $\begin{array}{l}\text { GRADAÇÃO DA APLICA- } \\
\text { ÇÃO DOS REQUISITOS } \\
\text { DO SISTEMA DE GESTÃO }\end{array}$ & NR & & NR & & & NR & & \\
\hline & $\begin{array}{c}2.37 \mathrm{a} \\
2.40\end{array}$ & & Abordagem por gradação & NR & & NR & & & NR & & \\
\hline & $\begin{array}{l}2.41 \mathrm{a} \\
2.44\end{array}$ & & Processo de gradação & NR & & NR & & & NR & & \\
\hline & & $\begin{array}{l}\text { Ap. } \\
\text { VII.2 }\end{array}$ & $\begin{array}{l}\text { Gradação dos requisitos do } \\
\text { SG para estágio de operação }\end{array}$ & NR & & NR & & & NR & & \\
\hline & & 3.15 & $\begin{array}{l}\text { Políticas de segurança, saúde } \\
\text { e ambiental }\end{array}$ & NR & & SP & 4.2 & Política ambiental & SP & 4.2 & Política de SST \\
\hline & & 3.17 & Política de mudança de gestão & NR & & NR & & & NR & & \\
\hline & & 3.18 & Política de proteção física & NR & & NR & & & NR & & \\
\hline & 4.3 & & Envolvimento dos indivíduos & NR & & NR & & & SP & $\begin{array}{l}4.4 .3 . \\
2\end{array}$ & Participação e consulta \\
\hline & 4.5 & & Recursos financeiros & NR & & $\mathrm{NCp}$ & 4.4.1 & $\begin{array}{l}\text { Recursos, funções, responsabilidades e } \\
\text { autoridades }\end{array}$ & $\mathrm{NCp}$ & 4.4 .1 & $\begin{array}{l}\text { Recursos, funções, responsabilidades, } \\
\text { prestação de contas e autoridades }\end{array}$ \\
\hline & & $\begin{array}{l}4.16 \mathrm{a} \\
4.17\end{array}$ & $\begin{array}{l}\text { Substituição de tecnologias } \\
\text { obsoletas }\end{array}$ & NR & & NR & & & NR & & \\
\hline 5 & 5 & 5 & $\begin{array}{l}\text { IMPLEMENTAÇ̃̃O DO } \\
\text { PROCESSO (Título) }\end{array}$ & & & & & & & & \\
\hline & & $\begin{array}{c}5.2 \mathrm{a} \\
5.4\end{array}$ & Modelo de processo & NR & & NR & & & NR & & \\
\hline
\end{tabular}




\begin{tabular}{|c|c|c|c|c|c|c|c|c|c|c|c|}
\hline \multirow{2}{*}{\begin{tabular}{|c|} 
GS-R-3 \\
5.11
\end{tabular}} & \multirow[t]{2}{*}{ GS-G-3.1 } & \multirow[t]{2}{*}{ DS 349} & \multirow{2}{*}{\begin{tabular}{l}
\multicolumn{1}{c}{$\begin{array}{c}\text { Sistema de Gestão } \\
\text { IAEA }\end{array}$} \\
PROCESSOS DE SISTEMA \\
DE GESTÃO GENÉRICOS \\
(Título)
\end{tabular}} & \multicolumn{2}{|r|}{$\begin{array}{c}\text { Sistema de Gestão da Qualidade } \\
\text { ISO 9001 }\end{array}$} & \multicolumn{3}{|r|}{$\begin{array}{l}\text { Sistema de Gestão Ambiental } \\
\text { ISO 14001 }\end{array}$} & \multicolumn{3}{|c|}{$\begin{array}{c}\text { Sistema de Gestão de Segurança e Saúde no Trabalho } \\
\text { OHSAS 18001 }\end{array}$} \\
\hline & & & & & & & & & & & \\
\hline & & $\begin{array}{l}5.23 \mathrm{a} \\
5.161 \\
\end{array}$ & $\begin{array}{l}\text { PROCESSOS COMUNS A } \\
\text { TODOS OS ESTÁGIOS } \\
\text { (Título) }\end{array}$ & & & & & & & & \\
\hline & & $\begin{array}{c}5.44 \mathrm{a} \\
5.51\end{array}$ & $\begin{array}{l}\text { Avaliação do risco do local } \\
\text { de trabalho }\end{array}$ & NR & & NR & 4.3 .1 & $\begin{array}{l}\text { Aspectos ambientais e determinação de } \\
\text { impactos ambientais }\end{array}$ & SP & 4.3.1 & $\begin{array}{l}\text { Identificação de perigo, avaliação de riscos } \\
\text { e determinação de controles }\end{array}$ \\
\hline & & $\begin{array}{c}5.52 \mathrm{a} \\
5.58 \\
\end{array}$ & Segurança do Pessoal (Título) & NR & & & & & & & \\
\hline & & $\begin{array}{l}5.52 \mathrm{a} \\
5.57\end{array}$ & Segurança industrial & NR & & NR & 4.4 .6 & Controle operacional & $\mathrm{NCp}$ & 4.4.6 & Controle Operacional \\
\hline & & $\begin{array}{c}5.52 \mathrm{a} \\
5.57 \\
\end{array}$ & Segurança industrial & NR & & NR & 4.4.6 & Controle operacional & $\mathrm{Cp}$ & 4.4.6 & $\begin{array}{l}\text { Procedimento situacões que possam } \\
\text { acarretar desvios de SST }\end{array}$ \\
\hline & & $\begin{array}{c}5.52 \mathrm{a} \\
5.57\end{array}$ & Segurança industrial & NR & & NR & 4.4 .7 & Preparação e resposta a emergência & $\mathrm{NCp}$ & 4.4.7 & Preparação e resposta a emergência \\
\hline & & 5.58 & Segurança radiológica & NR & & NR & 4.4 .6 & Controle operacional & $\mathrm{NCp}$ & 4.4.6 & Controle Operacional \\
\hline & & 5.58 & Segurança radiológica & NR & & $\mathrm{NCp}$ & 4.4 .7 & Preparação e resposta a emergência & $\mathrm{NCp}$ & 4.4.7 & Preparação e resposta a emergência \\
\hline & & 5.58 & Segurança radiológica & NR & & $\mathrm{NCp}$ & 4.5 .1 & Monitoração e medição & $\mathrm{NCp}$ & 4.5 .1 & Monitoramento e medição do desempenho \\
\hline & & 5.58 & Segurança radiológica & NR & & $\mathrm{Cp}$ & 4.5 .1 & \begin{tabular}{|l} 
Documentos com informações para \\
monitorar desempenho, controles \\
operacionais e conformidade objetivos
\end{tabular} & $\mathrm{Cp}$ & 4.5 .1 & \begin{tabular}{|l|} 
Registrar dados e resultados do \\
monitoramento e medição para análise de \\
ações corretivas e preventivas \\
\end{tabular} \\
\hline & & $\begin{array}{c}5.83 \mathrm{a} \\
5.84\end{array}$ & $\begin{array}{l}\text { Seleção de ferramentas de } \\
\text { projeto e software }\end{array}$ & NR & & NR & & & NR & & \\
\hline & & 5.92 & $\begin{array}{l}\text { Definição do envelope de } \\
\text { operação segura }\end{array}$ & NR & & NR & & & NR & & \\
\hline & & $\begin{array}{l}5.140 \mathrm{a} \\
5.141 \\
\end{array}$ & Gestão do inventário & NR & & NR & & & NR & & \\
\hline & & $\begin{array}{l}5.144 \mathrm{a} \\
5.149 \\
\end{array}$ & Gestão de rejeito & NR & & $\mathrm{NCp}$ & 4.4 .6 & Controle operacional & $\mathrm{NCp}$ & 4.4.6 & Controle operacional \\
\hline & & $\begin{array}{l}5.150 \mathrm{a} \\
5.154 \\
\end{array}$ & Gestão ambiental & NR & & SP & 4.3.1 & $\begin{array}{l}\text { Aspectos ambientais e determinação de } \\
\text { impactos ambientais }\end{array}$ & NR & 4.3.1 & $\begin{array}{l}\text { Identificação de perigo, avaliação de riscos } \\
\text { e determinação de controles }\end{array}$ \\
\hline & & $\begin{array}{l}5.150 \mathrm{a} \\
5.154\end{array}$ & Gestão ambiental & NR & & $\mathrm{NCp}$ & 4.4 .6 & Controle operacional & NR & 4.4.6 & Controle operacional \\
\hline & & $\begin{array}{c}5.150 \mathrm{a} \\
5.154\end{array}$ & Gestão ambiental & NR & & $\mathrm{Cp}$ & 4.4.6 & $\begin{array}{l}\text { Procedimentos para controlar situações } \\
\text { possam acarretar desvios do SGA }\end{array}$ & NR & 4.4.6 & Controle operacional \\
\hline & & $\begin{array}{l}5.150 \mathrm{a} \\
5.154\end{array}$ & Gestão ambiental & NR & & $\mathrm{NCp}$ & 4.4.7 & Preparação e resposta a emergência & NR & 4.4.7 & Preparação e resposta a emergência \\
\hline
\end{tabular}




\begin{tabular}{|c|c|c|c|c|c|c|c|c|c|c|c|}
\hline \multirow[t]{2}{*}{ GS-R-3 } & \multirow[t]{2}{*}{ GS-G-3.1 } & \multirow{2}{*}{$\begin{array}{r}\text { DS } 349 \\
5.155\end{array}$} & \multirow{2}{*}{$\begin{array}{c}\begin{array}{c}\text { Sistema de Gestão } \\
\text { IAEA }\end{array} \\
\text { Interface reguladora }\end{array}$} & \multicolumn{2}{|r|}{$\begin{array}{c}\text { Sistema de Gestão da Qualidade } \\
\text { ISO 9001 }\end{array}$} & \multicolumn{3}{|r|}{$\begin{array}{c}\text { Sistema de Gestão Ambiental } \\
\text { ISO } 14001 \\
\end{array}$} & \multicolumn{3}{|c|}{$\begin{array}{c}\text { Sistema de Gestão de Segurança e Saúde no Trabalho } \\
\text { OHSAS } 18001\end{array}$} \\
\hline & & & & NR & & $\mathrm{Ad}$ & 4.4 .3 & Comunicação & $\mathrm{Ad}$ & $\begin{array}{l}4.4 .3 . \\
2\end{array}$ & Participação e consulta \\
\hline & & $\begin{array}{c}5.156 \mathrm{a} \\
5.159\end{array}$ & Tecnologia da informação & NR & & NR & & & NR & & \\
\hline & & 5.160 & Proteção contra incêndio & NR & & $\mathrm{NCp}$ & 4.4 .7 & Preparação e resposta a emergência & $\mathrm{NCp}$ & 4.4.7 & Preparação e resposta a emergência \\
\hline & & 5.161 & Proteção física (Security) & NR & & $\mathrm{Ad}$ & 4.4.6 & Controle operacional & $\mathrm{Ad}$ & 4.4.6 & Controle operacional \\
\hline & & 5.161 & Proteção física (Security) & NR & & $\mathrm{Ad}$ & 4.4.7 & Preparação e resposta a emergência & $\mathrm{Ad}$ & 4.4.7 & Preparação e resposta a emergência \\
\hline 6.2 & & & AUTO-AVALIAÇÃO & NR & & NR & & & NR & & \\
\hline & 6.6 a 6.11 & $\begin{array}{c}6.2 \mathrm{a} \\
6.3\end{array}$ & $\begin{array}{l}\text { Auto-avaliação pela alta } \\
\text { direção }\end{array}$ & NR & & NR & & & NR & & \\
\hline & $\begin{array}{c}6.12 \mathrm{a} \\
6.21\end{array}$ & $\begin{array}{l}6.4 \mathrm{a} \\
6.20\end{array}$ & $\begin{array}{l}\text { Auto-avaliação pelos gerentes } \\
\text { e indivíduos }\end{array}$ & NR & & NR & & & NR & & \\
\hline & 6.22 & 6.21 & $\begin{array}{l}\text { Tipos de avaliação } \\
\text { independente }\end{array}$ & NR & & NR & & & NR & & \\
\hline & & $\begin{array}{c}6.22 \mathrm{a} \\
6.25\end{array}$ & Avaliação pelos pares & NR & & NR & & & NR & & \\
\hline & & $\begin{array}{c}6.26 \mathrm{a} \\
6.29\end{array}$ & Revisão técnica & NR & & NR & & & NR & & \\
\hline & $\begin{array}{c}6.26 \mathrm{a} \\
6.30\end{array}$ & & Supervisão & NR & & NR & & & NR & & \\
\hline & $\begin{array}{c}6.31 \mathrm{a} \\
6.44\end{array}$ & & $\begin{array}{l}\text { Responsabilidades da unidade } \\
\text { de avaliação }\end{array}$ & NR & & NR & & & NR & & \\
\hline & & $\begin{array}{c}6.30 \mathrm{a} \\
6.34\end{array}$ & $\begin{array}{l}\text { Avaliação da cultura de } \\
\text { segurança }\end{array}$ & NR & & NR & & & NR & & \\
\hline & & $\begin{array}{c}6.50 \mathrm{a} \\
6.51\end{array}$ & Relato de evento & NR & & $\mathrm{Ad}$ & 4.4 .3 & Comunicação & $\mathrm{Ad}$ & $\begin{array}{c}4.4 .3 . \\
2\end{array}$ & Participação e consulta \\
\hline & & & & & & & & & & 4.4.3 & $\begin{array}{l}\begin{array}{l}\text { Comunicação, participação e consulta } \\
\text { (Título) }\end{array} \\
\end{array}$ \\
\hline
\end{tabular}


APÊNDICE I - Correlação das Normas de SG da IAEA (GS-R-3, GS-G-3.1 e DS349) e as ISO 14001 e OHSAS 18001.

Grau de correlação: Elementos das normas de SG da IAEA, descritos na linha:

SC $\quad$ Satisfazem completamente um dado elemento de outra norma.

SP $\quad$ Satisfazem um dado elemento de outra norma, quando tratado em conjunto com outros elementos das normas de SG da IAEA, indicados nas outras linhas.

NCp Necessitam complemento (Cp) para satisfazer um dado elemento de outra norma, que não são obtidos em outros elementos das normas de SG da IAEA.

$\mathrm{Cp}$ Complemento a ser incorporado aos elementos das normas de SG da IAEA, para satisfazer um dado elemento de outra norma.

$\mathrm{Ad}$ Adicionam detalhes ou orientações a um dado elemento de outra norma.

NR Não possui correlação com dado elemento de outra norma.

JC Já foram considerados para o dado elemento de outra norma.

Não possui correlação com elementos da IAEA, mas há correlação entre elementos das ISO 14001 e OHSAS 18001, entre si.

\begin{tabular}{|c|c|c|c|c|c|c|c|c|c|c|c|c|}
\hline \multirow{2}{*}{$\frac{\text { GS-R-3 }}{2}$} & \multirow{2}{*}{$\begin{array}{c}\text { GS-G-3.1 } \\
2\end{array}$} & \multirow{2}{*}{$\begin{array}{c}\text { DS } 349 \\
2\end{array}$} & \multirow{2}{*}{\begin{tabular}{l}
\multicolumn{1}{c}{$\begin{array}{c}\text { Sistema de Gestão } \\
\text { IAEA }\end{array}$} \\
$\begin{array}{l}\text { SISTEMA DE GESTÃo } \\
\text { (Título) }\end{array}$
\end{tabular}} & \multicolumn{3}{|r|}{$\begin{array}{l}\text { Sistema de Gestão Ambiental } \\
\text { ISO } 14001\end{array}$} & \multicolumn{3}{|c|}{$\begin{array}{c}\text { Sistema de Gestão de Segurança e Saúde no Trabalho } \\
\text { OHSAS } 18001\end{array}$} & \multicolumn{3}{|c|}{$\begin{array}{l}\text { Sistema de Gestão da Qualidade } \\
\text { ISO } 9001\end{array}$} \\
\hline & & & & & 4 & REQUISITOS DO SGA (Título) & & 4 & REQUISITOS DO SGSST (Título) & & 4 & $\begin{array}{l}\text { SISTEMA DE GESTÃO DA } \\
\text { QUALIDADE (Título) }\end{array}$ \\
\hline $\begin{array}{c}2.1 \mathrm{a} \\
2.4 \\
\end{array}$ & & & REQUISITOS GERAIS & $\mathrm{SC}$ & 4.1 & Requisitos gerais & $\mathrm{SC}$ & 4.1 & Requisitos gerais & $\mathrm{Ad}$ & 4.1 & Requisitos gerais \\
\hline \multirow[t]{5}{*}{3.7} & $\begin{array}{c}3.10 \mathrm{a} \\
3.12\end{array}$ & & $\begin{array}{l}\text { POLÍTICAS } \\
\text { ORGANIZACIONAIS }\end{array}$ & SP & 4.2 & Política ambiental & SP & 4.2 & Política de SST & SP & 5.3 & Política da qualidade \\
\hline & & 3.15 & $\begin{array}{l}\text { Políticas de segurança, saúde } \\
\text { e ambiental }\end{array}$ & SP & 4.2 & Política ambiental & SP & 4.2 & Política de SST & NR & & \\
\hline & & $\begin{array}{l}3.6 \mathrm{a} \\
3.8\end{array}$ & $\begin{array}{l}\text { Desenvolvimento das } \\
\text { políticas }\end{array}$ & Ad & 4.2 & Política ambiental & $\mathrm{Ad}$ & 4.2 & Política de SST & $\mathrm{Ad}$ & 5.3 & Política da qualidade \\
\hline & & $\begin{array}{l}3.9 \mathrm{a} \\
3.14\end{array}$ & Implementação das politicas & $\mathrm{Ad}$ & 4.2 & Política ambiental & $\mathrm{Ad}$ & 4.2 & Política de SST & $\mathrm{Ad}$ & 5.3 & Política da qualidade \\
\hline & & & & & 4.3 & PLANEJAMENTO (Título) & & 4.3 & PLANEJAMENTO (Título) & & 5.4 & PLANEJAMENTO (Título) \\
\hline 3.6 & 3.8 & & $\begin{array}{l}\text { SATISFAÇÃO DAS } \\
\text { PARTES INTERESSADAS }\end{array}$ & Ad & 4.3.1 & $\begin{array}{l}\text { Aspectos ambientais e determinação de } \\
\text { impactos ambientais }\end{array}$ & $\mathrm{Ad}$ & 4.3.1 & $\begin{array}{l}\text { Identificação de perigo, avaliação de riscos } \\
\text { e determinação de controles }\end{array}$ & $\begin{array}{c}\mathrm{NC} \\
\mathrm{p}\end{array}$ & 7.2.1 & $\begin{array}{l}\text { Determinação de requisitos } \\
\text { relacionados ao produto }\end{array}$ \\
\hline \multirow[t]{2}{*}{3.6} & 3.8 & & $\begin{array}{l}\text { SATISFAÇÃO DAS } \\
\text { PARTES INTERESSADAS }\end{array}$ & $\mathrm{JC}$ & 4.3.1 & $\begin{array}{l}\text { Aspectos ambientais e determinação de } \\
\text { impactos ambientais }\end{array}$ & $\mathrm{JC}$ & 4.3.1 & $\begin{array}{l}\text { Identificação de perigo, avaliação de riscos } \\
\text { e determinação de controles }\end{array}$ & $\mathrm{SC}$ & 5.2 & Foco no cliente \\
\hline & & $\begin{array}{c}3.1 \mathrm{a} \\
3.5\end{array}$ & $\begin{array}{l}\text { SATISFACCÃO DAS } \\
\text { PARTES INTERESSADAS }\end{array}$ & Ad & 4.3.1 & $\begin{array}{l}\text { Aspectos ambientais e determinação de } \\
\text { impactos ambientais }\end{array}$ & Ad & 4.3.1 & $\begin{array}{l}\text { Identificação de perigo, avaliação de riscos } \\
\text { e determinação de controles }\end{array}$ & $\mathrm{SC}$ & 8.2 .1 & Satisfação dos clientes \\
\hline $\begin{array}{c}5.28 \mathrm{a} \\
5.29\end{array}$ & $\begin{array}{c}5.56 \mathrm{a} \\
5.71\end{array}$ & & $\begin{array}{l}\text { Gestão de alteração } \\
\text { organizacional }\end{array}$ & $\mathrm{JC}$ & 4.6 & $\begin{array}{l}\text { Análise pela administração (Neste caso, } \\
\text { não relacionado ISO 9001e OHSAS } \\
\text { 18001) }\end{array}$ & SP & 4.3 .1 & $\begin{array}{l}\text { Identificação de perigo, avaliação de riscos } \\
\text { e determinação de controles }\end{array}$ & $\mathrm{Ad}$ & 5.6 .1 & Generalidades \\
\hline \multirow[t]{2}{*}{$\begin{array}{c}5.28 \mathrm{a} \\
5.29\end{array}$} & $\begin{array}{c}5.56 \mathrm{a} \\
5.71\end{array}$ & & $\begin{array}{l}\text { Gestão de alteração } \\
\text { organizacional }\end{array}$ & $\mathrm{JC}$ & 4.6 & $\begin{array}{l}\text { Análise pela administração (Neste caso, } \\
\text { não relacionado ISO 9001e OHSAS } \\
\text { 18001) }\end{array}$ & $\mathrm{JC}$ & 4.3 .1 & $\begin{array}{l}\text { Identificação de perigo, avaliação de riscos } \\
\text { e determinação de controles }\end{array}$ & SP & 5.4 .2 & Planejamento do SGQ \\
\hline & & $\begin{array}{l}5.42 \mathrm{a} \\
5.43\end{array}$ & $\begin{array}{l}\text { Planejamento e controle do } \\
\text { trabalho }\end{array}$ & SP & 4.3.1 & $\begin{array}{l}\text { Aspectos ambientais e determinação de } \\
\text { impactos ambientais }\end{array}$ & SP & 4.3 .1 & $\begin{array}{l}\text { Identificação de perigo, avaliação de riscos } \\
\text { e determinação de controles }\end{array}$ & SP & 7.1 & $\begin{array}{l}\text { Planejamento da realização do } \\
\text { produto }\end{array}$ \\
\hline
\end{tabular}




\begin{tabular}{|c|c|c|c|c|c|c|c|c|c|c|c|c|}
\hline \multirow[t]{2}{*}{ GS-R-3 } & \multirow[t]{2}{*}{ GS-G-3.1 } & \multirow{2}{*}{$\begin{array}{c}\text { DS } 349 \\
5.44 \mathrm{a} \\
5.51 \\
\end{array}$} & \multirow{2}{*}{\begin{tabular}{l}
\multicolumn{1}{c}{$\begin{array}{c}\text { Sistema de Gestão } \\
\text { IAEA }\end{array}$} \\
$\begin{array}{l}\text { Avaliação do risco do local } \\
\text { de trabalho }\end{array}$ \\
\end{tabular}} & \multicolumn{3}{|r|}{$\begin{array}{l}\text { Sistema de Gestão Ambiental } \\
\text { ISO } 14001\end{array}$} & \multicolumn{3}{|c|}{$\begin{array}{l}\text { Sistema de Gestão de Segurança e Saúde no Trabalho } \\
\text { OHSAS } 18001\end{array}$} & \multicolumn{3}{|c|}{$\begin{array}{l}\text { Sistema de Gestão da Qualidade } \\
\text { ISO 9001 }\end{array}$} \\
\hline & & & & NR & 4.3 .1 & $\begin{array}{l}\text { Aspectos ambientais e determinação de } \\
\text { impactos ambientais }\end{array}$ & SP & 4.3 .1 & $\begin{array}{l}\text { Identificação de perigo, avaliação de riscos } \\
\text { e determinação de controles }\end{array}$ & NR & & \\
\hline & & $\begin{array}{c}5.77 \mathrm{a} \\
5.80\end{array}$ & $\begin{array}{l}\text { Identificação e controle das } \\
\text { entradas de projeto }\end{array}$ & Ad & 4.3 .1 & $\begin{array}{l}\text { Aspectos ambientais e determinação de } \\
\text { impactos ambientais }\end{array}$ & $\mathrm{Ad}$ & 4.3 .1 & $\begin{array}{l}\text { Identificação de perigo, avaliação de riscos } \\
\text { e determinação de controles }\end{array}$ & $\mathrm{SC}$ & 7.3.2 & $\begin{array}{l}\text { Entradas de projeto e } \\
\text { desenvolvimento }\end{array}$ \\
\hline & & $\begin{array}{c}5.85 \mathrm{a} \\
5.86 \\
\end{array}$ & $\begin{array}{l}\text { Condução de análise concei- } \\
\text { tual de projeto e seguraņ̧a }\end{array}$ & Ad & 4.3 .1 & $\begin{array}{l}\text { Aspectos ambientais e determinação de } \\
\text { impactos ambientais }\end{array}$ & Ad & 4.3.1 & $\begin{array}{l}\text { Identificação de perigo, avaliação de riscos } \\
\text { e deterrminação de controles }\end{array}$ & Ad & 7.3.2 & $\begin{array}{l}\text { Entradas de projeto e } \\
\text { desenvolvimento }\end{array}$ \\
\hline & & $\begin{array}{c}5.87 \mathrm{a} \\
5.89\end{array}$ & $\begin{array}{l}\text { Condução do detalhamento } \\
\text { do projeto e produção da } \\
\text { documentação de projeto }\end{array}$ & $\mathrm{Ad}$ & 4.3 .1 & $\begin{array}{l}\text { Aspectos ambientais e determinação de } \\
\text { impactos ambientais }\end{array}$ & Ad & 4.3.1 & $\begin{array}{l}\text { Identificação de perigo, avaliação de riscos } \\
\text { e determinação de controles }\end{array}$ & $\mathrm{SC}$ & 7.3.3 & Saídas de projeto e desenvolvimento \\
\hline & & $\begin{array}{c}5.90 \mathrm{a} \\
5.91\end{array}$ & $\begin{array}{l}\text { Condução de análise } \\
\text { detalhada de segurança }\end{array}$ & SP & 4.3 .1 & $\begin{array}{l}\text { Aspectos ambientais e determinação de } \\
\text { impactos ambientais }\end{array}$ & SP & 4.3 .1 & $\begin{array}{l}\text { Identificação de perigo, avaliação de riscos } \\
\text { e determinação de controles }\end{array}$ & $\mathrm{Ad}$ & 7.3.3 & Saídas de projeto e desenvolvimento \\
\hline & & $\begin{array}{l}5.93 \mathrm{a} \\
5.113 \\
\end{array}$ & $\begin{array}{l}\text { Realização da verificação e } \\
\text { validação de projeto }\end{array}$ & Ad & 4.3 .1 & $\begin{array}{l}\text { Aspectos ambientais e determinação de } \\
\text { impactos ambientais }\end{array}$ & $\mathrm{Ad}$ & 4.3.1 & $\begin{array}{l}\text { Identificação de perigo, avaliação de riscos } \\
\text { e determinação de controles }\end{array}$ & $\mathrm{SC}$ & 7.3.4 & $\begin{array}{l}\text { Análise crítica de projeto e } \\
\text { desenvolvimento }\end{array}$ \\
\hline & & $\begin{array}{ll}5.93 \mathrm{a} \\
5.113 \\
\end{array}$ & $\begin{array}{l}\text { Realização da verificação e } \\
\text { validação de projeto }\end{array}$ & $\mathrm{JC}$ & 4.3.1 & $\begin{array}{l}\text { Aspectos ambientais e determinação de } \\
\text { impactos ambientais }\end{array}$ & $\mathrm{JC}$ & 4.3 .1 & $\begin{array}{l}\text { Identificação de perigo, avaliação de riscos } \\
\text { e determinação de controles }\end{array}$ & $\mathrm{SC}$ & 7.3.5 & $\begin{array}{l}\text { Verificação de projeto e } \\
\text { desenvolvimento }\end{array}$ \\
\hline & & $\begin{array}{ll}5.93 \mathrm{a} \\
5.113 \\
\end{array}$ & $\begin{array}{l}\text { Realização da verificação e } \\
\text { validação de projeto }\end{array}$ & $\mathrm{JC}$ & 4.3 .1 & $\begin{array}{l}\text { Aspectos ambientais e determinação de } \\
\text { impactos ambientais }\end{array}$ & $\mathrm{JC}$ & 4.3 .1 & $\begin{array}{l}\text { Identificação de perigo, avaliação de riscos } \\
\text { e determinação de controles }\end{array}$ & $\mathrm{SC}$ & 7.3.6 & \begin{tabular}{|l|} 
Validação de projeto e \\
desenvolvimento
\end{tabular} \\
\hline & & 5.128 & Modificação da instalação & Ad & 4.3.1 & $\begin{array}{l}\text { Aspectos ambientais e determinação de } \\
\text { impactos ambientais }\end{array}$ & Ad & 4.3 .1 & $\begin{array}{l}\text { Identificação de perigo, avaliação de riscos } \\
\text { e determinação de controles }\end{array}$ & $\mathrm{Ad}$ & 7.3.7 & $\begin{array}{l}\text { Controle de alterações de projeto e } \\
\text { desenvolvimento }\end{array}$ \\
\hline & & $\begin{array}{l}5.150 \mathrm{a} \\
5.154 \\
\end{array}$ & Gestão ambiental & SP & 4.3 .1 & $\begin{array}{l}\text { Aspectos ambientais e determinação de } \\
\text { impactos ambientais }\end{array}$ & NR & 4.3 .1 & $\begin{array}{l}\text { Identificação de perigo, avaliação de riscos } \\
\text { e determinação de controles }\end{array}$ & NR & & \\
\hline \multirow[t]{4}{*}{$\begin{array}{c}2.1 \mathrm{a} \\
2.4 \\
\end{array}$} & & & REQUISITOS GERAIS & $\mathrm{SP}$ & 4.3.2 & Requisitos legais e outros & SP & 4.3 .2 & Requisitos legais e outros & $\begin{array}{c}\mathrm{NC} \\
\mathrm{p}\end{array}$ & 7.2 .1 & $\begin{array}{l}\text { Determinação de requisitos } \\
\text { relacionados ao produto }\end{array}$ \\
\hline & $\begin{array}{l}2.22 \mathrm{a} \\
2.23\end{array}$ & & $\begin{array}{l}\text { Implementando o sistema de } \\
\text { gestão }\end{array}$ & SP & 4.3.2 & Requisitos legais e outros & SP & 4.3 .2 & Requisitos legais e outros & Ad & 7.2 .2 & $\begin{array}{l}\text { Análise crítica dos requisitos } \\
\text { relacionados ao produto }\end{array}$ \\
\hline & 3.9 & & $\begin{array}{l}\text { Atendimento (compliance) a } \\
\text { requisitos estatutários e } \\
\text { regulatórios }\end{array}$ & Ad & 4.3.2 & Requisitos legais e outros & Ad & 4.3.2 & Requisitos legais e outros & $\begin{array}{c}\mathrm{NC} \\
\mathrm{p}\end{array}$ & 7.2 .1 & $\begin{array}{l}\text { Determinação de requisitos } \\
\text { relacionados ao produto }\end{array}$ \\
\hline & & $\begin{array}{c}5.68 \mathrm{a} \\
5.69\end{array}$ & $\begin{array}{l}\text { Identificação dos requisitos } \\
\text { de projeto }\end{array}$ & Ad & 4.3.2 & Requisitos legais e outros & Ad & 4.3 .2 & Requisitos legais e outros & Ad & 7.3.2 & $\begin{array}{l}\text { Entradas de projeto e } \\
\text { desenvolvimento }\end{array}$ \\
\hline \multirow[t]{2}{*}{$\begin{array}{c}5.26 \mathrm{a} \\
5.27\end{array}$} & & & Comunicação & $\mathrm{JC}$ & 4.4.3 & $\begin{array}{l}\text { Comunicação (Neste caso, não relacionado } \\
\text { ISO 9001e OHSAS 18001) }\end{array}$ & SP & 4.3 .2 & Requisitos legais e outros & $\mathrm{JC}$ & 5.5 .3 & Comunicação interna \\
\hline & $\begin{array}{c}2.24 \mathrm{a} \\
2.27 \\
\end{array}$ & & Plano de implementação & Ad & 4.3.3 & Objetivos, metas e programas & Ad & 4.3 .3 & Objetivos e programas & $\mathrm{SP}$ & 5.4 .2 & Planejamento do SGQ \\
\hline $\begin{array}{l}3.8 \mathrm{a} \\
3.11\end{array}$ & $\begin{array}{c}3.13 \mathrm{a} \\
3.16\end{array}$ & & PLANEJAMENTO & SP & 4.3.3 & Objetivos, metas e programas & SP & 4.3 .3 & Objetivos e programas & $\mathrm{SC}$ & 5.4 .1 & Objetivos da qualidade \\
\hline \multirow[t]{2}{*}{$\begin{array}{l}3.8 \mathrm{a} \\
3.11\end{array}$} & $\begin{array}{c}3.13 \mathrm{a} \\
3.16\end{array}$ & & PLANEJAMENTO & $\mathrm{JC}$ & 4.3.3 & Objetivos, metas e programas & $\mathrm{JC}$ & 4.3 .3 & Objetivos e programas & SP & 5.4 .2 & Planejamento do SGQ \\
\hline & & $\begin{array}{c}5.42 \mathrm{a} \\
5.43\end{array}$ & $\begin{array}{l}\text { Planejamento e controle do } \\
\text { trabalho }\end{array}$ & SP & 4.3.3 & Objetivos, metas e programas & SP & 4.3 .3 & Objetivos e programas & $\mathrm{JC}$ & 7.1 & $\begin{array}{l}\text { Planejamento da realização do } \\
\text { produto }\end{array}$ \\
\hline
\end{tabular}




\begin{tabular}{|c|c|c|c|c|c|c|c|c|c|c|c|c|}
\hline \multirow[t]{2}{*}{ GS-R-3 } & \multirow[t]{2}{*}{ GS-G-3.1 } & \multirow[t]{2}{*}{ DS 349} & \multirow[t]{2}{*}{$\begin{array}{l}\text { Sistema de Gestão } \\
\text { IAEA }\end{array}$} & \multicolumn{3}{|r|}{$\begin{array}{l}\text { Sistema de Gestão Ambiental } \\
\text { ISO } 14001\end{array}$} & \multicolumn{3}{|c|}{$\begin{array}{c}\text { Sistema de Gestão de Segurança e Saúde no Trabalho } \\
\text { OHSAS } 18001\end{array}$} & \multicolumn{3}{|c|}{$\begin{array}{l}\text { Sistema de Gestão da Qualidade } \\
\text { ISO 9001 }\end{array}$} \\
\hline & & & & & 4.4 & $\begin{array}{l}\text { IMPLEMENTAÇÃO E OPERAÇÃo } \\
\text { (Título) }\end{array}$ & & 4.4 & $\begin{array}{l}\text { IMPLEMENTAÇÃO E OPERAÇÃO } \\
\text { (Título) }\end{array}$ & & 7 & $\begin{array}{l}\text { REALIZAÇÃO DO PRODUTO } \\
\text { (Título) }\end{array}$ \\
\hline $\begin{array}{l}2.8 \mathrm{a} \\
2.10\end{array}$ & & & $\begin{array}{l}\text { DOCUMENTAÇ̃̃O DO } \\
\text { SISTEMA DE GESTÃO }\end{array}$ & $\mathrm{NCp}$ & 4.4 .1 & $\begin{array}{l}\text { Recursos, funções, responsabilidades e } \\
\text { autoridades }\end{array}$ & $\mathrm{NCp}$ & 4.4.1 & \begin{tabular}{|l|}
$\begin{array}{l}\text { Recursos, funções, responsabilidades, } \\
\text { prestação de contas e autoridades }\end{array}$ \\
\end{tabular} & SP & 5.5 .1 & Responsabilidade e autoridade \\
\hline $\begin{array}{l}3.1 \mathrm{a} \\
3.5\end{array}$ & 3.1 a 3.7 & & $\begin{array}{l}\text { COMPROMETIMENTO DA } \\
\text { DIREÇÃO }\end{array}$ & $\mathrm{NCp}$ & 4.4.1 & $\begin{array}{l}\text { Recursos, funções, responsabilidades e } \\
\text { autoridades }\end{array}$ & $\mathrm{NCp}$ & 4.4.1 & $\begin{array}{l}\text { Recursos, funções, responsabilidades, } \\
\text { prestação de contas e autoridades }\end{array}$ & $\mathrm{SP}$ & 5.5 .1 & Responsabilidade e autoridade \\
\hline $\begin{array}{l}3.1 \mathrm{a} \\
3.5\end{array}$ & 3.1 a 3.7 & & $\begin{array}{l}\text { COMPROMETIMENTO DA } \\
\text { DIREÇÃO }\end{array}$ & $\mathrm{JC}$ & 4.4 .1 & $\begin{array}{l}\text { Recursos, funções, responsabilidades e } \\
\text { autoridades }\end{array}$ & $\mathrm{JC}$ & 4.4.1 & $\begin{array}{l}\text { Recursos, funções, responsabilidades, } \\
\text { prestação de contas e autoridades }\end{array}$ & $\mathrm{SC}$ & 5.1 & Comprometimento da direção \\
\hline \multirow[t]{2}{*}{$\begin{array}{l}3.12 \mathrm{a} \\
3.14\end{array}$} & $\begin{array}{l}3.17 \mathrm{a} \\
3.20\end{array}$ & $\begin{array}{c}3.19 \mathrm{a} \\
3.20\end{array}$ & $\begin{array}{l}\text { RESPONSABILIDADE / } \\
\text { AUTORIDADE PELO } \\
\text { SISTEMA DE GESTÃO }\end{array}$ & $\mathrm{NCp}$ & 4.4.1 & $\begin{array}{l}\text { Recursos, funções, responsabilidades e } \\
\text { autoridades }\end{array}$ & $\mathrm{NCp}$ & 4.4.1 & $\begin{array}{l}\text { Recursos, funções, responsabilidades, } \\
\text { prestação de contas e autoridades }\end{array}$ & SP & 5.5 .1 & Responsabilidade e autoridade \\
\hline & 5.14 a 17 & & $\begin{array}{l}\text { Responsabilidades pelos } \\
\text { processos }\end{array}$ & $\mathrm{JC}$ & 4.4 .1 & $\begin{array}{l}\text { Recursos, funções, responsabilidades e } \\
\text { autoridades }\end{array}$ & $\mathrm{Cp}$ & 4.4.1 & $\begin{array}{l}\text { Assegurar que pessoas nos locais trabalho } \\
\text { assumam responsabilidades por aspectos de } \\
\text { SST }\end{array}$ & Ad & 5.5 .1 & Responsabilidade e autoridade \\
\hline 3.13 & 3.18 & 3.19 & $\begin{array}{l}\text { Indivíduo com responsabili- } \\
\text { dade e autoridade pelo SG }\end{array}$ & $\mathrm{Cp}$ & 4.4.1 & Representantes da direção pelo SGA & $\mathrm{Cp}$ & 4.4.1 & Representantes da direção pelo SGSST & $\mathrm{SC}$ & 5.5 .2 & Representante da direção pelo $\mathrm{SGQ}$ \\
\hline $\begin{array}{c}4.1 \mathrm{a} \\
4.2 \\
\end{array}$ & 4.1 a 4.2 & & PROVISÃO DE RECURSOS & $\mathrm{NCp}$ & 4.4.1 & $\begin{array}{l}\text { Recursos, funções, responsabilidades e } \\
\text { autoridades }\end{array}$ & $\mathrm{NCp}$ & 4.4.1 & $\begin{array}{l}\text { Recursos, funções, responsabilidades, } \\
\text { prestação de contas e autoridades }\end{array}$ & $\mathrm{SC}$ & 6.1 & Provisão de recursos \\
\hline \multirow[t]{2}{*}{4.5} & $\begin{array}{c}4.26 \mathrm{a} \\
4.28\end{array}$ & & $\begin{array}{l}\text { INFRA-ESTRUTURA E } \\
\text { AMBIENTE DE } \\
\text { TRABALHO }\end{array}$ & $\mathrm{NCp}$ & 4.4 .1 & $\begin{array}{l}\text { Recursos, funções, responsabilidades e } \\
\text { autoridades }\end{array}$ & $\mathrm{NCp}$ & 4.4.1 & $\begin{array}{l}\text { Recursos, funções, responsabilidades, } \\
\text { prestação de contas e autoridades }\end{array}$ & SC & 6.3 & Infra-estrutura \\
\hline & 4.5 & & Recursos financeiros & $\mathrm{NCp}$ & 4.4.1 & $\begin{array}{l}\text { Recursos, funções, responsabilidades e } \\
\text { autoridades }\end{array}$ & $\mathrm{NCp}$ & 4.4.1 & $\begin{array}{l}\text { Recursos, funções, responsabilidades, } \\
\text { prestação de contas e autoridades }\end{array}$ & NR & & \\
\hline $\begin{array}{c}4.3 \mathrm{a} \\
4.4 \\
\end{array}$ & & & RECURSOS HUMANOS & $\mathrm{JC}$ & 4.4 .2 & $\begin{array}{l}\text { Competência, treinamento e } \\
\text { conscientizaçãa. }\end{array}$ & $\mathrm{JC}$ & 4.4.2 & $\begin{array}{l}\text { Competência, treinamento e } \\
\text { conscientizaçãao. }\end{array}$ & $\mathrm{SC}$ & 6.2 .1 & Generalidades \\
\hline \multirow[t]{3}{*}{$\begin{array}{c}4.3 \mathrm{a} \\
4.4\end{array}$} & 4.6 a 4.25 & & RECURSOS HUMANOS & $\mathrm{SC}$ & 4.4.2 & $\begin{array}{l}\text { Competência, treinamento e } \\
\text { conscientização. }\end{array}$ & $\mathrm{SC}$ & 4.4.2 & $\begin{array}{l}\text { Competência, treinamento e } \\
\text { conscientização. }\end{array}$ & $\mathrm{SC}$ & 6.2 .2 & $\begin{array}{l}\text { Competência, conscientização e } \\
\text { treinamento }\end{array}$ \\
\hline & & 4.11 & RECURSOS HUMANOS & Ad & 4.4.2 & $\begin{array}{l}\text { Competência, treinamento e } \\
\text { conscientização. }\end{array}$ & Ad & 4.4.2 & $\begin{array}{l}\text { Competência, treinamento e } \\
\text { conscientização. }\end{array}$ & Ad & 6.2 .1 & Generalidades \\
\hline & & & & & & & & 4.4.3 & $\begin{array}{l}\text { Comunicação, participação e consulta } \\
\text { (Título) }\end{array}$ & & & \\
\hline $\begin{array}{c}5.26 \mathrm{a} \\
5.27\end{array}$ & $\begin{array}{c}5.52 \mathrm{a} \\
5.55\end{array}$ & & Comunicação & $\mathrm{JC}$ & 4.4 .3 & Comunicação & $\mathrm{JC}$ & 4.4.3 & Comunicação, participação e consulta & SP & 7.2 .3 & Comunicação com o cliente \\
\hline \multirow[t]{2}{*}{$\begin{array}{c}5.26 \mathrm{a} \\
5.27\end{array}$} & $\begin{array}{c}5.52 \mathrm{a} \\
5.55\end{array}$ & & Comunicação & $\mathrm{SC}$ & 4.4.3 & Comunicação & $\mathrm{SC}$ & $\begin{array}{c}4.4 .3 . \\
1\end{array}$ & Comunicação & $\mathrm{SC}$ & 5.5 .3 & Comunicação interna \\
\hline & 4.3 & & Envolvimento dos indivíduos & NR & & & SP & $\begin{array}{c}4.4 .3 . \\
2\end{array}$ & Participação e consulta & NR & & \\
\hline \multirow[t]{2}{*}{$\begin{array}{c}5.28 \mathrm{a} \\
5.29\end{array}$} & $\begin{array}{c}5.56 \mathrm{a} \\
5.71\end{array}$ & & $\begin{array}{l}\text { Gestão de alteração } \\
\text { organizacional }\end{array}$ & Ad & 4.4.3 & Comunicação & SP & $\begin{array}{c}4.4 .3 . \\
2\end{array}$ & Participação e consulta & $\mathrm{JC}$ & 5.6 .2 & Entradas para a análise crítica \\
\hline & & $\begin{array}{l}5.93 \mathrm{a} \\
5.113\end{array}$ & $\begin{array}{l}\text { Realização da verificação e } \\
\text { validação de projeto }\end{array}$ & NR & & & $\mathrm{Ad}$ & $\begin{array}{c}4.4 .3 . \\
2\end{array}$ & Participação e consulta & $\mathrm{JC}$ & 7.3.6 & $\begin{array}{l}\text { Validação de projeto e } \\
\text { desenvolvimento }\end{array}$ \\
\hline
\end{tabular}




\begin{tabular}{|c|c|c|c|c|c|c|c|c|c|c|c|c|}
\hline \multirow[t]{2}{*}{ GS-R-3 } & \multirow[t]{2}{*}{ GS-G-3.1 } & \multirow{2}{*}{$\begin{array}{r}\text { DS } 349 \\
5.155\end{array}$} & \multirow{2}{*}{$\begin{array}{c}\begin{array}{c}\text { Sistema de Gestão } \\
\text { IAEA }\end{array} \\
\text { Interface reguladora }\end{array}$} & \multicolumn{3}{|r|}{$\begin{array}{l}\text { Sistema de Gestão Ambiental } \\
\text { ISO } 14001\end{array}$} & \multicolumn{3}{|c|}{$\begin{array}{c}\text { Sistema de Gestão de Segurança e Saúde no Trabalho } \\
\text { OHSAS } 18001\end{array}$} & \multicolumn{3}{|c|}{$\begin{array}{l}\text { Sistema de Gestão da Qualidade } \\
\text { ISO 9001 }\end{array}$} \\
\hline & & & & $\mathrm{Ad}$ & 4.4 .3 & Comunicação & $\mathrm{Ad}$ & $\begin{array}{l}4.4 .3 . \\
2\end{array}$ & Participação e consulta & NR & & \\
\hline & & $\begin{array}{c}6.50 \mathrm{a} \\
6.51\end{array}$ & Relato de evento & Ad & 4.4 .3 & Comunicação & Ad & $\begin{array}{c}4.4 .3 . \\
2\end{array}$ & Participação e consulta & NR & & \\
\hline $\begin{array}{l}2.8 \mathrm{a} \\
2.10\end{array}$ & & & $\begin{array}{l}\text { DOCUMENTAÇ̃̃O DO } \\
\text { SISTEMA DE GESTÃO }\end{array}$ & $\mathrm{NCp}$ & 4.4.4 & Documentação & $\mathrm{NCp}$ & 4.4.4 & Documentação & $\begin{array}{c}\mathrm{NC} \\
\mathrm{p}\end{array}$ & 4.2 .1 & Generalidades \\
\hline $\begin{array}{l}2.8 \mathrm{a} \\
2.10\end{array}$ & & & $\begin{array}{l}\text { DOCUMENTAÇÃO DO } \\
\text { SISTEMA DE GESTÃO }\end{array}$ & $\mathrm{Cp}$ & 4.4.4 & $\begin{array}{l}\text { Documentos (Procedimentos controle } \\
\text { situações ambientais) }\end{array}$ & $\mathrm{Cp}$ & 4.4 .4 & $\begin{array}{l}\text { Documentos (Procedimentos para cobrir } \\
\text { situações de SST) }\end{array}$ & $\mathrm{Cp}$ & 4.2 .1 & $\begin{array}{l}\text { Generalidades (6 procedimentos } \\
\text { documentados requeridos pela norma) }\end{array}$ \\
\hline $\begin{array}{l}2.8 \mathrm{a} \\
2.10\end{array}$ & & & $\begin{array}{l}\text { DOCUMENTAÇÃO DO } \\
\text { SISTEMA DE GESTÃOO }\end{array}$ & $\mathrm{Cp}$ & 4.4.4 & $\begin{array}{l}\text { Documentos (Registros requeridos pela } \\
\text { norma) }\end{array}$ & $\mathrm{Cp}$ & 4.4 .4 & $\begin{array}{l}\text { Documentos (Registros requeridos pela } \\
\text { norma) }\end{array}$ & $\mathrm{Cp}$ & 4.2 .1 & $\begin{array}{l}\text { Generalidades (Registros requeridos } \\
\text { pela norma) }\end{array}$ \\
\hline $\begin{array}{l}2.8 \mathrm{a} \\
2.10\end{array}$ & $\begin{array}{c}2.45 \mathrm{a} \\
2.62\end{array}$ & $\begin{array}{c}2.36 \mathrm{a} \\
2.38\end{array}$ & $\begin{array}{l}\text { DOCUMENTAÇÃO DO } \\
\text { SISTEMA DE GESTÃO }\end{array}$ & Ad & 4.4.4 & Documentação & Ad & 4.4 .4 & Documentação & $\mathrm{Cp}$ & 4.2 .2 & Manual da qualidade \\
\hline $\begin{array}{l}3.8 \mathrm{a} \\
3.11\end{array}$ & $\begin{array}{l}3.13 \mathrm{a} \\
3.16\end{array}$ & & PLANEJAMENTO & $\mathrm{NCp}$ & 4.4.4 & Documentação (Objetivos SGA) & $\mathrm{NCp}$ & 4.4.4 & Documentação (Objetivos SGSST) & $\begin{array}{c}\mathrm{NC} \\
\mathrm{p}\end{array}$ & 4.2 .1 & Generalidades (Objetivos SGQ) \\
\hline $\begin{array}{l}5.12 \mathrm{a} \\
5.13 \\
\end{array}$ & $\begin{array}{c}5.24 \mathrm{a} \\
5.28 \\
\end{array}$ & & Controle de documentos & $\mathrm{SC}$ & 4.4 .5 & Controle de documentos & $\mathrm{SC}$ & 4.4 .5 & Controle de documentos & $\begin{array}{c}\mathrm{NC} \\
\mathrm{p}\end{array}$ & 4.2 .3 & Controle de documentos \\
\hline \multirow[t]{3}{*}{$\begin{array}{c}5.12 \mathrm{a} \\
5.13\end{array}$} & $\begin{array}{c}5.24 \mathrm{a} \\
5.28\end{array}$ & & Controle de documentos & $\mathrm{JC}$ & 4.4 .5 & Controle de documentos & $\mathrm{JC}$ & 4.4 .5 & Controle de documentos & $\mathrm{Cp}$ & 4.2 .3 & \begin{tabular}{|l}
$\begin{array}{l}\text { Controle de documento } \\
\text { (Procedimento documentado) }\end{array}$ \\
\end{tabular} \\
\hline & & $\begin{array}{l}4.1 \mathrm{a} \\
4.5\end{array}$ & $\begin{array}{l}\text { Recursos providos por } \\
\text { fornecedores e parceiros }\end{array}$ & Ad & 4.4.6 & Controle operacional & Ad & 4.4 .6 & Controle operacional & Ad & 7.4.1 & Processo de aquisição \\
\hline & 4.4 & $\begin{array}{l}4.6 \mathrm{a} \\
4.10\end{array}$ & $\begin{array}{l}\text { Gestão de informação e } \\
\text { conhecimento }\end{array}$ & $\mathrm{Ad}$ & 4.4.6 & Controle operacional & $\mathrm{Ad}$ & 4.4 .6 & Controle operacional & SC & 8.4 & Análise de dados \\
\hline $\begin{array}{c}5.1 \mathrm{a} \\
5.5 \\
\end{array}$ & 5.1 a 5.9 & 5.1 & $\begin{array}{l}\text { DESENVOLVIMENTO DE } \\
\text { PROCESSOS }\end{array}$ & $\mathrm{NCp}$ & 4.4.6 & Controle operacional & $\mathrm{NCp}$ & 4.4.6 & Controle operacional & $\mathrm{SC}$ & 4.1 & Requisitos gerais \\
\hline $\begin{array}{c}5.1 \mathrm{a} \\
5.5\end{array}$ & 5.1 a 5.9 & 5.1 & $\begin{array}{l}\text { DESENVOLVIMENTO DE } \\
\text { PROCESSOS }\end{array}$ & $\mathrm{JC}$ & 4.4.6 & Controle operacional & $\mathrm{JC}$ & 4.4.6 & Controle operacional & SP & 7.1 & $\begin{array}{l}\text { Planejamento da realização do } \\
\text { produto }\end{array}$ \\
\hline $\begin{array}{l}5.6 \mathrm{a} \\
5.10\end{array}$ & $\begin{array}{c}5.10 \mathrm{a} \\
5.23\end{array}$ & & GESTÃO DE PROCESSO & $\mathrm{NCp}$ & 4.4.6 & Controle operacional & $\mathrm{NCp}$ & 4.4.6 & Controle operacional & $\mathrm{SP}$ & 7.5.1 & $\begin{array}{l}\text { Controle de produção e fornecimento } \\
\text { de serviço }\end{array}$ \\
\hline $\begin{array}{c}5.14 \mathrm{a} \\
5.20\end{array}$ & $\begin{array}{c}5.29 \mathrm{a} \\
5.33\end{array}$ & & Controle de produtos & $\mathrm{Ad}$ & 4.4.6 & Controle operacional & $\mathrm{Ad}$ & 4.4.6 & Controle operacional & SP & 7.5.1 & $\begin{array}{l}\text { Controle de produção e fornecimento } \\
\text { de serviço }\end{array}$ \\
\hline $\begin{array}{c}5.14 \mathrm{a} \\
5.20\end{array}$ & $\begin{array}{l}5.29 \mathrm{a} \\
5.33\end{array}$ & & Controle de produtos & $\mathrm{JC}$ & 4.4.6 & Controle operacional & $\mathrm{JC}$ & 4.4 .6 & Controle operacional & $\begin{array}{c}\mathrm{NC} \\
\mathrm{p}\end{array}$ & 7.5.2 & $\begin{array}{l}\text { Validação dos processos de produção } \\
\text { e fornecimento de serviço }\end{array}$ \\
\hline $\begin{array}{c}5.14 \mathrm{a} \\
5.20\end{array}$ & $\begin{array}{l}5.29 \mathrm{a} \\
5.33\end{array}$ & & Controle de produtos & $\mathrm{JC}$ & 4.4.6 & Controle operacional & $\mathrm{JC}$ & 4.4.6 & Controle operacional & $\mathrm{Cp}$ & 7.5.2 & $\begin{array}{l}\text { Validação de processos onde saída } \\
\text { não possa ser verificada por } \\
\text { monitoração }\end{array}$ \\
\hline $\begin{array}{c}5.14 \mathrm{a} \\
5.20\end{array}$ & $\begin{array}{c}5.29 \mathrm{a} \\
5.33\end{array}$ & & Controle de produtos & $\mathrm{JC}$ & 4.4.6 & Controle operacional & $\mathrm{JC}$ & 4.4 .6 & Controle operacional & SP & 7.5.3 & Identificação e rastreabilidade \\
\hline $\begin{array}{c}5.23 \mathrm{a} \\
5.25\end{array}$ & $\begin{array}{c}5.50 \mathrm{a} \\
5.51\end{array}$ & & Aquisição & $\mathrm{Ad}$ & 4.4.6 & Controle operacional & Ad & 4.4.6 & Controle operacional & $\mathrm{SC}$ & 7.4 .1 & Processo de aquisição \\
\hline
\end{tabular}




\begin{tabular}{|c|c|c|c|c|c|c|c|c|c|c|c|c|}
\hline \multirow{2}{*}{$\begin{array}{c}\text { GS-R-3 } \\
5.23 \mathrm{a} \\
5.25\end{array}$} & \multirow{2}{*}{$\begin{array}{c}\text { GS-G-3.1 } \\
5.50 \mathrm{a} \\
5.51 \\
\end{array}$} & \multirow[t]{2}{*}{ DS 349} & \multirow{2}{*}{$\begin{array}{l}\begin{array}{c}\text { Sistema de Gestão } \\
\text { IAEA }\end{array} \\
\text { Aquisição }\end{array}$} & \multicolumn{3}{|r|}{$\begin{array}{l}\text { Sistema de Gestão Ambiental } \\
\text { ISO } 14001\end{array}$} & \multicolumn{3}{|c|}{$\begin{array}{c}\text { Sistema de Gestão de Segurança e Saúde no Trabalho } \\
\text { OHSAS } 18001\end{array}$} & \multicolumn{3}{|c|}{$\begin{array}{l}\text { Sistema de Gestão da Qualidade } \\
\text { ISO } 9001\end{array}$} \\
\hline & & & & $\mathrm{JC}$ & 4.4.6 & Controle operacional & $\mathrm{JC}$ & 4.4 .6 & Controle operacional & $\mathrm{SC}$ & 7.4.2 & Informações de aquisição \\
\hline \multirow[t]{13}{*}{$\begin{array}{ll}5.23 \mathrm{a} \\
5.25\end{array}$} & $\begin{array}{c}5.50 \mathrm{a} \\
5.51\end{array}$ & & Aquisição & $\mathrm{JC}$ & 4.4.6 & Controle operacional & JC & 4.4 .6 & Controle operacional & $\mathrm{SC}$ & 7.4 .3 & Verificação do produto adquirido \\
\hline & & $\begin{array}{c}5.52 \mathrm{a} \\
5.57\end{array}$ & Segurança industrial & NR & 4.4.6 & Controle operacional & $\mathrm{NCp}$ & 4.4 .6 & Controle Operacional & NR & & \\
\hline & & $\begin{array}{c}5.52 \mathrm{a} \\
5.57\end{array}$ & Segurança industrial & NR & 4.4.6 & Controle operacional & $\mathrm{Cp}$ & 4.4 .6 & $\begin{array}{l}\text { Procedimento situações que possam } \\
\text { acarretar desvios de SST }\end{array}$ & NR & & \\
\hline & & 5.58 & Segurança radiológica & NR & 4.4.6 & Controle operacional & $\mathrm{NCp}$ & 4.4 .6 & Controle Operacional & NR & & \\
\hline & & $\begin{array}{c}5.59 \mathrm{a} \\
5.63\end{array}$ & $\begin{array}{l}\text { Controle e supervisão de } \\
\text { contratados }\end{array}$ & $\mathrm{Ad}$ & 4.4.6 & Controle operacional & $\mathrm{Ad}$ & 4.4 .6 & Controle Operacional & Ad & 7.4 .3 & Verificação do produto adquirido \\
\hline & & 5.129 & Manutenção & $\mathrm{Ad}$ & 4.4.6 & Controle operacional & $\mathrm{Ad}$ & 4.4.6 & Controle operacional & $\mathrm{Ad}$ & 6.3 & Infra-estrutura \\
\hline & & 5.130 & Housekeeping e limpeza & $\mathrm{Ad}$ & 4.4.6 & Controle operacional & $\mathrm{Ad}$ & 4.4.6 & Controle operacional & Ad & 6.4 & Ambiente de trabalho \\
\hline & & $\begin{array}{l}5.131 \mathrm{a} \\
5.139\end{array}$ & Manuseio e armazenamento & $\mathrm{Ad}$ & 4.4.6 & Controle operacional & $\mathrm{Ad}$ & 4.4.6 & Controle operacional & SP & 7.5 .3 & Identificação e rastreabilidade \\
\hline & & $\begin{array}{l}5.131 \mathrm{a} \\
5.139\end{array}$ & Manuseio e armazenamento & $\mathrm{JC}$ & 4.4.6 & Controle operacional & $\mathrm{JC}$ & 4.4.6 & Controle operacional & $\mathrm{SC}$ & 7.5 .5 & Preservação do produto \\
\hline & & $\begin{array}{l}5.144 \mathrm{a} \\
5.149\end{array}$ & Gestão de rejeito & $\mathrm{NCp}$ & 4.4 .6 & Controle operacional & $\mathrm{NCp}$ & 4.4 .6 & Controle operacional & NR & & \\
\hline & & $\begin{array}{l}5.150 \mathrm{a} \\
5.154\end{array}$ & Gestão ambiental & $\mathrm{NCp}$ & 4.4.6 & Controle operacional & NR & 4.4 .6 & Controle operacional & NR & & \\
\hline & & $\begin{array}{l}5.150 \mathrm{a} \\
5.154\end{array}$ & Gestão ambiental & $\mathrm{Cp}$ & 4.4.6 & $\begin{array}{l}\text { Procedimentos para controlar situações } \\
\text { possam acarretar desvios do SGA }\end{array}$ & NR & 4.4 .6 & Controle operacional & NR & & \\
\hline & & 5.161 & Proteção física (Security) & $\mathrm{Ad}$ & 4.4.6 & Controle operacional & $\mathrm{Ad}$ & 4.4 .6 & Controle operacional & NR & & \\
\hline \multirow[t]{5}{*}{$\begin{array}{l}5.1 \mathrm{a} \\
5.5\end{array}$} & 5.1 a 5.9 & 5.1 & $\begin{array}{l}\text { DESENVOLVIMENTO DE } \\
\text { PROCESSOS }\end{array}$ & $\mathrm{Cp}$ & 4.4.7 & $\begin{array}{l}\text { Preparação e resposta a emergência } \\
\text { (Definir processo) }\end{array}$ & $\mathrm{Cp}$ & 4.4 .7 & $\begin{array}{l}\text { Preparação e resposta a emergência (Definir } \\
\text { processo) }\end{array}$ & $\mathrm{JC}$ & 7.1 & $\begin{array}{l}\text { Planejamento realização produto } \\
\text { (Neste caso, não relacionado ISO } \\
\text { 14001 e OHSAS 18001) }\end{array}$ \\
\hline & & $\begin{array}{c}5.52 \mathrm{a} \\
5.57\end{array}$ & Segurança industrial & NR & 4.4.7 & Preparação e resposta a emergência & $\mathrm{NCp}$ & 4.4 .7 & Preparação e resposta a emergência & NR & & \\
\hline & & 5.58 & Segurança radiológica & $\mathrm{NCp}$ & 4.4.7 & Preparação e resposta a emergência & $\mathrm{NCp}$ & 4.4 .7 & Preparação e resposta a emergência & NR & & \\
\hline & & $\begin{array}{c}5.90 \mathrm{a} \\
5.91\end{array}$ & $\begin{array}{l}\text { Condução de análise } \\
\text { detalhada de segurança }\end{array}$ & $\mathrm{NCp}$ & 4.4.7 & Preparação e resposta a emergência & $\mathrm{NCp}$ & 4.4.7 & Preparação e resposta a emergência & $\mathrm{JC}$ & 7.3.3 & Saídas de projeto e desenvolvimento \\
\hline & & $\begin{array}{l}5.150 \mathrm{a} \\
5.154\end{array}$ & Gestão ambiental & $\mathrm{NCp}$ & 4.4.7 & Preparação e resposta a emergência & NR & 4.4 .7 & Preparação e resposta a emergência & NR & & \\
\hline
\end{tabular}




\begin{tabular}{|c|c|c|c|c|c|c|c|c|c|c|c|c|}
\hline \multirow[t]{2}{*}{ GS-R-3 } & \multirow[t]{2}{*}{ GS-G-3.1 } & \multirow{2}{*}{$\begin{array}{r}\text { DS } 349 \\
5.160\end{array}$} & \multirow{2}{*}{$\begin{array}{c}\text { Sistema de Gestão } \\
\text { IAEA }\end{array}$} & \multicolumn{3}{|r|}{$\begin{array}{l}\text { Sistema de Gestão Ambiental } \\
\text { ISO } 14001\end{array}$} & \multicolumn{3}{|c|}{$\begin{array}{c}\text { Sistema de Gestão de Segurança e Saúde no Trabalho } \\
\text { OHSAS } 18001\end{array}$} & \multicolumn{3}{|c|}{$\begin{array}{l}\text { Sistema de Gestão da Qualidade } \\
\text { ISO 9001 }\end{array}$} \\
\hline & & & & $\mathrm{NCp}$ & 4.4.7 & Preparação e resposta a emergência & $\mathrm{NCp}$ & 4.4.7 & Preparação e resposta a emergência & NR & & \\
\hline & & 5.161 & Proteção física (Security) & $\mathrm{Ad}$ & 4.4.7 & Preparação e resposta a emergência & $\mathrm{Ad}$ & 4.4.7 & Preparação e resposta a emergência & NR & & \\
\hline $\begin{array}{c}6.11 \mathrm{a} \\
6.16\end{array}$ & $\begin{array}{c}6.50 \mathrm{a} \\
6.58\end{array}$ & & $\begin{array}{l}\text { NÃO-CONFORMIDADES, } \\
\text { AÇÕES CORRETIVAS E } \\
\text { PREVENTIVAS }\end{array}$ & $\mathrm{Ad}$ & 4.4.7 & Preparação e resposta a emergência & Ad & 4.4.7 & Preparação e resposta a emergência & $\mathrm{JC}$ & 8.3 & Controle de produto não-conforme \\
\hline \multirow[t]{3}{*}{6} & 6 & 6 & $\begin{array}{l}\text { MEDIÇÃO, AVALIAÇ̃̃o } \\
\text { E MELHORIA (Título) }\end{array}$ & & 4.5 & VERIFICAÇÃO (Título) & & 4.5 & VERIFICAÇÃO (Título) & & 8 & $\begin{array}{l}\text { MEDIÇÃO, ANÁLISE E } \\
\text { MELHORIA (Título) }\end{array}$ \\
\hline & & $\begin{array}{c}4.12 \mathrm{a} \\
4.15\end{array}$ & $\begin{array}{l}\text { Gestão de patrimônio } \\
\text { material }\end{array}$ & $\mathrm{JC}$ & 4.5 .1 & Monitoração e medição & $\mathrm{JC}$ & 4.5.1 & Monitoramento e medição do desempenho & $\mathrm{Cp}$ & 7.5.4 & Propriedade do cliente \\
\hline & & $\begin{array}{c}4.12 \mathrm{a} \\
4.15\end{array}$ & $\begin{array}{l}\text { Gestão de patrimônio } \\
\text { material }\end{array}$ & $\mathrm{Ad}$ & 4.5 .1 & Monitoração e medição & $\mathrm{Ad}$ & 4.5.1 & Monitoramento e medição do desempenho & SP & 8.2 .3 & $\begin{array}{l}\text { Medição e monitoramento de } \\
\text { processos }\end{array}$ \\
\hline \multirow[t]{9}{*}{$\begin{array}{l}5.6 \mathrm{a} \\
5.10\end{array}$} & $\begin{array}{c}5.10 \mathrm{a} \\
5.12\end{array}$ & & $\begin{array}{l}\text { GESTÃO DE PROCESSO } \\
\text { (Geral) }\end{array}$ & $\mathrm{Ad}$ & 4.5 .1 & Monitoração e medição & $\mathrm{Ad}$ & 4.5.1 & Monitoramento e medição do desempenho & SP & 8.2 .3 & $\begin{array}{l}\text { Medição e monitoramento de } \\
\text { processos }\end{array}$ \\
\hline & $\begin{array}{c}5.18 \mathrm{a} \\
5.23\end{array}$ & & $\begin{array}{l}\text { Processos contratados de } \\
\text { outras organizações }\end{array}$ & $\mathrm{Ad}$ & 4.5 .1 & Monitoração e medição & Ad & 4.5.1 & Monitoramento e medição do desempenho & $\mathrm{Ad}$ & 4.1 & Requisitos gerais \\
\hline & $\begin{array}{c}5.18 \mathrm{a} \\
5.23\end{array}$ & & $\begin{array}{l}\text { Processos contratados de } \\
\text { outras organizações }\end{array}$ & $\mathrm{JC}$ & 4.5 .1 & Monitoração e medição & $\mathrm{JC}$ & 4.5.1 & Monitoramento e medição do desempenho & $\mathrm{Ad}$ & 8.2 .3 & $\begin{array}{l}\text { Medição e monitoramento de } \\
\text { processos }\end{array}$ \\
\hline & & $\begin{array}{l}5.5 \mathrm{a} \\
5.14\end{array}$ & Inspeção e teste & $\mathrm{NCp}$ & 4.5 .1 & Monitoração e medição & $\mathrm{NCp}$ & 4.5 .1 & Monitoramento e medição do desempenho & SP & 7.5.1 & $\begin{array}{l}\text { Controle de produção e fornecimento } \\
\text { de serviço }\end{array}$ \\
\hline & & $\begin{array}{l}5.5 \mathrm{a} \\
5.14\end{array}$ & Inspeção e teste & $\mathrm{JC}$ & 4.5 .1 & Monitoração e medição & $\mathrm{JC}$ & 4.5.1 & Monitoramento e medição do desempenho & SP & 8.2 .4 & Medição e monitoramento de produto \\
\hline & 5.34 & $\begin{array}{c}5.15 \mathrm{a} \\
5.19\end{array}$ & $\begin{array}{l}\text { Equipamentos de medição e } \\
\text { testes }\end{array}$ & $\mathrm{NCp}$ & 4.5 .1 & Monitoração e medição & $\mathrm{NCp}$ & 4.5 .1 & Monitoramento e medição do desempenho & $\mathrm{SC}$ & 7.6 & $\begin{array}{l}\text { Controle de dispositivos de medição e } \\
\text { monitoramento }\end{array}$ \\
\hline & & 5.58 & Segurança radiológica & $\mathrm{NCp}$ & 4.5 .1 & Monitoração e medição & $\mathrm{NCp}$ & 4.5.1 & Monitoramento e medição do desempenho & NR & & \\
\hline & & 5.58 & Segurança radiológica & $\mathrm{Cp}$ & 4.5 .1 & $\begin{array}{l}\text { Documentos com informações para } \\
\text { monitorar desempenho, controles } \\
\text { operacionais e conformidade objetivos }\end{array}$ & $\mathrm{Cp}$ & 4.5 .1 & $\begin{array}{l}\text { Registrar dados e resultados do } \\
\text { monitoramento e medição para análise de } \\
\text { ações corretivas e preventivas }\end{array}$ & NR & & \\
\hline & & 5.129 & Manutenção & $\mathrm{NCp}$ & 4.5 .1 & Monitoração e medição & $\mathrm{NCp}$ & 4.5 .1 & Monitoramento e medição do desempenho & $\mathrm{JC}$ & 6.3 & Infra-estrutura \\
\hline 6.1 & 6.4 a 6.5 & & $\begin{array}{l}\text { MONITORAÇ̃̃O E } \\
\text { MEDIÇÃO }\end{array}$ & $\mathrm{NCp}$ & 4.5 .1 & Monitoração e medição & $\mathrm{NCp}$ & 4.5.1 & Monitoramento e medição do desempenho & $\mathrm{SP}$ & 8.2 .3 & $\begin{array}{l}\text { Medição e monitoramento de } \\
\text { processos }\end{array}$ \\
\hline 6.1 & 6.4 a 6.5 & & $\begin{array}{l}\text { MONITORAÇ̃̃O E } \\
\text { MEDIÇÃO }\end{array}$ & $\mathrm{Cp}$ & 4.5 .1 & $\begin{array}{l}\text { Documentos com informações para } \\
\text { monitorar desempenho, controles } \\
\text { operacionais e conformidade objetivos }\end{array}$ & $\mathrm{Cp}$ & 4.5 .1 & $\begin{array}{l}\text { Registrar dados e resultados do } \\
\text { monitoramento e medição para análise de } \\
\text { ações corretivas e preventivas }\end{array}$ & $\mathrm{JC}$ & 8.2 .3 & $\begin{array}{l}\text { Medição e monitoramento de } \\
\text { processos }\end{array}$ \\
\hline \multirow[t]{2}{*}{6.1} & 6.4 a 6.5 & & $\begin{array}{l}\text { MONITORAÇ̃̃O E } \\
\text { MEDIÇÃO }\end{array}$ & $\mathrm{JC}$ & 4.5 .1 & Monitoração e medição & $\mathrm{JC}$ & 4.5.1 & Monitoramento e medição do desempenho & $\mathrm{SP}$ & 8.2 .4 & Medição e monitoramento de produto \\
\hline & & 6.1 & Gestão de inadvertência & $\mathrm{Ad}$ & 4.5 .1 & Monitoração e medição & $\mathrm{NCp}$ & 4.5 .1 & Monitoramento e medição do desempenho & $\mathrm{Ad}$ & 8.2 .3 & $\begin{array}{l}\text { Medição e monitoramento de } \\
\text { processos }\end{array}$ \\
\hline
\end{tabular}




\begin{tabular}{|c|c|c|c|c|c|c|c|c|c|c|c|c|}
\hline \multirow[t]{2}{*}{ GS-R-3 } & \multirow{2}{*}{$\begin{array}{c}\text { GS-G-3.1 } \\
3.9\end{array}$} & \multirow[t]{2}{*}{ DS 349} & \multirow{2}{*}{ 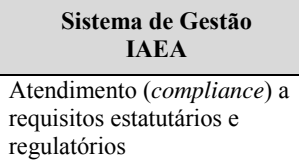 } & \multicolumn{3}{|r|}{$\begin{array}{l}\text { Sistema de Gestão Ambiental } \\
\text { ISO } 14001\end{array}$} & \multicolumn{3}{|c|}{$\begin{array}{c}\text { Sistema de Gestão de Segurança e Saúde no Trabalho } \\
\text { OHSAS } 18001\end{array}$} & \multicolumn{3}{|c|}{$\begin{array}{l}\text { Sistema de Gestão da Qualidade } \\
\text { ISO } 9001\end{array}$} \\
\hline & & & & $\mathrm{NCp}$ & 4.5 .2 & $\begin{array}{l}\text { Avaliação do atendimento a requisitos } \\
\text { legais }\end{array}$ & $\mathrm{NCp}$ & 4.5 .2 & $\begin{array}{l}\text { Avaliação do atendimento a requisitos } \\
\text { legais }\end{array}$ & Ad & 8.2 .4 & Medição e monitoramento de produto \\
\hline & 3.9 & & $\begin{array}{l}\text { Atendimento (compliance) a } \\
\text { requisitos estatutários e } \\
\text { regulatórios }\end{array}$ & $\mathrm{Cp}$ & 4.5 .2 & $\begin{array}{l}\text { Registros de avaliações periódicas } \\
\text { atendimento requisitos legais e outros }\end{array}$ & $\mathrm{Cp}$ & 4.5 .2 & $\begin{array}{l}\text { Registros de avaliações periódicas } \\
\text { atendimento requisitos legais e outros }\end{array}$ & $\mathrm{JC}$ & 8.2 .4 & $\begin{array}{l}\text { Medição e monitoramento de produto } \\
\text { (Neste caso, não relacionado ISO } \\
14001 \text { e OHSAS) }\end{array}$ \\
\hline & 3.9 & & $\begin{array}{l}\text { Atendimento (compliance) a } \\
\text { requisitos estatutários e } \\
\text { regulatórios }\end{array}$ & $\mathrm{Cp}$ & $\begin{array}{l}4.5 .2 . \\
2\end{array}$ & $\begin{array}{l}\text { Avaliação do atendimento a outros } \\
\text { requisitos (incluir) }\end{array}$ & $\mathrm{Cp}$ & 4.5 .2 & $\begin{array}{l}\text { Avaliação do atendimento a outros } \\
\text { requisitos (incluir) }\end{array}$ & $\mathrm{JC}$ & 8.2 .4 & $\begin{array}{l}\text { Medição e monitoramento de produto } \\
\text { (Neste caso, não relacionado ISO } \\
14001 \text { e OHSAS 18001) }\end{array}$ \\
\hline $\begin{array}{c}6.11 \mathrm{a} \\
6.16\end{array}$ & $\begin{array}{c}6.50 \mathrm{a} \\
6.58\end{array}$ & & $\begin{array}{l}\text { NÃO-CONFORMIDADES, } \\
\text { AÇÕES CORRETIVAS E } \\
\text { PREVENTIVAS }\end{array}$ & $\mathrm{SC}$ & 4.5 .3 & $\begin{array}{l}\text { Não-conformidade, ação corretiva e ação } \\
\text { preventiva }\end{array}$ & $\mathrm{SC}$ & 4.5 .3 & $\begin{array}{l}\text { Investigação de acidente, não- } \\
\text { conformidade, ação corretiva e ação } \\
\text { preventiva }\end{array}$ & $\begin{array}{c}\mathrm{NC} \\
\mathrm{p}\end{array}$ & 8.3 & Controle de produto não-conforme \\
\hline $\begin{array}{c}6.11 \mathrm{a} \\
6.16\end{array}$ & $\begin{array}{c}6.50 \mathrm{a} \\
6.58\end{array}$ & & $\begin{array}{l}\text { NÃO-CONFORMIDADES, } \\
\text { AÇÕES CORRETIVAS E } \\
\text { PREVENTIVAS }\end{array}$ & $\mathrm{JC}$ & 4.5 .3 & $\begin{array}{l}\text { Não-conformidade, ação corretiva e ação } \\
\text { preventiva }\end{array}$ & $\mathrm{JC}$ & 4.5 .3 & $\begin{array}{l}\text { Investigação de acidente, não- } \\
\text { conformidade, ação corretiva e ação } \\
\text { preventiva }\end{array}$ & $\mathrm{Ad}$ & 8.5 .2 & Ação corretiva \\
\hline \multirow[t]{7}{*}{$\begin{array}{c}6.11 \mathrm{a} \\
6.16\end{array}$} & $\begin{array}{c}6.50 \mathrm{a} \\
6.58\end{array}$ & & $\begin{array}{l}\text { NÃO-CONFORMIDADES, } \\
\text { AÇÕES CORRETIVAS E } \\
\text { PREVENTIVAS }\end{array}$ & $\mathrm{JC}$ & 4.5 .3 & $\begin{array}{l}\text { Não-conformidade, ação corretiva e ação } \\
\text { preventiva }\end{array}$ & $\mathrm{JC}$ & 4.5 .3 & $\begin{array}{l}\text { Investigação de acidente, não- } \\
\text { conformidade, ação corretiva e ação } \\
\text { preventiva }\end{array}$ & $\mathrm{Ad}$ & 8.5 .3 & Ação preventiva \\
\hline & $\begin{array}{c}6.59 \mathrm{a} \\
6.65\end{array}$ & & $\begin{array}{l}\text { Controle de não- } \\
\text { conformidade }\end{array}$ & Ad & 4.5 .3 & $\begin{array}{l}\text { Não-conformidade, ação corretiva e ação } \\
\text { preventiva }\end{array}$ & Ad & 4.5 .3 & $\begin{array}{l}\text { Investigação de acidente, não- } \\
\text { conformidade, ação corretiva e ação } \\
\text { preventiva }\end{array}$ & Ad & 8.3 & Controle de produto não-conforme \\
\hline & $\begin{array}{c}6.59 \mathrm{a} \\
6.65\end{array}$ & & $\begin{array}{l}\text { Controle de não- } \\
\text { conformidade }\end{array}$ & $\mathrm{JC}$ & 4.5 .3 & $\begin{array}{l}\text { Não-conformidade, ação corretiva e ação } \\
\text { preventiva }\end{array}$ & $\mathrm{JC}$ & 4.5 .3 & $\begin{array}{l}\text { Investigação de acidente, não- } \\
\text { conformidade, ação corretiva e ação } \\
\text { preventiva }\end{array}$ & $\mathrm{Cp}$ & 8.3 & $\begin{array}{l}\text { Controle de produto não-conforme } \\
\text { (Procedimento documentado) }\end{array}$ \\
\hline & $\begin{array}{c}6.66 \mathrm{a} \\
6.75\end{array}$ & $\begin{array}{c}6.35 \mathrm{a} \\
6.46\end{array}$ & Ações corretivas & Ad & 4.5 .3 & $\begin{array}{l}\text { Não-conformidade, ação corretiva e ação } \\
\text { preventiva }\end{array}$ & Ad & 4.5 .3 & $\begin{array}{l}\text { Investigação de acidente, não- } \\
\text { conformidade, ação corretiva e ação } \\
\text { preventiva }\end{array}$ & $\begin{array}{c}\mathrm{NC} \\
\mathrm{p}\end{array}$ & 8.5 .2 & Ação corretiva \\
\hline & $\begin{array}{l}6.66 \mathrm{a} \\
6.75\end{array}$ & $\begin{array}{c}6.35 \mathrm{a} \\
6.46\end{array}$ & Ações corretivas & $\mathrm{JC}$ & 4.5 .3 & $\begin{array}{l}\text { Não-conformidade, ação corretiva e ação } \\
\text { preventiva }\end{array}$ & $\mathrm{JC}$ & 4.5 .3 & $\begin{array}{l}\text { Investigação de acidente, não- } \\
\text { conformidade, ação corretiva e ação } \\
\text { preventiva }\end{array}$ & $\mathrm{Cp}$ & 8.5 .2 & $\begin{array}{l}\text { Ação corretiva (Procedimento } \\
\text { documentado) }\end{array}$ \\
\hline & $\begin{array}{c}6.76 \mathrm{a} \\
6.77\end{array}$ & $\begin{array}{c}6.47 \mathrm{a} \\
6.49\end{array}$ & Ações preventivas & $\mathrm{Ad}$ & 4.5 .3 & $\begin{array}{l}\text { Não-conformidade, ação corretiva e ação } \\
\text { preventiva }\end{array}$ & Ad & 4.5 .3 & $\begin{array}{l}\text { Investigação de acidente, não- } \\
\text { conformidade, ação corretiva e ação } \\
\text { preventiva }\end{array}$ & $\begin{array}{c}\mathrm{NC} \\
\mathrm{p}\end{array}$ & 8.5 .3 & Ação preventiva \\
\hline & $\begin{array}{c}6.76 \mathrm{a} \\
6.77\end{array}$ & $\begin{array}{c}6.47 \mathrm{a} \\
6.49\end{array}$ & Ações preventivas & $\mathrm{JC}$ & 4.5 .3 & $\begin{array}{l}\text { Não-conformidade, ação corretiva e ação } \\
\text { preventiva }\end{array}$ & $\mathrm{JC}$ & 4.5 .3 & $\begin{array}{l}\text { Investigação de acidente, não- } \\
\text { conformidade, ação corretiva e ação } \\
\text { preventiva }\end{array}$ & $\mathrm{Cp}$ & 8.5 .3 & $\begin{array}{l}\text { Ação preventiva (Procedimento } \\
\text { documentado) }\end{array}$ \\
\hline $\begin{array}{c}5.21 \mathrm{a} \\
5.22\end{array}$ & $\begin{array}{c}5.35 \mathrm{a} \\
5.49\end{array}$ & & Controle de registros & $\mathrm{SC}$ & 4.5 .4 & Controle de registros & $\mathrm{SC}$ & 4.5.4 & Controle de registros & $\begin{array}{c}\mathrm{NC} \\
\mathrm{p}\end{array}$ & 4.2.4 & Controle de registros \\
\hline $\begin{array}{c}5.21 \mathrm{a} \\
5.22 \\
\end{array}$ & $\begin{array}{c}5.35 \mathrm{a} \\
5.49\end{array}$ & & Controle de registros & $\mathrm{JC}$ & 4.5 .4 & Controle de registros & $\mathrm{JC}$ & 4.5 .4 & Controle de registros & $\mathrm{Cp}$ & 4.2 .4 & $\begin{array}{l}\text { Controle de registros (Procedimento } \\
\text { documentado) }\end{array}$ \\
\hline \multirow[t]{3}{*}{$\begin{array}{c}6.3 \mathrm{a} \\
6.6 \\
\end{array}$} & & & $\begin{array}{l}\text { AVALIAČ̃̃ } \\
\text { INDEPENDENTE }\end{array}$ & $\mathrm{Ad}$ & 4.5 .5 & Auditoria interna & $\mathrm{Ad}$ & 4.5 .5 & Auditoria interna & Ad & 8.2 .2 & Auditoria interna \\
\hline & $\begin{array}{c}6.23 \mathrm{a} \\
6.25\end{array}$ & & Auditorias internas & $\mathrm{SC}$ & 4.5 .5 & Auditoria interna & $\mathrm{SC}$ & 4.5 .5 & Auditoria interna & $\begin{array}{c}\mathrm{NC} \\
\mathrm{p}\end{array}$ & 8.2 .2 & Auditoria interna \\
\hline & $\begin{array}{c}6.23 \mathrm{a} \\
6.25\end{array}$ & & Auditorias internas & $\mathrm{JC}$ & 4.5 .5 & Auditoria interna & $\mathrm{JC}$ & 4.5 .5 & Auditoria interna & $\mathrm{Cp}$ & 8.2 .2 & $\begin{array}{l}\text { Auditoria interna (Procedimento } \\
\text { documentado) }\end{array}$ \\
\hline
\end{tabular}




\begin{tabular}{|c|c|c|c|c|c|c|c|c|c|c|c|c|}
\hline \multirow{2}{*}{\begin{tabular}{c|} 
GS-R-3 \\
$6.7 \mathrm{a}$ \\
6.10 \\
\end{tabular}} & \multirow{2}{*}{\begin{tabular}{|c|} 
GS-G-3.1 \\
$6.45 \mathrm{a}$ \\
6.46
\end{tabular}} & \multirow[t]{2}{*}{ DS 349} & \multirow{2}{*}{$\begin{array}{c}\begin{array}{c}\text { Sistema de Gestão } \\
\text { IAEA }\end{array} \\
\text { ANÁLISE CRÍTICA DO } \\
\text { SISTEMA DE GESTÃO }\end{array}$} & \multicolumn{3}{|r|}{$\begin{array}{l}\text { Sistema de Gestão Ambiental } \\
\text { ISO } 14001\end{array}$} & \multicolumn{3}{|c|}{$\begin{array}{c}\text { Sistema de Gestão de Segurança e Saúde no Trabalho } \\
\text { OHSAS } 18001\end{array}$} & \multicolumn{3}{|c|}{$\begin{array}{l}\text { Sistema de Gestão da Qualidade } \\
\text { ISO } 9001\end{array}$} \\
\hline & & & & $\mathrm{SC}$ & 4.6 & Análise pela administração & $\mathrm{SC}$ & 4.6 & Análise crítica pela direção & $\mathrm{SC}$ & 5.6 .1 & Generalidades \\
\hline \multirow[t]{3}{*}{$\begin{array}{c}5.28 \mathrm{a} \\
5.29\end{array}$} & $\begin{array}{c}5.56 \mathrm{a} \\
5.71\end{array}$ & & $\begin{array}{l}\text { Gestão de alteração } \\
\text { organizacional }\end{array}$ & $\mathrm{Ad}$ & 4.6 & Análise pela administração & $\mathrm{Ad}$ & 4.6 & Análise crítica pela direção & $\mathrm{Ad}$ & 5.6 .2 & Entradas para a análise crítica \\
\hline & 6.47 & & Entradas da análise crítica & $\mathrm{Ad}$ & 4.6 & Análise pela administração & $\mathrm{Ad}$ & 4.6 & Análise crítica pela direção & $\mathrm{SC}$ & 5.6 .2 & Entradas para a análise crítica \\
\hline & $\begin{array}{c}6.48 \mathrm{a} \\
6.49\end{array}$ & & Saídas da análise crítica & Ad & 4.6 & Análise pela administração & Ad & 4.6 & Análise crítica pela direção & $\mathrm{SC}$ & 5.6 .3 & Saídas da análise crítica \\
\hline $\begin{array}{c}6.17 \mathrm{a} \\
6.18\end{array}$ & $\begin{array}{c}6.78 \mathrm{a} \\
6.84 \\
\end{array}$ & $\begin{array}{c}6.52 \mathrm{a} \\
6.56 \\
\end{array}$ & MELHORIAS & $\mathrm{Ad}$ & 4.6 & Análise pela administração & $\mathrm{Ad}$ & 4.6 & Análise crítica pela direção & $\mathrm{SC}$ & 8.5 .1 & Melhoria continua \\
\hline \multirow[t]{6}{*}{$\begin{array}{c}6.17 \mathrm{a} \\
6.18 \\
\end{array}$} & $\begin{array}{c}6.78 \mathrm{a} \\
6.84\end{array}$ & $\begin{array}{c}6.52 \mathrm{a} \\
6.56\end{array}$ & MELHORIAS & $\mathrm{JC}$ & 4.6 & Análise pela administração & SP & $\begin{array}{c}4.5 .3 . \\
1\end{array}$ & Investigação de incidente & $\mathrm{JC}$ & 8.5 .1 & Melhoria continua \\
\hline & & $\begin{array}{l}2.1 \mathrm{a} \\
2.3\end{array}$ & REQUISITOS GERAIS & NR & & & NR & & & NR & & \\
\hline & & $\begin{array}{l}\text { Ap. } \\
\text { VII.1 }\end{array}$ & $\begin{array}{l}\text { Requisitos de SG para o } \\
\text { estagio de operação }\end{array}$ & NR & & & NR & & & NR & & \\
\hline & 2.1 a 2.6 & & $\begin{array}{l}\text { SISTEMA INTEGRADO DE } \\
\text { GESTÃO }\end{array}$ & NR & & & NR & & & NR & & \\
\hline & 2.7 a 2.31 & & ASPECTOS GERAIS & NR & & & NR & & & NR & & \\
\hline & $\begin{array}{c}2.28 \mathrm{a} \\
2.31\end{array}$ & & Organização das interfaces & NR & & & NR & & & NR & & \\
\hline \multirow[t]{8}{*}{2.5} & $\begin{array}{c}2.32 \mathrm{a} \\
2.36\end{array}$ & $\begin{array}{c}2.4 \mathrm{a} \\
2.8\end{array}$ & $\begin{array}{l}\text { CULTURA DE } \\
\text { SEGURANÇA }\end{array}$ & NR & & & NR & & & NR & & \\
\hline & & 2.9 & $\begin{array}{l}\text { A segurança ocupacional é } \\
\text { um valor claramente } \\
\text { reconhecido }\end{array}$ & NR & & & NR & & & NR & & \\
\hline & & 2.10 & $\begin{array}{l}\text { A liderança pela segurança } \\
\text { ocupacional está evidente }\end{array}$ & NR & & & NR & & & NR & & \\
\hline & & 2.11 & $\begin{array}{l}\text { A responsabilidade final pela } \\
\text { segurança ocupacional está } \\
\text { evidente }\end{array}$ & NR & & & NR & & & NR & & \\
\hline & & 2.12 & $\begin{array}{l}\text { A segurança ocupacional está } \\
\text { integrada todas as atividades }\end{array}$ & NR & & & NR & & & NR & & \\
\hline & & $\begin{array}{c}2.13 \mathrm{a} \\
2.16\end{array}$ & $\begin{array}{l}\text { A segurança ocupacional é } \\
\text { uma aprendizagem dirigida }\end{array}$ & NR & & & NR & & & NR & & \\
\hline & & $\begin{array}{c}2.17 \mathrm{a} \\
2.21\end{array}$ & $\begin{array}{l}\text { Melhorando a cultura de } \\
\text { segurança }\end{array}$ & NR & & & NR & & & NR & & \\
\hline & & $\begin{array}{c}2.22 \mathrm{a} \\
2.24\end{array}$ & $\begin{array}{l}\text { Sinais de atenção antecipados } \\
\text { declínio cultura de segurança }\end{array}$ & NR & & & NR & & & NR & & \\
\hline
\end{tabular}




\begin{tabular}{|c|c|c|c|c|c|c|c|c|c|c|}
\hline \multirow[t]{2}{*}{ GS-R-3 } & \multirow[t]{2}{*}{ GS-G-3.1 } & \multirow{2}{*}{$\begin{array}{c}\text { DS } 349 \\
2.25 \mathrm{a} \\
2.31\end{array}$} & \multirow{2}{*}{ 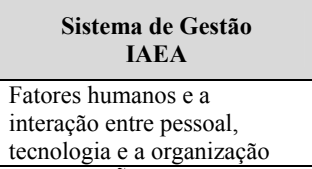 } & \multicolumn{2}{|r|}{$\begin{array}{l}\text { Sistema de Gestão Ambiental } \\
\text { ISO } 14001\end{array}$} & \multicolumn{2}{|r|}{$\begin{array}{c}\text { Sistema de Gestão de Segurança e Saúde no Trabalho } \\
\text { OHSAS } 18001\end{array}$} & \multicolumn{3}{|c|}{$\begin{array}{l}\text { Sistema de Gestão da Qualidade } \\
\text { ISO } 9001\end{array}$} \\
\hline & & & & NR & & NR & & NR & & \\
\hline \multirow[t]{4}{*}{$\begin{array}{l}2.6 \mathrm{a} \\
2.7\end{array}$} & & $\begin{array}{l}2.32 \mathrm{a} \\
2.35\end{array}$ & $\begin{array}{l}\text { GRADAÇÃO DA APLICA- } \\
\text { ÇÃO DOS REQUISITOS } \\
\text { DO SISTEMA DE GESTÃO }\end{array}$ & NR & & NR & & NR & & \\
\hline & $\begin{array}{c}2.37 \mathrm{a} \\
2.40\end{array}$ & & Abordagem por gradação & NR & & NR & & NR & & \\
\hline & $\begin{array}{l}2.41 \mathrm{a} \\
2.44\end{array}$ & & Processo de gradação & NR & & NR & & NR & & \\
\hline & & $\begin{array}{l}\text { Ap. } \\
\text { VII.2 }\end{array}$ & $\begin{array}{l}\text { Gradação dos requisitos do } \\
\text { SG para estágio de operação }\end{array}$ & NR & & NR & & NR & & \\
\hline \multirow[t]{4}{*}{3} & 3 & 3 & $\begin{array}{l}\text { RESPONSABILIDADE DA } \\
\text { DIREÇÃO (Título) }\end{array}$ & & & & & & 5 & $\begin{array}{l}\text { RESPONSABILIDADE DA } \\
\text { DIREÇÃO (Título) }\end{array}$ \\
\hline & & 3.16 & Política da qualidade & NR & & NR & & SP & 5.3 & Política da qualidade \\
\hline & & 3.17 & $\begin{array}{l}\text { Política de mudança de } \\
\text { gestão }\end{array}$ & NR & & NR & & NR & & \\
\hline & & 3.18 & Política de proteção física & NR & & NR & & NR & & \\
\hline \multirow[t]{3}{*}{4} & 4 & 4 & $\begin{array}{l}\text { GESTÃO DE RECURSOS } \\
\text { (Título) }\end{array}$ & & & & & & 6 & GESTÃO DE RECURSOS (Título) \\
\hline & 4.29 & & Ambiente de trabalho & NR & & NR & & $\mathrm{SC}$ & 6.4 & Ambiente de trabalho \\
\hline & & $\begin{array}{c}4.16 \mathrm{a} \\
4.17\end{array}$ & $\begin{array}{l}\text { Substituição de tecnologias } \\
\text { obsoletas }\end{array}$ & NR & & NR & & NR & & \\
\hline \multirow[t]{2}{*}{5} & 5 & 5 & $\begin{array}{l}\text { IMPLEMENTAÇÃO DO } \\
\text { PROCESSO (Título) }\end{array}$ & & & & & & & \\
\hline & & $\begin{array}{l}5.2 \mathrm{a} \\
5.4\end{array}$ & Modelo de processo & NR & & NR & & NR & & \\
\hline \multirow[t]{5}{*}{5.11} & & & $\begin{array}{l}\text { PROCESSOS DE SISTEMA } \\
\text { DE GESTÃO GENÉRICOS } \\
\text { (Título) }\end{array}$ & & & & & & & \\
\hline & & $\begin{array}{c}5.20 \mathrm{a} \\
5.22\end{array}$ & $\begin{array}{l}\text { Produtos de categoria } \\
\text { comercial }\end{array}$ & NR & & NR & & Ad & 7.4.1 & Processo de aquisição \\
\hline & & $\begin{array}{l}5.23 \mathrm{a} \\
5.161\end{array}$ & $\begin{array}{l}\text { PROCESSOS COMUNS A } \\
\text { TODOS OS ESTÁGIOS } \\
\text { (Título) }\end{array}$ & & & & & & & \\
\hline & & $\begin{array}{l}5.24 \mathrm{a} \\
5.41\end{array}$ & $\begin{array}{l}\text { Administração do } \\
\text { empreendimento (Project) }\end{array}$ & NR & & NR & & $\mathrm{SP}$ & 7.1 & $\begin{array}{l}\text { Planejamento da realização do } \\
\text { produto }\end{array}$ \\
\hline & & $\begin{array}{c}5.24 \mathrm{a} \\
5.41\end{array}$ & $\begin{array}{l}\text { Administração do } \\
\text { empreendimento (Project) }\end{array}$ & NR & & NR & & $\begin{array}{c}\mathrm{NC} \\
\mathrm{p}\end{array}$ & 7.2.1 & $\begin{array}{l}\text { Determinação de requisitos } \\
\text { relacionados ao produto }\end{array}$ \\
\hline
\end{tabular}




\begin{tabular}{|c|c|c|c|c|c|c|c|c|c|c|}
\hline \multirow[t]{2}{*}{ GS-R-3 } & \multirow[t]{2}{*}{ GS-G-3.1 } & \multirow{2}{*}{$\begin{array}{c}\text { DS } 349 \\
5.24 \mathrm{a} \\
5.41 \\
\end{array}$} & \multirow{2}{*}{\begin{tabular}{c}
\multicolumn{1}{c}{$\begin{array}{c}\text { Sistema de Gestão } \\
\text { IAEA }\end{array}$} \\
$\begin{array}{l}\text { Administração do } \\
\text { empreendimento (Project) }\end{array}$
\end{tabular}} & \multicolumn{2}{|r|}{$\begin{array}{l}\text { Sistema de Gestão Ambiental } \\
\text { ISO } 14001\end{array}$} & \multicolumn{2}{|r|}{$\begin{array}{c}\text { Sistema de Gestão de Segurança e Saúde no Trabalho } \\
\text { OHSAS } 18001\end{array}$} & \multicolumn{3}{|c|}{$\begin{array}{l}\text { Sistema de Gestão da Qualidade } \\
\text { ISO } 9001\end{array}$} \\
\hline & & & & NR & & NR & & $\mathrm{Cp}$ & 7.2 .1 & $\begin{array}{l}\text { Requisitos de entrega e pós-entrega e } \\
\text { outros não declarados, relacionados } \\
\text { ao produto }\end{array}$ \\
\hline & & $\begin{array}{c}5.24 \mathrm{a} \\
5.41\end{array}$ & $\begin{array}{l}\text { Administração do } \\
\text { empreendimento (Project) }\end{array}$ & NR & & NR & & $\mathrm{SC}$ & 7.2 .2 & $\begin{array}{l}\text { Análise crítica dos requisitos } \\
\text { relacionados ao produto }\end{array}$ \\
\hline & & $\begin{array}{c}5.24 \mathrm{a} \\
5.41\end{array}$ & $\begin{array}{l}\text { Administração do } \\
\text { empreendimento (Project) }\end{array}$ & NR & & NR & & SP & 7.2 .3 & Comunicação com o cliente \\
\hline & & $\begin{array}{c}5.52 \mathrm{a} \\
5.58\end{array}$ & Segurança do Pessoal (Título) & & & & & NR & & \\
\hline & & $\begin{array}{c}5.64 \mathrm{a} \\
5.66\end{array}$ & Projeto & NR & & NR & & SP & 7.3.1 & $\begin{array}{l}\text { Planejamento do projeto e } \\
\text { desenvolvimento }\end{array}$ \\
\hline & & 5.67 & $\begin{array}{l}\text { Iniciação, escopo e } \\
\text { planejamento de projeto }\end{array}$ & NR & & NR & & Ad & 7.3.1 & $\begin{array}{l}\text { Planejamento do projeto e } \\
\text { desenvolvimento }\end{array}$ \\
\hline & & $\begin{array}{c}5.70 \mathrm{a} \\
5.71\end{array}$ & $\begin{array}{l}\text { Seleção do projetista } \\
\text { principal }\end{array}$ & NR & & NR & & Ad & 7.3.1 & $\begin{array}{l}\text { Planejamento do projeto e } \\
\text { desenvolvimento }\end{array}$ \\
\hline & & $\begin{array}{c}5.72 \mathrm{a} \\
5.76\end{array}$ & $\begin{array}{l}\text { Controle do trabalho e } \\
\text { planejamento das atividades } \\
\text { de projeto }\end{array}$ & NR & & NR & & SP & 7.3.1 & $\begin{array}{l}\text { Planejamento do projeto e } \\
\text { desenvolvimento }\end{array}$ \\
\hline & & $\begin{array}{c}5.81 \mathrm{a} \\
5.82\end{array}$ & $\begin{array}{l}\text { Análise crítica dos conceitos } \\
\text { de projeto e seleção da } \\
\text { abordagem apropriada }\end{array}$ & NR & & NR & & Ad & 7.3.2 & $\begin{array}{l}\text { Entradas de projeto e } \\
\text { desenvolvimento }\end{array}$ \\
\hline & & $\begin{array}{c}5.83 \mathrm{a} \\
5.84\end{array}$ & $\begin{array}{l}\text { Seleção de ferramentas de } \\
\text { projeto e software }\end{array}$ & NR & & NR & & NR & & \\
\hline & & 5.92 & $\begin{array}{l}\text { Definição do envelope de } \\
\text { operação segura }\end{array}$ & NR & & NR & & NR & & \\
\hline & & $\begin{array}{l}5.114 \mathrm{a} \\
5.119\end{array}$ & $\begin{array}{l}\text { Gestão das linhas de base e } \\
\text { controle de alteração de } \\
\text { projeto }\end{array}$ & NR & & NR & & $\mathrm{SC}$ & 7.3.7 & $\begin{array}{l}\text { Controle de alterações de projeto e } \\
\text { desenvolvimento }\end{array}$ \\
\hline & & $\begin{array}{l}5.120 \mathrm{a} \\
5.127\end{array}$ & Gestão de configuração & NR & & NR & & $\mathrm{Ad}$ & 7.5.3 & Identificação e rastreabilidade \\
\hline & & $\begin{array}{c}5.140 \mathrm{a} \\
5.141\end{array}$ & Gestão do inventário & NR & & NR & & NR & & \\
\hline & & $\begin{array}{l}5.142 \mathrm{a} \\
5.143\end{array}$ & $\begin{array}{l}\text { Identificação e etiquetagem } \\
\text { de sistemas, estruturas e } \\
\text { componentes }\end{array}$ & NR & & NR & & SP & 7.5.3 & Identificação e rastreabilidade \\
\hline & & $\begin{array}{c}5.156 \mathrm{a} \\
5.159\end{array}$ & Tecnologia da informação & NR & & NR & & NR & & \\
\hline & 6.1 a 6.3 & & Aspectos gerais & NR & & NR & & $\mathrm{SC}$ & 8.1 & Generalidades \\
\hline 6.2 & & & AUTO-AVALIAÇ̃̃O & NR & & NR & & NR & & \\
\hline
\end{tabular}




\begin{tabular}{|c|c|c|c|c|c|c|c|c|c|c|}
\hline \multirow[t]{2}{*}{ GS-R-3 } & \multirow{2}{*}{$\begin{array}{l}\text { GS-G-3.1 } \\
6.6 \text { a } 6.11\end{array}$} & \multirow{2}{*}{$\begin{array}{c}\text { DS } 349 \\
6.2 \mathrm{a} \\
6.3 \\
\end{array}$} & \multirow{2}{*}{\begin{tabular}{l}
\multicolumn{1}{c}{$\begin{array}{c}\text { Sistema de Gestão } \\
\text { IAEA }\end{array}$} \\
$\begin{array}{l}\text { Auto-avaliação pela alta } \\
\text { direção }\end{array}$ \\
\end{tabular}} & \multicolumn{2}{|r|}{$\begin{array}{l}\text { Sistema de Gestão Ambiental } \\
\text { ISO } 14001\end{array}$} & \multicolumn{2}{|r|}{$\begin{array}{c}\text { Sistema de Gestão de Segurança e Saúde no Trabalho } \\
\text { OHSAS } 18001\end{array}$} & \multicolumn{3}{|c|}{$\begin{array}{l}\text { Sistema de Gestão da Qualidade } \\
\text { ISO } 9001\end{array}$} \\
\hline & & & & NR & & NR & & NR & & \\
\hline & $\begin{array}{c}6.12 \mathrm{a} \\
6.21\end{array}$ & $\begin{array}{l}6.4 \mathrm{a} \\
6.20 \\
\end{array}$ & $\begin{array}{l}\text { Auto-avaliação pelos } \\
\text { gerentes e indivíduos }\end{array}$ & NR & & NR & & NR & & \\
\hline & 6.22 & 6.21 & $\begin{array}{l}\text { Tipos de avaliação } \\
\text { independente }\end{array}$ & NR & & NR & & NR & & \\
\hline & & $\begin{array}{c}6.22 \mathrm{a} \\
6.25\end{array}$ & Avaliação pelos pares & NR & & NR & & NR & & \\
\hline & & $\begin{array}{c}6.26 \mathrm{a} \\
6.29\end{array}$ & Revisão técnica & NR & & NR & & NR & & \\
\hline & $\begin{array}{c}6.26 \mathrm{a} \\
6.30\end{array}$ & & Supervisão & NR & & NR & & NR & & \\
\hline & $\begin{array}{c}6.31 \mathrm{a} \\
6.44 \\
\end{array}$ & & $\begin{array}{l}\text { Responsabilidades da } \\
\text { unidade de avaliação }\end{array}$ & NR & & NR & & NR & & \\
\hline & & $\begin{array}{c}6.30 \mathrm{a} \\
6.34\end{array}$ & $\begin{array}{l}\text { Avaliação da cultura de } \\
\text { segurança }\end{array}$ & NR & & NR & & NR & & \\
\hline & & & & & & & & & 4.2 & $\begin{array}{l}\text { REQUISITOS DE } \\
\text { DOCUMENTAÇÃO (Título) }\end{array}$ \\
\hline & & & & & & & & & 5.5 & $\begin{array}{l}\text { RESPONSABILIDADE, } \\
\text { AUTORIDADE E } \\
\text { COMUNICAÇÃO (Título) }\end{array}$ \\
\hline & & & & & & & & & 5.6 & $\begin{array}{l}\text { ANÁLISE CRÍTICA PELA } \\
\text { DIREÇÃO (Título) }\end{array}$ \\
\hline & & & & & & & & & 6.2 & RECURSOS HUMANOS (Título) \\
\hline & & & & & & & & & 7.2 & $\begin{array}{l}\text { PROCESSOS RELACIONADOS A } \\
\text { CLIENTES (Título) }\end{array}$ \\
\hline & & & & & & & & & 7.3 & $\begin{array}{l}\text { PROJETO E } \\
\text { DESENVOLVIMENTO (Título) }\end{array}$ \\
\hline & & & & & & & & & 7.4 & AQUISIÇÃO (Título) \\
\hline & & & & & & & & & 7.5 & $\begin{array}{l}\text { PRODUÇÃO E FORNECIMENTO } \\
\text { DE SERVIÇO (Título) }\end{array}$ \\
\hline & & & & & & & & & 8.2 & $\begin{array}{l}\text { MEDIÇÃO E } \\
\text { MONITORAMENTO (Título) }\end{array}$ \\
\hline & & & & & & & & & 8.5 & MELHORIAS (Título) \\
\hline
\end{tabular}


APÊNDICE J - Correlação da Documentação Requerida pelas Normas de SG da IAEA (GS-R-3, GS-G-3.1 e DS349) e ISO 9001, ISO 14001 e OHSAS 18001.

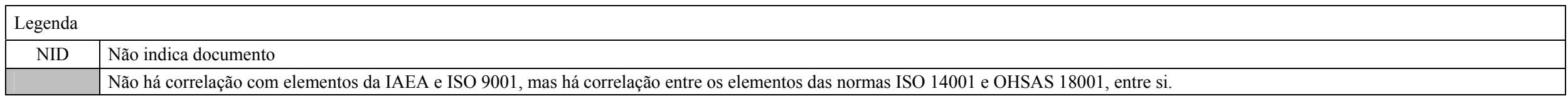

\begin{tabular}{|c|c|c|c|c|c|c|c|c|c|c|}
\hline PROCESSO & 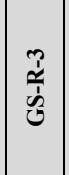 & $\begin{array}{l}\overline{0} \\
\vdots \\
\dot{b}\end{array}$ & $\begin{array}{l}\hat{\mathrm{m}} \\
\hat{n}\end{array}$ & $\begin{array}{c}\text { DOCUMENTAÇ̃̃o DO SG IAEA } \\
\text { (Geral) }\end{array}$ & $\begin{array}{l}\bar{\Xi} \\
\vdots \\
o \\
\mathscr{2}\end{array}$ & DOCUMENTAÇÃO DO SGQ (Geral) & 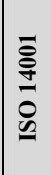 & DOCUMENT AÇÃO DO SGA (Geral) & 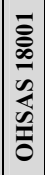 & DOCUMENTAÇÃO DO SGSST (Geral) \\
\hline \multirow{7}{*}{$\begin{array}{l}\text { Documentação do } \\
\text { SG }\end{array}$} & \begin{tabular}{|cc|c}
$\pi$ & 0 \\
0 & 0 \\
$i$ & $i$
\end{tabular} & & & $\begin{array}{l}\text { Documentação das políticas declaradas da } \\
\text { organização }\end{array}$ & \begin{tabular}{|l|}
$\vec{i}$ \\
$\dot{r}$ \\
\end{tabular} & $\begin{array}{l}\text { Declaração documentada da política da } \\
\text { qualidade }\end{array}$ & $\stackrel{\substack{+\dot{+}}}{+}$ & Documentação da política ambiental & \begin{tabular}{|l}
+ \\
$\stackrel{+}{+}$ \\
$\dot{+}$ \\
\end{tabular} & Documentação da política de SST \\
\hline & $\begin{array}{|ll|}\pi & 0 \\
\infty & 0 \\
i & i \\
i & i \\
\end{array}$ & & & Descrição do SG da organização & \begin{tabular}{|l|}
\multirow{H}{*}{} \\
$\dot{T}$ \\
\end{tabular} & Manual da qualidade - Escopo do SGQ & $\begin{array}{ll}\dot{H} \\
\dot{+} \\
\dot{*}\end{array}$ & Descrição do escopo do SGA & \begin{tabular}{|l|l}
$\stackrel{\leftrightarrow}{+}$ \\
$\dot{f}$ \\
\end{tabular} & Descrição do escopo do SGSST \\
\hline & 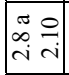 & & & Descrição do SG da organização & $\begin{array}{ll}\tilde{H} \\
\stackrel{+}{T} \\
\end{array}$ & Manual da qualidade - Escopo do SGQ & $\underset{+}{\stackrel{+}{+}}$ & Descrição do escopo do SGA & 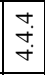 & Descrição do escopo do SGSST \\
\hline & $\begin{array}{ccc}\pi & 0 \\
\infty & 0 \\
i & i \\
\end{array}$ & & & Descrição da estrutura da organização & \begin{tabular}{|c|}
$-\vec{n}$ \\
$\dot{n}$ \\
$\dot{n}$
\end{tabular} & $\begin{array}{l}\text { Responsabilidade e autoridade definidas e } \\
\text { comunicadas (Norma não menciona } \\
\text { documentar) }\end{array}$ & $\underset{\sim}{\stackrel{+}{+}}$ & $\begin{array}{l}\text { Documentar funções, responsabilidades e } \\
\text { autoridade pelo SGA, com indicacão dos } \\
\text { representantes especificos pelo SGA }\end{array}$ & $\underset{+F}{\stackrel{+}{+}}$ & $\begin{array}{l}\text { Documentar funções, responsabilidades e } \\
\text { autoridade pelo SST, com identificação das } \\
\text { pessoas específicas pelo SST }\end{array}$ \\
\hline & \begin{tabular}{|l|}
0 \\
\\
$i$ \\
$\infty$ \\
$\infty$ \\
$i$ \\
\end{tabular} & & & $\begin{array}{l}\text { Descrição das responsabilidades funcionais, } \\
\text { prestação de contas, níveis de autoridade e } \\
\text { interação dos trabalhos gerenciais, de } \\
\text { execução e avaliação }\end{array}$ & $\begin{array}{c}\overrightarrow{\vec{n}} \\
\dot{n}\end{array}$ & $\begin{array}{l}\text { Responsabilidade e autoridade definidas e } \\
\text { comunicadas (Norma não menciona } \\
\text { documentar) }\end{array}$ & $\underset{+}{\stackrel{+}{+}}$ & $\begin{array}{l}\begin{array}{l}\text { Documentar funções, responsabilidades e } \\
\text { autoridade pelo SGA, com indicação dos } \\
\text { representantes específicos pelo SGA }\end{array} \\
\end{array}$ & $\underset{+\overrightarrow{+}}{\stackrel{+}{+}}$ & $\begin{array}{l}\text { Documentar funções, responsabilidades e } \\
\text { autoridade pelo SST, com identificação das } \\
\text { pessoas específicas pelo SST }\end{array}$ \\
\hline & $\begin{array}{|ll|}2 & 0 \\
\infty & 0 \\
i & i \\
i\end{array}$ & & & $\begin{array}{l}\text { Descrição dos processos e informações } \\
\text { suportes para os trabalhos SG da organização }\end{array}$ & $\underset{\substack{i \\
\dot{H}}}{ }$ & $\begin{array}{l}\text { Manual da qualidade - Descrição da interação } \\
\text { dos processos do SGQ }\end{array}$ & $\stackrel{\stackrel{t}{+}}{\underset{+}{+}}$ & $\begin{array}{l}\text { Descrição dos principais elementos do SGA } \\
\text { e sua interação }\end{array}$ & 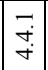 & $\begin{array}{l}\text { Descrição dos principais elementos do SGSST e } \\
\text { sua interação }\end{array}$ \\
\hline & & 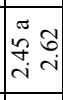 & 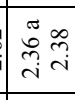 & $\begin{array}{l}\text { Documentos que descrevem o SG, } \\
\text { estabelecendo todos os controles e medidas } \\
\text { para a organização atingir suas metas }\end{array}$ & $\vec{i}$ & $\begin{array}{l}\text { Documentos para assegurar planejamento, a } \\
\text { operação e o controle eficazes de seus } \\
\text { processos }\end{array}$ & $\underset{\substack{++}}{+}$ & $\begin{array}{l}\text { Documentos, incluindo registros, para } \\
\text { assegurar planejamento, a operação e o } \\
\text { controle eficazes de seus processos }\end{array}$ & $\underset{\stackrel{+}{+}}{\stackrel{+}{+}}$ & $\begin{array}{l}\text { Documentos, incluindo registros, para assegurar } \\
\text { planejamento, a operação e o controle eficazes de } \\
\text { seus processos }\end{array}$ \\
\hline Planejamento & 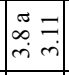 & & & $\begin{array}{l}\text { Estabelecimento de objetivos e metas (Plano } \\
\text { de negócio) }\end{array}$ & $\vec{i}$ & $\begin{array}{l}\text { Declaração documentada dos objetivos da } \\
\text { qualidade }\end{array}$ & $\stackrel{\stackrel{+}{+}}{\stackrel{+}{+}}$ & $\begin{array}{l}\text { Documentação dos objetivos e metas } \\
\text { ambientais }\end{array}$ & \begin{tabular}{l|}
$\stackrel{+}{+}$ \\
$\dot{+}$ \\
\end{tabular} & Documentação dos objetivos de SST \\
\hline $\begin{array}{l}\text { Responsabilidade } \\
\text { e autoridade pelo } \\
\text { SG }\end{array}$ & 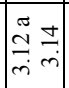 & & & $\begin{array}{l}\text { Indivíduo com responsabilidade e autoridade } \\
\text { específica pelo SG (Norma não menciona } \\
\text { documentar) }\end{array}$ & \begin{tabular}{|c|}
3 \\
$i$ \\
$i$ \\
\end{tabular} & $\begin{array}{l}\text { Membro da organização com responsabilidade } \\
\text { e autoridade específica pelo SG (Norma não } \\
\text { menciona documentar) }\end{array}$ & $\underset{\dot{F}}{F}$ & $\begin{array}{l}\text { Documentar funções, responsabilidades e } \\
\text { autoridade pelo SGA, com indicação dos } \\
\text { representantes específicos pelo SGA }\end{array}$ & $\underset{\dot{P}}{\overrightarrow{+}}$ & $\begin{array}{l}\text { Documentar funções, responsabilidades e } \\
\text { autoridade pelo SST, com identificação das } \\
\text { pessoas específicas pelo SST }\end{array}$ \\
\hline $\begin{array}{l}\text { Acordos de } \\
\text { interfaces }\end{array}$ & & 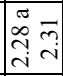 & & $\begin{array}{l}\text { Memorando de entendimento escrito que } \\
\text { formalize acordos de interfaces }\end{array}$ & $\hat{\mathrm{z}}$ & & $\hat{\mathrm{z}}$ & & $\mathrm{z}$ & \\
\hline \multirow{2}{*}{$\begin{array}{l}\text { Implementação do } \\
\text { SG }\end{array}$} & \multirow{2}{*}{\multicolumn{2}{|c|}{ 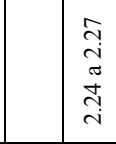 }} & & Plano para a completa implementação do SG & 至 & & 会 & & 至 & \\
\hline & & & & $\begin{array}{l}\text { Planos para avaliação da efetividade das } \\
\text { instruções de trabalho e suas implementações }\end{array}$ & 豆 & & 会 & & 至 & \\
\hline $\begin{array}{l}\text { Cultura de } \\
\text { segurança }\end{array}$ & & & iे & $\begin{array}{l}\text { Planos para objetivos e prioridades de curto e } \\
\text { longo prazo, incluindo cultura de segurança }\end{array}$ & 会 & & 会 & & 夏 & \\
\hline
\end{tabular}




\begin{tabular}{|c|c|c|c|c|c|c|c|c|c|c|}
\hline PROCESSO & 装 & $\begin{array}{l}\overline{0} \\
\vdots \\
\dot{3}\end{array}$ & $\begin{array}{l}\overrightarrow{\mathrm{m}} \\
\hat{n}\end{array}$ & $\begin{array}{l}\text { DOCUMENTAÇ̃̃O DO SG IAEA } \\
\text { (Geral) }\end{array}$ & 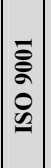 & DOCUMENTAÇÃO DO SGQ (Geral) & 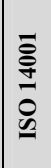 & DOCUMENTAÇÃO DO SGA (Geral) & 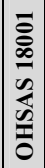 & DOCUMENTAÇÃO DO SGSST (Geral) \\
\hline & & & $\stackrel{\circ}{i}$ & $\begin{array}{l}\text { Plano para sucessão com desenvolvimento de } \\
\text { futuros gerentes, incluindo aspectos cultura } \\
\text { de segurança }\end{array}$ & 豆 & & 合 & & 豆 & \\
\hline & & & 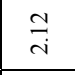 & $\begin{array}{l}\text { Registro de horas extras para avaliação das } \\
\text { condições (pressão) de trabalho }\end{array}$ & 豆 & & 豆 & & 豆 & \\
\hline & & & 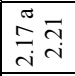 & $\begin{array}{l}\text { Programa específico de mudança de cultura } \\
\text { de segurança }\end{array}$ & 豆 & & 会 & & 会 & \\
\hline $\begin{array}{l}\text { Satisfação das } \\
\text { partes } \\
\text { interessadas }\end{array}$ & & $\dot{m}$ & & Não indica documento & 会 & & $\underset{r}{\ddot{q}}$ & $\begin{array}{l}\text { Registros de avaliações periódicas } \\
\text { atendimento requisitos legais e outros }\end{array}$ & $\mid \begin{array}{c}n \\
\sim \\
\sim \\
\sim\end{array}$ & $\begin{array}{l}\text { Registros de avaliações periódicas atendimento } \\
\text { requisitos legais e outros }\end{array}$ \\
\hline $\begin{array}{l}\text { Responsabilidade } \\
\text { e autoridade pelo } \\
\text { SG }\end{array}$ & & & 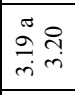 & $\begin{array}{l}\text { Relatórios periódicos, dos donos dos } \\
\text { processos, sobre o status de seus processos } \\
\text { de SG }\end{array}$ & 会 & & 合 & & 会 & \\
\hline \multirow{5}{*}{$\begin{array}{l}\text { Recursos } \\
\text { humanos }\end{array}$} & & & $\underset{ғ}{\exists}$ & $\begin{array}{l}\text { Plano de recurso humano que defina } \\
\text { quantidade e níveis de competência do } \\
\text { pessoal }\end{array}$ & 会 & & 会 & & 会 & \\
\hline & & \multirow{4}{*}{ 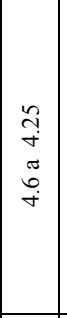 } & & Plano de treinamento para a organização & 豆 & & 宗 & & 至 & \\
\hline & & & & $\begin{array}{l}\text { Planos de treinamento individual para alta } \\
\text { direção }\end{array}$ & 会 & & 学 & & 豆 & \\
\hline & & & & \multirow{2}{*}{ Não indica documento } & \multirow{2}{*}{ సู่ } & \multirow{2}{*}{$\begin{array}{l}\text { Registro de educação, treinamento, habilidade } \\
\text { e experiência }\end{array}$} & 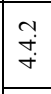 & $\begin{array}{l}\text { Registros associados à competência do } \\
\text { pessoal (formação, treinamento e } \\
\text { experiência) }\end{array}$ & 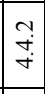 & $\begin{array}{l}\text { Registros associados à competência do pessoal } \\
\text { (formação, treinamento e experiência) }\end{array}$ \\
\hline & & & & & & & $\stackrel{\stackrel{\sim}{+}}{+}$ & $\begin{array}{l}\text { Registros associados ao treinamento, ou } \\
\text { outra ação, associação oos aspectos } \\
\text { ambientais e ao seu SGA }\end{array}$ & 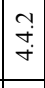 & $\begin{array}{l}\text { Registros associados ao treinamento, ou outra } \\
\text { ação, associado aos riscos e ao SST }\end{array}$ \\
\hline \multirow{3}{*}{ Infra-estrutura } & & 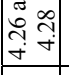 & & Planos para infra-estrutura & 会 & & 豆 & & 至 & \\
\hline & & \multirow{2}{*}{\multicolumn{2}{|c|}{$\begin{array}{l}\cong \\
\sim \\
\sim \\
\tilde{J} \\
\stackrel{+}{+}\end{array}$}} & $\begin{array}{l}\text { Plano de preservação, manutenção, destaque } \\
\text { ou substituição do patrimônio }\end{array}$ & 会 & & 学 & & 会 & \\
\hline & & & & $\begin{array}{l}\text { Registros de todos materiais patrimoniados } \\
\text { significativos }\end{array}$ & 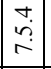 & Registro de propriedade do cliente & 合 & & 至 & \\
\hline \multirow[t]{4}{*}{$\begin{array}{l}\text { Controle de } \\
\text { documentos }\end{array}$} & \multirow{4}{*}{ 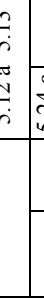 } & & & Registrar mudanças nos documentos de SG & 合 & & 官 & & 会 & \\
\hline & & 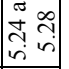 & & Não indica documento & 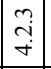 & Procedimento de controle de documentos & 会 & & 会 & \\
\hline & & 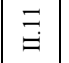 & & $\begin{array}{l}\text { Registro de comentários e resoluções de } \\
\text { análise crítica de documentos do SG }\end{array}$ & 合 & & 穵 & & 豆 & \\
\hline & & $\stackrel{\overbrace{}}{\Theta}$ & & $\begin{array}{l}\text { Registro de recebimento e correção de } \\
\text { documentos gerados e controlados } \\
\text { externamente }\end{array}$ & 至 & & 合 & & 豆 & \\
\hline
\end{tabular}




\begin{tabular}{|c|c|c|c|c|c|c|c|c|c|c|}
\hline PROCESSO & 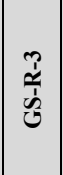 & $\begin{array}{l}\overline{0} \\
\vdots \\
\dot{1} \\
0\end{array}$ & $\begin{array}{l}\overrightarrow{\mathrm{m}} \\
\hat{n}\end{array}$ & $\begin{array}{c}\text { DOCUMENTAÇ̃̃o DO SG IAEA } \\
\text { (Geral) }\end{array}$ & $\begin{array}{l}\bar{\Xi} \\
\vdots \\
0 \\
\mathscr{n}\end{array}$ & DOCUMENTAÇÃO DO SGQ (Geral) & 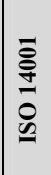 & DOCUMENTAÇÃO DO SGA (Geral) & 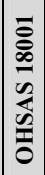 & DOCUMENTAÇÃO DO SGSST (Geral) \\
\hline & & 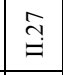 & & $\begin{array}{l}\text { Registro em forma de cópia mestra de } \\
\text { documentos dos SG, cancelados }\end{array}$ & 豆 & & 会 & & 豆 & \\
\hline \multirow{6}{*}{$\begin{array}{l}\text { Controle de } \\
\text { produtos }\end{array}$} & 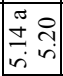 & & & $\begin{array}{l}\text { Registrar a identificação única do produto, } \\
\text { quando requerido rastreabilidade }\end{array}$ & 急 & $\begin{array}{l}\text { Registro de identificação única do produto e } \\
\text { rastreabilidade }\end{array}$ & 言 & & 豆 & \\
\hline & & \multirow{2}{*}{\multicolumn{2}{|c|}{$\begin{array}{l}n \\
i n \\
\tilde{n} \\
\tilde{n} \\
\tilde{n}\end{array}$}} & $\begin{array}{l}\text { Registrar a mudança nos valores dos } \\
\text { indicadores de desempenho de cada processo }\end{array}$ & 会 & & 会 & & 豆 & \\
\hline & & & & Não indica documento & $\stackrel{\substack{n\\
}}{\sim}$ & $\begin{array}{l}\text { Registro de validação de processos de } \\
\text { produção e de serviços associados }\end{array}$ & 会 & & 会 & \\
\hline & & & \multirow{3}{*}{ 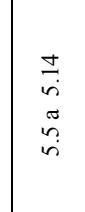 } & $\begin{array}{l}\text { Relatório de inspeções e testes, conforme } \\
\text { requerido }\end{array}$ & \multirow{2}{*}{$\vec{r}$} & \multirow{2}{*}{$\begin{array}{l}\text { Registro de evidência de que os processos de } \\
\text { realização e o produto resultante atende a } \\
\text { especificação }\end{array}$} & 穵 & & 至 & \\
\hline & & & & Documentar e avaliar os resultados de testes & & & 官 & & 会 & \\
\hline & & & & Planos de inspeção e testes & 会 & & $\hat{\mathrm{z}}$ & & $\hat{z}$ & \\
\hline \multirow{3}{*}{$\begin{array}{l}\text { Controle de } \\
\text { equipamentos de } \\
\text { inspeção e teste }\end{array}$} & & & & $\begin{array}{l}\text { Procedimentos de calibração de } \\
\text { equipamentos de inspeção e teste }\end{array}$ & 会 & & 学 & & 豆 & \\
\hline & & & $\begin{array}{l}n \\
\infty \\
\infty\end{array}$ & $\begin{array}{l}\text { Registro do status da calibração de } \\
\text { equipamentos de medição e teste }\end{array}$ & \multirow{2}{*}{$\stackrel{\circ}{r}$} & \multirow{2}{*}{$\begin{array}{l}\text { Registro de resultados de calibração e } \\
\text { verificação de dispositivos de medição e } \\
\text { monitoramento }\end{array}$} & \multirow{2}{*}{$\vec{n}$} & \multirow{2}{*}{$\begin{array}{l}\text { Registros associados à calibração e } \\
\text { verificação dos equipamentos utilizados na } \\
\text { monitoração e medição }\end{array}$} & \multirow{2}{*}{$\overrightarrow{i n}$} & \multirow{2}{*}{$\begin{array}{l}\text { Registros dos resultados da calibração e } \\
\text { manutençãa de equipamentos utilizados na } \\
\text { monitoração e medição }\end{array}$} \\
\hline & & & in & $\begin{array}{l}\text { Registros da extensão e freqüênncia do } \\
\text { controle da verificação de hardware e } \\
\text { software de teste, usados para inspeçãa }\end{array}$ & & & & & & \\
\hline $\begin{array}{l}\text { Controle de } \\
\text { registros }\end{array}$ & 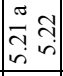 & 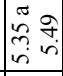 & & Não indica documento & 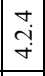 & Procedimento de controle de registro & 穵 & & 豆 & \\
\hline \multirow{4}{*}{ Aquisição } & \multirow{4}{*}{ 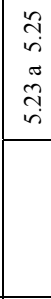 } & & & $\begin{array}{l}\text { Documentos de aquisição especificando } \\
\text { requisitos de compras }\end{array}$ & 合 & & 会 & & 豆 & \\
\hline & & & & Não indica documento & $\underset{\sim}{\stackrel{\sim}{\leftarrow}}$ & $\begin{array}{l}\text { Registro de avaliação de fornecedores e de } \\
\text { quaisquer ações necessárias }\end{array}$ & 会 & & 会 & \\
\hline & & & 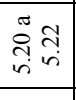 & $\begin{array}{l}\text { Registros e documentos que substanciem a } \\
\text { conformidade de produtos de grau comercial } \\
\text { usados em funções que envolvem segurança }\end{array}$ & 会 & & 合 & & 会 & \\
\hline & & $\stackrel{\sim}{\Xi}$ & & $\begin{array}{l}\text { Registros e amostras de materiais requeridos } \\
\text { de fornecedores }\end{array}$ & 会 & & 合 & & 至 & \\
\hline Comunicação & & $\begin{array}{ll}\pi & 0 \\
i & n \\
i n & i n\end{array}$ & & $\begin{array}{l}\text { Canal apropriado de comunicação (Cartas, e- } \\
\text { mail, reuniões) }\end{array}$ & $\hat{z}$ & & $\stackrel{\stackrel{m}{P}}{+}$ & $\begin{array}{l}\text { Documentar decisão de comunicar } \\
\text { externamente seus aspectos ambientais } \\
\text { significativos }\end{array}$ & 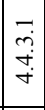 & $\begin{array}{l}\text { Documentar a comunicação pertinente sobre } \\
\text { perigos de SST oriundas de partes interessadas } \\
\text { externas }\end{array}$ \\
\hline $\begin{array}{l}\text { Gestão da } \\
\text { mudança } \\
\text { organizacional }\end{array}$ & 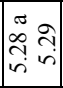 & & & $\begin{array}{l}\text { Registrar a implementação de mudanças } \\
\text { organizacionais do SG }\end{array}$ & 会 & & 学 & & 吾 & \\
\hline
\end{tabular}




\begin{tabular}{|c|c|c|c|c|c|c|c|c|c|c|}
\hline PROCESSO & 荇 & $\begin{array}{l}\bar{j} \\
\dot{b} \\
\dot{3}\end{array}$ & $\begin{array}{l}\hat{\mathrm{m}} \\
\hat{n}\end{array}$ & $\begin{array}{c}\text { DOCUMENTAÇ̃̃o DO SG IAEA } \\
\text { (Geral) }\end{array}$ & 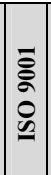 & DOCUMENTAÇÃO DO SGQ (Geral) & 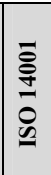 & DOCUMENTAÇÃO DO SGA (Geral) & 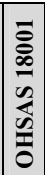 & DOCUMENTAÇÃO DO SGSST (Geral) \\
\hline \multirow{6}{*}{$\begin{array}{l}\text { Gestão de } \\
\text { empreendimentos } \\
\text { ("Project") }\end{array}$} & & & \multirow{6}{*}{$\begin{array}{l}\vec{F} \\
\dot{n} \\
\tilde{\sigma} \\
\tilde{J} \\
i \\
i\end{array}$} & Documentação de SG do empreendimento & $\hat{\mathrm{z}}$ & & $\mathrm{z}$ & & $\hat{z}$ & \\
\hline & & & & $\begin{array}{l}\text { Plano para implementação do } \\
\text { empreendimento }\end{array}$ & $\hat{z}$ & & 会 & & 会 & \\
\hline & & & & $\begin{array}{l}\text { Plano estruturação e mobilização organizaci- } \\
\text { onal fase de implementação empreendimento }\end{array}$ & 合 & & 会 & & 目 & \\
\hline & & & & $\begin{array}{l}\text { Plano gestão de risco (definir metodologia e } \\
\text { ferramentas p/ identificar e avaliar riscos do } \\
\text { empreendimento) }\end{array}$ & 夏 & & 学 & & 至 & \\
\hline & & & & \multirow{2}{*}{ Não indica documento } & 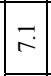 & $\begin{array}{l}\text { Registro evidência que processos realização e } \\
\text { produto resultante atende a especificação }\end{array}$ & 言 & & 会 & \\
\hline & & & & & 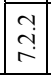 & $\begin{array}{l}\text { Registro de análise crítica dos requisitos } \\
\text { relacionados c/ produto e ações resultantes }\end{array}$ & 会 & & 会 & \\
\hline \multirow{2}{*}{$\begin{array}{l}\text { Avaliação de risco } \\
\text { do local de } \\
\text { trabalho }\end{array}$} & & & \multirow{2}{*}{ 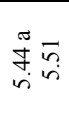 } & Documentar análise risco local de trabalho & \multirow{2}{*}{ 合 } & & \multirow{2}{*}{$\overrightarrow{\vec{m}}$} & \multirow{2}{*}{$\begin{array}{l}\text { Documentar a identificação dos aspectos } \\
\text { ambientais determinação dos impactos } \\
\text { significativos sobre o meio ambiente }\end{array}$} & \multirow{2}{*}{$\vec{j}$} & \multirow{2}{*}{$\begin{array}{l}\text { Documentar a identificação de perigos, a } \\
\text { avaliação de riscos e os controles determinados }\end{array}$} \\
\hline & & & & $\begin{array}{l}\text { Registro da completa avaliação de risco no } \\
\text { local de trabalho }\end{array}$ & & & & & & \\
\hline $\begin{array}{l}\text { Segurança } \\
\text { industrial }\end{array}$ & & & 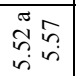 & Programa de segurança industrial & 豆 & & 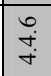 & $\begin{array}{l}\text { Procedimentos situações que possam } \\
\text { acarretar desvios de SGA }\end{array}$ & 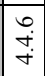 & $\begin{array}{l}\text { Procedimentos situações que possam acarretar } \\
\text { desvios de SST }\end{array}$ \\
\hline $\begin{array}{l}\text { Segurança } \\
\text { radiológica }\end{array}$ & & & $\stackrel{\infty}{n}$ & & & & $\overrightarrow{i n}$ & $\begin{array}{l}\text { Documentos com informações para } \\
\text { monitorar desempenho, controles } \\
\text { operacionais e conformidade com objetivos }\end{array}$ & $\overrightarrow{\dot{n}}$ & $\begin{array}{l}\text { Registrar dados e resultados do monitoramento e } \\
\text { medição para análise de ações corretivas e } \\
\text { preventivas }\end{array}$ \\
\hline $\begin{array}{l}\text { Controle e } \\
\text { supervisão de } \\
\text { contratados }\end{array}$ & & & 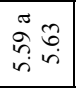 & $\begin{array}{l}\text { Relatório de análise de segurança de } \\
\text { contratados cujo trabalho tem impacto na } \\
\text { segurança nuclear }\end{array}$ & 会 & & $\overrightarrow{\dot{p}}$ & $\begin{array}{l}\text { Documentar a identificação dos aspectos } \\
\text { ambientais e a determinacão dos impactos } \\
\text { significativos sobre o meio ambiente }\end{array}$ & $\overrightarrow{\dot{m}}$ & $\begin{array}{l}\text { Documentar a identificação de perigos, a } \\
\text { avaliação de riscos e os controles determinados }\end{array}$ \\
\hline \multirow{4}{*}{ Projeto } & & & 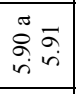 & $\begin{array}{l}\text { Relatórios de análise de segurança e análises } \\
\text { de segurança probabilística, atualizados } \\
\text { quando requerido }\end{array}$ & 会 & & $\overrightarrow{\dot{m}}$ & $\begin{array}{l}\text { Documentar a identificacac̃o dos aspectos } \\
\text { ambientais determinaça dos impactos } \\
\text { significativos sobre o meio ambiente }\end{array}$ & $\vec{i}$ & $\begin{array}{l}\text { Documentar a identificacãa de perigos, a } \\
\text { avaliação de riscos e os controles determinados }\end{array}$ \\
\hline & & & 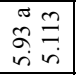 & $\begin{array}{l}\text { Documento de especificação de requisitos de } \\
\text { teste }\end{array}$ & 会 & & 会 & & 目 & \\
\hline & & & \multirow{2}{*}{ 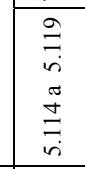 } & $\begin{array}{l}\text { Documentar mudanças permanentes ou } \\
\text { temporárias durante a construção, } \\
\text { comissionamento e operação }\end{array}$ & 夏 & & 会 & & 至 & \\
\hline & & & & $\begin{array}{l}\text { Procedimento para permissão de desvio e } \\
\text { concessões }\end{array}$ & 豆 & & 完 & & 会 & \\
\hline $\begin{array}{l}\text { Controle de } \\
\text { configuração }\end{array}$ & & & 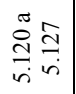 & $\begin{array}{l}\text { Documentação de configuração do } \\
\text { estabelecimento }\end{array}$ & 豆 & & 会 & & 至 & \\
\hline Manutenção & & & $\underset{i}{\vec{i}}$ & Não indica documento & 会 & & $\underset{\sim}{\ddot{q}}$ & $\begin{array}{l}\text { Documentos com informações para } \\
\text { monitorar desempenho, controles } \\
\text { operacionais e conformidade com objetivos }\end{array}$ & 会 & \\
\hline
\end{tabular}




\begin{tabular}{|c|c|c|c|c|c|c|c|c|c|c|}
\hline PROCESSO & $\frac{\hat{2}}{\frac{2}{3}}$ & $\begin{array}{l}\overline{0} \\
\vdots \\
\dot{1} \\
\dot{0}\end{array}$ & $\begin{array}{l}\text { से } \\
\stackrel{0}{a}\end{array}$ & $\begin{array}{c}\text { DOCUMENTAÇÃO DO SG IAEA } \\
\text { (Geral) }\end{array}$ & $\begin{array}{l}\bar{\vdots} \\
\hat{\vdots} \\
\vdots \\
\varrho\end{array}$ & DOCUMENTAÇÃO DO SGQ (Geral) & 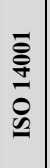 & DOCUMENTAÇÃO DO SGA (Geral) & 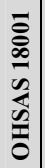 & DOCUMENTAÇÃO DO SGSST (Geral) \\
\hline $\begin{array}{l}\text { Manuseio e } \\
\text { estoque }\end{array}$ & & & 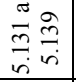 & $\begin{array}{l}\text { Documentar a remoção e entrada de itens } \\
\text { estocados }\end{array}$ & 会 & & 会 & & 合 & \\
\hline $\begin{array}{l}\text { Gestão do } \\
\text { inventário }\end{array}$ & & & 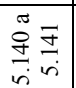 & $\begin{array}{l}\text { Registro de inventário do material estocado } \\
\text { (alinhado ao processo de aquisição) }\end{array}$ & 会 & & 会 & & 会 & \\
\hline \multirow{2}{*}{ Gestão de rejeitos } & & & \multirow{2}{*}{ 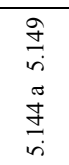 } & \multirow[t]{2}{*}{ Registros de controle de rejeitos radioativos } & \multirow{2}{*}{ 合 } & & $\vec{m} \dot{\sim}$ & $\begin{array}{l}\text { Documentar a identificação dos aspectos } \\
\text { ambientais determinação dos impactos } \\
\text { significativos sobre o meio ambiente }\end{array}$ & $\overrightarrow{\dot{m}}$ & $\begin{array}{l}\text { Documentar a identificação dos aspectos } \\
\text { ambientais determinação dos impactos } \\
\text { significativos sobre o meio ambiente }\end{array}$ \\
\hline & & & & & & & $\begin{array}{ll}\stackrel{\bullet}{+} \\
\stackrel{+}{+}\end{array}$ & $\begin{array}{l}\text { Procedimentos situações que possam } \\
\text { acarretar desvios de SGA }\end{array}$ & \begin{tabular}{|l|}
$\stackrel{+}{*}$ \\
$\dot{+}$ \\
\end{tabular} & $\begin{array}{l}\text { Procedimentos situações que possam acarretar } \\
\text { desvios de SGA }\end{array}$ \\
\hline \multirow{2}{*}{ Gestão ambiental } & & & \multirow{2}{*}{ 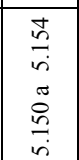 } & \multirow{2}{*}{ Não indica documento } & \multirow{2}{*}{ 豆 } & & $\underset{\dot{m}}{\overrightarrow{+}}$ & $\begin{array}{l}\text { Documentar a identificação dos aspectos } \\
\text { ambientais determinação dos impactos } \\
\text { significativos sobre o meio ambiente }\end{array}$ & $\underset{\dot{m}}{\dot{+}}$ & $\begin{array}{l}\text { Documentar a identificação dos aspectos } \\
\text { ambientais determinação dos impactos } \\
\text { significativos sobre o meio ambiente }\end{array}$ \\
\hline & & & & & & & \begin{tabular}{l|l}
$\stackrel{\circ}{+}$ \\
$\dot{+}$ \\
$\dot{f}$ \\
\end{tabular} & $\begin{array}{l}\text { Procedimentos situações que possam } \\
\text { acarretar desvios de SGA }\end{array}$ & \begin{tabular}{|l|}
$\stackrel{\circ}{+}$ \\
$\dot{+}$ \\
\end{tabular} & $\begin{array}{l}\text { Procedimentos situações que possam acarretar } \\
\text { desvios de SGA }\end{array}$ \\
\hline $\begin{array}{l}\text { Monitoração e } \\
\text { medição }\end{array}$ & $\overrightarrow{6}$ & 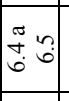 & & Não indica documento & 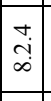 & $\begin{array}{l}\text { Registro de monitoramento e medição de } \\
\text { produto }\end{array}$ & $\vec{n}$ & $\begin{array}{l}\text { Documentos com informações para } \\
\text { monitorar desempenho, controles } \\
\text { operacionais e conformidade com objetivos }\end{array}$ & \begin{tabular}{|r|}
$\dot{m}$ \\
$\dot{+}$ \\
\end{tabular} & $\begin{array}{l}\text { Registrar dados e resultados do monitoramento e } \\
\text { medição para análise de ações corretivas e } \\
\text { preventivas }\end{array}$ \\
\hline \multirow{3}{*}{ Auto-avaliação } & & 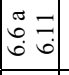 & & $\begin{array}{l}\text { Registrar resultados e decisões das auto- } \\
\text { avaliações realizadas pela alta direção }\end{array}$ & 合 & & 合 & & 会 & \\
\hline & & & \multirow{2}{*}{ 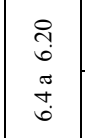 } & $\begin{array}{l}\text { Documentar razões não ser necessário ações } \\
\text { em assuntos identificados na auto-avaliação }\end{array}$ & 合 & & 会 & & 会 & \\
\hline & & & & Planejar auto-avaliações & 会 & & 会 & & 会 & \\
\hline \multirow{7}{*}{$\begin{array}{l}\text { Avaliação } \\
\text { independente }\end{array}$} & 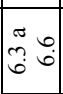 & & & $\begin{array}{l}\text { Registrar as decisões e razões das ações da } \\
\text { alta direção decorrentes dos resultados das } \\
\text { avaliações independentes }\end{array}$ & $\hat{z}$ & & 合 & & 会 & \\
\hline & & \multirow{2}{*}{ 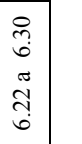 } & & Não indica documento & $\begin{array}{l}\tilde{N} \\
\infty \\
\end{array}$ & Procedimento de auditoria interna & 会 & & 吾 & \\
\hline & & & & Planos de avaliações independentes & 会 & & 会 & & 会 & \\
\hline & & \multirow{2}{*}{\multicolumn{2}{|c|}{ 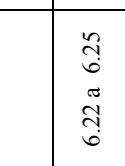 }} & $\begin{array}{l}\text { Relatórios escritos de problemas e boas } \\
\text { práticas observadas na avaliação } \\
\text { independente pelos colegas }\end{array}$ & 合 & & 会 & & 会 & \\
\hline & & & & $\begin{array}{l}\text { Plano de ação para melhoria decorrente da } \\
\text { avaliação independente pelos colegas }\end{array}$ & 会 & & 合 & & 豆 & \\
\hline & & 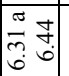 & & Relatórios de avaliação independente & $\begin{array}{l}\tilde{N} \\
\infty \\
\infty\end{array}$ & Registro de auditoria interna & $\begin{array}{l}n \\
n \\
\sim \\
+\end{array}$ & $\begin{array}{l}\text { Registros de planejamento e condução de } \\
\text { auditorias e relatar os resultados }\end{array}$ & $\begin{array}{r}n \\
\sim \\
\dot{r} \\
\end{array}$ & Registros para relatar os resultados das auditorias \\
\hline & & $\stackrel{2}{\geq}$ & & $\begin{array}{l}\text { Relatório de resultados da avaliação } \\
\text { independente }\end{array}$ & 官 & & 会 & & 会 & \\
\hline
\end{tabular}




\begin{tabular}{|c|c|c|c|c|c|c|c|c|c|c|}
\hline PROCESSO & 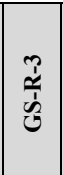 & $\begin{array}{l}\bar{j} \\
\vdots \\
0 \\
0\end{array}$ & $\begin{array}{l}\text { से } \\
\text { ڤै }\end{array}$ & $\begin{array}{c}\text { DOCUMENTAÇÃO DO SG IAEA } \\
\text { (Geral) }\end{array}$ & 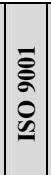 & DOCUMENTAÇÃO DO SGQ (Geral) & $\begin{array}{l}\bar{\Xi} \\
\frac{\partial}{0} \\
0 \\
0\end{array}$ & DOCUMENTAÇÃO DO SGA (Geral) & 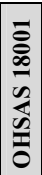 & DOCUMENTAÇÃO DO SGSST (Geral) \\
\hline $\begin{array}{l}\text { Análise crítica do } \\
\text { SG }\end{array}$ & & 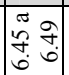 & & Não indica documento & $\begin{array}{ll}\overrightarrow{1} \\
\dot{\omega} \\
\dot{n}\end{array}$ & Registro de análise crítica do SQ pela Direção & $\stackrel{\circ}{+}$ & $\begin{array}{l}\text { Registros das análises crítica do SGA pela } \\
\text { alta administração }\end{array}$ & 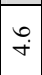 & $\begin{array}{l}\text { Registros das análises crítica do SGSST pela } \\
\text { direção }\end{array}$ \\
\hline \multirow{4}{*}{$\begin{array}{l}\text { Controle de Não } \\
\text { Conformidade }\end{array}$} & \multirow[t]{4}{*}{$\frac{\pi}{2}=0$} & & & $\begin{array}{l}\text { Registrar não-conformidades de produtos e } \\
\text { processos }\end{array}$ & \multirow{3}{*}{$\infty$} & \multirow{3}{*}{ Registro de controle do produto não-conforme } & 言 & & 会 & \\
\hline & & 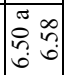 & & Registrar produtos não-conformes & & & 会 & & 会 & \\
\hline & & 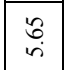 & & Relatório de não-conformidade & & & 会 & & 会 & \\
\hline & & ڤ్ర & & Não indica documento & $m_{\infty}$ & $\begin{array}{l}\text { Procedimento de controle de produto não- } \\
\text { conforme }\end{array}$ & 学 & & 会 & \\
\hline \multirow[t]{2}{*}{ Ações corretivas } & \multirow[t]{2}{*}{ 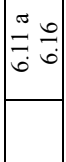 } & \multirow{2}{*}{$\begin{array}{l}n \\
2 \\
b \\
\tilde{b} \\
0 \\
0 \\
0\end{array}$} & \multirow{4}{*}{ 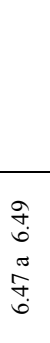 } & $\begin{array}{l}\text { Documentar não-conformidade e ações } \\
\text { tomadas para corrigi-la }\end{array}$ & $\begin{array}{l}1 \\
i \\
i \\
\infty\end{array}$ & Registro de ação corretiva executada & $\stackrel{m}{\dddot{m}}$ & $\begin{array}{l}\text { Registros dos resultados das ações } \\
\text { corretivas e preventivas executadas }\end{array}$ & $\mid \begin{array}{c}n \\
\tilde{z} \\
\dot{v} \\
\dot{v}\end{array}$ & $\begin{array}{l}\text { Registros dos resultados das ações corretivas e } \\
\text { ações preventivas }\end{array}$ \\
\hline & & & & Não indica documento & \begin{tabular}{|l|l}
1 \\
$i$ \\
$\infty$ \\
$\infty$
\end{tabular} \mid & Procedimento de ação corretiva & 合 & & 至 & \\
\hline \multirow{3}{*}{ Ações preventivas } & & & & \multirow{2}{*}{$\begin{array}{l}\text { Documentar todas as propostas de ações } \\
\text { preventivas }\end{array}$} & \multirow{2}{*}{$\begin{array}{c}n \\
i \\
\infty \\
\infty\end{array}$} & \multirow{2}{*}{ Registro de ação preventiva executada } & \multirow{2}{*}{ 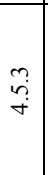 } & \multirow{2}{*}{$\begin{array}{l}\text { Registros dos resultados das ações } \\
\text { corretivas e preventivas executadas }\end{array}$} & \begin{tabular}{|c|}
$\vec{m}$ \\
$\ddot{n}$ \\
$\dot{+}$
\end{tabular} & $\begin{array}{l}\text { Documentação dos resultados das investigações } \\
\text { de incidentes }\end{array}$ \\
\hline & & & & & & & & & \begin{tabular}{|c|c|}
\multirow{2}{*}{} \\
$i$ \\
$\dot{r}$ \\
\end{tabular} & $\begin{array}{l}\text { Registros dos resultados das ações corretivas e } \\
\text { ações preventivas }\end{array}$ \\
\hline & & 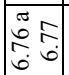 & & Não indica documento & $\left|\begin{array}{c}3 \\
i \\
\vdots \\
\infty\end{array}\right|$ & Procedimento de ação preventiva & 会 & & 会 & \\
\hline \multirow{2}{*}{ Melhoria do SG } & \multirow{2}{*}{ 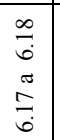 } & & & $\begin{array}{l}\text { Registrar ações para melhoria dos processos } \\
\text { SG }\end{array}$ & 豆 & & 合 & & 会 & \\
\hline & & & & $\begin{array}{l}\text { Planos de melhoramento, incluindo provisões } \\
\text { de recurso }\end{array}$ & 豆 & & 完 & & 至 & \\
\hline
\end{tabular}


APÊNDICE K - Correlação entre as Normas de SG da IAEA (GS-R-3, GS-G-3.1 e DS349), ISO 14001 e OHSAS 18001 e as Normas de Segurança da IAEA (DS316 e DS344).

Legenda:

\begin{tabular}{|l|l|}
\hline SG & Sistema de gestão \\
\hline SGQ & Sistema de gestão ambiental \\
\hline SGA & Sistema de gestão da qualidade \\
\hline SGSST & Sistema de gestão de segurança e saúde no trabalho \\
\hline
\end{tabular}

\begin{tabular}{|l|l|}
\hline GQ & Garantia da qualidade \\
\hline CQ & Controla da qualidade \\
\hline SST & Segurança e saúde no trabalho \\
\hline PGQ & Programa de garantia da qualidade \\
\hline
\end{tabular}

\begin{tabular}{|l|l|}
\hline IISN & Item importante à segurança nuclear \\
\hline ESC & $\begin{array}{l}\text { Estrutura, sistemas e componentes importantes à } \\
\text { segurança }\end{array}$ \\
\hline LCO & Limites e condições operacionais \\
\hline
\end{tabular}

Grau de correlação - Elemento da DS316 ou DS344:

\begin{tabular}{l|l} 
Dt & Detalha elementos das normas de SG da IAEA, ISO 14001 ou OHSAS 18001 para a aplicação específica.
\end{tabular}

NDt Não detalha, mas apresenta requisitos genéricos correlacionados aos elementos das normas de SG da IAEA, ISO 14001 ou OHSAS 18001

Não há correlação com elementos das normas de SG e de Segurança da IAEA, mas há correlação entre os elementos das normas ISO 14001 e OHSAS 18001, entre si.

\begin{tabular}{|c|c|c|c|c|c|c|c|c|c|c|c|c|c|c|c|}
\hline 感 & $\begin{array}{l}\bar{j} \\
\vdots \\
\dot{3} \\
\dot{3}\end{array}$ & 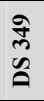 & SG - IAEA & & $\begin{array}{l}\text { SG - Ambiental } \\
\text { ISO } 14001\end{array}$ & & $\begin{array}{l}\text { - Segurança e Saúde no } \\
\text { Trabalho } \\
\text { OHSAS } 18001\end{array}$ & & & $\begin{array}{l}\text { urança - Ciclo do } \\
\text { Combustível } \\
\text { A DS316 Seção } 4\end{array}$ & Segu & $\begin{array}{l}\text { ança - Operação Ciclo do } \\
\text { Combustível } \\
\text { IAEA DS316 Seção } 9\end{array}$ & $\begin{array}{r}\text { Seguran } \\
\text { IAEA }\end{array}$ & $\begin{array}{l}\text { ça - Operação Conversão } \\
\text { DS316 Ap. III } 18 \text { a } 19\end{array}$ & $\begin{array}{c}\text { Segurança - Operação } \\
\text { Conversão } \\
\text { IAEA DS344 Seção } 7\end{array}$ \\
\hline 4 & N & n & $\begin{array}{l}\text { SISTEMA DE } \\
\text { GESTÃO (Título) }\end{array}$ & + & $\begin{array}{l}\text { REQUISITOS DO } \\
\text { SGA (Título) }\end{array}$ & t & $\begin{array}{l}\text { REQUISITOS DO } \\
\text { SGSST (Título) }\end{array}$ & & $\nabla$ & \begin{tabular}{|l|} 
GESTÃO E \\
VERIFICAÇÃO \\
DA SEGURANÇA \\
(Título)
\end{tabular} & $a$ & OPERAÇÃO (Título) & 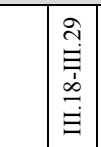 & OPERAÇÃO (Título) & \\
\hline 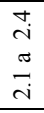 & & & $\begin{array}{l}\text { REQUISITOS } \\
\text { GERAIS }\end{array}$ & $F$ & Requisitos gerais & F & Requisitos gerais & $\overrightarrow{\mathrm{z}}$ & $\begin{array}{l}n \\
\stackrel{v}{\dot{q}} \\
\dot{\sigma}\end{array}$ & Generalidades & 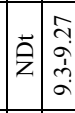 & $\begin{array}{l}\text { REQUISITOS GERAIS } \\
\text { DURANTE OPERAÇÃO } \\
\text { (Título) }\end{array}$ & & & \\
\hline 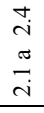 & & & $\begin{array}{l}\text { REQUISITOS } \\
\text { GERAIS }\end{array}$ & F & Requisitos gerais & 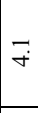 & Requisitos gerais & $\overrightarrow{\mathrm{Z}}$ & \begin{tabular}{l}
$n$ \\
$\dot{q}$ \\
\hdashline$\dot{q}$
\end{tabular} & Generalidades & 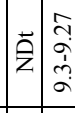 & $\begin{array}{l}\text { REQUISITOS GERAIS } \\
\text { DURANTE OPERAÇÃO } \\
\text { (Título) }\end{array}$ & & & \\
\hline $\begin{array}{l}\stackrel{j}{i} \\
\stackrel{a}{a} \\
\vec{i}\end{array}$ & & & $\begin{array}{l}\text { REQUISITOS } \\
\text { GERAIS }\end{array}$ & $\underset{\sim}{\sim}$ & $\begin{array}{l}\text { Requisitos legais e } \\
\text { outros }\end{array}$ & $\underset{\sim}{\tilde{r}}$ & $\begin{array}{l}\text { Requisitos legais e } \\
\text { outros }\end{array}$ & $\overrightarrow{\mathrm{z}}$ & $\mid \begin{array}{l}n \\
\dot{P} \\
\dot{f} \\
\dot{f}\end{array}$ & Generalidades & & & & & \\
\hline & & $\begin{array}{l}\tilde{i} \\
\vec{s} \\
\vec{i} \\
\end{array}$ & $\begin{array}{l}\text { REQUISITOS } \\
\text { GERAIS }\end{array}$ & & & & & & & & & & & & \\
\hline & $\begin{array}{l}0 \\
i \\
\tilde{T} \\
\vec{i}\end{array}$ & & $\begin{array}{l}\text { SISTEMA } \\
\text { INTEGRADO DE } \\
\text { GESTÃO }\end{array}$ & & & & & & & & & & & & \\
\hline & $\stackrel{i}{i} \vec{m}$ & & $\begin{array}{l}\text { ASPECTOS } \\
\text { GERAIS }\end{array}$ & & & & & & & & & & & & \\
\hline
\end{tabular}




\begin{tabular}{|c|c|c|c|c|c|c|c|c|c|c|c|c|c|c|}
\hline \multirow[t]{2}{*}{ 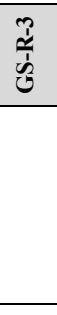 } & \multirow{2}{*}{ 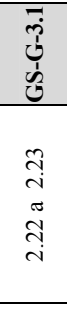 } & \multirow[t]{2}{*}{ 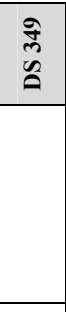 } & \multirow{2}{*}{$\begin{array}{r}\text { SG - IAEA } \\
\text { Implementando o } \\
\text { sistema de gestão }\end{array}$} & \multirow[b]{2}{*}{$\stackrel{\sim}{\vec{q}}$} & \multirow{2}{*}{ 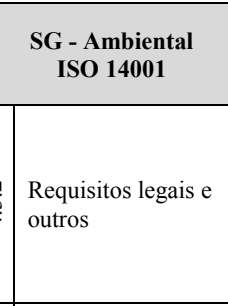 } & \multicolumn{2}{|c|}{$\begin{array}{l}\text { SG - Segurança e Saúde no } \\
\text { Trabalho } \\
\text { OHSAS } 18001\end{array}$} & \multicolumn{3}{|c|}{$\begin{array}{l}\text { Segurança - Ciclo do } \\
\text { Combustível } \\
\text { IAEA DS316 Seção } 4\end{array}$} & \multicolumn{2}{|c|}{$\begin{array}{c}\text { Segurança - Operação Ciclo do } \\
\text { Combustível } \\
\text { IAEA DS316 Seção } 9\end{array}$} & $\begin{array}{l}\text { Segurança - Operação Conversão } \\
\text { IAEA DS316 Ap. III } 18 \text { a } 19\end{array}$ & \multirow[t]{2}{*}{$\begin{array}{c}\text { Segurança - Operação } \\
\text { Conversão } \\
\text { IAEA DS344 Seção } 7\end{array}$} \\
\hline & & & & & & $\underset{\sim}{\stackrel{\sim}{\sim}}$ & $\begin{array}{l}\text { Requisitos legais e } \\
\text { outros }\end{array}$ & $\vec{\Delta}$ & $\stackrel{m}{\dot{r}}$ & $\begin{array}{l}\text { Planejar e executar } \\
\text { trabalhos relativos à } \\
\text { segurança acordo } \\
\text { códigos, normas, } \\
\text { especificações, } \\
\text { práticas e controles } \\
\text { administrativos. }\end{array}$ & & & & \\
\hline & 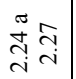 & & $\begin{array}{l}\text { Plano de } \\
\text { implementação }\end{array}$ & $\underset{m}{\dot{m}} \stackrel{2}{+}$ & $\begin{array}{l}\text { Objetivos, metas e } \\
\text { programas }\end{array}$ & $\stackrel{m}{\stackrel{m}{+}}$ & Objetivos e programas & & & & & & & \\
\hline & 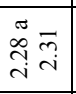 & & $\begin{array}{l}\text { Organização das } \\
\text { interfaces }\end{array}$ & & & & & & & & 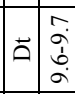 & $\begin{array}{l}\text { Assegurar independência } \\
\text { entre estabelecimentos } \\
\text { situados na mesma área }\end{array}$ & & \\
\hline$\ddot{n}$ & तु & $\begin{array}{l}\infty \\
\stackrel{\infty}{i} \\
\tilde{\sigma} \\
\stackrel{+}{i} \\
\stackrel{i}{i}\end{array}$ & $\begin{array}{l}\text { CULTURA DE } \\
\text { SEGURANÇA }\end{array}$ & & & & & 艺 & 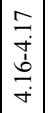 & $\begin{array}{l}\text { Adotar e implemen- } \\
\text { tar princípios e pro- } \\
\text { cessos p/ obter Cul- } \\
\text { tura de Segurança }\end{array}$ & $\vec{\Delta} \stackrel{R}{R}$ & $\begin{array}{l}\text { Avaliação cultura de } \\
\text { segurança }\end{array}$ & & \\
\hline & & ते & $\begin{array}{l}\text { A segurança ocupa- } \\
\text { cional é valor clara- } \\
\text { mente reconhecido }\end{array}$ & & & & & & & & & & & \\
\hline & & $\stackrel{\circ}{i}$ & $\begin{array}{l}\text { A liderança pela } \\
\text { segurança ocupa- } \\
\text { cional está evidente }\end{array}$ & & & & & & & & & & & \\
\hline & & $\overrightarrow{\vec{i}}$ & $\begin{array}{l}\text { A responsabilidade } \\
\text { final pela segurança } \\
\text { ocupacional está } \\
\text { evidente }\end{array}$ & & & & & & & & & & & \\
\hline & & $\stackrel{i}{i}$ & $\begin{array}{l}\text { A segurança ocupa- } \\
\text { cional está integrada } \\
\text { a todas as atividades }\end{array}$ & & & & & & & & & & & \\
\hline & & 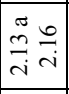 & $\begin{array}{l}\text { A segurança ocupa- } \\
\text { cional é uma apren- } \\
\text { dizagem dirigida }\end{array}$ & & & & & & & & & & & \\
\hline & & $\begin{array}{ll}\stackrel{\pi}{\vec{n}} \overrightarrow{\mathrm{T}} \\
\overrightarrow{\mathrm{i}}\end{array}$ & $\begin{array}{l}\text { Melhorando a cultura } \\
\text { de segurança }\end{array}$ & & & & & & & & & & & \\
\hline & & 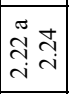 & $\begin{array}{l}\text { Sinais de atenção an- } \\
\text { tecipados declínio na } \\
\text { cultura de segurança }\end{array}$ & & & & & & & & & & & \\
\hline & & $\stackrel{\sim}{\tilde{i}} \overrightarrow{\tilde{i}}$ & $\begin{array}{l}\text { Fatores humanos e a } \\
\text { interação entre } \\
\text { pessoal, tecnologia e } \\
\text { a organização }\end{array}$ & & & & & & & & & & & \\
\hline $\begin{array}{l}\hat{i} \\
\tilde{\sigma} \\
\tilde{b} \\
i\end{array}$ & & $\begin{array}{l}\tilde{n} \\
\tilde{n} \\
\tilde{\sigma} \\
\tilde{n} \\
\end{array}$ & $\begin{array}{l}\text { GRADAÇÃO DA } \\
\text { APLICAÇÃO DOS } \\
\text { REQUISITOS DO } \\
\text { SISTEMA DE } \\
\text { GESTÃO }\end{array}$ & & & & & & & & & & & \\
\hline
\end{tabular}




\begin{tabular}{|c|c|c|c|c|c|c|c|c|c|c|c|c|c|c|}
\hline 峁 & $\overrightarrow{0}$ & $\begin{array}{l}\text { से } \\
\tilde{=}\end{array}$ & SG - IAEA & & $\begin{array}{l}\text { SG - Ambiental } \\
\text { ISO } 14001\end{array}$ & & $\begin{array}{c}\text { S - Segurança e Saúde no } \\
\text { Trabalho } \\
\text { OHSAS 18001 }\end{array}$ & & & $\begin{array}{l}\text { urança - Ciclo do } \\
\text { Combustível } \\
\text { A DS316 Seção } 4\end{array}$ & & $\begin{array}{l}\text { gurança - Operação Ciclo do } \\
\text { Combustível } \\
\text { IAEA DS316 Seção } 9\end{array}$ & $\begin{array}{l}\text { Segurança - Operação Conversão } \\
\text { IAEA DS316 Ap. III } 18 \text { a } 19\end{array}$ & $\begin{array}{c}\text { Segurança - Operação } \\
\text { Conversão } \\
\text { IAEA DS344 Seção } 7\end{array}$ \\
\hline & 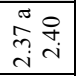 & & $\begin{array}{l}\text { Abordagem por } \\
\text { gradação }\end{array}$ & & & & & & & & & & & \\
\hline & $\underset{i}{\vec{\sigma}} \underset{i}{\mathbb{J}}$ & & Processo de gradação & & & & & & & & & & & \\
\hline $\begin{array}{cc}\infty & 0 \\
\infty & \stackrel{0}{i} \\
i & i\end{array}$ & & & $\begin{array}{l}\text { DOCUMENTAÇÃO } \\
\text { DO SISTEMA DE } \\
\text { GESTÃO }\end{array}$ & $\begin{array}{ll}\underset{+}{+} \\
\dot{+}\end{array}$ & $\begin{array}{l}\text { Recursos, funções, } \\
\text { responsabilidades e } \\
\text { autoridades }\end{array}$ & $\underset{f}{\stackrel{f}{+}}$ & $\begin{array}{l}\text { Recursos, funções, } \\
\text { responsabilidades, } \\
\text { prestação de contas e } \\
\text { autoridades }\end{array}$ & 艺 & $\begin{array}{l}\stackrel{P}{\rightarrow} \\
\stackrel{+}{+} \\
\stackrel{f}{+}\end{array}$ & $\begin{array}{l}\text { PROVISÕES } \\
\text { ORGANIZACIO- } \\
\text { NAIS }\end{array}$ & 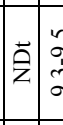 & \begin{tabular}{c|l}
$n$ & Estrutura e \\
\\
& responsabilidades da \\
organização operadora
\end{tabular} & & \\
\hline $\begin{array}{lll}\infty & 0 \\
\infty & \infty & \\
i & i\end{array}$ & & & $\begin{array}{l}\text { DOCUMENTAÇÃO } \\
\text { DO SISTEMA DE } \\
\text { GESTÃO }\end{array}$ & $\stackrel{\stackrel{+}{+}}{\stackrel{+}{+}}$ & Documentação & $\begin{array}{c}\stackrel{+}{+} \\
\dot{+}\end{array}$ & Documentação & & & & & & & \\
\hline $\begin{array}{ll}\infty & 0 \\
\infty & 0 \\
i & i\end{array}$ & & & $\begin{array}{l}\text { DOCUMENTAÇÃO } \\
\text { DO SISTEMA DE } \\
\text { GESTÃO }\end{array}$ & $\begin{array}{ll}\stackrel{+}{+} \\
\dot{*}\end{array}$ & \begin{tabular}{|l|} 
Documentação \\
(Procedimentos p/ \\
controle situações \\
ambientais)
\end{tabular} & $\begin{array}{l}\stackrel{+}{+} \\
+\end{array}$ & $\begin{array}{l}\text { Documentação } \\
\text { (Procedimentos para } \\
\text { cobrir situações de SST) }\end{array}$ & & & & & & & \\
\hline $\begin{array}{ccc}\infty & 0 \\
\infty & \stackrel{0}{i} & \\
i & i\end{array}$ & & & $\begin{array}{l}\text { DOCUMENTAÇÃO } \\
\text { DO SISTEMA DE } \\
\text { GESTÃO }\end{array}$ & $\stackrel{\stackrel{+}{+}}{\stackrel{+}{+}}$ & $\begin{array}{l}\begin{array}{l}\text { Documentação } \\
\text { (Registros requeridos } \\
\text { pela norma) }\end{array} \\
\end{array}$ & 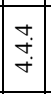 & \begin{tabular}{|l} 
Documentação \\
(Registros requeridos \\
pela norma)
\end{tabular} & & & & $\vec{a} \mid \frac{\infty}{\sigma}$ & 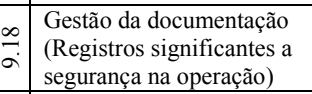 & & \\
\hline 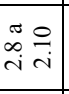 & $\begin{array}{l}\tilde{\sigma} \\
\stackrel{\sim}{\sigma} \\
i \\
i\end{array}$ & 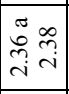 & $\begin{array}{l}\text { DOCUMENTAÇÃO } \\
\text { DO SISTEMA DE } \\
\text { GESTÃO }\end{array}$ & & & & & $\vec{\Delta}$ & $\overrightarrow{+}$ & $\begin{array}{l}\text { Programa QA pro- } \\
\text { duto incluindo rejei- } \\
\text { tos, todos estágios }\end{array}$ & & & & \\
\hline m & $m$ & m & $\begin{array}{l}\text { RESPONSABILI- } \\
\text { DADE DA } \\
\text { DIREÇÃO (Título) }\end{array}$ & & & & & & & & & & & \\
\hline$\frac{n}{m}$ & $\begin{array}{l}\dot{m} \\
\dot{m} \\
\dot{m}\end{array}$ & & $\begin{array}{l}\text { COMPROMETI- } \\
\text { MENTO DA } \\
\text { DIREÇÃO }\end{array}$ & $\underset{\dot{+}}{\stackrel{+}{+}}$ & $\begin{array}{l}\text { Recursos, funções, } \\
\text { responsabilidades e } \\
\text { autoridades }\end{array}$ & $\underset{\dot{+}}{\stackrel{+}{+}}$ & $\begin{array}{l}\text { Recursos, funções, } \\
\text { responsabilidades, } \\
\text { prestação de contas e } \\
\text { autoridades }\end{array}$ & 䒘 & $\begin{array}{l}\stackrel{O}{\circ} \\
\stackrel{+}{+} \\
\stackrel{+}{+}\end{array}$ & $\begin{array}{l}\text { PROVISÕES } \\
\text { ORGANIZACIO- } \\
\text { NAIS }\end{array}$ & 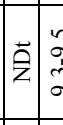 & \begin{tabular}{c|l}
2 & Estrutura e \\
& responsabilidades da \\
organização operadora
\end{tabular} & & \\
\hline $\begin{array}{l}\stackrel{n}{m} \\
\stackrel{\infty}{m} \\
\frac{m}{n}\end{array}$ & $\begin{array}{l}\hat{m} \\
\stackrel{\infty}{m}\end{array}$ & & $\begin{array}{l}\text { COMPROMETI- } \\
\text { MENTO DA } \\
\text { DIREÇÃO }\end{array}$ & $\underset{\dot{+}}{\dot{+}}$ & $\begin{array}{l}\text { Recursos, funções, } \\
\text { responsabilidades e } \\
\text { autoridades }\end{array}$ & $\underset{\dot{+}}{\stackrel{+}{+}}$ & $\begin{array}{l}\text { Recursos, funções, } \\
\text { responsabilidades, } \\
\text { prestação de contas e } \\
\text { autoridades }\end{array}$ & $\vec{\Delta}$ & 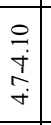 & $\begin{array}{l}\text { PROVISÕES } \\
\text { ORGANIZACIO- } \\
\text { NAIS }\end{array}$ & $\overrightarrow{\mathrm{Z}}$ & 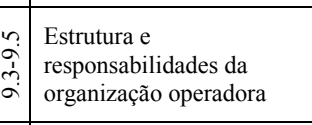 & & \\
\hline$\stackrel{\bullet}{\dot{r}}$ & $\stackrel{\infty}{\infty}$ & $\begin{array}{l}n \\
m \\
\infty \\
m \\
m\end{array}$ & $\begin{array}{l}\text { SATISFAÇÃO } \\
\text { DAS PARTES } \\
\text { INTERESSADAS } \\
\end{array}$ & $\overrightarrow{\dot{m}}$ & $\begin{array}{l}\text { Aspectos ambientais } \\
\text { e determinação de } \\
\text { impactos ambientais } \\
\end{array}$ & $\underset{\dot{p}}{\overrightarrow{\dot{p}}}$ & \begin{tabular}{|l|} 
Identificação perigo, \\
avaliação de riscos e \\
determinação controles \\
\end{tabular} & & & & & & & \\
\hline & ले & & $\begin{array}{l}\text { Atendimento } \\
\text { (Compliance) a } \\
\text { requisitos estatutá- } \\
\text { rios e regulatórios }\end{array}$ & 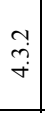 & $\begin{array}{l}\text { Requisitos legais e } \\
\text { outros }\end{array}$ & 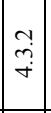 & $\begin{array}{l}\text { Requisitos legais e } \\
\text { outros }\end{array}$ & & & & & & & \\
\hline & ले & & $\begin{array}{l}\text { Atendimento } \\
\text { (Compliance) a } \\
\text { requisitos estatutá- } \\
\text { rios e regulatórios }\end{array}$ & 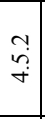 & $\begin{array}{l}\text { Avaliação do } \\
\text { atendimento a } \\
\text { requisitos legais }\end{array}$ & 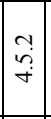 & $\begin{array}{l}\text { Avaliação do } \\
\text { atendimento a requisitos } \\
\text { legais }\end{array}$ & & & & & & & \\
\hline & ले & & $\begin{array}{l}\text { Atendimento } \\
\text { (Compliance) a } \\
\text { requisitos estatutá- } \\
\text { rios e regulatórios }\end{array}$ & 水 & $\begin{array}{l}\text { Registros de } \\
\text { avaliações periódicas } \\
\text { atendimento } \\
\text { requisitos legais e } \\
\text { outros }\end{array}$ & $\begin{array}{c}y \\
\ddot{r} \\
\dot{v}\end{array}$ & $\begin{array}{l}\text { Registros de avaliações } \\
\text { periódicas atendimento } \\
\text { requisitos legais e outros }\end{array}$ & & & & $\vec{a} \mid \begin{array}{ll}n \\
a\end{array}$ & $\begin{array}{l}\text { Registros de descarga } \\
\text { efluentes radioativos e de } \\
\text { produtos químicos } \\
\text { perigosos }\end{array}$ & & \\
\hline
\end{tabular}




\begin{tabular}{|c|c|c|c|c|c|c|c|c|c|c|c|c|c|c|c|}
\hline \multirow[t]{2}{*}{ 竞 } & \multirow{2}{*}{$\begin{array}{l}\overline{\dot{j}} \\
\dot{y} \\
\dot{b} \\
\dot{m}\end{array}$} & \multirow{2}{*}{$\begin{array}{l}\text { के } \\
\text { â } \\
0\end{array}$} & \multirow{2}{*}{$\begin{array}{l}\quad \text { SG - IAEA } \\
\text { Atendimento } \\
\text { (Compliance) a } \\
\text { requisitos estatutá- } \\
\text { rios e regulatórios }\end{array}$} & \multicolumn{2}{|r|}{$\begin{array}{l}\text { SG - Ambiental } \\
\text { ISO } 14001\end{array}$} & \multicolumn{2}{|c|}{$\begin{array}{c}\text { SG - Segurança e Saúde no } \\
\text { Trabalho } \\
\text { OHSAS } 18001 \\
\end{array}$} & \multicolumn{3}{|c|}{$\begin{array}{l}\text { Segurança - Ciclo do } \\
\text { Combustível } \\
\text { IAEA DS316 Seção } 4 \\
\end{array}$} & \multicolumn{3}{|c|}{$\begin{array}{c}\text { Segurança - Operação Ciclo do } \\
\text { Combustível } \\
\text { IAEA DS316 Seção } 9\end{array}$} & $\begin{array}{l}\text { Segurança - Operação Conversão } \\
\text { IAEA DS316 Ap. III } 18 \text { a } 19\end{array}$ & $\begin{array}{c}\text { Segurança - Operação } \\
\text { Conversão } \\
\text { IAEA DS344 Seção } 7 \\
\end{array}$ \\
\hline & & & & $\stackrel{n}{n}$ & $\begin{array}{l}\text { Avaliação do } \\
\text { atendimento a } \\
\text { requisitos legais }\end{array}$ & $\begin{array}{c}\tilde{n} \\
\tilde{y} \\
\dot{\gamma}\end{array}$ & $\begin{array}{l}\text { Avaliação do } \\
\text { atendimento a requisitos } \\
\text { legais }\end{array}$ & & & & $\vec{a}$ & $\hat{n}$ & $\begin{array}{l}\text { Monitorar e verificar des- } \\
\text { carga efluentes radioati- } \\
\text { vos e produtos químicos } \\
\text { perigosos, em atendimen- } \\
\text { to autoridades nacionais }\end{array}$ & & \\
\hline & $\dot{m}$ & & $\begin{array}{l}\text { Atendimento } \\
\text { (Compliance) a } \\
\text { requisitos estatutá- } \\
\text { rios e regulatórios } \\
\end{array}$ & 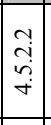 & $\begin{array}{l}\text { Avaliação do } \\
\text { atendimento a outros } \\
\text { requisitos (Incluir) }\end{array}$ & $\begin{array}{c}\tilde{y} \\
\dot{y}\end{array}$ & $\begin{array}{l}\text { Avaliação do } \\
\text { atendimento a outros } \\
\text { requisitos (Incluir) }\end{array}$ & & & & & & & & \\
\hline$\hat{n}$ & 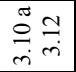 & & $\begin{array}{l}\text { POLÍTICAS OR- } \\
\text { GANIZACIONAIS }\end{array}$ & $\stackrel{\text { F }}{+}$ & Política ambiental & $\stackrel{\sim}{+}$ & Política de SST & & & & & & & & \\
\hline & & 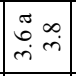 & $\begin{array}{l}\text { Desenvolvimento das } \\
\text { políticas }\end{array}$ & $\stackrel{\Upsilon}{\stackrel{\sim}{+}}$ & Política ambiental & $\stackrel{\sim}{+}$ & Política de SST & & & & & & & & \\
\hline & & $\stackrel{\pi}{\vec{m}} \stackrel{t}{m}$ & $\begin{array}{l}\text { Implementação das } \\
\text { políticas }\end{array}$ & $\stackrel{\sim}{+}$ & Política ambiental & $\stackrel{?}{\rightarrow}$ & Política de SST & & & & & & & & \\
\hline & & $\stackrel{n}{m}$ & $\begin{array}{l}\text { Políticas de } \\
\text { segurança, saúde e } \\
\text { ambiental }\end{array}$ & $\stackrel{\sim}{\rightarrow}$ & Política ambiental & $\stackrel{\sim}{+}$ & Política de SST & 艺 & \begin{tabular}{|l|}
+ \\
+ \\
\end{tabular} & $\begin{array}{l}\text { POLÍTICA DE } \\
\text { SEGURANÇA, } \\
\text { SAUUDE E } \\
\text { AMBIENTAL } \\
\end{array}$ & & & & & \\
\hline & & $\underset{m}{\stackrel{0}{m}}$ & Política da qualidade & & & & & & & & & & & & \\
\hline & & $\stackrel{=}{m}$ & $\begin{array}{l}\text { Política de mudança } \\
\text { de gestão }\end{array}$ & & & & & & & & & & & & \\
\hline & & $\stackrel{\infty}{m}$ & $\begin{array}{l}\text { Políitica de proteção } \\
\text { física }\end{array}$ & & & & & & & & & & & & \\
\hline \begin{tabular}{cl|l}
$\infty$ & $=1$ \\
$\infty$ & $=$ & $=$ \\
$\dot{m}$ & $\dot{m}$
\end{tabular} & $\begin{array}{ll}\ddot{n} & 0 \\
\stackrel{m}{m} & \stackrel{m}{m}\end{array}$ & & PLANEJAMENTO & $\stackrel{\stackrel{+}{+}}{+}$ & $\begin{array}{l}\text { Documentação } \\
\text { (Objetivos SGA) }\end{array}$ & $\stackrel{\stackrel{+}{+}}{+}$ & $\begin{array}{l}\text { Documentação } \\
\text { (Objetivos SGSST) }\end{array}$ & & & & & & & & \\
\hline $\begin{array}{ll}\infty & = \\
\infty & = \\
\dot{m} & =1\end{array}$ & $\begin{array}{ll}m & 0 \\
m & = \\
m & m\end{array}$ & & PLANEJAMENTO & $\begin{array}{ll}m \\
\dot{m} \\
\dot{q}\end{array}$ & $\begin{array}{l}\text { Objetivos, metas e } \\
\text { programas }\end{array}$ & $\begin{array}{c}m \\
\dot{m} \\
\dot{q} \\
\end{array}$ & Objetivos e programas & & & & & & & & \\
\hline 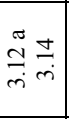 & 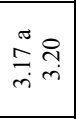 & 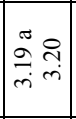 & $\begin{array}{l}\text { RESPONSABILI- } \\
\text { DADE / AUTORI- } \\
\text { DADE PELO SISTE- } \\
\text { MA DE GESTÃO }\end{array}$ & $\underset{+}{\stackrel{+}{+}}$ & $\begin{array}{l}\text { Recursos, funções, } \\
\text { responsabilidades e } \\
\text { autoridades }\end{array}$ & $\underset{\dot{+}}{\stackrel{+}{+}}$ & $\begin{array}{l}\text { Recursos, funções, } \\
\text { responsabilidades, } \\
\text { prestação de contas e } \\
\text { autoridades }\end{array}$ & 艺 & 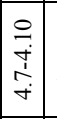 & $\begin{array}{l}\text { PROVISÕES } \\
\text { ORGANIZACIO- } \\
\text { NAIS }\end{array}$ & $\overrightarrow{\mathrm{z}}$ & 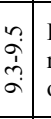 & $\begin{array}{l}\text { Estrutura e } \\
\text { responsabilidades da } \\
\text { organizaçẫo operadora }\end{array}$ & & \\
\hline$\stackrel{m}{m}$ & $\stackrel{\infty}{m}$ & $\stackrel{\vec{m}}{\vec{m}}$ & $\begin{array}{l}\text { Indivíduo com } \\
\text { responsabilidade e } \\
\text { autoridade pelo SG }\end{array}$ & $\underset{+}{\stackrel{+}{+}}$ & $\begin{array}{l}\text { Representantes da } \\
\text { direção pelo SGA }\end{array}$ & $\underset{\dot{+}}{\dot{+}}$ & $\begin{array}{l}\text { Representantes da } \\
\text { direção pelo SGSST }\end{array}$ & & & & $\overrightarrow{\mathrm{a}}$ & $\begin{array}{lll}n & 1 \\
a & i\end{array}$ & $\begin{array}{l}\text { Comitês de segurança } \\
\text { interna (Um ou mais) }\end{array}$ & & \\
\hline$\stackrel{m}{m}$ & $\stackrel{\infty}{m}$ & $\stackrel{े}{m}$ & $\begin{array}{l}\text { Indivíduo com } \\
\text { responsabilidade e } \\
\text { autoridade pelo SG }\end{array}$ & $\underset{\dot{f}}{\stackrel{f}{+}}$ & $\begin{array}{l}\text { Representantes da } \\
\text { direção pelo SGA }\end{array}$ & $\underset{\dot{f}}{\stackrel{f}{+}}$ & $\begin{array}{l}\text { Representantes da } \\
\text { direção pelo SGSST }\end{array}$ & & & & $\vec{a}$ & 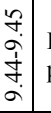 & $\begin{array}{l}\text { Estabelecer função de } \\
\text { proteção radiológica }\end{array}$ & & \\
\hline 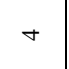 & $\nabla$ & + & $\begin{array}{l}\text { GESTÃO DE RE- } \\
\text { CURSOS (Título) }\end{array}$ & & & & & & & & & & & & \\
\hline
\end{tabular}




\begin{tabular}{|c|c|c|c|c|c|c|c|c|c|c|c|c|c|c|c|c|c|c|c|}
\hline \multirow{2}{*}{ 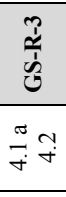 } & \multirow{2}{*}{ 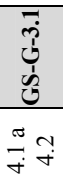 } & \multirow[t]{2}{*}{$\begin{array}{l}\text { ले } \\
\text { है }\end{array}$} & \multirow{2}{*}{$\begin{array}{l}\text { SG - IAEA } \\
\text { PROVISÃO DE } \\
\text { RECURSOS }\end{array}$} & \multicolumn{2}{|r|}{$\begin{array}{l}\text { SG - Ambiental } \\
\text { ISO } 14001\end{array}$} & \multicolumn{2}{|r|}{$\begin{array}{c}\text { SG - Segurança e Saúde no } \\
\text { Trabalho } \\
\text { OHSAS 18001 }\end{array}$} & \multicolumn{3}{|c|}{$\begin{array}{l}\text { Segurança - Ciclo do } \\
\text { Combustível } \\
\text { IAEA DS316 Seção } 4\end{array}$} & \multicolumn{3}{|c|}{$\begin{array}{c}\text { Segurança - Operação Ciclo do } \\
\text { Combustivel } \\
\text { IAEA DS316 Seção } 9\end{array}$} & \multicolumn{3}{|c|}{$\begin{array}{l}\text { Segurança - Operação Conversão } \\
\text { IAEA DS316 Ap. III } 18 \text { a } 19\end{array}$} & \multicolumn{3}{|c|}{$\begin{array}{l}\text { Segurança - Operação } \\
\text { Conversão } \\
\text { IAEA DS344 Seção } 7\end{array}$} \\
\hline & & & & $\underset{\dot{+}}{\dot{t}}$ & \begin{tabular}{|l} 
Recursos, funções, \\
responsabilidades e \\
autoridades
\end{tabular} & $\underset{+\overrightarrow{+}}{\stackrel{+}{+}}$ & $\begin{array}{l}\text { Recursos, funções, res- } \\
\text { ponsabilidades, presta- } \\
\text { ção contas e autoridades } \\
\end{array}$ & & & & & & & & & & & & \\
\hline & & 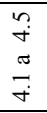 & $\begin{array}{l}\text { Recursos providos } \\
\text { por fornecedores e } \\
\text { parceiros }\end{array}$ & $\begin{array}{l}\stackrel{\circlearrowright}{+} \\
\dot{+}\end{array}$ & Controle operacional & $\begin{array}{l}\stackrel{0}{+} \\
+ \\
+\end{array}$ & Controle operacional & $\overrightarrow{\mathrm{a}}$ & 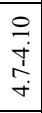 & $\begin{array}{l}\text { PROVISÕES } \\
\text { ORGANIZACIO- } \\
\text { NAIS }\end{array}$ & & & & & & & & & \\
\hline & $\stackrel{?}{\rightarrow}$ & & $\begin{array}{l}\text { Envolvimento dos } \\
\text { indivíduos }\end{array}$ & 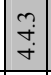 & Comunicação & 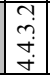 & Participação e consulta & & & & & & & & & & & & \\
\hline & $\stackrel{+}{+}$ & 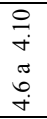 & $\begin{array}{l}\text { Gestão de informa- } \\
\text { ção e conhecimento }\end{array}$ & $\begin{array}{l}\stackrel{b}{+} \\
\dot{+}\end{array}$ & Controle operacional & $\begin{array}{l}\stackrel{0}{+} \\
+ \\
+\end{array}$ & Controle operacional & & & & $\vec{a}$ & $\stackrel{0}{a}$ & $\begin{array}{l}\text { Realimentação da } \\
\text { experiência operacional }\end{array}$ & & & & & & \\
\hline & $\stackrel{n}{+}$ & & Recursos financeiros & $\underset{\dot{+}}{\overrightarrow{+}}$ & $\begin{array}{l}\text { Recursos, funções, } \\
\text { responsabilidades e } \\
\text { autoridades }\end{array}$ & $\underset{\dot{+}}{\dot{+}}$ & $\begin{array}{l}\text { Recursos, funções, res- } \\
\text { ponsabilidades, presta- } \\
\text { ção contas e autoridades }\end{array}$ & $\overrightarrow{\mathrm{z}}$ & $\stackrel{?}{+}$ & $\begin{array}{l}\text { Recursos financei- } \\
\text { ros } \mathrm{p} / \text { segurança e } \mathrm{p} / \\
\text { cumprir requisitos }\end{array}$ & & & & & & & & & \\
\hline $\begin{array}{l}\stackrel{+}{+} \\
\stackrel{\sim}{\infty} \\
\stackrel{\sim}{+}\end{array}$ & 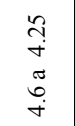 & & $\begin{array}{l}\text { RECURSOS } \\
\text { HUMANOS }\end{array}$ & $\stackrel{\substack{f \\
\dot{f}}}{ }$ & $\begin{array}{l}\text { Competência, } \\
\text { treinamento e } \\
\text { conscientização. }\end{array}$ & 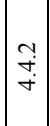 & $\begin{array}{l}\text { Competência, } \\
\text { treinamento e } \\
\text { conscientização. }\end{array}$ & $\overrightarrow{\mathrm{z}}$ & $\begin{array}{l}\stackrel{P}{\jmath} \\
\dot{+} \\
\stackrel{+}{+}\end{array}$ & $\begin{array}{l}\text { PROVISÕES } \\
\text { ORGANIZACIO- } \\
\text { NAIS }\end{array}$ & $\vec{\Delta}$ & $\begin{array}{l}m \\
a \\
\dot{\alpha} \\
\dot{\alpha} \\
a\end{array}$ & $\begin{array}{l}\text { Qualificação e } \\
\text { treinamento do pessoal }\end{array}$ & & & & & & \\
\hline $\begin{array}{l}\stackrel{+}{+} \\
\stackrel{\sigma}{*} \\
\stackrel{\sim}{+}\end{array}$ & $\begin{array}{l}\tilde{N} \\
\stackrel{\sim}{\sigma} \\
\tilde{\sigma} \\
\stackrel{+}{+}\end{array}$ & & $\begin{array}{l}\text { RECURSOS } \\
\text { HUMANOS }\end{array}$ & $\stackrel{\substack{f \\
\dot{\sim}}}{ }$ & $\begin{array}{l}\text { Competência, } \\
\text { treinamento e } \\
\text { conscientização. }\end{array}$ & $\stackrel{\stackrel{T}{\sim}}{\stackrel{\sim}{+}}$ & $\begin{array}{l}\text { Competência, } \\
\text { treinamento e } \\
\text { conscientização. }\end{array}$ & $\overrightarrow{\mathrm{z}}$ & $\begin{array}{l}\stackrel{P}{\vec{f}} \\
\stackrel{+}{+} \\
\dot{+}\end{array}$ & $\begin{array}{l}\text { PROVISÕES } \\
\text { ORGANIZACIO- } \\
\text { NAIS }\end{array}$ & $\vec{a}$ & $\stackrel{8}{\circ}$ & $\begin{array}{l}\text { Treinamento regular em } \\
\text { segurança contra incêndio }\end{array}$ & $\vec{a}$ & $\overrightarrow{\widehat{G}}$ & $\begin{array}{l}\text { Treinamentos específicos } \\
\mathrm{p} / \text { incêndio externo e res- } \\
\text { pectivo salvamento } \\
\text { pessoal }\end{array}$ & & & \\
\hline $\begin{array}{l}\stackrel{+}{+} \\
\stackrel{\sigma}{*} \\
\stackrel{\sim}{+}\end{array}$ & $\begin{array}{l}\stackrel{\sim}{r} \\
\dot{+} \\
\tilde{\sigma} \\
\stackrel{+}{+}\end{array}$ & & $\begin{array}{l}\text { RECURSOS } \\
\text { HUMANOS }\end{array}$ & 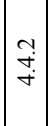 & $\begin{array}{l}\text { Competência, } \\
\text { treinamento e } \\
\text { conscientização. }\end{array}$ & $\stackrel{\stackrel{\sim}{\sim}}{\stackrel{f}{+}}$ & $\begin{array}{l}\text { Competência, } \\
\text { treinamento e } \\
\text { conscientização. }\end{array}$ & $\overrightarrow{\mathrm{z}}$ & $\begin{array}{l}\stackrel{P}{\jmath} \\
+ \\
\stackrel{+}{+}\end{array}$ & $\begin{array}{l}\text { PROVISÕES } \\
\text { ORGANIZACIO- } \\
\text { NAIS }\end{array}$ & $\vec{a}$ & 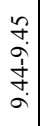 & $\begin{array}{l}\text { Pessoal qualificado para } \\
\text { função de proteção } \\
\text { radiológica }\end{array}$ & & & & $\vec{\Delta}$ & $\stackrel{2}{2}$ & $\begin{array}{l}\text { Pessoal para inspeção, } \\
\text { qualificado e experiente }\end{array}$ \\
\hline $\begin{array}{l}\stackrel{+}{+} \\
\stackrel{\sim}{\sigma} \\
\stackrel{\sim}{+}\end{array}$ & $\begin{array}{l}\stackrel{\sim}{r} \\
\dot{\sigma} \\
\tilde{\sigma} \\
\stackrel{+}{+}\end{array}$ & & $\begin{array}{l}\text { RECURSOS } \\
\text { HUMANOS }\end{array}$ & $\underset{\stackrel{T}{+}}{\stackrel{f}{*}}$ & $\begin{array}{l}\text { Competência, } \\
\text { treinamento e } \\
\text { conscientização. }\end{array}$ & 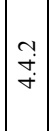 & $\begin{array}{l}\text { Competência, } \\
\text { treinamento e } \\
\text { conscientização. }\end{array}$ & $\overrightarrow{\mathrm{z}}$ & $\begin{array}{l}\stackrel{P}{f} \\
\dot{+} \\
\stackrel{+}{+}\end{array}$ & $\begin{array}{l}\text { PROVISÕES } \\
\text { ORGANIZACIO- } \\
\text { NAIS }\end{array}$ & $\vec{a}$ & $\begin{array}{l}8 \\
0 \\
0\end{array}$ & $\begin{array}{l}\text { Treinamento regular em } \\
\text { segurança contra incêndio }\end{array}$ & $\vec{\Delta}$ & $\stackrel{\overbrace{}}{\stackrel{G}{G}}$ & $\begin{array}{l}\text { Treinamento em } \\
\text { prevenção e mitigação } \\
\text { incêndio e explosão com } \\
\text { liberação radiológica }\end{array}$ & $\overrightarrow{0}$ & $?$ & $\begin{array}{l}\text { Treinamento em III.20, } \\
\text { cobrir explosão de } \mathrm{H}_{2} \mathrm{em} \\
\text { forno de redução }\end{array}$ \\
\hline $\begin{array}{l}\stackrel{+}{+} \\
\stackrel{\sim}{m} \\
\stackrel{\sim}{+}\end{array}$ & $\begin{array}{l}\tilde{y} \\
\dot{+} \\
\tilde{\sigma} \\
\stackrel{\sigma}{+}\end{array}$ & & $\begin{array}{l}\text { RECURSOS } \\
\text { HUMANOS }\end{array}$ & 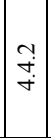 & $\begin{array}{l}\text { Competência, } \\
\text { treinamento e } \\
\text { conscientização. }\end{array}$ & $\stackrel{\substack{++}}{+}$ & $\begin{array}{l}\text { Competência, } \\
\text { treinamento e } \\
\text { conscientização. }\end{array}$ & $\overrightarrow{\mathrm{Z}}$ & $\begin{array}{l}\stackrel{O}{+} \\
\stackrel{+}{T} \\
\stackrel{+}{+}\end{array}$ & $\begin{array}{l}\text { PROVISÕES } \\
\text { ORGANIZACIO- } \\
\text { NAIS }\end{array}$ & $\vec{a}$ & গุ. & $\begin{array}{l}\text { Treinamento adicional } \\
\text { pessoal relevante à } \\
\text { operação nas instruções } \\
\text { operacionais }\end{array}$ & $\vec{\Delta}$ & 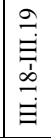 & $\begin{array}{l}\text { Treinamentos específicos } \\
\text { para pessoal na operação } \\
\text { da conversão }\end{array}$ & $\vec{a}$ & 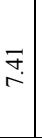 & $\begin{array}{l}\text { Perigos convencionais - } \\
\text { Treinar operadores em } \\
\text { detecção nuvem } \mathrm{UO}_{2} \mathrm{~F}_{2}\end{array}$ \\
\hline $\begin{array}{l}\stackrel{+}{+} \\
\stackrel{\infty}{\infty} \\
\stackrel{\sim}{+}\end{array}$ & 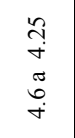 & & $\begin{array}{l}\text { RECURSOS } \\
\text { HUMANOS }\end{array}$ & 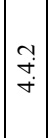 & $\begin{array}{l}\text { Competência, } \\
\text { treinamento e } \\
\text { conscientização. }\end{array}$ & $\underset{\mathfrak{T}}{\stackrel{+}{+}}$ & $\begin{array}{l}\text { Competência, } \\
\text { treinamento e } \\
\text { conscientização. }\end{array}$ & $\vec{a}$ & $\overrightarrow{\vec{r}}$ & $\begin{array}{l}\text { Exercícios periódi- } \\
\text { cos dentro e fora do } \\
\text { sítio em preparação } \\
\text { de emergência }\end{array}$ & $\vec{a}$ & $\begin{array}{l}8 \\
0 \\
1 \\
b \\
0 \\
0\end{array}$ & $\begin{array}{l}\text { Exercícios em plano de } \\
\text { emergência antes começar } \\
\text { operação }\end{array}$ & & & & & & \\
\hline
\end{tabular}




\begin{tabular}{|c|c|c|c|c|c|c|c|c|c|c|c|c|c|c|c|c|c|c|c|}
\hline vi & $\begin{array}{l}\overline{0} \\
\vdots \\
\dot{b} \\
\dot{0}\end{array}$ & $\begin{array}{l}\text { हे } \\
\text { है }\end{array}$ & SG - IAEA & & $\begin{array}{l}\text { SG - Ambiental } \\
\text { ISO } 14001\end{array}$ & & $\begin{array}{l}\text { - Segurança e Saúde no } \\
\text { Trabalho } \\
\text { OHSAS } 18001\end{array}$ & & $\begin{array}{l}\text { Segu } \\
\text { IAE }\end{array}$ & $\begin{array}{l}\text { urança - Ciclo do } \\
\text { Combustível } \\
\text { A DS316 Seção } 4\end{array}$ & & geura & $\begin{array}{l}\text { ança - Operação Ciclo do } \\
\text { Combustível } \\
\text { AEA DS316 Seção } 9\end{array}$ & & $\begin{array}{l}\text { uran } \\
\text { AEA }\end{array}$ & $\begin{array}{l}\text { ça - Operação Conversão } \\
\text { DS316 Ap. III } 18 \text { a } 19\end{array}$ & & & $\begin{array}{l}\text { egurança - Operação } \\
\text { Conversão } \\
\text { AEAA DS344 Seção } 7\end{array}$ \\
\hline \multirow[t]{2}{*}{ 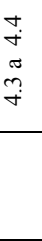 } & $\begin{array}{l}\stackrel{2}{i} \\
+ \\
\tilde{\sigma} \\
\stackrel{+}{+} \\
\dot{+}\end{array}$ & & $\begin{array}{l}\text { RECURSOS } \\
\text { HUMANOS }\end{array}$ & $\underset{+}{\stackrel{+}{*}}$ & $\begin{array}{l}\text { Competência, } \\
\text { treinamento e } \\
\text { conscientização. }\end{array}$ & $\stackrel{\stackrel{\sim}{+}}{+}$ & $\begin{array}{l}\text { Competência, } \\
\text { treinamento e } \\
\text { conscientização. }\end{array}$ & $\vec{a}$ & 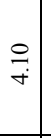 & $\begin{array}{l}\text { Registros treina- } \\
\text { mento pessoal e } \\
\text { contratados envol- } \\
\text { vidos c/ segurança }\end{array}$ & & & & & & & & & \\
\hline & & $\underset{F}{Z}$ & $\begin{array}{l}\text { RECURSOS } \\
\text { HUMANOS }\end{array}$ & $\underset{\stackrel{\sim}{+}}{+}$ & $\begin{array}{l}\text { Competência, } \\
\text { treinamento e } \\
\text { conscientização. }\end{array}$ & 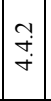 & $\begin{array}{l}\text { Competência, } \\
\text { treinamento e } \\
\text { conscientização. }\end{array}$ & 苂 & 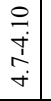 & $\begin{array}{l}\text { PROVISÕES } \\
\text { ORGANIZACIO- } \\
\text { NAIS }\end{array}$ & $\vec{a}$ & $\stackrel{ \pm}{a}$ & $\begin{array}{l}\text { Pessoal mínimo assegurar } \\
\text { segurança na operação e } \\
\text { condições de acidente }\end{array}$ & & & & & & \\
\hline$\stackrel{n}{q}$ & 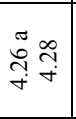 & & $\begin{array}{l}\text { INFRA- } \\
\text { ESTRUTURA E } \\
\text { AMBIENTE DE } \\
\text { TRABALHO }\end{array}$ & $\underset{+}{\dot{+}}$ & $\begin{array}{l}\text { Recursos, funções, } \\
\text { responsabilidades e } \\
\text { autoridades }\end{array}$ & $\underset{\dot{+}}{\dot{+}}$ & $\begin{array}{l}\text { Recursos, funções, res- } \\
\text { ponsabilidades, presta- } \\
\text { ção contas e autoridades }\end{array}$ & & & & $\overrightarrow{\mathrm{z}}$ & $\begin{array}{l}n \\
\vdots \\
\vdots \\
\vdots \\
\vdots\end{array}$ & $\begin{array}{l}\text { Estrutura e } \\
\text { responsabilidades da } \\
\text { organizaçãoo operadora }\end{array}$ & & & & & & \\
\hline \multirow[t]{5}{*}{ 㫗 } & 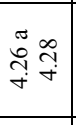 & & $\begin{array}{l}\text { INFRA- } \\
\text { ESTRUTURA E } \\
\text { AMBIENTE DE } \\
\text { TRABALHO } \\
\end{array}$ & $\underset{+}{\dot{+}}$ & $\begin{array}{l}\text { Recursos, funções, } \\
\text { responsabilidades e } \\
\text { autoridades }\end{array}$ & $\underset{+}{\stackrel{f}{+}}$ & $\begin{array}{l}\text { Recursos, funções, res- } \\
\text { ponsabilidades, presta- } \\
\text { ção contas e autoridades }\end{array}$ & & & & $\vec{\Delta}$ & $\hat{\sigma}$ & $\begin{array}{l}\text { Disponibilidade de infra- } \\
\text { estrutura usada em } \\
\text { emergência }\end{array}$ & & & & & & \\
\hline & సे & & Ambiente de trabalho & & & & & & & & & & & & & & & & \\
\hline & & 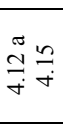 & $\begin{array}{l}\text { Gestão de patrimônio } \\
\text { material }\end{array}$ & $\begin{array}{l}\vec{n} \\
\dot{v}\end{array}$ & $\begin{array}{l}\text { Monitoração e } \\
\text { medição }\end{array}$ & $\vec{i}$ & $\begin{array}{l}\text { Monitoramento e } \\
\text { medição do desempenho }\end{array}$ & $\vec{\Delta}$ & $\stackrel{\leftrightarrow}{+}$ & $\begin{array}{l}\text { Projeto e implemen- } \\
\text { tação de controle } \\
\text { material nuclear e } \\
\text { prestação de contas }\end{array}$ & & & & & & & & & \\
\hline & & 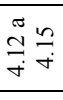 & $\begin{array}{l}\text { Gestão de patrimônio } \\
\text { material }\end{array}$ & $\overrightarrow{\vec{n}}$ & $\begin{array}{l}\text { Monitoração e } \\
\text { medição }\end{array}$ & $\overrightarrow{\dot{n}}$ & $\begin{array}{l}\text { Monitoramento e } \\
\text { medição do desempenho }\end{array}$ & $\vec{\Delta}$ & 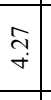 & $\begin{array}{l}\text { Esquema prestação } \\
\text { contas e verificação } \\
\text { de material nuclear }\end{array}$ & $\vec{\Delta}$ & $\stackrel{\infty}{a}$ & $\begin{array}{l}\text { Registro de quantidade e } \\
\text { movimentos de material } \\
\text { radioativo }\end{array}$ & & & & & & \\
\hline & & 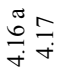 & $\begin{array}{l}\text { Substituição de tec- } \\
\text { nologias obsoletas }\end{array}$ & & & & & & & & & & & & & & & & \\
\hline in & in & in & $\begin{array}{l}\text { IMPLEMENTA- } \\
\text { ÇÃO DO } \\
\text { PROCESSO (Título) }\end{array}$ & & & & & & & & & & & & & & & & \\
\hline 年 & $\begin{array}{l}\frac{a}{n} \\
\frac{\pi}{n} \\
\dot{n}\end{array}$ & $\vec{n}$ & $\begin{array}{l}\text { DESENVOLVI- } \\
\text { MENTO DE } \\
\text { PROCESSOS }\end{array}$ & ' & Introdução & ' & Introdução & & & & & & & & & & & & \\
\hline 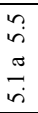 & $\begin{array}{l}\vec{a} \\
\dot{n} \\
\frac{\pi}{n}\end{array}$ & $\vec{n}$ & $\begin{array}{l}\text { DESENVOLVI- } \\
\text { MENTO DE } \\
\text { PROCESSOS }\end{array}$ & $\begin{array}{l}\dot{0} \\
\dot{+} \\
+\end{array}$ & Controle operacional & $\begin{array}{l}\stackrel{0}{+} \\
\stackrel{+}{+}\end{array}$ & Controle operacional & & & & $\overrightarrow{\mathrm{z}}$ & 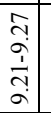 & $\begin{array}{l}\text { REQUISITOS } \\
\text { ESPECÍFICOS PARA } \\
\text { OPERAÇÃO (Geral) }\end{array}$ & & & & $\overrightarrow{\mathrm{z}}$ & 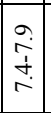 & $\begin{array}{l}\text { OPERAÇÃO DO } \\
\text { ESTABELECIMENTO }\end{array}$ \\
\hline 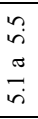 & 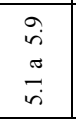 & $\vec{n}$ & $\begin{array}{l}\text { DESENVOLVI- } \\
\text { MENTO DE } \\
\text { PROCESSOS }\end{array}$ & $\stackrel{r}{\dot{f}}$ & \begin{tabular}{|l|} 
Preparação e \\
resposta a \\
emergência (Definir \\
processo) \\
\end{tabular} & $\stackrel{\stackrel{\sim}{+}}{\stackrel{+}{+}}$ & $\begin{array}{l}\text { Preparação e resposta a } \\
\text { emergência (Definir } \\
\text { processo) }\end{array}$ & $\vec{\Delta}$ & $\frac{\partial}{\vec{\sigma}}$ & $\begin{array}{l}\text { Preparação procedi- } \\
\text { mento emergência } \\
\text { dentro e, quando } \\
\text { aplicável, fora sítio }\end{array}$ & $\vec{\Delta}$ & 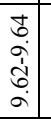 & $\begin{array}{l}\text { Preparaçã̃o plano emer- } \\
\text { gência perigos radioló- } \\
\text { gicos e não (Em coor- } \\
\text { denação c/ outros órgãos) }\end{array}$ & $\vec{\Delta}$ & $\stackrel{\infty}{\leftrightarrows}$ & $\begin{array}{l}\text { No plano de emergência } \\
\text { foco na resposta a } \\
\text { toxicidade } \mathrm{UF}_{6} \text { e seus } \\
\text { reagentes }\left(\mathrm{HF} \mathrm{e} \mathrm{UO}_{2} \mathrm{~F}_{2}\right)\end{array}$ & $\vec{\Delta}$ & 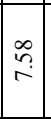 & $\begin{array}{l}\text { No plano de emergência } \\
\text { considerar grande } \\
\text { liberação de } \mathrm{UF}_{6}, \mathrm{HF}, \mathrm{F}_{2}, \\
\mathrm{NH}_{3} \text {, incêndio e explosão. }\end{array}$ \\
\hline
\end{tabular}




\begin{tabular}{|c|c|c|c|c|c|c|c|c|c|c|c|c|c|c|c|c|c|}
\hline 荘 & 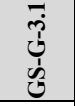 & $\begin{array}{l}\text { से } \\
\text { है }\end{array}$ & SG - IAEA & & $\begin{array}{l}\text { SG - Ambiental } \\
\text { ISO } 14001\end{array}$ & & $\begin{array}{c}\text { S - Segurança e Saúde no } \\
\text { Trabalho } \\
\text { OHSAS } 18001\end{array}$ & $\begin{array}{l}\text { Segurança - Ciclo do } \\
\text { Combustível } \\
\text { IAEA DS316 Seção } 4 \\
\end{array}$ & & $\begin{array}{r}\text { egur: } \\
\text { I }\end{array}$ & $\begin{array}{l}\text { ança - Operação Ciclo do } \\
\text { Combustível } \\
\text { IAEA DS316 Seção } 9\end{array}$ & & IJuran & $\begin{array}{l}\text { lça - Operação Conversão } \\
\text { I DS316 Ap. III } 18 \text { a } 19\end{array}$ & & & $\begin{array}{l}\text { gurança - Operação } \\
\text { Conversão } \\
\text { AEA DS344 Seção } 7\end{array}$ \\
\hline & & 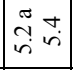 & Modelo de processo & ' & Introdução & ' & Introdução & & & & & & & & & & \\
\hline $\begin{array}{l}0 \\
\dot{1} \\
\tilde{\sigma} \\
0 \\
\dot{n} \\
\dot{n}\end{array}$ & $\begin{array}{l}\underset{\hat{n}}{n} \\
\tilde{\sigma} \\
\stackrel{0}{1} \\
\dot{n}\end{array}$ & & $\begin{array}{l}\text { GESTÃO DE } \\
\text { PROCESSO }\end{array}$ & $\begin{array}{l}\stackrel{\bullet}{+} \\
\dot{+}\end{array}$ & Controle operacional & $\begin{array}{l}\stackrel{0}{+} \\
\stackrel{+}{+}\end{array}$ & Controle operacional & & $\vec{a}$ & 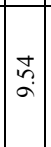 & $\begin{array}{l}\text { Minimizar produção } \\
\text { rejeitos assegurando } \\
\text { menor liberação ao } \\
\text { ambiente }\end{array}$ & & & & $\vec{\Delta}$ & 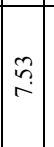 & $\begin{array}{l}\text { Descarga gases } \\
\text { radioativos e químicos } \\
\text { tratados - Filtros ar de } \\
\text { alta eficiência e sistemas } \\
\text { de esfregaço químico }\end{array}$ \\
\hline $\begin{array}{l}0 \\
\stackrel{1}{n} \\
\tilde{n} \\
\tilde{b} \\
\dot{n} \\
\end{array}$ & 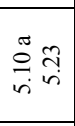 & & $\begin{array}{l}\text { GESTÃO DE } \\
\text { PROCESSO }\end{array}$ & $\begin{array}{l}\stackrel{\bullet}{+} \\
\dot{r}\end{array}$ & Controle operacional & $\begin{array}{l}\stackrel{0}{+} \\
\stackrel{+}{+}\end{array}$ & Controle operacional & & $\vec{\theta}$ & 芯 & $\begin{array}{l}\text { Minimizar produção rejei- } \\
\text { tos assegurando menor } \\
\text { liberaçãa ao ambiente }\end{array}$ & & & & $\vec{\Delta}$ & 点 & $\begin{array}{l}\text { Descarga de líquidos } \\
\text { efetivamente tratados. } \\
\text { Recuperar e reusar se } \\
\text { possível. }\end{array}$ \\
\hline $\begin{array}{l}0 \\
\dot{n} \\
i \\
\tilde{\sigma} \\
\dot{\sigma} \\
\dot{n}\end{array}$ & 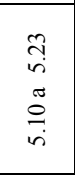 & & $\begin{array}{l}\text { GESTÃO DE } \\
\text { PROCESSO }\end{array}$ & $\begin{array}{l}\stackrel{\bullet}{\dot{P}} \\
\dot{+}\end{array}$ & Controle operacional & $\begin{array}{l}\stackrel{0}{+} \\
+ \\
+\end{array}$ & Controle operacional & & $\vec{a}$ & 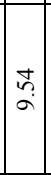 & $\begin{array}{l}\text { Minimizar produção } \\
\text { rejeitos assegurando } \\
\text { menor liberação ao } \\
\text { ambiente }\end{array}$ & & & & $\vec{\Delta}$ & $\stackrel{n}{n}$ & $\begin{array}{l}\text { Minimizar geração } \\
\text { rejeitos sólidos } \\
\text { radioativos, removendo o } \\
\text { mais possível o pacote } \\
\text { externo antes transferir } \\
\text { área de contaminação }\end{array}$ \\
\hline $\begin{array}{l}\stackrel{0}{\cdots} \\
\dot{n} \\
\tilde{\sigma} \\
\stackrel{0}{n} \\
\dot{n}\end{array}$ & $\begin{array}{l}\tilde{n} \\
i \\
\pi \\
0 \\
i \\
i\end{array}$ & & $\begin{array}{l}\text { GESTÃO DE } \\
\text { PROCESSO }\end{array}$ & $\begin{array}{l}\stackrel{0}{+} \\
\dot{+}\end{array}$ & Controle operacional & $\begin{array}{l}\stackrel{\circ}{+} \\
+\end{array}$ & Controle operacional & & $\vec{a}$ & 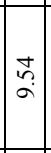 & $\begin{array}{l}\text { Minimizar produção } \\
\text { rejeitos assegurando } \\
\text { menor liberação ao } \\
\text { ambiente }\end{array}$ & & & & $\vec{\Delta}$ & $\stackrel{n}{n}$ & $\begin{array}{l}\text { Tratar cinzas não } \\
\text { queimadas resultado da } \\
\text { fluoração do urânio, } \mathrm{p} / \\
\text { recuperar conteúdo de } \\
\text { urânio }\end{array}$ \\
\hline $\begin{array}{l}0 \\
\ddot{n} \\
\tilde{\sigma} \\
0 \\
\dot{n}\end{array}$ & $\begin{array}{l}\tilde{N} \\
i \\
\pi \\
\stackrel{\pi}{1} \\
i\end{array}$ & & $\begin{array}{l}\text { GESTÃO DE } \\
\text { PROCESSO }\end{array}$ & $\underset{\stackrel{\bullet}{+}}{+}$ & Controle operacional & $\begin{array}{l}\stackrel{0}{+} \\
+ \\
+\end{array}$ & Controle operacional & & $\vec{a}$ & م̊ & $\begin{array}{l}\text { Executar atividades que } \\
\text { envolvem radiação e pro- } \\
\text { dutos químicos perigosos, } \\
\text { acordo políticas rejeitos, } \\
\text { PGQ e requisitos agência } \\
\text { reguladora }\end{array}$ & & & & & & \\
\hline $\begin{array}{l}\stackrel{0}{1} \\
i \\
\tilde{n} \\
\stackrel{0}{n} \\
\dot{n}\end{array}$ & $\begin{array}{l}\tilde{n} \\
i n \\
\tilde{\sigma} \\
0 \\
\dot{n}\end{array}$ & & $\begin{array}{l}\text { GESTÃO DE } \\
\text { PROCESSO }\end{array}$ & 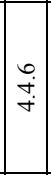 & Controle operacional & $\begin{array}{l}\stackrel{0}{+} \\
+ \\
+\end{array}$ & Controle operacional & & & & & $\vec{\Delta}$ & $\stackrel{\stackrel{\leftrightarrow}{\leftrightarrows}}{\Xi}$ & $\begin{array}{l}\text { Verificação peso abaixo } \\
\text { limite enchimento com } \\
\text { escala (ESC) onde possa } \\
\text { ocorrer ponto triplo } \\
\text { durante aquecimento } \\
\text { cilindros }\end{array}$ & $\vec{\Delta}$ & 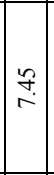 & $\begin{array}{l}\text { Em caso de sobre } \\
\text { enchimento transferência } \\
\text { excesso de } \mathrm{UF}_{6} \text { por } \\
\text { sublimação }\end{array}$ \\
\hline $\begin{array}{l}0 \\
\ddot{n} \\
\tilde{\sigma} \\
0 \\
\dot{n}\end{array}$ & $\begin{array}{l}\tilde{n} \\
i n \\
\tilde{\sigma} \\
\stackrel{0}{n} \\
\dot{n}\end{array}$ & & $\begin{array}{l}\text { GESTÃO DE } \\
\text { PROCESSO }\end{array}$ & $\begin{array}{l}\underset{\bullet}{+} \\
\dot{f} \\
\dot{f}\end{array}$ & Controle operacional & $\begin{array}{l}\stackrel{0}{+} \\
+ \\
+\end{array}$ & Controle operacional & & & & & $\vec{a}$ & $\stackrel{\widehat{\hat{y}}}{\Xi}$ & $\begin{array}{l}\text { Limitar temperatura por } \\
\text { dois sistemas } \\
\text { independentes durante } \\
\text { aquecimento } \mathrm{p} / \text { evitar } \\
\text { ruptura hidráulica }\end{array}$ & $\vec{\Delta}$ & $\stackrel{\substack{q \\
\sim}}{r}$ & $\begin{array}{l}\text { Em caso de sobre } \\
\text { enchimento transferência } \\
\text { excesso de } \mathrm{UF}_{6} \text { por } \\
\text { sublimação }\end{array}$ \\
\hline 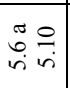 & $\begin{array}{l}\pi \\
\stackrel{\pi}{\approx} \\
\sin \end{array}$ & & $\begin{array}{l}\text { GESTÃO DE } \\
\text { PROCESSO }\end{array}$ & $\underset{\stackrel{\bullet}{+}}{\dot{f}}$ & Controle operacional & $\underset{\stackrel{\circ}{+}}{+}$ & Controle operacional & & $\vec{a}$ & $\tilde{n}$ & $\begin{array}{l}\text { Gestão rejeitos sólidos, } \\
\text { líquidos e gasosos, acordo } \\
\text { IAEA WS-R-2 }\end{array}$ & & & & & & \\
\hline $\begin{array}{l}\stackrel{0}{1} \\
\dot{n} \\
\tilde{\sigma} \\
0 \\
\dot{n}\end{array}$ & $\begin{array}{l}\tilde{n} \\
i n \\
\tilde{0} \\
0 \\
\dot{n}\end{array}$ & & $\begin{array}{l}\text { GESTÃO DE } \\
\text { PROCESSO }\end{array}$ & $\begin{array}{l}\underset{\dot{P}}{+} \\
\dot{+}\end{array}$ & Controle operacional & $\stackrel{\substack{++}}{+}$ & Controle operacional & & $\vec{O}$ & $\tilde{n}$ & $\begin{array}{l}\text { Monitora e verificar des- } \\
\text { carga efluentes radioa- } \\
\text { tivos e produtos químicos } \\
\text { perigosos, em atendimen- } \\
\text { to autoridade nacional } \\
\end{array}$ & & & & & & \\
\hline
\end{tabular}




\begin{tabular}{|c|c|c|c|c|c|c|c|c|c|c|c|c|c|c|c|c|c|c|c|}
\hline \multirow{2}{*}{ 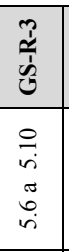 } & \multirow{2}{*}{ 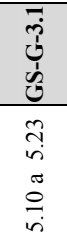 } & \multirow[t]{2}{*}{$\begin{array}{l}\text { ले } \\
\text { है }\end{array}$} & \multirow{2}{*}{$\begin{array}{l}\text { SG - IAEA } \\
\text { GESTÃO DE } \\
\text { PROCESSO }\end{array}$} & \multirow{2}{*}{\multicolumn{2}{|c|}{\begin{tabular}{c|c} 
& \multicolumn{1}{c}{$\begin{array}{c}\text { SG - Ambiental } \\
\text { ISO 14001 }\end{array}$} \\
& \\
\multirow{+}{+}{} & Controle operacional \\
+ &
\end{tabular}}} & \multicolumn{2}{|c|}{$\begin{array}{c}\text { SG - Segurança e Saúde no } \\
\text { Trabalho } \\
\text { OHSAS 18001 }\end{array}$} & \multicolumn{3}{|c|}{$\begin{array}{l}\text { Segurança - Ciclo do } \\
\text { Combustível } \\
\text { IAEA DS316 Seção } 4\end{array}$} & \multicolumn{3}{|c|}{$\begin{array}{c}\text { Segurança - Operação Ciclo do } \\
\text { Combustível } \\
\text { IAEA DS316 Seção } 9\end{array}$} & \multicolumn{3}{|c|}{$\begin{array}{l}\text { Segurança - Operação Conversão } \\
\text { IAEA DS316 Ap. III } 18 \text { a } 19\end{array}$} & \multicolumn{3}{|c|}{$\begin{array}{c}\text { Segurança - Operação } \\
\text { Conversão } \\
\text { IAEA DS344 Seção } 7\end{array}$} \\
\hline & & & & & & $\begin{array}{l}\stackrel{i}{+} \\
\dot{f} \\
\dot{f}\end{array}$ & Controle operacional & & & & & & & $\vec{\Delta}$ & $\stackrel{\sim}{\stackrel{G}{\Xi}}$ & $\begin{array}{l}\text { Estabelecer limite de } \\
\text { enchimento para evitar } \\
\text { ruptura por aquecimento }\end{array}$ & $\vec{\Delta}$ & 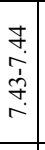 & $\begin{array}{l}\text { Estabelecer limite enchi- } \\
\text { mento para assegurar que } \\
\text { expansão } \mathrm{UF}_{6} \text { pela } \\
\text { liquefação não provoque } \\
\text { ruptura hidráulica }\end{array}$ \\
\hline 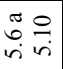 & 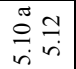 & & $\begin{array}{l}\text { GESTÃO DE } \\
\text { PROCESSO (Geral) }\end{array}$ & $\overrightarrow{\vec{n}}$ & $\begin{array}{l}\text { Monitoração e } \\
\text { medição }\end{array}$ & $\overrightarrow{i n}$ & $\begin{array}{l}\text { Monitoramento e } \\
\text { medição do desempenho }\end{array}$ & & & & & & & & & & & & \\
\hline & 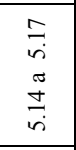 & & $\begin{array}{l}\text { Responsabilidades } \\
\text { pelos processos }\end{array}$ & $\overrightarrow{\dot{+}}$ & $\begin{array}{l}\text { Recursos, funções, } \\
\text { responsabilidades e } \\
\text { autoridades }\end{array}$ & $\underset{\stackrel{+}{+}}{\stackrel{f}{+}}$ & $\begin{array}{l}\text { Assegurar que pessoas } \\
\text { nos locais de trabalho } \\
\text { assumam } \\
\text { responsabilidades por } \\
\text { aspectos de SST }\end{array}$ & $\overrightarrow{0}$ & $\ddot{f}$ & $\begin{array}{l}\text { Identificar supervi- } \\
\text { sor e pessoal que } \\
\text { controlam e condu- } \\
\text { zem operações que } \\
\text { afetam segurança } \\
\end{array}$ & & & & & & & & & \\
\hline & 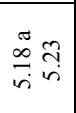 & & $\begin{array}{l}\text { Processos } \\
\text { contratados de outras } \\
\text { organizações }\end{array}$ & $\overrightarrow{\vec{n}}$ & $\begin{array}{l}\text { Monitoração e } \\
\text { medição }\end{array}$ & $\overrightarrow{\dot{n}}$ & $\begin{array}{l}\text { Monitoramento e } \\
\text { medição do desempenho }\end{array}$ & $\vec{\Delta}$ & $\stackrel{n}{+}$ & $\begin{array}{l}\text { Responsabilidades e } \\
\text { controle trabalhos } \\
\text { delegados outras } \\
\text { organizacões }\end{array}$ & & & & & & & & & \\
\hline$\vec{F}$ & & & $\begin{array}{l}\text { PROCESSOS DE } \\
\text { SISTEMA DE } \\
\text { GESTÃO GENÉ- } \\
\text { RICOS (Título) } \\
\end{array}$ & & & & & & & & & & & & & & & & \\
\hline 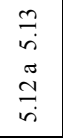 & 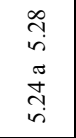 & & $\begin{array}{l}\text { Controle de } \\
\text { documentos }\end{array}$ & $\stackrel{n}{\stackrel{n}{+}+\infty}$ & $\begin{array}{l}\text { Controle de } \\
\text { documentos }\end{array}$ & $\stackrel{n}{\stackrel{n}{+}} \underset{+}{+}$ & Controle de documentos & & & & $\vec{\Delta}$ & 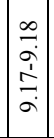 & $\begin{array}{l}\text { Gestão de documentos } \\
\text { (Duplicação de } \\
\text { documentos essenciais) }\end{array}$ & & & & & & \\
\hline 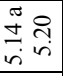 & $\begin{array}{c}\tilde{n} \\
\grave{n} \\
\ddot{n}\end{array}$ & & Controle de produtos & $\begin{array}{l}\stackrel{0}{+} \\
\dot{+} \\
+\end{array}$ & Controle operacional & $\mid \begin{array}{l}\stackrel{\bullet}{+} \\
\dot{+} \\
\dot{+}\end{array}$ & Controle operacional & & & & & & & & & & & & \\
\hline & & $\stackrel{\pi}{n} \frac{0}{\sin }$ & Inspeção e teste & $\begin{array}{l}\overrightarrow{\dot{n}} \\
\dot{v}\end{array}$ & $\begin{array}{l}\text { Monitoração e } \\
\text { medição }\end{array}$ & $\overrightarrow{\dot{n}}$ & $\begin{array}{l}\text { Monitoramento e } \\
\text { medição do desempenho }\end{array}$ & & & & $\vec{\Delta}$ & $\underset{\substack{0 \\
\alpha}}{\mid}$ & \begin{tabular}{|l|} 
Testes e inspeções \\
periódicas para adequado \\
funcionamento ESC
\end{tabular} & $\overrightarrow{0}$ & $\underset{\Xi}{\Xi}$ & $\begin{array}{l}\text { Inspeção periódica em } \\
\text { Cilindros } \mathrm{UF}_{6}\end{array}$ & $\vec{\Delta}$ & $\stackrel{m}{\sim}$ & $\begin{array}{l}\text { Inspeção de cilindros } \\
\text { durante operação }\end{array}$ \\
\hline & & 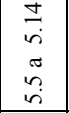 & Inspeção e teste & $\overrightarrow{\ddot{n}}$ & $\begin{array}{l}\text { Monitoração e } \\
\text { medição }\end{array}$ & $\overrightarrow{\dot{n}}$ & $\begin{array}{l}\text { Monitoramento e } \\
\text { medição do desempenho }\end{array}$ & & & & $\vec{\Delta}$ & $\begin{array}{c}0 \\
\dot{m} \\
\sigma\end{array}$ & $\begin{array}{l}\text { Frequiência p/ testes e ins- } \\
\text { peções ESC, acordo LCO }\end{array}$ & & & & $\vec{\Delta}$ & 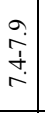 & $\begin{array}{l}\text { OPERAÇÃO DO } \\
\text { ESTABELECIMENTO } \\
\text { (Inspeções) }\end{array}$ \\
\hline & & 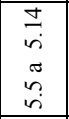 & Inspeção e teste & $\overrightarrow{\dot{n}}$ & $\begin{array}{l}\text { Monitoração e } \\
\text { medição }\end{array}$ & $\vec{n}$ & $\begin{array}{l}\text { Monitoramento e } \\
\text { medição do desempenho }\end{array}$ & & & & $\vec{\Delta}$ & ָุ̀ & $\begin{array}{l}\text { Programa e procedimen- } \\
\text { tos escritos p/manuten- } \\
\text { cão, testes, inspeções } \\
\text { periódicas em ESC }\end{array}$ & $\overrightarrow{0}$ & $\underset{\Xi}{\Xi}$ & $\begin{array}{l}\text { Programa de inspeç̃o } \\
\text { periódica de cilindro de } \\
\mathrm{UF}_{6} \text { (particularmente } \\
\text { válvula e "plugs") }\end{array}$ & $\vec{\Delta}$ & $\stackrel{2}{r}$ & $\begin{array}{l}\text { Programa de inspeção } \\
\text { para confirmar operação } \\
\text { acordo LCO }\end{array}$ \\
\hline & & $\begin{array}{l} \pm \\
i n \\
\pi \\
n \\
n \\
n\end{array}$ & Inspeção e teste & $\overrightarrow{\dot{n}}$ & $\begin{array}{l}\text { Monitoração e } \\
\text { medição }\end{array}$ & $\overrightarrow{\vec{n}}$ & $\begin{array}{l}\text { Registrar dados e resul- } \\
\text { tados do monitoramento } \\
\text { e medição para análise } \\
\text { de ações corretivas e } \\
\text { preventivas }\end{array}$ & & & & $\vec{a}$ & $\mid \begin{array}{c}\tilde{2} \\
2 \\
0 \\
0 \\
\infty \\
a \\
a\end{array}$ & $\begin{array}{l}\text { Registros manutenção, } \\
\text { testes e inspeções em ESC }\end{array}$ & $\vec{\theta}$ & $\underset{\Xi}{\Xi}$ & $\begin{array}{l}\text { Registro de inspeção } \\
\text { periódica de cilindro de } \\
\text { UF }_{6} \text { (particularmente } \\
\text { válvula e "plugs") }\end{array}$ & & & \\
\hline & $\underset{m}{m}$ & 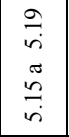 & $\begin{array}{l}\text { Equipamentos de } \\
\text { medição e testes }\end{array}$ & $\overrightarrow{\ddot{n}}$ & $\begin{array}{l}\text { Monitoração e } \\
\text { medição }\end{array}$ & $\overrightarrow{\dot{n}}$ & $\begin{array}{l}\text { Monitoramento e } \\
\text { medição do desempenho }\end{array}$ & & & & & 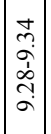 & $\begin{array}{l}\text { Controlar equipamentos e } \\
\text { itens usados para } \\
\text { manutenção, inspeções e } \\
\text { testes }\end{array}$ & & & & & & \\
\hline
\end{tabular}




\begin{tabular}{|c|c|c|c|c|c|c|c|c|c|c|c|c|c|c|}
\hline 站 & $\begin{array}{l}\overline{3} \\
\dot{b} \\
\dot{3}\end{array}$ & $\begin{array}{l}\text { ले } \\
\text { है }\end{array}$ & SG - IAEA & & $\begin{array}{l}\text { SG - Ambiental } \\
\text { ISO } 14001\end{array}$ & & $\begin{array}{l}\text { - Segurança e Saúde no } \\
\text { Trabalho } \\
\text { OHSAS } 18001\end{array}$ & & & $\begin{array}{l}\text { urança - Ciclo do } \\
\text { Combustível } \\
\text { A DS316 Seção } 4\end{array}$ & $\begin{array}{r}\text { Segura } \\
\text { I }\end{array}$ & $\begin{array}{l}\text { ança - Operação Ciclo do } \\
\text { Combustível } \\
\text { IAEA DS316 Seção } 9\end{array}$ & $\begin{array}{c}\text { Segurança - Operação Conversão } \\
\text { IAEA DS316 Ap. III } 18 \text { a } 19\end{array}$ & $\begin{array}{c}\text { Segurança - Operação } \\
\text { Conversão } \\
\text { IAEA DS344 Seção } 7\end{array}$ \\
\hline $\begin{array}{l}\overrightarrow{0} \\
\vec{n} \\
\sin \end{array}$ & 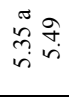 & & Controle de registros & 苞 & Controle de registros & $\begin{array}{c}\stackrel{\dot{m}}{i} \\
\dot{q}\end{array}$ & Controle de registros & & & & $\vec{a} \mid$\begin{tabular}{c|c}
$\vec{a}$ \\
$\frac{a}{2}$
\end{tabular} & $\begin{array}{l}\text { Gestão de documentos } \\
\text { (Duplicação de } \\
\text { documentos essenciais) }\end{array}$ & & \\
\hline 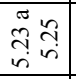 & 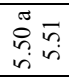 & & Aquisição & $\begin{array}{ll}\stackrel{0}{+} \\
+ \\
+ \\
\end{array}$ & Controle operacional & $\begin{array}{ll}\stackrel{\bullet}{0} \\
\dot{+} \\
\dot{+}\end{array}$ & Controle operacional & & & & & & & \\
\hline $\begin{array}{l}\tilde{\imath} \\
i n \\
\approx \\
\tilde{n} \\
i n\end{array}$ & $\begin{array}{l}\vec{n} \\
i n \\
\tilde{n} \\
\tilde{n} \\
i n\end{array}$ & & Aquisição & & & & & $\vec{\Delta}$ & $\stackrel{\vec{t}}{\dot{r}}$ & $\begin{array}{l}\text { Aquisição IISN su- } \\
\text { jeitos GQ. (Forne- } \\
\text { cedores avaliados e } \\
\text { selecionados, desvio } \\
\text { e ação corretiva re- } \\
\text { latados, evidencia } \\
\text { item atende espec.) }\end{array}$ & & & & \\
\hline & & 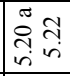 & $\begin{array}{l}\text { Produtos de categoria } \\
\text { comercial }\end{array}$ & & & & & & & & & & & \\
\hline 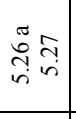 & & & Comunicação & $\stackrel{m}{\stackrel{?}{+}}$ & $\begin{array}{l}\text { Requisitos legais e } \\
\text { outros }\end{array}$ & $\stackrel{\sim}{\tilde{r}}$ & $\begin{array}{l}\text { Requisitos legais e } \\
\text { outros }\end{array}$ & 艺 & $\begin{array}{c}\stackrel{O}{+} \\
\dot{+} \\
\stackrel{+}{\dot{r}} \\
\end{array}$ & $\begin{array}{l}\text { PROVISÕES } \\
\text { ORGANIZACIO- } \\
\text { NAIS }\end{array}$ & & & & \\
\hline 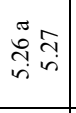 & 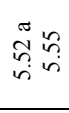 & & Comunicação & $\stackrel{m}{+}$ & Comunicação & $\underset{\substack{f \\
+}}{+}$ & $\begin{array}{l}\text { Comunicação, } \\
\text { participaçao e consulta }\end{array}$ & 艺 & 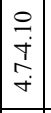 & $\begin{array}{l}\text { PROVISÕES } \\
\text { ORGANIZACIO- } \\
\text { NAIS }\end{array}$ & & & & \\
\hline 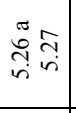 & 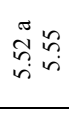 & & Comunicação & $\stackrel{m}{+}+$ & Comunicação & $\begin{array}{c}\overrightarrow{\dot{p}} \\
\dot{+} \\
\dot{+}\end{array}$ & Comunicação & 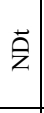 & 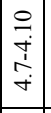 & $\begin{array}{l}\text { PROVISÕES } \\
\text { ORGANIZACIO- } \\
\text { NAIS }\end{array}$ & & & & \\
\hline 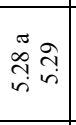 & 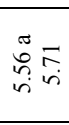 & & $\begin{array}{l}\text { Gestão de alteração } \\
\text { organizacional }\end{array}$ & $\overrightarrow{\dot{m}}$ & $\begin{array}{l}\text { Aspectos ambientais } \\
\text { e determinação de } \\
\text { impactos ambientais }\end{array}$ & $\overrightarrow{\dot{m}}$ & $\begin{array}{l}\text { Identificação perigo, } \\
\text { avaliação de riscos e } \\
\text { determinação de } \\
\text { controles }\end{array}$ & & & & $\overrightarrow{\mathrm{Z}}$ & $\begin{array}{l}\text { Controle de alterações } \\
\text { organizacionais }\end{array}$ & & \\
\hline 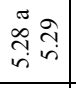 & 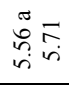 & & $\begin{array}{l}\text { Gestão de alteração } \\
\text { organizacional }\end{array}$ & $\stackrel{\substack{++}}{+}$ & Comunicação & 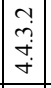 & Participação e consulta & & & & & & & \\
\hline 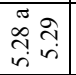 & 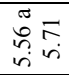 & & $\begin{array}{l}\text { Gestão de alteração } \\
\text { organizacional }\end{array}$ & $\stackrel{+}{+}$ & $\begin{array}{l}\text { Análise pela } \\
\text { administração }\end{array}$ & $\stackrel{\odot}{+}$ & $\begin{array}{l}\text { Análise crítica pela } \\
\text { direção }\end{array}$ & & & & & & & \\
\hline & & 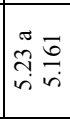 & \begin{tabular}{|l|} 
PROCESSOS \\
COMUNS A \\
TODOS OS \\
ESTÁGIOS (Título) \\
\end{tabular} & & & & & & & & & & & \\
\hline & & 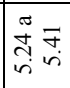 & \begin{tabular}{|l|} 
Administração do \\
empreendimento \\
(Project)
\end{tabular} & & & & & $\vec{a}$ & $\underset{\dot{P}}{\overrightarrow{+}}$ & $\begin{array}{l}\text { Programa QA pro- } \\
\text { dutos incluindo re- } \\
\text { jeitos todos estágios }\end{array}$ & & & & \\
\hline & & 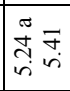 & $\begin{array}{l}\text { Administração do } \\
\text { empreendimento } \\
\text { (Project) }\end{array}$ & & & & & $\overrightarrow{\mathrm{a}}$ & $\stackrel{m}{\vec{\sigma}}$ & $\begin{array}{l}\text { GQ - Identificar e } \\
\text { controlar IISN }\end{array}$ & & & & \\
\hline
\end{tabular}




\begin{tabular}{|c|c|c|c|c|c|c|c|c|c|c|c|c|c|c|c|c|c|c|c|}
\hline w & $\begin{array}{l}\overline{0} \\
\vdots \\
1 \\
03\end{array}$ & $\begin{array}{l}\text { से } \\
\text { ă }\end{array}$ & SG - IAEA & & $\begin{array}{l}\text { SG - Ambiental } \\
\text { ISO } 14001\end{array}$ & & $\begin{array}{l}\text { - Segurança e Saúde no } \\
\text { Trabalho } \\
\text { OHSAS } 18001\end{array}$ & & & $\begin{array}{l}\text { urança - Ciclo do } \\
\text { Combustível } \\
\text { A DS316 Seção } 4\end{array}$ & & $\begin{array}{r}\text { egura } \\
\text { I }\end{array}$ & $\begin{array}{l}\text { ança - Operação Ciclo do } \\
\text { Combustível } \\
\text { IAEA DS316 Seção } 9\end{array}$ & & $\begin{array}{l}\text { uran } \\
\text { AEA }\end{array}$ & $\begin{array}{l}\text { çç - Operação Conversão } \\
\text { DS316 Ap. III } 18 \text { a } 19\end{array}$ & & & $\begin{array}{l}\text { egurança - Operação } \\
\text { Conversão } \\
\text { AEA DS344 Seção } 7\end{array}$ \\
\hline & & 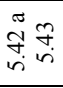 & $\begin{array}{l}\text { Planejamento e } \\
\text { controle do trabalho }\end{array}$ & $\overrightarrow{\dot{m}}$ & \begin{tabular}{|l} 
Aspectos ambientais \\
e determinação de \\
impactos ambientais
\end{tabular} & $\vec{m}$ & $\begin{array}{l}\text { Identificação perigo, } \\
\text { avaliação de riscos e } \\
\text { determinação controles }\end{array}$ & & & & & & & & & & & & \\
\hline & & \begin{tabular}{l}
$\underset{f}{q}$ \\
$\dot{n}$ \\
$\tilde{a}$ \\
\multirow{+}{+}{} \\
$\dot{n}$
\end{tabular} & $\begin{array}{l}\text { Planejamento e } \\
\text { controle do trabalho }\end{array}$ & $\stackrel{m}{\rightarrow}$ & $\begin{array}{l}\text { Objetivos, metas e } \\
\text { programas }\end{array}$ & $\stackrel{m}{\stackrel{\sim}{+}}$ & Objetivos e programas & $\vec{\Delta}$ & $\stackrel{m}{+}$ & $\begin{array}{l}\text { GQ - Planejar e } \\
\text { executar trabalhos } \\
\text { relativos segurança } \\
\text { acordo códigos, nor- } \\
\text { mas, especificações, } \\
\text { práticas e controles } \\
\text { administrativos. }\end{array}$ & & & & & & & & & \\
\hline & & $\begin{array}{l}\vec{n} \\
i n \\
\tilde{a} \\
j \\
\dot{j}\end{array}$ & $\begin{array}{l}\text { Avaliação do risco do } \\
\text { local de trabalho }\end{array}$ & $\overrightarrow{\dot{p}}$ & $\begin{array}{l}\text { Aspectos ambientais } \\
\text { e determinação de } \\
\text { impactos ambientais }\end{array}$ & $\overrightarrow{\dot{m}}$ & $\begin{array}{l}\text { Identificação de perigo, } \\
\text { avaliação de riscos e } \\
\text { determinação de } \\
\text { controles }\end{array}$ & & & & $\vec{a}$ & م & $\begin{array}{l}\text { Ter acesso especialista e } \\
\text { introduzir formas de mini- } \\
\text { mizar riscos perigos a se- } \\
\text { gurança industrial e } \\
\text { química }\end{array}$ & & & & $\vec{a}$ & $\underset{\substack{q \\
\sim}}{ }$ & $\begin{array}{l}\text { Perigos convencionais } \\
\text { são: químicos, de } \\
\text { explosão e de asfixia }\end{array}$ \\
\hline & & $\begin{array}{l}\vec{n} \\
i n \\
\pi \\
j \\
j \\
i n\end{array}$ & $\begin{array}{l}\text { Avaliação do risco do } \\
\text { local de trabalho }\end{array}$ & $\vec{m}$ & $\begin{array}{l}\text { Aspectos ambientais } \\
\text { e determinação de } \\
\text { impactos ambientais }\end{array}$ & $\overrightarrow{\dot{m}}$ & $\begin{array}{l}\text { Identificação de perigo, } \\
\text { avaliação de riscos e } \\
\text { determinação de } \\
\text { controles }\end{array}$ & & & & & & & $\ddot{\theta}$ & $\stackrel{\sim}{\stackrel{9}{\exists}}$ & $\begin{array}{l}\text { Estabelecer limite de } \\
\text { enchimento para evitar } \\
\text { ruptura por aquecimento }\end{array}$ & $\ddot{a}$ & 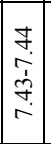 & $\begin{array}{l}\text { Estabelecer limite de } \\
\text { enchimento para assegurar } \\
\text { que expansão } \mathrm{UF}_{6} \text { pela } \\
\text { liquefação não provoque } \\
\text { ruptura hidráulica }\end{array}$ \\
\hline & & $\begin{array}{l}\vec{n} \\
i n \\
\tilde{n} \\
\dot{+} \\
i n\end{array}$ & $\begin{array}{l}\text { Avaliação do risco do } \\
\text { local de trabalho }\end{array}$ & $\vec{m} \dot{p}$ & $\begin{array}{l}\text { Aspectos ambientais } \\
\text { e determinação de } \\
\text { impactos ambientais }\end{array}$ & $\overrightarrow{\dot{m}}$ & $\begin{array}{l}\text { Identificação de perigo, } \\
\text { avaliação de riscos e } \\
\text { determinação de } \\
\text { controles }\end{array}$ & & & & & & & $\vec{\Delta}$ & $\stackrel{\text { Iִ }}{\stackrel{\Xi}{\Xi}}$ & $\begin{array}{l}\text { Verificacão do peso } \\
\text { abaixo limite de } \\
\text { enchimento com escala } \\
\text { (ESC) onde possa ocorrer } \\
\text { ponto triplo durante } \\
\text { aquecimento cilindros }\end{array}$ & $\vec{\Delta}$ & 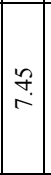 & $\begin{array}{l}\text { Em caso de sobre } \\
\text { enchimento transferência } \\
\text { excesso de } \mathrm{UF}_{6} \text { por } \\
\text { sublimação }\end{array}$ \\
\hline & & 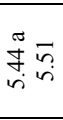 & $\begin{array}{l}\text { Avaliação do risco do } \\
\text { local de trabalho }\end{array}$ & $\vec{m}$ & $\begin{array}{l}\text { Aspectos ambientais } \\
\text { e determinação de } \\
\text { impactos ambientais }\end{array}$ & $\overrightarrow{\dot{m}}$ & $\begin{array}{l}\text { Identificação de perigo, } \\
\text { avaliação de riscos e } \\
\text { determinação de } \\
\text { controles }\end{array}$ & & & & & & & $\vec{\Delta}$ & $\stackrel{\widehat{̣}}{\Xi}$ & $\begin{array}{l}\text { Limitar temperatura por } 2 \\
\text { sistemas independentes } \\
\text { durante aquecimento } \mathrm{p} / \\
\text { evitar ruptura hidráulica }\end{array}$ & $\vec{\Delta}$ & $\stackrel{n}{\stackrel{n}{r}}$ & $\begin{array}{l}\text { Em caso de sobre } \\
\text { enchimento transferência } \\
\text { excesso de } \mathrm{UF}_{6} \text { por } \\
\text { sublimação }\end{array}$ \\
\hline & & 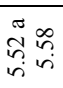 & $\begin{array}{l}\text { Segurança do Pessoal } \\
\text { (Título) }\end{array}$ & & & & & & & & & & & & & & & & \\
\hline & & $\begin{array}{l}\tilde{n} \\
n \\
\tilde{n} \\
\tilde{n} \\
i n\end{array}$ & Segurança industrial & 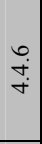 & $\begin{array}{l}\text { Controle } \\
\text { Operacional }\end{array}$ & \begin{tabular}{l|l}
$\stackrel{0}{+}$ \\
$\stackrel{+}{+}$
\end{tabular} & Controle Operacional & & & & $\vec{\Delta}$ & $\begin{array}{c}\infty \\
n \\
2\end{array}$ & $\begin{array}{l}\text { Ter acesso a especialista e } \\
\text { introduzir formas de } \\
\text { minimizar riscos de } \\
\text { perigos à segurança } \\
\text { industrial e química }\end{array}$ & & & & $\vec{\Delta}$ & 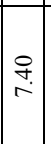 & $\begin{array}{l}\text { Perigos químicos, de } \\
\text { explosão e de asfixia }\end{array}$ \\
\hline & & 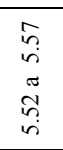 & Segurança industrial & 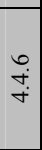 & $\begin{array}{l}\text { Controle } \\
\text { Operacional }\end{array}$ & \begin{tabular}{l|l}
$\stackrel{0}{+}$ \\
$\dot{+}$
\end{tabular} & Controle Operacional & & & & & & & $\vec{\Delta}$ & $\stackrel{\sim}{\stackrel{\leftrightarrow}{G}}$ & $\begin{array}{l}\text { Estabelecer limite de } \\
\text { enchimento para evitar } \\
\text { ruptura por aquecimento }\end{array}$ & $\vec{a}$ & 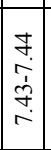 & $\begin{array}{l}\text { Estabelecer limite de } \\
\text { enchimento para assegurar } \\
\text { que expansão de } \mathrm{UF}_{6} \text { pela } \\
\text { liquefação não provoque } \\
\text { ruptura hidráulica }\end{array}$ \\
\hline & & $\begin{array}{l}n \\
n \\
n \\
\approx \\
i n \\
n \\
n\end{array}$ & Segurança industrial & $\begin{array}{l}\stackrel{0}{+} \\
\dot{+} \\
+\end{array}$ & $\begin{array}{l}\text { Controle } \\
\text { Operacional }\end{array}$ & $\mid \begin{array}{l}\stackrel{0}{\dot{P}} \\
\dot{+}\end{array}$ & Controle Operacional & & & & & & & $\vec{\Delta}$ & 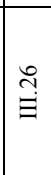 & $\begin{array}{l}\text { Verificação peso abaixo } \\
\text { limite enchimento com } \\
\text { escala (ESC) onde possa } \\
\text { ocorrer ponto triplo } \\
\text { durante aquecimento } \\
\text { cilindros }\end{array}$ & $\vec{\Delta}$ & $\stackrel{n}{\stackrel{n}{r}}$ & $\begin{array}{l}\text { Em caso de sobre } \\
\text { enchimento transferência } \\
\text { excesso de } \mathrm{UF}_{6} \text { por } \\
\text { sublimação }\end{array}$ \\
\hline
\end{tabular}




\begin{tabular}{|c|c|c|c|c|c|c|c|c|c|c|c|c|c|c|c|c|c|c|c|}
\hline w & $\begin{array}{l}\overline{0} \\
\dot{b} \\
\dot{3}\end{array}$ & 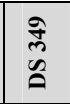 & SG - IAEA & & $\begin{array}{l}\text { SG - Ambiental } \\
\text { ISO } 14001\end{array}$ & & $\begin{array}{c}\text { - Segurança e Saúde no } \\
\text { Trabalho } \\
\text { OHSAS } 18001\end{array}$ & & & $\begin{array}{l}\text { urança - Ciclo do } \\
\text { Combustível } \\
\text { A DS316 Seção } 4\end{array}$ & & & $\begin{array}{l}\text { ança - Operação Ciclo do } \\
\text { Combustível } \\
\text { [AEA DS316 Seção } 9\end{array}$ & & IAEA & $\begin{array}{l}\text { çç - Operação Conversão } \\
\text { DS316 Ap. III } 18 \text { a } 19\end{array}$ & & & $\begin{array}{l}\text { egurança - Operação } \\
\text { Conversão } \\
\text { AEA DS344 Seção } 7\end{array}$ \\
\hline & & 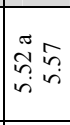 & Segurança industrial & $\begin{array}{l}\stackrel{0}{+} \\
\dot{+} \\
\dot{+}\end{array}$ & $\begin{array}{l}\text { Controle } \\
\text { Operacional }\end{array}$ & $\mid \begin{array}{l}\stackrel{\bullet}{\dot{v}} \\
\dot{v}\end{array}$ & Controle Operacional & & & & & & & $\vec{\Delta}$ & $\stackrel{\widehat{y}}{\exists}$ & $\begin{array}{l}\text { Limitar temperatura por } 2 \\
\text { sistemas independentes } \\
\text { durante aqueci-mento } \mathrm{p} / \\
\text { evitar ruptura hidráulica }\end{array}$ & $\vec{\Delta}$ & $\underset{n}{\stackrel{n}{r}}$ & $\begin{array}{l}\text { Em caso de sobre } \\
\text { enchimento transferência } \\
\text { excesso de UF } \mathrm{UF}_{6} \text { por } \\
\text { sublimação }\end{array}$ \\
\hline & & $\begin{array}{l}n \\
n \\
n \\
\tilde{n} \\
n \\
n\end{array}$ & Segurança industrial & $\begin{array}{l}\stackrel{0}{+} \\
\dot{+} \\
\dot{+}\end{array}$ & $\begin{array}{l}\text { Procedimentos } \\
\text { situações que possam } \\
\text { acarretar desvios de } \\
\text { SGA }\end{array}$ & 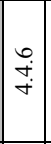 & $\begin{array}{l}\text { Procedimentos situações } \\
\text { que possam acarretar } \\
\text { desvios de SST }\end{array}$ & & & & $\vec{\Delta}$ & $\begin{array}{l}8 \\
\dot{a} \\
0 \\
\infty \\
\vec{a} \\
\vec{a}\end{array}$ & $\begin{array}{l}\text { Procedimentos escritos } \\
\text { sobre concentração de } \\
\text { gases inflamáveis }\end{array}$ & & & & $\vec{\Delta}$ & $\stackrel{\infty}{\sim}$ & $\begin{array}{l}\text { Procedimentos operacio- } \\
\text { nais específicos p/ manter } \\
\text { estado de segurança para } \\
\text { todas as ocorrências } \\
\text { previstas antecipadamente }\end{array}$ \\
\hline & & $\begin{array}{l}n \\
i n \\
i n \\
\tilde{n} \\
\tilde{n} \\
i n\end{array}$ & Segurança industrial & 管 & $\begin{array}{l}\text { Procedimentos } \\
\text { situações que possam } \\
\text { acarretar desvios de } \\
\text { SGA }\end{array}$ & $\begin{array}{l}0 \\
\dot{+} \\
\dot{+}\end{array}$ & $\begin{array}{l}\text { Procedimentos situações } \\
\text { que possam acarretar } \\
\text { desvios de SST }\end{array}$ & & & & & & & & & & $\vec{\Delta}$ & $\stackrel{\infty}{\sim}$ & $\begin{array}{l}\text { Procedimentos operacio- } \\
\text { nais específicos p/ manter } \\
\text { estado de segurança para } \\
\text { todas as ocorrências } \\
\text { previstas antecipadamente }\end{array}$ \\
\hline & & 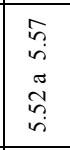 & Segurança industrial & 家 & $\begin{array}{l}\text { Procedimentos } \\
\text { situações que possam } \\
\text { acarretar desvios de } \\
\text { SGA }\end{array}$ & $\begin{array}{l}\stackrel{\leftrightarrow}{+} \\
\stackrel{+}{+}\end{array}$ & $\begin{array}{l}\text { Procedimentos situações } \\
\text { que possam acarretar } \\
\text { desvios de SST }\end{array}$ & & & & $\vec{a}$ & \begin{tabular}{l}
\multirow{2}{a}{} \\
$a$ \\
0 \\
$\infty$ \\
$\vec{a}$
\end{tabular} & $\begin{array}{l}\text { Instruções operacionais } \\
\text { com métodos de operação, } \\
\text { testes, inspeções, } \\
\text { calibrações aderentes aos } \\
\text { LCO }\end{array}$ & & & & $\overrightarrow{\mathrm{A}}$ & $\stackrel{\infty}{\sim}$ & $\begin{array}{l}\text { Procedimentos operacio- } \\
\text { nais específicos p/ manter } \\
\text { estado de segurança para } \\
\text { todas as ocorrências } \\
\text { previstas antecipadamente }\end{array}$ \\
\hline & & $\begin{array}{l}i n \\
i n \\
\tilde{n} \\
i n \\
i n\end{array}$ & Segurança industrial & $\underset{f}{\dot{f}}$ & $\begin{array}{l}\text { Preparação e } \\
\text { resposta a } \\
\text { emergência }\end{array}$ & $\underset{\sim}{\stackrel{r}{+}}$ & $\begin{array}{l}\text { Preparação e resposta a } \\
\text { emergência }\end{array}$ & $\overrightarrow{\mathrm{Z}}$ & 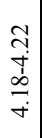 & $\begin{array}{l}\text { GESTÃO DE } \\
\text { ACIDENTE E } \\
\text { PREPARAÇÃO A } \\
\text { EMERGÊNCIA }\end{array}$ & $\overrightarrow{\mathrm{z}}$ & 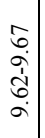 & $\begin{array}{l}\text { PREPARAÇÃO PARA } \\
\text { EMERGÊNCIA }\end{array}$ & 芝 & 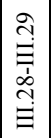 & $\begin{array}{l}\text { PLANEJAMENTO E } \\
\text { PREPARAÇÃO PARA } \\
\text { EMERGÊNCIA }\end{array}$ & $\overline{\mathrm{z}}$ & $\stackrel{\infty}{n}$ & $\begin{array}{l}\text { PLANEJAMENTO E } \\
\text { PREPARAÇÃO PARA } \\
\text { EMERGÊNCIA }\end{array}$ \\
\hline & & 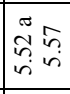 & Segurança industrial & $\underset{\dot{f}}{\dot{f}}$ & $\begin{array}{l}\text { Preparação e } \\
\text { resposta a } \\
\text { emergência }\end{array}$ & $\stackrel{\stackrel{f}{\dot{f}}}{+}$ & $\begin{array}{l}\text { Preparação e resposta a } \\
\text { emergência }\end{array}$ & $\vec{\Delta}$ & $\stackrel{\vec{r}}{\vec{r}}$ & $\begin{array}{l}\text { Procedimentos de } \\
\text { gestão de acidentes }\end{array}$ & & & & & & & & & \\
\hline & & 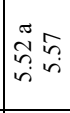 & Segurança industrial & $\stackrel{\sim}{\dot{f}}$ & $\begin{array}{l}\text { Preparação e } \\
\text { resposta a } \\
\text { emergência }\end{array}$ & $\stackrel{r}{\stackrel{r}{+}}$ & $\begin{array}{l}\text { Preparação e resposta a } \\
\text { emergência }\end{array}$ & $\vec{\Delta}$ & $\stackrel{\vec{r}}{\vec{r}}$ & $\begin{array}{l}\text { Procedimentos de } \\
\text { emergência dentro } \\
\text { e, quando aplicável, } \\
\text { fora do sítio }\end{array}$ & $\vec{\Delta}$ & 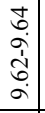 & $\begin{array}{l}\text { Plano de emergência } \\
\text { perigos radiológicos e não } \\
\text { (Em coordenação com } \\
\text { outros órgãos) }\end{array}$ & & & & & & \\
\hline & & $\begin{array}{l}\infty \\
n \\
n\end{array}$ & $\begin{array}{l}\text { Segurança } \\
\text { radiológica }\end{array}$ & \begin{tabular}{l|l}
$\stackrel{0}{+}$ \\
$\dot{+}$
\end{tabular} & $\begin{array}{l}\text { Controle } \\
\text { Operacional }\end{array}$ & \begin{tabular}{l|l}
$\stackrel{0}{+}$ \\
$\stackrel{+}{+}$
\end{tabular} & Controle Operacional & & & & $\vec{a}$ & $\begin{array}{l}\hat{2} \\
\hat{a} \\
\grave{b} \\
\stackrel{0}{2}\end{array}$ & $\begin{array}{l}\text { Proteção radiológica - } \\
\text { Exposição à radiação } \\
\text { pessoal operação, } \\
\text { contratados, publico }\end{array}$ & & & & $\ddot{\Delta}$ & 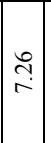 & $\begin{array}{l}\text { Controle exposição } \\
\text { público com remoção } \\
\text { material radioativo dos } \\
\text { gases antes descarregar } \\
\text { atmosfera }\end{array}$ \\
\hline & & $\begin{array}{l}\infty \\
n \\
n\end{array}$ & $\begin{array}{l}\text { Segurança } \\
\text { radiológica }\end{array}$ & $\begin{array}{l}\stackrel{\dot{m}}{+} \\
\dot{+}\end{array}$ & $\begin{array}{l}\text { Controle } \\
\text { Operacional }\end{array}$ & $\mid \begin{array}{l}\dot{0} \\
\dot{+} \\
\dot{+}\end{array}$ & Controle Operacional & & & & $\overrightarrow{0}$ & ơ & $\begin{array}{l}\text { Controle de dose } \\
\text { ocupacional }\end{array}$ & & & & $\ddot{\theta}$ & 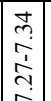 & Controle da dose interna \\
\hline & & 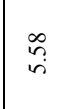 & $\begin{array}{l}\text { Segurança } \\
\text { radiológica }\end{array}$ & $\begin{array}{l}\stackrel{0}{+} \\
+\end{array}$ & $\begin{array}{l}\text { Controle } \\
\text { Operacional }\end{array}$ & \begin{tabular}{l|l}
$\stackrel{0}{+}$ \\
$\stackrel{+}{+}$
\end{tabular} & Controle Operacional & & & & $\vec{a}$ & 占. & $\begin{array}{l}\text { Controle de dose } \\
\text { ocupacional }\end{array}$ & & & & $\vec{\Delta}$ & 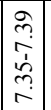 & Controle da dose externa \\
\hline & & $\begin{array}{l}\infty \\
i n \\
i n\end{array}$ & $\begin{array}{l}\text { Segurança } \\
\text { radiológica }\end{array}$ & \begin{tabular}{l|l}
$\stackrel{0}{+}$ \\
+
\end{tabular} & $\begin{array}{l}\text { Controle } \\
\text { Operacional }\end{array}$ & $\begin{array}{l}\stackrel{0}{+} \\
\dot{+}\end{array}$ & Controle Operacional & & & & $\vec{\Delta}$ & 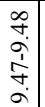 & Controle de contaminação & & & & & & \\
\hline
\end{tabular}




\begin{tabular}{|c|c|c|c|c|c|c|c|c|c|c|c|c|c|c|c|c|c|c|c|}
\hline 范 & $\begin{array}{l}\overline{0} \\
b \\
1 \\
0\end{array}$ & 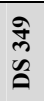 & SG - IAEA & & $\begin{array}{l}\text { SG - Ambiental } \\
\text { ISO } 14001\end{array}$ & & $\begin{array}{l}\text { - Segurança e Saúde no } \\
\text { Trabalho } \\
\text { OHSAS } 18001\end{array}$ & & & $\begin{array}{l}\text { urança - Ciclo do } \\
\text { Combustível } \\
\text { A DS316 Seção } 4\end{array}$ & & & $\begin{array}{l}\text { ança - Operação Ciclo do } \\
\text { Combustível } \\
\text { IAEA DS316 Seção } 9\end{array}$ & & $\begin{array}{l}\text { guran } \\
\text { IAEA }\end{array}$ & $\begin{array}{l}\text { ça - Operação Conversão } \\
\text { DS316 Ap. III } 18 \text { a } 19\end{array}$ & & & $\begin{array}{l}\text { geurança - Operação } \\
\text { Conversão } \\
\text { AEA DS344 Seção } 7\end{array}$ \\
\hline & & in & $\begin{array}{l}\text { Segurança } \\
\text { radiológica }\end{array}$ & $\begin{array}{l}\stackrel{0}{+} \\
+ \\
+\end{array}$ & $\begin{array}{l}\text { Controle } \\
\text { Operacional }\end{array}$ & $\mid \begin{array}{l}\stackrel{\bullet}{+} \\
\dot{+}\end{array}$ & Controle Operacional & & & & & & & $\vec{\Delta}$ & $\stackrel{\stackrel{\sim}{c}}{\exists}$ & $\begin{array}{l}\text { Estabelecer limite de } \\
\text { enchimento para evitar } \\
\text { ruptura por aquecimento }\end{array}$ & $\vec{\Delta}$ & 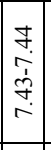 & $\begin{array}{l}\text { Estabelecer limite de } \\
\text { enchimento para assegurar } \\
\text { que expansão } \mathrm{UF}_{6} \text { pela } \\
\text { liquefação não provoque } \\
\text { ruptura hidráulica }\end{array}$ \\
\hline & & $\begin{array}{l}\infty \\
n \\
n\end{array}$ & $\begin{array}{l}\text { Segurança } \\
\text { radiológica }\end{array}$ & $\begin{array}{l}\stackrel{0}{+} \\
+ \\
+\end{array}$ & $\begin{array}{l}\text { Controle } \\
\text { Operacional }\end{array}$ & $\begin{array}{l}\stackrel{0}{+} \\
\dot{+}\end{array}$ & Controle Operacional & & & & & & & $\vec{\Delta}$ & 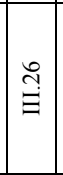 & $\begin{array}{l}\text { Verificação peso abaixo } \\
\text { limite enchimento com } \\
\text { escala (ESC) onde possa } \\
\text { ocorrer ponto triplo } \\
\text { durante aquecimento } \\
\text { cilindros }\end{array}$ & $\vec{\Delta}$ & $\underset{\substack{n \\
\hdashline\\
}}{ }$ & $\begin{array}{l}\text { Em caso de sobre } \\
\text { enchimento transferência } \\
\text { excesso de } \mathrm{UF}_{6} \text { por } \\
\text { sublimação }\end{array}$ \\
\hline & & in & $\begin{array}{l}\text { Segurança } \\
\text { radiológica }\end{array}$ & $\begin{array}{ll}\stackrel{0}{+} \\
+ \\
+\end{array}$ & $\begin{array}{l}\text { Controle } \\
\text { Operacional }\end{array}$ & $\begin{array}{ll}\stackrel{0}{+} \\
\stackrel{+}{+}\end{array}$ & Controle Operacional & & & & & & & $\vec{\Delta}$ & $\stackrel{\widehat{̣}}{\Xi}$ & $\begin{array}{l}\text { Limitar temperatura por } \\
\text { dois sistemas } \\
\text { independentes durante } \\
\text { aquecimento } p / \text { evitar } \\
\text { ruptura hidráulica }\end{array}$ & $\vec{\Delta}$ & $\stackrel{n}{i}$ & $\begin{array}{l}\text { Em caso de sobre } \\
\text { enchimento transferência } \\
\text { excesso de } \mathrm{UF}_{6} \text { por } \\
\text { sublimação }\end{array}$ \\
\hline & & $\begin{array}{l}\infty \\
n \\
n\end{array}$ & $\begin{array}{l}\text { Segurança } \\
\text { radiológica }\end{array}$ & $\begin{array}{l}0 \\
\stackrel{+}{+} \\
+\end{array}$ & $\begin{array}{l}\text { Controle } \\
\text { Operacional }\end{array}$ & \begin{tabular}{l|l}
$\stackrel{0}{+}$ \\
+
\end{tabular} & Controle Operacional & & & & $\vec{\theta}$ & $\stackrel{\dot{m}}{2}$ & $\begin{array}{l}\text { Atenção descontaminação } \\
\text { para manutenção, testes e } \\
\text { inspeções periódicas }\end{array}$ & & & & $\begin{array}{l}n \\
0\end{array}$ & $\stackrel{9}{\sim}$ & $\begin{array}{l}\text { Atenção com } \\
\text { contaminação radioativa } \\
\text { na manutenção }\end{array}$ \\
\hline & & $\begin{array}{l}\infty \\
n \\
n\end{array}$ & $\begin{array}{l}\text { Segurança } \\
\text { radiológica }\end{array}$ & $\begin{array}{l}\stackrel{0}{+} \\
+ \\
+\end{array}$ & $\begin{array}{l}\text { Controle } \\
\text { Operacional }\end{array}$ & $\underset{\stackrel{+}{+}}{+}$ & Controle Operacional & & & & & & & & & & n & $\stackrel{2}{2}$ & $\begin{array}{l}\text { Atenção manuseio fontes } \\
\text { radioativas que são usadas } \\
\text { na inspeção }\end{array}$ \\
\hline & & $\begin{array}{l}\infty \\
n \\
n\end{array}$ & $\begin{array}{l}\text { Segurança } \\
\text { radiológica }\end{array}$ & $\begin{array}{l}\stackrel{0}{+} \\
+ \\
+\end{array}$ & $\begin{array}{l}\text { Controle } \\
\text { Operacional }\end{array}$ & $\begin{array}{l}\stackrel{0}{+} \\
\stackrel{+}{+}\end{array}$ & Controle Operacional & & & & $\vec{\Delta}$ & $\begin{array}{l}\hat{2} \\
\hat{a} \\
\hat{b} \\
2 \\
2\end{array}$ & $\begin{array}{l}\text { Proteção radiológica - } \\
\text { Exposição à radiação } \\
\text { pessoal operação, } \\
\text { contratados, publico }\end{array}$ & & & & & & \\
\hline & & $\begin{array}{l}\infty \\
i n \\
i n\end{array}$ & $\begin{array}{l}\text { Segurança } \\
\text { radiológica }\end{array}$ & $\begin{array}{l}0 \\
\stackrel{0}{+} \\
+\end{array}$ & $\begin{array}{l}\text { Controle } \\
\text { Operacional }\end{array}$ & $\begin{array}{l}\stackrel{0}{+} \\
\stackrel{+}{+}\end{array}$ & Controle Operacional & & & & $\overrightarrow{0}$ & 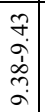 & $\begin{array}{l}\text { Programa de proteção } \\
\text { radiológica }\end{array}$ & & & & $\begin{array}{ll}n \\
0\end{array}$ & $\underset{\substack{n\\
}}{1}$ & $\begin{array}{l}\text { Programa de proteção } \\
\text { radiológica, comparado } \\
\text { com LCO }\end{array}$ \\
\hline & & $\begin{array}{l}\infty \\
n \\
n\end{array}$ & $\begin{array}{l}\text { Segurança } \\
\text { radiológica }\end{array}$ & $\underset{f}{\dot{f}}$ & $\begin{array}{l}\text { Preparação e } \\
\text { resposta a } \\
\text { emergência }\end{array}$ & $\stackrel{\sim}{+}$ & $\begin{array}{l}\text { Preparação e resposta a } \\
\text { emergência }\end{array}$ & 芝 & 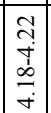 & $\begin{array}{l}\text { GESTÃO DE } \\
\text { ACIDENTE E } \\
\text { PREPARAĈ̃̃O A } \\
\text { EMERGÊNCIA }\end{array}$ & 艺 & 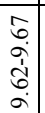 & $\begin{array}{l}\text { PREPARAÇÃO PARA } \\
\text { EMERGÊNCIA }\end{array}$ & & कृ & $\begin{array}{l}\text { PLANEJAMENTO E } \\
\text { PREPARAÇÃO PARA } \\
\text { EMERGÊNCIA }\end{array}$ & $\overrightarrow{\mathrm{z}}$ & $\stackrel{\infty}{n}$ & $\begin{array}{l}\text { PLANEJAMENTO E } \\
\text { PREPARAÇÃO PARA } \\
\text { EMERGÊNCIA }\end{array}$ \\
\hline & & $\begin{array}{l}\infty \\
i n \\
n\end{array}$ & $\begin{array}{l}\text { Segurança } \\
\text { radiológica }\end{array}$ & $\begin{array}{l}\vec{n} \\
\dot{v}\end{array}$ & $\begin{array}{l}\text { Monitoração e } \\
\text { medição }\end{array}$ & $\begin{array}{l}\overrightarrow{\dot{n}} \\
\dot{+}\end{array}$ & $\begin{array}{l}\text { Monitoramento e } \\
\text { medição do desempenho }\end{array}$ & & & & $\overrightarrow{0}$ & $\begin{array}{l}f \\
\sigma \\
\dot{a} \\
\infty \\
2 \\
\sigma\end{array}$ & $\begin{array}{l}\text { Programa de proteção } \\
\text { radiológica }\end{array}$ & & & & $\vec{\Delta}$ & $\stackrel{r}{r}$ & $\begin{array}{l}\text { Programas de rotinas de } \\
\text { supervisão e } \\
\text { contaminação por } \\
\text { radiação no ar e } \\
\text { superficies. }\end{array}$ \\
\hline & & $\begin{array}{l}\infty \\
n \\
n\end{array}$ & $\begin{array}{l}\text { Segurança } \\
\text { radiológica }\end{array}$ & $\begin{array}{l}\vec{n} \\
\dot{+}\end{array}$ & $\begin{array}{l}\text { Monitoração e } \\
\text { medição }\end{array}$ & $\begin{array}{l}\overrightarrow{\dot{n}} \\
\dot{+}\end{array}$ & $\begin{array}{l}\text { Monitoramento e } \\
\text { medição do desempenho }\end{array}$ & & & & & & & & & & $\vec{a}$ & $\underset{\stackrel{2}{\sim}}{\stackrel{2}{r}}$ & $\begin{array}{l}\text { Programa de supervisão a } \\
\text { saúde (Efeitos } \\
\text { radiológicos e químicos) }\end{array}$ \\
\hline & & 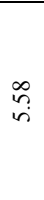 & $\begin{array}{l}\text { Segurança } \\
\text { radiológica }\end{array}$ & $\overrightarrow{\vec{n}}$ & $\begin{array}{l}\text { Documentos c/ infor- } \\
\text { maç̃es p/monitorar } \\
\text { desempenho, } \\
\text { controles } \\
\text { operacionais e } \\
\text { conformidade c/ } \\
\text { objetivos }\end{array}$ & $\vec{r}$ & $\begin{array}{l}\text { Registrar dados e resul- } \\
\text { tados do monitoramento } \\
\text { e medição p/ análise de } \\
\text { ações corretivas e } \\
\text { preventivas }\end{array}$ & & & & $\vec{\Delta}$ & $\begin{array}{lll}0 \\
0 \\
0 \\
0\end{array}$ & $\begin{array}{l}\text { Registros de dados de } \\
\text { proteção radiológica, } \\
\text { incluindo monitoração } \\
\text { pessoal }\end{array}$ & & & & & & \\
\hline
\end{tabular}




\begin{tabular}{|c|c|c|c|c|c|c|c|c|c|c|c|c|c|c|c|}
\hline \multirow[t]{2}{*}{ 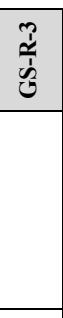 } & \multirow{2}{*}{$\begin{array}{l}\overline{0} \\
\dot{0} \\
\dot{1} \\
0\end{array}$} & \multirow{2}{*}{ 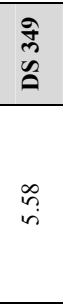 } & \multirow{2}{*}{$\begin{array}{l}\text { SG - IAEA } \\
\begin{array}{l}\text { Segurança } \\
\text { radiológica }\end{array}\end{array}$} & \multirow{2}{*}{\multicolumn{2}{|c|}{ 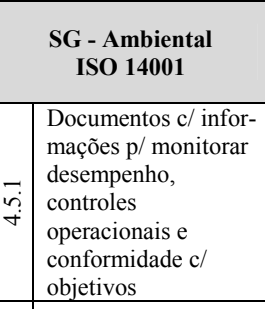 }} & \multicolumn{2}{|c|}{$\begin{array}{c}\text { SG - Segurança e Saúde no } \\
\text { Trabalho } \\
\text { OHSAS } 18001\end{array}$} & \multicolumn{3}{|c|}{$\begin{array}{l}\text { Segurança - Ciclo do } \\
\text { Combustível } \\
\text { IAEA DS316 Seção } 4 \\
\end{array}$} & \multicolumn{3}{|c|}{$\begin{array}{c}\text { Segurança - Operação Ciclo do } \\
\text { Combustível } \\
\text { IAEA DS316 Seção } 9 \\
\end{array}$} & $\begin{array}{l}\text { Segurança - Operação Conversão } \\
\text { IAEA DS316 Ap. III } 18 \text { a } 19\end{array}$ & \multirow[t]{2}{*}{$\begin{array}{c}\text { Segurança - Operação } \\
\text { Conversão } \\
\text { IAEA DS344 Seção } 7\end{array}$} \\
\hline & & & & & & $\overrightarrow{\ddot{n}}$ & $\begin{array}{l}\text { Registrar dados e resul- } \\
\text { tados do monitoramento } \\
\text { e medição p/análise de } \\
\text { ações corretivas e } \\
\text { preventivas }\end{array}$ & & & & $\vec{\Delta}$ & $\stackrel{0}{+}$ & $\begin{array}{l}\text { Registros de controle de } \\
\text { dose ocupacional de } \\
\text { radiação }\end{array}$ & & \\
\hline & & 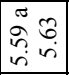 & $\begin{array}{l}\text { Controle e supervisão } \\
\text { de contratados }\end{array}$ & $\begin{array}{ll}\stackrel{0}{+} \\
\dot{+} \\
\dot{+}\end{array}$ & Controle operacional & $\begin{array}{l}\dot{b} \\
\dot{+} \\
\dot{+}\end{array}$ & Controle Operacional & & & & & & & & \\
\hline & & 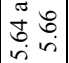 & Projeto & & & & & & & & & & & & \\
\hline & & $\begin{array}{l}\hat{\sigma} \\
\dot{n}\end{array}$ & $\begin{array}{l}\text { Iniciação, escopo e } \\
\text { planejamento de } \\
\text { projeto }\end{array}$ & & & & & & & & & & & & \\
\hline & & 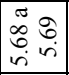 & $\begin{array}{l}\text { Identificação dos } \\
\text { requisitos de projeto }\end{array}$ & $\begin{array}{l}\tilde{y} \\
\dot{\sim} \\
\end{array}$ & $\begin{array}{l}\text { Requisitos legais e } \\
\text { outros }\end{array}$ & $\begin{array}{l}\vec{n} \\
\dot{\sim} \\
\dot{\sim}\end{array}$ & $\begin{array}{l}\text { Requisitos legais e } \\
\text { outros }\end{array}$ & & & & & & & & \\
\hline & & 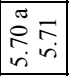 & $\begin{array}{l}\text { Seleção do projetista } \\
\text { principal }\end{array}$ & & & & & & & & & & & & \\
\hline & & 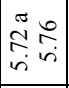 & $\begin{array}{l}\text { Controle do trabalho } \\
\text { e planejamento das } \\
\text { atividades de projeto }\end{array}$ & & & & & & & & & & & & \\
\hline & & 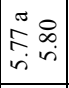 & $\begin{array}{l}\text { Identificação e } \\
\text { controle das entradas } \\
\text { de projeto }\end{array}$ & $\overrightarrow{\dot{m}}$ & $\begin{array}{l}\text { Aspectos ambientais } \\
\text { e determinação de } \\
\text { impactos ambientais }\end{array}$ & $\overrightarrow{\dot{m}}$ & $\begin{array}{l}\text { Identificaçãao de perigo, } \\
\text { avaliação de riscos e } \\
\text { determinação controles }\end{array}$ & & & & & & & & \\
\hline & & 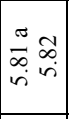 & $\begin{array}{l}\text { Análise crítica dos } \\
\text { conceitos de projeto } \\
\text { e seleção da abor- } \\
\text { dagem apropriada }\end{array}$ & & & & & & & & & & & & \\
\hline & & 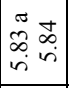 & $\begin{array}{l}\text { Seleção de } \\
\text { ferramentas de } \\
\text { projeto e software }\end{array}$ & & & & & & & & & & & & \\
\hline & & 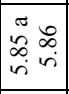 & $\begin{array}{l}\text { Condução de análise } \\
\text { conceitual de projeto } \\
\text { e segurança }\end{array}$ & $\underset{\dot{m}}{\overrightarrow{+}}$ & $\begin{array}{l}\text { Aspectos ambientais } \\
\text { e determinação de } \\
\text { impactos ambientais } \\
\end{array}$ & $\underset{\dot{p}}{\overrightarrow{+}}$ & $\begin{array}{l}\text { Identificação de perigo, } \\
\text { avaliação de riscos e } \\
\text { determinação controles } \\
\end{array}$ & & & & & & & & \\
\hline & & 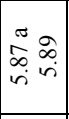 & $\begin{array}{l}\text { Condução de deta- } \\
\text { lhamento do projeto } \\
\text { e produçãa da docu- } \\
\text { mentação de projeto }\end{array}$ & $\overrightarrow{\vec{m}}$ & $\begin{array}{l}\text { Aspectos ambientais } \\
\text { e determinação de } \\
\text { impactos ambientais }\end{array}$ & $\underset{\dot{m}}{\stackrel{+}{+}}$ & $\begin{array}{l}\text { Identificação de perigo, } \\
\text { avaliação de riscos e } \\
\text { determinação controles }\end{array}$ & & & & & & & & \\
\hline & & 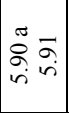 & $\begin{array}{l}\text { Condução de análise } \\
\text { detalhada de } \\
\text { segurança }\end{array}$ & $\vec{m}$ & $\begin{array}{l}\text { Aspectos ambientais } \\
\text { e determinação de } \\
\text { impactos ambientais }\end{array}$ & $\overrightarrow{\dot{m}}$ & $\begin{array}{l}\text { Identificação de perigo, } \\
\text { avaliação de riscos e } \\
\text { determinação controles }\end{array}$ & $\vec{\Delta}$ & \begin{tabular}{|c|} 
\\
$i$ \\
$i$ \\
$O$ \\
$i$ \\
$i$
\end{tabular} & $\begin{array}{l}\text { "Safety case" } \\
\text { atualizado }\end{array}$ & $\vec{\Delta}$ & $\vec{a}$ & $\begin{array}{l}\text { Limites e condições } \\
\text { operacionais (LCO) }\end{array}$ & & \\
\hline & & 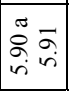 & $\begin{array}{l}\text { Condução de análise } \\
\text { detalhada de segu- } \\
\text { rança (Inclui RAS) }\end{array}$ & $\overrightarrow{\dot{m}}$ & $\begin{array}{l}\text { Aspectos ambientais } \\
\text { e determinação de } \\
\text { impactos ambientais } \\
\end{array}$ & $\overrightarrow{\mid \vec{j}}$ & $\begin{array}{l}\text { Identificação de perigo, } \\
\text { avaliação de riscos e } \\
\text { determinação controles } \\
\end{array}$ & & & & $\vec{\Delta}$ & $\stackrel{\infty}{a}$ & $\begin{array}{l}\text { Registro de análise crítica } \\
\text { de segurança periódica }\end{array}$ & & \\
\hline
\end{tabular}




\begin{tabular}{|c|c|c|c|c|c|c|c|c|c|c|c|c|c|c|c|c|c|c|c|}
\hline \multirow[t]{2}{*}{$\frac{3}{1}$} & \multirow[t]{2}{*}{$\begin{array}{l}\bar{j} \\
\vdots \\
\dot{y} \\
0\end{array}$} & \multirow{2}{*}{ 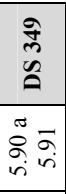 } & \multirow{2}{*}{\begin{tabular}{l}
\multicolumn{1}{c|}{ SG - IAEA } \\
$\begin{array}{l}\text { Condução de análise } \\
\text { detalhada de } \\
\text { segurança }\end{array}$
\end{tabular}} & \multicolumn{2}{|r|}{$\begin{array}{l}\text { SG - Ambiental } \\
\text { ISO } 14001\end{array}$} & \multicolumn{2}{|c|}{$\begin{array}{c}\text { SG - Segurança e Saúde no } \\
\text { Trabalho } \\
\text { OHSAS } 18001\end{array}$} & \multicolumn{3}{|c|}{$\begin{array}{l}\text { Segurança - Ciclo do } \\
\text { Combustível } \\
\text { IAEA DS316 Seção } 4\end{array}$} & \multicolumn{3}{|c|}{$\begin{array}{c}\text { Segurança - Operação Ciclo do } \\
\text { Combustível } \\
\text { IAEA DS316 Seção } 9\end{array}$} & \multicolumn{3}{|c|}{$\begin{array}{l}\text { Segurança - Operação Conversão } \\
\text { IAEA DS316 Ap. III } 18 \text { a } 19\end{array}$} & \multicolumn{3}{|r|}{$\begin{array}{l}\text { Segurança - Operação } \\
\text { Conversão } \\
\text { IAEA DS344 Seção } 7\end{array}$} \\
\hline & & & & $\stackrel{+}{+}$ & \begin{tabular}{|l} 
resposta a \\
emergência
\end{tabular} & $\stackrel{+}{+}$ & emergência & & & & & & & & & & & & \\
\hline & & $\tilde{\alpha}$ & $\begin{array}{l}\text { Definição do } \\
\text { envelope de operação } \\
\text { segura }\end{array}$ & & & & & & & & & & & & & & $\vec{\Delta}$ & $\stackrel{\pi}{4}$ & $\begin{array}{l}\text { Envelope de operação } \\
\text { definido mais baixo nível } \\
\text { do que LCO }\end{array}$ \\
\hline & & iूn & $\begin{array}{l}\text { Realização da } \\
\text { verificação e } \\
\text { validação de projeto }\end{array}$ & $\overrightarrow{\dot{m}}$ & $\begin{array}{l}\text { Aspectos ambientais } \\
\text { e determinação de } \\
\text { impactos ambientais }\end{array}$ & $\overrightarrow{\dot{m}}$ & $\begin{array}{l}\text { Identificação de perigo, } \\
\text { avaliação de riscos e } \\
\text { determinação controles }\end{array}$ & & & & & & & & & & & & \\
\hline & & $\underset{\sim}{\stackrel{n}{=}} \stackrel{m}{=}$ & $\begin{array}{l}\text { Realização da } \\
\text { verificação e } \\
\text { validação de projeto }\end{array}$ & $\stackrel{m}{?}+$ & Comunicação & $\begin{array}{c}\stackrel{\sim}{~} \\
\stackrel{r}{+} \\
\dot{+}\end{array}$ & Participação e consulta & & & & & & & & & & & & \\
\hline & & 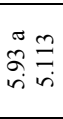 & $\begin{array}{l}\text { Realizaçãa da } \\
\text { verificação e } \\
\text { validação de projeto }\end{array}$ & & & & & 艺 & 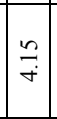 & $\begin{array}{l}\text { GARANTIA DA } \\
\text { QUALIDADE } \\
\text { (Códigos de } \\
\text { computadores) }\end{array}$ & & & & & & & 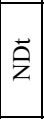 & $\stackrel{n}{\vec{r}}$ & $\begin{array}{l}\text { GARANTIA DA } \\
\text { QUALIDADE (Códigos } \\
\text { de computador) }\end{array}$ \\
\hline & & 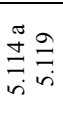 & $\begin{array}{l}\text { Gestão das linhas de } \\
\text { base e controle de } \\
\text { alteraçẫo de projeto }\end{array}$ & & & & & & & & $\vec{\Delta}$ & $\frac{\infty}{a}$ & $\begin{array}{l}\text { Histórico e dados de } \\
\text { modificações }\end{array}$ & & & & $\vec{\Delta}$ & 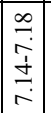 & $\begin{array}{l}\text { Formulário de controle de } \\
\text { modificação ou } \\
\text { equivalente }\end{array}$ \\
\hline & & 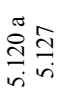 & $\begin{array}{l}\text { Gestão de } \\
\text { configuração }\end{array}$ & & & & & & & & & & & & & & & & \\
\hline & & 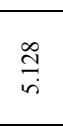 & $\begin{array}{l}\text { Modificação da } \\
\text { instalação }\end{array}$ & $\overrightarrow{\dot{m}}$ & $\begin{array}{l}\text { Aspectos ambientais } \\
\text { e determinação de } \\
\text { impactos ambientais }\end{array}$ & $\overrightarrow{\dot{m}}$ & $\begin{array}{l}\text { Identificação de perigo, } \\
\text { avaliação de riscos e } \\
\text { determinação de } \\
\text { controles }\end{array}$ & & & & $\vec{\Delta}$ & $\stackrel{n}{2}$ & $\begin{array}{l}\text { Controlar as modificações } \\
\text { - Avaliar e escrutinar sua } \\
\text { significância à segurança }\end{array}$ & & & & $\vec{\Delta}$ & 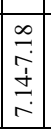 & $\begin{array}{l}\text { Controlar as modificações } \\
\text { - Avaliar e escrutinar sua } \\
\text { significância à segurançą }\end{array}$ \\
\hline & & 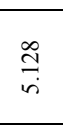 & $\begin{array}{l}\text { Modificação da } \\
\text { instalação }\end{array}$ & $\overrightarrow{\dot{m}}$ & $\begin{array}{l}\text { Aspectos ambientais } \\
\text { e determinação de } \\
\text { impactos ambientais }\end{array}$ & $\underset{\dot{m}}{\vec{f}}$ & $\begin{array}{l}\text { Identificação de perigo, } \\
\text { avaliação de riscos e } \\
\text { determinação de } \\
\text { controles }\end{array}$ & & & & & & & & & & $\vec{\Delta}$ & \begin{tabular}{|c|}
$\stackrel{2}{~}$ \\
$\stackrel{n}{n}$ \\
\\
\\
\end{tabular} & \begin{tabular}{|l|} 
Nas intervenções para \\
modificaçõe ter atenção \\
às proteções à radiação
\end{tabular} \\
\hline & & 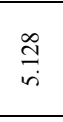 & $\begin{array}{l}\text { Modificação da } \\
\text { instalação }\end{array}$ & $\overrightarrow{\dot{m}}$ & $\begin{array}{l}\text { Aspectos ambientais } \\
\text { e determinação de } \\
\text { impactos ambientais }\end{array}$ & $\underset{\dot{m}}{\stackrel{+}{q}}$ & $\begin{array}{l}\text { Identificação de perigo, } \\
\text { avaliação de riscos e } \\
\text { determinação de } \\
\text { controles } \\
\end{array}$ & & & & $\vec{\Delta}$ & $\frac{\infty}{a}$ & $\begin{array}{l}\text { Histórico e dados de } \\
\text { modificações }\end{array}$ & & & & $\vec{\Delta}$ & \begin{tabular}{|c|}
$\frac{\infty}{\pi}$ \\
$\stackrel{+}{\dot{I}}$ \\
$\stackrel{n}{r}$ \\
\end{tabular} & $\begin{array}{l}\begin{array}{l}\text { Formulário de controle de } \\
\text { modificação ou } \\
\text { equivalente }\end{array} \\
\end{array}$ \\
\hline & & $\begin{array}{l}\text { ते } \\
\text { in }\end{array}$ & Manutenção & $\begin{array}{l}0 \\
\dot{+} \\
+\end{array}$ & Controle operacional & $\mid \begin{array}{l}\dot{p} \\
\dot{+}\end{array}$ & Controle operacional & & & & $\vec{\Delta}$ & $\hat{b}$ & $\begin{array}{l}\text { Manter condições opera- } \\
\text { cionais da infra-estrutura } \\
\text { usada em emergência }\end{array}$ & & & & $\vec{\Delta}$ & \begin{tabular}{|l|l}
\multirow{2}{*}{} \\
\\
\\
\\
\\
\end{tabular} & $\begin{array}{l}\text { Nas intervenções para } \\
\text { modificações preparar } \\
\text { proteções à radiação }\end{array}$ \\
\hline & & 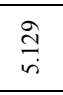 & Manutenção & $\begin{array}{l}\text { : } \\
\dot{+}\end{array}$ & Controle operacional & $\underset{\substack{f \\
\dot{f}}}{ }$ & Controle operacional & & & & $\vec{\Delta}$ & å & $\begin{array}{l}\text { Manutenção periódica } \\
\text { para adequado } \\
\text { funcionamento ESC }\end{array}$ & $\vec{\Delta}$ & 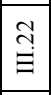 & $\begin{array}{l}\text { Inspeção periódica em } \\
\text { Cilindros } \mathrm{UF}_{6}\end{array}$ & & & \\
\hline & & $\frac{\text { ते }}{\text { in }}$ & Manutenção & $\begin{array}{l}\stackrel{0}{+} \\
+ \\
+\end{array}$ & Controle operacional & $\underset{\substack{f \\
\dot{f}}}{ }$ & Controle operacional & & & & & 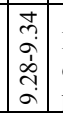 & $\begin{array}{l}\text { Manutenções decorrentes } \\
\text { de ações corretivas e } \\
\text { preventivas }\end{array}$ & $\vec{a}$ & 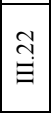 & $\begin{array}{l}\text { Inspeção periódica em } \\
\text { Cilindros } \mathrm{UF}_{6}\end{array}$ & & & \\
\hline
\end{tabular}




\begin{tabular}{|c|c|c|c|c|c|c|c|c|c|c|c|c|c|c|c|c|c|}
\hline \multirow[t]{2}{*}{$\frac{3}{4}$} & \multirow[t]{2}{*}{$\begin{array}{l}\bar{j} \\
\vdots \\
\dot{0} \\
0\end{array}$} & \multirow{2}{*}{$\begin{array}{l}\text { ले } \\
\text { aे } \\
\text { సे } \\
\text { iे }\end{array}$} & \multirow{2}{*}{$\begin{array}{r}\text { SG - IAEA } \\
\text { Manutenção }\end{array}$} & \multicolumn{2}{|r|}{$\begin{array}{l}\text { SG - Ambiental } \\
\text { ISO } 14001\end{array}$} & \multicolumn{2}{|c|}{$\begin{array}{c}\text { SG - Segurança e Saúde no } \\
\text { Trabalho } \\
\text { OHSAS 18001 } \\
\end{array}$} & \multicolumn{3}{|c|}{$\begin{array}{l}\text { Segurança - Ciclo do } \\
\text { Combustível } \\
\text { IAEA DS316 Seção } 4\end{array}$} & \multicolumn{3}{|c|}{$\begin{array}{c}\text { Segurança - Operação Ciclo do } \\
\text { Combustível } \\
\text { IAEA DS316 Seção } 9\end{array}$} & $\begin{array}{l}\text { Segurança - Operação Conversão } \\
\text { IAEA DS316 Ap. III } 18 \text { a } 19\end{array}$ & \multicolumn{3}{|c|}{$\begin{array}{l}\text { Segurança - Operação } \\
\text { Conversão } \\
\text { IAEA DS344 Seção } 7\end{array}$} \\
\hline & & & & $\begin{array}{l}\text { lo } \\
\dot{+} \\
\dot{f}\end{array}$ & Controle operacional & $\begin{array}{ll}\stackrel{0}{+} \\
\stackrel{+}{+}\end{array}$ & Controle operacional & & & & $\vec{\Delta}$ & s. & $\begin{array}{l}\text { Atenção na descontamina- } \\
\text { ção para manutenção, tes- } \\
\text { tes e inspeções periódicas } \\
\end{array}$ & & $\vec{\theta}$ & $\stackrel{\circ}{\stackrel{2}{\sim}}$ & $\begin{array}{l}\text { Atenção com } \\
\text { contaminação radioativa } \\
\text { na manutenção }\end{array}$ \\
\hline & & ते & Manutenção & $\stackrel{\substack{++}}{+}$ & Controle operacional & $\begin{array}{ll}\stackrel{0}{+} \\
\stackrel{+}{+}\end{array}$ & Controle operacional & & & & $\vec{a}$ & ָे & $\begin{array}{l}\begin{array}{l}\text { Permissão de serviço } \\
\text { (Sistema) }\end{array} \\
\text { (Silla }\end{array}$ & & $\vec{\theta}$ & $\underset{\square}{\rightleftharpoons}$ & $\begin{array}{l}\text { Seguir melhores práticas } \\
\text { de proteção à radiação na } \\
\text { manutenção (comunica- } \\
\text { ção; isolamento tubula- } \\
\text { ção; segurança; etc.) }\end{array}$ \\
\hline & & 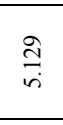 & Manutenção & $\overrightarrow{i n}$ & $\begin{array}{l}\text { Monitoração e } \\
\text { medição }\end{array}$ & $\begin{array}{l}\overrightarrow{\dot{n}} \\
\dot{v}\end{array}$ & $\begin{array}{l}\text { Monitoramento e } \\
\text { medição do desempenho }\end{array}$ & & & & $\vec{a}$ & ָे & $\begin{array}{l}\text { Programa e procedimen- } \\
\text { tos escritos para manuten- } \\
\text { ção, testes, inspeções } \\
\text { periódicas em ESC } \\
\end{array}$ & & & & \\
\hline & & ते & Manutenção & & & & & & & & $\vec{\Delta}$ & $\begin{array}{c}1 \\
2 \\
a \\
0 \\
\infty \\
a \\
a\end{array}$ & $\begin{array}{l}\text { Registros manutenção, } \\
\text { testes e inspeções em ESC }\end{array}$ & & & & \\
\hline & & $\underset{m}{i n}$ & $\begin{array}{l}\text { Housekeeping e } \\
\text { limpeza }\end{array}$ & $\underset{+}{+}+$ & Controle operacional & $\begin{array}{l}\stackrel{0}{+} \\
\dot{+}\end{array}$ & Controle operacional & & & & & & & & $\vec{\Delta}$ & 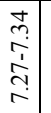 & Controle da dose interna \\
\hline & & $\frac{\pi}{m} \underset{m}{m} \frac{m}{\dot{m}}$ & $\begin{array}{l}\text { Manuseio e } \\
\text { armazenamento }\end{array}$ & $\begin{array}{l}0 \\
\dot{+} \\
+\end{array}$ & Controle operacional & $\underset{\stackrel{\bullet}{+}}{\stackrel{+}{+}}$ & Controle operacional & & & & & & & & $\vec{\Delta}$ & 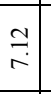 & $\begin{array}{l}\text { Atenção manuseio fontes } \\
\text { radioativas usadas para } \\
\text { inspeção }\end{array}$ \\
\hline & & $\frac{\pi}{m} \stackrel{g}{m}$ & $\begin{array}{l}\text { Manuseio e } \\
\text { armazenamento }\end{array}$ & $\underset{+}{+}+$ & Controle operacional & $\begin{array}{l}\stackrel{0}{+} \\
\dot{+} \\
+\end{array}$ & Controle operacional & & & & & & & & $\vec{\theta}$ & 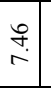 & $\begin{array}{l}\text { Minimizar manuseio de } \\
\text { cilindros com UF líquido } \\
\text { (Usar ESC, LCO) }\end{array}$ \\
\hline & & $\begin{array}{l}\text { mे } \\
\text { in } \\
\frac{\pi}{m} \\
\vec{m} \\
\vec{n}\end{array}$ & $\begin{array}{l}\text { Manuseio e } \\
\text { armazenamento }\end{array}$ & $\begin{array}{l}\stackrel{0}{+} \\
+ \\
+\end{array}$ & Controle operacional & 官 & Controle operacional & & & & $\vec{\theta}$ & $\vec{b}$ & $\begin{array}{l}\text { Considerar materiais } \\
\text { nucleares na avaliação } \\
\text { convencional sobre } \\
\text { incêndio }\end{array}$ & & $\vec{\Delta}$ & 宪 & $\begin{array}{l}\text { Manuseio cilindros } \mathrm{UF}_{6} \\
\text { dentro sítio, aguardar tem- } \\
\text { po suficiente p/ solidifica- } \\
\text { ção (Usar ESC e atenção } \\
\text { impacto de incêndio) }\end{array}$ \\
\hline & & 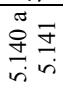 & Gestão do inventário & & & & & $\vec{\Delta}$ & $\stackrel{+}{+}$ & Proteção física & & & & & & & \\
\hline & & 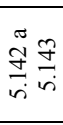 & $\begin{array}{l}\text { Identificação e } \\
\text { etiquetagem de } \\
\text { sistemas, estruturas e } \\
\text { componentes }\end{array}$ & & & & & & & & $\vec{\Delta}$ & $\vec{m}$ & $\begin{array}{l}\text { Identificação e controle de } \\
\text { equipamentos e itens } \\
\text { usados manutenção, testes } \\
\text { e inspeções em ESC }\end{array}$ & & & & \\
\hline & & 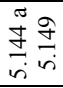 & Gestão de rejeito & 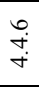 & Controle operacional & 焉 & Controle operacional & & & & $\vec{a}$ & ñ & $\begin{array}{l}\text { Gestão rejeitos sólidos, } \\
\text { líquidos e gasosos, acordo } \\
\text { IAEA WS-R-2 }\end{array}$ & & & & \\
\hline & & 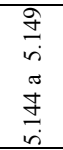 & Gestão de rejeito & $\begin{array}{l}\stackrel{0}{+} \\
+ \\
+\end{array}$ & Controle operacional & 它 & Controle operacional & & & & $\vec{\theta}$ & ñ & $\begin{array}{l}\text { Atividades envolvem ra- } \\
\text { diação e produtos quími- } \\
\text { cos perigosos acordo po- } \\
\text { lítica rejeitos, PGQ e re- } \\
\text { quisitos agência reguladora }\end{array}$ & & & & \\
\hline
\end{tabular}




\begin{tabular}{|c|c|c|c|c|c|c|c|c|c|c|c|c|c|c|c|c|c|c|}
\hline \multirow[t]{2}{*}{$\begin{array}{l}3 \\
\frac{2}{4} \\
\dot{3}\end{array}$} & \multirow[t]{2}{*}{$\begin{array}{l}\overline{0} \\
\vdots \\
\dot{1} \\
0\end{array}$} & \multirow{2}{*}{ 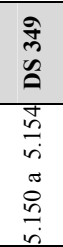 } & \multirow{2}{*}{$\begin{array}{r}\text { SG - IAEA } \\
\text { Gestão ambiental }\end{array}$} & \multirow{2}{*}{\multicolumn{2}{|c|}{ 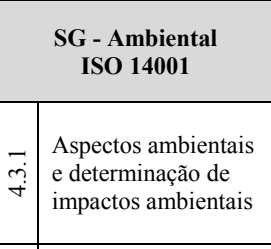 }} & \multicolumn{2}{|c|}{$\begin{array}{c}\text { SG - Segurança e Saúde no } \\
\text { Trabalho } \\
\text { OHSAS 18001 } \\
\end{array}$} & \multicolumn{3}{|c|}{$\begin{array}{l}\text { Segurança - Ciclo do } \\
\text { Combustível } \\
\text { IAEA DS316 Seção } 4 \\
\end{array}$} & \multicolumn{3}{|c|}{$\begin{array}{c}\text { Segurança - Operação Ciclo do } \\
\text { Combustível } \\
\text { IAEA DS316 Seção } 9\end{array}$} & \multicolumn{2}{|c|}{$\begin{array}{l}\text { Segurança - Operação Conversão } \\
\text { IAEA DS316 Ap. III } 18 \text { a } 19\end{array}$} & \multicolumn{3}{|r|}{$\begin{array}{l}\text { Segurança - Operação } \\
\text { Conversão } \\
\text { IAEA DS344 Seção } 7\end{array}$} \\
\hline & & & & & & $\overrightarrow{\dot{m}}$ & $\begin{array}{l}\text { Identificacãa perigo, } \\
\text { avaliação de riscos e } \\
\text { determinação de } \\
\text { controles }\end{array}$ & & & & $\vec{a}$ & 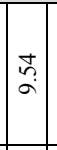 & $\begin{array}{l}\text { Minimizar produção } \\
\text { rejeitos assegurando } \\
\text { menor liberação ao } \\
\text { ambiente }\end{array}$ & & & $\vec{\Delta}$ & $\stackrel{n}{n}$ & $\begin{array}{l}\text { Descarga gases radioati- } \\
\text { vos e químicos tratados - } \\
\text { Filtros de partícula de ar } \\
\text { de alta eficiência e siste- } \\
\text { mas de esfregaço químico } \\
\end{array}$ \\
\hline & & 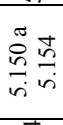 & Gestão ambiental & $\vec{m}$ & $\begin{array}{l}\text { Aspectos ambientais } \\
\text { e determinação de } \\
\text { impactos ambientais }\end{array}$ & $\overrightarrow{\dot{m}}$ & $\begin{array}{l}\text { Identificação perigo, } \\
\text { avaliação de riscos e } \\
\text { determinação de } \\
\text { controles }\end{array}$ & & & & $\vec{\theta}$ & 芯 & $\begin{array}{l}\text { Minimizar produção rejei- } \\
\text { tos assegurando menor } \\
\text { liberação ao ambiente }\end{array}$ & & & $\vec{\Delta}$ & $\stackrel{\leftrightarrow}{\stackrel{n}{\sim}}$ & $\begin{array}{l}\text { Descarga líquidos efetiva- } \\
\text { mente tratados. Recuperar } \\
\text { e reusar se possível. }\end{array}$ \\
\hline & & 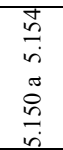 & Gestão ambiental & $\overrightarrow{\dot{m}}$ & $\begin{array}{l}\text { Aspectos ambientais } \\
\text { e determinação de } \\
\text { impactos ambientais }\end{array}$ & $\overrightarrow{m \vec{r}}$ & $\begin{array}{l}\text { Identificação de perigo, } \\
\text { avaliação de riscos e } \\
\text { determinação de } \\
\text { controles }\end{array}$ & & & & $\vec{\Delta}$ & 芯 & $\begin{array}{l}\text { Minimizar produção } \\
\text { rejeitos assegurando } \\
\text { menor liberação ao } \\
\text { ambiente }\end{array}$ & & & $\vec{\Delta}$ & $\stackrel{n}{n}$ & $\begin{array}{l}\text { Minimizar geração rejei- } \\
\text { tos sólidos radioativos, re- } \\
\text { movendo o mais possível } \\
\text { pacote externo antes trans- } \\
\text { ferir área de contaminação }\end{array}$ \\
\hline & & 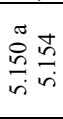 & Gestão ambiental & $\overrightarrow{\vec{m}}$ & $\begin{array}{l}\text { Aspectos ambientais } \\
\text { e determinação de } \\
\text { impactos ambientais }\end{array}$ & $\vec{m} \dot{\vec{m}}$ & $\begin{array}{l}\text { Identificação de perigo, } \\
\text { avaliação de riscos e } \\
\text { determinação de } \\
\text { controles }\end{array}$ & & & & $\vec{\Delta}$ & مُ & $\begin{array}{l}\text { Minimizar produção } \\
\text { rejeitos assegurando } \\
\text { menor liberação ao } \\
\text { ambiente }\end{array}$ & & & $\vec{\Delta}$ & $\stackrel{?}{\sim}$ & $\begin{array}{l}\text { Tratar cinzas não queima- } \\
\text { das resultado da fluoração } \\
\text { do urânio, para recuperar } \\
\text { conteúdo de urânio }\end{array}$ \\
\hline & & $\begin{array}{l}\dot{H} \\
\stackrel{n}{n} \\
\dot{n} \\
\tilde{n} \\
\stackrel{n}{n} \\
\vec{n}\end{array}$ & Gestão ambiental & $\overrightarrow{\dot{m}}$ & $\begin{array}{l}\text { Aspectos ambientais } \\
\text { e determinação de } \\
\text { impactos ambientais }\end{array}$ & $\overrightarrow{\dot{m}}$ & $\begin{array}{l}\text { Identificação de perigo, } \\
\text { avaliação de riscos e } \\
\text { determinação de } \\
\text { controles }\end{array}$ & & & & $\vec{\Delta}$ & in & $\begin{array}{l}\text { Descarga efluentes radio- } \\
\text { ativos e produtos quími- } \\
\text { cos perigosos monitoradas } \\
\text { c/ verificação atendimento } \\
\text { autoridade nacional }\end{array}$ & & & & & \\
\hline & & 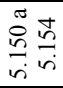 & Gestão ambiental & 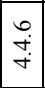 & Controle operacional & $\mid \begin{array}{l}\stackrel{0}{+} \\
\dot{+} \\
\dot{r}\end{array}$ & Controle operacional & & & & & & & & & & & \\
\hline & & 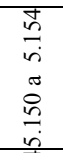 & Gestão ambiental & $\begin{array}{ll}0 \\
\stackrel{0}{+} \\
+\end{array}$ & $\begin{array}{l}\text { Procedimentos } \\
\text { situações que possam } \\
\text { acarretar desvios de } \\
\text { SGA }\end{array}$ & 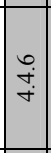 & $\begin{array}{l}\text { Procedimentos situações } \\
\text { que possam acarretar } \\
\text { desvios de SST }\end{array}$ & & & & $\vec{\circ}$ & $\begin{array}{c}0 \\
0 \\
0 \\
0 \\
0 \\
0 \\
0\end{array}$ & $\begin{array}{l}\text { Procedimentos escritos } \\
\text { sobre concentração de } \\
\text { gases inflamáveis }\end{array}$ & & & $\vec{\Delta}$ & $\stackrel{\infty}{\sim}$ & $\begin{array}{l}\text { Procedimentos operacio- } \\
\text { nais específicos p/ manter } \\
\text { estado de segurança para } \\
\text { todas as ocorrências } \\
\text { previstas antecipadamente }\end{array}$ \\
\hline & & 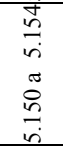 & Gestão ambiental & $\begin{array}{ll}\stackrel{0}{+} \\
\dot{+} \\
+\end{array}$ & $\begin{array}{l}\text { Procedimentos } \\
\text { situações que possam } \\
\text { acarretar desvios de } \\
\text { SGA }\end{array}$ & 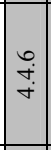 & $\begin{array}{l}\text { Procedimentos situações } \\
\text { que possam acarretar } \\
\text { desvios de SST }\end{array}$ & & & & $\vec{\Delta}$ & 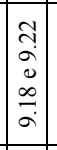 & $\begin{array}{l}\text { Instruções operacionais } \\
\text { com métodos de operação, } \\
\text { testes, inspeções, } \\
\text { calibrações aderentes aos } \\
\text { LCO }\end{array}$ & & & $\vec{\Delta}$ & $\underset{\infty}{\infty}$ & $\begin{array}{l}\text { Procedimentos operacio- } \\
\text { nais específicos p/ manter } \\
\text { estado de segurança para } \\
\text { todas as ocorrências } \\
\text { previstas antecipadamente }\end{array}$ \\
\hline & & 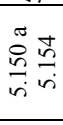 & Gestão ambiental & & \begin{tabular}{|l} 
Preparação e \\
resposta a \\
emergência
\end{tabular} & $\stackrel{r}{\stackrel{f}{+}}$ & $\begin{array}{l}\text { Preparação e resposta a } \\
\text { emergência }\end{array}$ & $\overrightarrow{\mathrm{z}}$ & 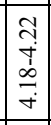 & $\begin{array}{l}\text { GESTÃO DE } \\
\text { ACIDENTE E } \\
\text { PREPARAÇÃO A } \\
\text { EMERGÊNCIA }\end{array}$ & $\overrightarrow{\mathrm{z}}$ & 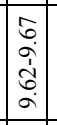 & $\begin{array}{l}\text { PREPARAÇÃO PARA } \\
\text { EMERGÊNCIA }\end{array}$ & 芝 容 & $\begin{array}{l}\text { PLANEJAMENTO E } \\
\text { PREPARAÇÃO PARA } \\
\text { EMERGÊNCIA }\end{array}$ & 艺 & $\stackrel{\infty}{\stackrel{\infty}{n}}$ & $\begin{array}{l}\text { PLANEJAMENTO E } \\
\text { PREPARACCÃO PARA } \\
\text { EMERGÊNCIA }\end{array}$ \\
\hline & & 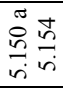 & Gestão ambiental & 䇡 & $\begin{array}{l}\text { Preparação e } \\
\text { resposta a } \\
\text { emergência }\end{array}$ & $\stackrel{r}{\dot{f}}+$ & $\begin{array}{l}\text { Preparação e resposta a } \\
\text { emergência }\end{array}$ & $\vec{a}$ & $\stackrel{\vartheta}{\vec{f}}$ & $\begin{array}{l}\text { Procedimentos de } \\
\text { gestão de acidentes }\end{array}$ & & & & & & & & \\
\hline & & 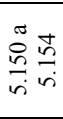 & Gestão ambiental & $\stackrel{+}{+}$ & $\begin{array}{l}\text { Preparação e } \\
\text { resposta a } \\
\text { emergência }\end{array}$ & $\stackrel{\stackrel{f}{+}}{\dot{r}}$ & $\begin{array}{l}\text { Preparação e resposta a } \\
\text { emergência }\end{array}$ & $\vec{a}$ & $\stackrel{\vartheta}{\vec{f}}$ & $\begin{array}{l}\text { Procedimentos de } \\
\text { emergência dentro, } \\
\text { e quando aplicável, } \\
\text { fora do sítio }\end{array}$ & $\vec{\Delta}$ & 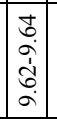 & $\begin{array}{l}\text { Plano de emergência } \\
\text { perigos radiológicos e não } \\
\text { (Em coordenação com } \\
\text { outros órgãos) }\end{array}$ & & & & & \\
\hline
\end{tabular}




\begin{tabular}{|c|c|c|c|c|c|c|c|c|c|c|c|c|c|c|c|c|c|}
\hline 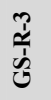 & $\begin{array}{l}\overline{3} \\
\dot{b} \\
\dot{3}\end{array}$ & $\begin{array}{l}\hat{े} \\
\tilde{c} \\
\tilde{a}\end{array}$ & SG - IAEA & & $\begin{array}{l}\text { SG - Ambiental } \\
\text { ISO } 14001\end{array}$ & & $\begin{array}{l}\text { - Segurança e Saúde no } \\
\text { Trabalho } \\
\text { OHSAS } 18001\end{array}$ & & & $\begin{array}{l}\text { urança - Ciclo do } \\
\text { Combustível } \\
\text { A DS316 Seção } 4\end{array}$ & & gera & $\begin{array}{l}\text { aça - Operação Ciclo do } \\
\text { Combustível } \\
\text { AEA DS316 Seção } 9\end{array}$ & $\begin{array}{c}\text { Segurança - Operação Conversão } \\
\text { IAEA DS316 Ap. III } 18 \text { a } 19\end{array}$ & & & $\begin{array}{l}\text { gurança - Operação } \\
\text { Conversão } \\
\text { IEA DS344 Seção } 7\end{array}$ \\
\hline & & $\frac{n}{n}$ & Interface reguladora & $\stackrel{m}{+}+$ & Comunicação & 永 & Participação e consulta & $\vec{\Delta}$ & $\frac{\partial}{\vec{r}}$ & $\begin{array}{l}\text { Participação pro- } \\
\text { cedimentos gestão } \\
\text { acidentes emergên- } \\
\text { cia dentro do sítio }\end{array}$ & $\overrightarrow{\mathrm{A}}$ & : & $\begin{array}{l}\text { Participação no plano de } \\
\text { emergência perigos } \\
\text { radiológicos e não }\end{array}$ & & & & \\
\hline & & $\frac{n}{n}$ & Interface reguladora & 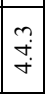 & Comunicação & 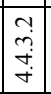 & Participação e consulta & $\vec{\Delta}$ & & & $\overrightarrow{\mathrm{A}}$ & ๙ุ & $\begin{array}{l}\text { Comunicação de mudança } \\
\text { com impacto significativo } \\
\text { à segurança }\end{array}$ & & & & \\
\hline & & $\begin{array}{l}n \\
\frac{n}{n} \\
n\end{array}$ & Interface reguladora & $\stackrel{?}{+}$ & Comunicação & $\begin{array}{l}\stackrel{N}{\sim} \\
\dot{f} \\
\dot{+}\end{array}$ & Participação e consulta & $\vec{\Delta}$ & & & $\overrightarrow{\mathrm{Q}}$ & 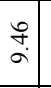 & $\begin{array}{l}\text { Disponibilidade de regis- } \\
\text { tros de controle de dose } \\
\text { ocupacional de radiação }\end{array}$ & & & & \\
\hline & & $\frac{n}{n}$ & Interface reguladora & $\begin{array}{l}m \\
\stackrel{n}{+} \\
\dot{+}\end{array}$ & Comunicação & 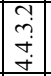 & Participação e consulta & $\vec{\Delta}$ & & & $\overrightarrow{\mathrm{a}}$ & $\begin{array}{l}8 \\
\dot{\sigma} \\
\end{array}$ & $\begin{array}{l}\text { Resultados análise crítica } \\
\text { periódica da segurança }\end{array}$ & & & & \\
\hline & & $\frac{n}{n}$ & Interface reguladora & $\underset{m}{\stackrel{m}{+}}$ & Comunicação & 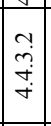 & Participação e consulta & & & & $\vec{a}$ & $\sqrt{n}$ & $\begin{array}{l}\text { Relatar periodicamente } \\
\text { descarga efluentes } \\
\text { radioativos e de produtos } \\
\text { químicos perigosos }\end{array}$ & & & & \\
\hline & & 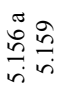 & $\begin{array}{l}\text { Tecnologia da } \\
\text { informação }\end{array}$ & & & & & & & & & & & & & & \\
\hline & & $\underset{i}{\stackrel{8}{i n}}$ & $\begin{array}{l}\text { Proteção contra } \\
\text { incêndio }\end{array}$ & $\stackrel{r}{\dot{f}}$ & $\begin{array}{l}\text { Preparação e } \\
\text { resposta a } \\
\text { emergência }\end{array}$ & $\underset{f}{\stackrel{f}{+}}$ & $\begin{array}{l}\text { Preparação e resposta a } \\
\text { emergência }\end{array}$ & $\vec{\Delta}$ & 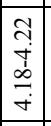 & $\begin{array}{l}\text { GESTÃO DE } \\
\text { ACIDENTE E } \\
\text { PREPARAÇÃO A } \\
\text { EMERGÊNCIA } \\
\end{array}$ & $\overrightarrow{\mathrm{A}}$ & ڤ̆ & $\begin{array}{l}\text { Estruturar formas de } \\
\text { assegurar segurança } \\
\text { contra incêndio com base } \\
\text { na análise de segurança }\end{array}$ & & & & \\
\hline & & $\begin{array}{l}8 \\
\text { in } \\
\text { n }\end{array}$ & $\begin{array}{l}\text { Proteção contra } \\
\text { incêndio }\end{array}$ & $\underset{f}{+}$ & $\begin{array}{l}\text { Preparação e } \\
\text { resposta a } \\
\text { emergência }\end{array}$ & 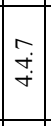 & $\begin{array}{l}\text { Preparação e resposta a } \\
\text { emergência }\end{array}$ & $\vec{\Delta}$ & 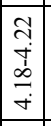 & $\begin{array}{l}\text { GESTÃO DE } \\
\text { ACIDENTE E } \\
\text { PREPARAÇÃO A } \\
\text { EMERGÊNCIA }\end{array}$ & $\vec{\Delta}$ & $\vec{b}$ & $\begin{array}{l}\text { Considerar materiais } \\
\text { nucleares na avaliação } \\
\text { convencional sobre } \\
\text { incêndio }\end{array}$ & & & & \\
\hline & & $\frac{\vec{b}}{i n}$ & $\begin{array}{l}\text { Proteção física } \\
\text { (Security) }\end{array}$ & $\begin{array}{ll}\dot{0} \\
\dot{+} \\
\dot{+}\end{array}$ & Controle operacional & \begin{tabular}{l|l}
$\stackrel{0}{+}$ \\
$\stackrel{+}{+}$
\end{tabular} & Controle operacional & $\vec{\Delta}$ & 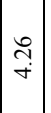 & $\begin{array}{l}\text { PROTEÇÃO } \\
\text { FÍSICA }\end{array}$ & & & & & $\vec{a}$ & 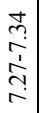 & Controle de dose interna \\
\hline & & $\begin{array}{l}\vec{b} \\
\dot{n}\end{array}$ & $\begin{array}{l}\text { Proteção física } \\
\text { (Security) }\end{array}$ & $\begin{array}{l}\stackrel{0}{+} \\
+ \\
+\end{array}$ & Controle operacional & $\begin{array}{ll}\stackrel{0}{+} \\
\stackrel{+}{+}\end{array}$ & Controle operacional & $\vec{\Delta}$ & $\stackrel{+}{\dot{r}}$ & $\begin{array}{l}\text { Projeto e } \\
\text { implementação } \\
\text { proteção fisica }\end{array}$ & & & & & $\vec{\Delta}$ & 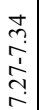 & Controle de dose interna \\
\hline & & $\begin{array}{l}\overrightarrow{\vec{b}} \\
\text { in }\end{array}$ & $\begin{array}{l}\text { Proteção física } \\
\text { (Security) }\end{array}$ & $\underset{+}{+}$ & $\begin{array}{l}\text { Preparação e } \\
\text { resposta a } \\
\text { emergência }\end{array}$ & $\stackrel{\overbrace{}}{\dot{f}}$ & $\begin{array}{l}\text { Preparação e resposta a } \\
\text { emergência }\end{array}$ & $\vec{\Delta}$ & 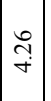 & $\begin{array}{l}\text { Plano de proteção } \\
\text { física, alinhado ao } \\
\text { plano de emergência }\end{array}$ & & & & & & & \\
\hline 0 & o & 6 & $\begin{array}{l}\text { MEDIÇÃO, AVA- } \\
\text { LIAÇÃO E ME- } \\
\text { LHORIA (Título) }\end{array}$ & $\because$ & $\begin{array}{l}\text { VERIFICAÇão } \\
\text { (Título) }\end{array}$ & $\because$ & $\begin{array}{l}\text { VERIFICAÇão } \\
\text { (Título) }\end{array}$ & & & & & & & & & & \\
\hline & $\frac{\pi}{6} \cdot 3$ & & Aspectos gerais & & & & & & & & & & & & & & \\
\hline
\end{tabular}




\begin{tabular}{|c|c|c|c|c|c|c|c|c|c|c|c|c|c|c|c|c|c|}
\hline 竞 & $\begin{array}{l}\vec{j} \\
\vdots \\
\dot{b} \\
\dot{b}\end{array}$ & $\begin{array}{l}\text { ले } \\
\text { है }\end{array}$ & SG - IAEA & & $\begin{array}{l}\text { SG - Ambiental } \\
\text { ISO } 14001\end{array}$ & & $\begin{array}{l}\text { - Segurança e Saúde no } \\
\text { Trabalho } \\
\text { OHSAS } 18001\end{array}$ & & & $\begin{array}{l}\text { urança - Ciclo do } \\
\text { Combustível } \\
\text { A DS316 Seção } 4\end{array}$ & & gera & $\begin{array}{l}\text { ança - Operação Ciclo do } \\
\text { Combustivel } \\
\text { AEA DS316 Seção } 9\end{array}$ & $\begin{array}{c}\text { Segurança - Operação Conversão } \\
\text { IAEA DS316 Ap. III } 18 \text { a } 19\end{array}$ & & & $\begin{array}{l}\text { egurança - Operação } \\
\text { Conversão } \\
\text { AEA DS344 Seção } 7\end{array}$ \\
\hline $\overrightarrow{6}$ & \begin{tabular}{l}
$n$ \\
$b$ \\
$\tilde{0}$ \\
\multirow{f}{0}{}
\end{tabular} & & $\begin{array}{l}\text { MONITORAÇÃO E } \\
\text { MEDIÇÃO }\end{array}$ & $\begin{array}{l}\overrightarrow{\dot{m}} \\
\dot{v}\end{array}$ & $\begin{array}{l}\text { Monitoração e } \\
\text { medição }\end{array}$ & $\overrightarrow{\vec{n}}$ & $\begin{array}{l}\text { Monitoramento e } \\
\text { medição do desempenho }\end{array}$ & 艺 & 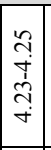 & $\begin{array}{l}\text { VERIFICAÇÃO } \\
\text { DA SEGURANÇA }\end{array}$ & $\vec{\Delta}$ & $\sqrt{n}$ & $\begin{array}{l}\text { Descarga efluentes radio- } \\
\text { ativos e de produtos quí- } \\
\text { micos perigosos monito- } \\
\text { radas p/ verificar atendi- } \\
\text { mento autoridade nacional }\end{array}$ & & & & \\
\hline $\overrightarrow{6}$ & 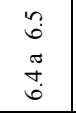 & & $\begin{array}{l}\text { MONITORAÇÃO E } \\
\text { MEDIÇÃOO }\end{array}$ & $\overrightarrow{\dot{m}}$ & $\begin{array}{l}\text { Monitoraçã̃o e } \\
\text { medição }\end{array}$ & $\overrightarrow{\vec{n}}$ & $\begin{array}{l}\text { Monitoramento e } \\
\text { medição do desempenho }\end{array}$ & 艺 & 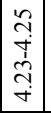 & $\begin{array}{l}\text { VERIFICAÇÃO } \\
\text { DA SEGURANÇA }\end{array}$ & $\vec{\Delta}$ & $\stackrel{8}{\circ}$ & $\begin{array}{l}\text { Monitorar concentração } \\
\text { de gases inflamáveis }\end{array}$ & & & & \\
\hline $\overrightarrow{6}$ & 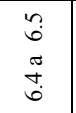 & & $\begin{array}{l}\text { MONITORAÇÃO E } \\
\text { MEDIÇÃOO }\end{array}$ & $\begin{array}{l}\overrightarrow{\dot{m}} \\
\dot{+}\end{array}$ & $\begin{array}{l}\text { Monitoração e } \\
\text { medição }\end{array}$ & $\overrightarrow{\dot{n}}$ & $\begin{array}{l}\text { Monitoramento e } \\
\text { medição do desempenho }\end{array}$ & 艺 & 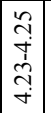 & $\begin{array}{l}\text { VERIFICAÇÃO } \\
\text { DA SEGURANÇA }\end{array}$ & & & & & $\vec{a}$ & 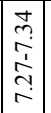 & Controle de dose interna \\
\hline $\overrightarrow{6}$ & 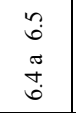 & & $\begin{array}{l}\text { MONITORAÇÃO E } \\
\text { MEDIÇÃO }\end{array}$ & $\begin{array}{c}\overrightarrow{\dot{n}} \\
\dot{+}\end{array}$ & $\begin{array}{l}\text { Monitoração e } \\
\text { medição }\end{array}$ & $\begin{array}{c}\overrightarrow{\dot{n}} \\
\dot{+}\end{array}$ & $\begin{array}{l}\text { Monitoramento e } \\
\text { medição do desempenho }\end{array}$ & 艺 & 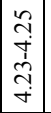 & $\begin{array}{l}\text { VERIFICAÇÃO } \\
\text { DA SEGURANÇA }\end{array}$ & & & & & $\vec{\Delta}$ & 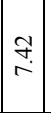 & $\begin{array}{l}\text { Monitorar saúde } \\
\text { trabalhadores (Efeitos } \\
\text { radiológicos e químicos) }\end{array}$ \\
\hline $\overrightarrow{6}$ & 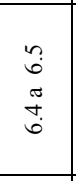 & & $\begin{array}{l}\text { MONITORAÇÃO E } \\
\text { MEDIÇÃOO }\end{array}$ & $\begin{array}{l}\vec{n} \\
\dot{v}\end{array}$ & \begin{tabular}{|l|} 
Documentos c/ infor- \\
mações p/monitorar \\
desempenho, contro- \\
les operacionais e \\
conformidade com \\
objetivos \\
\end{tabular} & $\overrightarrow{\ddot{n}}$ & $\begin{array}{l}\text { Registrar dados e resul- } \\
\text { tados do monitoramento } \\
\text { e medição para análise } \\
\text { de ações corretivas e } \\
\text { preventivas }\end{array}$ & & & & $\vec{\Delta}$ & $\stackrel{\infty}{\circ}$ & $\begin{array}{l}\text { Registro de dados de } \\
\text { operação do } \\
\text { estabelecimento }\end{array}$ & & & & \\
\hline & & $\overline{6}$ & $\begin{array}{l}\text { Gestão de } \\
\text { inadvertências }\end{array}$ & $\begin{array}{l}\overrightarrow{\dot{n}} \\
\dot{+}\end{array}$ & $\begin{array}{l}\text { Monitoração e } \\
\text { medição }\end{array}$ & 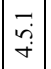 & $\begin{array}{l}\text { Monitoramento e } \\
\text { medição do desempenho }\end{array}$ & & & & & & & & & & \\
\hline กู & & & $\begin{array}{l}\text { AUTO- } \\
\text { AVALIAÇÃO }\end{array}$ & & & & & & & & & & & & & & \\
\hline & 要: & 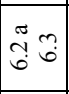 & $\begin{array}{l}\text { Auto-avaliação pela } \\
\text { alta direção }\end{array}$ & & & & & & & & $\vec{\Delta}$ & $\vec{s}$ & $\begin{array}{l}\text { Auto-avaliação p/ avaliar } \\
\text { desempenho operacional } \\
\text { e de segurança }\end{array}$ & & & & \\
\hline & 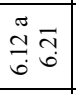 & 苟 & $\begin{array}{l}\text { Auto-avaliação pelos } \\
\text { gerentes e indivíduos }\end{array}$ & & & & & & & & $\vec{\Delta}$ & $\vec{a}$ & $\begin{array}{l}\text { Auto-avaliação p/ avaliar } \\
\text { desempenho operacional } \\
\text { e de segurança }\end{array}$ & & & & \\
\hline గొ & & & $\begin{array}{l}\text { AVALIAÇÃO } \\
\text { INDEPENDENTE }\end{array}$ & $\begin{array}{ll}n \\
n \\
\dot{n} \\
+\end{array}$ & Auditoria interna & $\begin{array}{ll}n \\
n \\
\dot{n} \\
+\end{array}$ & Auditoria interna & & & & & & & & & & \\
\hline & तु & $\overrightarrow{\widehat{\sigma}}$ & $\begin{array}{l}\text { Tipos de avaliação } \\
\text { independente }\end{array}$ & & & & & & & & & & & & & & \\
\hline & & 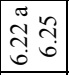 & $\begin{array}{l}\text { Avaliação pelos } \\
\text { colegas }\end{array}$ & & & & & & & & & & & & & & \\
\hline & & 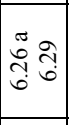 & Revisão técnica & & & & & & & & $\vec{\theta}$ & $\begin{array}{r}\text { a } \\
\text { a }\end{array}$ & $\begin{array}{l}\text { Revisão de instruções } \\
\text { operacionais }\end{array}$ & & $\vec{\Delta}$ & 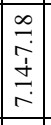 & $\begin{array}{l}\text { Avaliar e escrutinar a } \\
\text { significância da } \\
\text { modificação quanto à } \\
\text { segurança }\end{array}$ \\
\hline & & 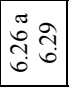 & Revisão técnica & & & & & & & & & & $\begin{array}{l}\text { Revisão de programas de } \\
\text { manutenção e inspeções e } \\
\text { testes periódicos }\end{array}$ & & & & \\
\hline
\end{tabular}




\begin{tabular}{|c|c|c|c|c|c|c|c|c|c|c|c|c|c|c|c|}
\hline \multirow[t]{2}{*}{ 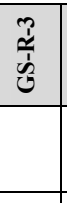 } & \multirow{2}{*}{ 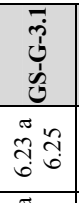 } & \multirow[t]{2}{*}{$\begin{array}{l}\text { से } \\
\text { है }\end{array}$} & \multirow{2}{*}{$\begin{array}{c}\text { SG - IAEA } \\
\text { Auditorias internas }\end{array}$} & \multicolumn{2}{|r|}{$\begin{array}{l}\text { SG - Ambiental } \\
\text { ISO } 14001\end{array}$} & \multicolumn{2}{|c|}{$\begin{array}{c}\text { SG - Segurança e Saúde no } \\
\text { Trabalho } \\
\text { OHSAS 18001 }\end{array}$} & \multicolumn{3}{|c|}{$\begin{array}{l}\text { Segurança - Ciclo do } \\
\text { Combustível } \\
\text { IAEA DS316 Seção } 4\end{array}$} & \multicolumn{3}{|c|}{$\begin{array}{l}\text { Segurança - Operação Ciclo do } \\
\text { Combustível } \\
\text { IAEA DS316 Seção } 9\end{array}$} & $\begin{array}{l}\text { Segurança - Operação Conversão } \\
\text { IAEA DS316 Ap. III } 18 \text { a } 19\end{array}$ & $\begin{array}{l}\text { Segurança - Operação } \\
\text { Conversão } \\
\text { IAEA DS344 Seção } 7\end{array}$ \\
\hline & & & & $\begin{array}{l}n \\
\ddot{q} \\
\dot{q}\end{array}$ & Auditoria interna & $\begin{array}{l}n \\
i \\
i \\
\sim\end{array}$ & Auditoria interna & & & & $\vec{a}$ & $\stackrel{R}{?}$ & $\begin{array}{l}\text { Auditoria para avaliar } \\
\text { desempenho operacional } \\
\text { e de segurança }\end{array}$ & & \\
\hline & 迎 & & Supervisão & & & & & & & & & & & & \\
\hline & लु & & $\begin{array}{l}\text { Responsabilidades da } \\
\text { unidade de avaliação }\end{array}$ & & & & & & & & & & & & \\
\hline & & లై & $\begin{array}{l}\text { Avaliação da cultura } \\
\text { de segurança }\end{array}$ & & & & & & & & $\vec{a}$ & $\stackrel{2}{?}$ & $\begin{array}{l}\text { Avaliação cultura de } \\
\text { segurança }\end{array}$ & & \\
\hline \multirow[t]{3}{*}{ 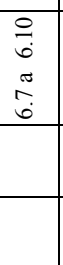 } & 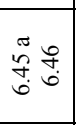 & & $\begin{array}{l}\text { ANÁLISE CRÍTI- } \\
\text { CA DO SISTEMA } \\
\text { DE GESTÃO }\end{array}$ & $\stackrel{\circ}{+}$ & $\begin{array}{l}\text { Análise pela } \\
\text { administração }\end{array}$ & $\stackrel{\circ}{+}$ & $\begin{array}{l}\text { Análise crítica pela } \\
\text { direção }\end{array}$ & 艺 & 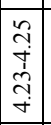 & $\begin{array}{l}\text { VERIFICAÇÃO } \\
\text { DA SEGURANÇA }\end{array}$ & $\vec{a}$ & \begin{tabular}{l|l}
$\infty$ \\
$\infty$ \\
$\infty$ \\
$\infty$ \\
$\infty$
\end{tabular} & $\begin{array}{l}\text { Análise crítica da segu- } \\
\text { rança acordo requisitos } \\
\text { órgão regulador nacional } \\
\text { ("Safety Case" atualizado) }\end{array}$ & & \\
\hline & fٌ̧ & & $\begin{array}{l}\text { Entradas da análise } \\
\text { crítica }\end{array}$ & $\begin{array}{l}+ \\
+ \\
\end{array}$ & $\begin{array}{l}\text { Análise pela } \\
\text { administração }\end{array}$ & \begin{tabular}{ll}
\multirow{+}{*}{} \\
\end{tabular} & $\begin{array}{l}\text { Análise crítica pela } \\
\text { direção }\end{array}$ & & & & & & & & \\
\hline & 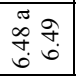 & & $\begin{array}{l}\text { Saídas da análise } \\
\text { crítica }\end{array}$ & $\begin{array}{l}\stackrel{0}{+} \\
\dot{+}\end{array}$ & $\begin{array}{l}\text { Análise pela } \\
\text { administração }\end{array}$ & 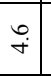 & $\begin{array}{l}\text { Análise crítica pela } \\
\text { direção }\end{array}$ & & & & & & & & \\
\hline 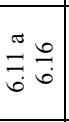 & 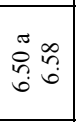 & & $\begin{array}{l}\text { NÃO-CONFORMI- } \\
\text { DADES, AÇÕES } \\
\text { CORRETIVAS E } \\
\text { PREVENTIVAS }\end{array}$ & $\stackrel{r}{\dot{f}}$ & $\begin{array}{l}\text { Preparação e } \\
\text { resposta a } \\
\text { emergência }\end{array}$ & $\stackrel{r}{\stackrel{+}{+}}$ & $\begin{array}{l}\text { Preparação e resposta a } \\
\text { emergência }\end{array}$ & & & & & & & & \\
\hline \multirow[t]{6}{*}{$\frac{\pi}{7}=\frac{0}{6}$} & 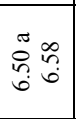 & & $\begin{array}{l}\text { NÃO-CONFORMI- } \\
\text { DADES, AÇÕES } \\
\text { CORRETIVAS E } \\
\text { PREVENTIVAS }\end{array}$ & $\begin{array}{c}m \\
\ddot{+} \\
\ddot{+}\end{array}$ & $\begin{array}{l}\text { Não-conformidade, } \\
\text { ação corretiva e ação } \\
\text { preventiva }\end{array}$ & $\underset{m}{m}$ & $\begin{array}{l}\text { Investigação de aciden- } \\
\text { te, não-conformidade, } \\
\text { ação corretiva e ação } \\
\text { preventiva }\end{array}$ & & & & $\vec{a}$ & $\stackrel{\infty}{a}$ & $\begin{array}{l}\text { Registro de eventos e } \\
\text { incidentes }\end{array}$ & & \\
\hline & 至 & & $\begin{array}{l}\text { Controle de não- } \\
\text { conformidade }\end{array}$ & $\underset{m}{m}$ & $\begin{array}{l}\text { Não-conformidade, } \\
\text { ação corretiva e ação } \\
\text { preventiva }\end{array}$ & 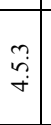 & $\begin{array}{l}\text { Investigação de aciden- } \\
\text { te, não-onformidade, } \\
\text { ação corretiva e ação } \\
\text { preventiva }\end{array}$ & & & & & & & & \\
\hline & 焉 & 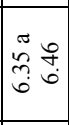 & Ações corretivas & $\begin{array}{l}m \\
\ddot{n} \\
\dot{\sim}\end{array}$ & $\begin{array}{l}\text { Não-conformidade, } \\
\text { ação corretiva e ação } \\
\text { preventiva }\end{array}$ & $\begin{array}{l} \\
m \\
n \\
\dot{q} \\
\end{array}$ & $\begin{array}{l}\text { Investigação de aciden- } \\
\text { te, não-conformidade, } \\
\text { ação corretiva e ação } \\
\text { preventiva }\end{array}$ & & & & & & & & \\
\hline & $\frac{\pi}{\stackrel{R}{R}}$ & 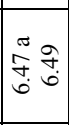 & Ações preventivas & $\underset{m}{m}$ & $\begin{array}{l}\text { Não-conformidade, } \\
\text { ação corretiva e ação } \\
\text { preventiva }\end{array}$ & 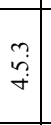 & $\begin{array}{l}\text { Investigação de aciden- } \\
\text { te, não-conformidade, } \\
\text { ação corretiva e ação } \\
\text { preventiva }\end{array}$ & 艺 & 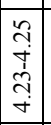 & $\begin{array}{l}\text { VERIFICAÇÃO } \\
\text { DA SEGURANÇA }\end{array}$ & $\vec{a}$ & å. & $\begin{array}{l}\text { Investigação de desvios } \\
\text { significantes das } \\
\text { instruções de operação }\end{array}$ & & \\
\hline & 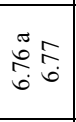 & 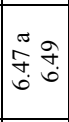 & Ações preventivas & $\underset{m}{m}$ & $\begin{array}{l}\text { Não-conformidade, } \\
\text { ação corretiva e ação } \\
\text { preventiva }\end{array}$ & 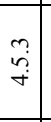 & $\begin{array}{l}\text { Investigação de aciden- } \\
\text { te, não-conformidade, } \\
\text { ação corretiva e ação } \\
\text { preventiva }\end{array}$ & & & & $\vec{a}$ & $\stackrel{n}{a}$ & $\begin{array}{l}\text { Realimentação de } \\
\text { experiência operacional }\end{array}$ & & \\
\hline & & :ึّ & Relato de evento & $\stackrel{\substack{f \\
+}}{+}$ & Comunicação & \begin{tabular}{l|l|l}
$\substack{n \\
\tilde{f} \\
\dot{+} \\
+}$ \\
\end{tabular} & Participação e consulta & $\vec{\Delta}$ & 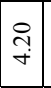 & $\begin{array}{l}\text { Relato de incidentes } \\
\text { significativos a au- } \\
\text { toridade reguladora }\end{array}$ & & & & & \\
\hline
\end{tabular}




\begin{tabular}{|c|c|c|c|c|c|c|c|c|c|c|c|c|c|}
\hline 殅 & $\begin{array}{l}\bar{j} \\
\vdots \\
\dot{3}\end{array}$ & $\begin{array}{l}\text { से } \\
\text { है }\end{array}$ & SG - IAEA & & $\begin{array}{l}\text { SG - Ambiental } \\
\text { ISO } 14001\end{array}$ & & $\begin{array}{c}\text { - Segurança e Saúde no } \\
\text { Trabalho } \\
\text { OHSAS } 18001\end{array}$ & $\begin{array}{l}\text { Segurança - Ciclo do } \\
\text { Combustível } \\
\text { IAEA DS316 Seção } 4 \\
\end{array}$ & & gera & $\begin{array}{l}\text { ança - Operação Ciclo do } \\
\text { Combustivel } \\
\text { AEA DS316 Seção } 9\end{array}$ & $\begin{array}{l}\text { Segurança - Operação Conversão } \\
\text { IAEA DS316 Ap. III } 18 \text { a } 19\end{array}$ & $\begin{array}{c}\text { Segurança - Operação } \\
\text { Conversão } \\
\text { IAEA DS344 Seção } 7\end{array}$ \\
\hline & & 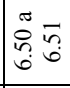 & Relato de evento & $\stackrel{m}{+}+$ & Comunicação & 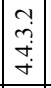 & Participação e consulta & & $\overrightarrow{\mathrm{a}}$ & â. & $\begin{array}{l}\text { Notificar desvios } \\
\text { significativos na operação } \\
\text { que violam os LCO }\end{array}$ & & \\
\hline & & $\begin{array}{ll}\pi & \\
0 & 5 \\
0 & 5 \\
0 & 0\end{array}$ & Relato de evento & 管 & Comunicação & 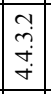 & Participação e consulta & & $\overrightarrow{\mathrm{A}}$ & ڤa & $\begin{array}{l}\text { Reportar descarga efluen- } \\
\text { tes radioativos e produtos } \\
\text { químicos perigosos }\end{array}$ & & \\
\hline$\frac{\pi}{0}=\frac{\infty}{6}$ & 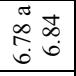 & $\begin{array}{ll}\pi & 0 \\
\tilde{n} & 0 \\
0 & 0 \\
0\end{array}$ & MELHORIAS & & & \begin{tabular}{l|l}
$\overrightarrow{\dot{n}}$ \\
$\dot{n}$ \\
$\dot{v}$
\end{tabular} & $\begin{array}{l}\text { Investigação de } \\
\text { incidente }\end{array}$ & & & & & & \\
\hline$\frac{\pi}{2} \frac{\infty}{6}$ & 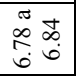 & $\begin{array}{ll}\pi \\
\tilde{n} \\
\tilde{n} & 0 \\
0 & 0 \\
0\end{array}$ & MELHORIAS & $\stackrel{0}{+}$ & $\begin{array}{l}\text { Análise pela } \\
\text { administração }\end{array}$ & $\stackrel{\circ}{+}$ & $\begin{array}{l}\text { Análise crítica pela } \\
\text { direção }\end{array}$ & & & & & & \\
\hline & & & & $\stackrel{?}{+}$ & $\begin{array}{l}\text { PLANEJAMENTO } \\
\text { (Título) }\end{array}$ & $\stackrel{?}{+}$ & $\begin{array}{l}\text { PLANEJAMENTO } \\
\text { (Título) }\end{array}$ & & & & & & \\
\hline & & & & $\stackrel{+}{+}$ & $\begin{array}{l}\text { IMPLEMENTAÇ̃̃ } \\
\text { O E OPERAÇ̃̃O } \\
\text { (Título) } \\
\end{array}$ & $\stackrel{+}{+}$ & $\begin{array}{l}\text { IMPLEMENTAÇ̃̃O E } \\
\text { OPERAÇÃO (Título) }\end{array}$ & & & & & & \\
\hline & & & & & & $\stackrel{?}{+}$ & $\begin{array}{l}\text { Comunicação, participa- } \\
\text { ção e consulta (Título) }\end{array}$ & & & & & & \\
\hline & & & & & & 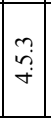 & $\begin{array}{l}\text { Investigação de inciden- } \\
\text { te, não-conformidade, } \\
\text { ação corretiva e ação } \\
\text { preventiva (Título) }\end{array}$ & & & & & & \\
\hline
\end{tabular}


APÊNDICE L - Correlação entre Documentos Requeridos pelas Normas de SG e Segurança da IAEA (GS-R-3, GS-G-3.1, DS349, DS316 e DS344) e ISO 9001, ISO 14001 e OHSAS 18001.

Legenda

NID Não indica documento

Documento do processo que pode ser considerado para racionalização em um único tipo.

Procedimento da ISO 14001 ou OHSAS 18001 que não requer necessariamente documentação.

Documento com similaridade entre normas ISO 14001 e OHSAS 18001, que pode ser considerado para racionalização.

Documento específico à função de segurança nuclear, único ou um caso particular de aplicação do tipo de documento do processo.

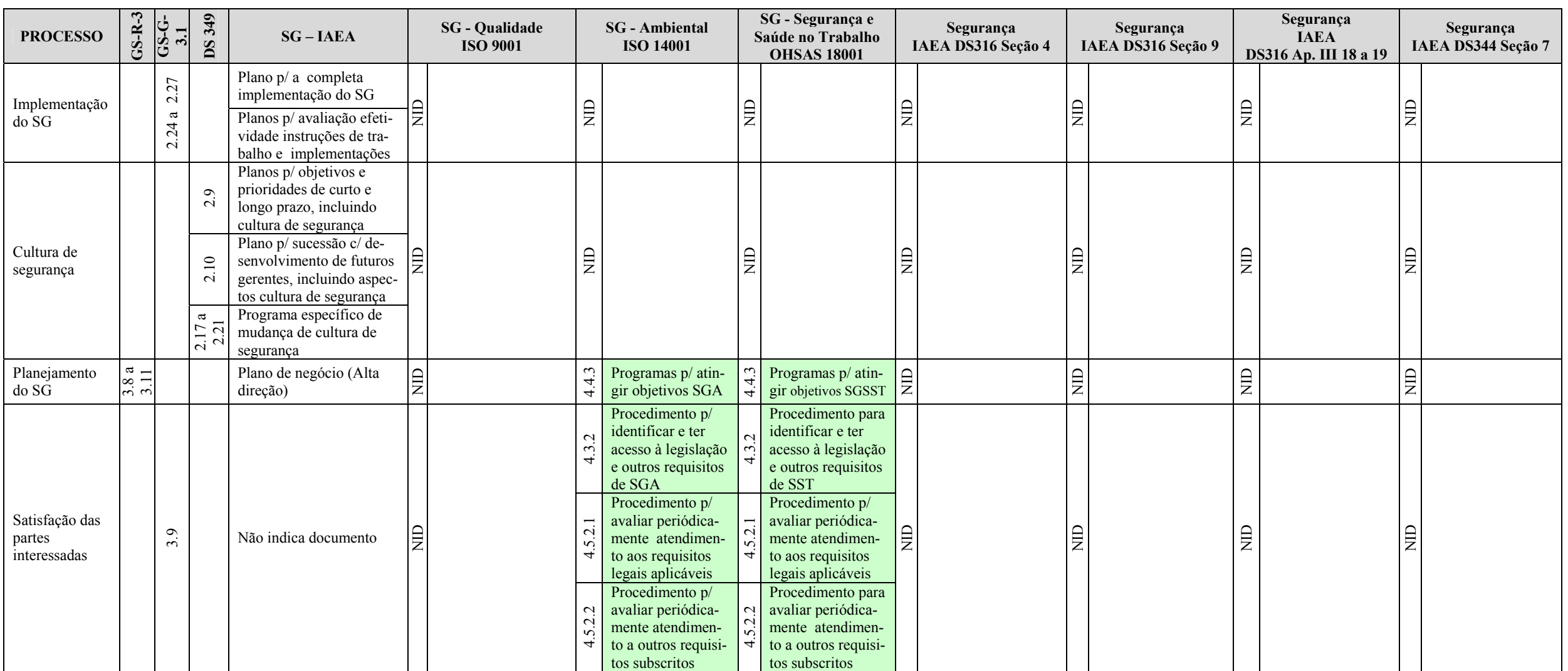




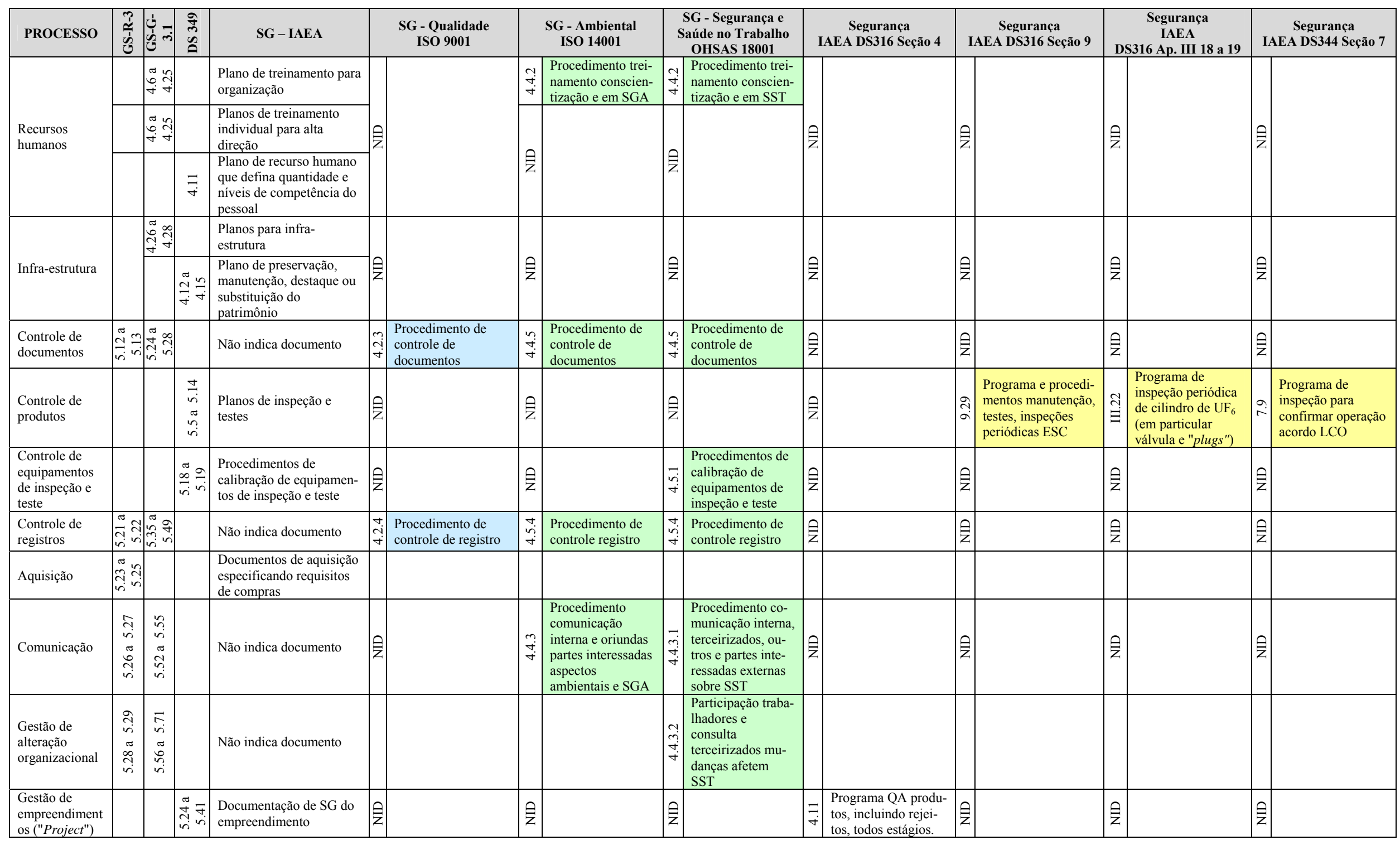




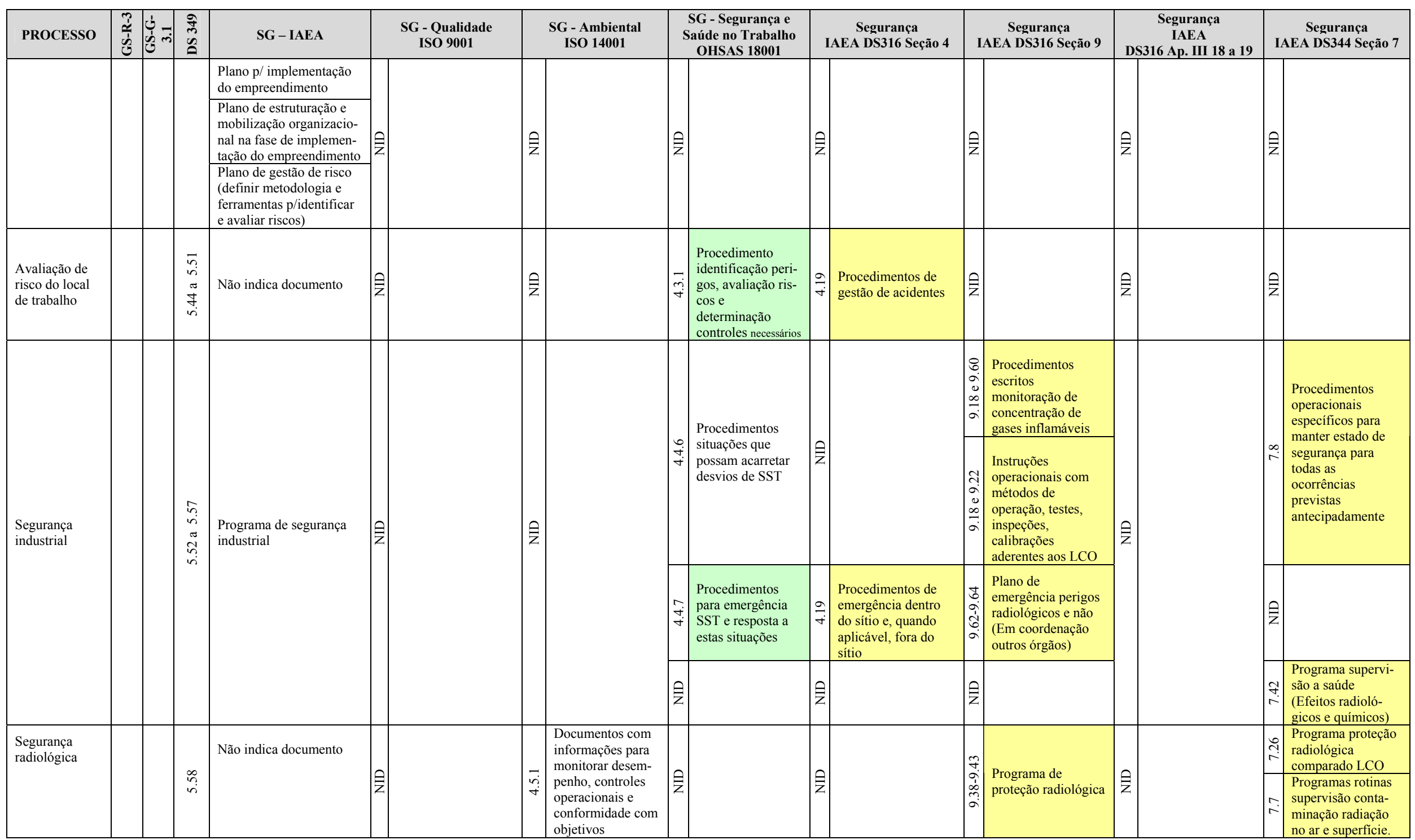




\begin{tabular}{|c|c|c|c|c|c|c|c|c|c|c|c|c|c|c|c|c|c|}
\hline PROCESSO & 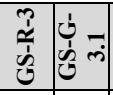 & 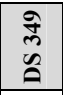 & SG - IAEA & & $\begin{array}{l}\text { SG - Qualidade } \\
\text { ISO 9001 }\end{array}$ & & $\begin{array}{l}\text { SG - Ambiental } \\
\text { ISO } 14001\end{array}$ & & $\begin{array}{l}\text { SG - Segurança e } \\
\text { Saúde no Trabalho } \\
\text { OHSAS } 18001\end{array}$ & & $\begin{array}{c}\text { Segurança } \\
\text { AEA DS316 Seção } 4\end{array}$ & & $\begin{array}{c}\text { Segurança } \\
\text { AEA DS316 Seção } 9\end{array}$ & & $\begin{array}{l}\text { Segurança } \\
\text { IAEA } \\
\text { 316 Ap. III } 18 \text { a } 19\end{array}$ & & $\begin{array}{c}\text { Segurança } \\
\text { AEA DS344 Seção } 7\end{array}$ \\
\hline & & & & & & & & & & & & z & & & & $\left(\begin{array}{r}-1 \\
7 \\
1\end{array}\right.$ & \begin{tabular}{|l} 
Programa de super- \\
visão da saúde \\
(Efeitos radio- \\
lógicos e químicos)
\end{tabular} \\
\hline \multirow{3}{*}{ Projeto } & & $\begin{array}{l}\bar{a} \\
\dot{n} \\
\tilde{\sigma} \\
\therefore \\
\dot{n}\end{array}$ & Não indica documento & \multirow{3}{*}{ z } & & $\vec{m} \dot{\vec{r}}$ & \begin{tabular}{|l|} 
Procedimento \\
identificação as- \\
pectos ambientais \\
e determinação \\
impactos ambien- \\
tais significativos \\
\end{tabular} & $\overrightarrow{\dot{p}}$ & \begin{tabular}{|l} 
Procedimento \\
identificação peri- \\
gos, avaliação \\
riscos e determina- \\
ção controles \\
necessários
\end{tabular} & \multirow{3}{*}{$\mathrm{z}$} & & \multirow{3}{*}{ 吾 } & & \multirow{3}{*}{ 合 } & & \multirow{3}{*}{$\mathrm{z}$} & \\
\hline & & $\begin{array}{l}\stackrel{m}{\vec{z}} \\
\dot{n} \\
\tilde{\sigma} \\
\tilde{\sigma} \\
i\end{array}$ & Não indica documento & & & \multirow[t]{2}{*}{$\mathrm{O}$} & & $\mid \begin{array}{l}\tilde{y} \\
\tilde{f} \\
\dot{f} \\
\dot{f}\end{array}$ & \begin{tabular}{|l} 
Procedimento par- \\
ticipacãa trabalha- \\
dores e consulta \\
terceirizados mu- \\
danças afetem \\
SST \\
\end{tabular} & & & & & & & & \\
\hline & & 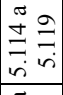 & $\begin{array}{l}\text { Procedimento para } \\
\text { permissão de desvio e } \\
\text { concessões }\end{array}$ & & & & & 至 & & & & & & & & & \\
\hline $\begin{array}{l}\text { Controle de } \\
\text { configuração }\end{array}$ & & 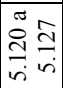 & $\begin{array}{l}\text { Documentação de } \\
\text { configuraçao do } \\
\text { estabelecimento }\end{array}$ & 言 & & 会 & & 会 & & 至 & & 会 & & 学 & & 至 & \\
\hline \multirow[b]{2}{*}{ Manutenção } & & \multirow[b]{2}{*}{$\underset{\text { ते }}{\text { in }}$} & \multirow[b]{2}{*}{ Não indica documento } & \multirow[b]{2}{*}{$\hat{z}$} & & \multirow[b]{2}{*}{ 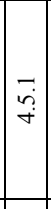 } & \multirow{2}{*}{$\begin{array}{l}\text { Documentos } \mathrm{c} / \text { in- } \\
\text { formações } \mathrm{p} / \mathrm{mo} \text { - } \\
\text { nitorar desempe- } \\
\text { nho, controles } \\
\text { operacionais e } \\
\text { conformidade } \\
\text { objetivos }\end{array}$} & \multirow[b]{2}{*}{ 豆 } & & \multirow[b]{2}{*}{ 合 } & & ๙ૂે & $\begin{array}{l}\text { Permissão de } \\
\text { serviço (Sistema) }\end{array}$ & \multirow[b]{2}{*}{ 合 } & & \multirow[b]{2}{*}{ 至 } & \\
\hline & & & & & & & & & & & & సे & $\begin{array}{l}\text { Programa e procedi- } \\
\text { mentos de manuten- } \\
\text { ção, testes, inspe- } \\
\text { ções periódicas ESC }\end{array}$ & & & & \\
\hline \multirow[t]{4}{*}{$\begin{array}{l}\text { Gestão } \\
\text { ambiental }\end{array}$} & & \multirow{4}{*}{ 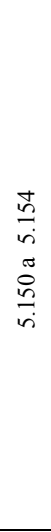 } & \multirow[t]{4}{*}{ Não indica documento } & \multirow{4}{*}{ z } & & & Procedimentos & & Procedimentos & & & $\mid \begin{array}{c}0 \\
0 \\
0 \\
0 \\
\infty \\
0 \\
0\end{array}$ & $\begin{array}{l}\text { Procedimentos } \\
\text { sobre concentração } \\
\text { de gases } \\
\text { inflamáveis }\end{array}$ & \multirow{4}{*}{ 言 } & & \multirow[b]{2}{*}{$\mid \begin{array}{c}\infty \\
-1 \\
r\end{array}$} & \multirow{2}{*}{$\begin{array}{l}\text { Procedimentos } \\
\text { operacionais } \\
\text { específicos para } \\
\text { manter estado de } \\
\text { segurança para } \\
\text { todas as } \\
\text { ocorrências } \\
\text { previstas } \\
\text { antecipadamente }\end{array}$} \\
\hline & & & & & & $\stackrel{\dot{f}}{\dot{f}}$ & $\begin{array}{l}\text { possam acarretar } \\
\text { desvios de SGA }\end{array}$ & $\dot{+}$ & $\begin{array}{l}\text { possam acarretar } \\
\text { desvios de SST }\end{array}$ & $\bar{z}$ & & \begin{tabular}{|c|}
\multirow{2}{*}{} \\
2 \\
0 \\
$\infty$ \\
0 \\
2 \\
\end{tabular} & $\begin{array}{l}\text { Instruções operacio- } \\
\text { nais com métodos } \\
\text { de operação, testes, } \\
\text { ins-peções, } \\
\text { calibrações } \\
\text { aderentes aos LCO }\end{array}$ & & & & \\
\hline & & & & & & \multirow{2}{*}{\multicolumn{2}{|c|}{ 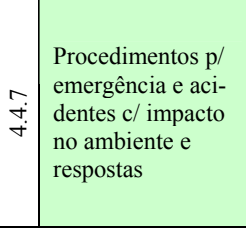 }} & \multirow{2}{*}{\multicolumn{2}{|c|}{$\begin{array}{l}\text { Procedimentos } \\
\text { para emergência } \\
\dot{f} \\
\text { SST e resposta a } \\
\text { estas situações }\end{array}$}} & $\stackrel{\vec{f}}{\vec{F}}$ & $\begin{array}{l}\text { Procedimentos de } \\
\text { gestão de acidentes }\end{array}$ & $\hat{z}$ & & & & \multirow[b]{2}{*}{ 至 } & \\
\hline & & & & & & & & & & $\stackrel{\leftrightarrow}{\overrightarrow{+}}$ & $\begin{array}{l}\text { Procedimentos emer- } \\
\text { gência dentro, e } \\
\text { quando aplicável, } \\
\text { fora do sítio }\end{array}$ & 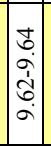 & $\begin{array}{l}\text { Plano de } \\
\text { emergência perigos } \\
\text { radiológicos e não } \\
\text { (Em coordenação } \\
\text { outros órgãos) }\end{array}$ & & & & \\
\hline
\end{tabular}




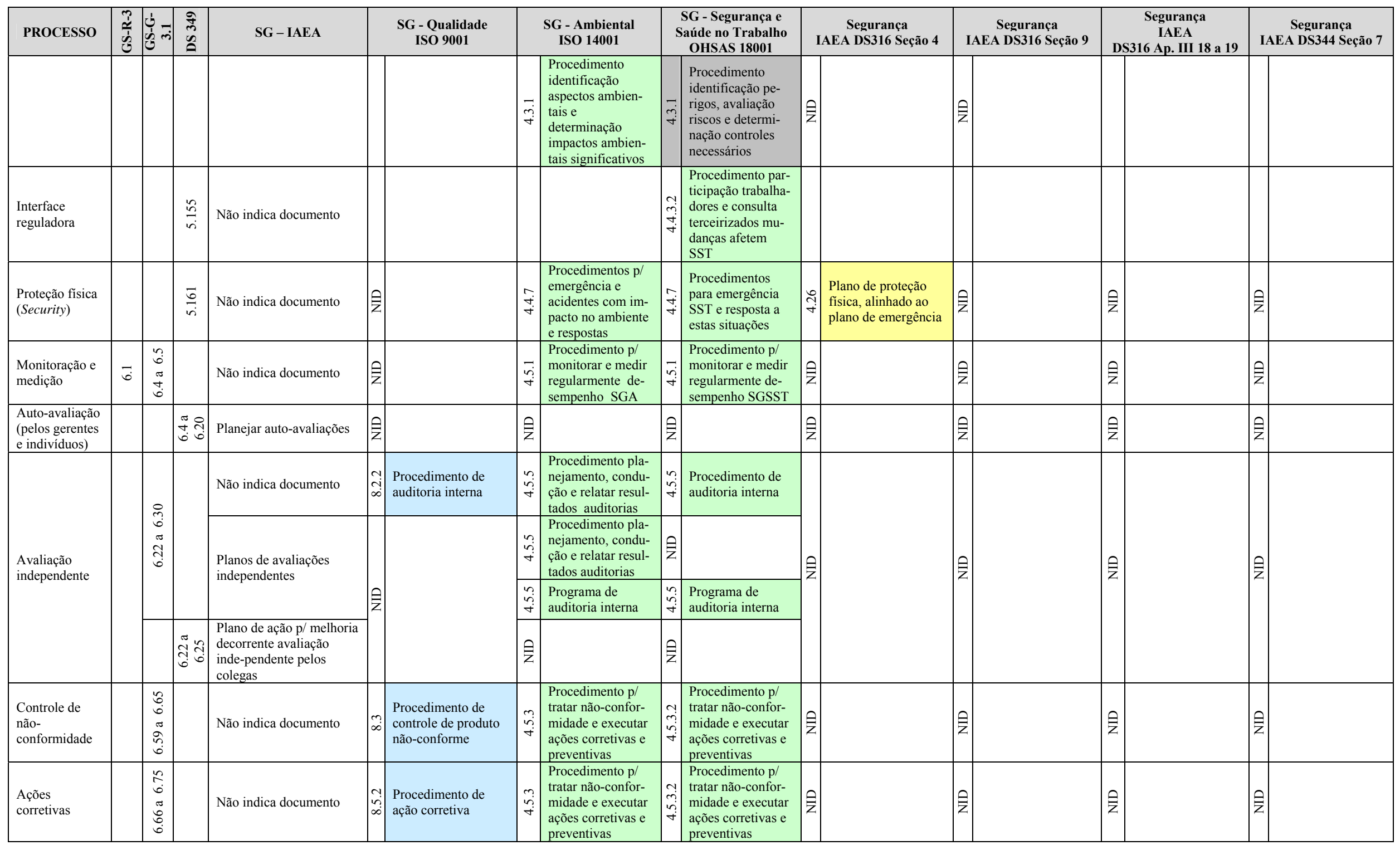




\begin{tabular}{|c|c|c|c|c|c|c|c|c|c|c|c|c|c|c|c|c|c|c|}
\hline PROCESSO & 童 & 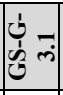 & 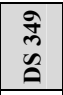 & SG - IAEA & & $\begin{array}{l}\text { SG - Qualidade } \\
\text { ISO } 9001\end{array}$ & & $\begin{array}{l}\text { SG - Ambiental } \\
\text { ISO } 14001\end{array}$ & & $\begin{array}{l}\text { SG - Segurança e } \\
\text { auúde no Trabalho } \\
\text { OHSAS } 18001\end{array}$ & & $\begin{array}{c}\text { Segurança } \\
\text { TEA DS316 Seção } 4\end{array}$ & & $\begin{array}{c}\text { Segurança } \\
\text { AEA DS316 Seção } 9\end{array}$ & & $\begin{array}{l}\text { Segurança } \\
\text { IAEA } \\
\text { 316 Ap. III } 18 \text { a } 19\end{array}$ & & $\begin{array}{c}\text { Segurança } \\
\text { AEA DS344 Seção } 7\end{array}$ \\
\hline \multirow{2}{*}{$\begin{array}{l}\text { Ações } \\
\text { preventivas }\end{array}$} & & 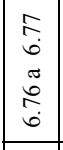 & & Não indica documento & $\begin{array}{c}m \\
\infty \\
\infty \\
\infty\end{array}$ & $\begin{array}{l}\text { Procedimento de } \\
\text { ação preventiva }\end{array}$ & 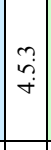 & $\begin{array}{l}\text { Procedimento p/ } \\
\text { tratar não-confor- } \\
\text { midade e executar } \\
\text { ações corretivas e } \\
\text { preventivas }\end{array}$ & $\begin{array}{c}\tilde{c} \\
\tilde{m} \\
\dot{\sim} \\
\dot{\sim} \\
\end{array}$ & $\begin{array}{l}\text { Procedimento p/ } \\
\text { tratar não-confor- } \\
\text { midade e executar } \\
\text { ações corretivas e } \\
\text { preventivas }\end{array}$ & \multirow{2}{*}{ 至 } & & & \multirow{2}{*}{ 合 } & \multirow{2}{*}{ 至 } & \multirow{2}{*}{ 亚 } & & \multirow{2}{*}{ 至 } \\
\hline & & $\begin{array}{l}0 \\
0 \\
0 \\
0 \\
0\end{array}$ & 离 & Não indica documento & 官 & & & & 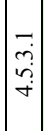 & $\begin{array}{l}\text { Procedimento p/ } \\
\text { registrar, investi- } \\
\text { gar e analisar } \\
\text { incidentes }\end{array}$ & & & & & & & & \\
\hline $\begin{array}{l}\text { Relato de } \\
\text { evento }\end{array}$ & & & $\begin{array}{l}\vec{n} \\
0 \\
0 \\
0 \\
0 \\
0 \\
0\end{array}$ & Não indica documento & 合 & & & & 光 & \begin{tabular}{|l|} 
Procedimento p/ \\
participação traba- \\
lhadores e consul- \\
ta terceirizados \\
mudanças afetem \\
SST \\
\end{tabular} & 会 & & 会 & & 豆 & & \multicolumn{2}{|l|}{ 官 } \\
\hline $\begin{array}{l}\text { Melhoria do } \\
\text { SG }\end{array}$ & 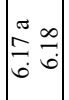 & & & $\begin{array}{l}\text { Planos de melhoramento, } \\
\text { incluindo provisões de } \\
\text { recurso }\end{array}$ & 至 & & 豆 & & 会 & & $\hat{z}$ & & 至 & & 合 & & z & \\
\hline
\end{tabular}


APÊNDICE M - Correlação entre Registros Requeridos pelas Normas de SG e Segurança da IAEA (GS-R-3, GS-G-3.1, DS349, DS316 e DS344) e ISO 9001, ISO 14001 e OHSAS 18001.

\begin{tabular}{|c|c|}
\hline \multicolumn{2}{|c|}{ genda } \\
\hline NIR & Não indica registro \\
\hline & Registro do processo que pode ser considerado para racionalização em um único tipo. \\
\hline & Registro com similaridade entre normas ISO 14001 e OHSAS 18001, que pode ser considerado para racionalização. \\
\hline & Registro específico à função de segurança nuclear, único ou um caso particular de aplicação do tipo de registro do processo. \\
\hline
\end{tabular}

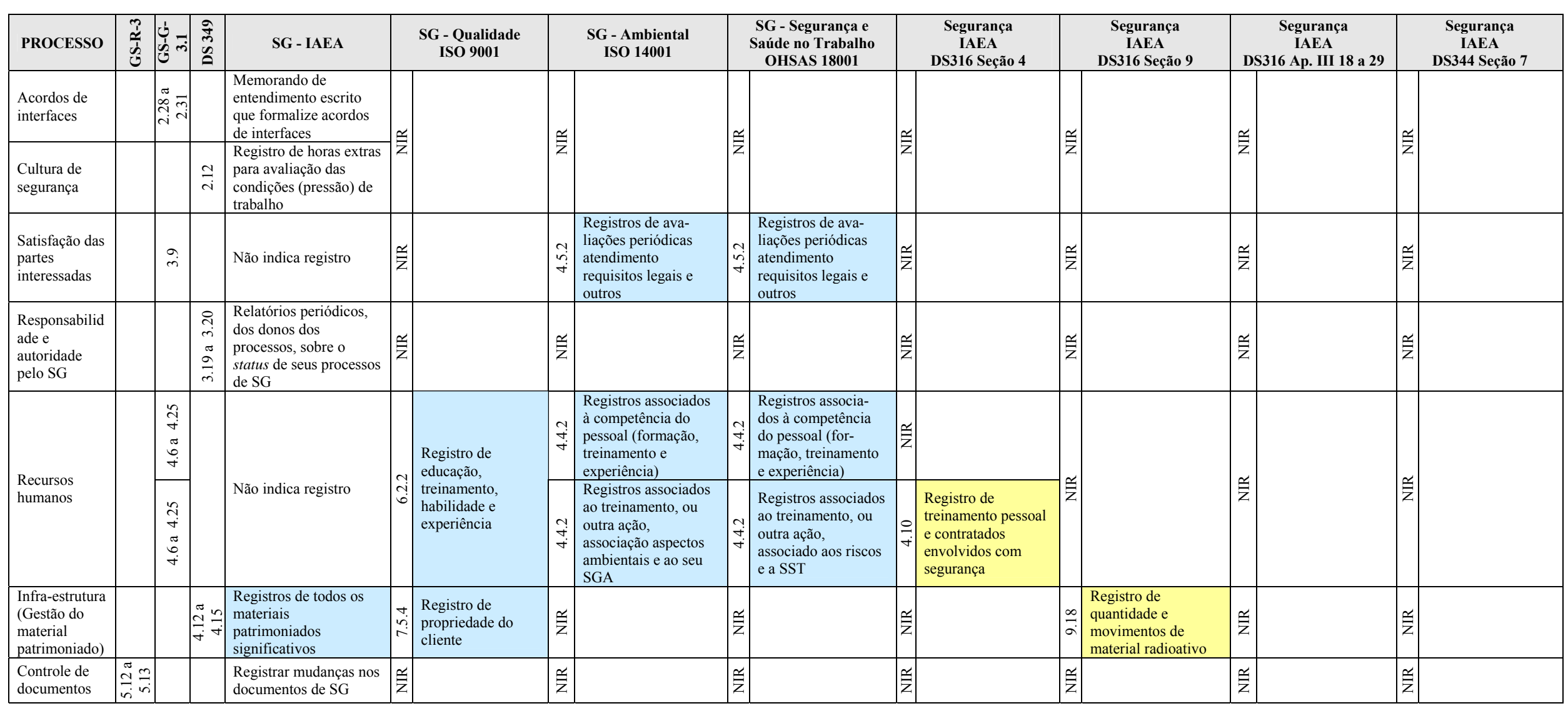




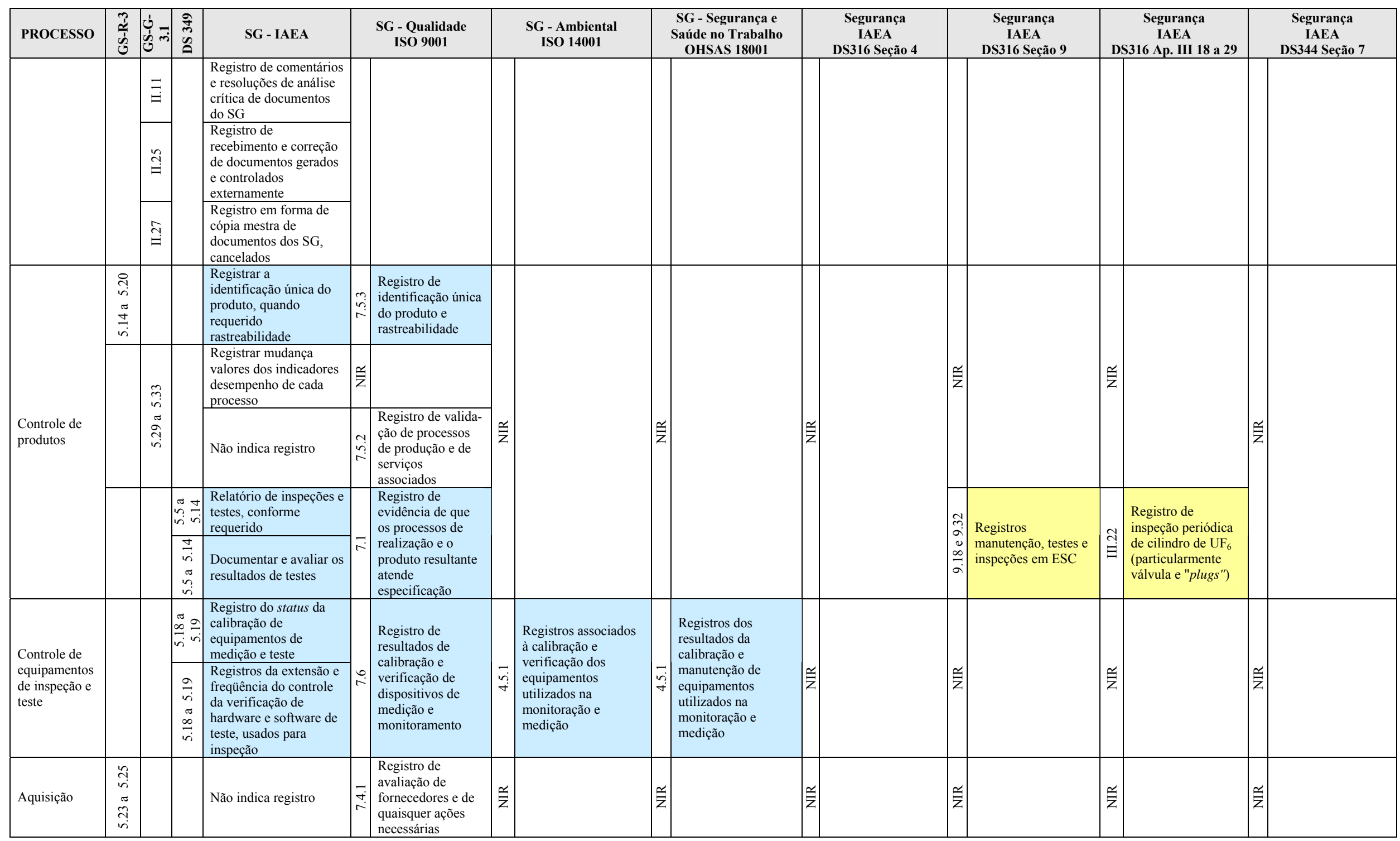




\begin{tabular}{|c|c|c|c|c|c|c|c|c|c|c|c|c|c|c|c|c|c|c|}
\hline PROCESSO & 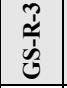 & لे & $\begin{array}{l}\text { ने } \\
\text { है }\end{array}$ & SG - IAEA & & $\begin{array}{l}\text { SG - Qualidade } \\
\text { ISO } 9001\end{array}$ & & $\begin{array}{l}\text { SG - Ambiental } \\
\text { ISO } 14001\end{array}$ & & $\begin{array}{l}\text { SG - Segurança e } \\
\text { Saúde no Trabalho } \\
\text { OHSAS } 18001\end{array}$ & & $\begin{array}{c}\text { Segurança } \\
\text { IAEA } \\
\text { DS316 Seção } 4\end{array}$ & & $\begin{array}{c}\text { Segurança } \\
\text { IAEA } \\
\text { DS316 Seção } 9\end{array}$ & & $\begin{array}{l}\text { Segurança } \\
\text { IAEA } \\
\text { 316 Ap. III 18 a } 29\end{array}$ & & $\begin{array}{c}\text { Segurança } \\
\text { IAEA } \\
\text { DS344 Seção } 7\end{array}$ \\
\hline & & $\stackrel{\check{E}}{\Xi}$ & $\begin{array}{l}\text { ĩ } \\
i \\
\tilde{n} \\
\tilde{n} \\
i\end{array}$ & $\begin{array}{l}\text { Registros e documentos } \\
\text { que substanciem a con- } \\
\text { formidade de produtos } \\
\text { de grau comercial } \\
\text { usados em funções que } \\
\text { envolvem segurança } \\
\text { Registros e amostras de } \\
\text { materiais requeridos de } \\
\text { fornecedores }\end{array}$ & $\underline{z}$ & & & & & & & & & & & & & \\
\hline Comunicação & & $\begin{array}{l}n \\
n \\
i n \\
\pi \\
i n \\
n \\
n\end{array}$ & & $\begin{array}{l}\text { Canal apropriado de } \\
\text { comunicação (Cartas, e- } \\
\text { mail, reuniões) }\end{array}$ & $\cong$ & & $\underset{\substack{++}}{+}$ & $\begin{array}{l}\text { Documentar decisão } \\
\text { de comunicar } \\
\text { externamente seus } \\
\text { aspectos ambientais } \\
\text { significativos }\end{array}$ & 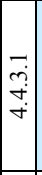 & $\begin{array}{l}\text { Documentar comu- } \\
\text { nicação pertinente } \\
\text { sobre perigos de } \\
\text { SST oriundas de } \\
\text { partes interessadas } \\
\text { externas }\end{array}$ & $\frac{\mathfrak{z}}{z}$ & & $\tilde{z}$ & & 号 & & $\mathfrak{z}$ & \\
\hline $\begin{array}{l}\text { Gestão da } \\
\text { mudança or- } \\
\text { ganizacional }\end{array}$ & 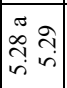 & & & $\begin{array}{l}\text { Registrar a implemen- } \\
\text { tação de mudanças } \\
\text { organizacionais do SG }\end{array}$ & $\frac{\tilde{z}}{z}$ & & 毛 & & 毛 & & $\underline{z}$ & & $\frac{\mathfrak{z}}{\mathrm{z}}$ & & $\frac{n}{z}$ & & $\mathfrak{z}$ & \\
\hline $\begin{array}{l}\text { Gestão de } \\
\text { empreendime } \\
\text { ntos } \\
\text { ("Project") }\end{array}$ & & & 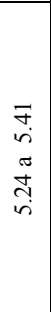 & Não indica registro & 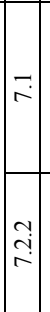 & $\begin{array}{l}\text { Registro de evi- } \\
\text { dência de que os } \\
\text { processos de rea- } \\
\text { lização e o produto } \\
\text { resultante atende } \\
\text { especificação } \\
\text { Registro de análise } \\
\text { crítica dos requi- } \\
\text { sitos relacionados } \\
\text { com o produto e } \\
\text { ações resultantes }\end{array}$ & 品 & & $\frac{\mathfrak{z}}{\mathrm{z}}$ & & $\frac{\tilde{z}}{z}$ & & 点 & & 品 & & $\tilde{z}$ & \\
\hline $\begin{array}{l}\text { Avaliação de } \\
\text { risco do local } \\
\text { de trabalho }\end{array}$ & & & $\begin{array}{l}\vec{n} \\
\ddot{n} \\
\tilde{\sigma} \\
\dot{y} \\
\ddot{n}\end{array}$ & $\begin{array}{l}\begin{array}{l}\text { Documentar análise de } \\
\text { risco do local de } \\
\text { trabalho }\end{array} \\
\text { Registro da completa } \\
\text { avaliação de risco no } \\
\text { local de trabalho }\end{array}$ & $\frac{\tilde{z}}{z}$ & & $\overrightarrow{\dot{m}}$ & $\begin{array}{l}\text { Documentar iden- } \\
\text { tificação aspectos } \\
\text { ambientais e de- } \\
\text { terminacão impactos } \\
\text { ambientais } \\
\text { significativos }\end{array}$ & & \begin{tabular}{|l|} 
Documentar a \\
identificação de \\
perigos, a avaliação \\
de riscos e os \\
controles \\
determinados
\end{tabular} & $\frac{a}{z}$ & & $\frac{\tilde{z}}{\mathrm{z}}$ & & 号 & & $\tilde{z}$ & \\
\hline $\begin{array}{l}\text { Segurança } \\
\text { radiológica }\end{array}$ & & & $\begin{array}{l}\infty \\
n \\
n\end{array}$ & Não indica registro & $\underline{z}$ & & $\mid$ & $\begin{array}{l}\text { Documentos com } \\
\text { informações para } \\
\text { monitorar desem- } \\
\text { penho, controles } \\
\text { operacionais e } \\
\text { conformidade com } \\
\text { objetivos }\end{array}$ & & \begin{tabular}{|l|} 
Registrar dados e \\
resultados do \\
monitoramento e \\
medição para análise \\
de açôes corretivas e \\
preventivas
\end{tabular} & $\approx$ & & 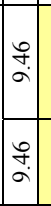 & $\begin{array}{l}\text { Registros de dados } \\
\text { de proteção radio- } \\
\text { lógica, incluindo } \\
\text { monitoração pessoal } \\
\text { Registros de controle } \\
\text { de dose ocupacional } \\
\text { de radiação }\end{array}$ & $\tilde{z}$ & & $\frac{\mathfrak{z}}{\mathrm{z}}$ & \\
\hline $\begin{array}{l}\text { Controle e } \\
\text { supervisão de } \\
\text { contratados }\end{array}$ & & & $\begin{array}{l}\hat{b} \\
\dot{n} \\
\approx \\
\tilde{n} \\
i n\end{array}$ & $\begin{array}{l}\text { Relatório de análise de } \\
\text { segurança de } \\
\text { contratados cujo } \\
\text { trabalho tem impacto na } \\
\text { segurança nuclear }\end{array}$ & 孚 & & $\vec{m}$ & $\begin{array}{l}\text { Documentar iden- } \\
\text { tificação aspectos } \\
\text { ambientais e de- } \\
\text { terminação impactos } \\
\text { ambientais } \\
\text { significativos }\end{array}$ & $\overrightarrow{\dot{m}}$ & $\begin{array}{l}\text { Documentar a } \\
\text { identificação de } \\
\text { perigos, a avaliação } \\
\text { de riscos e os } \\
\text { controles } \\
\text { determinados }\end{array}$ & $\frac{\pi}{z}$ & & $\tilde{z}$ & & $\mathfrak{z}$ & & $\tilde{z}$ & \\
\hline
\end{tabular}




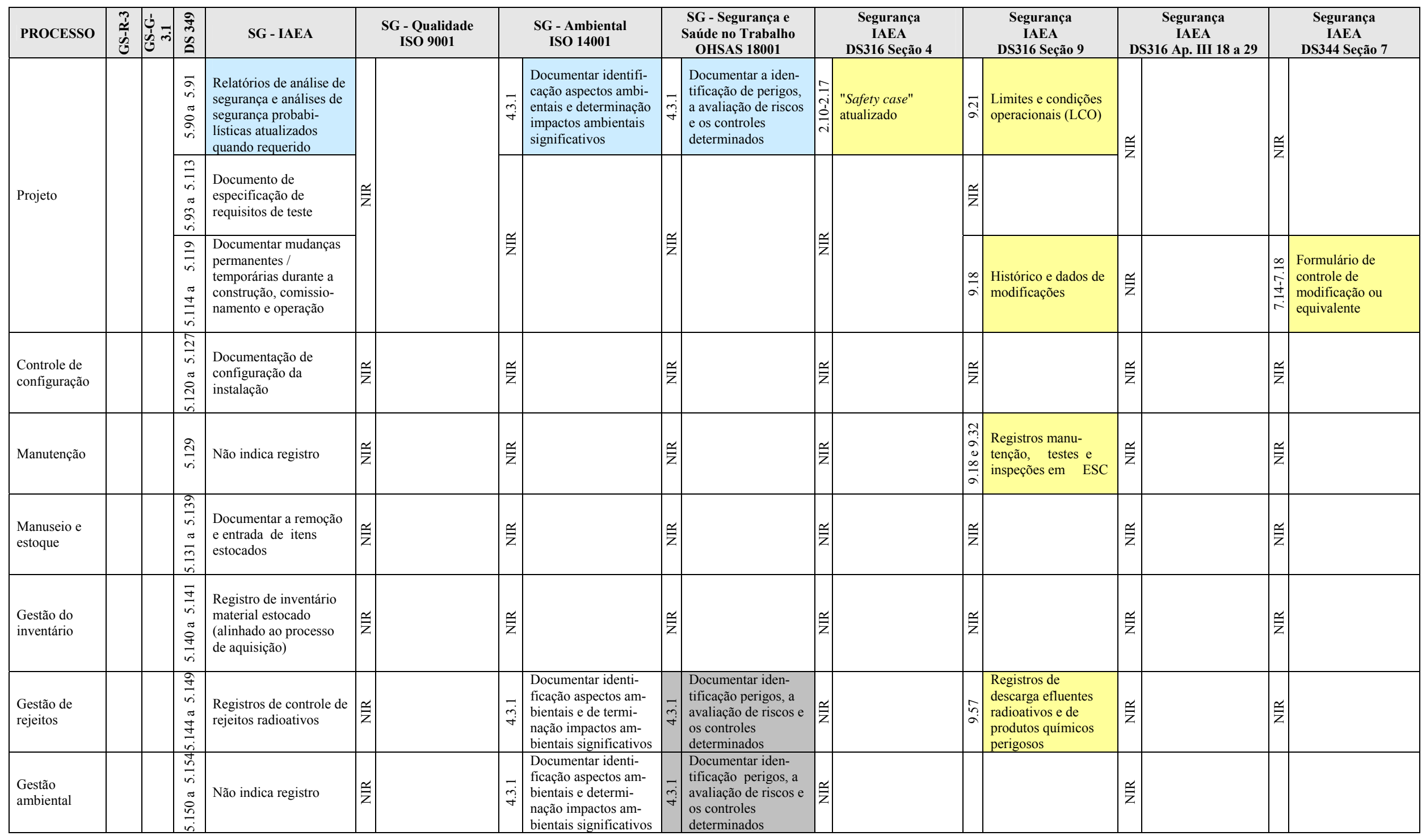




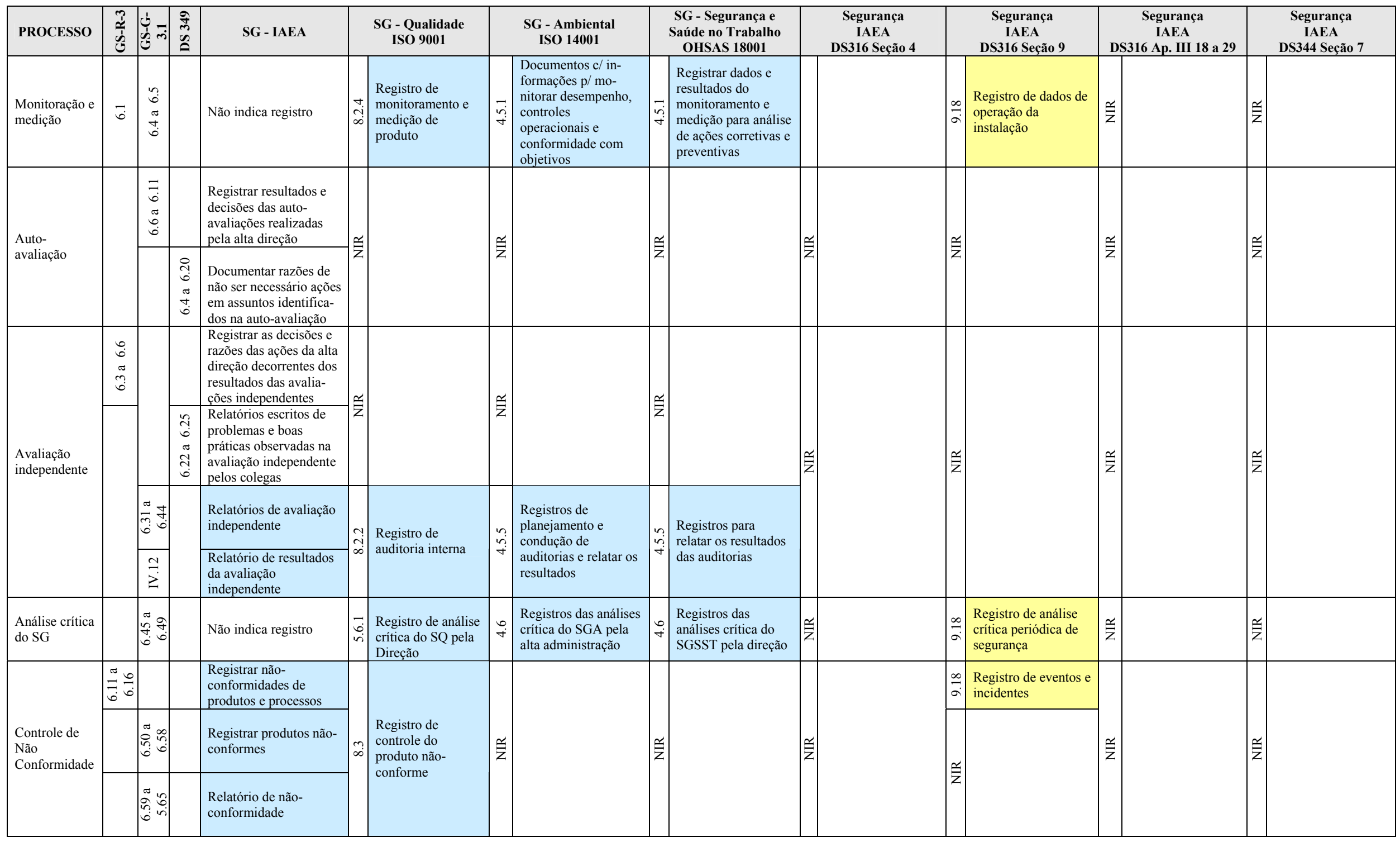




\begin{tabular}{|c|c|c|c|c|c|c|c|c|c|c|c|c|c|c|c|c|c|c|}
\hline PROCESSO & in & نे & $\begin{array}{l}\text { जे } \\
\text { ڤ̊ }\end{array}$ & SG - IAEA & & $\begin{array}{l}\text { SG - Qualidade } \\
\text { ISO } 9001\end{array}$ & & $\begin{array}{l}\text { SG - Ambiental } \\
\text { ISO } 14001\end{array}$ & & $\begin{array}{l}\text { SG - Segurança e } \\
\text { Saúde no Trabalho } \\
\text { OHSAS } 18001\end{array}$ & & $\begin{array}{l}\text { Segurança } \\
\text { IAEA } \\
\text { DS316 Seção } 4 \\
\end{array}$ & & $\begin{array}{c}\text { Segurança } \\
\text { IAEA } \\
\text { DS316 Seção } 9 \\
\end{array}$ & & $\begin{array}{l}\text { Segurança } \\
\text { IAEA } \\
\text { S316 Ap. III } 18 \text { a } 29 \\
\end{array}$ & & $\begin{array}{c}\text { Segurança } \\
\text { IAEA } \\
\text { DS344 Seção } 7 \\
\end{array}$ \\
\hline $\begin{array}{l}\text { Ações } \\
\text { corretivas }\end{array}$ & $\underset{0}{=} \frac{0}{6}$ & 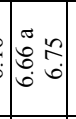 & & $\begin{array}{l}\text { Documentar não- } \\
\text { conformidade e ações } \\
\text { tomadas para corrigi-la }\end{array}$ & $\begin{array}{c}\sim \\
n \\
n \\
\infty \\
1\end{array}$ & $\begin{array}{l}\text { Registro de ação } \\
\text { corretiva } \\
\text { executada }\end{array}$ & 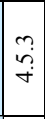 & $\begin{array}{l}\text { Registros dos resulta- } \\
\text { dos das accões correti- } \\
\text { vas e preventivas } \\
\text { executadas }\end{array}$ & 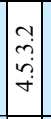 & \begin{tabular}{|l|} 
Registros dos \\
resultados das ações \\
corretivas e ações \\
preventivas \\
\end{tabular} & $\frac{\tilde{z}}{\mathrm{z}}$ & & 点 & & 觉 & & $\tilde{z}$ & \\
\hline $\begin{array}{l}\text { Ações } \\
\text { preventivas }\end{array}$ & & & 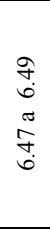 & $\begin{array}{l}\text { Documentar todas as } \\
\text { propostas de ações } \\
\text { preventivas }\end{array}$ & $\begin{array}{c}n \\
n \\
\infty \\
\infty\end{array}$ & $\begin{array}{l}\text { Registro de ação } \\
\text { preventiva } \\
\text { executada }\end{array}$ & 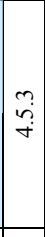 & $\begin{array}{l}\text { Registros dos } \\
\text { resultados das ações } \\
\text { corretivas e } \\
\text { preventivas } \\
\text { executadas }\end{array}$ & 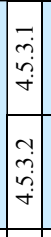 & \begin{tabular}{|l|}
$\begin{array}{l}\text { Documentação dos } \\
\text { resultados das } \\
\text { investigações de } \\
\text { incidentes }\end{array}$ \\
Registros dos \\
resultados das ações \\
corretivas e açôes \\
preventivas
\end{tabular} & $\frac{a}{z}$ & & 学 & & 孚 & & 学 & \\
\hline $\begin{array}{l}\text { Melhoria do } \\
\text { SG }\end{array}$ & $\begin{array}{l}\frac{\infty}{6} \\
\pi \\
= \\
0\end{array}$ & & & $\begin{array}{l}\text { Registrar ações para } \\
\text { melhoria dos processos } \\
\text { SG }\end{array}$ & $\tilde{z}$ & & 妾 & & $\frac{a}{z}$ & & $\underline{z}$ & & $\tilde{z}$ & & 孚 & & $\bar{z}$ & \\
\hline
\end{tabular}




\section{ANEXO A - Processos das Plantas de Conversão da CONVERDYN, CAMECO e} AREVA.

\section{I - Planta de conversão Honeywell-MTW da ConverDyn dos Estados Unidos da América.}

A seqüência dos processos utilizados na planta de conversão HoneywellMTW, chamado de hidrofluoração por via seca ("dry fluoride volatility conversion process"), compreende (ConverDyn, 2008):

- Redução - Uma vez alimentado no processo de conversão, o “yellowcake" é uniformemente distribuído reagindo com hidrogênio à alta temperatura para formar o $\mathrm{UO}_{2}$.

- Hidrofluoração - $\mathrm{O}_{\mathrm{UO}_{2}}$ reage com o $\mathrm{HF}$ anidro em reator de leito fluidizado ("fluidized bed reactors") para produzir $\mathrm{UF}_{4}$.

- Fluoração - $\mathrm{O} \mathrm{UF}_{4}$ reage com flúor gasoso para produzir o gás $\mathrm{UF}_{6}$ impuro.

- Destilação - Os gases leves ("light fraction gases") e impurezas são removidos para produzir um $\mathrm{UF}_{6}$ líquido purificado. $\mathrm{O} \mathrm{UF}_{6}$ líquido é drenado para cilindros de 14 ton. onde, após resfriado por 5 dias, se cristaliza.

Segundo o disposto no sítio na Internet da ConverDyn (2008) o processo possibilita fornecer de forma consistente um produto $\left(\mathrm{UF}_{6}\right)$ de alta qualidade, com $99.99 \%$ de pureza, sendo em termos ambientais o mais eficiente em uso em todo o mundo. Uma das vantagens do processo de acordo com a ConverDyn é de ser completamente integrado, isto é, ser um processo contínuo, realizado em um único local, enquanto nas demais plantas os processos são realizados em duas unidades separadas, requerendo a embalagem e o transporte dos produtos intermediários entre as unidades.

\section{Canadá.}

\section{II - Refinaria Blind River e planta de conversão Port Hope da Cameco do}

A Cameco do Canadá informa em seu sítio na Internet (2008) que opera o refino e a conversão do urânio em duas unidades em separado. Na refinaria Blind River o concentrado de urânio é processado para produzir um $\mathrm{UO}_{3}$ de alta pureza. $\mathrm{O} \mathrm{UO}_{3}$ é enviado para a planta de conversão Port Hope onde é processado para produzir o $\mathrm{UF}_{6}$. A refinaria Blind River fornece também $\mathrm{UO}_{3}$ para a planta de conversão Springfields, no Reino Unido, onde a Cameco produz $\mathrm{UF}_{6}$ utilizando a capacidade ociosa da empresa.

A seqüência dos processos utilizados pela refinaria Blind River, compreende (Cameco, 2008):

- Recebimento - Tambores contendo concentrado de minério de urânio são recebidos e pesados, sendo retiradas amostras para analise da qualidade e do conteúdo do material antes de entrar no processo.

- Digestão - Ácido nítrico é acrescentado ao concentrado de urânio para produzir uma solução de nitrato de uranilo.

- Extração por solvente - Impurezas são removidas da solução de nitrato de uranilo usando um processo de extração em três estágios.

- Concentração ("boildown”) - Remoção de água por evaporação do nitrato de uranilo para produzir um concentrado de nitrato de uranilo líquido hexahidratado, grau nuclear.

para $\mathrm{UO}_{3}$

- Denitração - O nitrato de uranilo concentrado é termicamente decomposto 
- Transporte - $\mathrm{O} \mathrm{UO}_{3}$ é transportado para Port Hope em latões especialmente projetados para despacho, com capacidade de 9.5 toneladas de produto cada.

A planta de conversão Port Hope da Cameco converte a maioria do $\mathrm{UO}_{3}$ recebido em $\mathrm{UF}_{6}$, o restante é convertido em $\mathrm{UO}_{2}$ para abastecer os reatores do tipo CANDU do Canadá. A instalação é a única que converte o urânio usando o processo via úmido para produzir o $\mathrm{UF}_{4}$ do $\mathrm{UO}_{2}$ - portanto reduzindo o consumo de ácido fluorídrico (HF). A seqüência dos processos utilizados pela Port Hope para conversão do $\mathrm{UF}_{6}$, compreende (Cameco, 2008):

- Redução - $\mathrm{O} \mathrm{UO}_{3}$ é pulverizado em um pó fino, quando então reage com o gás hidrogênio para produzir $\mathrm{UO}_{2}$.

- Hidrofluoração - $\mathrm{O}_{\mathrm{UO}_{2}}$ reage com o ácido fluorídrico para converter o $\mathrm{UO}_{2}$ em $\mathrm{UF}_{4}$ o qual é calcinado para remoção da água.

- Fluoração - $\mathrm{O}$ pó de $\mathrm{UF}_{4}$ calcinado reage com o flúor $\left(\mathrm{F}_{2}\right)$ gasoso para produzir $\mathrm{UF}_{6}$ gasoso. Este gás passa através de filtros, quando então é solidificado em dispositivos chamados - "cold traps", de forma a armazenar o $\mathrm{UF}_{6}$ na forma cristalizada. Após completar o enchimento dos "cold traps", o $\mathrm{UF}_{6}$ é liquefeito por aquecimento e drenado para cilindros de aço especialmente projetados para despacho, de 10 e 14 toneladas.

\section{III - Plantas de conversão COMURHES-Malvési e COMURHES- Pierrelatte da AREVA da França.}

A AREVA da França informa em seu sítio na Internet (2008) que a conversão do concentrado de urânio em $\mathrm{UF}_{6}$ é realizada em dois estágios de processos de transformação química, em duas plantas em separado. Na planta COMURHES-Malvési localizada em Malvési (Aude) transforma o concentrado de urânio em UF $_{4}$ onde se obtém um concentrado de urânio de alto grau de purificação, antes de se realizar o primeiro estágio de fluoração, obtendo-se o $\mathrm{UF}_{4}$. A planta COMURHES-Pierrelatte localizada em Pierrelatte (Drôme) transforma o $\mathrm{UF}_{4} \mathrm{em} \mathrm{UF}_{6}$ por meio da realização do segundo estágio de fluoração.

A seqüência dos processos utilizados na COMURHES-Malvési compreende (AREVA, 2008):

- Recepção e controle do concentrado de urânio.

- Dissolução - O concentrado de urânio é dissolvido em ácido nítrico para obtenção do nitrato de uranilo.

- Purificação - A solução de nitrato de uranilo é removida de suas impurezas por agitação em uma coluna de purificação, de 28 metros. O grau de pureza do urânio obtido atende as exigências definidas para utilização em centrais nucleares.

- Precipitação e Calcinação - A solução de nitrato de uranilo purificado é em seguida concentrada. O diuranato de amônio (DUA) é obtido pela injeção de amônia gasosa. O DUA é calcinado em fornos a temperatura muito alta para obtenção do $\mathrm{UO}_{3}$.

- Redução e Hidrofluoração - $\mathrm{O}_{\mathrm{UO}_{3}}$ é primeiro reduzido a $\mathrm{UO}_{2}$ pela passagem dentro de fornos, em seguida transformado em $\mathrm{UF}_{4}$ ao contato com o ácido fluorídrico.

- Transporte - $\mathrm{O} \mathrm{UF}_{4}$ é acondicionado em tambores especiais e encaminhado em caminhão para a usina COMURHEX Pierrelatte.

A COMURHES-Pierrelatte converte o $\mathrm{UF}_{4}$ em $\mathrm{UF}_{6}$ por meio da realização do segundo estágio de fluoração (AREVA, 2008). 
ANEXO B - Itemização da ISO 9001:2000.

\begin{tabular}{|c|c|}
\hline Seções & ISO 9001 \\
\hline 1 & Objetivo \\
\hline 1.1 & Generalidades \\
\hline 1.2 & Aplicação \\
\hline 2 & Referência normativa \\
\hline 3 & Termos e definições \\
\hline 4 & Sistema de gestão da qualidade \\
\hline 4.1 & Requisitos gerais \\
\hline 4.2 & Requisitos de documentação \\
\hline 4.2 .1 & Generalidades \\
\hline 4.2 .2 & Manual da qualidade \\
\hline 4.2 .3 & Controle de documentos \\
\hline 4.2 .4 & Controle de registros \\
\hline 5 & Responsabilidade da direção \\
\hline 5.1 & Comprometimento da direção \\
\hline 5.2 & Foco no cliente \\
\hline 5.3 & Política da qualidade \\
\hline 5.4 & Planejamento \\
\hline 5.4 .1 & Objetivos da qualidade \\
\hline 5.4 .2 & Planejamento do sistema de gestão da qualidade \\
\hline 5.5 & Responsabilidade, autoridade e comunicação \\
\hline 5.5 .1 & Responsabilidade e autoridade \\
\hline 5.5 .2 & Representante da direção \\
\hline 5.5 .3 & Comunicação Interna \\
\hline 5.6 & Análise crítica pela direção \\
\hline 5.6 .1 & Generalidades \\
\hline 5.6 .2 & Entradas para análise crítica \\
\hline 5.6 .3 & Saídas para análise crítica \\
\hline 6 & Gestão de recursos \\
\hline 6.1 & Provisão de recursos \\
\hline 6.2 & Recursos humanos \\
\hline 6.2 .1 & Generalidades \\
\hline 6.2 & Competência, conscientização e treinamento \\
\hline 6.3 & Infra-estrutura \\
\hline 6.4 & Ambiente de trabalho \\
\hline 7 & Realização do produto \\
\hline 7.1 & Planejamento da realização do produto \\
\hline 7.2 & Processos relacionados a clientes \\
\hline 7.2 .1 & Determinação de requisitos relacionados ao produto \\
\hline 7.2 .2 & Análise crítica dos requisitos relacionados ao produto \\
\hline 7.2 .3 & Comunicação com o cliente \\
\hline 7.3 & Projeto e desenvolvimento \\
\hline 7.3 .1 & Planejamento do projeto e desenvolvimento \\
\hline 7.3 .2 & Entradas de projeto e desenvolvimento \\
\hline 7.3 .3 & Saídas de projeto e desenvolvimento \\
\hline 7.3 .4 & Análise crítica de projeto e desenvolvimento \\
\hline
\end{tabular}




\begin{tabular}{|l|l|}
\hline \multicolumn{1}{|c|}{ Seções } & \\
\hline 7.3 .5 & ISO 9001 \\
\hline 7.3 .6 & Validação de projeto e desenvolvimento \\
\hline 7.3 .7 & Controle de alterações de projeto e desenvolvimento \\
\hline 7.4 & Aquisição \\
\hline 7.4 .1 & Processo de aquisição \\
\hline 7.4 .2 & Informações de aquisição \\
\hline 7.4 .3 & Verificação do produto adquirido \\
\hline 7.5 & Produção e fornecimento de serviço \\
\hline 7.5 .1 & Controle de produção e fornecimento de serviço \\
\hline 7.5 .2 & Validação dos processos de produção e fornecimento de serviço \\
\hline 7.5 .3 & Identificação e rastreabilidade \\
\hline 7.5 .4 & Propriedade do cliente \\
\hline 7.5 .5 & Preservação do produto \\
\hline 7.6 & Controle de dispositivos de medição e monitoramento \\
\hline 8 & Medição, análise e melhoria \\
\hline 8.1 & Generalidades \\
\hline 8.2 & Medição e monitoramento \\
\hline 8.2 .1 & Satisfação de clientes \\
\hline 8.2 .2 & Auditoria interna \\
\hline 8.2 .3 & Medição e monitoramento de processos \\
\hline 8.2 .4 & Medição e monitoramento do produto \\
\hline 8.3 & Controle de produto não-conforme \\
\hline 8.4 & Análise de dados \\
\hline 8.5 & Melhorias \\
\hline 8.5 .1 & Melhoria contínua \\
\hline 8.5 .2 & Ação corretiva \\
\hline 8.5 .3 & Ação preventiva \\
\hline
\end{tabular}




\section{ANEXO C - Recomendações da ABNT ISO/TR 10013:2002 para Documentação do SGQ.}

A norma propõe em seu anexo A uma hierarquia típica para estruturação do sistema de gestão da qualidade, como aquela apresentada na FIG. abaixo, sendo o conteúdo dos documentos sumariados a seguir.

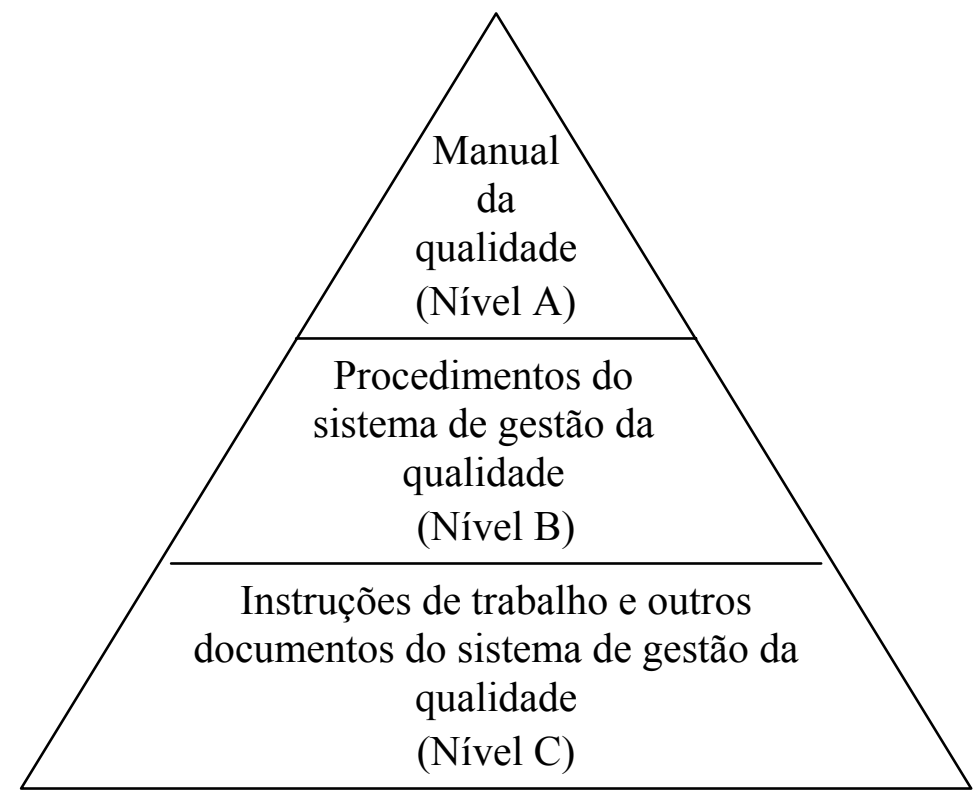

Segundo a norma o número de níveis pode ser ajustado para satisfazer as necessidades da organização, e os formulários (Item D abaixo) podem ser utilizados em todos os níveis da hierarquia.

\section{A - MANUAL DA QUALIDADE.}

\section{A.1 - Conteúdo.}

O manual da qualidade é único para cada organização. O relatório técnico (ABNT, 2002) permite flexibilidade na definição de sua estrutura, formato, conteúdo ou método de apresentação para a documentação do SGQ, de todos os tipos de organizações.

Uma pequena organização pode julgar apropriado incluir a descrição de todo seu SGQ em um único manual, incluindo todos os procedimentos documentados requeridos pela ISO 9001. Grandes organizações ou multinacionais normalmente precisam de vários manuais, nos níveis globais, regionais ou nacionais, e uma hierarquia de documentação mais complexa.

Convém que o manual da qualidade inclua o escopo do SGQ, detalhes e justificativas para quaisquer exclusões, procedimentos documentados ou referência a estes, e descrições dos processos do SGQ e suas interações.

Convém que informações sobre a organização, tais como nome, local e meios de comunicação, sejam incluídas no manual da qualidade. Outras informações, tais como a linha de negócios, uma breve descrição de sua experiência, sua história, e tamanho, também podem ser incluídas. 
Convém que a organização documente seu SGQ específico, seguindo a seqüência do fluxo de processos ou a estrutura da norma selecionada ou em qualquer seqüência apropriada à organização.

\section{A.2 - Itemização.}

1 - Título e escopo.

2 - Sumário.

3 - Análise crítica, aprovação e revisão.

4 - Política e objetivos da qualidade.

5 - Organização, responsabilidade e autoridade.

6 - Referências.

7 - Descrição do SGQ.

8 - Apêndices.

\section{B - PROCEDIMENTO DOCUMENTADO ${ }^{52}$.}

\section{B.1 - Estrutura, formato e conteúdo.}

Convêm que os procedimentos documentados sejam definidos pela organização das seguintes maneiras: texto, fluxogramas, tabelas, uma combinação destes, ou qualquer outro método adequado às necessidades da organização.

Convém que os procedimentos documentados contenham as informações necessárias e possuam uma identificação única. O nível de detalhamento pode variar dependendo da complexidade das atividades, dos métodos utilizados e dos níveis de habilidades e treinamento de pessoal necessário para que as atividades sejam realizadas.

\section{B.1 - Itemização.}

1 - Título.

2 - Propósito.

3 - Escopo.

4 - Responsabilidade e autoridade.

5 - Descrição de atividades.

6 - Registros.

7 - Apêndices (Tabelas, gráficos, fluxogramas, formulários, etc.).

8 - Análise crítica, aprovação e revisão.

9 - Identificação das alterações.

\section{C - INSTRUÇÕES DE TRABALHO ${ }^{53}$.}

\section{C.1 - Estrutura, formato e conteúdo.}

Convém que as instruções de trabalho sejam desenvolvidas e mantidas para descrever o desempenho do trabalho que pode ser afetado adversamente por sua falta.

Convém que sejam descritas as atividades críticas e que sejam evitados os detalhes que não forneçam maior controle da atividade.

\footnotetext{
${ }^{52}$ Os procedimentos documentados podem fazer referência às instruções de trabalho que definem como uma atividade é executada. Procedimentos documentados geralmente descrevem atividades comuns a diferentes funções, enquanto instruções de trabalho geralmente se referem às tarefas limitadas a uma função.

${ }^{53}$ Idem da nota anterior.
} 
Convém que o nível de detalhamento utilizado seja adaptado à necessidade do pessoal da organização e dependa da complexidade do trabalho, dos métodos utilizados, do treinamento realizado e das habilidades e qualificações do pessoal.

\section{C.2 - Tipos de instruções de trabalho.}

Existem várias maneiras de preparar e apresentar instruções de trabalho. Embora não haja uma estrutura ou formato requerido para elas, convém que estas: contenham um título e uma identificação única; incluam o propósito e o escopo do trabalho e os objetivos; façam referência aos procedimentos documentados pertinentes; sejam analisadas criticamente, aprovadas e revisadas; definam os registros necessários; e sejam identificadas suas alterações.

\section{D - FORMULÁRIOS.}

Formulários são desenvolvidos e mantidos para registrar dados que demonstrem a conformidade dos requisitos do SGQ.

\section{E - PLANOS DA QUALIDADE.}

Um plano da qualidade é uma parte da documentação do SGQ. Ele especifica quais procedimentos e recursos associados devem ser aplicados, por quem e quando, a um empreendimento, produto ou contrato específico (ABNT, 2005a, p.17). A ABNT ISO/TR 10013 complementa que ele é aplicado a uma situação específica, identificando e documentando como a organização atingirá os requisitos que são exclusivos para um particular produto, processo, projeto ou contrato.

Convém que o escopo do plano da qualidade seja definido. O plano da qualidade pode incluir procedimentos exclusivos, instruções de trabalho e/ou registros.

\section{E - ESPECIFICAÇÕES.} organização.

Especificações são documentos que estabelecem requisitos dos produtos da 


\section{ANEXO D - Sumário das Normas ISO 14001:2004 e de seu Anexo A ABNT (2004, p.1-20)}

\begin{tabular}{|c|c|c|}
\hline Seções & Anexo A & Tópicos \\
\hline & & Introdução \\
\hline 1 & & Objetivo e campo de aplicação \\
\hline 2 & & Referência normativa \\
\hline 3 & & Termos e definições \\
\hline 4 & & Requisitos do sistema de gestão ambiental \\
\hline 4.1 & A.1 & Requisitos gerais \\
\hline 4.2 & A.2 & Política ambiental \\
\hline 4.3 & A.3 & Planejamento \\
\hline 4.3 .1 & A.3.1 & Aspectos ambientais \\
\hline 4.3 .2 & A.3.2 & Requisitos legais e outros \\
\hline 4.3 .3 & A.3.3 & Objetivos, metas e programas \\
\hline 4.4 & A.4 & Implementação e operação \\
\hline 4.4 .1 & A.4.1 & Recursos, funções, responsabilidades e autoridades \\
\hline 4.4 .2 & A.4.2 & Competência, treinamento e conscientização \\
\hline 4.4 .3 & A.4.3 & Comunicação \\
\hline 4.4 .4 & A.4.4 & Documentação \\
\hline 4.4 .5 & A.4.5 & Controle de documentos \\
\hline 4.4 .6 & A.4.6 & Controle operacional \\
\hline 4.4 .7 & A.4.7 & Preparação e resposta a emergências \\
\hline 4.5 & A.5 & Verificação \\
\hline 4.5 .1 & A.5.1 & Monitoração e medição \\
\hline 4.5 .2 & A.5.2 & Avaliação do atendimento a requisitos legais e outros \\
\hline 4.5 .3 & A.5.3 & Não-conformidade, ação corretiva e ação preventiva \\
\hline 4.5 .4 & A.5.4 & Controle de registros \\
\hline 4.5 .5 & A.5.5 & Auditoria interna \\
\hline 4.6 & A.6 & Análise pela administração \\
\hline
\end{tabular}




\section{ANEXO E - Sumário das Seções da Norma OHSAS 18001:2007. \\ Risk (2007, p. 7-28)}

\begin{tabular}{|l|l|}
\hline \multicolumn{1}{|c|}{ Seção } & \\
\hline & OHSAS 18001 \\
\hline 1 & Introdução \\
\hline 2 & Objetivo e campo de aplicação \\
\hline 3 & Publicações de referência \\
\hline 4 & Termos e definições \\
\hline 4.1 & Requisitos do sistema de gestão da SST \\
\hline 4.2 & Requisitos gerais \\
\hline 4.3 & Política de SST \\
\hline 4.3 .1 & Planejamento \\
\hline 4.3 .2 & Rentificação de perigos, avaliação de riscos e determinação de controles \\
\hline 4.3 .3 & Objetivos e programas \\
\hline 4.4 & Implementação e operação \\
\hline 4.4 .1 & Recursos, funções, responsabilidades, prestações de contas e autoridades \\
\hline 4.4 .2 & Competência, treinamento e conscientização \\
\hline 4.4 .3 & Comunicação, participação e consulta \\
\hline 4.4 .3 .1 & Comunicação \\
\hline 4.4 .3 .2 & Participação e consulta \\
\hline 4.4 .4 & Documentação \\
\hline 4.4 .5 & Controle de documentos \\
\hline 4.4 .6 & Controle operacional \\
\hline 4.4 .7 & Preparação e resposta a emergências \\
\hline 4.5 & Verificação \\
\hline 4.5 .1 & Monitoração e medição do desempenho \\
\hline 4.5 .2 & Avaliação do atendimento a requisitos legais e outros \\
\hline 4.5 .3 & Investigação de incidentes, não-conformidade, ação corretiva e ação \\
\hline 4.5 .3 .1 & Investigação de incidentes \\
\hline 4.5 .3 .2 & Não-conformidade, ação corretiva e ação preventiva \\
\hline 4.5 .4 & Controle de registros \\
\hline 4.5 .5 & Auditoria interna \\
\hline 4.6 & Análise pela administração \\
\hline & \\
\hline & \\
\hline
\end{tabular}


ANEXO F - Correspondência entre os Requisitos da OHSAS 18001:2007, ISO

14001:2004 e ISO 9001:2000.

(Risk, 2007, P.29-31)

\begin{tabular}{|c|c|c|c|c|c|}
\hline \multicolumn{2}{|c|}{ OHSAS 18001:2007 } & \multicolumn{2}{|c|}{ ISO 14001:2004 } & \multicolumn{2}{|c|}{ ISO 9001:2000 } \\
\hline & \multirow{5}{*}{ Introdução } & & \multirow{5}{*}{ Introdução } & 0 & Introdução \\
\hline & & & & 0.1 & Generalidades \\
\hline & & & & 0.2 & $\begin{array}{l}\text { Abordagem de } \\
\text { processo }\end{array}$ \\
\hline & & & & 0.3 & $\begin{array}{l}\text { Relação com a ISO } \\
9004\end{array}$ \\
\hline & & & & 0.4 & $\begin{array}{l}\text { Compatibilidade } \\
\text { com outros sistemas } \\
\text { de gestão }\end{array}$ \\
\hline \multirow{3}{*}{1} & \multirow{3}{*}{$\begin{array}{l}\text { Objetivo e campo } \\
\text { de aplicação }\end{array}$} & \multirow{3}{*}{1} & \multirow{3}{*}{$\begin{array}{l}\text { Objetivo e campo } \\
\text { de aplicação }\end{array}$} & 1 & $\begin{array}{l}\text { Objetivo e campo de } \\
\text { aplicação }\end{array}$ \\
\hline & & & & 1.1 & Generalidades \\
\hline & & & & 1.2 & Aplicação \\
\hline 2 & $\begin{array}{l}\text { Publicação de } \\
\text { referencia }\end{array}$ & 2 & $\begin{array}{l}\text { Referências } \\
\text { normativas }\end{array}$ & 2 & $\begin{array}{l}\text { Referências } \\
\text { normativas }\end{array}$ \\
\hline 3 & $\begin{array}{l}\text { Termos e } \\
\text { definições }\end{array}$ & 3 & $\begin{array}{l}\text { Termos e } \\
\text { definições }\end{array}$ & 3 & Termos e definições \\
\hline 4 & $\begin{array}{l}\text { Requisitos do } \\
\text { sistema de gestão } \\
\text { da SST (somente } \\
\text { título) }\end{array}$ & 4 & $\begin{array}{l}\text { Requisitos do } \\
\text { sistema de gestão } \\
\text { ambiental } \\
\text { (somente título) }\end{array}$ & 4 & $\begin{array}{l}\text { Sistema de gestão da } \\
\text { qualidade (somente } \\
\text { título) }\end{array}$ \\
\hline \multirow{3}{*}{4.1} & \multirow{3}{*}{ Requisitos gerais } & \multirow{3}{*}{4.1} & \multirow{3}{*}{ Requisitos gerais } & 4.1 & Requisitos gerais \\
\hline & & & & 5.5 & $\begin{array}{l}\text { Responsabilidade, } \\
\text { autoridade e } \\
\text { comunicação }\end{array}$ \\
\hline & & & & 5.5 .1 & $\begin{array}{l}\text { Responsabilidade e } \\
\text { autoridade }\end{array}$ \\
\hline \multirow{3}{*}{4.2} & \multirow{3}{*}{ Política de SST } & \multirow{3}{*}{4.2} & \multirow{3}{*}{$\begin{array}{l}\text { Política } \\
\text { ambiental }\end{array}$} & 5.1 & $\begin{array}{l}\text { Comprometimento } \\
\text { da direção }\end{array}$ \\
\hline & & & & 5.3 & $\begin{array}{l}\text { Política da } \\
\text { Qualidade }\end{array}$ \\
\hline & & & & 8.5 .1 & Melhoria contínua \\
\hline 4.3 & $\begin{array}{l}\text { Planejamento } \\
\text { (somente título) }\end{array}$ & 4.3 & $\begin{array}{l}\text { Planejamento } \\
\text { (somente título) }\end{array}$ & 5.4 & $\begin{array}{l}\text { Planejamento } \\
\text { (somente título) }\end{array}$ \\
\hline \multirow{3}{*}{4.3 .1} & \multirow{3}{*}{$\begin{array}{l}\text { Identificação de } \\
\text { perigos, avaliação } \\
\text { de riscos e } \\
\text { determinação de } \\
\text { controles }\end{array}$} & \multirow{3}{*}{$\begin{array}{l}4.3 . \\
1\end{array}$} & \multirow{3}{*}{$\begin{array}{l}\text { Aspectos } \\
\text { ambientais }\end{array}$} & 5.2 & Foco no cliente \\
\hline & & & & 7.2 .1 & $\begin{array}{l}\text { Determinação de } \\
\text { requisitos } \\
\text { relacionados ao } \\
\text { produto }\end{array}$ \\
\hline & & & & 7.2 .2 & $\begin{array}{l}\text { Análise crítica de } \\
\text { requisitos } \\
\text { relacionados ao } \\
\text { produto }\end{array}$ \\
\hline
\end{tabular}




\begin{tabular}{|c|c|c|c|c|c|}
\hline \multicolumn{2}{|c|}{ OHSAS 18001:2007 } & \multicolumn{2}{|c|}{ ISO 14001:2004 } & \multicolumn{2}{|c|}{ ISO 9001:2000 } \\
\hline \multirow[b]{2}{*}{4.3 .2} & \multirow[b]{2}{*}{$\begin{array}{l}\text { Requisitos legais e } \\
\text { outros }\end{array}$} & \multirow[b]{2}{*}{$\begin{array}{l}4.3 . \\
2\end{array}$} & \multirow[b]{2}{*}{$\begin{array}{l}\text { Requisitos legais } \\
\text { e outros }\end{array}$} & 5.2 & Foco no cliente \\
\hline & & & & $7,2.1$ & $\begin{array}{l}\text { Determinação de } \\
\text { requisitos relaciona- } \\
\text { dos ao produto }\end{array}$ \\
\hline \multirow{3}{*}{4.3 .3} & \multirow{3}{*}{$\begin{array}{l}\text { Objetivos e } \\
\text { programas }\end{array}$} & \multirow{3}{*}{$\begin{array}{l}4.3 . \\
3\end{array}$} & \multirow{3}{*}{$\begin{array}{l}\text { Objetivos, metas } \\
\text { e programa(s) }\end{array}$} & 5.4 .1 & $\begin{array}{l}\text { Objetivos de } \\
\text { qualidade }\end{array}$ \\
\hline & & & & 5.4 .2 & $\begin{array}{l}\text { Planejamento do } \\
\text { sistema de gestão da } \\
\text { qualidade }\end{array}$ \\
\hline & & & & 8.5 .1 & Melhoria contínua \\
\hline 4.4 & $\begin{array}{l}\text { Implementação e } \\
\text { operação (somente } \\
\text { título) }\end{array}$ & 4.4 & $\begin{array}{l}\text { Implementação e } \\
\text { operação } \\
\text { (somente título) }\end{array}$ & 7 & $\begin{array}{l}\text { Realização do } \\
\text { produto (somente } \\
\text { título) }\end{array}$ \\
\hline \multirow{5}{*}{4.4 .1} & \multirow{5}{*}{$\begin{array}{l}\text { Recursos, funções, } \\
\text { responsabilidade, } \\
\text { prestações de } \\
\text { contas e } \\
\text { autoridades }\end{array}$} & \multirow{5}{*}{$\begin{array}{l}4.4 . \\
1\end{array}$} & \multirow{5}{*}{$\begin{array}{l}\text { Recursos, } \\
\text { funções, } \\
\text { responsabilidades } \\
\text { e autoridades }\end{array}$} & 5.1 & $\begin{array}{l}\text { Comprometimento } \\
\text { da direção }\end{array}$ \\
\hline & & & & 5.5 .1 & $\begin{array}{l}\text { Responsabilidade e } \\
\text { autoridade }\end{array}$ \\
\hline & & & & 5.5 .2 & $\begin{array}{l}\text { Representante de } \\
\text { direção }\end{array}$ \\
\hline & & & & 6.1 & Provisão de recursos \\
\hline & & & & 6.3 & Infra-estrutura \\
\hline \multirow[b]{2}{*}{4.4 .2} & \multirow{2}{*}{$\begin{array}{l}\text { Competência, } \\
\text { treinamento e } \\
\text { conscientização }\end{array}$} & \multirow[b]{2}{*}{$\begin{array}{l}4.4 . \\
2\end{array}$} & \multirow{2}{*}{$\begin{array}{l}\text { Competência, } \\
\text { treinamento e } \\
\text { conscientização }\end{array}$} & 6.2 .1 & $\begin{array}{l}\text { (Recursos humanos) } \\
\text { Generalidades }\end{array}$ \\
\hline & & & & 6.2 .2 & $\begin{array}{l}\text { Competência, } \\
\text { conscientização e } \\
\text { treinamento }\end{array}$ \\
\hline \multirow[b]{2}{*}{4.4 .3} & \multirow{2}{*}{$\begin{array}{l}\text { Comunicação, } \\
\text { participação e } \\
\text { consulta }\end{array}$} & \multirow{2}{*}{$\begin{array}{l}4.4 . \\
3\end{array}$} & \multirow[b]{2}{*}{ Comunicação } & 5.5 .3 & Comunicação interna \\
\hline & & & & 7.2 .3 & $\begin{array}{l}\text { Comunicação com o } \\
\text { cliente }\end{array}$ \\
\hline 4.4 .4 & Documentação & $\begin{array}{l}4.4 \\
4\end{array}$ & Documentação & 4.2 .1 & $\begin{array}{l}\text { (Requisitos de } \\
\text { documentação) } \\
\text { Generalidades } \\
\end{array}$ \\
\hline 4.4 .5 & $\begin{array}{l}\text { Controle de } \\
\text { documentos }\end{array}$ & $\begin{array}{l}4.4 . \\
5 \\
\end{array}$ & $\begin{array}{l}\text { Controle de } \\
\text { documentos }\end{array}$ & 4.2 .3 & $\begin{array}{l}\text { Controle de } \\
\text { documentos }\end{array}$ \\
\hline \multirow[t]{5}{*}{4.4 .6} & \multirow[t]{5}{*}{$\begin{array}{l}\text { Controle } \\
\text { operacional }\end{array}$} & \multirow[t]{5}{*}{$\begin{array}{l}4.4 . \\
6\end{array}$} & \multirow[t]{5}{*}{$\begin{array}{l}\text { Controle } \\
\text { operacional }\end{array}$} & 7.1 & $\begin{array}{l}\text { Planejamento da rea- } \\
\text { lização do produto }\end{array}$ \\
\hline & & & & 7.2 & $\begin{array}{l}\text { Processos relaciona- } \\
\text { dos a clientes }\end{array}$ \\
\hline & & & & 7.2 .1 & $\begin{array}{l}\text { Determinação de re- } \\
\text { quisitos relacionados } \\
\text { ao produto }\end{array}$ \\
\hline & & & & 7.2 .2 & $\begin{array}{l}\text { Análise crítica de } \\
\text { requisitos relacio- } \\
\text { nados ao produto }\end{array}$ \\
\hline & & & & 7.3 .1 & $\begin{array}{l}\text { Planejamento de } \\
\text { projeto e } \\
\text { desenvolvimento }\end{array}$ \\
\hline
\end{tabular}




\begin{tabular}{|c|c|c|c|c|c|}
\hline \multicolumn{2}{|c|}{ OHSAS 18001:2007 } & \multicolumn{2}{|c|}{ ISO 14001:2004 } & \multicolumn{2}{|r|}{ ISO 9001:2000 } \\
\hline & & & & 7.3.2 & $\begin{array}{l}\text { Entradas de projeto e } \\
\text { desenvolvimento }\end{array}$ \\
\hline & & & & 7.3 .3 & $\begin{array}{l}\text { Saídas de projeto e } \\
\text { desenvolvimento }\end{array}$ \\
\hline & & & & 7.3 .4 & $\begin{array}{l}\text { Análise crítica de } \\
\text { projeto e } \\
\text { desenvolvimento }\end{array}$ \\
\hline & & & & 7.3 .5 & $\begin{array}{l}\text { Verificação de } \\
\text { projeto e } \\
\text { desenvolvimento }\end{array}$ \\
\hline & & & & 7.3.6 & $\begin{array}{l}\text { Validação de projeto } \\
\text { e desenvolvimento }\end{array}$ \\
\hline & & & & 7.3.7 & $\begin{array}{l}\text { Controle de } \\
\text { alterações de } \\
\text { projetos e } \\
\text { desenvolvimento }\end{array}$ \\
\hline & & & & 7.4.1 & $\begin{array}{l}\text { Processo de } \\
\text { aquisição }\end{array}$ \\
\hline & & & & 7.4 .2 & $\begin{array}{l}\text { Informação de } \\
\text { aquisição }\end{array}$ \\
\hline & & & & 7.4 .3 & $\begin{array}{l}\text { Verificação de } \\
\text { produto adquirido }\end{array}$ \\
\hline & & & & 7.5 & $\begin{array}{l}\text { Produção e } \\
\text { fornecimento de } \\
\text { serviço (somente } \\
\text { título) }\end{array}$ \\
\hline & & & & 7.5.1 & $\begin{array}{l}\text { Controle de } \\
\text { produção e serviço } \\
\text { de produção e } \\
\text { fornecimento de } \\
\text { serviço }\end{array}$ \\
\hline & & & & 7.5.2 & $\begin{array}{l}\text { Validação dos } \\
\text { processos de } \\
\text { produção e } \\
\text { fornecimento de } \\
\text { serviço }\end{array}$ \\
\hline & & & & 7.5.5 & $\begin{array}{l}\text { Preservação de } \\
\text { produto }\end{array}$ \\
\hline 4.4 .7 & $\begin{array}{l}\text { Preparação e } \\
\text { resposta a } \\
\text { emergências }\end{array}$ & $\begin{array}{l}4.4 . \\
7\end{array}$ & $\begin{array}{l}\text { Preparação a res- } \\
\text { posta a } \\
\text { emergências }\end{array}$ & 8.3 & $\begin{array}{l}\text { Controle de produto } \\
\text { não-conforme }\end{array}$ \\
\hline 4.5 & $\begin{array}{l}\text { Verificação } \\
\text { (somente título) }\end{array}$ & 4.5 & $\begin{array}{l}\text { Verificação } \\
\text { (somente título) }\end{array}$ & 8 & $\begin{array}{l}\text { Medição, análise e } \\
\text { melhoria (somente } \\
\text { título) }\end{array}$ \\
\hline 4.5 .1 & $\begin{array}{l}\text { Monitoramento e } \\
\text { medição do } \\
\text { desempenho }\end{array}$ & $\begin{array}{l}4.5 . \\
1\end{array}$ & $\begin{array}{l}\text { Monitoramento e } \\
\text { medição }\end{array}$ & 7.6 & $\begin{array}{l}\text { Controle de dispo- } \\
\text { sitivos de medição e } \\
\text { monitoramento }\end{array}$ \\
\hline
\end{tabular}




\begin{tabular}{|c|c|c|c|c|c|}
\hline \multicolumn{2}{|c|}{ OHSAS 18001:2007 } & \multicolumn{2}{|c|}{ ISO 14001:2004 } & \multicolumn{2}{|r|}{ ISO 9001:2000 } \\
\hline & & & & 8.1 & $\begin{array}{l}\text { (Medição, análise e } \\
\text { melhoria) } \\
\text { Generalidades }\end{array}$ \\
\hline & & & & 8.2 .3 & $\begin{array}{l}\text { Medição e melhora- } \\
\text { mento de processos }\end{array}$ \\
\hline & & & & 8.2 .4 & $\begin{array}{l}\text { Medição e melhora- } \\
\text { mento de produto }\end{array}$ \\
\hline & & & & 8.4 & Análise de dados \\
\hline \multirow{2}{*}{4.5 .2} & \multirow{2}{*}{$\begin{array}{l}\text { Avaliação do } \\
\text { atendimento a } \\
\text { requisitos legais e } \\
\text { outros }\end{array}$} & \multirow{2}{*}{$\begin{array}{l}4.5 . \\
2\end{array}$} & \multirow{2}{*}{$\begin{array}{l}\text { Avaliação do } \\
\text { atendimento a } \\
\text { requisitos legais e } \\
\text { outros }\end{array}$} & 8.2 .3 & $\begin{array}{l}\text { Medição e melhora- } \\
\text { mento de processos }\end{array}$ \\
\hline & & & & 8.2 .4 & $\begin{array}{l}\text { Medição e monito- } \\
\text { ramento de produto }\end{array}$ \\
\hline 4.5 .3 & $\begin{array}{l}\text { Investigação de } \\
\text { incidente, não- } \\
\text { conformidade, ação } \\
\text { corretiva e ação } \\
\text { preventiva } \\
\text { (somente título) }\end{array}$ & & & & \\
\hline $\begin{array}{l}4.5 .3 \\
.1\end{array}$ & $\begin{array}{l}\text { Investigação de } \\
\text { incidente, não- } \\
\text { conformidade, ação } \\
\text { corretiva e ação } \\
\text { preventiva } \\
\text { (somente título) }\end{array}$ & & & & \\
\hline \multirow{4}{*}{$\begin{array}{l}4.5 .3 \\
.2\end{array}$} & \multirow{4}{*}{$\begin{array}{l}\text { Não-conformidade, } \\
\text { ação corretiva e } \\
\text { ação preventiva }\end{array}$} & \multirow{4}{*}{$\begin{array}{l}4.5 . \\
3\end{array}$} & \multirow{4}{*}{$\begin{array}{l}\text { Não- } \\
\text { conformidade, } \\
\text { ação corretiva e } \\
\text { ação preventiva }\end{array}$} & 8.3 & $\begin{array}{l}\text { Controle de produto } \\
\text { não-conforme }\end{array}$ \\
\hline & & & & 8.4 & Análise de dados \\
\hline & & & & 8.5 .2 & Ação corretiva \\
\hline & & & & 8.5 .3 & Ação preventiva \\
\hline 4.5 .4 & $\begin{array}{l}\text { Controle de } \\
\text { registros }\end{array}$ & $\begin{array}{l}4.2 . \\
4 \\
\end{array}$ & $\begin{array}{l}\text { Controle de } \\
\text { registros }\end{array}$ & 4.2 .4 & Controle de registros \\
\hline 4.5 .5 & Auditoria interna & $\begin{array}{l}4.5 \\
5\end{array}$ & Auditoria interna & 8.2 .2 & Auditoria interna \\
\hline \multirow{6}{*}{4.6} & \multirow{6}{*}{$\begin{array}{l}\text { Análise crítica pela } \\
\text { direção }\end{array}$} & \multirow{6}{*}{4.6} & \multirow{6}{*}{$\begin{array}{l}\text { Análise pela } \\
\text { administração }\end{array}$} & 5.1 & $\begin{array}{l}\text { Comprometimento } \\
\text { da direção }\end{array}$ \\
\hline & & & & 5.6 & $\begin{array}{l}\text { Análise crítica pela } \\
\text { direção (somente } \\
\text { título) }\end{array}$ \\
\hline & & & & 5.6 .1 & Generalidades \\
\hline & & & & 5.6 .2 & $\begin{array}{l}\text { entradas para a } \\
\text { análise crítica }\end{array}$ \\
\hline & & & & 5.6 .3 & $\begin{array}{l}\text { Saídas da análise } \\
\text { crítica }\end{array}$ \\
\hline & & & & 8.5 .1 & Melhoria contínua \\
\hline
\end{tabular}




\section{ANEXO G - Recomendações da IAEA para Estrutura de Informação de SG.}

A norma IAEA GS-G-3.1 orienta (IAEA, 2006c, p. 14-15) a adoção da uma estrutura de informação em três níveis. Esta estrutura segundo a norma promove a clareza das informações e evita repetições, pelo estabelecimento da quantidade de informação e do nível de detalhe para cada tipo de documento e pelo uso de referencias cruzadas entre os documentos específicos nos diferentes níveis.

\section{Nível 1.}

Neste nível a norma IAEA GS-G-3.1 recomenda (IAEA, 2006c, p. 14-15) a apresentação de uma visão geral de como a organização e seu SG estão delineados para atender suas políticas e objetivos. Uma visão geral das políticas e objetivos da organização e a descrição do SG que direcione os requisitos que são aplicáveis aos trabalhos da organização. Segundo a norma, neste nível podem ser providas as seguintes informações:

- Visão, missão e metas da organização;

- Declaração das políticas da organização;

- Estrutura da organização;

- Níveis de autoridade e responsabilidades e prestações de contas da alta direção e das unidades organizacionais;

- Estrutura da documentação do SG;

- Uma visão geral dos processos da organização;

- Responsabilidades dos donos dos processos;

- Resumo das medições e avaliações da eficácia do SG.

\section{Nível 2.}

Neste nível a norma IAEA GS-G-3.1 recomenda (IAEA, 2006c, p. 15-16) a descrição dos processos que são implementados para atender as políticas e objetivos e a especificação de qual unidade organizacional é responsável por realizá-los. As informações segundo a norma podem incluir:

- Definição dos mapas dos processos do SG, incluindo a interação entre eles;

- Definição das responsabilidades e linhas de comunicação internas e externas a cada área de atividade;

- Definição dos objetivos mensuráveis. Especificação das atividades que devem ser realizadas e controladas e de quem é o responsável e prestador de contas pelas atividades, e, onde apropriado, as referências das informações suportes;

- Identificação e planejamento das atividades para assegurar que o trabalho está sendo bem executado de maneira segura, sistemática e em tempo.

Ainda segundo a norma IAEA GS-G-3.1 (IAEA, 2006c, p. 16) não é usual neste nível prover detalhes de como executar as tarefas técnicas, as quais são detalhadas nos documentos de nível 3.

\section{Nível 3.}

Neste nível a norma IAEA GS-G-3.1 coloca (IAEA, 2006c, p. 15) que são fornecidas instruções e orientações detalhadas que possibilitam a realização dos processos e que especifica o indivíduo ou a unidade que executa o trabalho. 
A norma IAEA GS-G-3.1 (IAEA, 2006c, p. 17) apresenta dois tipos de documentos para este nível:

- Documentos que detalham o trabalho - Segundo a norma IAEA GS-G-3.1 (IAEA, 2006c, p. 17) consiste de uma grande extensão de documentos que descrevem detalhes específicos para a execução das tarefas por indivíduos ou pequenos grupos funcionais. Os tipos e formatos desses documentos variam consideravelmente, dependendo da aplicação envolvida. Dentro destes tipos o projeto de norma IAEA DS349 (IAEA, 2007a, p. 27) inclui as instruções de trabalho, instruções técnicas e desenhos, e acrescenta que eles descrevem as tarefas dos processos executadas dentro dos departamentos ou por indivíduos.

- Descrição do cargo - Segundo a norma IAEA GS-G-3.1 (IAEA, 2006c, p. 17) a descrição de cargo pode ser desenvolvida para as diferentes competências ou tipos de trabalho, para definir o escopo de cada cargo individual. Ela pode ser usada para estabelecer a linha de base para as necessidades de treinamento e competência. Segundo ainda a norma a descrição é excelente para a alta direção comunicar responsabilidades, autoridades e interfaces para todos os indivíduos.

Item 1 - Seções Típicas de Documentos de Nível 2 (IAEA, 2006a).

Propósito.

Escopo.

Responsabilidades - Indivíduo responsável pelo documento e pelas atividades descritas no documento.

Definições e abreviaturas.

Referencias.

Detalhes - A informação pode tomar a forma de fluxogramas ou mapas de processo, descrevendo as seqüências das ações. Os detalhes das seções podem descrever o que fazer, tipicamente fornecendo as seguintes informações:

- Considerações sobre planejamento e cronograma;

- Informações administrativas e técnicas;

- Etapas do trabalho e ações a serem realizadas;

- Responsabilidades e autoridades;

- Interfaces;

- Linhas de comunicação

- Referências cruzadas entre documentos, incluindo os do nível 3 de informação.

Registros.

Apêndices (Quando aplicável).

Item 2 - Seções Típicas de Documentos de Trabalho de Nível 3 (IAEA, 2007a).

Propósito.

Escopo.

Responsabilidades - Define as obrigações dos indivíduos que implementam o documento.

Definições.

Referências.

Pré-requisitos.

Precauções - Para proteção dos equipamentos, indivíduos e do publico ou para evitar situações anormais ou de emergência. 
Limitações - Limitações dos parâmetros a serem controlados.

Ações - Descrição da função e da tarefa dentro do processo, nos detalhes suficientes para não seja necessário supervisão.

Verificações ou verificações independentes.

Critérios de aceitação.

Registros e listas de verificação.

Item 3 - Seções Típicas da Descrição de Cargo de Documentos de Nível 3 (IAEA, 2006c, p. 18).

Título do cargo.

Propósito do cargo.

Nome da organização.

Estrutura da organização.

Posição na organização.

Linhas de comunicação.

Obrigações e autoridade.

Tarefas chaves e responsabilidades.

Prestação de contas.

Necessidade mínima de treinamento.

Necessidade de qualificações.

Necessidade de conhecimento, perfil e habilidade.

Necessidade de educação.

Necessidade de experiência.

Necessidade de condições médicas. 


\section{GLOSSÁRIO}

\section{Acidente (accident)}

(Risk, 2007) - Incidente que resultou em lesão, doença ou fatalidade.

(IAEA, 2007b) - Qualquer evento não intencional, incluindo erros operacionais, falhas nos equipamentos e outros desastres, cujas conseqüências ou potenciais conseqüências não são desprezíveis do ponto de vista da proteção e segurança.

\section{Alta direção (top management, senior management).}

(ABNT, 2005a) - Pessoa ou grupo de pessoas que dirige e controla uma organização no mais alto nível.

(IAEA, 2006a) - Pessoa ou grupo de pessoas que dirige, controla e avalia uma organização, em seu nível mais alto. Muitos termos diferentes são usados, incluindo, por exemplo: executivo principal, diretor geral, grupo executivo, diretor da instalação, diretor principal, regulador principal, vice-presidente local, diretor administrativo e diretor de laboratório.

\section{Análise crítica (review).}

(ABNT, 2005a) - Atividade realizada para determinar a pertinência, a adequação e a eficácia do que está sendo examinado, para alcançar os objetivos estabelecidos.

\section{Análise crítica do sistema de gestão (management system review).}

(IAEA, 2006a) - Avaliação regular e sistemática pela alta direção de uma organização quanto à conformidade, adequação, efetividade e eficiência de seu sistema de gestão, em executar as políticas e em atingir as metas e objetivos da organização.

(IAEA, 2007b) - Atividade documentada que se realiza para determinar, mediante investigação, exame e avaliação, realizados com evidência objetiva, se há adequação ou adesão a procedimentos, instruções, especificações, códigos, normas, programas administrativos ou operacionais, e outros documentos aplicáveis estabelecidos, assim como a eficácia de sua implantação.

\section{Auditoria (audit).}

(ABNT, 2005a) - Processo sistemático, documentado e independente, para obter evidência da auditoria e avaliá-la objetivamente para determinar a extensão na qual os critérios de auditoria são atendidos.

\section{Auto-avaliação (self-assessment).}

(IAEA, 2007b) - Processo rotineiro e contínuo, efetuado pela gerência em todos os níveis, com o objetivo de avaliar a eficácia na realização de todas as tarefas sob sua responsabilidade. As atividades de auto-avaliação incluem revisões, supervisão e verificações distintas, orientadas à prevenção, identificação e correção dos problemas de gestão que dificultam a consecução dos objetivos da organização, particularmente os objetivos da segurança.

\section{Avaliação (assessment).}

(IAEA, 2007b) - Atividades realizadas para determinar quais requisitos são atendidos e quais processos estão adequados e efetivos, assim como para encorajar os gestores a implementar melhorias, incluindo melhorias na segurança.

- O uso do termo avaliação originou-se na garantia da qualidade e campos relacionados a ela. 
- As atividades de avaliação podem incluir revisão, verificação, inspeção, teste, supervisão, auditoria, avaliação pelos pares e revisão técnica. Estas atividades podem ser divididas em duas grandes categorias: auto-avaliação e avaliação independente.

Avaliação do risco (risk assessment).

(Risk, 2007) - Processo de avaliação de risco(s) proveniente(s) de perigo(s), levando em consideração a adequação de qualquer controle existente, e decidindo se o risco é ou não aceitável.

\section{Avaliação independente (self-assessment).}

(IAEA, 2007b) - Atividades de avaliação conduzidas por uma unidade organizacional independente, com o objetivo de determinar a eficácia dos processos de gestão, a adequação da realização de um trabalho e a qualidade de itens e serviços. Atividades de avaliação independentes incluem auditorias internas e externas, supervisão, avaliação pelos pares e revisões técnicas, as quais se concentram nos aspectos da segurança e nas áreas onde problemas foram encontrados.

\section{Ciclo do combustível nuclear (nuclear fuel cycle).}

(IAEA, 2007b) - Todas as operações associadas com a produção de energia nuclear, incluindo:

- Mineração, tratamento, processamento e enriquecimento de urânio e tório;

- Fabricação do combustível nuclear;

- Operação de reatores nucleares (incluindo os reatores de pesquisa);

- Reprocessamento do combustível nuclear;

- Quaisquer atividades de pesquisa e desenvolvimento relacionadas com as anteriores; e

- Todas as atividades de gestão de resíduos (incluindo o descomissionamento).

Cliente (customer).

(ABNT, 2005a) - Organização ou pessoa que recebe um produto

\section{Combustível nuclear (nuclear fuel).}

(CNEN-NN-1.04) - Material físsil, ou contendo nuclídeos físseis, que, quando utilizado em um reator nuclear, possibilita uma reação em cadeia. Este termo também aparece nas normas da CNEN simplesmente como combustível.

\section{Combustível irradiado (spent fuel).}

(Parlamento Europeu, 2006) - Combustível nuclear que foi irradiado no núcleo de um reator e removido permanentemente do mesmo; o combustível irradiado para eliminação, relativamente ao qual não esteja prevista qualquer outra utilização, será tratado como rejeito radioativo.

(USNRC, 2008) - Combustível do reator nuclear que foi usado até a extensão que não possa mais sustentar eficazmente a reação em cadeia.

\section{Conformidade (conformity)}

(ABNT, 2005a) - Atendimento a um requisito.

Controle da qualidade (quality control).

(IAEA, 2007b) - Parte da garantia da qualidade destinada a verificar que sistemas e componentes atendem a requisitos predeterminados. 
(ABNT, 2005a) - Parte da gestão da qualidade focada no atendimento dos requisitos da qualidade.

Cultura de segurança (safety culture).

(IAEA, 2007b) - Conjunto de características e atitudes de organizações e pessoas, que estabelece que, como uma prioridade essencial, os temas de proteção e segurança recebam a atenção que sua importância requer.

\section{Embalagem (packaging).}

(IAEA, 2007b) - Conjunto de componentes necessários para envolver completamente os conteúdos radioativos. Em particular, pode estar formado por um ou mais recipientes, materiais absorventes, estruturas separadoras, blindagem contra radiação e equipamentos auxiliares para encher, esvaziar, ventilar e aliviar a pressão; dispositivos de refrigeração, de absorção de choques mecânicos, de manuseio e amarração, de isolação térmica; e equipamentos auxiliares integrados ao item embalado. A embalagem pode ser uma caixa, um tambor, ou receptáculo similar, ou pode também ser um contêiner de transporte, tanque, ou contêiner de tamanho intermediário.

\section{Empreendimento (project).}

(ABNT, 2005a) - Processo único que consiste em um conjunto de atividades coordenadas e controladas, com datas de início e conclusão; realizado para atingir um objetivo em conformidade com requisitos especificados, incluindo as limitações de tempo, custo e recursos.

Instalação nuclear (nuclear facility).

(IAEA, 2007b) - Instalação, incluindo-se seus terrenos, edifícios e equipamentos, na qual materiais radioativos são produzidos, elaborados, usados, manuseados, armazenados, ou eliminados, em condições que justifiquem a aplicação de considerações de segurança. (IAEA, 2006a) - Usinas nucleoelétricas, outros reatores (tais como reatores de pesquisa e montagens críticas), e instalações do ciclo do combustível.

\section{Estruturas, sistemas e componentes (structures, systems and components).}

(IAEA, 2007b) - Termo geral que compreende todos os itens de uma instalação ou atividade que contribuem para sua proteção e segurança, com a exceção dos fatores humanos. As estruturas são os elementos passivos: edifícios, vasos, blindagem, etc. Um sistema compreende vários componentes, montados de maneira que desempenhem sua função (ativa) específica.

\section{Fornecedor (supplier).}

(ABNT, 2005a) - Organização ou pessoa que fornece um produto.

\section{Garantia da qualidade (quality assurance).}

(IAEA, 2007b) - Ações planejadas e sistemáticas necessárias para prover confiança adequada de que um item, processo ou serviço atenderá requisitos da qualidade preestabelecidos, por exemplo, aqueles especificados na licença. (ABNT, 2005a) - Parte da gestão da qualidade focada em prover confiança de que os requisitos da qualidade serão atendidos.

Gestão (management).

(ABNT, 2005a) - Atividades coordenadas para dirigir e controlar uma organização. 


\section{Gestão da qualidade (quality management).}

(ABNT, 2005a) - Atividades coordenadas para dirigir e controlar uma organização, no que diz respeito à qualidade.

\section{Gradação (grading).}

(IAEA, 2006a) - Classificação por categorias dos requisitos relativos ao sistema de gestão, em função das seguintes considerações:

- A importância e complexidade de cada produto ou atividade;

- Os perigos e a magnitude dos possíveis impactos (riscos) associados aos elementos de segurança, saúde, meio ambiente, proteção física, qualidade e econômicos de cada produto ou atividade;

- As possíveis conseqüências da falha de um produto ou de uma atividade não executada corretamente.

\section{Incidente (incident).}

(Risk, 2007) - Evento relacionado ao trabalho no qual uma lesão ou doença (independentemente da gravidade) ou fatalidade ocorreu ou poderia ter ocorrido.

\section{Instalação (installation).}

CNEN-NN-1.16 - Termo genérico, que inclui os reatores nucleares, de potência, de teste ou de pesquisa, as instalações do ciclo do combustível e as instalações radioativas.

\section{Instalação nuclear (nuclear installation).}

(IAEA, 2007b) - Fábrica de combustível nuclear, reator nuclear (incluídos os conjuntos críticos e subcríticos), reator de pesquisa, usina nucleoelétrica, instalação de armazenamento de combustível irradiado, instalação de enriquecimento ou instalação de reprocessamento. Instalação nuclear é, essencialmente, uma instalação autorizada que forma parte do ciclo do combustível nuclear, com exclusão das instalações para a gestão de resíduos radioativos.

\section{Instalações e atividades (facilities and activities).}

(IAEA, 2007b) - Expressão geral que compreende instalações nucleares, usos de todas as fontes de radiação ionizante, todas as atividades de gestão de resíduos radioativos, transporte de material radioativo, e qualquer outra prática ou circunstâncias nas quais pessoas possam ficar expostas às radiações procedentes de fontes naturais ou artificiais. - O termo "instalações" inclui as instalações nucleares, as instalações de irradiação, de mineração e tratamento de minerais, de gestão de resíduos, e qualquer outro lugar onde materiais radioativos sejam produzidos, tratados, usados, manuseados, armazenados, ou eliminados - ou onde geradores de radiação estejam instalados - em tal escala que sejam requeridas considerações de proteção e segurança. Atividades incluem a produção, uso, importação e exportação de fontes de radiação para uso industrial, médico ou de pesquisa, o transporte de material radioativo, a mineração e o processamento de minas radioativas e o fechamento de instalações associadas, descontaminação de locais afetados pelos resíduos de atividades prévias e atividades de gestão de resíduos radioativos tais como a descarga de efluentes.

- Esta expressão pretende prover uma alternativa à terminologia de fontes e práticas (ou intervenção) para referir-se a categorias de situações gerais. Por exemplo, uma prática pode envolver muitas instalações e/ou atividades, enquanto que a definição geral de fonte é muito ampla em alguns casos: uma instalação ou atividade poderia ser uma fonte, ou 
poderia requerer o uso de muitas fontes, dependendo da interpretação usada.

- A expressão "instalações e atividades" é muito geral e inclui aquelas que não requerem, ou que requerem pouco controle pela autoridade reguladora: as expressões mais específicas "instalação autorizada" e "atividade autorizada" deveriam ser usadas para distinguir aquelas instalações e atividades para as quais foi dada alguma forma de autorização.

\section{Item importante para a segurança (item important to safety).}

(IAEA, 2007b) - Item que faz parte de um grupo de segurança e/ou cujo mau funcionamento ou falha poderia causar a exposição à radiação do pessoal local ou de membros do público. Como itens importantes à segurança, se incluem:

- Aquelas estruturas, sistemas e componentes, cujo mau funcionamento ou falha poderia causar uma exposição indevida à radiação do pessoal ou de membros do público;

- Aquelas estruturas, sistemas e componentes que previnem que ocorrências operacionais antecipadas levem a condições de acidente;

- Aquelas características que se destinam a mitigar as conseqüências de mau funcionamento ou falha de estruturas, sistemas ou componentes.

Item relacionado com a segurança (safety related item).

(IAEA, 2007b) - Item importante para a segurança que não faz parte de um sistema de segurança.

\section{Licenciamento (licensing process).}

(IAEA, 2007b) - Processo no qual um organismo regulador emite um documento legal, denominado licença, concedendo autorização para realizar determinadas atividades relativas a uma instalação ou atividade.

- O possuidor de uma licença em vigor se chama licenciado. Outros termos derivados não são necessários; uma licença é o resultado de um processo de autorização (às vezes chamado de, pré processo de licenciamento), e uma prática com uma licença em vigor é uma prática autorizada.

- A autorização possui outros sinônimos, como registro e permissão.

\section{Limites e condições operacionais (operational limit and condition)}

(IAEA, 2006d) - Conjunto de regras estabelecendo parâmetros limites, a capabilidade funcional e os níveis de desempenho de equipamentos e pessoal aprovados pela agência reguladora para a operação segura de uma instalação.

Manual da qualidade (quality manual).

(ABNT, 2005a) - Documento que especifica o sistema de gestão da qualidade de uma organização.

\section{Material nuclear (nuclear material).}

(IAEA, 2007b) - Plutônio, exceto se contiver plutônio-238 em concentração isotópica superior a 80\%; urânio-233; urânio enriquecido nos isótopos 235 ou 233; urânio contendo uma mistura de isótopos, assim como ocorre na natureza, que não esteja na forma de mineral ou resíduo de mineral; qualquer material que contenha um ou mais daqueles citados anteriormente.

Melhoria contínua (continual improvement).

(ABNT, 2005a) Atividade recorrente para aumentar a capacidade de atender requisitos. 
Melhoria da qualidade (quality improvement).

(ABNT, 2005a) - Parte da gestão da qualidade focada no aumento da capacidade de atender os requisitos da qualidade.

Não-Conformidade (nonconformity).

(ABNT, 2005a) - Não atendimento a um requisito.

Norma (standard).

(ISO, 2004b): Um documento, estabelecido por consenso e aprovado por um corpo reconhecido, que estabelece para comum e repetido uso, regras, diretrizes, ou características para atividades ou seus resultados.

Objetivo da qualidade (quality objective).

(ABNT, 2005a) - Aquilo que é buscado ou almejado, no que diz respeito à qualidade.

\section{Operação (operation).}

(IAEA, 2007b) - Todas as atividades realizadas para atingir a finalidade para a qual a instalação foi construída. Para uma usina nucleoelétrica incluem-se: a manutenção, a recarga, a inspeção em serviço e outras atividades associadas.

\section{Operador (operator).}

(IAEA, 2006a) - Qualquer organização ou pessoa requerendo autorização ou autorizada e/ou responsável pelas seguranças nuclear, de radiação, de resíduo radioativo ou de transporte, no empreendimento de atividades ou em relação a quaisquer instalações ou fontes de radiação ionizante. Isto inclui, entre outras coisas, indivíduos particulares, órgãos governamentais, consignadores ou transportadores, licenciados, hospitais, profissionais autônomos, etc.

\section{Organismo regulador (regulatory body).}

(IAEA, 2007b) - Uma autoridade ou sistema de autoridades designado pelo governo de um país, como tendo autoridade legal para conduzir o processo regulador, incluindo a concessão de autorizações e conseqüentemente o controle de material nuclear, das radiações em geral, dos resíduos radioativos e da segurança no transporte. A autoridade competente nacional para o controle da segurança no transporte de material radioativo está incluída nesta descrição, como ocorre com a autoridade reguladora, quando se trata de segurança e proteção radiológica

\section{Parte interessada (interested party or stakeholders).}

(IAEA, 2006a) - Parte interessada, pessoa ou empresa, com interesse ou preocupação em assegurar o sucesso de uma organização, negócio, sistema, etc.

- Ter interesse em algo significa "figurativamente" ter algo a ganhar ou perder, ou ter um interesse na mudança de eventos.

- A expressão "interessado direto" é usada em sentido amplo para significar uma pessoa ou grupo com interesse no desempenho de uma organização.

- Aqueles que podem influenciar eventos podem tornar-se partes interessadas - mesmo se seu interesse seja notado como genuíno ou não - no sentido de que suas visões devam ser consideradas.

- As partes interessadas tipicamente incluem o seguinte: clientes, proprietários, operadores, empregadores, fornecedores, sócios, sindicatos, indústria ou profissionais regularizados; órgãos científicos; agências governamentais ou órgãos governamentais 
reguladores (locais, regionais e nacionais), cujas responsabilidades possam abranger a energia nuclear; a mídia; o público (indivíduos, grupos comunitários e grupos de interesse); e outros estados, especialmente estados vizinhos que entraram em acordos propondo uma troca de informação sobre possíveis impactos que ultrapassem as fronteiras, ou estados envolvidos na exportação ou importação de certas tecnologias ou materiais.

\section{Perigo (hazard).}

(Risk, 2007) - Fonte, situação ou ato com potencial para provocar danos humanos em termos de lesão ou doença, ou uma combinação destas.

\section{Política da qualidade (quality policy).}

(ABNT, 2005a) - Intenções e diretrizes globais de uma organização, relativas à qualidade, formalmente expressas pela Alta Direção.

\section{Preparação para emergências (emergency preparedness).}

(IAEA, 2007b) - Capacidade de tomar ações imediatas que efetivamente mitigarão as conseqüências de uma emergência sobre a saúde e a segurança das pessoas, seus bens e o meio ambiente.

\section{Processo (process).}

(IAEA, 2007b) - 1. Uma seqüência de ações ou procedimentos, especialmente um série de progressivos estágios na manufatura de um produto ou alguma outra operação

2. Um conjunto de atividades inter-relacionadas e interativas que transformam entradas em saídas.

(ABNT, 2005) - Conjunto de atividades inter-relacionadas ou interativas que transforma insumos (entradas) em produtos (saídas).

\section{Produto (product).}

(IAEA, 2006a) - Um produto é o resultado ou a saída de um processo. Exemplos incluem um radionuclídeos, um pacote de rejeito e eletricidade.

(IAEA, 2002a) - Material nuclear processado pronto para ser despachado de uma instalação, isto é, o UF6 de uma planta de enriquecimento ou um elemento combustível de uma fábrica de combustível.

(ABNT, 2005a) - Resultado de um processo

Programa de garantia da qualidade (quality assurance program).

(CNEN, 1999) - Documento, para fins de licenciamento, que descreve ou apresenta os compromissos para o estabelecimento do Sistema de Garantia da Qualidade de uma organização. Expressão também conhecida pela sigla PGQ.

\section{Projeto (design).}

(IAEA, 2007b) - Processo e resultado do desenvolvimento de um conceito, planos de detalhes, cálculos de apoio e especificações para uma instalação e suas partes.

\section{Projeto e desenvolvimento (design and development).}

(ABNT, 2005a) - Conjunto de processos que transformam requisitos em características especificadas ou na especificação de um produto, processo ou sistema. 


\section{Proteção física (physical protection).}

(IAEA, 2007b) - Medidas para proteger o material nuclear ou as instalações autorizadas, elaboradas para prevenir acesso não autorizado, ou a remoção de material físsil, ou sabotagem, com referência às salvaguardas, como por exemplo, na Convenção sobre a Proteção Física dos Materiais Nucleares.

\section{Proteção radiológica (radiation protection).}

(IAEA, 2007b) - Proteção das pessoas contra os efeitos da exposição à radiação ionizante, e os meios para consegui-la.

\section{Qualidade (quality).}

(ABNT, 2005a) - Grau no qual um conjunto de características inerentes satisfaz a requisitos.

\section{Radiação ionizante (ionizing radiation).}

(IAEA, 2007b) - Para fins de proteção radiológica, é a radiação capaz de produzir pares de íons em materiais biológicos.

- Nas publicações da IAEA, o termo radiação normalmente refere-se à radiação ionizante. A IAEA não tem responsabilidade estatutária em relação a radiações não ionizantes.

\section{Radioatividade (radioactivity).}

(IAEA, 2007b) - Fenômeno pelo qual os átomos passam por uma desintegração espontânea randômica, normalmente acompanhada pela emissão de radiação.

- Nas publicações da IAEA, o termo radioatividade deve ser usado somente para referirse a este fenômeno. Para referir-se a uma quantidade de substância radioativa, usa-se o termo atividade.

\section{Rastreabilidade (traceability)}

(ABNT, 2005a) - Capacidade de recuperar o histórico, a aplicação ou a localização daquilo que está sendo considerado.

\section{Recursos (resources).}

(IAEA, 2006a) - Este termo inclui indivíduos, infra-estrutura, ambiente de trabalho, informação e conhecimento, e fornecedores, bem como recursos materiais e financeiros.

\section{Rejeito de alto nível de atividade (high level waste).}

(IAEA, 2007b) - O líquido radioativo contido em muitos produtos de fissão e "actinides" presentes nos combustíveis irradiados - os quais formam o resíduo do primeiro ciclo de extração do solvente no reprocessamento - e alguns rejeitos fluidos associados; esse material seguido de solidificação; o combustível irradiado (se ele for declarado rejeito) ou algum outro rejeito com similar característica radiológica.

- As características típicas do rejeito de alto nível de atividade são o potencial térmico de aproximadamente $2 \mathrm{~kW} / \mathrm{m} 3$ e a concentração de radionuclídeos de longa vida excedendo os limites para rejeitos de vida curta.

\section{Registro (record).}

(ABNT, 2005a) - Documento que apresenta resultados obtidos ou fornece evidências de atividades realizadas. 


\section{Relatório de análise de segurança (safety analysis report)}

(IAEA, 2006d) - Documento provido por um candidato para a agência reguladora contendo informações a respeito de uma instalação do ciclo do combustível, seu projeto, análises de segurança, e provisões para minimizar o risco para o público, o pessoal de operação e o ambiente.

\section{Resposta à emergência (emergency response).}

(IAEA, 2007b) - Realização de ações para mitigar as conseqüências de uma emergência sobre a saúde e a segurança de pessoas, a qualidade de vida, os bens e o meio ambiente.

\section{Risco (risk)}

(Risk, 2007) - Combinação da probabilidade de ocorrência de um evento perigoso ou exposição(ões) com a gravidade da lesão ou doença que pode ser causada pelo evento ou exposição(ões).

\section{"Safety case"}

(IAEA, 2006d) - Um conjunto de argumentos e evidências para demonstrar a segurança de uma instalação ou atividade. Isso normalmente inclui uma análise de segurança e provisões para minimizar o risco ao público, ao pessoal de operação e ao meio ambiente.

(IAEA, 2006d, p. 7-8) 54 $^{54}$ O conteúdo do "safety case" para uma instalação pode variar entre os Estados Membros, mas no mínimo deve incluir o relatório de análise de segurança (RAS) e os limites e condições operacionais (LCO) ou equivalentes. Quando apropriado deve incluir considerações da implementação do princípio de otimização de proteção ALARA (Tão baixo quanto razoavelmente exeqüível) durante a operação da instalação. As funções de segurança e as estruturas, sistemas e componentes importantes à segurança (ESC) devem também ser identificados, assim como definidos os intervalos de testes e inspeções periódicos requeridos para as ESC.

\section{Segurança e saúde no trabalho (occupational health and safety)}

(Risk, 2007) - Condições e fatores que afetam, ou poderiam afetar, a segurança e a saúde de funcionários ou de outros trabalhadores (incluindo trabalhadores temporários e pessoal terceirizado), visitantes ou qualquer outra pessoa no local de trabalho.

\section{Segurança física (ou proteção física) (security)}

(IAEA, 2007b) - Medidas para prevenir a perda, furto, ou transferência não autorizada de fontes de radiação ou de material radioativo. Esta expressão é geralmente usada no contexto de risco radiológico que poderia resultar da perda ou furto de fontes ou material radioativo; mas também está relacionada com as implicações das salvaguardas nos casos de perda, furto ou transferência não autorizada de material físsil, para os quais a expressão proteção física é também usada.

\section{Segurança nuclear (nuclear safety or safety).}

(IAEA, 2007b) - Obtenção das condições adequadas de operação, prevenção de acidentes ou a mitigação das conseqüências dos acidentes, resultando na proteção dos trabalhadores, do público e do meio ambiente, contra os riscos indevidos da radiação ionizante.

- Esta expressão aparece freqüentemente abreviada como "segurança" nas publicações da IAEA, assim deve ser esclarecido particularmente quando outros tipos de segurança estão sendo discutidos (por exemplo, segurança contra incêndios, segurança industrial

\footnotetext{
${ }^{54}$ Descrição livre do autor com base em texto do projeto de norma DS316 (IAEA, 2006d, p. 7-8).
} 
convencional).

- Ver proteção e segurança para uma discussão da relação entre segurança nuclear e proteção radiológica.

Sistema (system).

(ABNT, 2005a) - Conjunto de elementos inter-relacionados ou interativos.

\section{Sistema de Gestão (management system).}

(IAEA, 2006a) - Conjunto de elementos inter-relacionados ou interativos (sistema) para estabelecer políticas e objetivos, permitindo que estes objetivos sejam atingidos de modo eficiente e efetivo. O sistema de gestão integra todos os elementos de uma organização em um sistema coerente, para permitir que todos os objetivos da organização sejam atingidos. Estes elementos incluem a estrutura, os recursos e os processos. O pessoal, os equipamentos e a cultura organizacional, bem como as políticas documentadas e os processos fazem parte do sistema de gestão. Os processos da organização devem tratar da totalidade dos requisitos submetidos à organização, como aqueles estabelecidos, por exemplo, nas normas de segurança da IAEA e em outros códigos e normas internacionais. (ABNT, 2005a) - Sistema para estabelecer política e objetivos, e para atingir estes objetivos.

Sistema de gestão da qualidade (quality management system).

(ABNT, 2005a) - Sistema de gestão para dirigir e controlar uma organização, no que diz respeito à qualidade.

Sítio (site).

(IAEA, 2006e) - A área que contém a instalação do ciclo do combustível definida pelos limites sob controle efetivo do gerente da instalação.

\section{Validação (validation)}

(IAEA, 2007b) - Processo para determinar se um produto ou serviço é adequado para realizar sua função satisfatoriamente.

- A validação tem um alcance maior e pode envolver maiores elementos de juízo do que a verificação.

(ABNT, 2005a) - Comprovação, através do fornecimento de evidência objetiva, de que os requisitos para uma aplicação ou uso específicos pretendidos foram atendidos.

\section{Verificação (verification)}

(IAEA, 2007b) - Processo que determina se a qualidade e/ou o funcionamento de um produto ou serviço estão conforme especificados, pretendidos ou requeridos.

- A verificação está proximamente relacionada com a garantia da qualidade e o controle da qualidade.

(ABNT, 2005a) - Comprovação, através de fornecimento de evidência objetiva, de que requisitos especificados foram atendidos. 


\section{REFERÊNCIA BIBLIOGRÁFICA}

(ABNT, 1994) ASSOCIAÇÃO BRASILEIRA DE NORMAS TÉCNICAS. Normas de gestão da qualidade e garantia da qualidade. Parte 1: Diretrizes para seleção de uso. Rio de Janeiro: ABNT, 1994. (NBR ISO 9000-1).

(ABNT, 2000a) ASSOCIAÇÃO BRASILEIRA DE NORMAS TÉCNICAS. Sistemas de gestão da qualidade - Requisitos. Rio de Janeiro: ABNT, 2000a. (NBR ISO 9001).

(ABNT, 2000b) ASSOCIAÇÃO BRASILEIRA DE NORMAS TÉCNICAS. Sistemas de gestão da qualidade - Diretrizes para melhoria de desempenho. Rio de Janeiro: ABNT, 2000b. (NBR ISO 9004).

(ABNT, 2000c) ASSOCIAÇÃO BRASILEIRA DE NORMAS TÉCNICAS. Sistemas de gestão da qualidade - Fundamentos e vocabulário. Rio de Janeiro: ABNT, 2000c. (NBR ISO 9000).

(ABNT, 2002) ASSOCIAÇÃO BRASILEIRA DE NORMAS TÉCNICAS. Diretrizes para a documentação de sistema de gestão da qualidade. Rio de Janeiro: ABNT, 2002. (ABNT ISO/TR 10013).

(ABNT, 2004) ASSOCIAÇÃO BRASILEIRA DE NORMAS TÉCNICAS. Sistemas de gestão ambiental - Requisitos com orientação para uso. Rio de Janeiro: ABNT, 2004. (NBR ISO 14001).

(ABNT, 2005a) ASSOCIAÇÃO BRASILEIRA DE NORMAS TÉCNICAS. Sistemas de gestão da qualidade - Fundamentos e vocabulário. Rio de Janeiro: ABNT, 2005a. (NBR ISO 9000).

(ABNT, 2005b) ASSOCIAÇÃO BRASILEIRA DE NORMAS TÉCNICAS. Sistemas de gestão ambiental - Diretrizes gerais sobre princípios, sistemas e técnicas de apoio. Rio de Janeiro: ABNT, 2005b. (NBR ISO 14004).

(ABNT, 2005c) ASSOCIAÇÃO BRASILEIRA DE NORMAS TÉCNICAS.

Responsabilidade social - Sistema de gestão - Requisitos. Rio de Janeiro: ABNT, 2005c. (NBR 16001:2005).

AQUINO, A. R.. Apostila do curso de fundamentos de tecnologia nuclear. São Paulo, SP: Instituto de Pesquisas Energéticas e Nucleares, mai. 2004.

(AREVA, 2008) AREVA. Nuclear Chemistry - Apresenta texto institucional sobre suas instalações e processos. Disponível em: < http://www.areva-nc.com/scripts/arevanc/publigen/content/templates/show.asp?P=7342\&L=EN>. Acesso em: 12 fev. 2008

ASIF, M.; SEARCY C.; BRUIJN E. J.; FISSCHER O. A.M. Process Embedded Design of Integrated Management Systems. In: POMS 19th Annual Conference, Mai 9-12, 2008, La Jolla, CA USA: Proceeding...

Abstract No. 008-0776. 
(ASQ, 2005) AMERICAN SOCIETY FOR QUALITY. The History of Quality. Apresenta texto sobre a evolução dos conceitos da qualidade. . Milwaukee, WI: ASQ. Disponível em: http://www.asq.org/portal/page?_pageid=33,32429,33_32562\&_dad=portal\&_schema=PO RTAL. Acesso em: 15 mai. 2005.

(ASQ, 2007) AMERICAN SOCIETY FOR QUALITY. Quality Glossary Quality Progress, Vol. 40, n. 6. Milwaukee, WI: ASQ, jun. 2007.

(ASTM, 1991) AMERICAN SOCIETY FOR TESTING AND MATERIALS. Standard guide for establishing quality assurance program for uranium conversion facilities. West Conshohocken, PA: ASTM, 1991 (C 1188).

(ASTM, 1996) AMERICAN SOCIETY FOR TESTING AND MATERIALS. Standard specification for uranium hexafluoride for enrichment. West Conshohocken, PA: ASTM, 1996 (C 787).

(AUA, 2007) AUSTRALIAN URANIUM ASSOCIATION - URANIUM INFORMATION CENTER. The nuclear fuel cycle. Melbourne, AU. Apresenta texto sobre o ciclo do combustível nuclear. Disponível em: http://www.uic.com.au/nfc.htm. Acesso em: 18 ago. 2007.

BÁES, V. E.; SANCHES, A. C.; LOURO, M.; MITTELDORF, M.. ISO série 9000: auto avaliação. Rio de Janeiro, RJ: Qualitymark Editora, 1993.

BENEDICT, M; PIGFORD, T. H.. Nuclear chemical engineering. New York, NY: McGraw-Hill Book Company, Inc., 1957.

BHUTTO, K.; GRIFFITH, A. The integrated management system for project quality, safety and environment: pilot study research findings of developments in IMS. The International Journal of Construction Management. p. 75-85. 2004.

BLOCK M. R.; MARASH I. R. Integrating ISO 14001 into a quality management system. Milwaukee, CA: ASQ Quality Press, 2002.

(BSI, 1999) BRITISH STANDARDS INSTITUTION. Occupational health and safety management systems - Specification. London: BSI, 1999. (OHSAS 18001).

(BSI, 2000) BRITISH STANDARDS INSTITUTION. Guidelines for the implementation of OHSAS 18001. London: BSI, 2000. (OHSAS 18002).

(BSI, 2004) BRITISH STANDARDS INSTITUTION AMERICAS. ISO 14001:1996ISO 14001:2004 comparison guide. London: BSI, dez. 2004. Apresenta texto sobre as mudanças ocorridas na revisão da ISO 14001. Disponível em:

$<$ http://www.bsiamericas.com/IntegratedAssessment/Standards/index.xalter $>$. Acesso em: 05 set. 2007.

(BSI, 2006) BRITISH STANDARDS INSTITUTION. Publicly available specification. London: BSI, 2006. (PAS 99). 
(BSI, 2007a) BRITISH STANDARDS INSTITUTION AMERICAS. What is an integrated management system?. London, UK. Apresenta texto sobre o conceito de sistema integrado de gestão. Disponível em:

$<$ http://www.bsiamericas.com/IntegratedAssessment/Overview/index.xalter $>$. Acesso em: 10 jan. $2007 \mathrm{a}$.

(BSI, 2007b) BRITISH STANDARDS INSTITUTION. PAS 99 integrated management A framework for successful integration the guide. London, UK: BSI, mai. 2007b.

Apresenta um resumo da estrutura e orientações sobre a PAS 99. Disponível em:

$<$ http://www.bsiamerica.com/en-us/Forms/Documents/Integrated-Management-DocumentDownload/Post.aspx>. Acesso em: 29 mai. de 2008.

(BSI, 2007c) BRITISH STANDARDS INSTITUTION AMERICAS. OHSAS 18001:2007. London: 2007c. Apresenta texto sobre as mudanças ocorridas na revisão da OHSAS 18001. Disponível em:

$<$ http://www.bsiamericas.com/IntegratedAssessment/Standards/index.xalter $>$. Acesso em: 18 dez. $2007 \mathrm{c}$.

CAMECO. Apresenta texto institucional sobre as instalações e processos da empresa. Disponível em: <>. Acesso em: 14 fev. 08

CAPELAS, L.; CASTILHO, A.. Manual prático para a certificação e gestão da qualidade com base nas normas ISO 9000:2000. Lisboa : Verlag Dashöfer-Edições Profissionais, 2001. Apud PATRÍCIO, M. E. Organização - estratégia:Integração dos sistemas de gestão. Porto, PT:UPT - Universidade Portucalense Infante D. Henrique, Departamento de Gestão, 2004.

CARVALHO, A. B. M.. A ISO 9001:2000 sem segredos. Banas Qualidade. Encarte especial No 117. São Paulo, SP: Editora Banas: fev. 2002.

(CNEN, 1999) COMISSÃO NACIONAL DE ENERGIA NUCLEAR. Garantia da qualidade para usinas nucleoelétricas e outras instalações. Rio de Janeiro: CNEN, 1999. (NN-1.16).

(CNEN, s.d.) COMISSÃO NACIONAL DE ENERGIA NUCLEAR. Ciclo do combustível nuclear - Da mina à fabricação de elemento combustível. Rio de Janeiro, RJ: CNEN [s.d.]

CONVERDYN. Honeywell dry fluoride volatility conversion process. Apresenta texto institucional sobre as instalações e processos da empresa. Disponível em:

$<$ http://www.converdyn.com/product/conversion.html $>$. Acesso em 14 fev. 2008.

DAHLGREN, K.; KERHOAS, K.; IGNATOV, M.; VINCZE, P.. Improving organizational performance - IAEA safety standards on management system. Vienna: IAEA - Division of Nuclear Power Newsletter Vol. 4, No. 3, ISSN 1816-9295, set. 2007. Disponível em: $<$ http://www-pub.iaea.org/MTCD/publications/PDF/Newsletters/NENP04-3.pdf>. Acesso em: nov. 2007. 
DE CICCO, F. Da reparação de danos aos sistemas de gestão. São Paulo: QSP - Centro da Qualidade, Segurança e Produtividade, abr. 1997. Disponível

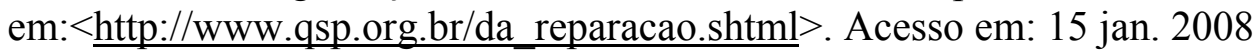

DE CICCO, F. Guia internacional para medição da satisfação do cliente - ISO 9000:2000 sistema de gestão da qualidade. Vol. 1. São Paulo: Coleção Risk Tecnologia, fev. 2003.

DE CICCO, F. Sistemas integrados de gestão. São Paulo: QSP - Centro da Qualidade, Segurança e Produtividade, Nov. 2006. Disponível em: $<$ http://www.qsp.org.br/finalmente.shtml $>$. Acesso em: 20 mar. 2008.

(FAO et. al., 2002) FOOD AND AGRICULTURE ORGANIZATION OF THE UNITED NATION, INTERNATIONAL ATOMIC ENERGY AGENCY, LABOUR ORGANIZATION, OECD NUCLEAR ENERGY AGENCY, PAN AMERICAN HEALTH ORGANIZATION, UNITED NATIONS OFFICE FOR THE COORDINATION OF HUMANITARIAN AFFAIRS, WORLD HEALTH ORGANIZATION. Preparedness and response for a nuclear or radiological emergency. Vienna: IAEA, 2002 (GS-R-2).

(FAS, 2008) FEDERATION OF AMERICAN SCIENTISTS. Nuclear weapons technology - Enrichment feedstock's production. Washington, DC: FAS. Apresenta texto sobre os processos de conversão e enriquecimento do $\mathrm{UF}_{6}$. Disponível em:

http://www.fas.org/irp/threat/mct198-2/p2sec05.pdf. Acesso em: 12 fev. 2008.

GIL, A.C. "Métodos e técnicas de pesquisa social". e. ed. - São Paulo: Atlas, 1999. ISBN 85-224-2270-2.

GRIFFITH, A. Integrated management systems: a single management system solution for project control?. Engineering, Construction and Architectural Management Journal, Vol. 7 Issue 3, p. 232-240, MCB UP Ltd, set. 2000.

GRIFFITH, ALAN. Integrated management systems for enhancing project quality, safety and environment. The International Journal of Construction Management, p. 25-37, 2002.

HARRINGTON, C. D.; RUEHLE A. E. Uranium production technology. Princeton, NJ: D Van Nostrand Company, Inc., 1959.

(IAEA, 1996) INTERNATIONAL ATOMIC ENERGY AGENCY. Quality assurance for safety in nuclear power plants and other nuclear installations. Vienna: IAEA, 1996. (50C/SG-Q1 to Q14).

(IAEA, 2002a) INTERNATIONAL ATOMIC ENERGY AGENCY. IAEA Safeguards glossary 2001 edition - International Nuclear Verification Series No. 3. Vienna: IAEA, 2002a. Disponível em: < www-pub.iaea.org/MTCD/publications/PDF/nvs-3cd/PDF/NVS3_scr.pdf >. Acesso em: 22 nov. 2006 
(IAEA, 2002b) INTERNATIONAL ATOMIC ENERGY AGENCY. Quality standards: comparison between IAEA 50-C/SG-Q and ISO 9001-2000 - Safety Reports Series No. 22. Vienna: IAEA, 2002b. Disponível em: $<$ http://wwwpub.iaea.org/MTCD/publications/PubDetails.asp?pubId=6458> Acesso em: 12 mai. 2007.

(IAEA, 2003a) INTERNATIONAL ATOMIC ENERGY AGENCY. Document preparation profile DPP338. Vienna: IAEA, abr. 2003a. Disponível em: < http://wwwns.iaea.org/standards/documents/default.asp?sub=130> Acesso em: 21 mar. 2006.

(IAEA, 2003b) INTERNATIONAL ATOMIC ENERGY AGENCY. Document preparation profile DPP339. Vienna: IAEA, abr. 2003b. Disponível em: < http://wwwns.iaea.org/standards/documents/default.asp?sub=130> Acesso em: 21 mar. 2006.

(IAEA, 2003c) INTERNATIONAL ATOMIC ENERGY AGENCY. Document preparation profile DPP349. Vienna: IAEA, abr. 2003c. Disponível em: < http://wwwns.iaea.org/standards/documents/default.asp?sub=130> Acesso em: 21 mar. 2006.

(IAEA, 2005) INTERNATIONAL ATOMIC ENERGY AGENCY. The management systems - DS338. Vienna: IAEA, fev. 2005. Disponível em: $<\underline{\text { http://www- }}$ ns.iaea.org/standards/documents/default.asp?sub=130> Acesso em: 21 mar. 2006.

(IAEA, 2006a) INTERNATIONAL ATOMIC ENERGY AGENCY. The Management system for facilities and activities - Safety requirements. Vienna: IAEA, 2006a. (GS-R3). Disponível em: $<$ http://wwwpub.iaea.org/MTCD/publications/PDF/Pub1252_web.pdf>. Acesso em: 07 out. 2006.

(IAEA, 2006b) INTERNATIONAL ATOMIC ENERGY AGENCY. Scope of the programme. Vienna: IAEA, Department of Nuclear Safety \& Security, 2006b. Apresenta texto institucional sobre seu escopo de atuação. Disponível em:

$<$ http://www.iaea.org/OurWork/SS/index.html>. Acesso em: 12 jun. 2006.

(IAEA, 2006c) INTERNATIONAL ATOMIC ENERGY AGENCY. Application of the management system for facilities and activities - Safety guide. Vienna: IAEA, 2006c. (GS-G-3.1). Disponível em: <http://wwwpub.iaea.org/MTCD/publications/PDF/Pub1253_web.pdf>. Acesso em: 07 out. 2006.

(IAEA, 2006d) INTERNATIONAL ATOMIC ENERGY AGENCY. Safety of fuel cycle facilities - Safety requirements. DS316. Vienna: IAEA, 24 ago. 2006. Disponível em: < http://www-ns.iaea.org/standards/documents/default.asp?sub=130> Acesso em: 07 out. 2006.

(IAEA, 2006e) INTERNATIONAL ATOMIC ENERGY AGENCY. Safety of conversion and enrichment facilities. Vienna: IAEA, ago. 2006. (DS344). Disponível em: < http://www-ns.iaea.org/standards/documents/default.asp?sub=130> Acesso em: 07 out. 2006.

(IAEA, 2007a) INTERNATIONAL ATOMIC ENERGY AGENCY. Management systems for nuclear facilities. DS349. Vienna: IAEA, jan. 2007a. Disponível em: < http://wwwns.iaea.org/standards/documents/default.asp?sub=130> Acesso em: 02 mar 2007. 
(IAEA, 2007b) INTERNATIONAL ATOMIC ENERGY AGENCY. IAEA Safety glossary - Terminology used in nuclear safety and radiation protection. Vienna: IAEA, 2007 Edition, jun. 2007b. Disponível em: <http://www-

pub.iaea.org/MTCD/publications/PDF/Pub1290_web.pdf>. Acesso em: 22 out. 2007.

(IAEA, 2007c) INTERNATIONAL ATOMIC ENERGY AGENCY. Management systems for the safe transport of radioactive material. DS326. Vienna: IAEA, ago. 2007c. Disponível em: < http://www-ns.iaea.org/standards/documents/default.asp?sub=130> Acesso em: 18 set 2007.

(IAEA, 2008a) INTERNATIONAL ATOMIC ENERGY AGENCY. Nuclear fuel cycle. Vienna: IAEA, NFCSS - Nuclear Fuel Cycle Simulation System, jan. 2008a. Base de dados da Agência sobre o ciclo do combustível nuclear. Disponível em: $<$ http://wwwnfcis.iaea.org/NFCSS/NFCSSMain.asp?RightP=Modeling\&EPage=1>. Acesso em: 20 jan. 2008.

(IAEA, 2008b) INTERNATIONAL ATOMIC ENERGY AGENCY. Nuclear power plant information. Vienna: IAEA, PRIS-Power Reactor Information System, fev. 2008b. Base de dados da Agência sobre plantas de potência. Atualizado em. Disponível em:

$<$ http://www.iaea.org/programmes/a2/index.html>. Acesso em: 15 fev. 2008.

(IAEA, 2008c) INTERNATIONAL ATOMIC ENERGY AGENCY. Status of the IAEA Safety Standards. Vienna: IAEA, Department of Nuclear Safety \& Security, mar. 2008c. Apresenta texto sobre a situação de publicação das normas de segurança da Agência.

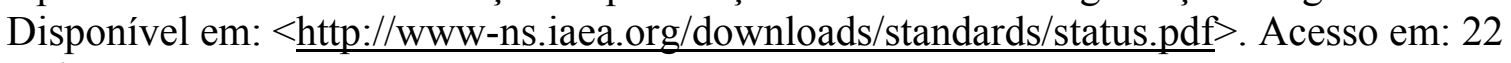
mai. 2008.

(IAEA, 2008d) INTERNATIONAL ATOMIC ENERGY AGENCY. The Management System for Technical Services in Radiation Safety. Vienna: IAEA, 2008d. (GS-G-3.2). Disponível em: <http://www-pub.iaea.org/MTCD/publications/PDF/Pub1319_web.pdf $>$. Acesso em: 01 jul. 2008.

(IAEA, 2008e) INTERNATIONAL ATOMIC ENERGY AGENCY The Management System for Processing, Handling and Storage of Radioactive Waste. Vienna: IAEA, 2008e. (GS-G-3.3). Disponível em: <http://www-

pub.iaea.org/MTCD/publications/PDF/Pub1329_web.pdf>. Acesso em: 01 jul. 2008.

(IAEA, 2008f) INTERNATIONAL ATOMIC ENERGY AGENCY. The Management System for the Disposal of Radioactive Waste. Vienna: IAEA, 2008f. (GS-G-3.4).

Disponível em: <http://www-pub.iaea.org/MTCD/publications/PDF/Pub1330_web.pdf $>$. Acesso em: 01 jul. 2008.

(ISO, 1994) INTERNATIONAL ORGANIZATION FOR STANDARDIZATION. Quality systems. Geneva: 1994 (ISO 9000).

(ISO, 1996) INTERNATIONAL ORGANIZATION FOR STANDARDIZATION. Environmental management systems - Specification with guidance for use. Geneva: 1996. (ISO 14001). 
(ISO, 2000a) INTERNATIONAL ORGANIZATION FOR STANDARDIZATION. Quality management systems - Requirements. Geneva: ISO, 2000a. (ISO 9001).

(ISO, 2000b) INTERNATIONAL ORGANIZATION FOR STANDARDIZATION. Quality management systems - Guidelines for performance improvements. Geneva: ISO, 2000b. (ISO 9004).

(ISO, 2001) INTERNATIONAL ORGANIZATION FOR STANDARDIZATION. ISO 9000 introduction and support package: Guidance on the documentation requirements of ISO 9001:2000. Document: ISO/TC 176/SC 2/N525R. Geneva: ISO, 2001. Disponível em:

$<$ http://www.iso.org/iso/search.htm?qt=ISO $\% 2 \mathrm{FTC}+176 \% 2 \mathrm{FSC}+2 \% 2 \mathrm{FN} 525 \mathrm{R} \&$ active_ta $\mathrm{b}=$ site\&published $=$ on $>$. Acesso em: 21 mar. 2006.

(ISO, 2004a) INTERNATIONAL ORGANIZATION FOR STANDARDIZATION. Environmental management systems - Requirements with guidance for use. Geneva: ISO, 2004a. (ISO 14001).

(ISO, 2004b) INTERNATIONAL ORGANIZATION FOR STANDARDIZATION. Standardization and related activities - General vocabulary. Geneva: ISO, 2004b. (ISO/IEC Guide 2).

(ISO, 2004c) INTERNATIONAL ORGANIZATION FOR STANDARDIZATION. Environmental management systems - General guidelines on principles, systems and support techniques. Geneva: ISO, 2004c. (ISO 14004).

(ISO, 2004d) INTERNATIONAL ORGANIZATION FOR STANDARDIZATION. ISO 9000 introduction and support package:

guidance on the concept and use of the process approach for management systems. Document: ISO/TC 176/SC 2/N544R2. Geneva: ISO, 2004d. Disponível em:

$<\mathrm{http}$ ://www.iso.org/iso/search.htm?qt=ISO $\% 2 \mathrm{FTC}+176 \% 2 \mathrm{FSC}+2 \% 2 \mathrm{FN} 544 \mathrm{R} 2 \&$ active_t $a b=$ site \&published $=$ on $>$. Acesso em: 21 mar. 2006

(ISO, 2005a) INTERNATIONAL ORGANIZATION FOR STANDARDIZATION.

Quality management systems - Fundamentals and vocabulary. Geneva: ISO, 2005a (ISO 9000).

(ISO, 2005b) INTERNATIONAL ORGANIZATION FOR STANDARDIZATION. ISO 9000:2005 the "A to Z" of quality management systems updated. Geneva: ISO, News and Media, 17 out. 2005b. Apresenta informações sobre as normas publicadas pela ISO.

Disponível em: $<$ http://www.iso.org/iso/pressrelease.htm?refid=Ref975>. Acesso em: 23 dez. 2007.

(ISO, 2007) INTERNATIONAL ORGANIZATION FOR STANDARDIZATION. Status of the ISO 9000 family of standards. Document: ISO, ISO/TC 176 N817R6. Geneva, ISO, dez 2007. Disponível em:

$<$ http://www.tc176.org/pdf/N817R6DocumentStatusReport2007_12.pdf>. Acesso em: 23 dez. 2007. 
(ISO, 2008a) INTERNATIONAL ORGANIZATION FOR STANDARDIZATION. Origins and ISO/TC 207. Geneva: ISO, Products, mai. 2008a. Apresenta texto resumo sobre a origem da família ISO 14000 e da introdução do comitê técnico TC 127.

Disponível em:

$<$ http://www.iso.org/iso/iso_catalogue/management_standards/iso_9000_iso_14000/origin s and iso tc207.htm>. Acesso em: 18 mai. 2008.

(ISO, 2008b) INTERNATIONAL ORGANIZATION FOR STANDARDIZATION. About ISO/TC ISO/TC 207. Mississauga, CA: ISO/TC207 - TECHNICAL COMMITTEE, mai. 2008b. Apresenta texto institucional sobre o escopo de atuação do comitê. Disponível em: $<$ http://www.tc207.org/About207.asp>. Acesso em: 19 mai. 2008.

JORGENSEN, T. H.; MELLADO M. D.; REMMEN, A.. E. Integrated management systems. Working paper 7. Aalborg Oest, DK: Division of Technology, Environment and Society, Department of Development and Planning Aalborg University, nov. 2004. (ISSN 1603-9890)

KIBRIT, E. Análise de requisitos normativos para o desenvolvimento e a implementação de um sistema de gestão da qualidade em instalações e atividades nucleares brasileiras. 2008. Dissertação (Mestrado) - Instituto de Pesquisas Energéticas e Nucleares, São Paulo.

LEONARD, D.; MCADAM, R. Corporate social responsibility. Quality Progress Magazine, n. 10, p. 27-32, out. 2003.

LOPES, J. R. M.; MATTOS, U. A. O. Economia, meio ambiente e gestão empresarial. In: CONGRESSO NACIONAL DE EXCELÊNCIA EM GESTÃO, nov. 2002.

MARANHÃO, M.. ISO Série 9000: manual de implementação. $2^{\mathrm{a}}$ Edição. Rio de Janeiro: Qualitymark Editora, 1994.

MARANHÃO, M.. ISO Série 9000: manual de implementação: versão ISO 2000, $6^{\mathrm{a}}$ Edição. Rio de Janeiro: Qualitymark Editora, 2001.

MARIN, M. P. A. Análise de perigos em uma instalação de produção de hexafluoreto de urânio. 1999. Dissertação (Mestrado) - Instituto de Pesquisas Energéticas e Nucleares. São Paulo.

MEDEIROS, E. B. Um modelo de gestão integrada de qualidade, meio ambiente, segurança e saúde ocupacional para o desenvolvimento sustentável: setor de mineração. 2003. Dissertação (Mestrado) - Universidade Federal de Santa Catarina. Florianópolis.

MENEZES, M. T.; MARTINS, R. A. ISO 9000:2000 e balanced scorecard: analise das oportunidades. In: ENCONTRO NACIONAL DE ENGENHARIA DE PRODUÇÃO, XXI, 2001, Salvador BA. Disponível em:

$<$ http://www.abepro.org.br/biblioteca/ENEGEP2001_TR23 0601.pdf $>$. Acesso em 17 jan. 2008.

MICHAELIS. Moderno dicionário da língua portuguesa. Dicionário Michaelis. São Paulo, SP: Companhia Melhoramentos, 1998. 
MITCHELL, M. E. Airborne effluent control at fuel enrichment, conversion, and fabrication plants. In: CONTROLLING AIR-BORNE EFFLUENTS FROM FUEL CYCLE PLANTS ANS-AICHE MEETING, ago. 5-6, 1976. Proceeding...

MOURA L. A. A. Qualidade e gestão ambiental. 4a Edição. São Paulo, SP: Editora Juarez da Oliveira, 2004.

OBADIA, I. J. Sistema de gestão adaptativo para organizações com tecnologia perigosa: a cultura de segurança como pressuposto de excelência nuclear. 2004. Tese (Doutorado) - Universidade Federal do Rio de Janeiro, COPPE, Rio de Janeiro.

OLDFIELD H.. Get ready to integrate. Quality World, n. 8, p. 1-2, London: 1998. Apud GRIFFITH, A. Integrated management systems for enhancing project quality, safety and environment. The International Journal of Construction Management, p. 25-37, 2002

OLIVEIRA, D. P.; ZOUAIN, D.M. Integrated management system - Management standard evolution and the IAEA new approach. In: INAC 2007, INTERNATIONAL NUCLEAR ATLANTIC CONFERENCE: NUCLEAR ENERGY AND ENERGETIC CHALLENGES FOR 21ST CENTURY; 15TH BRAZILIAN NATIONAL MEETING ON REACTOR PHYSICS AND THERMAL HYDRAULICS; 8TH BRAZILIAN NATIONAL MEETING ON NUCLEAR APPLICATIONS, Santos, SP (Brazil), 30 set. - 5 out. 2007. Proceedings... Santos, SP (Brasil): Associação Brasileira de Energia Nuclear (ABEN), 2007. DVD.

PARLAMENTO EUROPEU - COMISSÃO DA INDÚSTRIA, DA INVESTIGAÇÃO E DA ENERGIA. Proposta de directiva do Conselho relativa à fiscalização e ao controlo das transferências de resíduos radioactivos e de combustível nuclear irradiado. Lisboa: 02 mar. 2006. (COM(2005)0673 - C6-0031/2006 - 2005/0272(CNS))

PATRÍCIO, M. E. Organização - Estratégia: integração dos sistemas de gestão. Porto, PT: UPT - Universidade Portucalense Infante D. Henrique, Departamento de Gestão, 2004.

(RISK, 2007) RISK TECNOLOGIA. Sistemas de gestão da segurança e saúde no trabalho - Requisitos. $2^{\text {a }}$ Edição. São Paulo: Coleção Risk Tecnologia, 2007. (OHSAS 18001).

SANTOS, C. Gerenciamento Ambiental. Apostila do curso de tecnologia em saneamento ambiental. Campinas, SP: Centro Superior de Educação Tecnológica da Universidade Estadual de Campinas (Unicamp), mar. 2008.

SEDDON, J. The case against ISO 9000 - 2a edition. Cork, Ireland: Oak Tree Press, nov. 2000. Cap. 1, A brief history of ISO 9000. Disponível em: http://www.systemsthinking.co.uk/3-1-ARTICLE.ASP. Acesso em: 14 out. 2006.

SIGLER, T. H.; PEARSON, C. M. Creating an empowering culture: examining the relationship between organizational culture and perceptions of empowerment. Journal of Quality Management, v. 5(1), p. 27-52. 2000. Apud ASIF et. al. Process Embedded Design of Integrated Management Systems. In: POMS 19th Annual Conference, Mai 9-12, 2008, La Jolla, CA USA: Proceeding...

Abstract No. 008-0776. 
STIMSON, W. A. ISO 9001 and Sarbanes-Oxley: A System of Governance. Chico, CA: Paton Press LLC, 2006.

TERREMOTO, L. A. A.. Apostila do curso fundamentos de tecnologia nuclear Reatores. São Paulo, SP: Instituto de Pesquisas Energéticas e Nucleares, set. 2004.

TOWNSEND, P. F. Integrated management system - A key to re-thinking construction?: an overview of integrated management systems. In: CONSTRUCTION PRODUCTIVITY NETWORK (CPN) WORKSHOP, Construction Industry Research and Information Association (CIRIA), 1999, London. Proceeding ....Report No. E9080. Apud BHUTTO et. al. A. The integrated management system for project quality, safety and environment: Pilot study research findings of developments in IMS. The International Journal of Construction Management. p. 76. 2004.

(USNRC, 2007a) UNITED STATE NUCLEAR REGULATORY COMMISSION. Uranium conversion. Washington, DC: USNRC, 13 fev. 2007a. Apresenta texto sobre os processos sobre conversão de urânio. Disponível em: http:/www.nrc.gov/materials/fuelcycle-fac/ur-conversion.html. Acesso em: 08 dez. 2007.

(USNRC, 2007b) UNITED STATE NUCLEAR REGULATORY COMMISSION. Glossary. Washington, DC: 05 jun. 2007b. Disponível em: http://www.nrc.gov/readingrm/basic-ref/glossary.html. Acesso em: 13 fev. 2008.

(WNA, 2007) WORLD NUCLEAR ASSOCIATION. The nuclear fuel cycle. London, UK: out. 2007. Apresenta texto sobre os processos do ciclo de combustível. Disponível em: $<$ http://www.world-nuclear.org/info/inf03.html $>$. Acesso em: 27 dez. 2007.

(WNA, 2008a) WORLD NUCLEAR ASSOCIATION. Uranium enrichment. London, UK: mar. 2008a. Apresenta texto sobre os processos de conversão e enriquecimento de urânio.

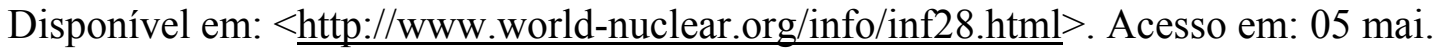
2008.

(WNA, 2008b) WORLD NUCLEAR ASSOCIATION. Nuclear Power Reactors. London, UK: mai. 2008b. Apresenta texto sobre plantas de potência. Disponível em: $<$ http://www.world-nuclear.org/info/inf32.html >. Acesso em: 19 mai. 2008.

VALLE, C. E. Qualidade ambiental: como se preparar para as normas ISO 14000. São Paulo: Pioneira, 1995. Apud MEDEIROS, E. B. Um modelo de gestão integrada de qualidade, meio ambiente, segurança e saúde ocupacional para o desenvolvimento sustentável: setor de mineração. 2003. Dissertação (Mestrado) - Universidade Federal de Santa Catarina. Florianópolis.

VINCZE, P. Development of new safety standards on management systems. Vienna: IAEA, 2004a. Disponível em:

$<$ http://www.iaea.org/OurWork/ST/NE/NENP/NPES/Activity/ic_current.htm $>$. Acesso em: 09 abr. 2007. 
VINCZE, P.. Management of continuous process improvement. Vienna: IAEA, 2004b. Disponível em: <http://www.iaea.org /OurWork/ST/NE/NENP/NPES/Activity/ic_current.html>. Acesso em: 09 abr. 2007.

VINCZE, P. IAEA Safety standards on management systems. In: 7TH JOINT WORKSHOP ON SUCCESSFUL MANAGEMENT OF ORGANIZATIONAL CHANGE. Lectures... Mamaia, Romania: IAEA, 16-19 mai. 2006. Disponível em:

$<$ http://entrac.iaea.org/ELibrary.aspx $>$. Acesso em: 26 nov. 2007.

VINCZE, P. IAEA Safety standards on management systems. In: TECHNICAL MEETING ON MANAGEMENT SYSTEMS. Lectures... Vienna, Áustria: IAEA, 19-23 mar. 2007.

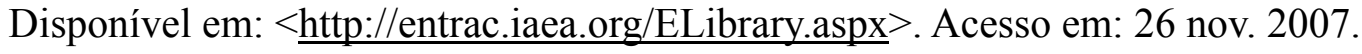

WILKINSON, G.; DALE, B. G.. Integrated management systems: an examination of the concept and theory. The Total Quality Management Magazine, v. 11(2), p. 95-104, 1999. Apud ASIF et. al. Process Embedded Design of Integrated Management Systems. In: POMS 19th Annual Conference, mai. 9-12, 2008, La Jolla, CA USA: Proceeding... Abstract No. 008-0776.

WILKINSON, G.; DALE, B. G. An examination of the ISO 9001:2000 standard and its influence on the integration of management systems. Production Planning and Control. v. 13. no. 3. p. 284-297, 2002. Apud JORGENSEN et. al. Integrated management systems. Working paper 7. Aalborg Oest, DK: Division of Technology, Environment and Society, Department of Development and Planning Aalborg University, nov. 2004. (ISSN 1603-9890)

ZOUAIN, D. M.. Metodologia de Avaliação das Estratégias para o Combustível Irradiado. 1981. Dissertação (Mestrado) - Universidade Federal do Rio de Janeiro, Coordenação do Programas de Pós-Graduação em Engenharia - COPPE, Rio de Janeiro. 